\title{
RELAP/MOD3.2 Assessment Using an 11\% Upper Plenum Break Experiment in the PSB Facility
}

Paul D. Bayless

January 2003

Idaho National Engineering and Environmental Laboratory Bechtel BWXT Idaho, LLC 
INEEL/EXT-03-00058

\title{
RELAP5/MOD3.2 Assessment Using an 11\% Upper Plenum Break Experiment in the PSB Facility
}

\author{
Paul D. Bayless
}

Published January 2003

Idaho National Engineering and Environmental Laboratory Advanced Nuclear Energy Idaho Falls, Idaho 83415

Prepared for the U.S. Department of Energy Assistant Secretary for Nonproliferation and National Security Under DOE Idaho Operations Office Contract DE-AC07-99ID13727 


\begin{abstract}
The RELAP/MOD3.2 computer code has been assessed using an 11\% upper plenum break experiment in the PSB test facility at the Electrogorsk Research and Engineering Center. This work was performed as part of the U.S. Department of Energy's International Nuclear Safety Program, and is part of the effort addressing the capability of the RELAP5/MOD3.2 code to model transients in Sovietdesigned reactors.

Designated VVER Standard Problem PSBV1, the test addressed several important phenomena related to VVER behavior that the code needs to simulate well. The code was judged to reasonably model the phenomena of two-phase flow natural circulation in the primary coolant system, asymmetric loop behavior, leak flow, loop seal clearance in the cold legs, heat transfer in a covered core, heat transfer in a partially covered core, pressurizer thermal-hydraulics, and integral system effects. The code was judged to be in minimal agreement with the experiment data for the mixture level and entrainment in the core, leading to a user recommendation to assess the sensitivity of transient calculations to the interphase drag modeling in the core. No judgments were made for the phenomena of phase separation without mixture level formation, mixture level and entrainment in the steam generators, pool formation in the upper plenum, or flow stratification in horizontal pipes because either the phenomenon did not occur in the test or there were insufficient measurements to characterize the behavior.
\end{abstract}




\section{CONTENTS}

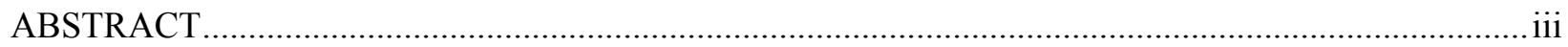

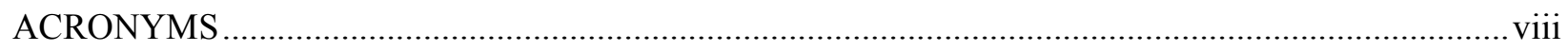

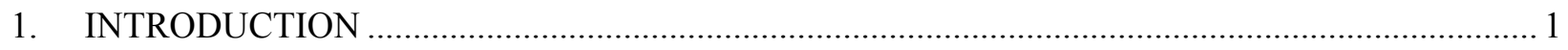

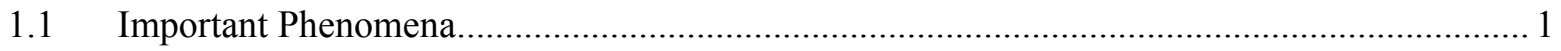

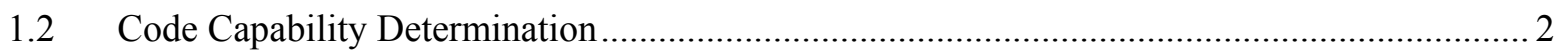

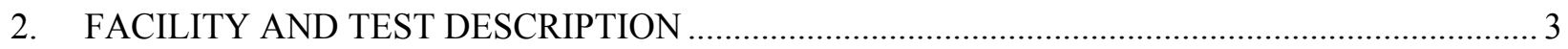

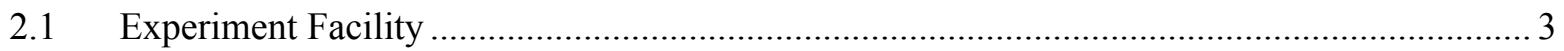

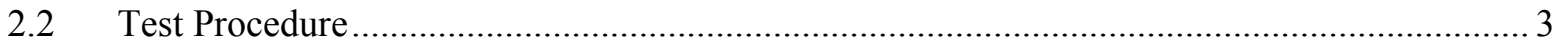

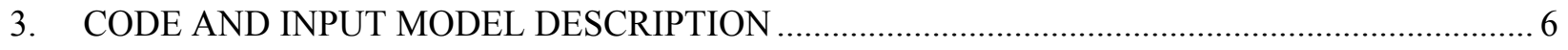

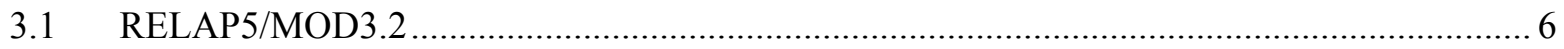

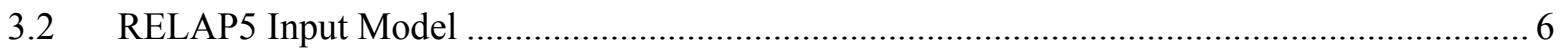

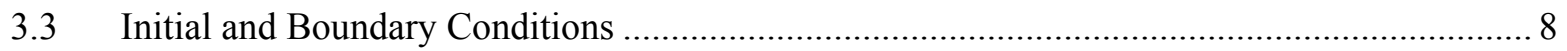

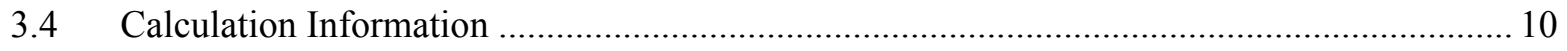

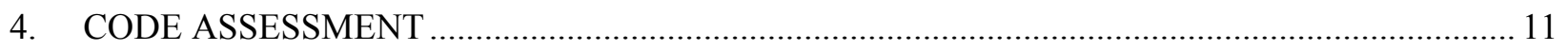

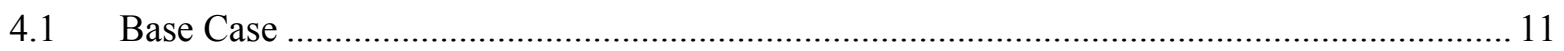

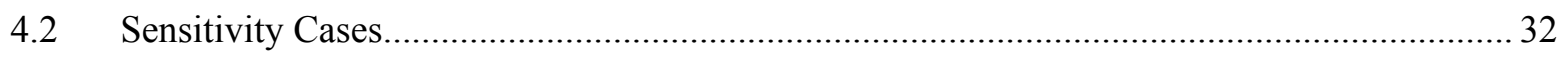

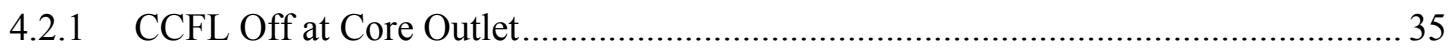

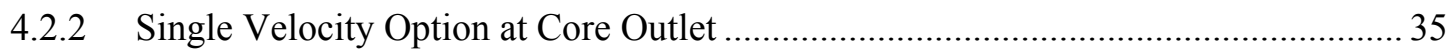

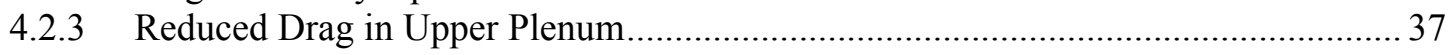

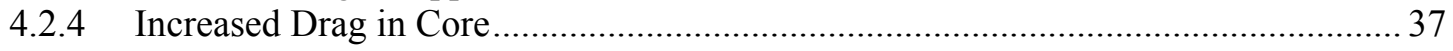

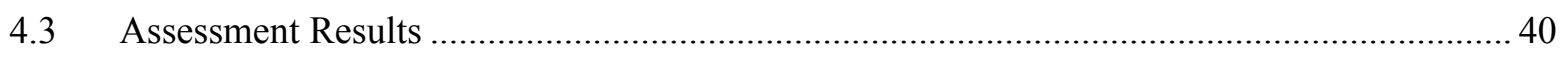

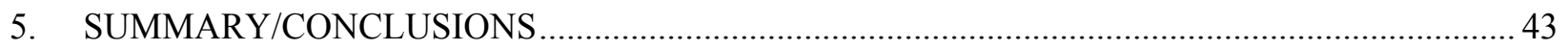

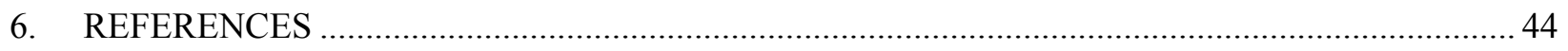

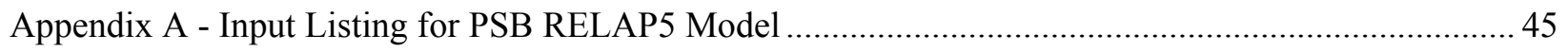

\section{FIGURES}

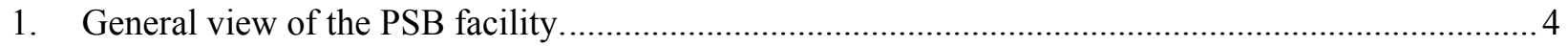

2. Nodalization of the PSB reactor vessel, pressurizer, and one coolant loop. .................................... 7 
3. Upper plenum pressure for the base case ...................................................................................... 11

4. Core power.

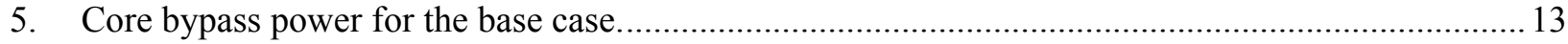

6. Pressurizer heater power for the base case ................................................................................. 14

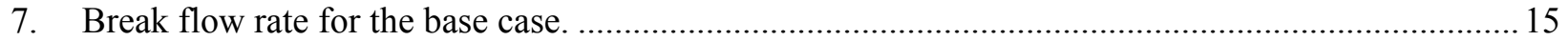

8. Fluid density in the break piping for the base case .................................................................... 15

9. Fluid temperature in the break piping for the base case.................................................................... 16

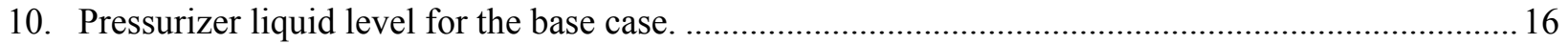

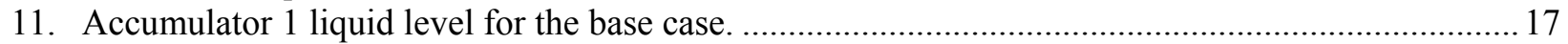

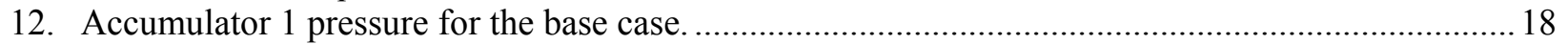

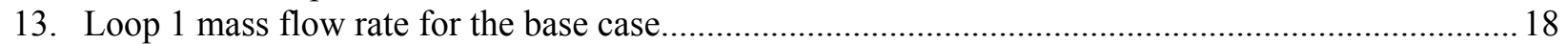

14. Loop 4 mass flow rate for the base case................................................................................ 19

15. Differential pressure in the lower portion of the core simulator for the base case..............................19

16. Differential pressure in the middle portion of the core simulator for the base case..........................20

17. Differential pressure in the upper portion of the core simulator for the base case..............................20

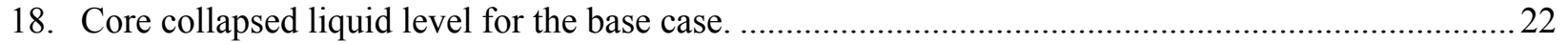

19. Core bypass differential pressure for the base case.......................................................................2

20. Differential pressure in the lower portion of the upper plenum for the base case...............................23

21. Differential pressure in the upper portion of the upper plenum for the base case................................2 23

22. Differential pressure in the lower portion of the upper head for the base case...................................2 24

23. Differential pressure in the upper portion of the upper head for the base case...................................24

24. Differential pressure in the lower portion of the downcomer for the base case..................................2

25. Differential pressure in the upper portion of the downcomer for the base case..................................2 25

26. Differential pressure in the steam generator 1 hot collector for the base case.....................................2 26

27. Differential pressure in the SG side of the loop 1 loop seal for the base case. ...................................2.27

28. Differential pressure in the pump side of the loop 1 loop seal for the base case. ..............................2 27

29. Differential pressure across the loop 1 pump for the base case ......................................................22

30. Measured heater rod surface temperatures........................................................................ 28

31. Calculated heater rod surface temperatures for the base case.........................................................2 29

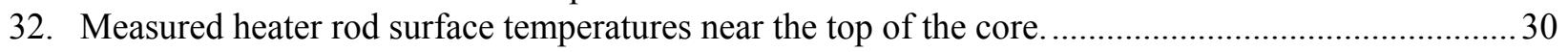

33. Fluid temperature at the top of the upper head for the base case. .................................................... 30

34. Loop 4 hot leg fluid temperature for the base case. ………………………………………........... 31

35. Loop 1 hot leg fluid temperature for the base case. ………………………………………….... 31

36. Loop 4 cold leg fluid temperature for the base case. ................................................................. 33

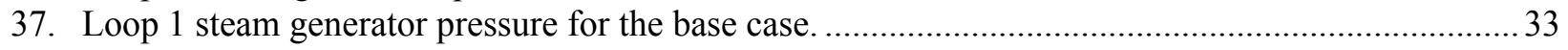

38. Loop 2 steam generator pressure for the base case ...................................................................... 34

39. Loop 1 steam generator collapsed liquid level for the base case. ....................................................... 34

40. Loop 2 steam generator collapsed liquid level for the base case. ..................................................... 35

41. Calculated heater rod surface temperatures for the CCFL sensitivity case............................................36

42. Core collapsed liquid level for the base and single velocity sensitivity cases. ......................................36

43. Calculated heater rod surface temperatures for the single velocity sensitivity case. ............................37

44. Differential pressure in the lower portion of the upper plenum for the base and upper plenum drag sensitivity cases................................................................................................................. 38

45. Differential pressure in the upper portion of the upper plenum for the base and upper plenum drag

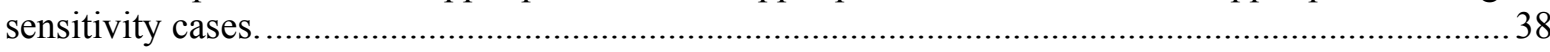

46. Calculated heater rod surface temperatures for the upper plenum drag sensitivity case......................39

47. Core collapsed liquid level for the base and core drag sensitivity cases............................................39

48. Calculated heater rod surface temperatures for the core drag sensitivity case.....................................40 


\section{TABLES}

1. Measured and calculated initial conditions for the PSB $11 \%$ upper plenum break experiment. ..........9

2. Sequence of events for the PSB 11\% upper plenum break experiment. ........................................ 12

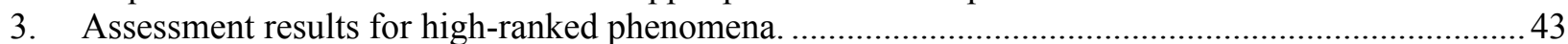




\section{ACRONYMS}

$\begin{array}{ll}\text { ACC } & \text { accumulator } \\ \text { CCFL } & \text { countercurrent flow limitation } \\ \text { ECC } & \text { emergency core coolant } \\ \text { ECCS } & \text { emergency core cooling system } \\ \text { EREC } & \text { Electrogorsk Research and Engineering Center on Nuclear Plants Safety } \\ \text { HPI } & \text { high pressure injection } \\ \text { INEEL } & \text { Idaho National Engineering and Environmental Laboratory } \\ \text { INSP } & \text { International Nuclear Safety Program } \\ \text { RBMK } & \text { boiling water-cooled, graphite-moderated reactor } \\ \text { SG } & \text { steam generator } \\ \text { VVER } & \text { water-cooled, water-moderated energy reactor }\end{array}$




\section{RELAP5/MOD3.2 Assessment Using an 11\% Upper Plenum Break Experiment in the PSB Facility}

\section{INTRODUCTION}

The RELAP5/MOD3.2 computer code is being investigated to determine its applicability for modeling transients in Soviet-designed reactors. Part of that investigation includes assessment of the code using experiment data. Such an assessment has been performed using data from the PSB facility at the Electrogorsk Research and Engineering Center for Nuclear Plants Safety (EREC).

This work has been undertaken as part of Joint Project \#6, "Verification of Software with Respect to VVER and RBMK Reactors," of the U.S. Department of Energy's International Nuclear Safety Program (INSP). Russian experts and scientists from the United States are collaborating in the code assessment process. The specific experiment being used for this study was an $11 \%$ break in the upper plenum, which is a counterpart to an earlier experiment performed in the ISB facility. That earlier experiment was analyzed as VVER Standard Problem \#5 in the INSP code validation effort; the current test is designated as Standard Problem PSBV1.

\subsection{Important Phenomena}

Reference 1 identifies the transient phenomena that are important for any code to be able to model well in order to provide confidence in the simulation of VVER transient behavior. The standard problem definition report ${ }^{2}$ identifies the following phenomena as being addressed by this experiment:

- Two-phase flow natural circulation in the primary coolant system

- Asymmetric loop behavior

- Leak flow

- Separation of phases without mixture level formation

- Mixture level and entrainment in the steam generators

- Mixture level and entrainment in the core

- Flow stratification in horizontal pipes

- Loop seal clearance in the cold legs

- Pool formation in the upper plenum

- Heat transfer in a covered core

- Heat transfer in a partially uncovered core

- Pressurizer thermal-hydraulics 
- Integral system effects.

\subsection{Code Capability Determination}

Judgments regarding code fidelity were made based on the code/data comparisons presented in this report. These judgments were based on the application of a standardized, consistent, and qualitative set of criteria. The terminology of these criteria is defined below.

"Excellent agreement" applies when the code exhibits no deficiencies in modeling a given behavior. Major and minor phenomena and trends are correctly predicted. The calculated results are judged to agree closely with the data. The calculation will, with few exceptions, lie within the uncertainty bands of the data. The code may be used with confidence in similar applications. (The term "major phenomena" refers to the phenomena that influence key parameters such as fuel rod cladding temperature, pressure, differential pressure, mass flow rate, and mass distribution. Predicting major trends means that the prediction shows the significant features of the data. Significant features include the magnitude of a given parameter through the transient, slopes, and inflection points that mark significant changes in the parameter.)

"Reasonable agreement" applies when the code exhibits minor deficiencies. Overall, the code provides an acceptable prediction. All major trends and phenomena are correctly predicted. Differences between calculation and data are greater than deemed necessary for excellent agreement. The calculation will occasionally lie outside the uncertainty bands of the data. However, the correct conclusions about trends and phenomena would be reached if the code were used in similar applications. The code models and/or facility model noding should be reviewed to see if improvements can be made.

"Minimal agreement" applies when the code exhibits significant deficiencies. Overall, the code provides a prediction that is only conditionally acceptable. Some major trends or phenomena are not predicted correctly, and some calculated values lie considerably outside the uncertainty bands of the data. Incorrect conclusions about trends and phenomena may be reached if the code were used in similar applications, and an appropriate warning needs to be issued to users. Selected code models and/or facility model noding need to be reviewed, modified, and assessed before the code can be used with confidence in similar applications.

"Insufficient agreement" applies when the code exhibits major deficiencies. The code provides an unacceptable prediction of the test. Major trends are not predicted correctly. Most calculated values lie outside the uncertainty bands of the data. Incorrect conclusions about trends and phenomena are probable if the code is used in similar applications, and an appropriate warning needs to be issued to users. Selected code models and/or facility model noding need to be reviewed, modified, and assessed before the code can be used with confidence in similar applications.

Assessment findings of "excellent" or "reasonable" indicate that the code can model those phenomena acceptably.

Subsequent sections of the report present a description of the test facility and experiment, the RELAP5 code and test facility input model, the assessment results, the conclusions reached in the assessment study, and references. 


\section{FACILITY AND TEST DESCRIPTION}

Standard Problem PSBV1 is based on an 11\% upper plenum break in the PSB-VVER test facility. The facility and the specific test are described in the following subsections.

\subsection{Experiment Facility}

The PSB-VVER facility (see Figure 1) is a full-height scale model of a VVER-1000 reactor that is approximately $1 / 300$ scale in volume and power. The facility has four coolant loops. The pressurizer surge line is connected to two of the hot legs, with only one flow path being used in a given experiment. Emergency core coolant (ECC) injection is provided by four accumulators and by an active pump simulating the high- and low-pressure injection system pumps. All system components are insulated from the environment with glass wool insulation, but during initial steady state operation about $3.4 \%$ of the input heat is lost to the environment.

The internals of the VVER vessel are represented in the facility by separate pipes for the downcomer, the core and upper plenum, and the core bypass. A horizontal pipe connects the lower portion of the downcomer to the core and core bypass pipes. There is also a small pipe connecting the top of the downcomer to the upper plenum. The core contains 168 full height hollow fuel rod simulators (hereinafter, heater rods) with a uniform power profile and a center unheated rod. About $3 \%$ of the downcomer flow is diverted through the core bypass instead of going through the core. Special flow restrictors, each consisting of a plate with 2 holes of $7 \mathrm{~mm}$ diameter, were inserted at either end of the core bypass section. The bypass section is heated over the same elevation range as the core but only receives about $1 \%$ of the core power.

Each coolant loop includes a hot leg, steam generator, pump suction piping, pump, and cold leg. The primary side of each steam generator contains hot and cold collectors, and 27 steam generator tubes. Each tube is a coil with ten complete turns, inclined slightly downward from the hot collector to the cold collector. The secondary side has a feedwater ring in the plenum above the steam generator tubes, and no separate downcomer region. The four steam generators are connected to a common steam header. Feedwater flow to the steam generators is not continuous. Flow is provided when needed to keep the water level within the desired operating band.

The break was located in a special pipe connected to the upper plenum. An insert with an inner diameter of $16 \mathrm{~mm}$ and a length-to-diameter ratio of 10 was installed in the 45 -mm diameter break piping. A valve downstream of the insert was opened to initiate the transient.

Cylinders in the downcomer and upper plenum are used to separate the ECC flows from the break and the hot and cold leg nozzles. The break piping and hot and cold legs are connected to the outer walls of the upper plenum and downcomer. The ECC is connected to the inside of these cylinders, providing a barrier to immediate bypass of the ECC flow into the loop piping or out the break.

\subsection{Test Procedure}

The $11 \%$ upper plenum break represented a rupture of an emergency core cooling system (ECCS) injection line. The ECCS equipment available for this experiment was high pressure injection (HPI) to the loop 4 hot leg and all four accumulators.

The experiment was initiated from steady state conditions by opening the break. The electrical power supplied to the heater rods and the core bypass heaters was reduced to simulate reactor scram. Following 


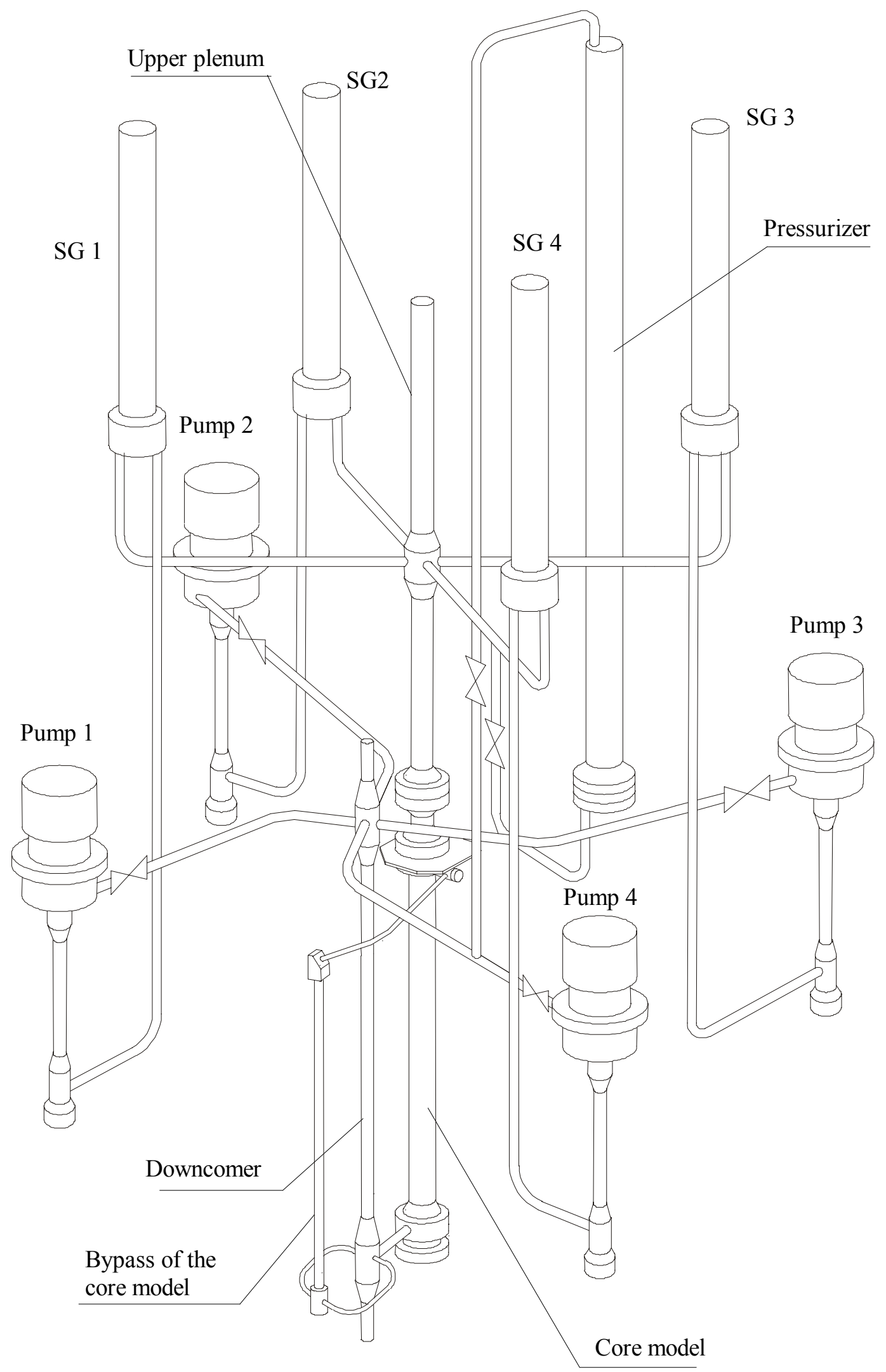

Figure 1. General view of the PSB facility. 
the simulated scram, feedwater flow to the steam generators was stopped, and the steam line isolation valves were closed. The main circulation pumps were tripped near $10 \mathrm{~s}$. High pressure injection flow was initiated at an upper plenum pressure of $10.5 \mathrm{MPa}$, providing coolant flow to the loop 4 hot leg. The transient was then allowed to progress until elevated temperatures were measured in the core and core bypass structures. When the core bypass structure temperature reached $673 \mathrm{~K}$, the bypass heaters were deenergized. Power to the core was turned off at $1037 \mathrm{~s}$, terminating the test, when the peak measured heater rod temperature was near $1100 \mathrm{~K}$. 


\section{CODE AND INPUT MODEL DESCRIPTION}

The RELAP5/MOD3.2 code and input model used for the assessment calculations are described below. Also addressed are the initial and boundary conditions used for the transient calculations.

\subsection{RELAP5/MOD3.2}

The RELAP5/MOD3.2 computer $\operatorname{code}^{3}$ was developed at the Idaho National Engineering and Environmental Laboratory (INEEL) for use in analyzing transients in light water reactors. It can be used for simulating a wide variety of system transients of interest in reactor safety. The core, primary system, secondary system, feedwater train, and system controls can be simulated.

RELAP5/MOD3.2 uses a one-dimensional, two fluid, nonequilibrium, six equation hydrodynamic model with a simplified capability to treat multi-dimensional flows. This model provides continuity, momentum, and energy equations for both the liquid and the vapor phases within a control volume. The energy equation contains source terms which couple the hydrodynamic model to the heat structure conduction model by a convective heat transfer formulation. The code contains special process models for critical flow, abrupt area changes, branching, crossflow junctions, pumps, accumulators, valves, core neutronics, and control systems. A countercurrent flow limitation model can also be applied at vertical junctions. The reflood model does not work properly in this version of the code.

The code has been developed to run on a variety of computing platforms, from mainframes to personal computers. Configuration control is maintained on all versions of the code developed at the INEEL.

\subsection{RELAP5 Input Model}

All of the major features of the experiment facility were included in the RELAP5 input model. Each of the four coolant loops included a hot leg, steam generator, pump suction loop seal piping, main coolant pump, and a cold leg. The downcomer, core, core bypass, upper plenum, and bypass piping between the downcomer and upper plenum were also included in the model. The pressurizer was modeled, with surge lines connecting to two of the hot legs. The secondary side of the steam generators included main and auxiliary feedwater, individual steam lines and the common steam header. High pressure injection flow was provided to the loop 4 hot leg, and four accumulators provided flow to the downcomer and upper plenum (two to each location). Relief valves were included on the pressurizer and each of the steam lines. Figure 2 provides a nodalization diagram for the model, showing the reactor vessel components and one coolant loop with the pressurizer; the other three loops have identical nodalizations, except that two loops are not connected to the pressurizer. The model contains 534 volumes, 557 junctions, and 521 heat structures with 5549 mesh points. Standard modeling guidelines were followed in developing the nodalization of the system. The nodalization approach was peer reviewed. Appendix A provides a listing of the input model.

The steam generator secondary side is modeled with a single stack of volumes in the tube bundle region. There is no physical barrier between the tube bundle and the outer shell of the steam generator, and attempts to model a downcomer region separate from the riser, with crossflow junctions between them, resulted in unphysical flow rates.

The heat transfer coefficient on the inside of the steam generator tubes was increased by $20 \%$ by using a fouling factor of 1.2. This was done to estimate the convective heat transfer enhancement caused 


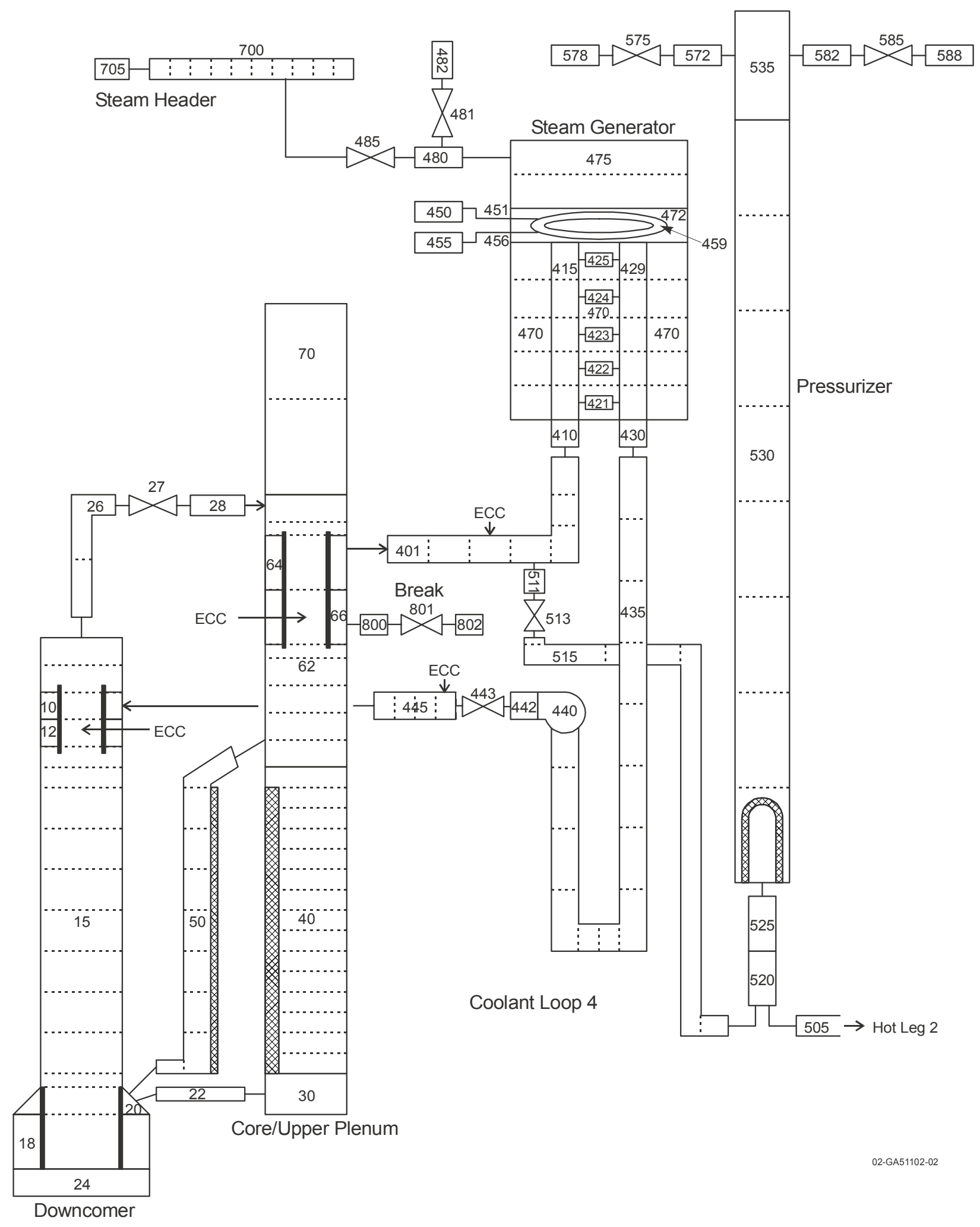

Figure 2. Nodalization of the PSB reactor vessel, pressurizer, and one coolant loop. 
by the coiled tubes, ${ }^{4}$ because the wall heat transfer model available in RELAP5 was developed for straight tubes.

No data were available on the pump performance, so built-in data for Westinghouse pumps were used. No two-phase degradation was modeled because no appropriate data were available; this is not expected to affect the transient behavior because the pumps coast down very quickly $(\sim 4 \mathrm{~s})$ after being tripped.

There was no measurement of the flow through the core bypass. The loss coefficients through the bypass flow path were adjusted during the steady state calculation so that the calculated coolant temperature at the top of the core bypass matched the measured value of $570 \mathrm{~K}$ (measurement YC01T03).

Choking was turned off at most of the junctions, as recommended in the code user guidelines. Exceptions were the break, at valves, at the pressurizer connection to the surge line and the surge line connections to the hot leg, and at the core outlet. The break piping was attached to the upper plenum one volume below the hot leg connections. The break was modeled as an abrupt area change with user-input loss coefficients of 1.465 (calculated for the break geometry). No characterization data were available for the break geometry. Based on previous experience, a subcooled discharge coefficient of 0.80 was used; the saturated and superheated discharge coefficients were left at the default value of 1.0.

The RELAP5/MOD3.2 countercurrent flow limitation (CCFL) model was applied at five locations in the model: in the downcomer below the accumulator injection nozzles, at the core outlet, in the upper plenum below the accumulator injection nozzles, at the plate between the upper plenum and the upper head, and at the outlet of the riser section on the secondary side of the steam generators. These junctions were selected because they were vertically oriented, represented places where the flow area changed, and modeled regions of the facility where CCFL might be expected to occur.

The heat loss from the primary and secondary was represented in the RELAP5/MOD3.2 model by entering the thickness of the insulation on the outside of all the pipes and other system components. Appropriate material properties were input for the insulation. A constant boundary temperature was applied. The heat transfer coefficient on the outer surface of the insulation was determined from model benchmarking calculations using heat loss data from the facility. ${ }^{5}$

\subsection{Initial and Boundary Conditions}

A steady state calculation was performed to establish the desired initial conditions in the PSB facility model for the transient calculation. Results from this calculation are compared to the values from the experiment in Table 1. Except for the steam generator pressures, all of the calculated initial conditions were in good agreement with the measured values. The steam generator pressures are lower than the measured values. In the steady state calculation, the steam header pressure was adjusted to achieve the desired reactor vessel inlet temperature; the resulting pressure required to remove the heat from the tubes was lower than in the experiment. This is likely the result of not having appropriate, specific heat transfer correlations for the coiled geometry of the steam generator tubes. The accumulator levels and pressures are also slightly different in some cases. The measured values in the table were taken from the experiment data report, ${ }^{6}$ while the RELAP5 input model initial values were adjusted to match the initial values from the electronic data file.

The initial conditions for the test were not all steady. For example, the feedwater flow to the steam generators was not continuous in the facility. Intermittent flow was used to keep the liquid level within a desired band. By contrast, a steady feedwater flow was maintained to keep the level constant at the 
Table 1. Measured and calculated initial conditions for the PSB 11\% upper plenum break experiment.

\begin{tabular}{lcc}
\hline \multicolumn{1}{c}{ Parameter } & Measured & Calculated \\
\hline Upper plenum pressure (MPa) & 16.9 & 16.9 \\
Downcomer inlet temperature (K) & 559.7 & 559.7 \\
Upper plenum outlet temperature (K) & 589.7 & 589.5 \\
Core power (kW) & 1520 & 1520 \\
Core bypass power (kW) & 17.4 & 17.4 \\
Pressurizer level ${ }^{\mathrm{a}}(\mathrm{m})$ & 6.99 & 6.99 \\
Loop flow (kg/s) & & \\
Loop 1 & 2.3 & 2.3 \\
Loop 2 & 2.3 & 2.3 \\
Loop 3 & 2.3 & 2.3 \\
Loop 4 & 2.4 & 2.4 \\
Liquid level (m) & & \\
Steam generator 1 & 1.71 & 1.71 \\
Steam generator 2 & 1.71 & 1.71 \\
Steam generator 3 & 1.84 & 1.84 \\
Steam generator 4 & 1.74 & 1.74 \\
Pressure (MPa) & & \\
Steam generator 1 & 7.43 & 7.17 \\
Steam generator 2 & 7.47 & 7.17 \\
Steam generator 3 & 7.33 & 7.17 \\
Steam generator 4 & 7.43 & 7.17 \\
Liquid level (m) & & \\
Accumulator 1 & 4.84 & 4.83 \\
Accumulator 2 & 4.84 & 4.84 \\
Accumulator 3 & 4.86 & 4.86 \\
Accumulator 4 & 4.85 & 4.84 \\
Pressure (MPa) & & 5.9 \\
Accumulator 1 & 5.8 & 6.0 \\
Accumulator 2 & 5.8 & 5.9 \\
Accumulator 3 & 5.9 & 5.9 \\
Accumulator 4 & 5.9 &
\end{tabular}

a. The specified pressurizer level is the reading from measurement YP01L02, whose lower tap is $1.885 \mathrm{~m}$ above the bottom of the pressurizer.

desired initial value in the RELAP5 calculation. The impact of the different approach in the calculation is that although the initial liquid level is at the desired value, the feedwater flow rate is different from the measured value in each of the steam generators. Since the steam generator secondary behavior is not significant in this transient, this anomaly is not expected to have a noticeable impact on the primary coolant system behavior.

The core power measured during the experiment was input as the power table in the RELAP5 calculation. The measured core bypass power was also input as a boundary condition, with the power being held constant at $11.6 \mathrm{~kW}$ until the maximum temperature in the core bypass piping reached $673 \mathrm{~K}$; at that time, the power was turned off to protect the heater. 
HPI flow and temperature were also input as boundary conditions for the calculation, based on the measured data; the HPI flow was a specified boundary condition for the test as well. HPI flow was started when the upper plenum pressure decreased to $10.5 \mathrm{MPa}$; in the calculation, a $0.7-\mathrm{s}$ delay was included to account for signal processing time. The timing of the feedwater and steam valve closings in the input deck were also based on the measured data.

The transient calculations were terminated when the peak heater rod temperature reached $1073 \mathrm{~K}$.

\subsection{Calculation Information}

The RELAP5 calculations were run on a DEC AlphaStation 600 computer. The semi-implicit solution scheme was used. The base case transient calculation ran $830 \mathrm{~s}$ of transient in $4112 \mathrm{~s}$ of cpu time. The calculated mass error in the primary coolant system was less than $0.5 \%$ of the total system coolant mass at the end of the calculation, indicating that the calculated response was not compromised by the accuracy of the numerical solution. 


\section{CODE ASSESSMENT}

Once acceptable steady state conditions were established, transient calculations were undertaken. In addition to the base case calculation, several sensitivity calculations were performed to investigate certain aspects of the transient and code performance that were of particular interest.

Assessment judgments were made for the high-ranked phenomena believed to be addressed by this experiment. These phenomena were listed in Section 1, as were the assessment definitions and criteria.

\subsection{Base Case}

The behavior in the four loops was very similar. The discussions below will generally address only one loop, with the understanding that the same behavior was observed or calculated in the other three coolant loops. In those cases where different phenomena were observed, they will be presented.

Measured and calculated pressures in the upper plenum are presented in Figure 3. Table 2 provides the sequence of significant events for the experiment. A brief overview of the behavior observed in the experiment is provided here, then the comparisons between the data and calculations will be presented and discussed. Following the break opening, the system pressure decreased rapidly. The depressurization slowed near $50 \mathrm{~s}$, as liquid began to boil in the core. As the pressure continued to decrease, accumulator injection began near $200 \mathrm{~s}$. Condensation of some of the steam in the system by the cold ECC liquid caused the depressurization rate to increase. The ECC injection flow could not fully compensate for the break flow, allowing the core liquid level to drop low enough that the core began to heat up above the coolant saturation temperature. A cyclic behavior was then observed in the primary coolant system. The accumulator injection increased the depressurization rate because of steam condensing on the cold water

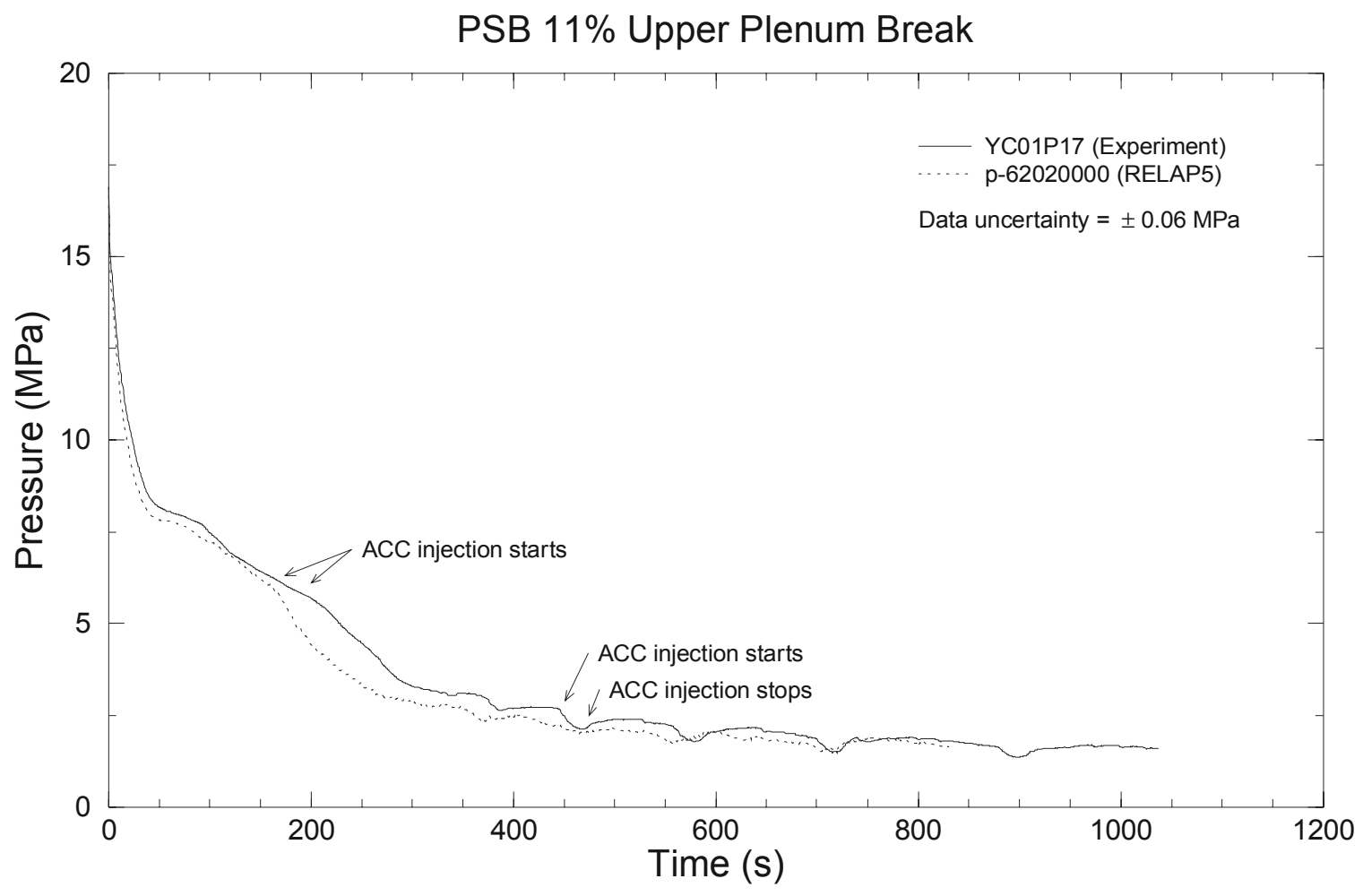

Figure 3. Upper plenum pressure for the base case. 
Table 2. Sequence of events for the PSB 11\% upper plenum break experiment.

\begin{tabular}{|l|c|c|}
\hline \multirow{2}{*}{ Event } & \multicolumn{2}{c|}{ Time (s) } \\
\cline { 2 - 3 } & Data & Calculation \\
\hline Break opens & 0 & 0 \\
\hline Scram/power decrease & 5 & $5^{\text {a }}$ \\
\hline Pressurizer heaters turned off & 6 & 5 \\
\hline Main coolant pumps tripped & 10 & $10^{\text {a }}$ \\
\hline Steam generator 4 feedwater flow ends & 10 & $10^{\text {a }}$ \\
\hline Steam generator 1 feedwater flow ends & 13 & $13^{\text {a }}$ \\
\hline Steam generator 3 feedwater flow ends & 14 & $14^{\text {a }}$ \\
\hline Steam generator 2 steam flow ends & 17 & $17^{\text {a }}$ \\
\hline Pressurizer above heaters empties (measurement YP01L02) & 19 & 16 \\
\hline Steam generator 1 steam flow ends & 20 & $20^{\text {a }}$ \\
\hline HPI starts & 21 & 18 \\
\hline Steam generator 4 steam flow ends & 23 & $23^{\text {a }}$ \\
\hline Steam generator 3 steam flow ends & 24 & $24^{\text {a }}$ \\
\hline Primary pressure drops below secondary pressure & 86 & 83 \\
\hline Accumulator 4 injection starts & 165 & 163 \\
\hline Accumulator 2 injection starts & 175 & 157 \\
\hline Accumulator 3 injection starts & 184 & 163 \\
\hline Accumulator 1 injection starts & 194 & 163 \\
\hline Core heatup starts & 222 & 170 \\
\hline Core bypass heater tripped & 559 & -- \\
\hline Experiment terminated & 1037 & 830 \\
\hline
\end{tabular}

a. Specified boundary condition in the calculation, based on the experiment data.

being injected. This further increased the accumulator flow, refilling parts of the downcomer and core. As the liquid level in the core increased, the heater rods were quenched, and the increased vapor generation caused the pressure to increase, stopping accumulator injection. Without the accumulator injection, the liquid level in the core decreased, and the heater rods began to heat up again. The vapor generation rate was reduced because less liquid was available to boil, so the pressure decreased, allowing the accumulators to inject liquid again. This cyclic accumulator injection continued through much of the experiment, although the injection became less effective in stopping the core heatup; after $700 \mathrm{~s}$, the injection was unable to completely quench the core. The test was terminated shortly after $1000 \mathrm{~s}$ to protect the heater rods, when the maximum heater rod temperature was near $1100 \mathrm{~K}$.

The calculated pressure decreased a little more rapidly than was measured immediately after the break was opened, and again when accumulator injection began. The calculation exhibited the same effects of the accumulator injection as the test, with the depressurization rate increasing as the injection began, then the pressure increasing to temporarily stop the injection as more liquid was boiled in the core, although the magnitude of the pressure changes was smaller than in the test.

Measured and code input core and core bypass powers are shown in Figures 4 and 5, respectively. The bypass heater was turned off when high heater temperatures were achieved, which occurred in the test but not in the calculation. Figure 6 shows the power to the pressurizer heaters. In the test, full power to the heaters was provided for about $5 \mathrm{~s}$. In the calculation, the pressure decreased more rapidly, and full power to the heaters was provided for about $4 \mathrm{~s}$. In both cases, power to the heaters was shut off when the pressure decreased to $13.73 \mathrm{MPa}$. 


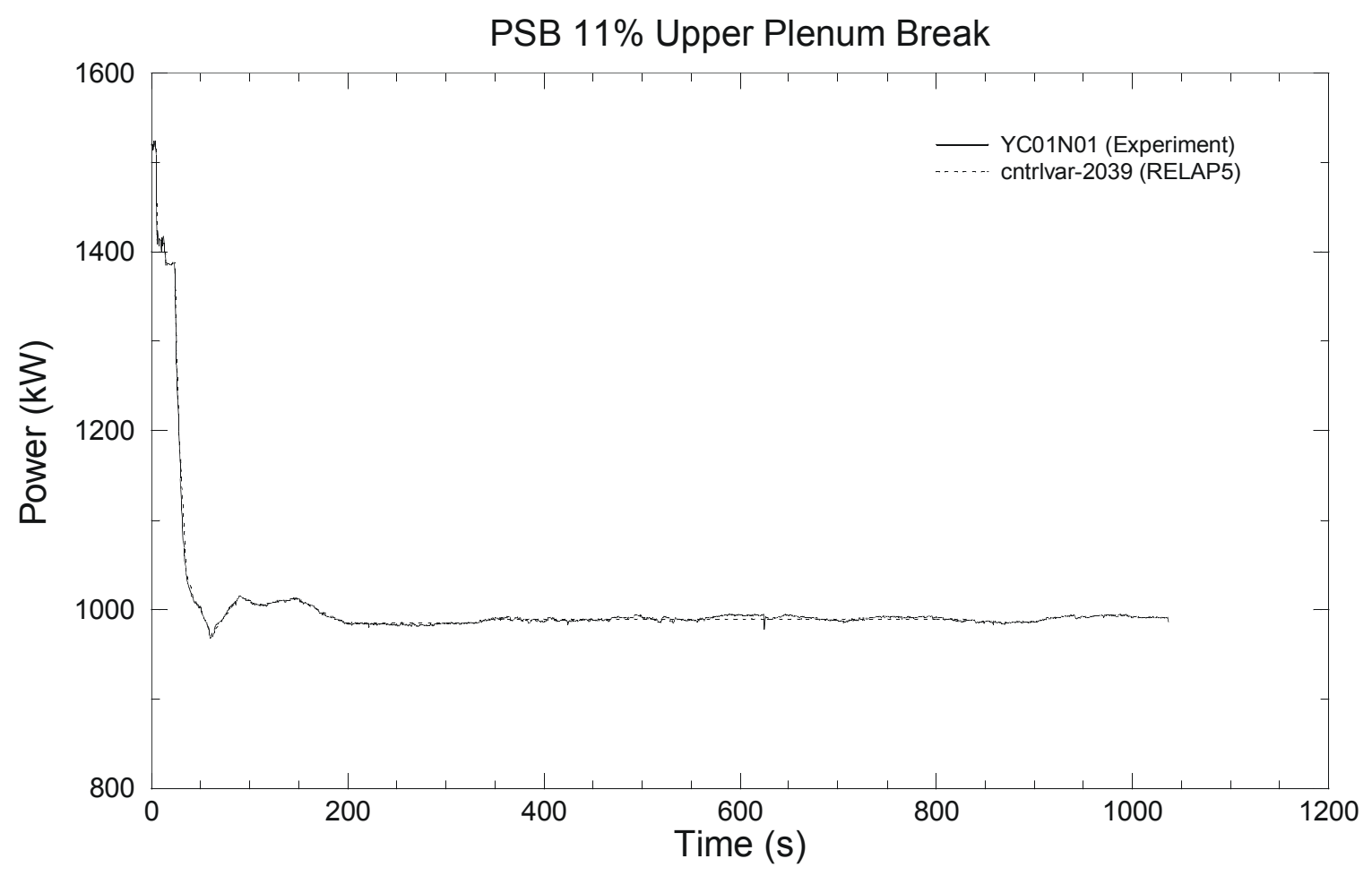

Figure 4. Core power.

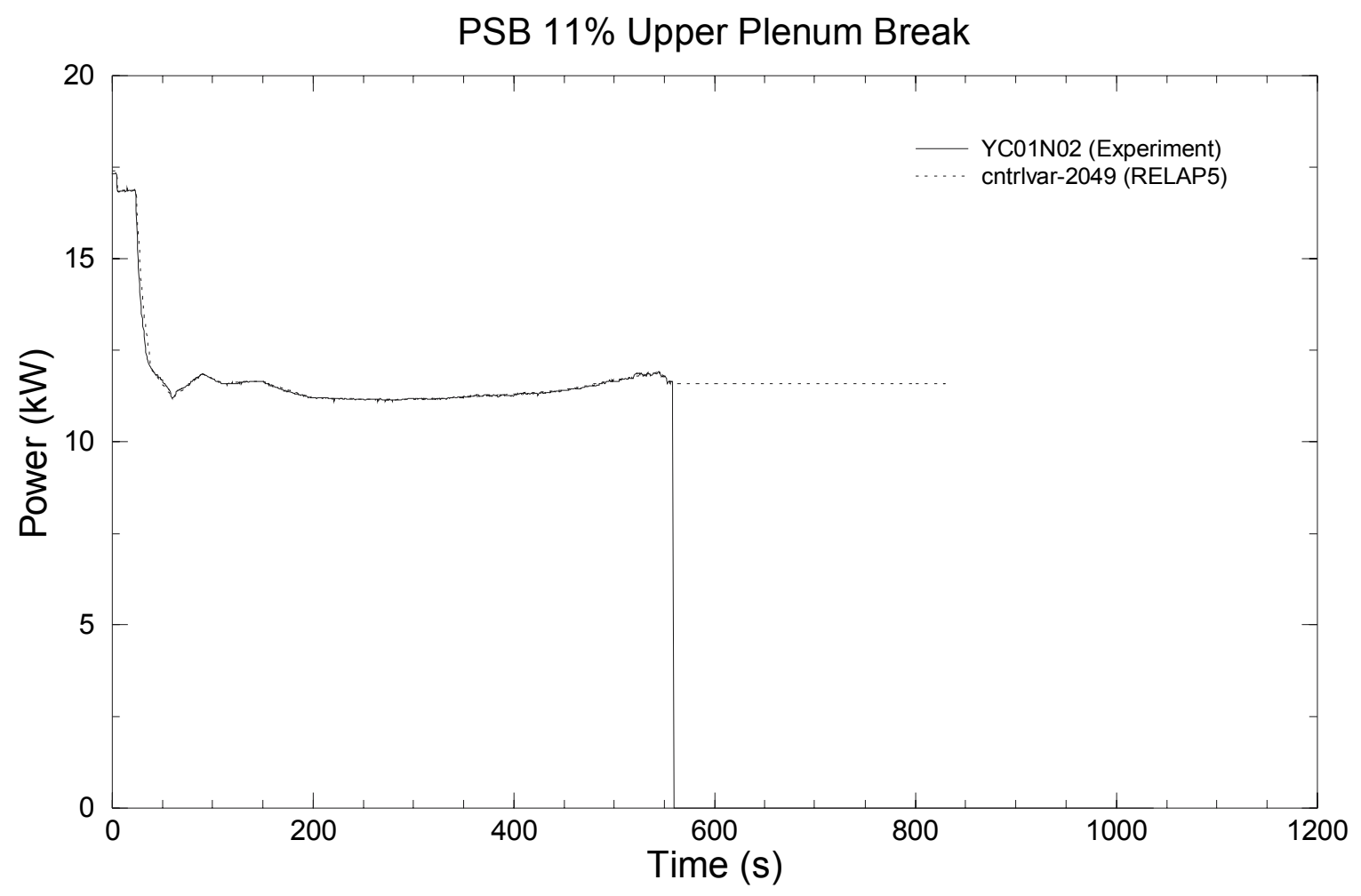

Figure 5. Core bypass power for the base case. 


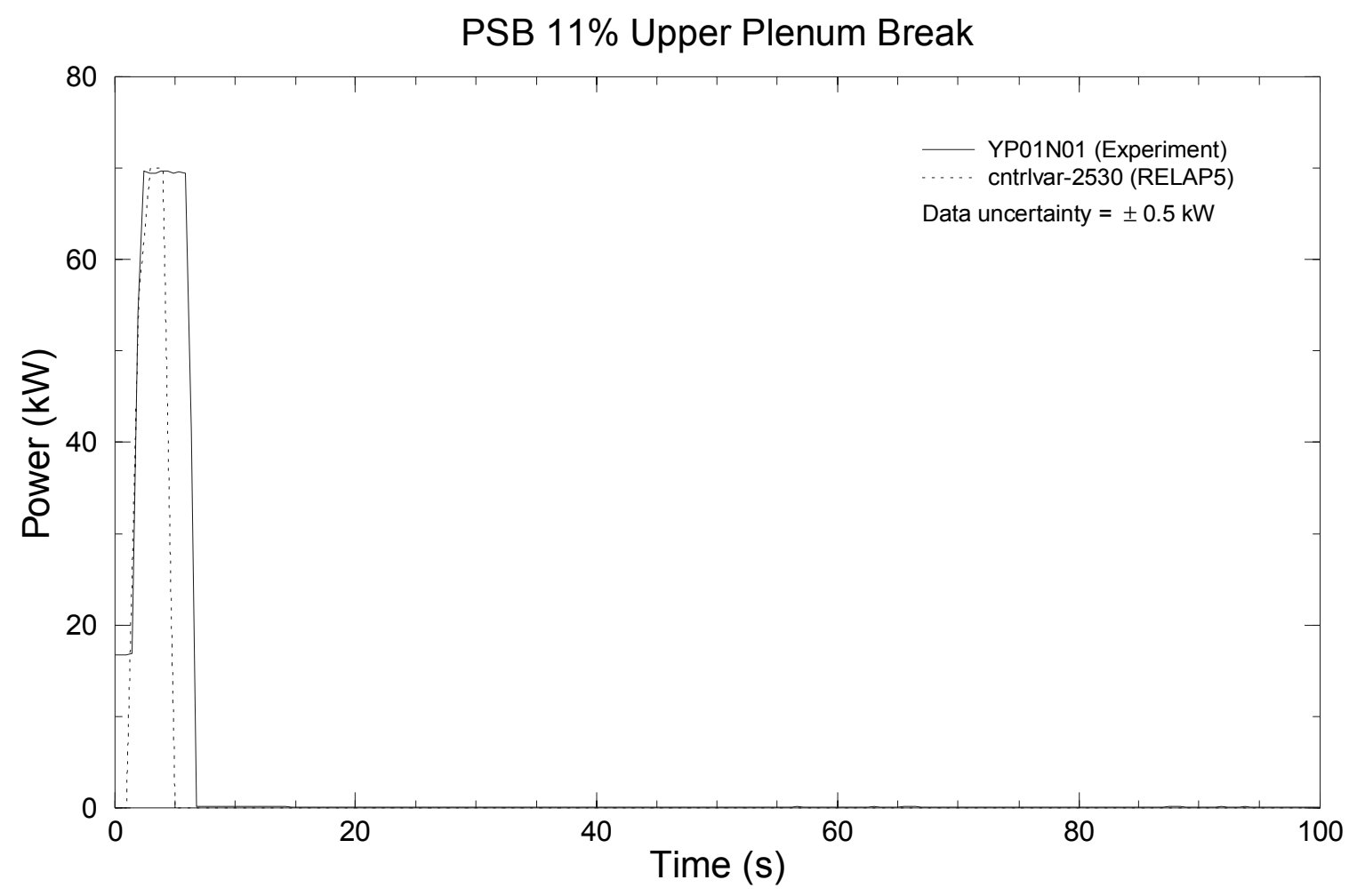

Figure 6. Pressurizer heater power for the base case.

Figure 7 shows the mass flow rate through the break. Despite the higher calculated peak flow rate, the calculation released about the same total mass through the break during the first $20 \mathrm{~s}$. The calculated flow rate was then higher than the measured value for about $50 \mathrm{~s}$, although the upstream fluid densities, shown in Figure 8, were the same; this is an indication that using a smaller discharge coefficient in the input model would provide a better match to the data. The calculated flow made the transition to a high quality mixture faster than the test, resulting in a lower flow rate from 100-300 s. The periodic accumulator injection had a more noticeable effect in the test than in the calculation, causing small increases in the mass flow rate as some of the liquid being injected into the upper plenum was entrained through the break. This is also seen in the fluid density figure. Both the measurement and the calculation show large variations in the fluid density upstream of the break through much of the transient. The measured density increase at the beginning of the transient is questionable. The measured temperature, shown in Figure 9, indicates that in the first $20 \mathrm{~s}$ both the temperature and density have increased from their initial values, while the pressure has decreased, which is not self-consistent. The measured temperature was very close to the saturation temperature throughout the test, with a few sharp decreases in temperature indicating colder liquid flowing to the break. This effect was more pronounced in the calculation, where the discrete nodalization allows the colder ECCS flow to be transported to the break piping with less heating than appears to be occurring in the test.

Figure 10 presents the measured and calculated pressurizer levels, for the instrument that spans the portion of the pressurizer from just above the heaters to the top of the tank. This portion of the pressurizer drained slightly faster in the calculation than in the test, emptying at $16 \mathrm{~s}$ compared to $19 \mathrm{~s}$. Using a smaller break discharge coefficient, as mentioned above, would improve the draining comparison.

Liquid levels in accumulator 1, which are representative of all the accumulators, are shown in Figure 11. In both the data and the calculation, the periodic injection is reflected in the level response. 


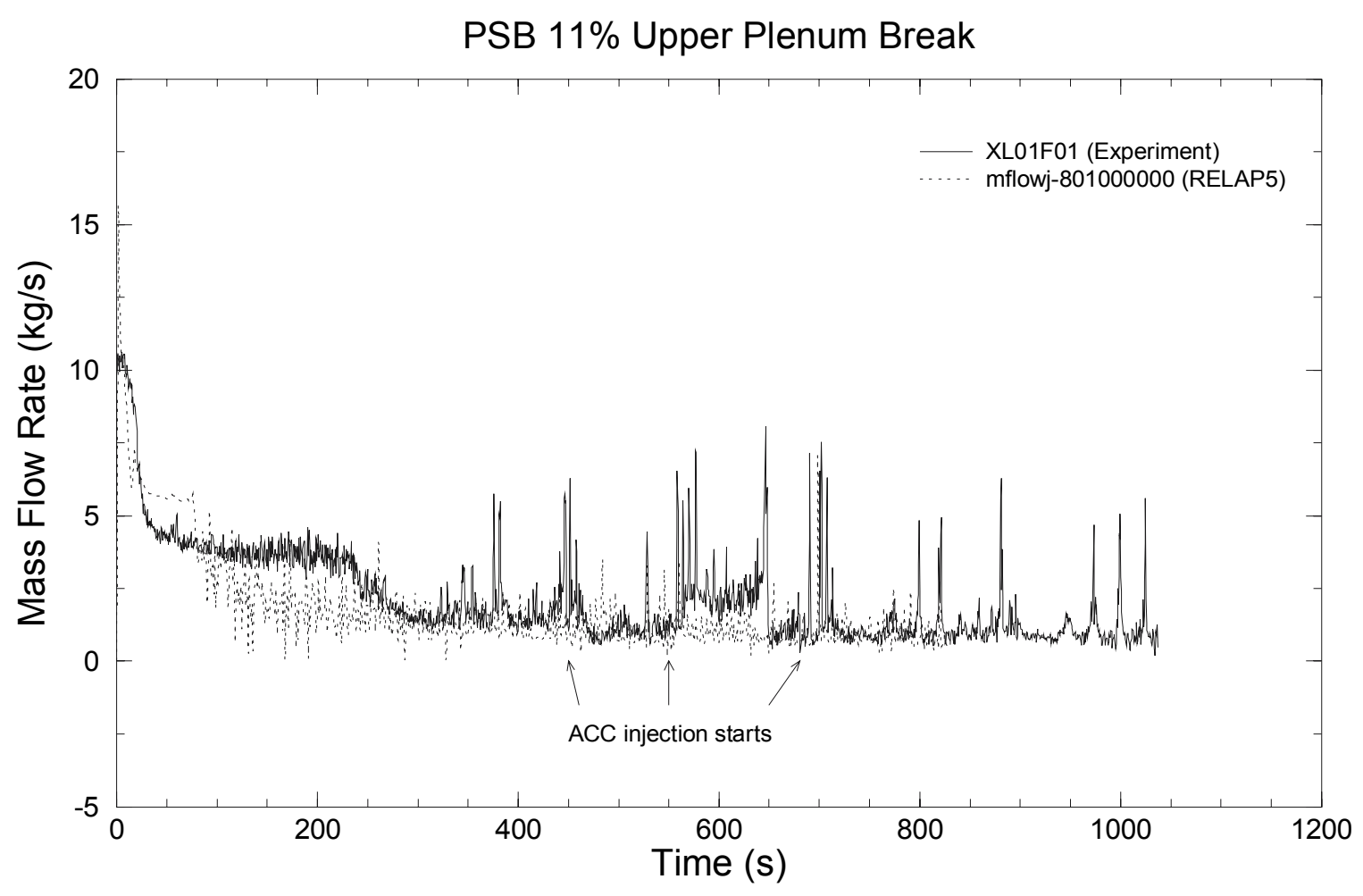

Figure 7. Break flow rate for the base case.

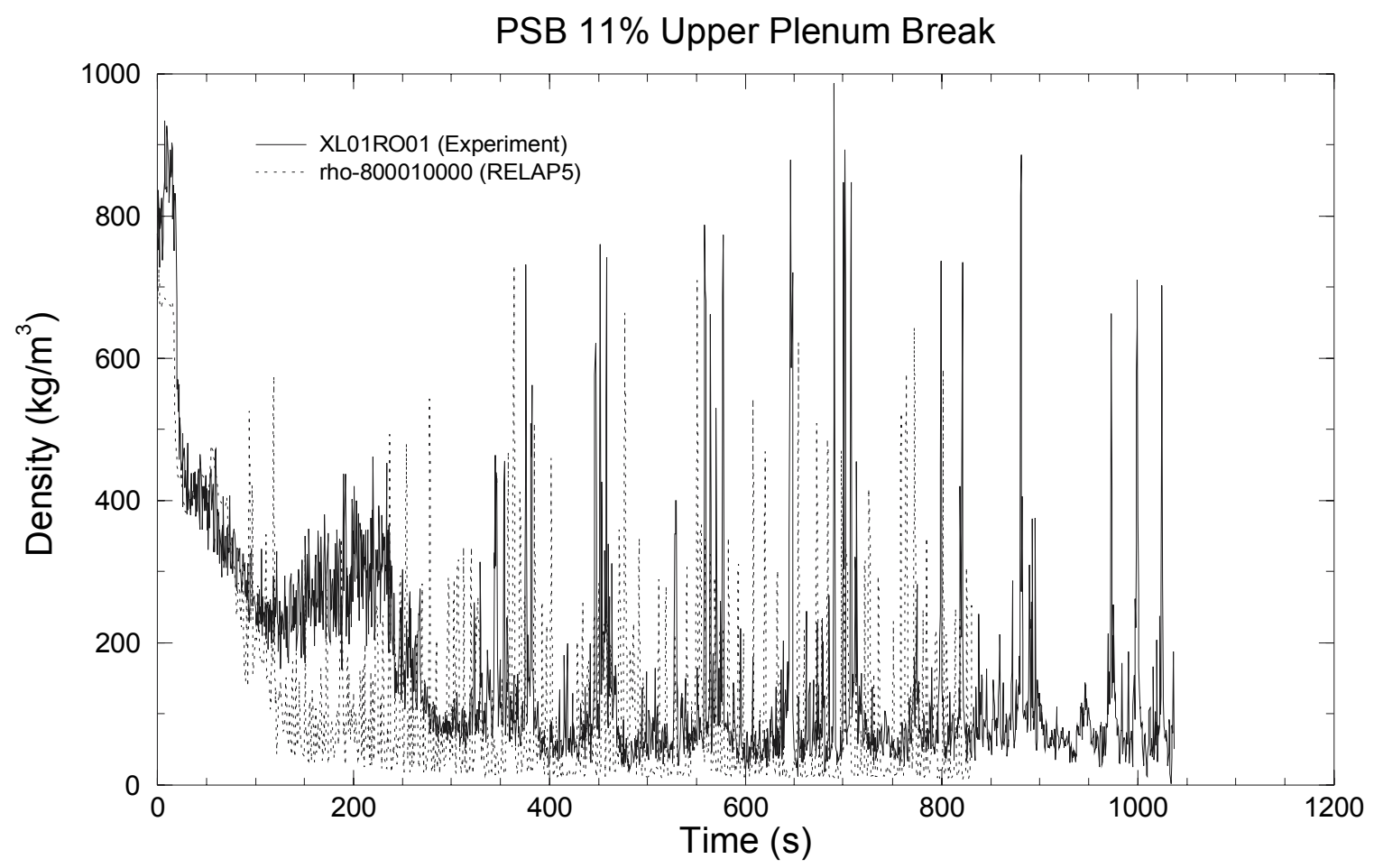

Figure 8. Fluid density in the break piping for the base case. 


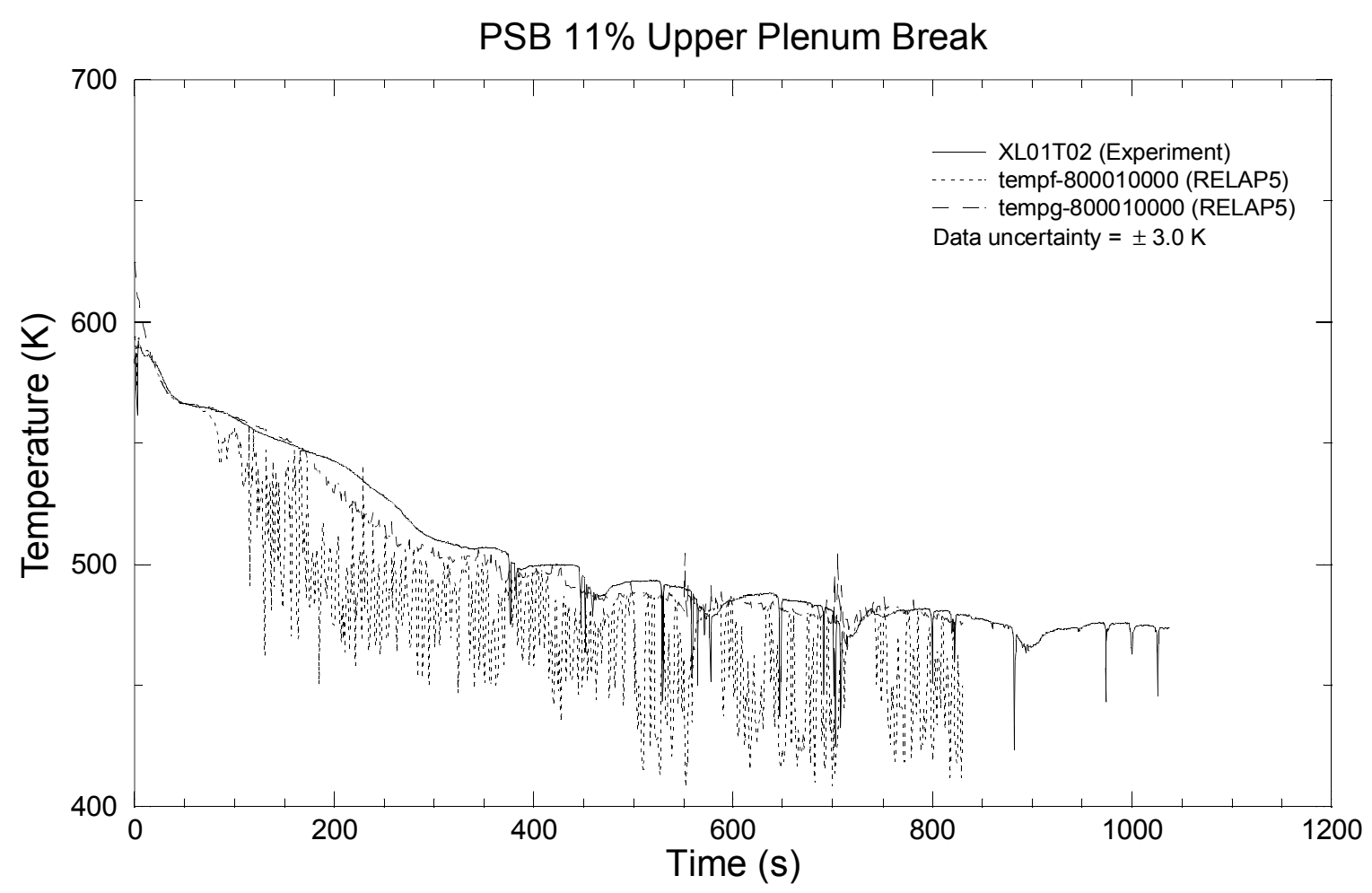

Figure 9. Fluid temperature in the break piping for the base case.

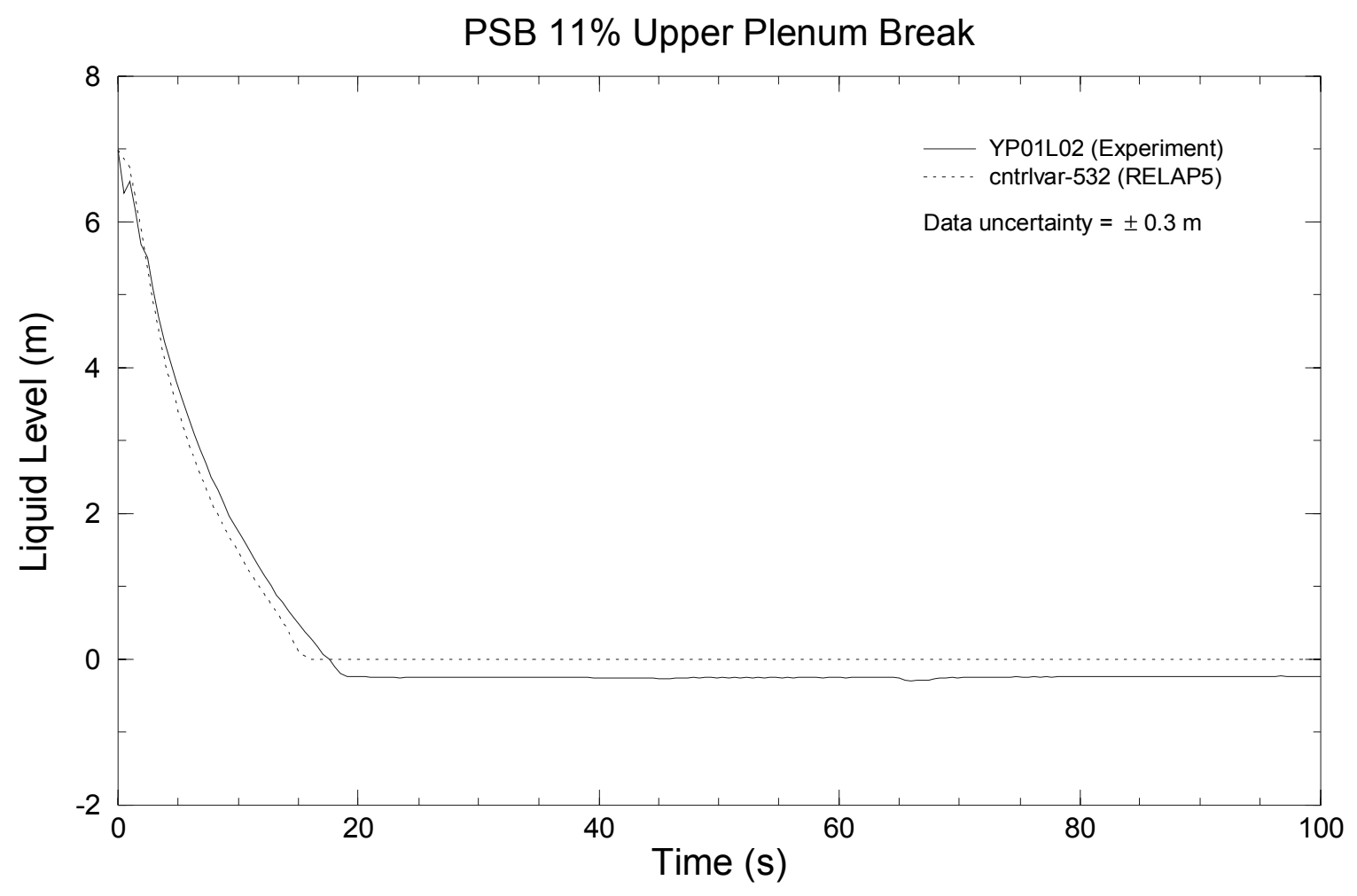

Figure 10. Pressurizer liquid level for the base case. 


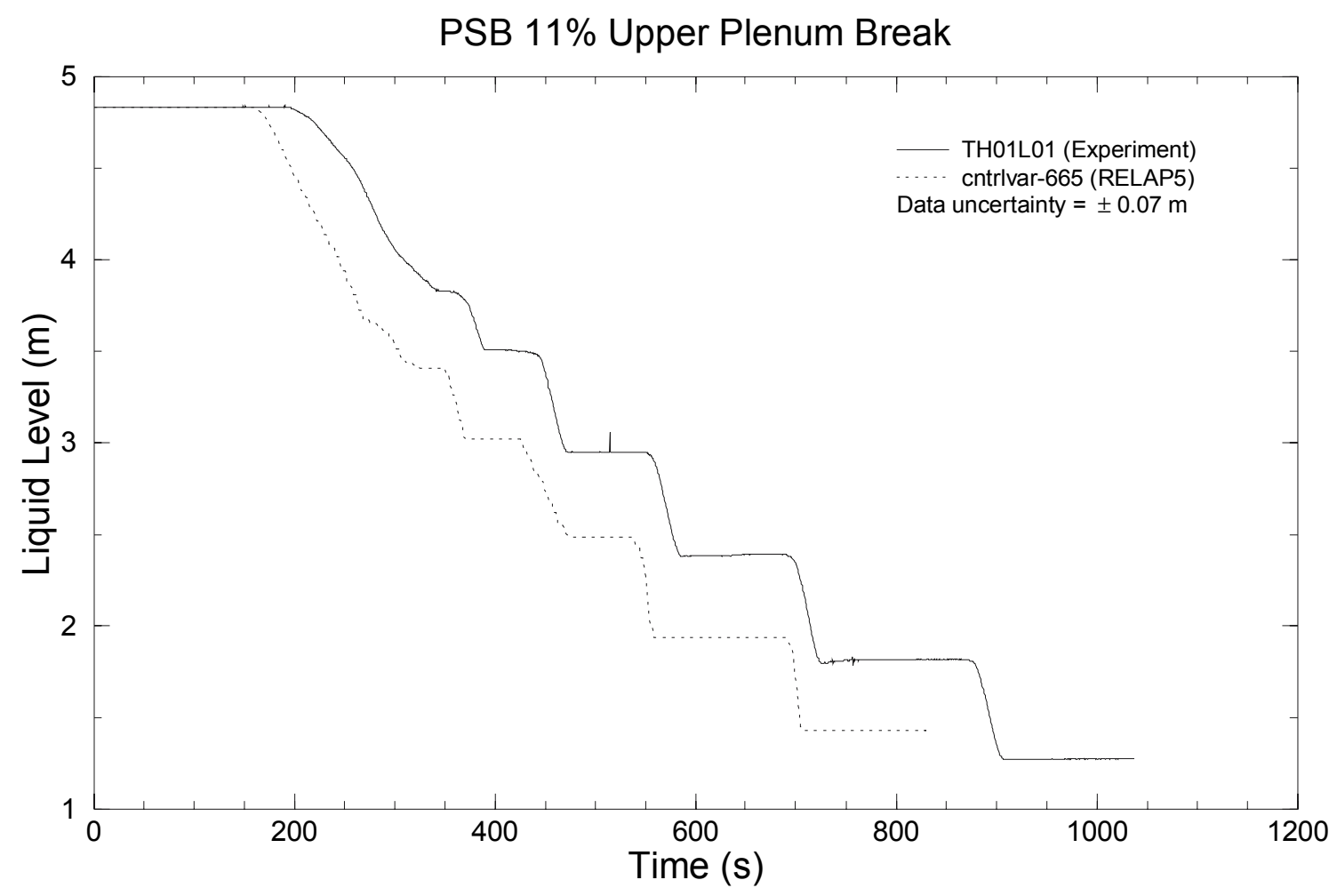

Figure 11. Accumulator 1 liquid level for the base case.

The level decreased more rapidly in the calculation than in the test because the calculated primary system pressure was lower than the measured value.

Accumulator 1 pressures are shown in Figure 12. As with the accumulator levels, the pressure reflects the periodic injection to the primary system, with the calculated pressure dropping earlier because of the lower calculated primary system pressure. The small increases in pressure between injections in the data were not captured in the calculation. The pressure increased because of heat transfer from the hotter walls to the vapor in the accumulator, an effect that was underpredicted by the code.

Mass flow rates through two of the coolant loops are shown in Figures 13 and 14. According to the experiment data report, ${ }^{6}$ the measurements are only reliable until $50 \mathrm{~s}$. This time period includes the pump coastdown, starting at $10 \mathrm{~s}$, and the transition to natural circulation flow. The calculations for both loops 1 and 4 are in excellent agreement with the data during this period. Once natural circulation was established in the loops, it did not last long. As steam continued to be generated in the system, it displaced liquid in the steam generators, causing a steady decline in the loop flow rate; by $200 \mathrm{~s}$, there was essentially no flow through the coolant loops in the calculation.

With no forced flow through the system, the differential pressure measurements provide an indication of the collapsed liquid level, or average void fraction, between the pressure taps. The indicated differential pressure will move toward zero (the absolute value decreases) as the liquid between the pressure taps is replaced by steam (as the void fraction increases or the collapsed level decreases). These instruments can be used to determine how the liquid is distributed in the facility.

Differential pressures in different axial regions of the core are shown in Figures 15-17. The initial void formation in the core was reasonably simulated by the code. In the experiment, the upper portion of 


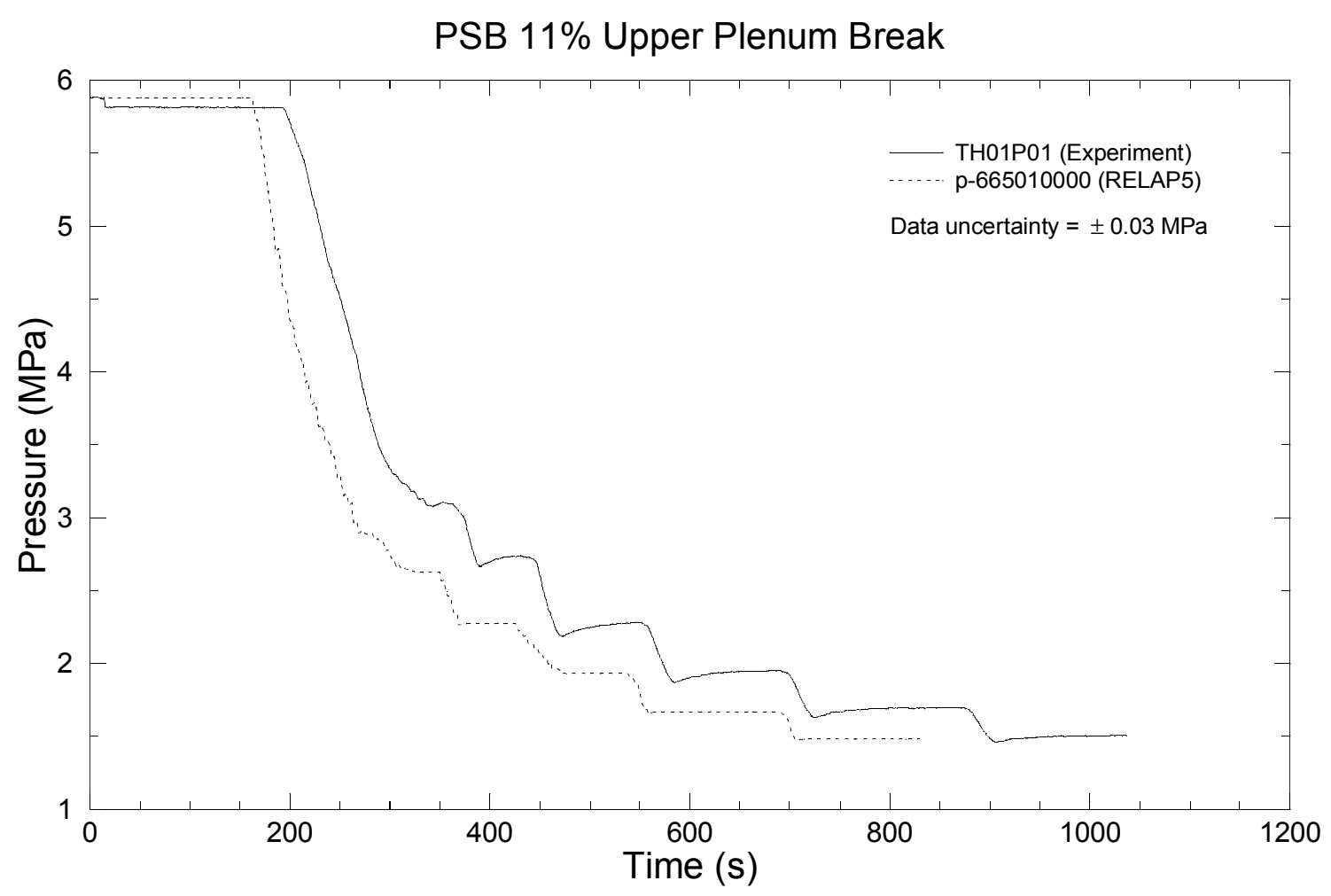

Figure 12. Accumulator 1 pressure for the base case.

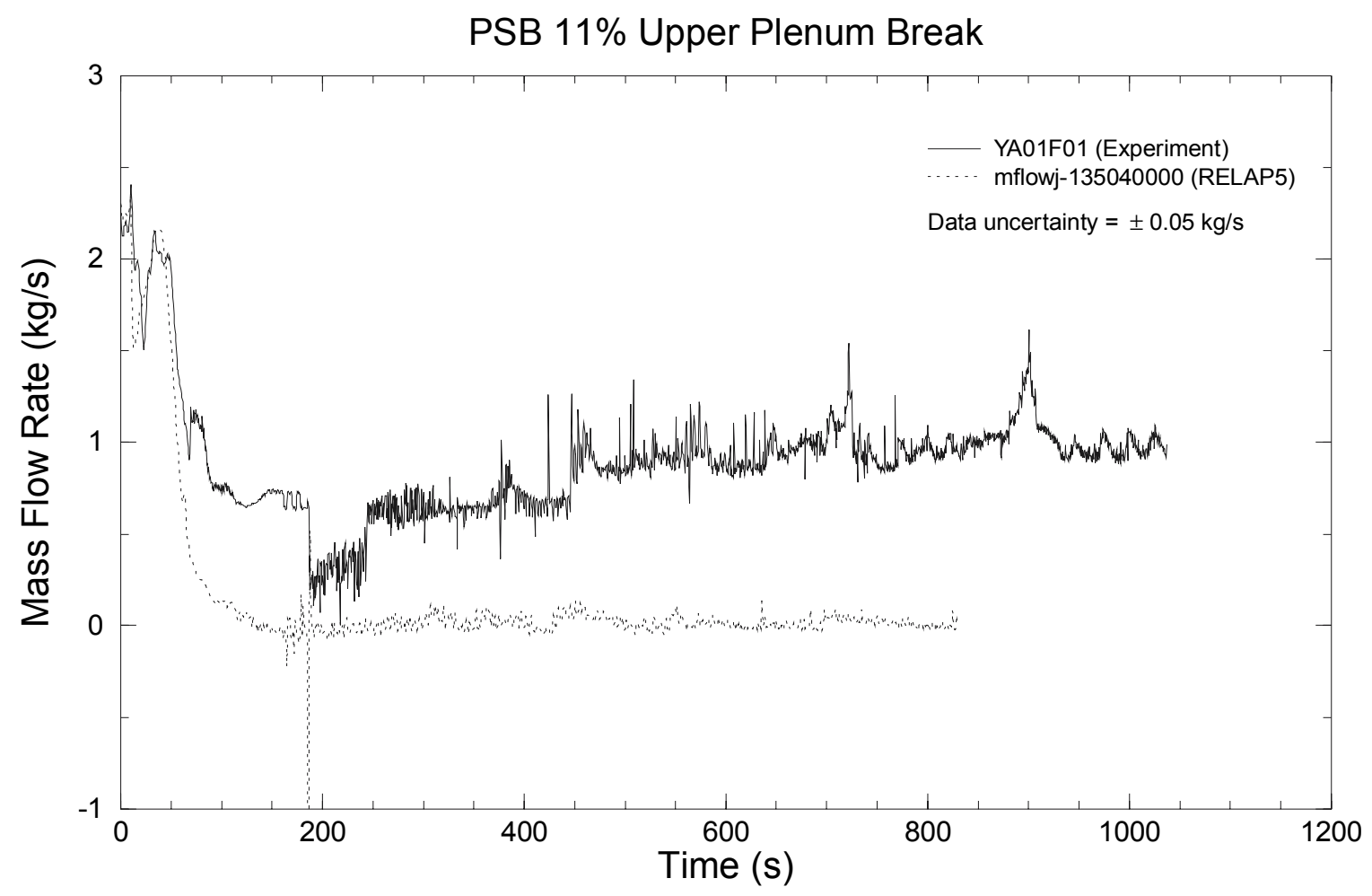

Figure 13. Loop 1 mass flow rate for the base case. 


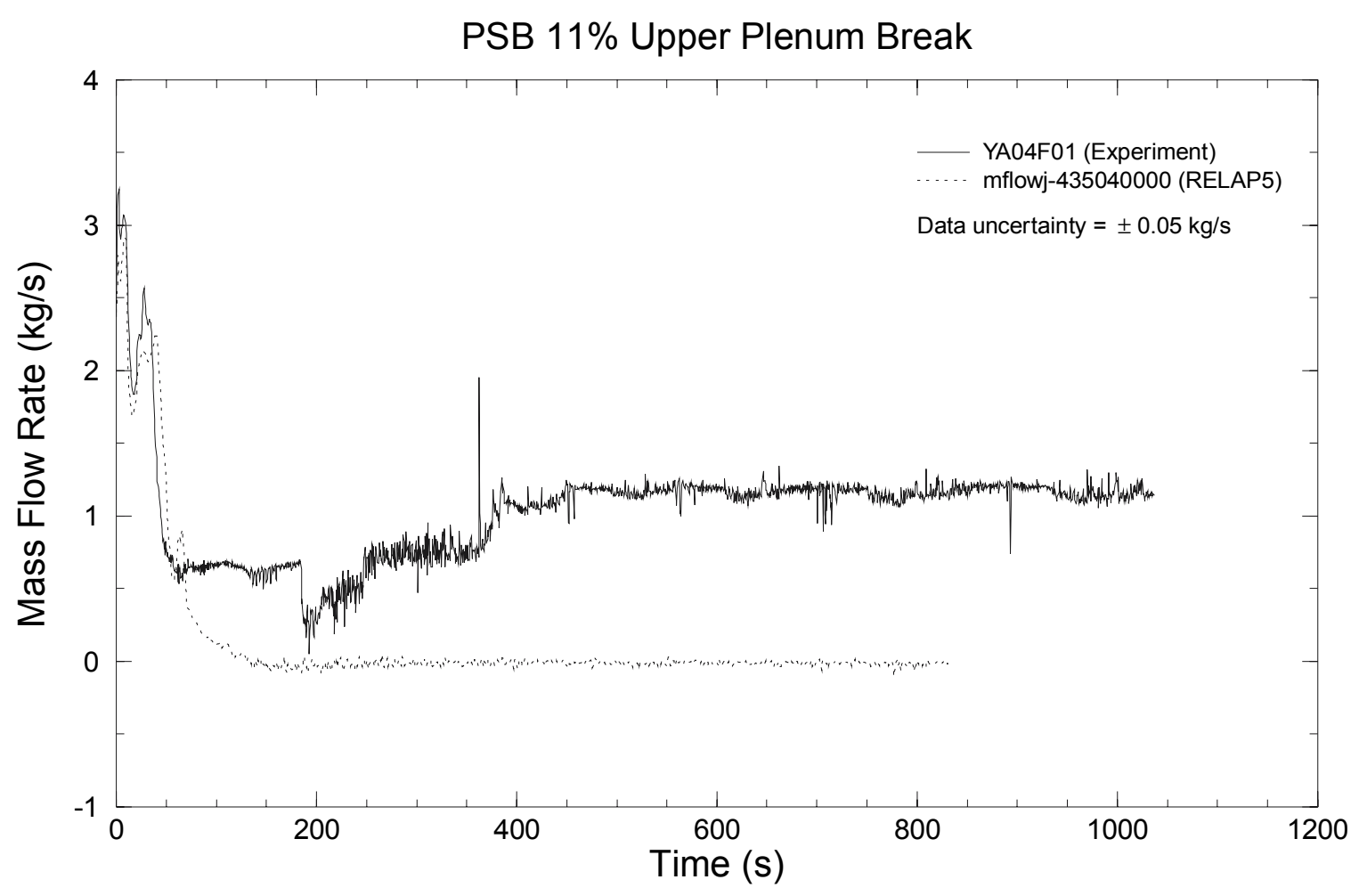

Figure 14. Loop 4 mass flow rate for the base case.

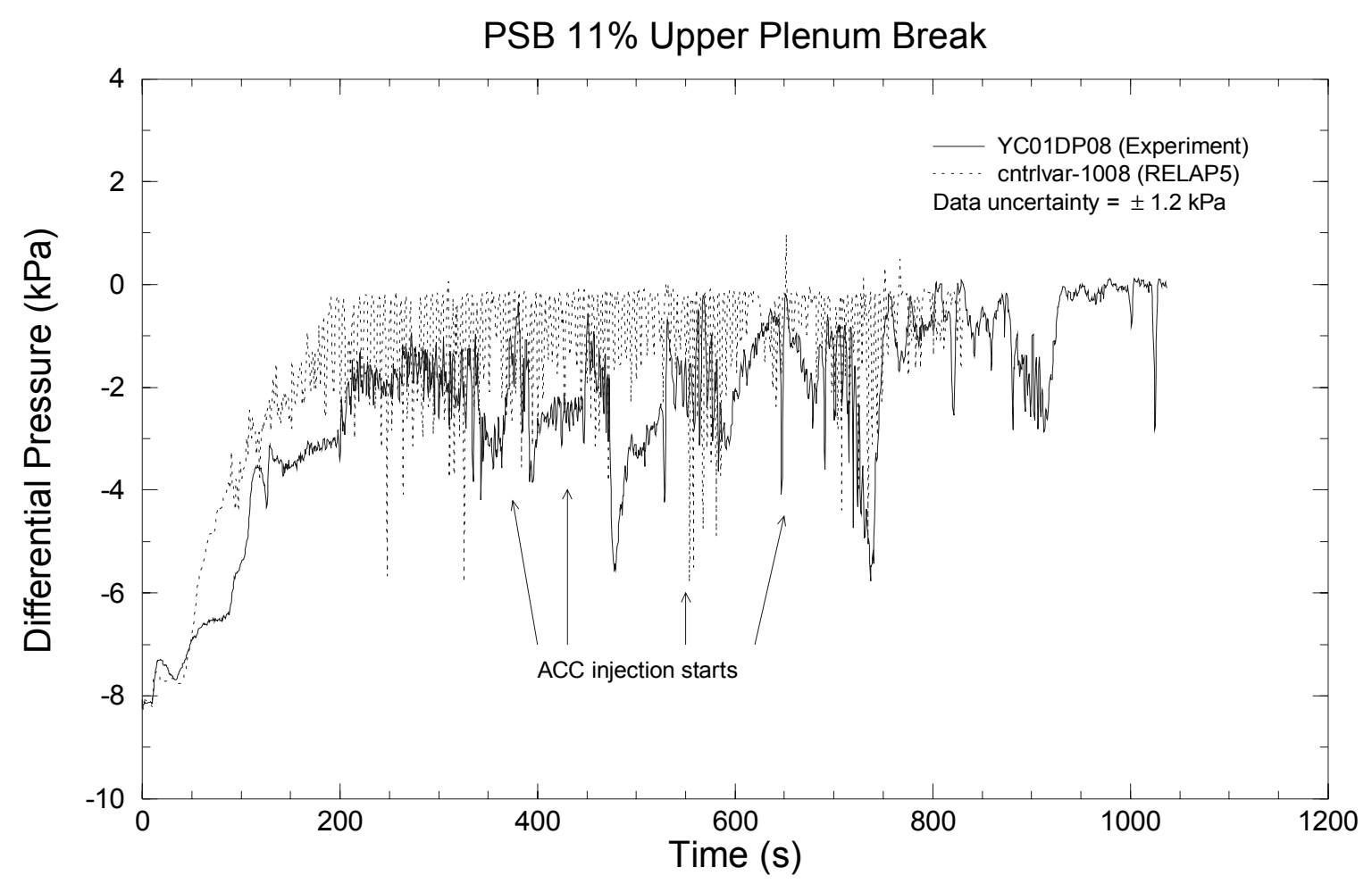

Figure 15. Differential pressure in the lower portion of the core simulator for the base case. 


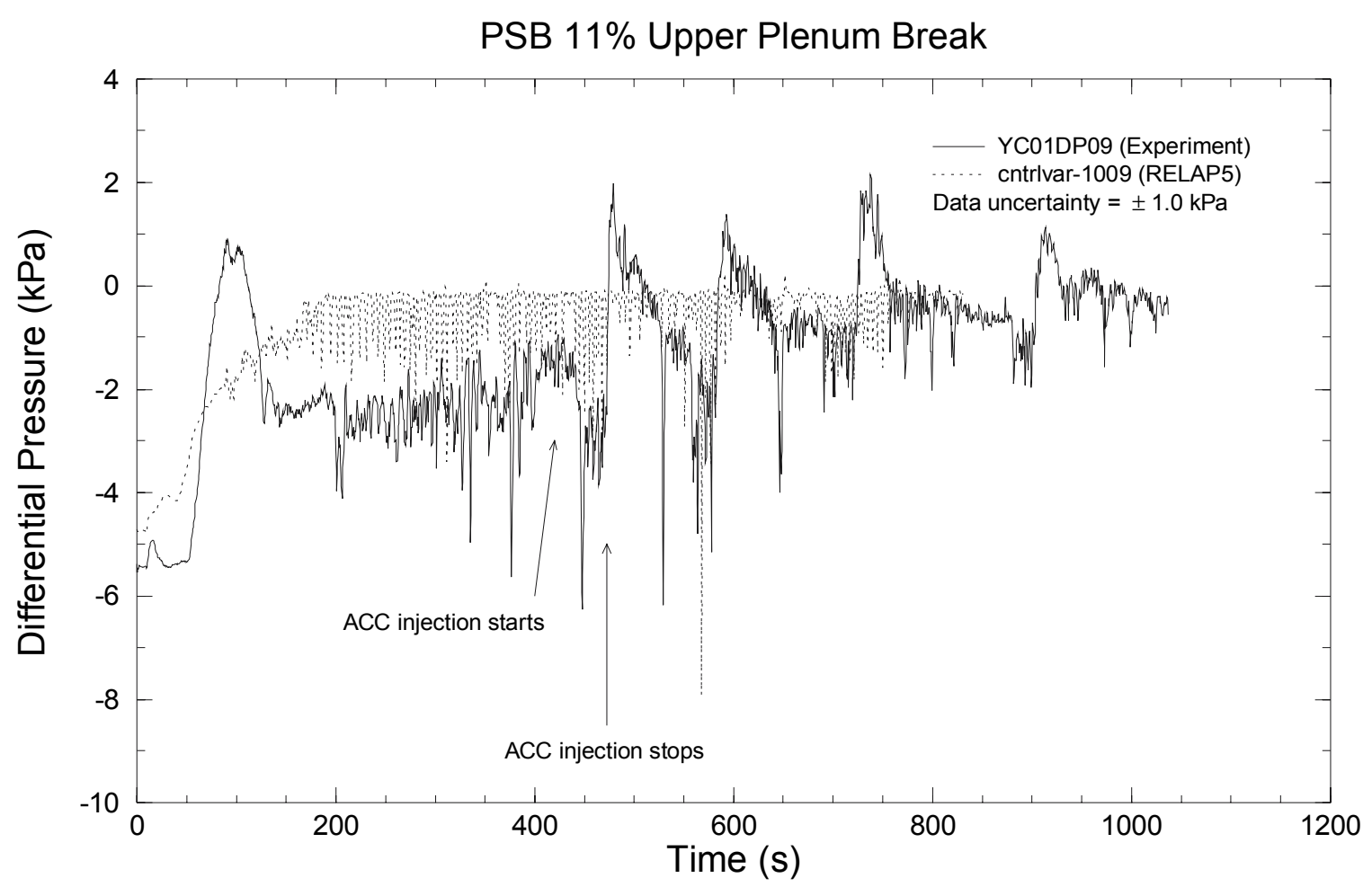

Figure 16. Differential pressure in the middle portion of the core simulator for the base case.

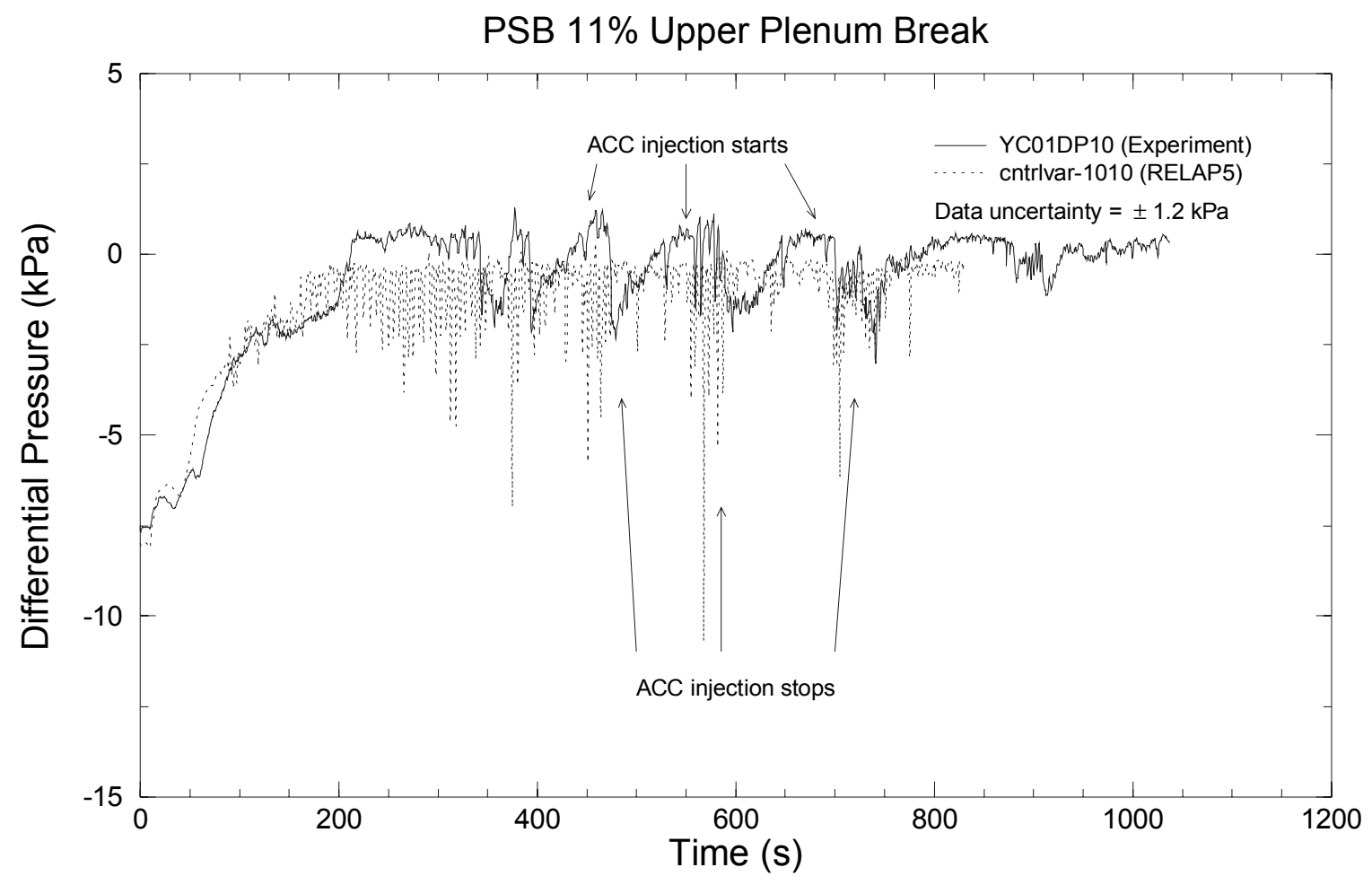

Figure 17. Differential pressure in the upper portion of the core simulator for the base case. 
the core had less liquid than the lower portions, while in the calculation the axial void profile was fairly uniform. The effects of the accumulator injection were also different in the test and calculation. In the test, the beginning of the accumulator injection cycle resulted in decreases in the differential pressure after a short delay. After the injection stopped, the differential pressures in the upper and lower portions slowly moved toward their previous values, and the middle of the core saw a rapid increase to values above zero. Since the measurement should read slightly below zero when the region is steam filled, this may be an indication of a problem with the measurement. In the calculation, there was no noticeable effect of the accumulator injection on the differential pressures. This is further illustrated by the core collapsed level response, shown in Figure 18, where there is very little change in the core liquid content during most of the transient.

The differential pressure across the core bypass is shown in Figure 19. The calculation agrees well with the data before accumulator injection begins, then generally has less liquid than in the test. When accumulator injection starts before $200 \mathrm{~s}$, the initial effect is a reduction in the liquid level in the core bypass. The reduced system pressure resulting from condensation on the injection liquid allows some of the remaining liquid to flash or boil. Subsequent injections of liquid from the accumulators resulted in level increases in both the data and calculation, which are reflected as decreases in the differential pressure. The impact of the injection is more pronounced in the test than in the calculation. Despite retaining less liquid, the core bypass wall temperatures were lower in the calculation than were measured. With lower temperatures, the bypass heater power remained on throughout the calculation, whereas in the test the power was reduced to protect the heaters when the peak temperature reached $673 \mathrm{~K}$ near $560 \mathrm{~s}$.

Differential pressures in the upper plenum are shown in Figures 20 and 21. More liquid was retained in the calculation than in the experiment, particularly in the upper portion of the upper plenum. Possible reasons for the overprediction of the liquid inventory in the upper plenum are that CCFL at the core exit is preventing liquid from falling back into the core region in the calculation, that the interphase drag is overpredicted at the core exit, again preventing liquid from separating from the vapor flow and draining to lower portions of the reactor vessel, or that interphase drag is underpredicted at the connection to the break piping, not allowing enough liquid to be entrained from the upper plenum into the break piping.

Differential pressures in the upper head are shown in Figures 22 and 23. The early draining of the upper head region was well calculated by the code.

Differential pressures in the downcomer are shown in Figures 24 and 25. In the test, the upper portion of the downcomer drained completely before $200 \mathrm{~s}$. Water injection from the accumulators temporarily restored liquid to this region, but it drained completely between injection cycles. The calculated level did not drop that far, retaining some liquid between injection cycles. Accordingly, the calculated differential pressure in the lower portion of the downcomer did not show as much of an effect of the accumulator injections, especially later in the transient. A major feature not captured in the calculation is the apparent complete draining of the downcomer near $200 \mathrm{~s}$. This was the only time during the test that the level dropped nearly that far, and it is not clear what caused this response, as there is no corresponding change in other differential pressure measurements that indicate that liquid has flowed from the downcomer to some other location in the system; in fact, the core and core bypass differential pressures also show a reduction in liquid inventory at this time.

Figure 26 shows the differential pressure in the steam generator 1 hot collector, which is typical of the behavior seen in all four loops. The hot collector drains within about $70 \mathrm{~s}$ in the test, and a little earlier in the calculation, not long after boiling began in the core. The steam generator tubes then drained into the cold collector; in the calculation, all of the tubes were dry by about $180 \mathrm{~s}$. 


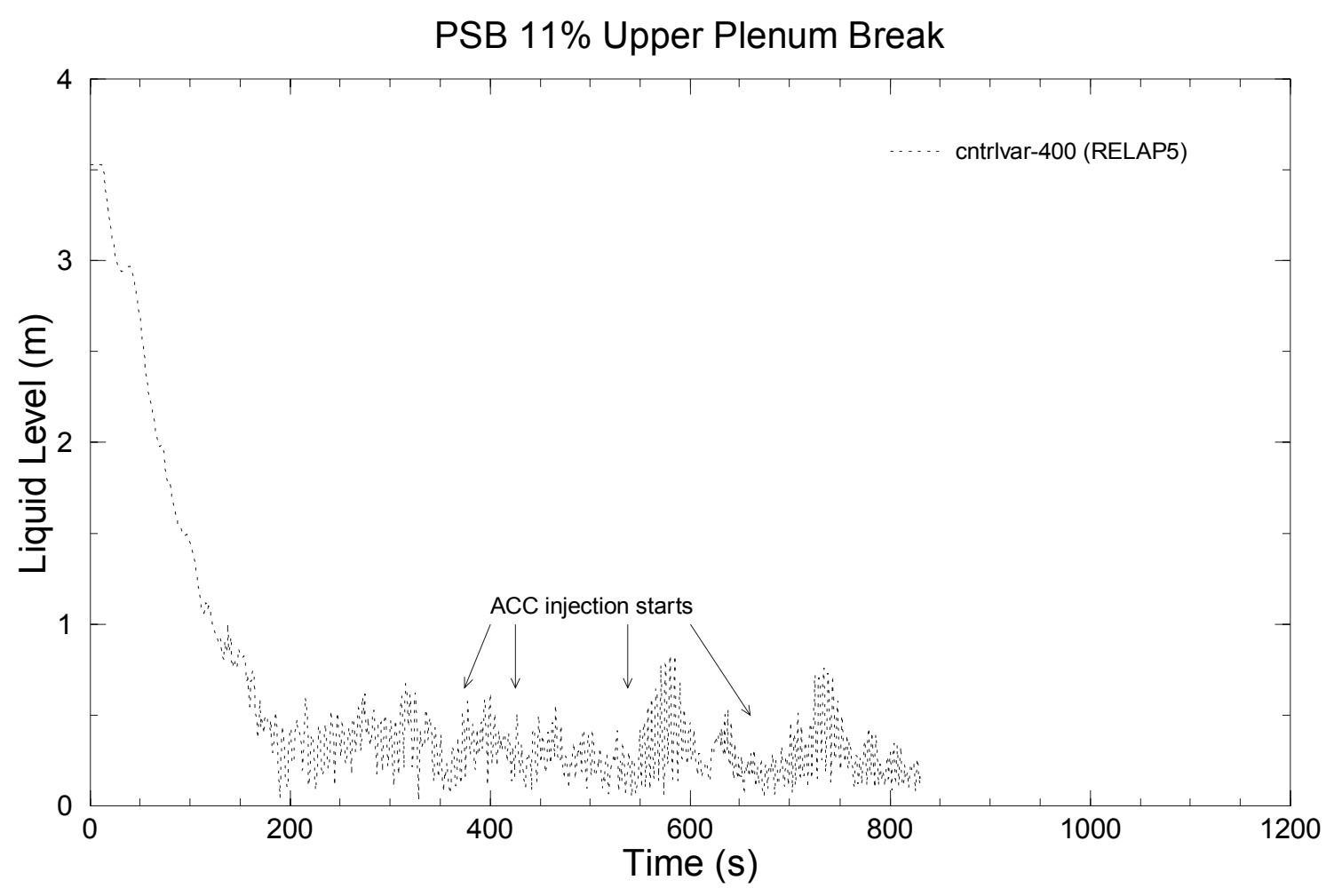

Figure 18. Core collapsed liquid level for the base case.

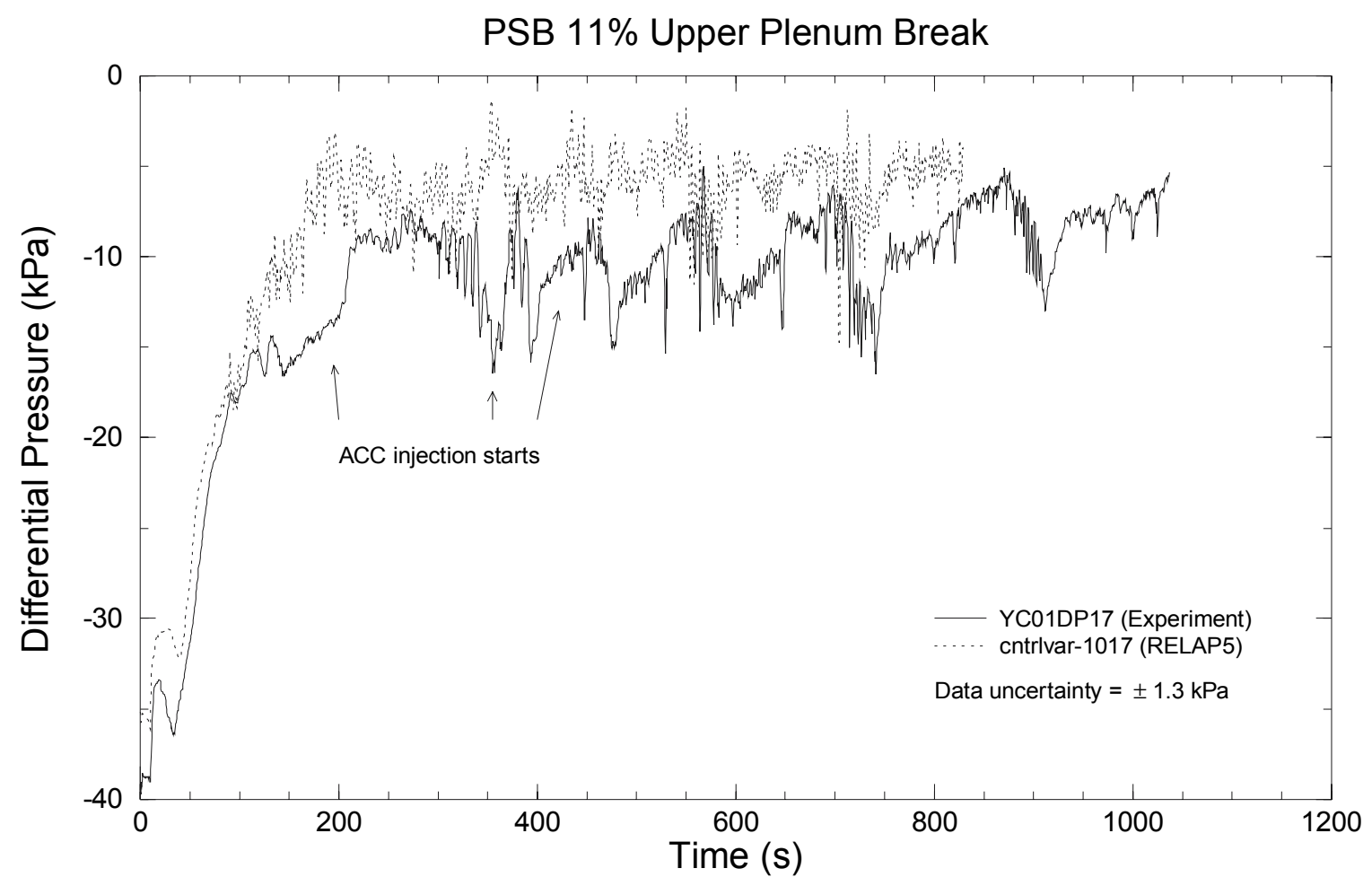

Figure 19. Core bypass differential pressure for the base case. 


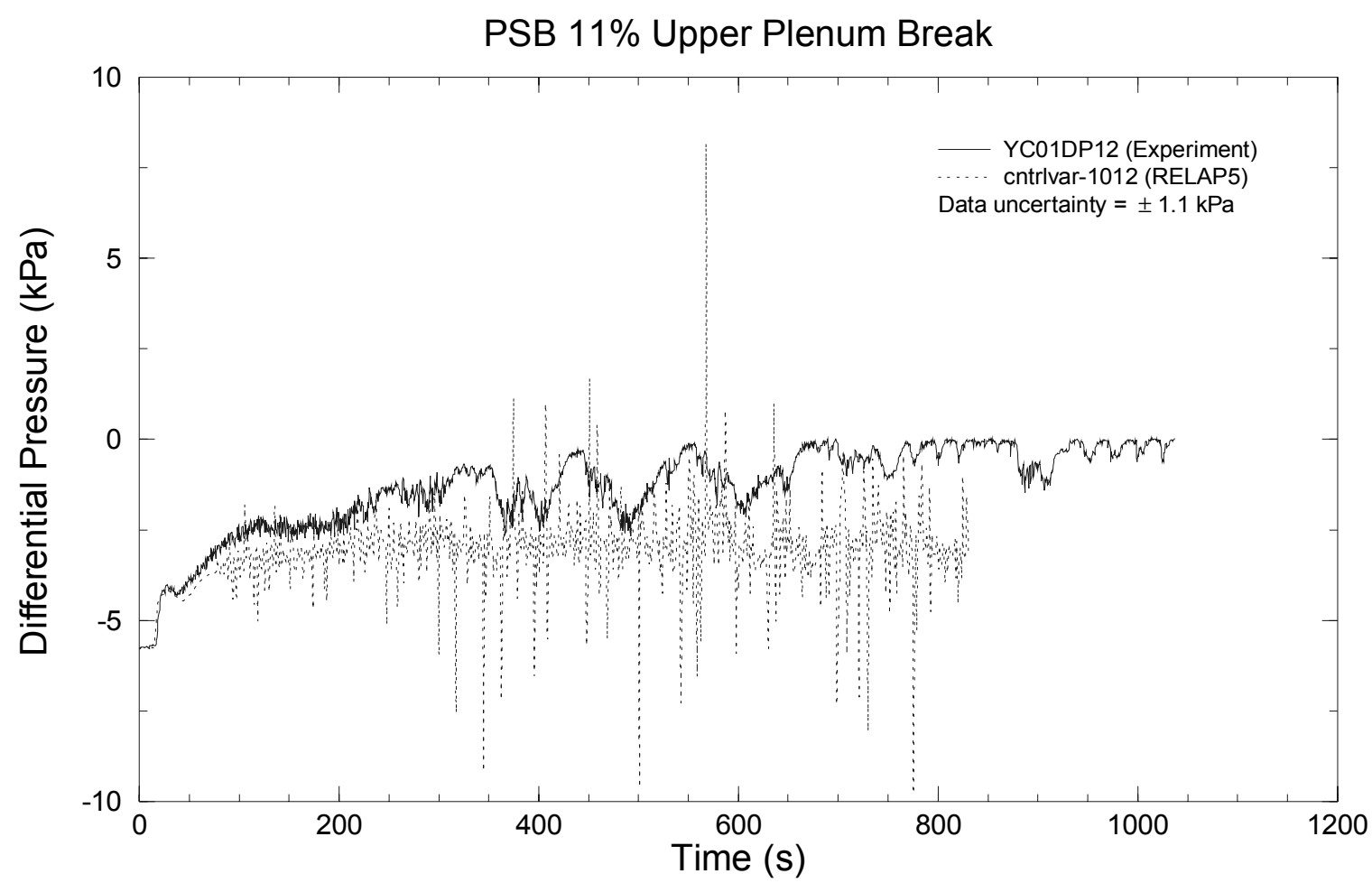

Figure 20. Differential pressure in the lower portion of the upper plenum for the base case.

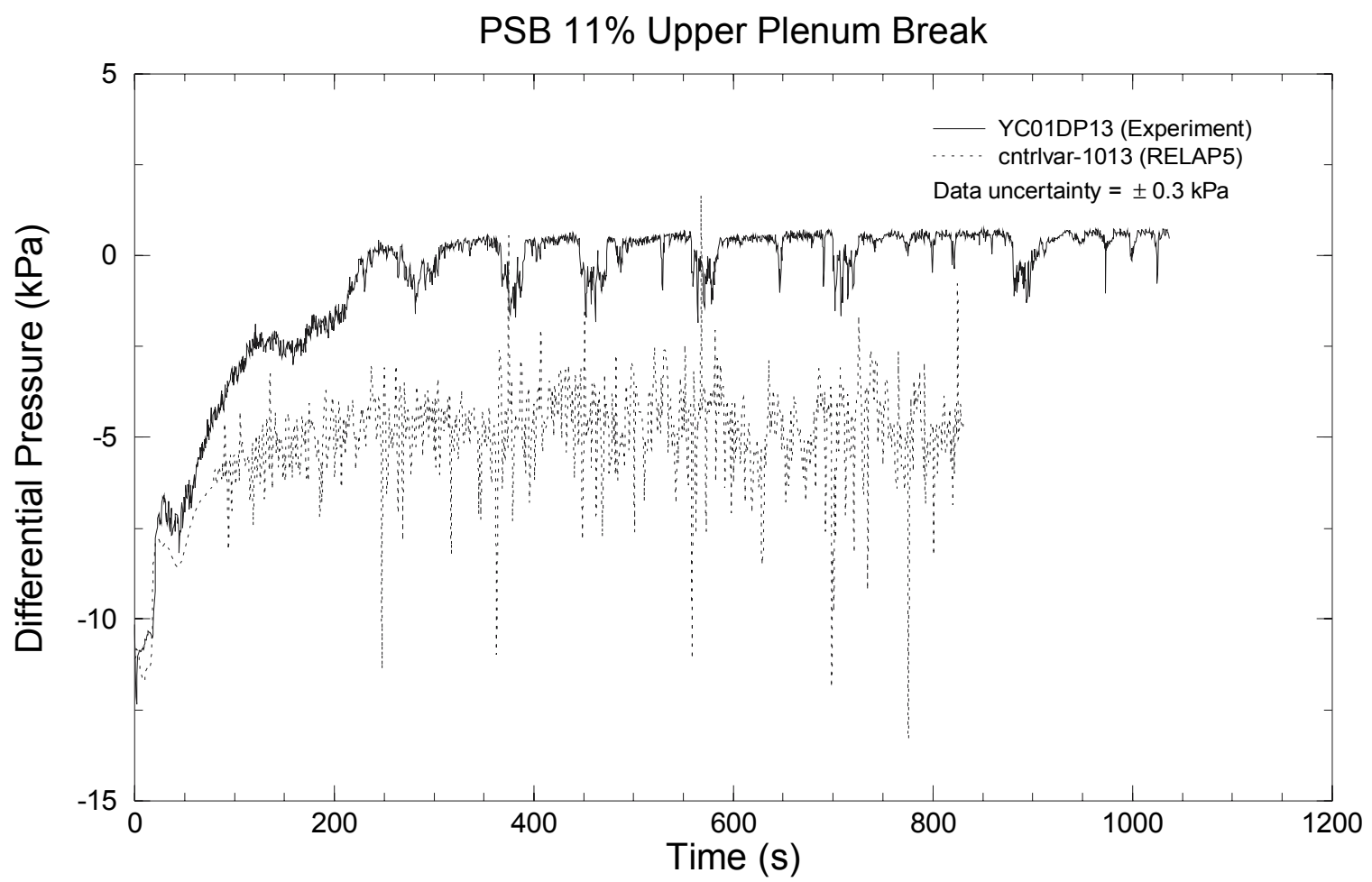

Figure 21. Differential pressure in the upper portion of the upper plenum for the base case. 


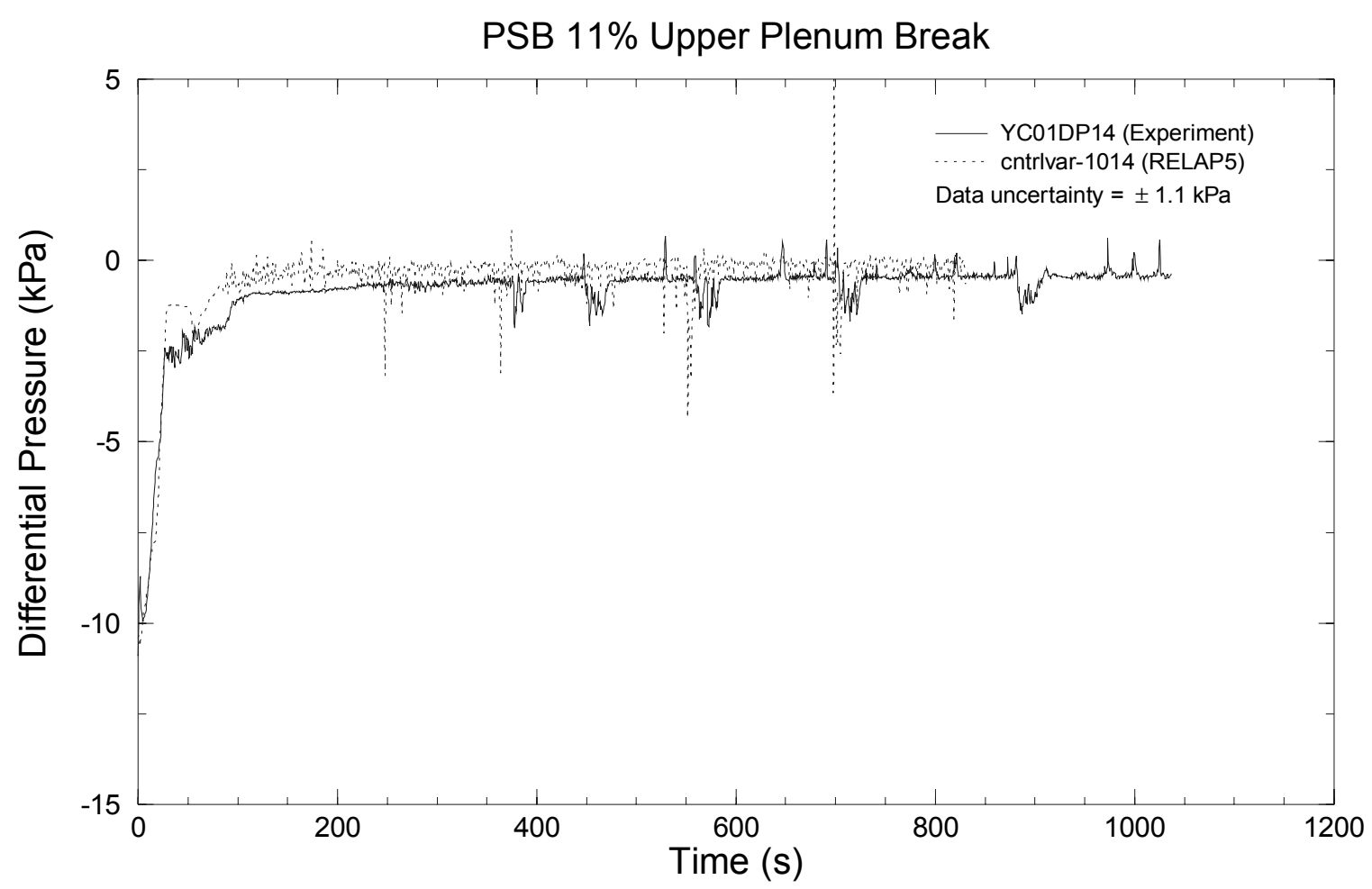

Figure 22. Differential pressure in the lower portion of the upper head for the base case.

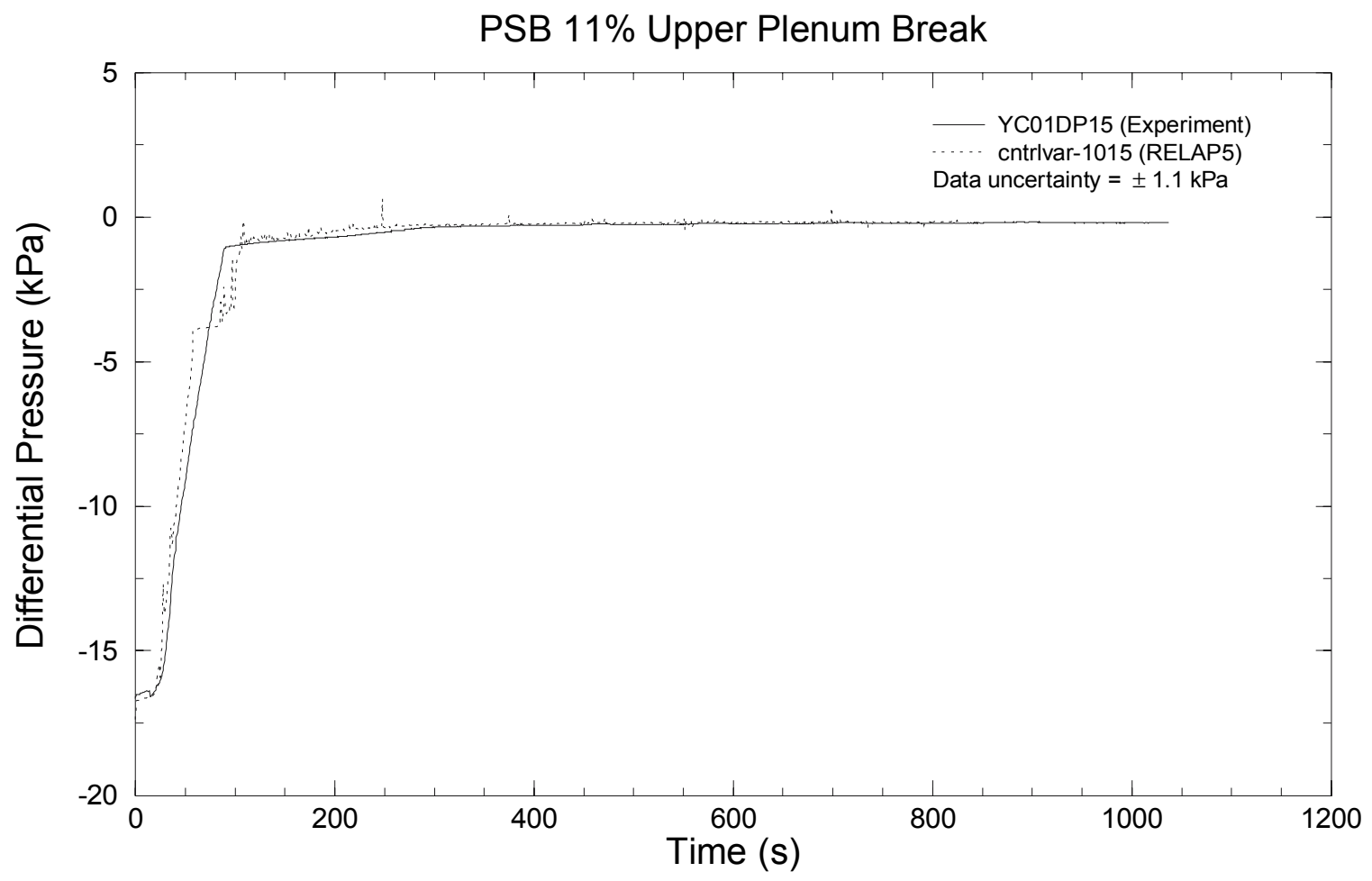

Figure 23. Differential pressure in the upper portion of the upper head for the base case. 


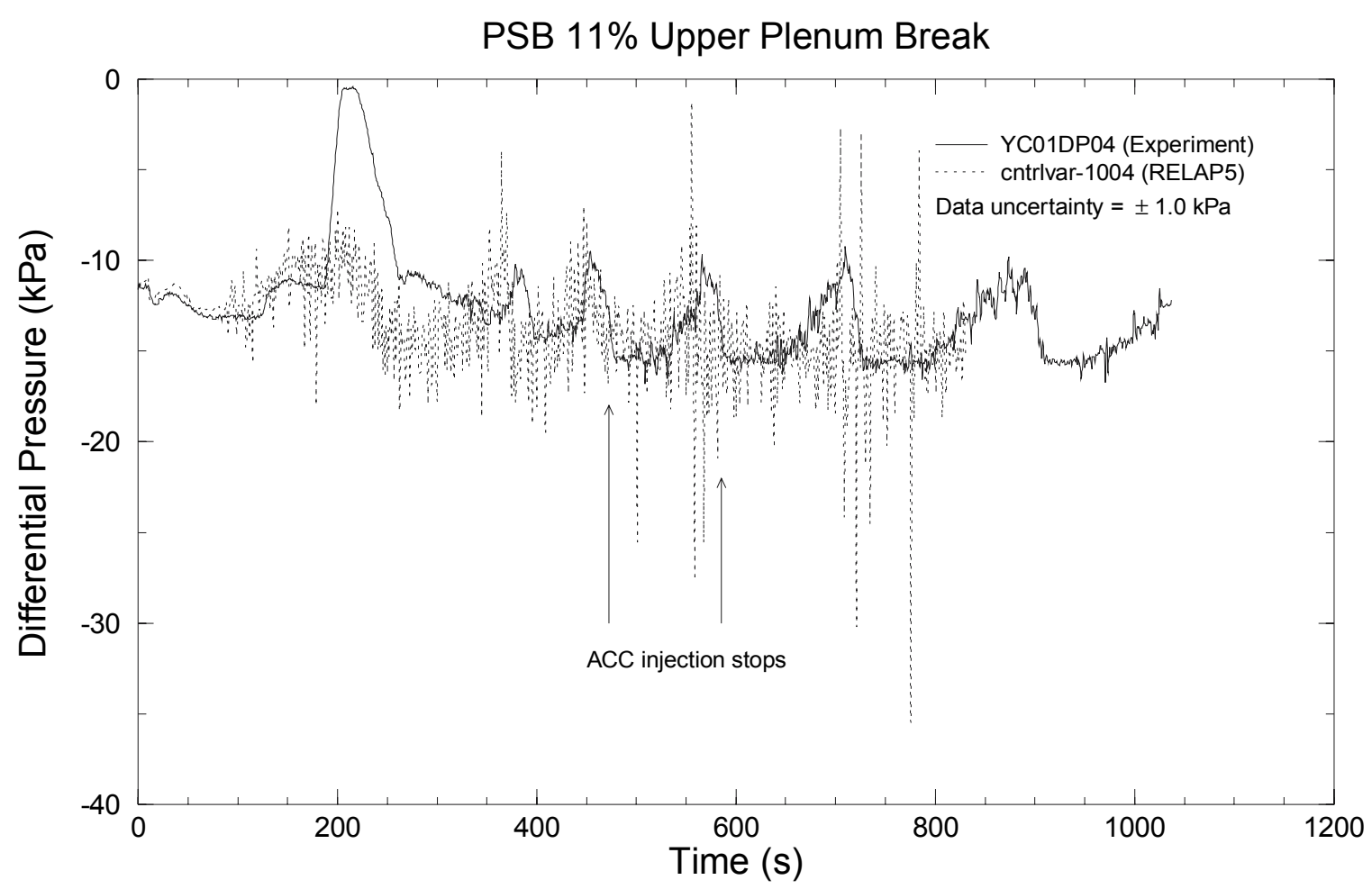

Figure 24. Differential pressure in the lower portion of the downcomer for the base case.

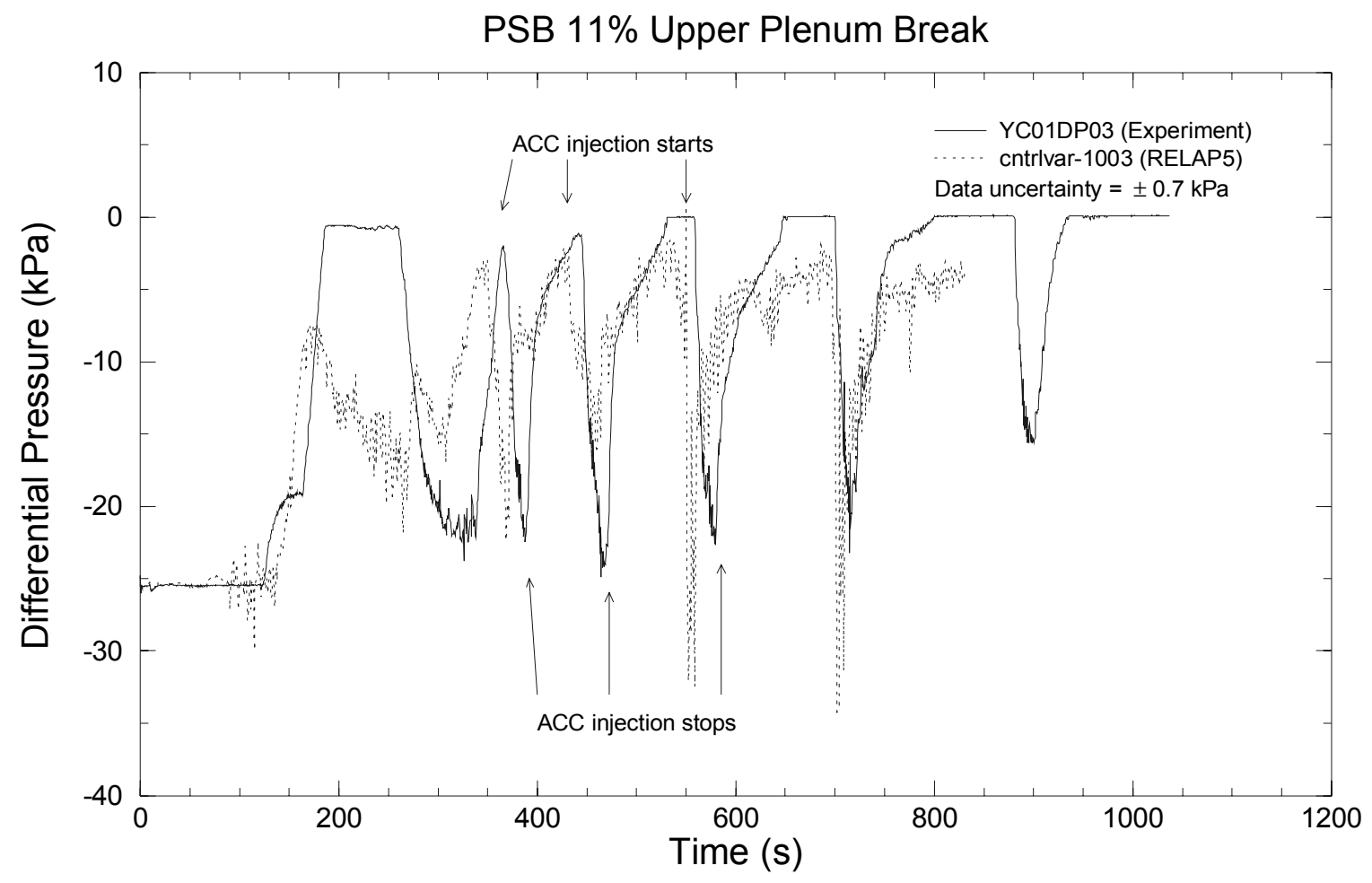

Figure 25. Differential pressure in the upper portion of the downcomer for the base case. 


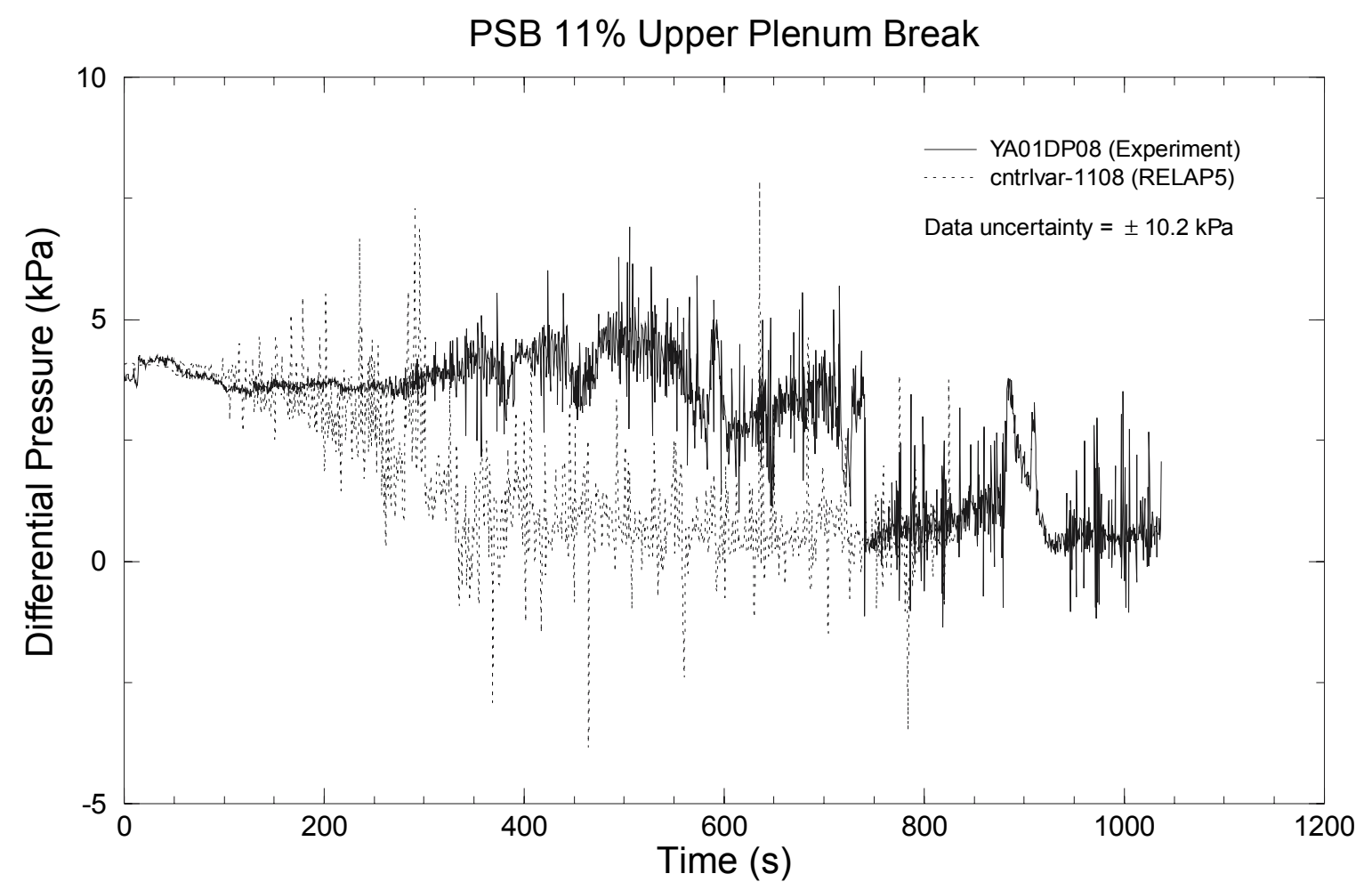

Figure 26. Differential pressure in the steam generator 1 hot collector for the base case.

The behavior of the loop seals is illustrated by the differential pressures in Figures 27-29. When the accumulators were injecting liquid, condensation in the vessel drew liquid from the steam generator side of the loop seals into the pump side; since the pump side was full during the first half of the transient, the evidence is in the pump differential pressure measurement. When the injection stopped, the liquid levels on the two sides of the loop seal equilibrated, moving liquid from the pump side to the steam generator side. However, some of the liquid flowed through the cold leg to the downcomer during the injection phase, so that the amount of liquid in the loop seals decreased with each injection cycle, leading to loop seal clearing near $750 \mathrm{~s}$. In the calculation, the loop seals had cleared by about $400 \mathrm{~s}$. As in the test, the pump differential pressure calculation (Figure 29) showed that liquid was being drawn from the loop seal into the pump when the accumulators were injecting.

Measured and calculated fuel simulator cladding surface temperatures are shown in Figures 30 and 31 , respectively. The data show a series of top-down core heatups that were terminated by accumulator injection, returning the cladding to the coolant saturation temperature. As the transient progressed, the accumulator injection became less effective in terminating the heatup, as more of the length of the heater rods became involved in the heatup. By the end of the transient, the accumulator injection could only partially cool (not quench) the core, and the heatup continued until the power was reduced to protect the heater rods. In the calculation, the heatup started about $50 \mathrm{~s}$ earlier than in the test, because of the lower system pressure, and there were almost continuous small heatups of 20-30 K over the entire length of the core. While a greater portion of the core was involved than in the test, the heatups were not as extensive. Near $350 \mathrm{~s}$, a more extensive heatup was calculated in the top portion of the core, which was subsequently quenched by accumulator injection. The next two periods of extended core heatup were only partially quenched by the accumulator injection, and the temperatures increased sufficiently that the calculation was terminated at $830 \mathrm{~s}$. 


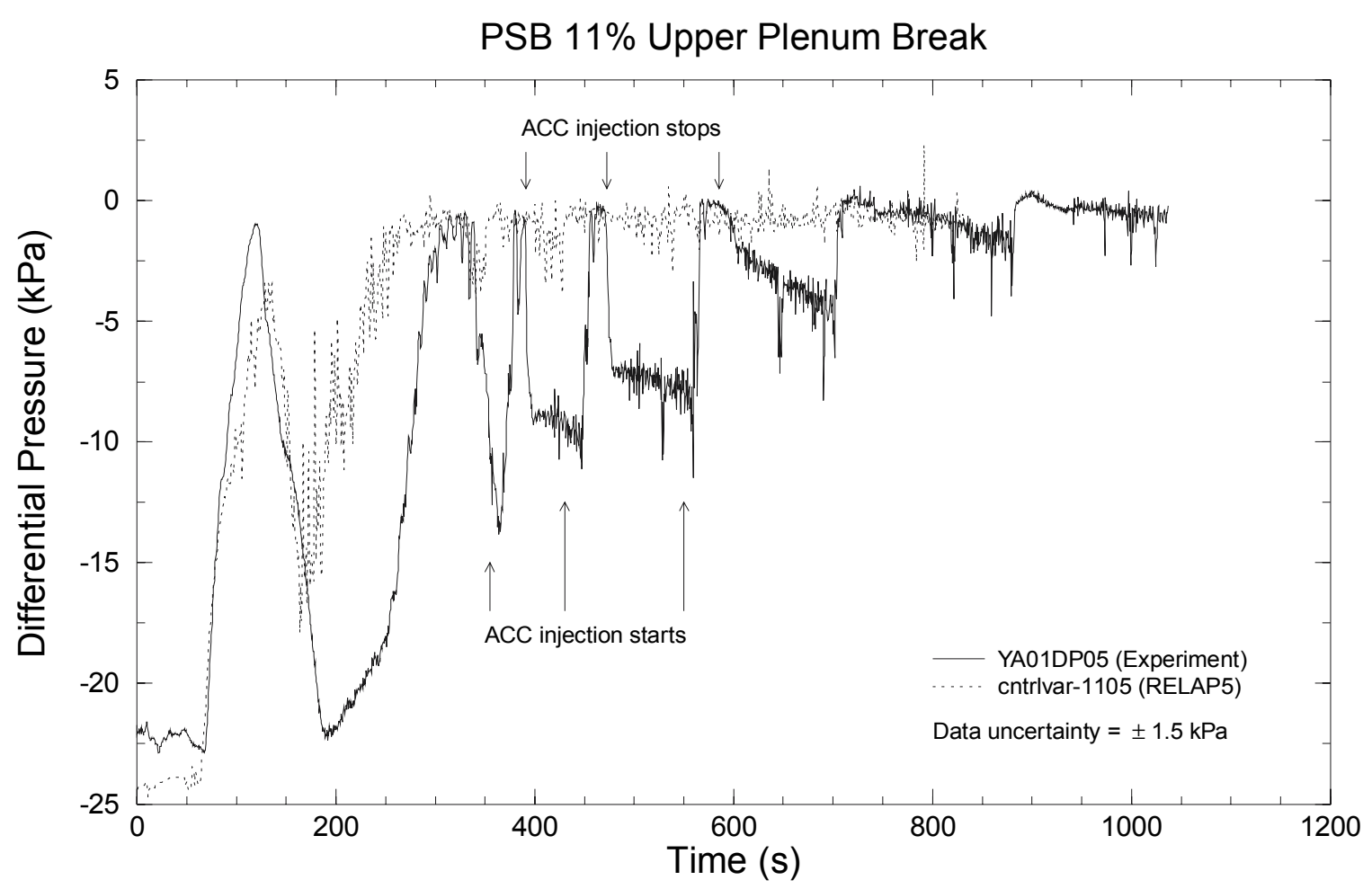

Figure 27. Differential pressure in the SG side of the loop 1 loop seal for the base case.

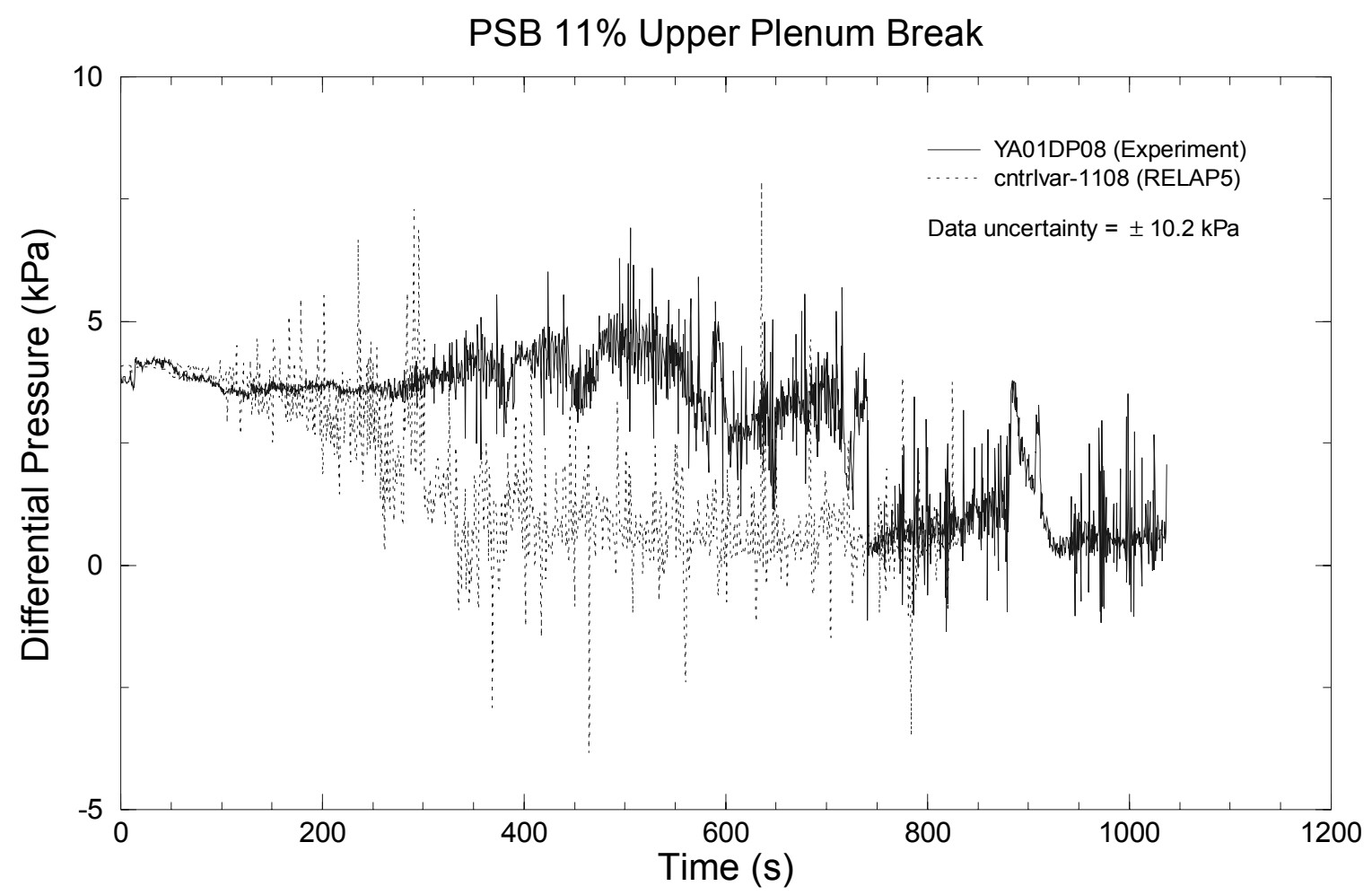

Figure 28. Differential pressure in the pump side of the loop 1 loop seal for the base case. 


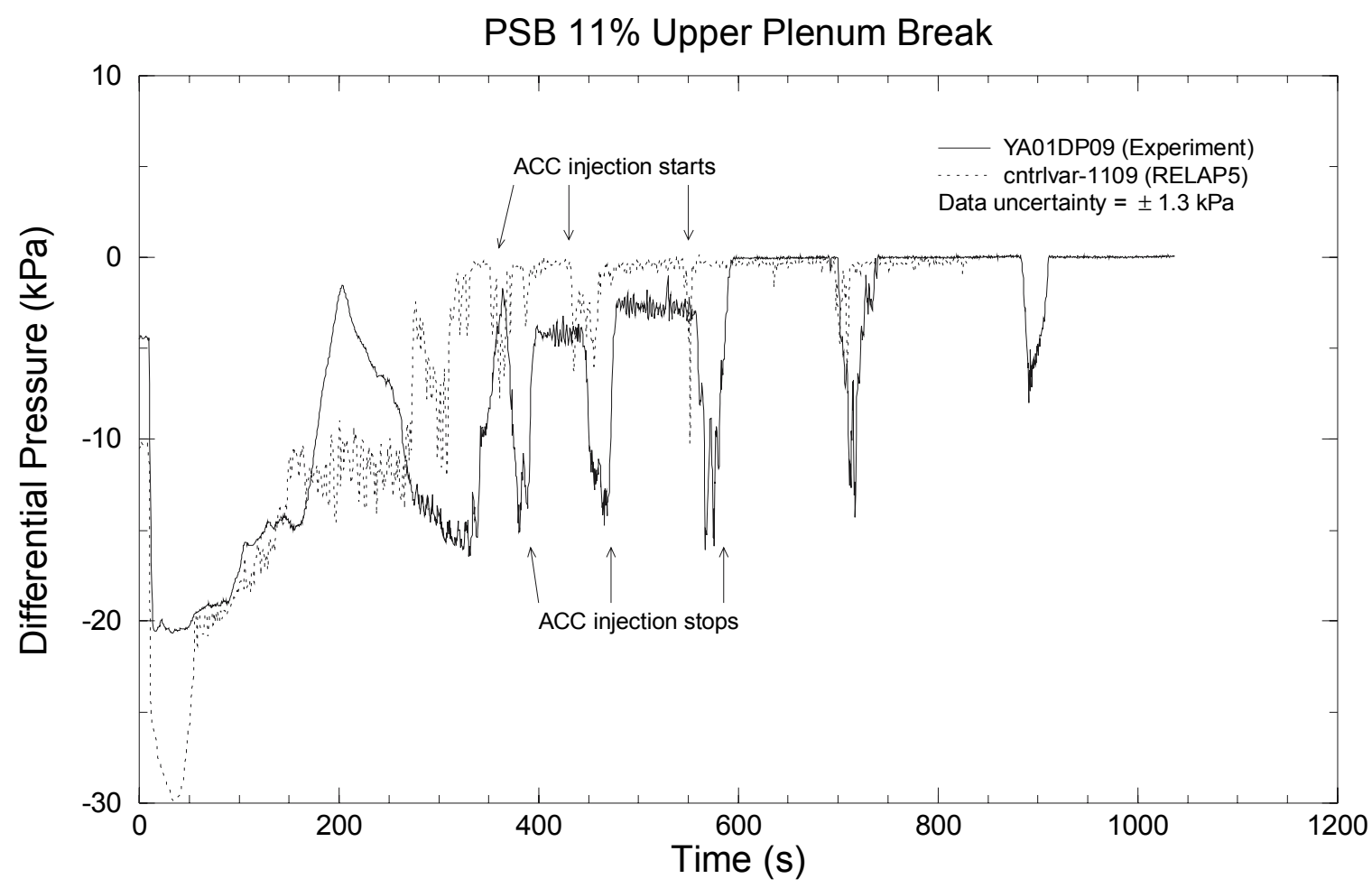

Figure 29. Differential pressure across the loop 1 pump for the base case.

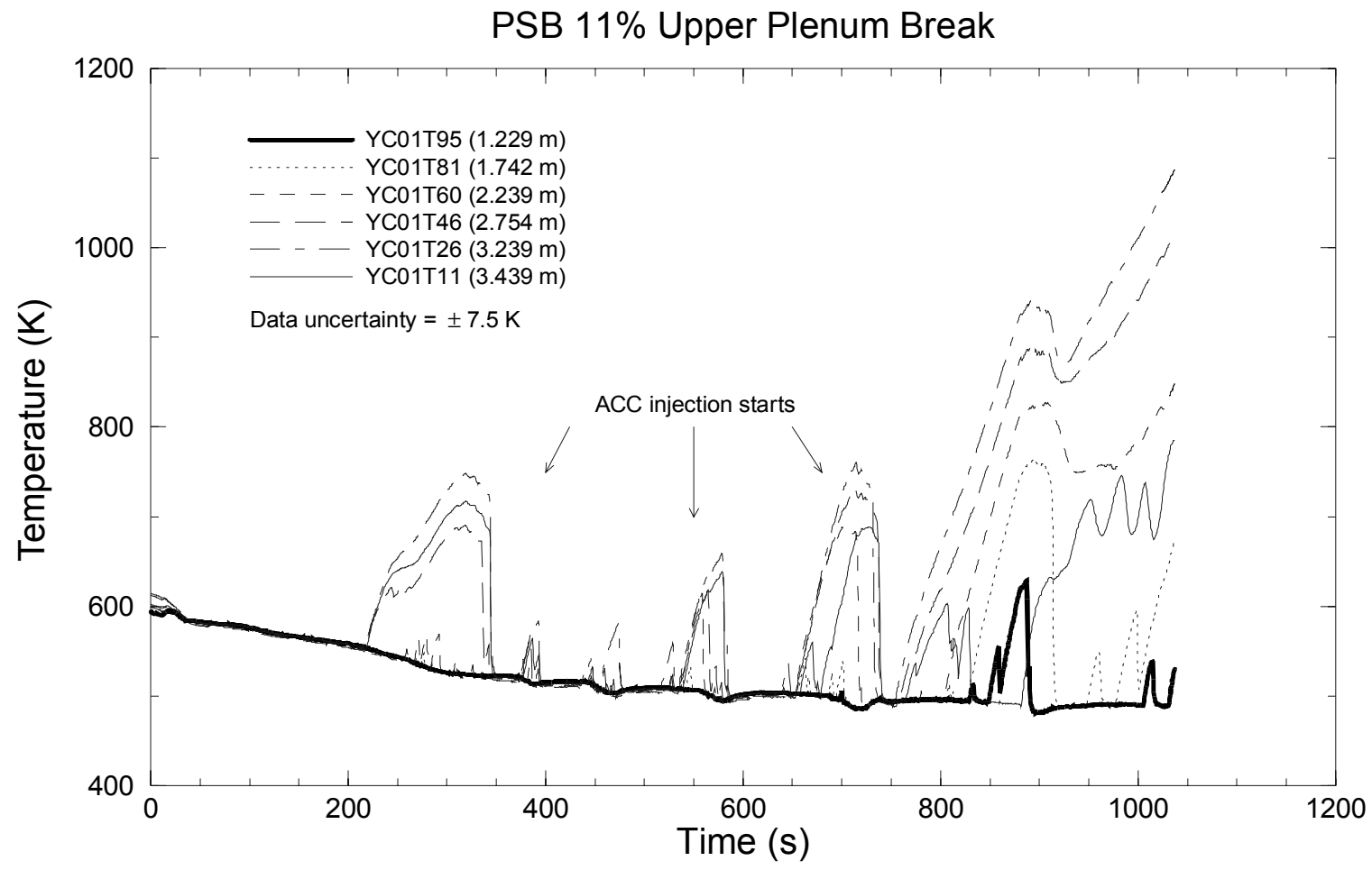

Figure 30. Measured heater rod surface temperatures. 


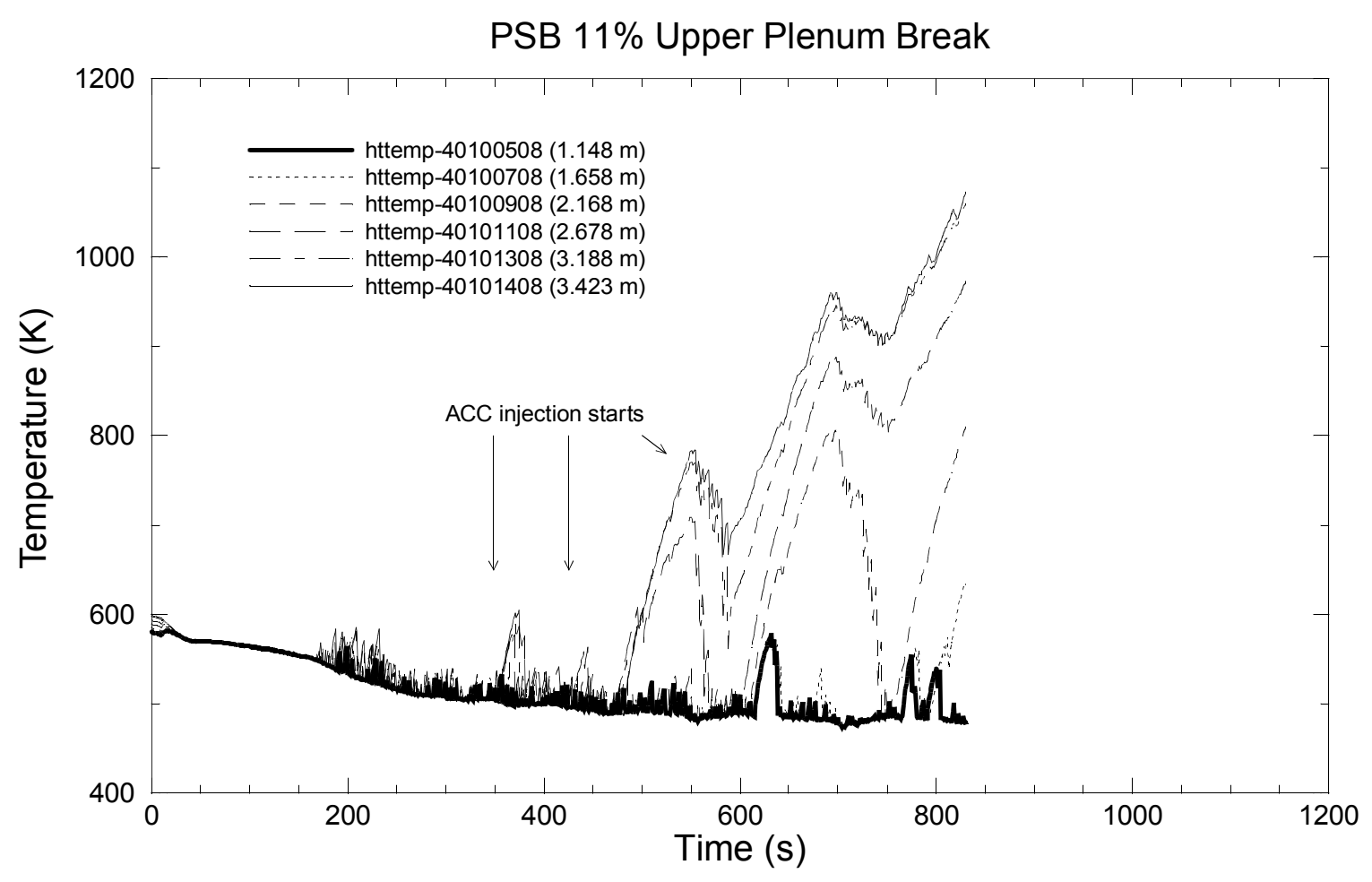

Figure 31. Calculated heater rod surface temperatures for the base case.

The response of the top-most measured temperature near the end of the test suggests that there may have been some liquid entering the core from the upper plenum to partially cool the upper end of the heater rods. This was not predicted in the calculation, where the CCFL model was invoked at the core outlet junction more than $70 \%$ of the time after the core heatup began, often preventing liquid in the upper plenum from flowing down into the core. Measured temperatures near the top of the core from several different heater rods are shown in Figure 32, where it is seen that there is some radial variation in the temperatures. There are likely some multi-dimensional effects in the experiment that allow some liquid penetration from the upper plenum into the core, but these cannot be captured with the one-dimensional nodalization used in the RELAP5 model.

Fluid temperatures in the top of the upper head are presented in Figure 33. In both the test and the calculation, this region is stagnant, and the vapor temperature remains superheated because of heat transfer from the hot vessel wall.

Coolant temperatures in the loop 4 hot leg are shown in Figure 34. The effect of the HPI flow is evident in both the data and the calculation. The highly subcooled liquid being injected flows toward the reactor vessel, sharply reducing the temperature being measured when it contacts the thermocouple. This effect is seen much earlier in the calculation than in the data.

Coolant temperatures in the loop 1 hot leg are presented in Figure 35. After natural circulation flow ends, the measured temperature begins to show superheating. This could be the result of actual superheating of the vapor, or the thermocouple could be reading a wall temperature rather than the fluid temperature. In either case, the superheated temperature is an indication that there is little to no flow through the loop. The temperature returns to the saturation temperature as the accumulators empty. The condensation caused by the accumulator injection moves fluid through the pipes, causing the temperature 


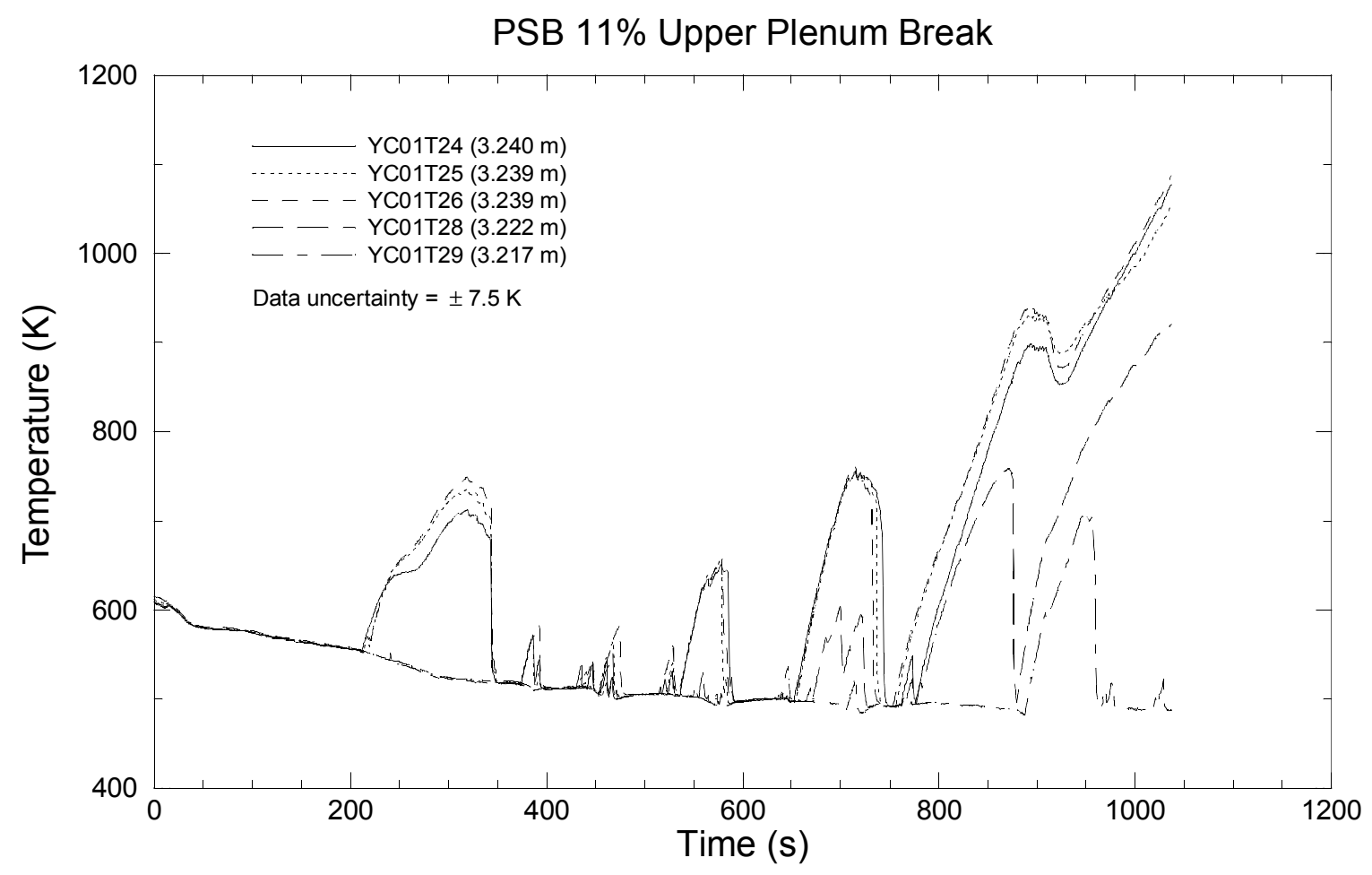

Figure 32. Measured heater rod surface temperatures near the top of the core.

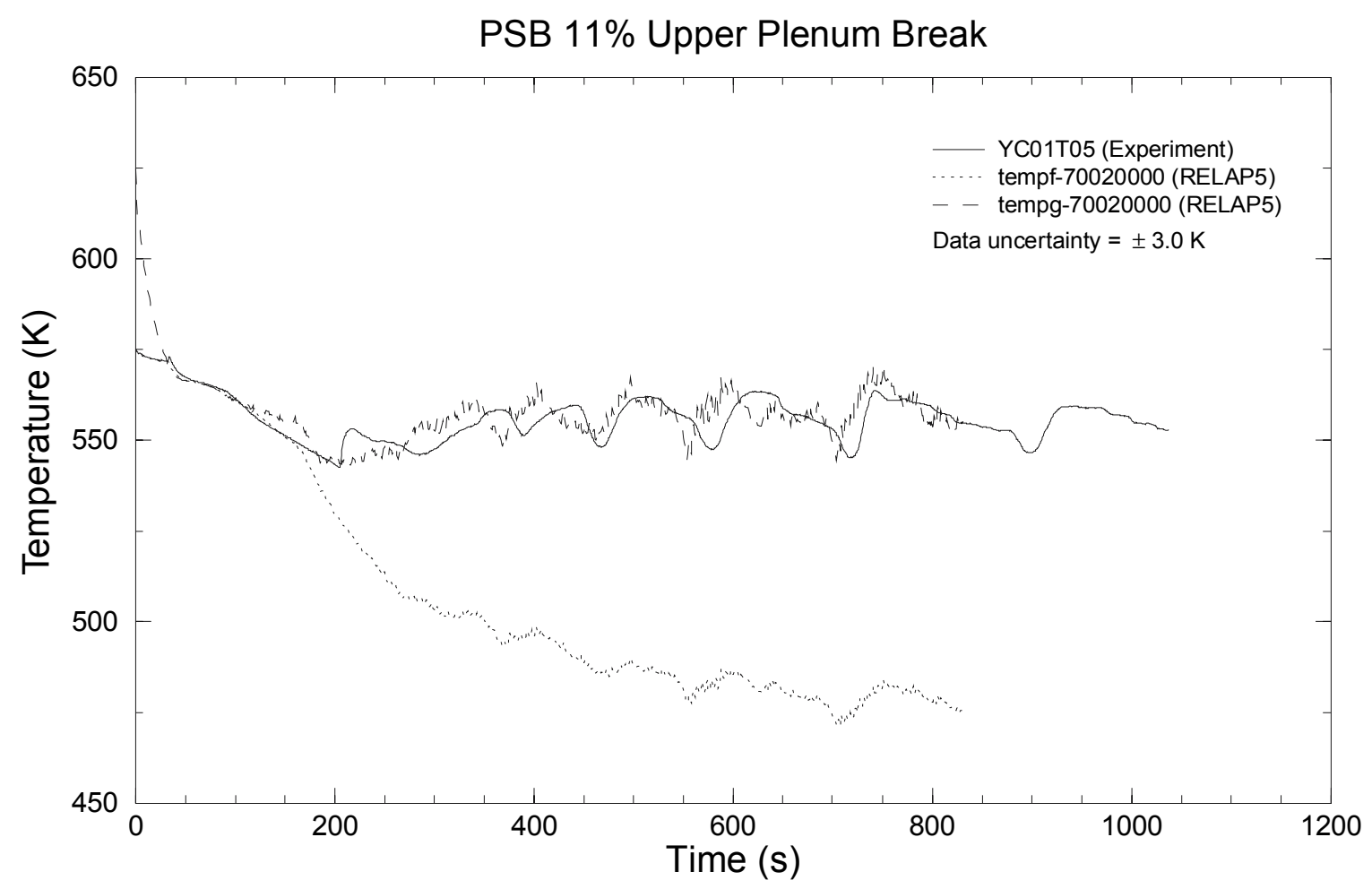

Figure 33. Fluid temperature at the top of the upper head for the base case. 


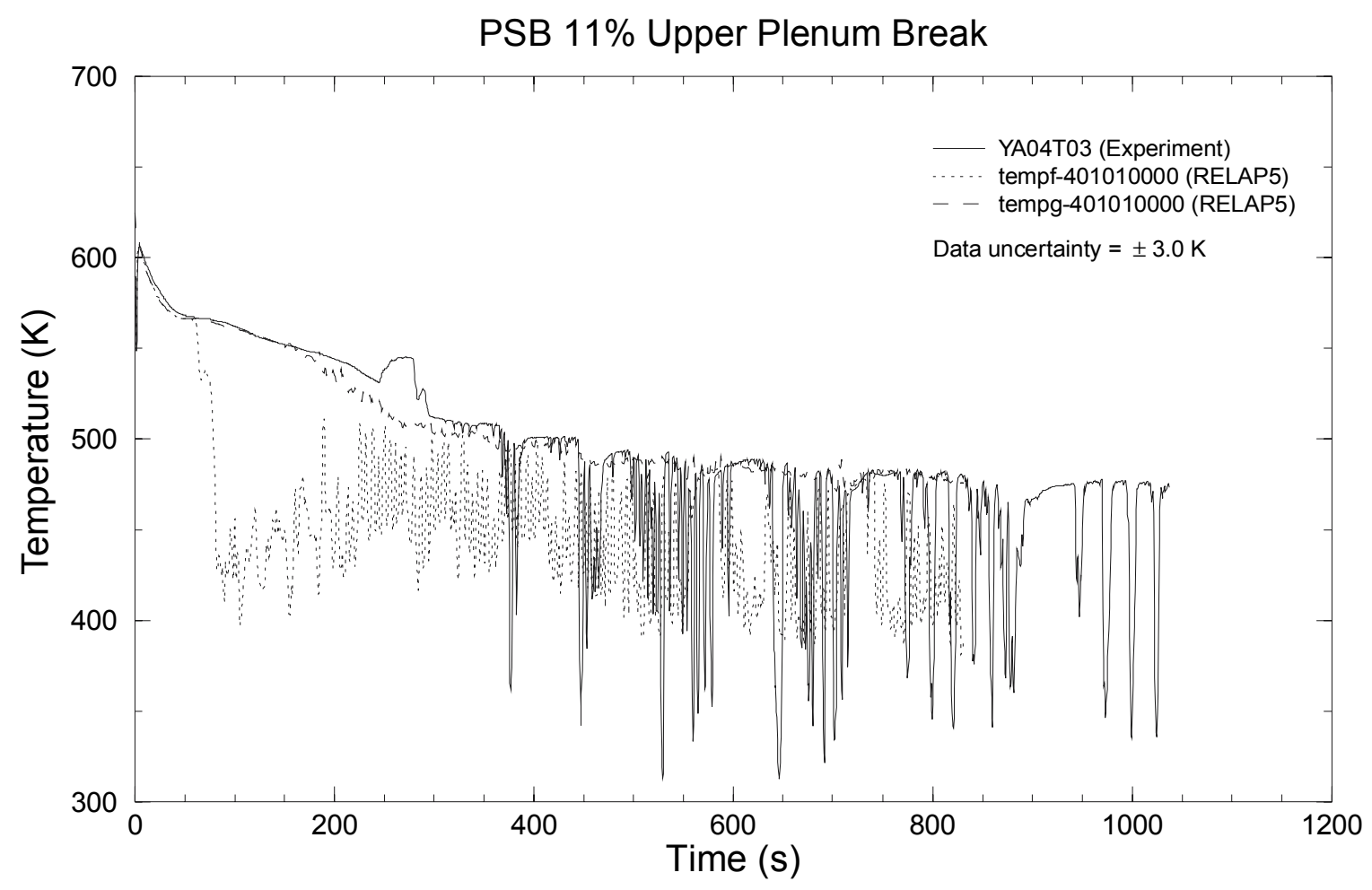

Figure 34. Loop 4 hot leg fluid temperature for the base case.

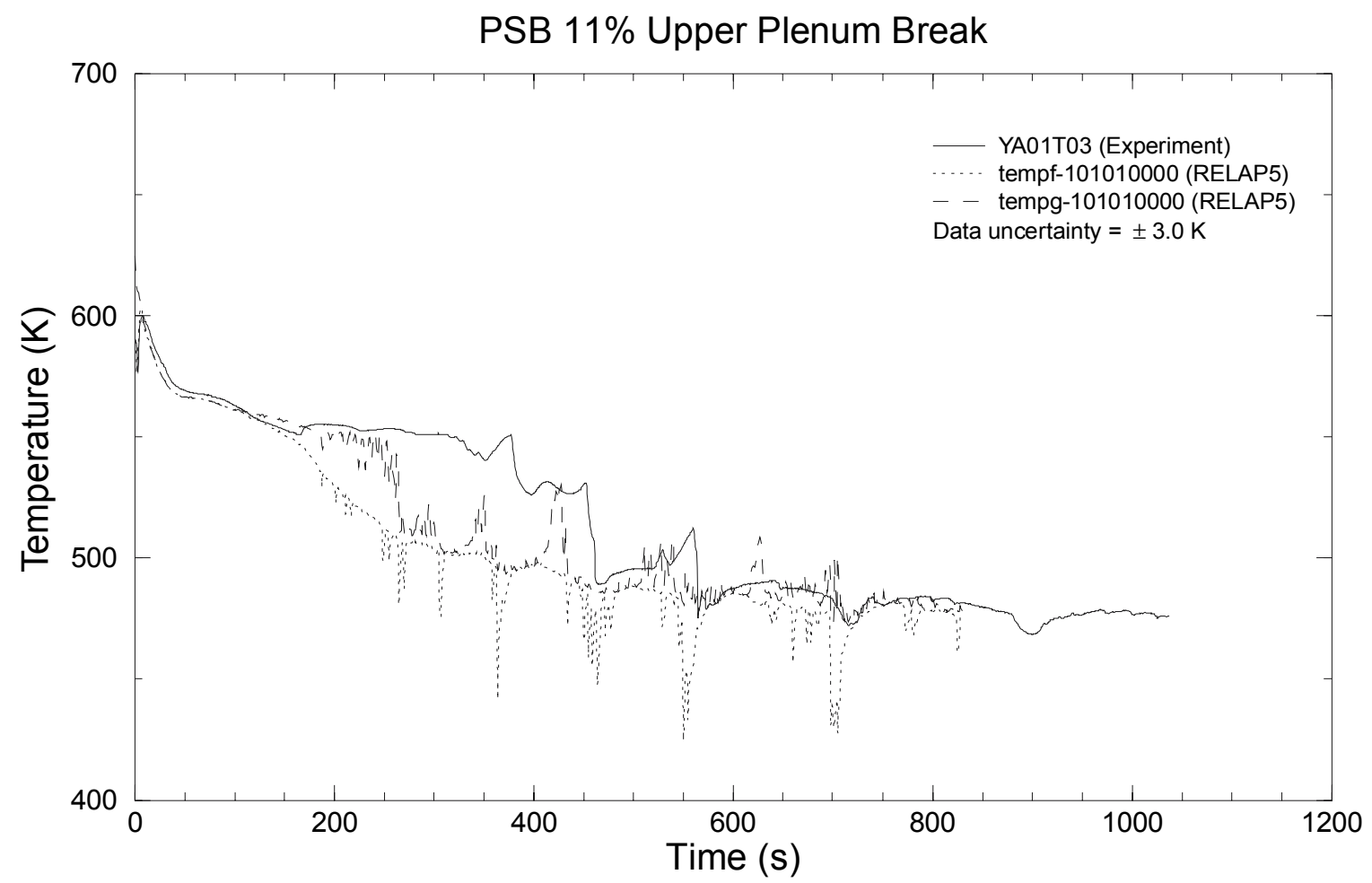

Figure 35. Loop 1 hot leg fluid temperature for the base case. 
to drop. In the calculation, less superheat is observed, and there is some colder liquid appearing in the hot leg from either the HPI in the loop 4 hot leg or the accumulator injection to the upper plenum.

Coolant temperatures in the loop 4 cold leg are presented in Figure 36. In the RELAP5 calculation, the coolant became slightly superheated after the cold leg drained; the liquid phase was at the saturation temperature from about $150 \mathrm{~s}$ until the end of the transient. The periodic decreases in coolant temperature after $300 \mathrm{~s}$ in both the data and the calculation were caused by accumulator injection. The injection of cold water caused some of the steam in the system to condense, reducing the pressure and saturation temperature.

The pressure in steam generator 1 is presented in Figure 37. The measured pressure increased rapidly to a peak value of about $8.1 \mathrm{MPa}$ when the steam line isolation valve was closed. Heat transfer back to the primary system and heat loss to the environment caused the pressure to decrease steadily for the rest of the transient. The calculated pressure mirrored the measured value, with a nearly constant offset over the course of the transient. The pressure response in steam generators 3 and 4 was very similar to that in steam generator 1, but steam generator 2 behaved a little differently in the test. Figure 38 shows reductions in pressure coincident with the periods of accumulator injection. The accumulator injections appeared to move some liquid into the loop 2 steam generator tubes, increasing the heat transfer back to the primary system and causing the pressure to drop further than in the other steam generators.

Figure 39 presents the secondary side liquid levels in steam generator 1 . The level increased at the beginning of the transient because feedwater flow was still being provided, but the heat transfer from the primary system was reduced because the core power was decreasing, resulting in less liquid being boiled in the steam generator. It continued to increase in the calculation until about $50 \mathrm{~s}$ as liquid drained from the feedwater ring and liquid that had been entrained into the upper region of the steam generator fell back into the measurement range as the boiling in the steam generator subsided. The level slowly decreased until about $100 \mathrm{~s}$, when the primary system pressure dropped below the secondary system pressure. The level then decreased more rapidly, as heat transfer to the primary coolant system cooled the liquid in the steam generators, causing it to contract. The level then steadily decreased until about $250 \mathrm{~s}$ in the test, and about $150 \mathrm{~s}$ in the calculation, when the rate of decrease slowed, reflecting a slower depressurization in the primary coolant system.

The liquid level in steam generator 2 is shown in Figure 40. Behavior generally similar to that in steam generator 1 was observed, except that the liquid level was decreasing at the beginning of the transient because there was no feedwater being supplied. The measured behavior was also a bit unusual after about $300 \mathrm{~s}$. The abrupt changes in level seem to be coincident with the accumulator injection cycles. Decreases in level might occur if the accumulator injection resulted in some liquid reaching the steam generator tubes, enhancing the heat transfer back to the primary system, thereby cooling the secondary side liquid (and hence reducing the specific volume and liquid level). There is no apparent explanation for the level increases, since the primary system pressure is well below that of the secondary system (precluding coolant expansion from causing the increase in measured level).

\subsection{Sensitivity Cases}

Sensitivity calculations were performed to investigate the impact of various parameters or code options on the predicted transient response. The major area of concern was the amount of liquid present in the upper plenum and core. A second concern was the heater rod temperature response. 


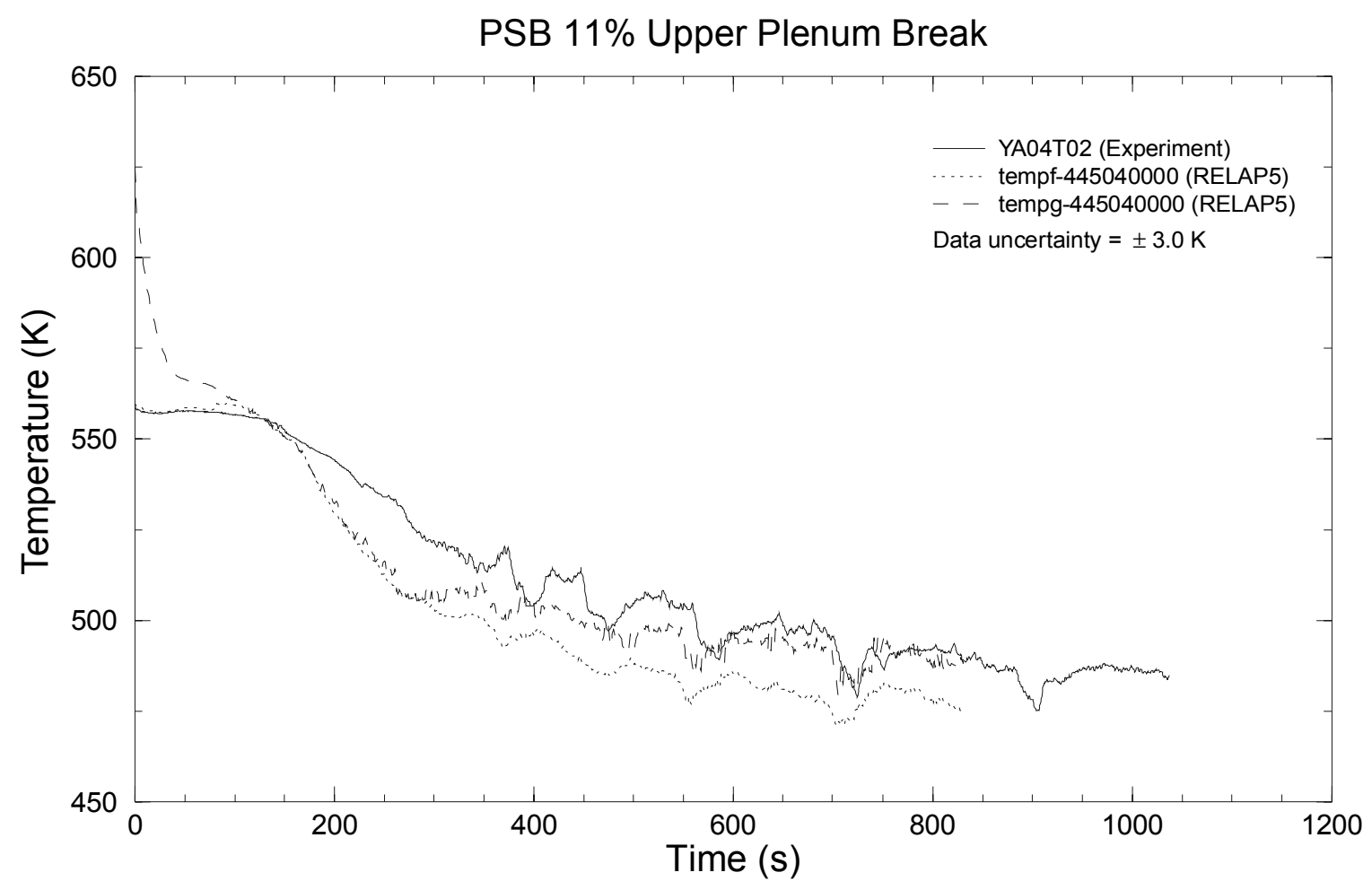

Figure 36. Loop 4 cold leg fluid temperature for the base case.

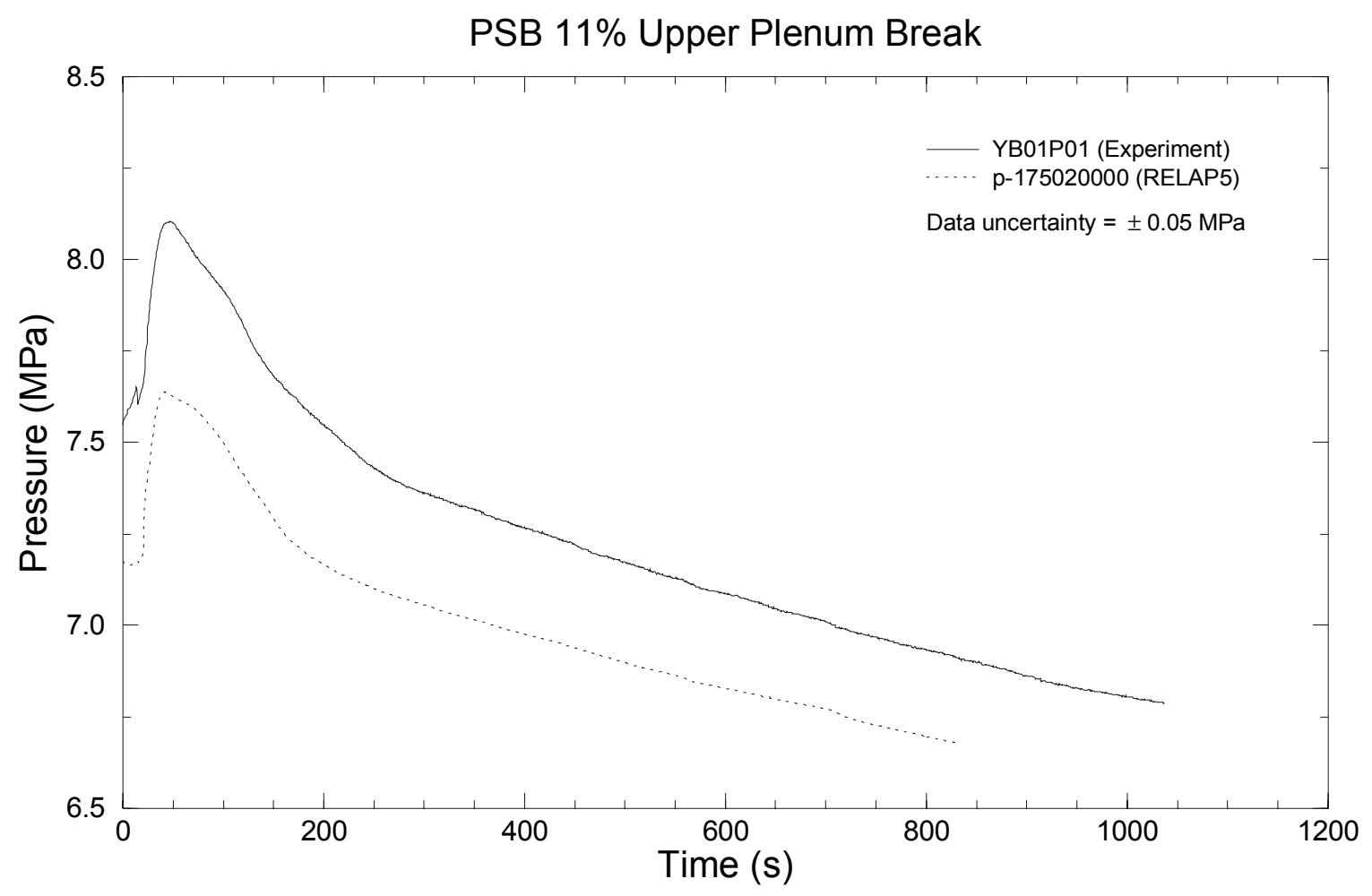

Figure 37. Loop 1 steam generator pressure for the base case. 


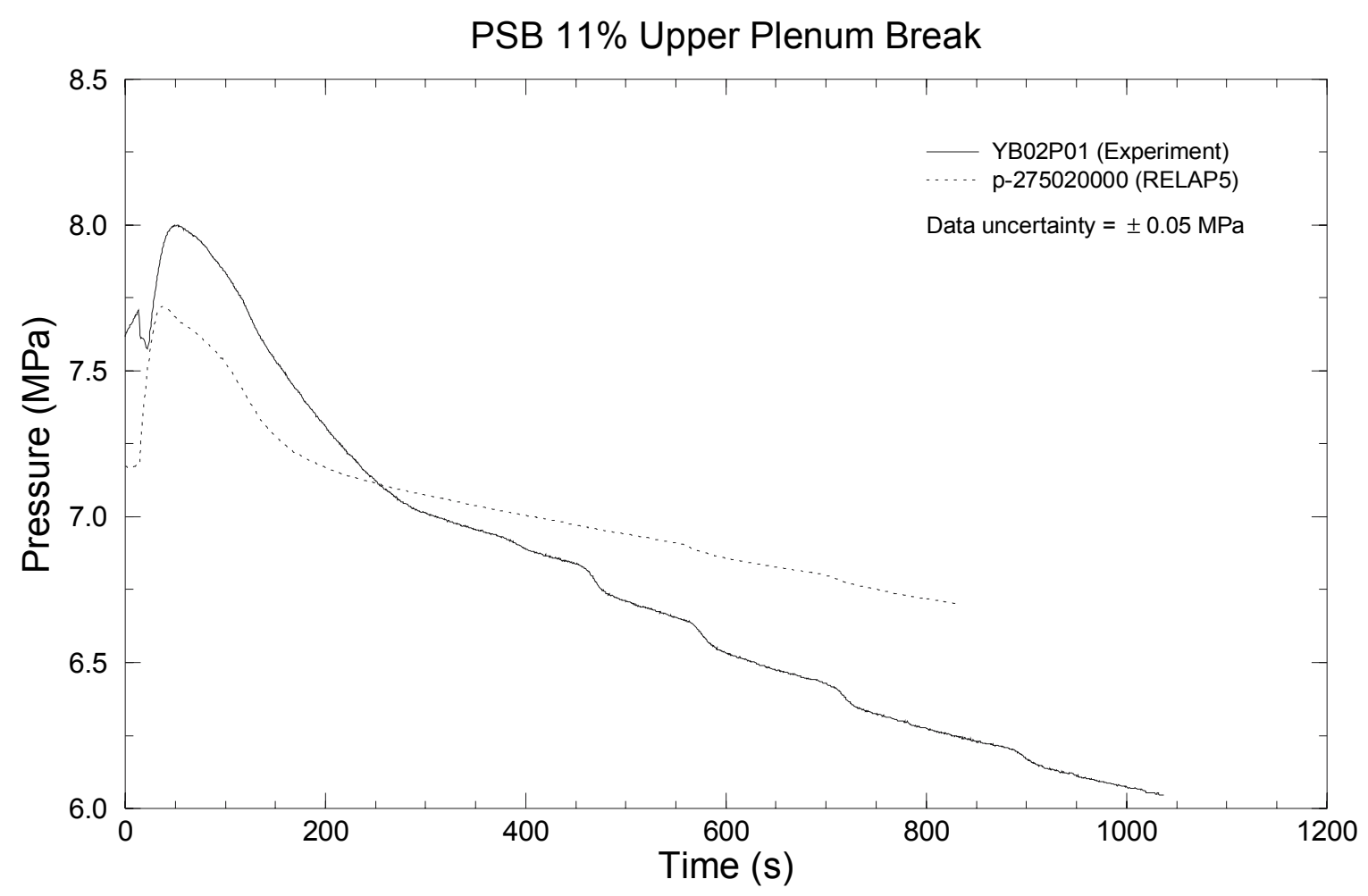

Figure 38. Loop 2 steam generator pressure for the base case.

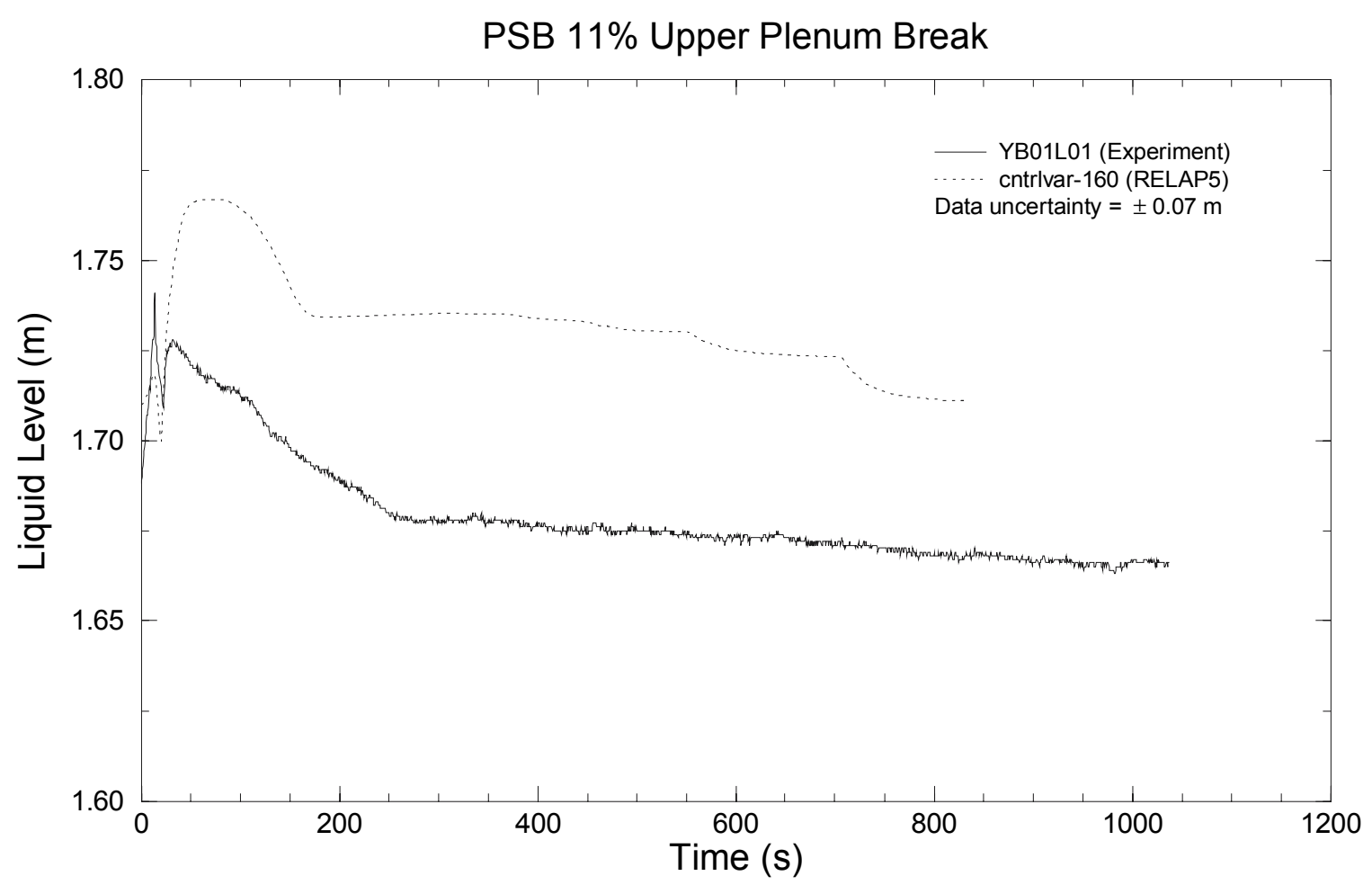

Figure 39. Loop 1 steam generator collapsed liquid level for the base case. 


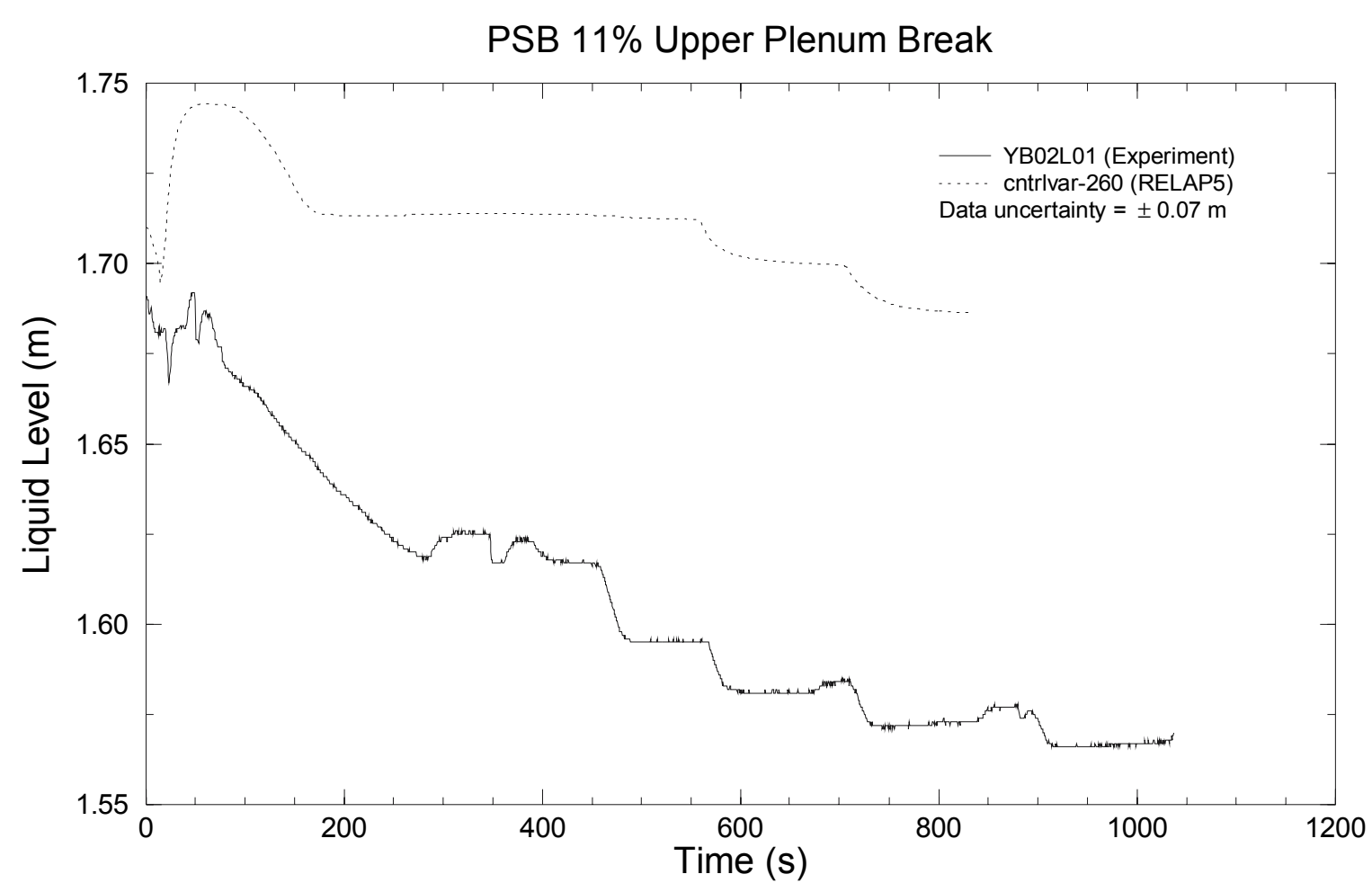

Figure 40. Loop 2 steam generator collapsed liquid level for the base case.

\subsubsection{CCFL Off at Core Outlet}

A sensitivity calculation was performed in which the CCFL model was turned off at the core exit (junction flag f set to 0 instead of 1). This provides a lower bound on the effects of the CCFL model by allowing the maximum amount of liquid to flow from the upper plenum back into the core. The objective of this run was to try to reduce the amount of liquid in the upper plenum.

The result showed little difference in any of the system parameters, except that the core heatup was significantly delayed because water penetration into the core from the upper accumulator injection helped cool the heater rods. Liquid inventories in the upper plenum, core, and downcomer were nearly the same as in the base case calculation. The heatup was also different in that the top portion of the heater rod remained cooled, with the maximum temperature occurring lower in the core, as illustrated in Figure 41.

\subsubsection{Single Velocity Option at Core Outlet}

In this calculation, the single velocity option was used at the core outlet junction (junction flag h set to 2 instead of 0 ). This prevented liquid from flowing from the upper plenum back down into the core by forcing the liquid to flow with the vapor. This calculation thus provided an upper bound on the possible CCFL effects.

Figure 42 shows that there was little material change in the amount of liquid in the core, compared to the base case calculation. With no liquid entering the top of the core, however, the core heatup was accelerated, as illustrated by the heater rod temperatures near the top of the core in Figure 43. As in the core, there was no noticeable change in the liquid inventory in the upper plenum, either. 


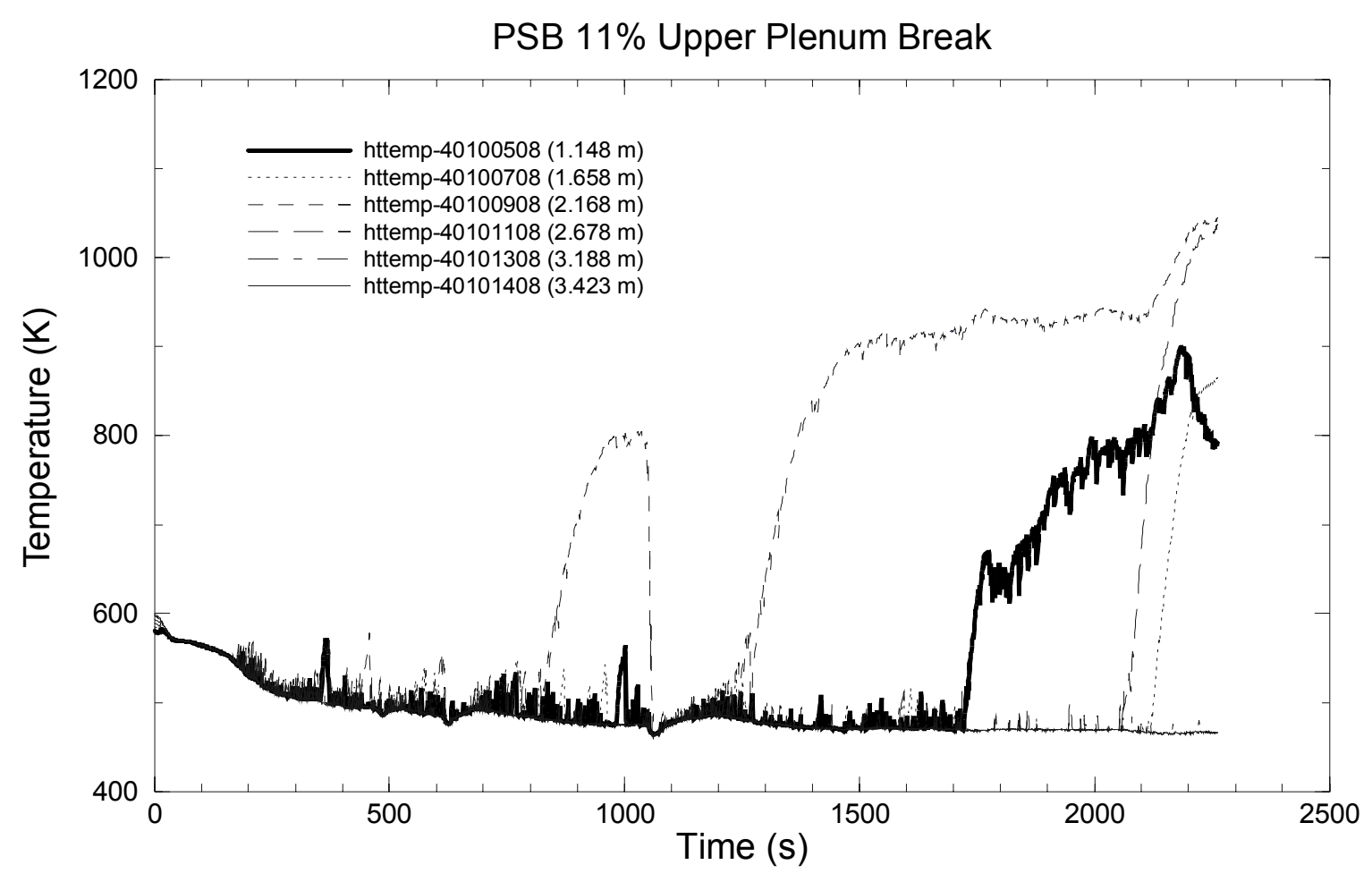

Figure 41. Calculated heater rod surface temperatures for the CCFL sensitivity case.

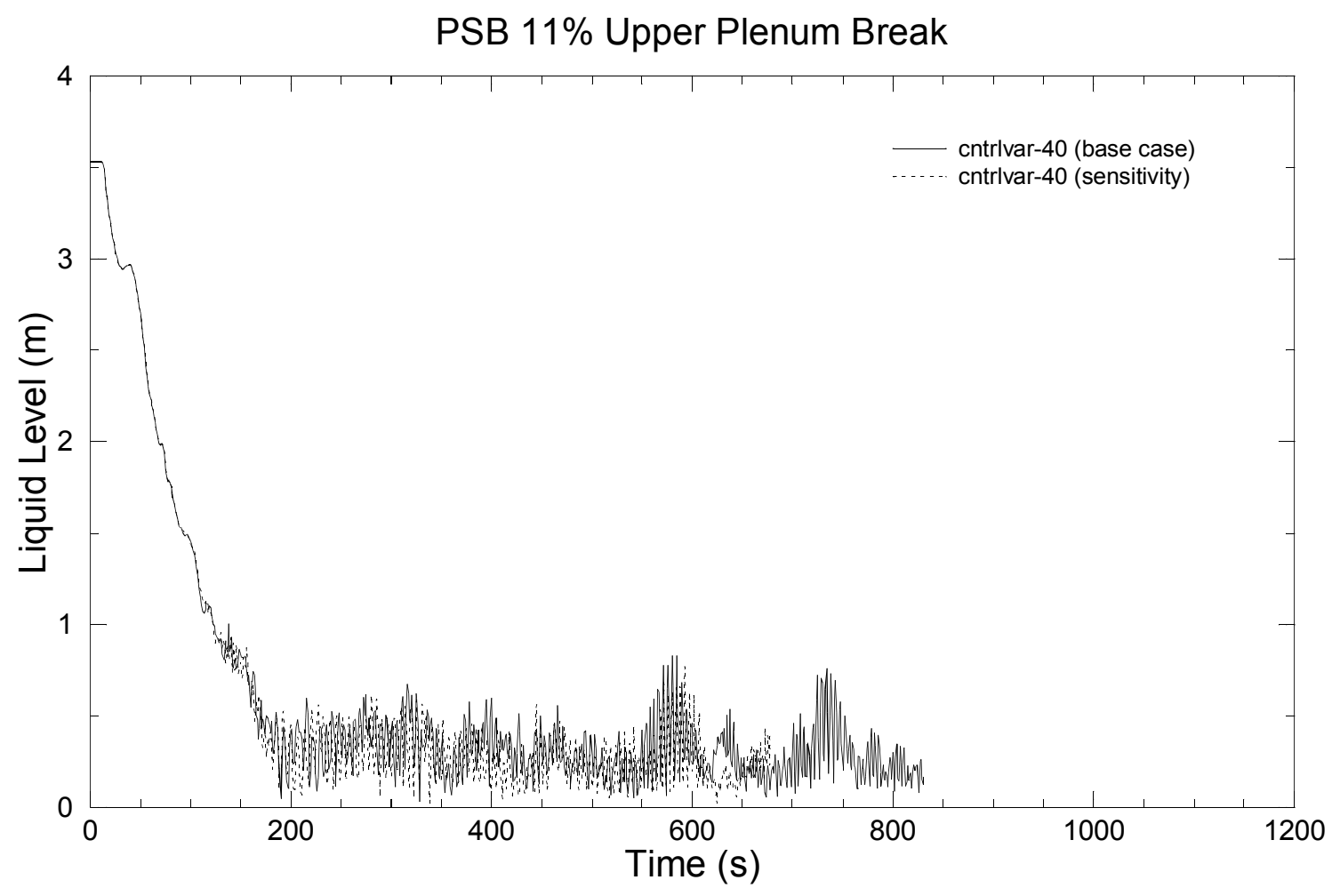

Figure 42. Core collapsed liquid level for the base and single velocity sensitivity cases. 


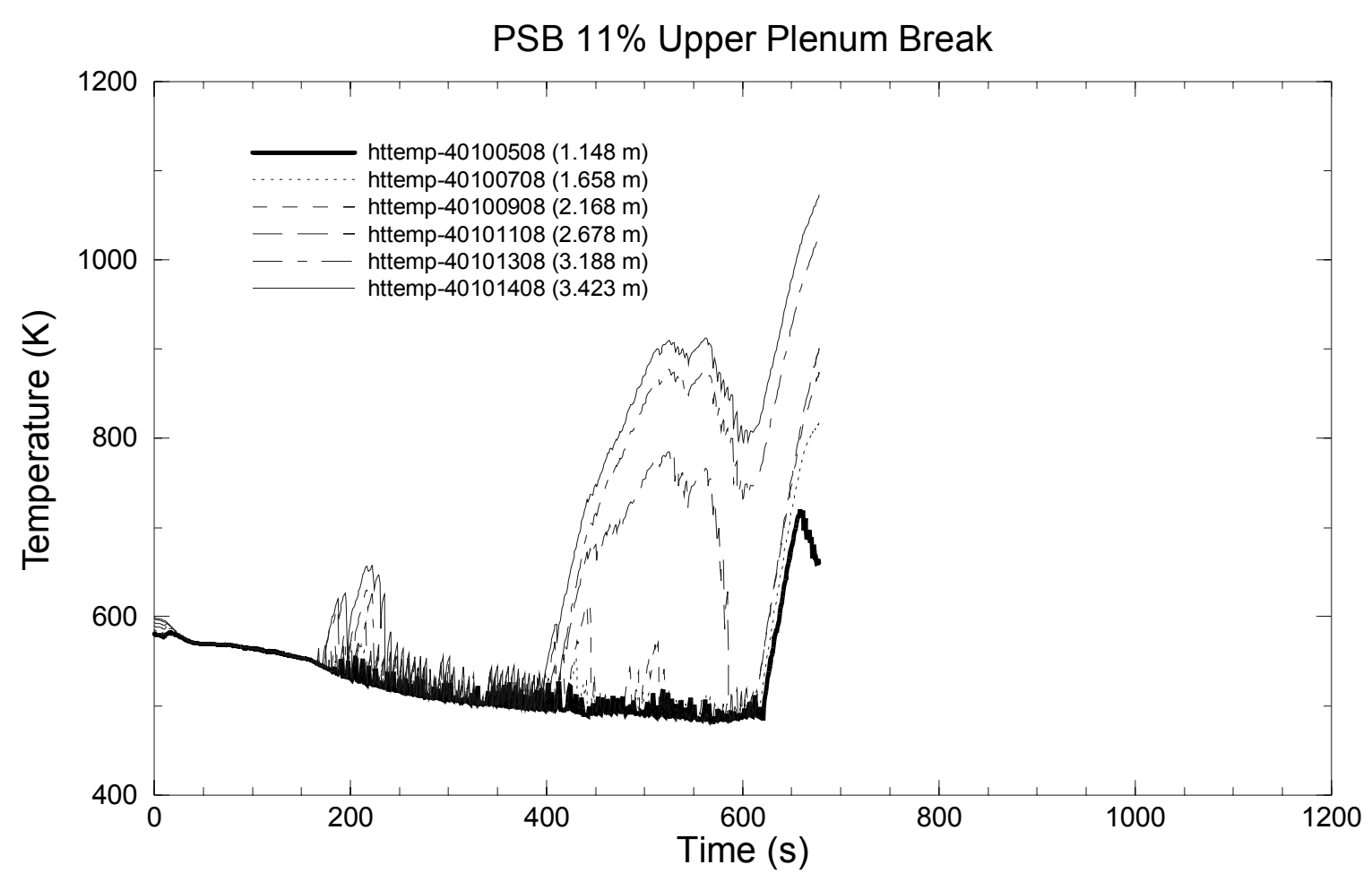

Figure 43. Calculated heater rod surface temperatures for the single velocity sensitivity case.

\subsubsection{Reduced Drag in Upper Plenum}

A sensitivity calculation was performed in which the bundle interphase drag model was turned on in the upper plenum region (volume flag b set to 1 instead of 0 ); this will tend to reduce the calculated drag. The objective was to reduce the amount of liquid in the upper plenum.

Figures 44 and 45 show that the amount of liquid in the upper plenum was reduced in the sensitivity calculation, resulting in better agreement with the measured data. The core liquid inventory was increased somewhat after $400 \mathrm{~s}$. The effect on the heater rod temperatures is shown in Figure 46. The early, smaller heatups are more pronounced than in the base calculation (see Figure 31), and the heatup near $500 \mathrm{~s}$ is completely quenched in the sensitivity calculation (it was not in the base calculation) because of the additional water in the core. However, the calculation was terminated on high temperatures about $90 \mathrm{~s}$ earlier than in the base case.

\subsubsection{Increased Drag in Core}

A sensitivity calculation was performed in which the bundle interphase drag model was turned off in the core region (volume flag $\mathrm{b}$ set to 0 instead of 1); this will tend to increase the calculated drag.

In this calculation, more liquid was retained in both the core (see Figure 47) and the downcomer, while the liquid inventory in the upper plenum was essentially unchanged from the base case. The core liquid level also showed changes corresponding to the accumulator injection cycles that were much more obvious than in the base case calculation. The void profile in the core was also different, with the void fraction increasing with elevation in the core, whereas in the base case the void fraction was nearly constant along the core height. 


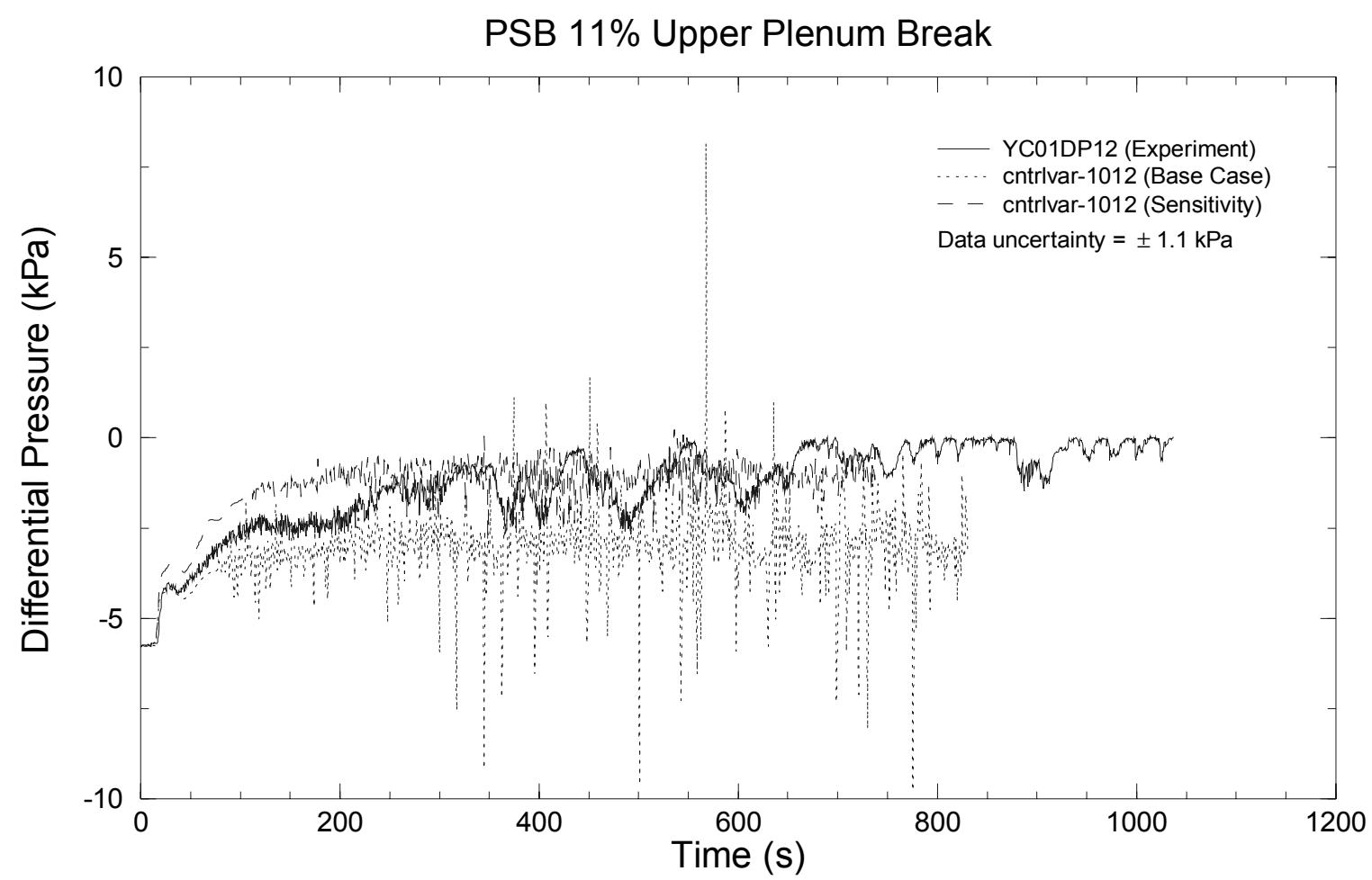

Figure 44. Differential pressure in the lower portion of the upper plenum for the base and upper plenum drag sensitivity cases.

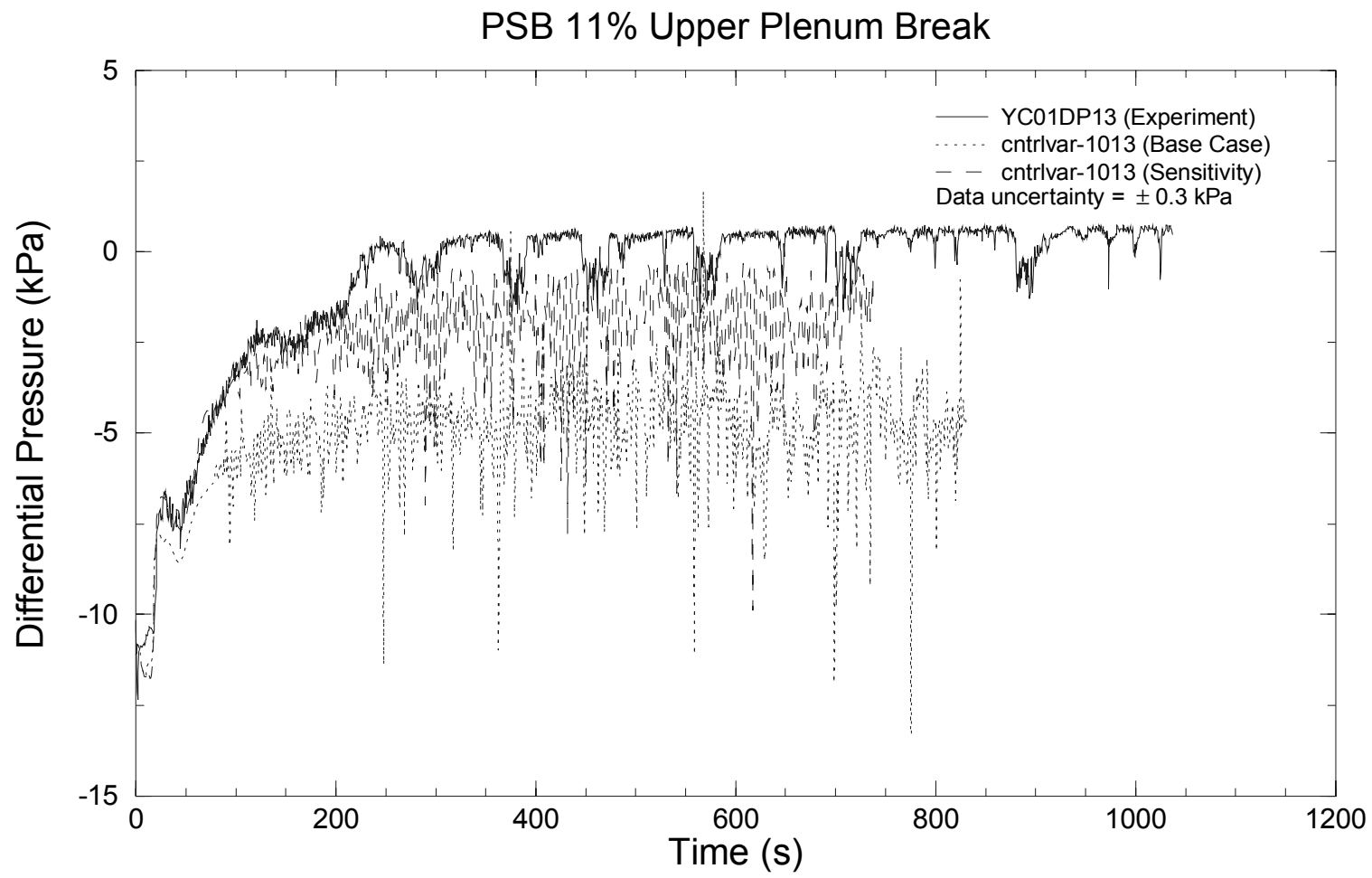

Figure 45. Differential pressure in the upper portion of the upper plenum for the base and upper plenum drag sensitivity cases. 


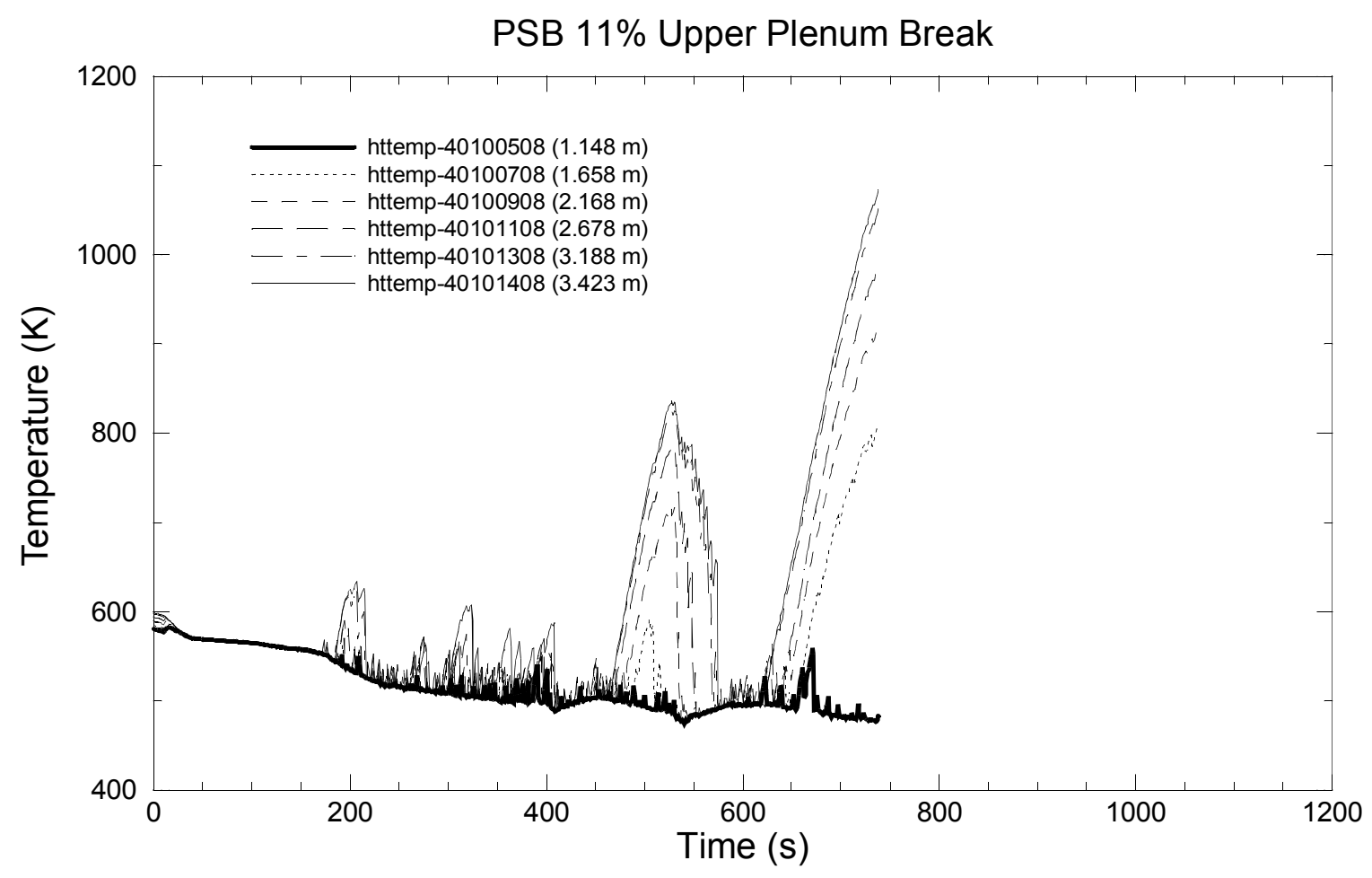

Figure 46. Calculated heater rod surface temperatures for the upper plenum drag sensitivity case.

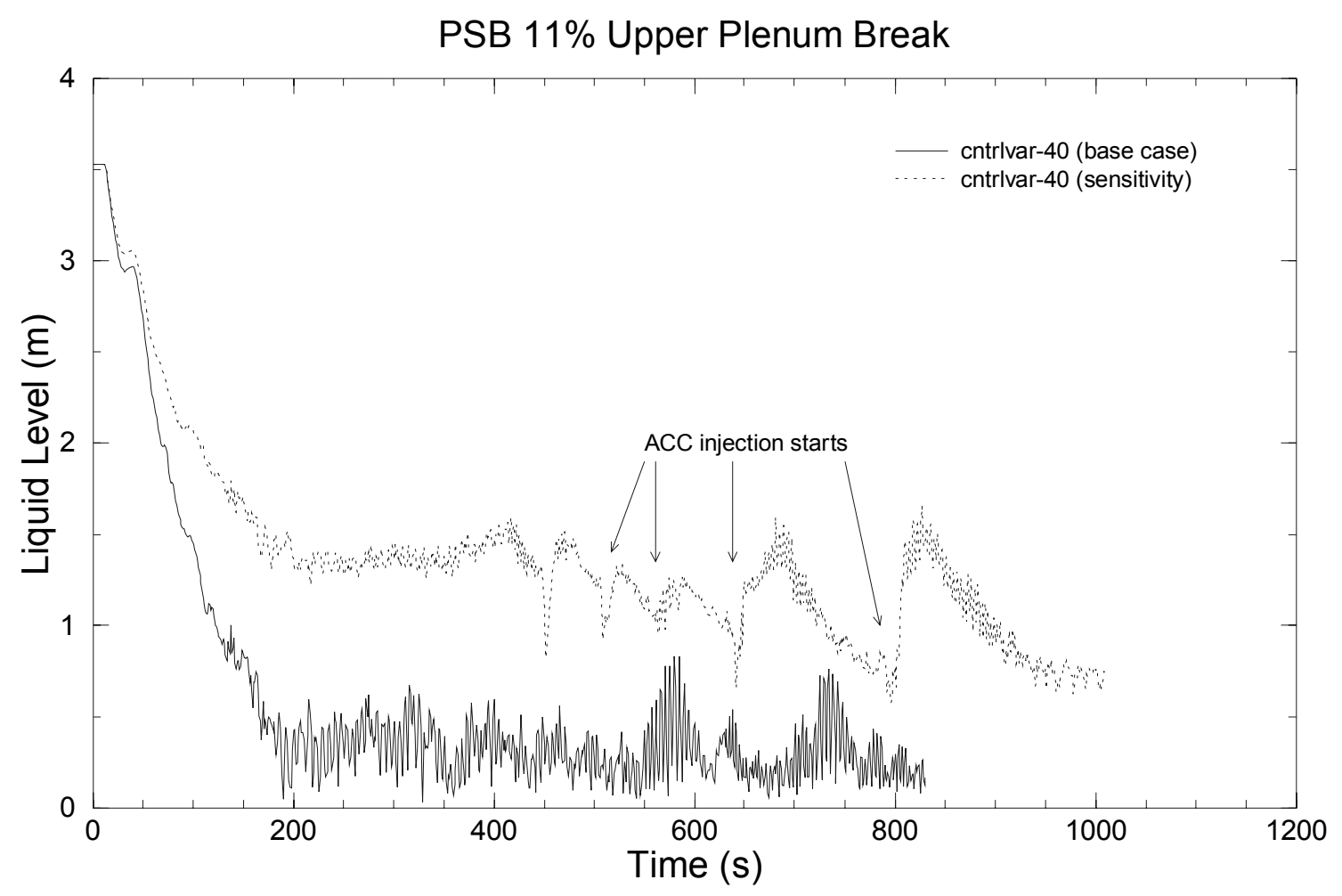

Figure 47. Core collapsed liquid level for the base and core drag sensitivity cases. 
Figure 48 shows the resulting heater rod temperatures in the core. The numerous small heatups that were present in the base case calculation have been eliminated. The heatup behavior is more like that in the experiment, although the top of the core did not quench as often as in the test. The heatup is also delayed compared to the base case, resulting in the calculation being terminated on high temperatures at nearly the same time as the test.

\subsection{Assessment Results}

The assessment findings for the important phenomena expected to be addressed by the experiment are presented below.

Primary system two-phase natural circulation is judged to have been reasonably simulated by the code. Natural circulation flow only existed for a relatively short period in the test, with the hot collectors in the steam generators draining by $70 \mathrm{~s}$ and the primary coolant system pressure dropping below the secondary system pressure by $90 \mathrm{~s}$. The loop flow rates were well predicted in making the transition from forced to natural convection, and the calculation was in excellent agreement with the measured data during the time the measurement was valid.

Asymmetric loop behavior is judged to be reasonably simulated, although it was not very important in either the test or the calculation. The only notable difference between the loops was the high pressure injection to the loop 4 hot leg. The effects of this injection, indications of much colder water in that hot leg, were seen in both the data and the calculation. The input model, which included all four loops in the facility explicitly, would allow differences in loop behavior in other transients to be simulated.

Leak flow is judged to be reasonably simulated. The fluid conditions upstream of the break were calculated well, reflecting both the transient liquid flow and the occasional liquid subcooling. With no

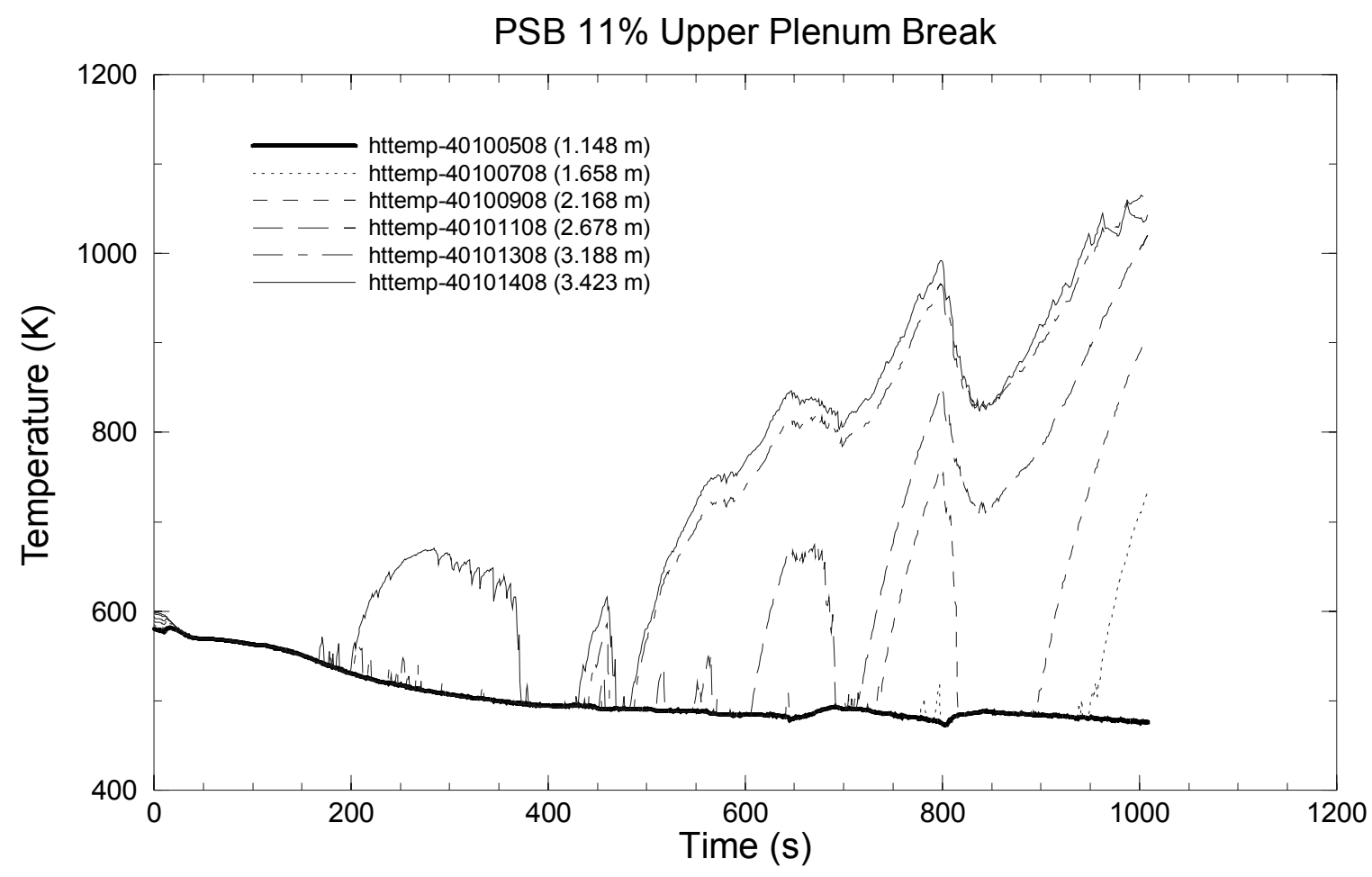

Figure 48. Calculated heater rod surface temperatures for the core drag sensitivity case. 
break characterization data, an assumed set of discharge coefficients was used in the input model. Additional sensitivity calculations could be performed to find a set of discharge coefficients that would result in a close match to the data. There were no indications of problems with the RELAP5 critical flow model.

No judgment is made for the phenomenon of phase separation without mixture level formation. There were not detailed enough measurements to indicate if this occurred in any location in the system other than the core, where there were sufficient instruments but a mixture level existed.

The differential pressure measurements in the steam generators provide information on the collapsed liquid level, but by themselves do not provide sufficient information to make a judgment on mixture level and entrainment in the steam generator. There are no measurements in the steam generator to determine where the mixture level is, or how much liquid is being entrained either out of the tube bundle region or into the steam lines during the short period when the steam valves are open. The trend of the steam generator levels during the first $50 \mathrm{~s}$ indicates that the code may be overpredicting the amount of liquid being held above the measurement location, as more liquid appears to be falling back in the calculations than in the test. However, the steam generator feedwater is not at a steady state in the test, while it is in the calculation. Also, the steam generator geometry is not prototypic, and conclusions drawn from the experiment behavior would not necessarily apply to the horizontal steam generators in the power plants.

The code modeling of mixture level and entrainment in the core is judged to be minimal in the base case calculation. While the code correctly predicted the top-down uncovering and heatup, the void distribution in the core was much different from that in the test. The heater rods were heating up above the coolant saturation temperature over most of their length in the calculation, but not in the test. The impact of the accumulator injection on the core differential pressures observed in the test was not reproduced well by the code. The behavior was improved, however, in the sensitivity calculation with the bundle interphase drag model turned off in the core.

There were insufficient experiment data to address the phenomenon of flow stratification in horizontal pipes. No measurements were available to determine the flow regimes in the piping, so no judgment of the code's capability to model the phenomenon is made.

Loop seal clearance in the cold legs is judged to be reasonably simulated. While the calculated loop seal clearing occurred earlier than was measured, it did occur in both the test and calculation through the same mechanism. Condensation in the vessel associated with accumulator injection drew liquid from the loop seal toward the cold legs, where some of it flowed to the vessel. When the accumulator injection stopped, the liquid levels in the two sides of the loop seal equilibrated, but at successively lower levels with each accumulator injection cycle until the loop seal cleared.

No judgment is made on the code capability to model pool formation in the upper plenum because a pool did not form in either the test or the calculation. Based on the differential pressure measurements, the calculation retained more liquid in the upper plenum than was measured in the test. However, that liquid did not separate into a pool, remaining a fairly uniform two-phase mixture below the nozzle elevations.

Heat transfer in a covered core is judged to be reasonably simulated. The heat fluxes were low enough that the core remained in nucleate boiling until it began to uncover, and no early heatup was observed in the test or predicted by the code.

The code capability to model heat transfer in a partially uncovered core is judged to be reasonable. When the core was heating up, the heatup rate matched that in the test. In addition, the heatup rates 
differed axially in the core, with regions toward the center of the core heating up faster than did those toward the ends in both the calculation and the data.

The code is judged to reasonably simulate pressurizer thermal hydraulics in this test. The pressurizer behavior was relatively simple, with the liquid initially in the pressurizer either rapidly draining or flashing in response to the upper plenum break. The code adequately modeled the draining/flashing behavior, based on the good agreement in both the system pressure (affected by the flashing) and liquid level during the first $20 \mathrm{~s}$ of the transient.

The code's capability to model the integral system effects is judged to be reasonable. The shape of the measured pressure curve was similar to that of the test, indicating that all of the significant events that occurred in the test were present in the calculation. There were no phenomena in the test that were not present in the calculation, nor were there calculated behaviors that were not observed in the test. 


\section{SUMMARY/CONCLUSIONS}

RELAP5/MOD3.2 calculations of an 11\% upper plenum break in the PSB facility reasonably simulated the basic transient behavior. The experiment progression and controlling phenomena were well reproduced by the code. The code assessment findings for the high-ranked phenomena are summarized in Table 3.

Most of the phenomena that were present in the test were reasonably simulated by the code. The major difference between the test and the calculation was the timing of the core heatup, and the thermal response to the accumulator injection cycles. The calculation had a more extensive axial heatup, with most of the core experiencing small heatups. The accumulator injection was more effective in quenching the core in the test than in the calculation. This difference is attributed to the liquid distribution in the core, rather than to the heat transfer models in the code. The code calculation had a more uniform axial distribution of the liquid in the core, and the accumulator injection did not have much impact on the core liquid inventory. Based on this, the code simulation of the mixture level and entrainment in the core was judged to be minimal.

An improved simulation of the core behavior was achieved in the sensitivity calculation in which the interphase drag in the core was increased by turning off the bundle volume flag. The current user recommendation is to use the bundle flag in vertical rod bundles. These results suggest that that may not be appropriate for the VVER bundle geometry. However, this was only a single bundle, and the results may differ at full scale. Users should at least investigate the sensitivity of their results to the interphase drag modeling in the core.

Assessment judgments were not made for several phenomena, either because they did not occur in the test or because there were insufficient measurements to characterize them.

Table 3. Assessment results for high-ranked phenomena.

\begin{tabular}{|l|l|}
\hline Phenomenon & Judgment \\
\hline Primary system two-phase natural circulation & Reasonable \\
\hline Asymmetric loop behavior & Reasonable \\
\hline Leak flow & Reasonable \\
\hline Phase separation without mixture level formation & None made \\
\hline Mixture level and entrainment in the steam generator & None made \\
\hline Mixture level and entrainment in the core & Minimal \\
\hline Flow stratification in horizontal pipes & None made \\
\hline Loop seal clearance in the cold legs & Reasonable \\
\hline Pool formation in the upper plenum & None made \\
\hline Heat transfer in a covered core & Reasonable \\
\hline Heat transfer in a partially uncovered core & Reasonable \\
\hline Pressurizer thermal-hydraulics & Reasonable \\
\hline Integral system effects & Reasonable \\
\hline
\end{tabular}




\section{REFERENCES}

1. V. N. Blinkov and A. G. Kraev, Computer Code Validation for Transient Analysis of VVER and RBMK Reactors, Phase 2, Final RELAP5 Validation Plan for Application to VVER, International Nuclear Safety Center, 1998.

2. V. N. Blinkov and A. G. Kraev, Computer Code Validation for Transient Analysis of VVER and RBMK Reactors, Phase 4, Standard Problem Definition Report for INSCSP-PSBV1: 11\% Upper Plenum Break, International Nuclear Safety Center of Russian Minatom, 2002.

3. Idaho National Engineering Laboratory, RELAP5/MOD3 Code Manual, NUREG/CR-5535, INEL-95/0174, August 1995.

4. L. Guo, Z. Feng and X. Chen, "Transient convective heat transfer of steam-water two-phase flow in a helical tube under pressure drop type oscillations," International Journal of Heat and Mass Transfer, Vol. 45 (2002), pp. 533-542.

5. O. I. Melikhov, PSB-VVER Heat Losses, Electrogorsk 2002.

6. V. N. Blinkov and A. G. Kraev, Computer Code Validation for Transient Analysis of VVER and RBMK Reactors, Phase 4, Experimental Data Report for INSCSP-PSBV1: 11\% Upper Plenum Break Test, International Nuclear Safety Center of Russian Minatom, 2002. 
Appendix A Input Listing for PSB RELAP5 Model 


\section{Appendix A \\ Input Listing for PSB RELAP5 Model}
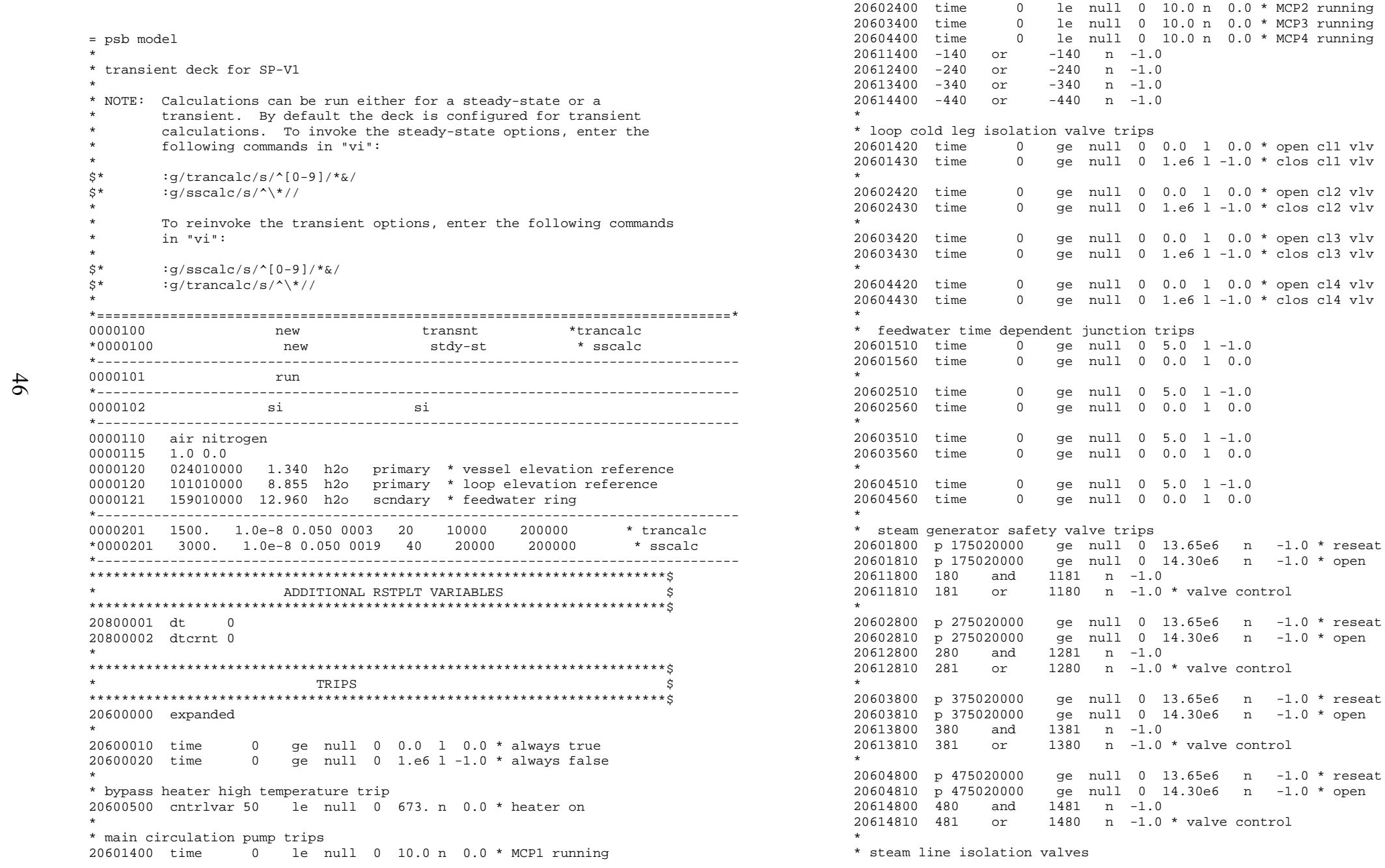


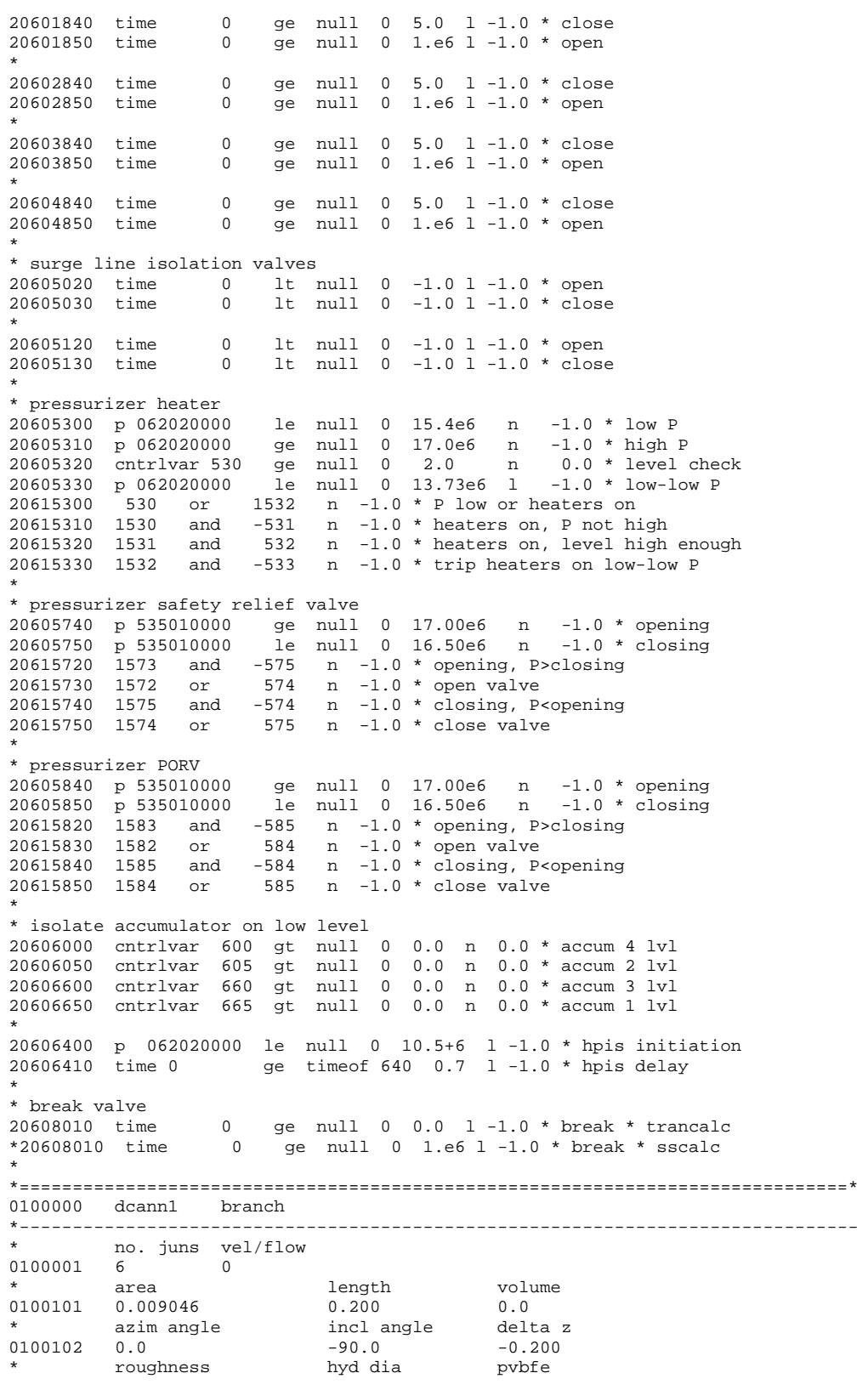

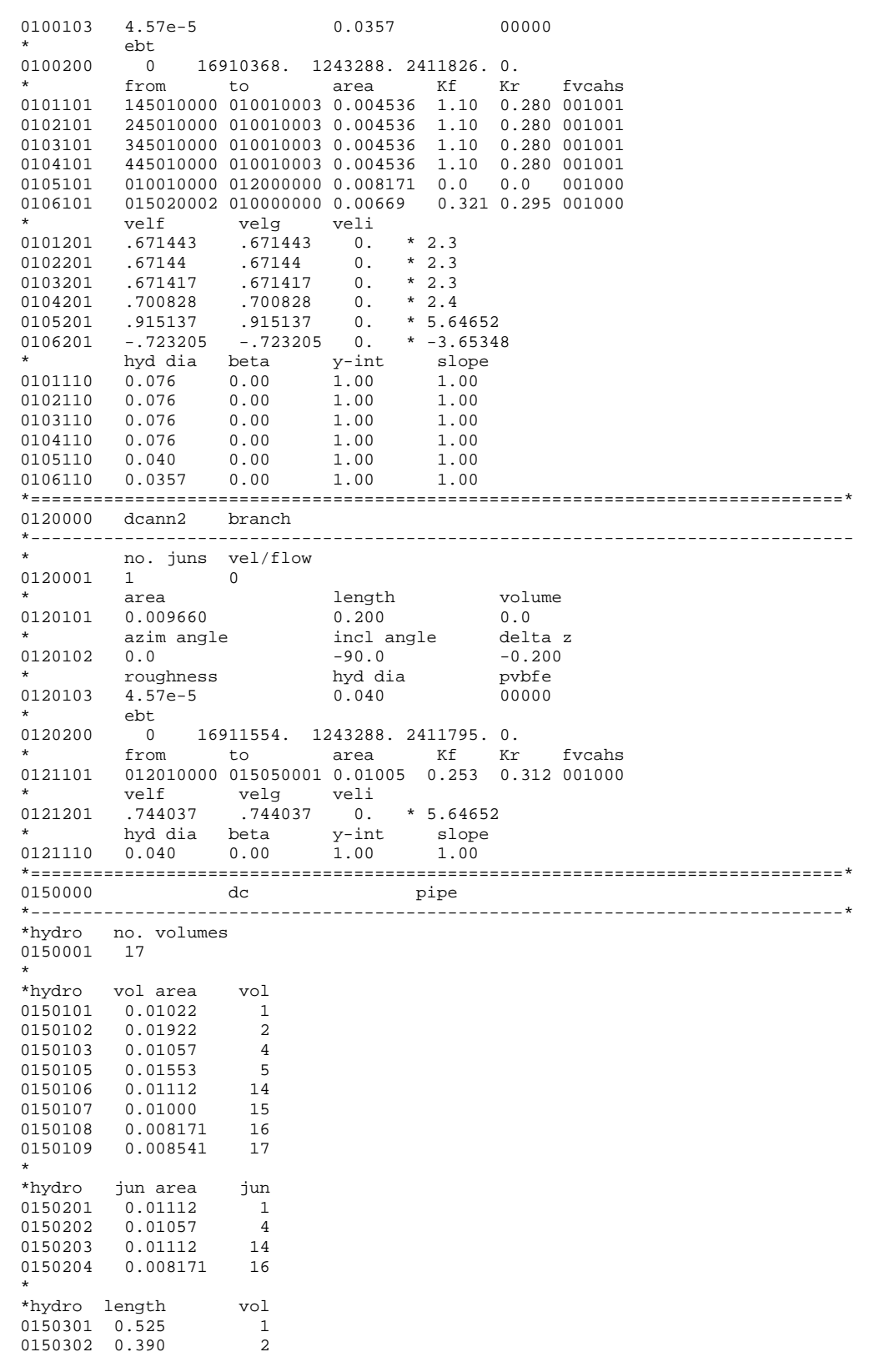




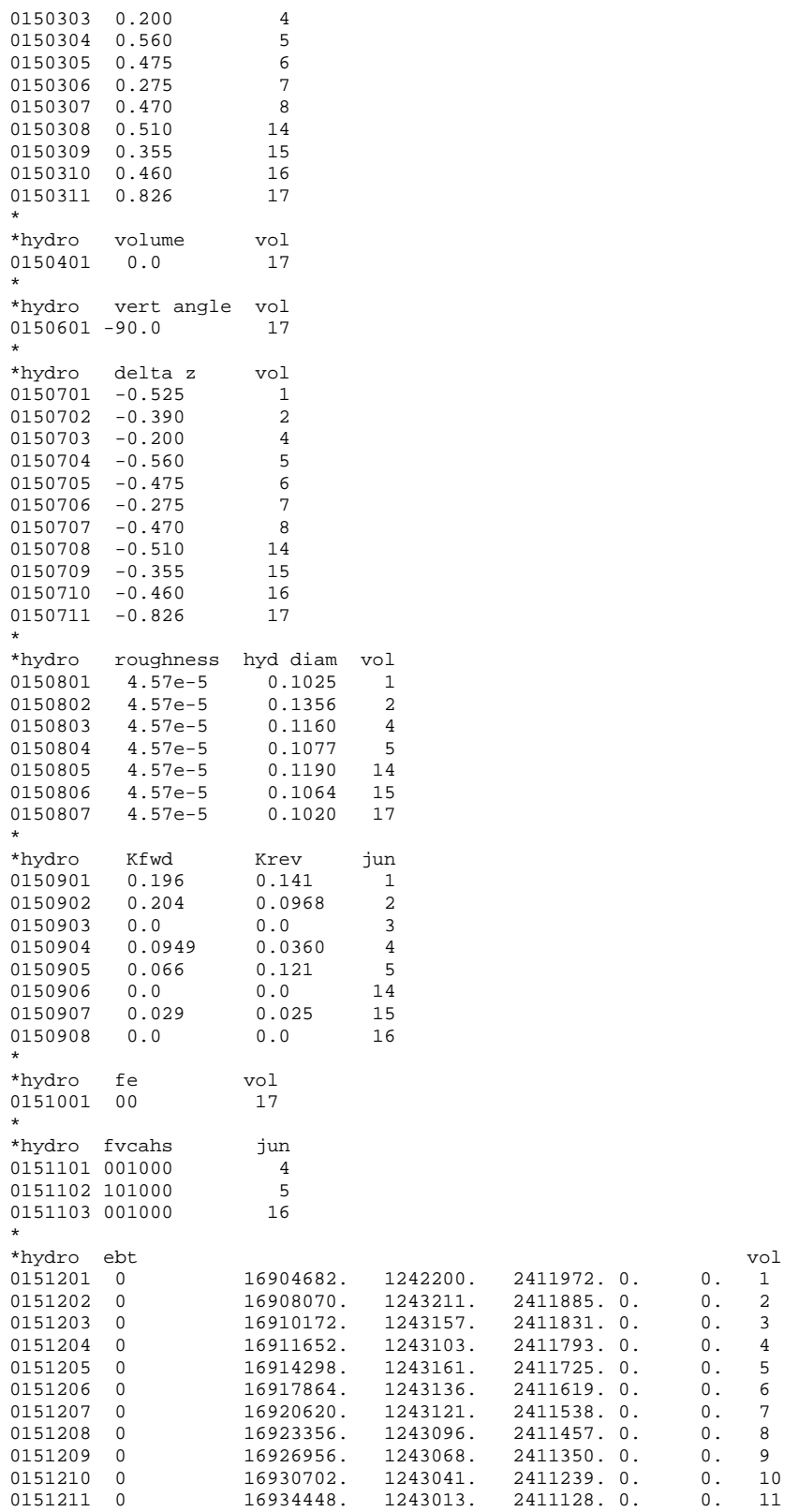

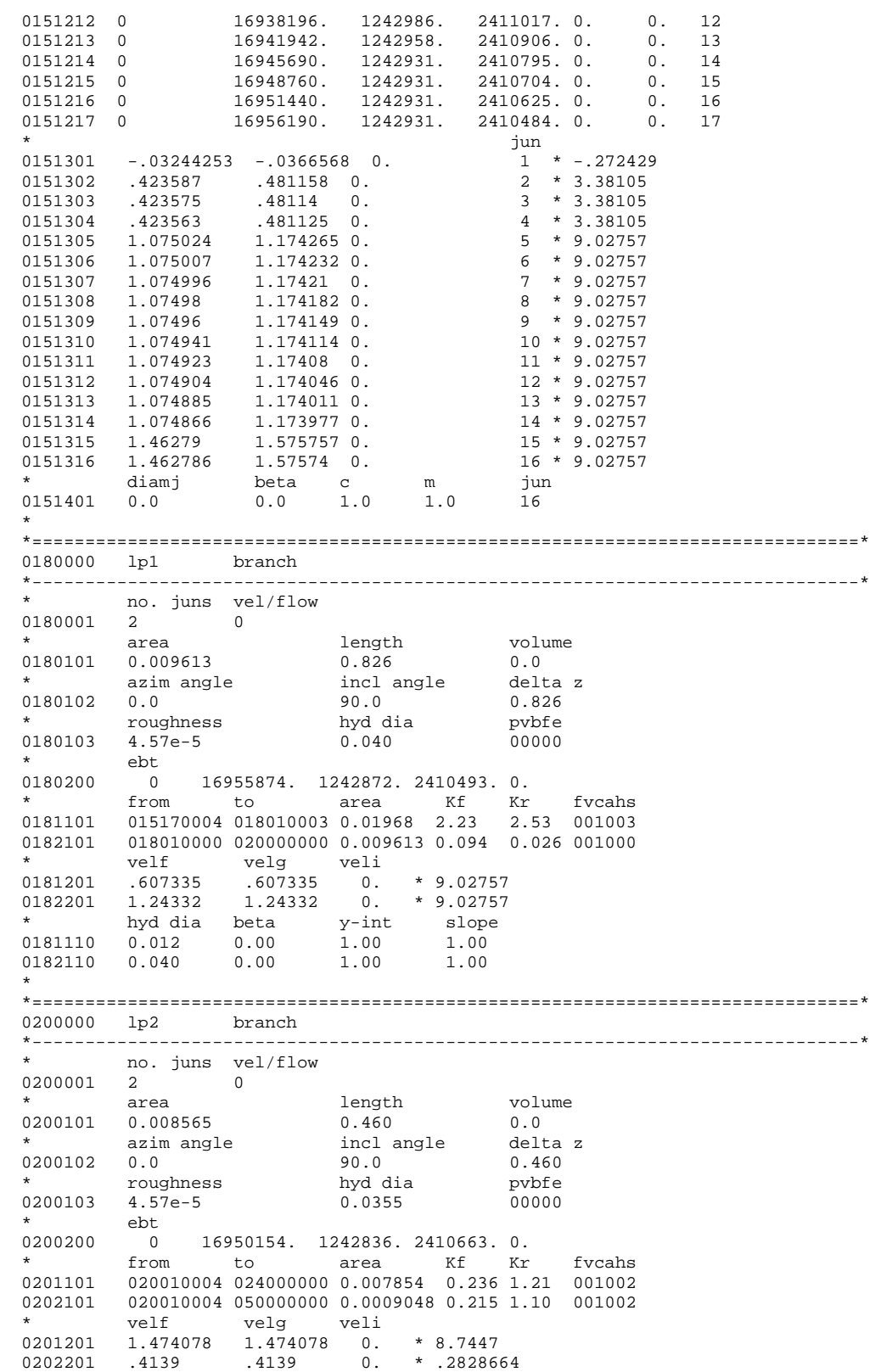




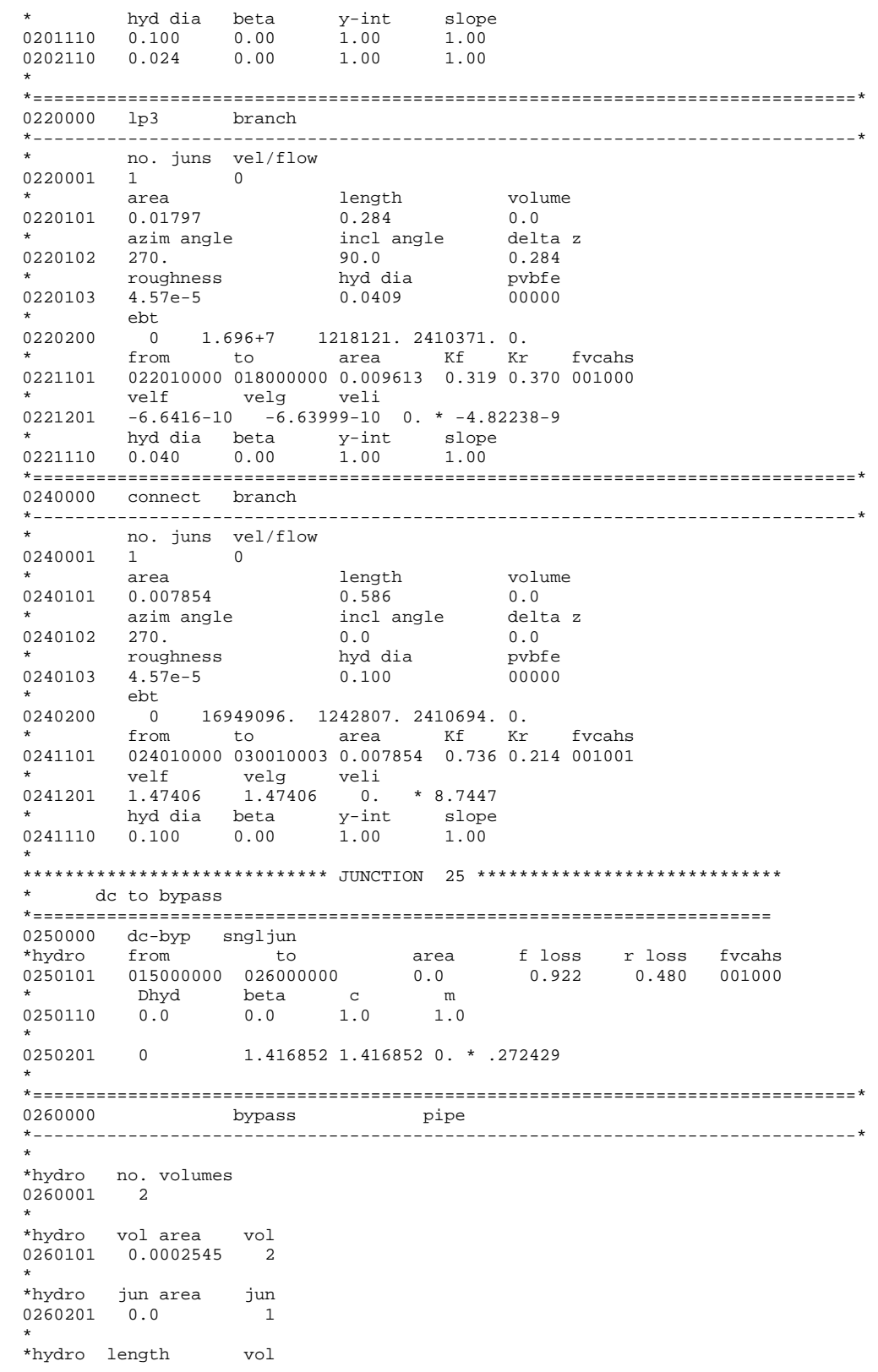

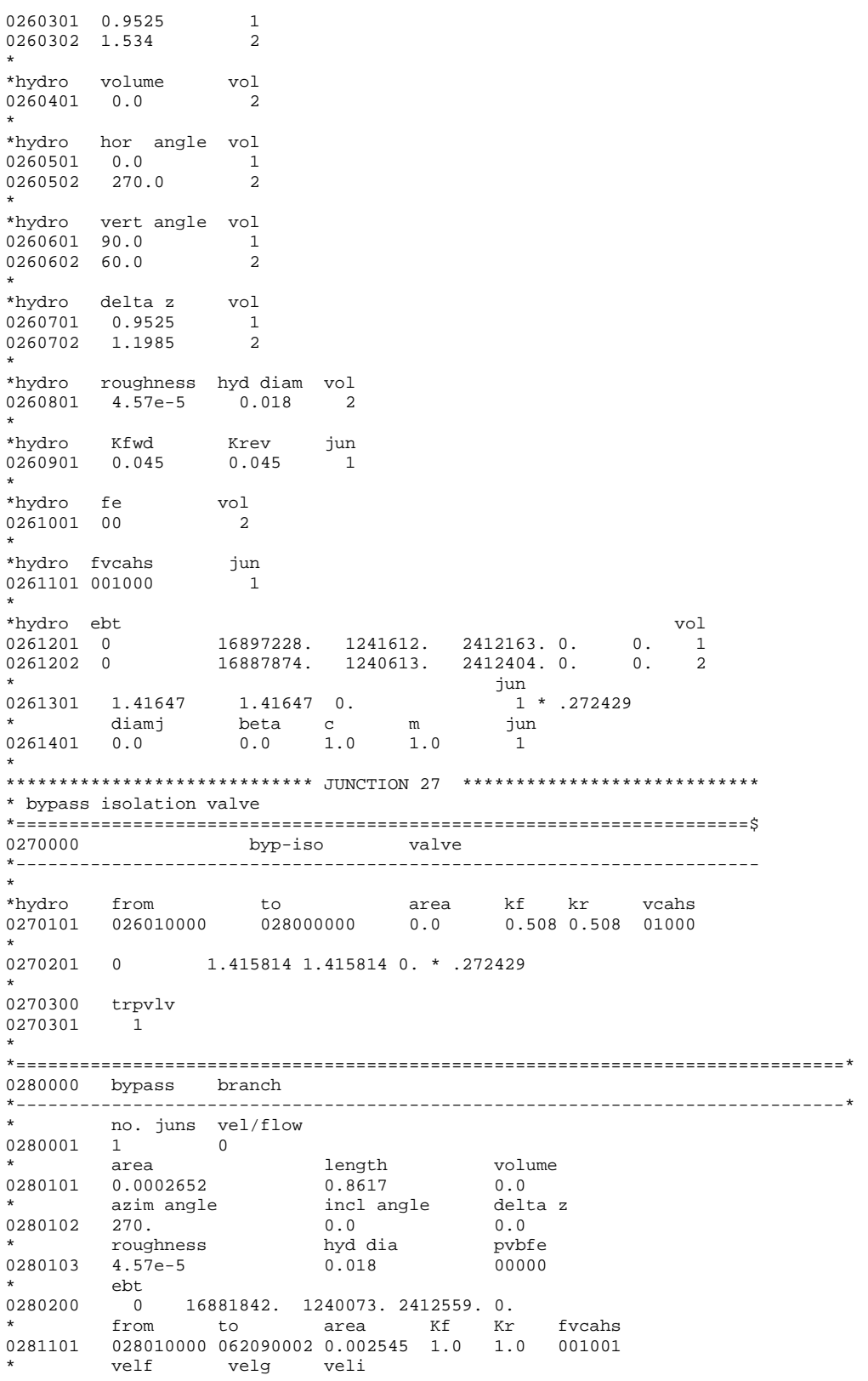




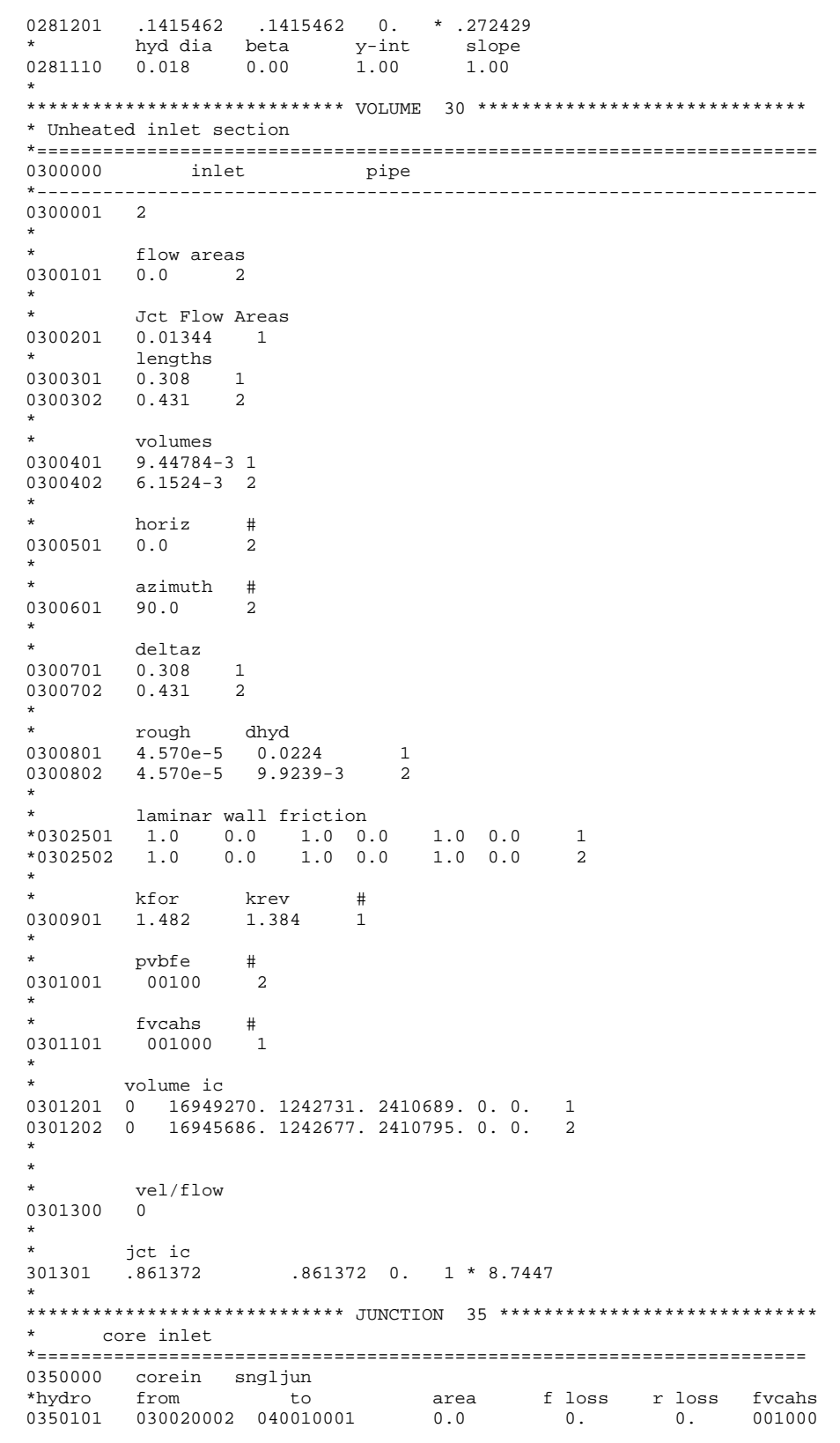

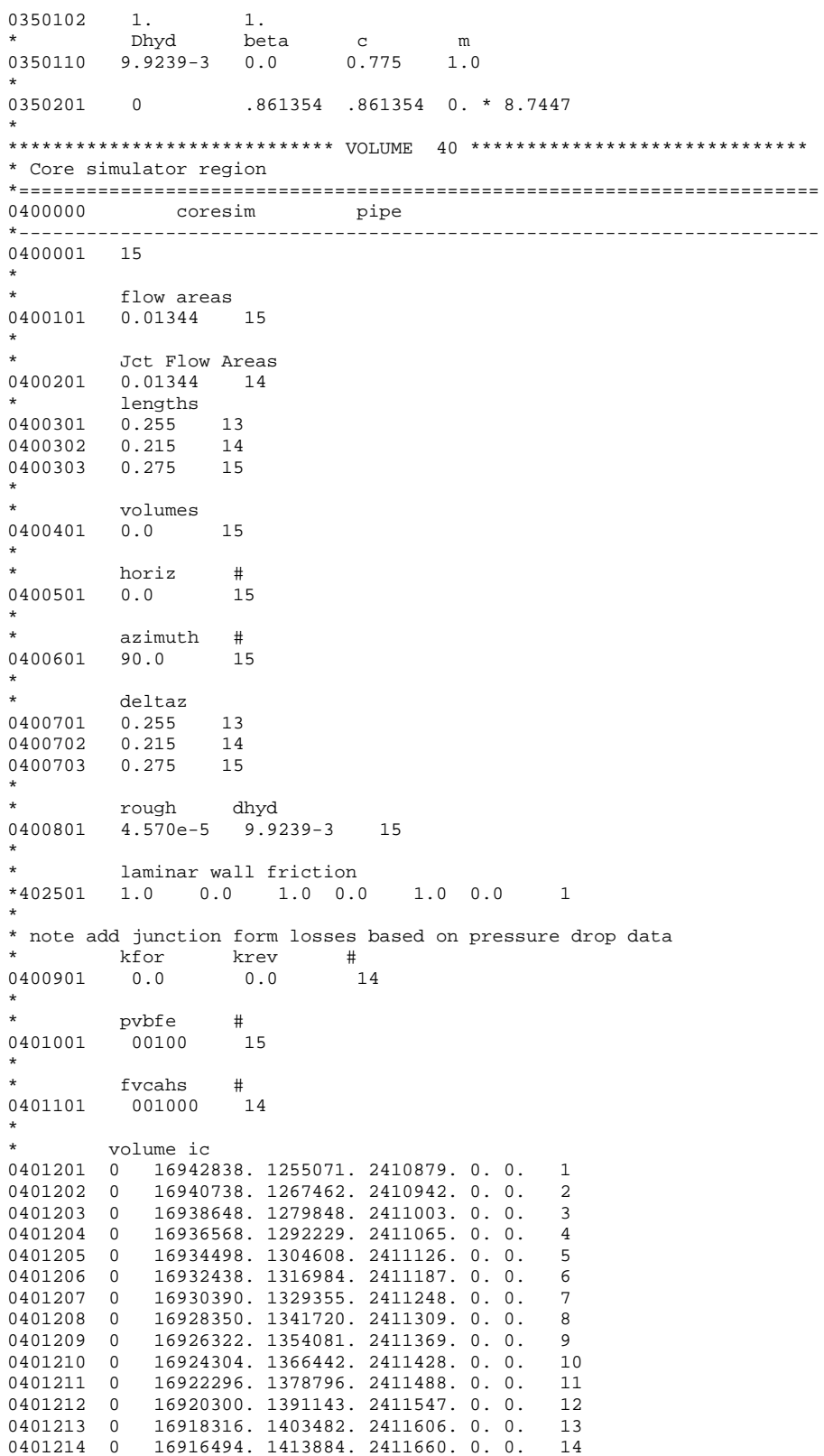


04012150 16914602. 1413841. 2411716. 0. 0. 15

\begin{tabular}{|c|c|c|c|c|}
\hline${ }^{\star}{ }^{\star} 401300$ & $\begin{array}{l}\text { vel/flow } \\
0\end{array}$ & & & \\
\hline & jet ic & & & \\
\hline 0401301 & $\begin{array}{r}.866379 \\
871533\end{array}$ & $\begin{array}{l}.866379 \\
871533\end{array}$ & 0. & $1 * 8.7447$ \\
\hline $\begin{array}{l}0401302 \\
0401303\end{array}$ & $\begin{array}{l}.871533 \\
.876855\end{array}$ & $\begin{array}{l}.871533 \\
.876855\end{array}$ & 0. & $\begin{array}{l}2 * 8.7447 \\
3 * 8.747\end{array}$ \\
\hline $\begin{array}{l}0401303 \\
0401304\end{array}$ & $\begin{array}{l}.876855 \\
.882355\end{array}$ & $\begin{array}{l}.876855 \\
.882355\end{array}$ & 0. & $\begin{array}{l}3 * 8.7447 \\
4 * 8.7447\end{array}$ \\
\hline 0401304 & .882355 & $\begin{array}{l}.882355 \\
887902\end{array}$ & 0. & $\begin{array}{l}4 * 8.7447 \\
5 * 8.7447\end{array}$ \\
\hline 0401305 & .887902 & $\begin{array}{r}.887902 \\
893559\end{array}$ & 0. & \\
\hline 0401306 & .893559 & .893559 & 0. & $\begin{array}{l}6 * 8.7447 \\
7 * 8.7447\end{array}$ \\
\hline 0401307 & .899416 & .899416 & 0. & $\begin{array}{l}7 * 8.7447 \\
8 * 8.7447\end{array}$ \\
\hline 0401308 & .905488 & .905488 & 0. & $8 * 8.7447$ \\
\hline 0401309 & .911705 & .911705 & 0. & $9 * 8.7447$ \\
\hline 0401310 & .917928 & .917928 & 0. & $10 * 8.7447$ \\
\hline 0401311 & .924391 & .924391 & 0. & $11 * 8.7447$ \\
\hline 0401312 & .931116 & .931116 & 0. & $12 * 8.7447$ \\
\hline 0401313 & .938124 & .938124 & 0 . & $13 * 8.7447$ \\
\hline 0401314 & .944094 & .944094 & 0. & $14 * 8.7447$ \\
\hline
\end{tabular}

$\begin{array}{lllll}.944094 & .944094 & 0 . & 14 * 8.7447\end{array}$

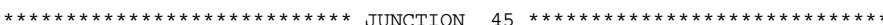
core tie plate

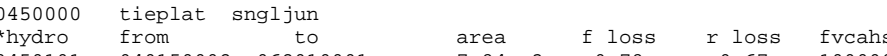

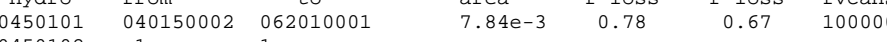
$\begin{array}{lllll}* & \text { Dhyd } & \text { beta } & \mathrm{c} & \mathrm{m} \\ 0450110 & 5.5 \mathrm{e}-3 & 0.0 & 0.775 & 1.0\end{array}$

$\begin{array}{lllll}* 450201 & 0 & 1.61841 & 1.61841 & 0 . * 8.7447\end{array}$

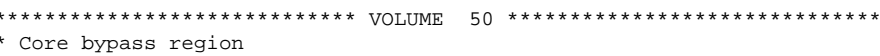

\begin{tabular}{|c|c|c|}
\hline 0500000 & bypass & pipe \\
\hline
\end{tabular}

$0500001 \quad 10$

* flow areas

$\begin{array}{lll}0500101 & 0.0010 & 1 \\ 0500102 & 0.00132 & 9\end{array}$

$\begin{array}{lll}0500103 & 0.00145 & 10\end{array}$

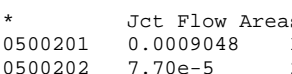

$\begin{array}{ll}0500202 & 7.70 e-5 \\ 0500203 & 0.00132\end{array}$

$\begin{array}{ll}0500301 & \begin{array}{l}\text { lengths } \\ 1.0375\end{array}\end{array}$

$\begin{array}{ll}0500302 & 0.585 \\ 0500303 & 0.510\end{array}$

0.510

$\begin{array}{lll}0500305 & 0.636 & 9 \\ 0500306 & 2.1475 & 10\end{array}$

*

$0500401 \quad$ volumes

$\begin{array}{lll}* & \text { horiz } & \# \\ 0500501 & 0.0 & 10\end{array}$

*
*500601 azimuth
0.0 


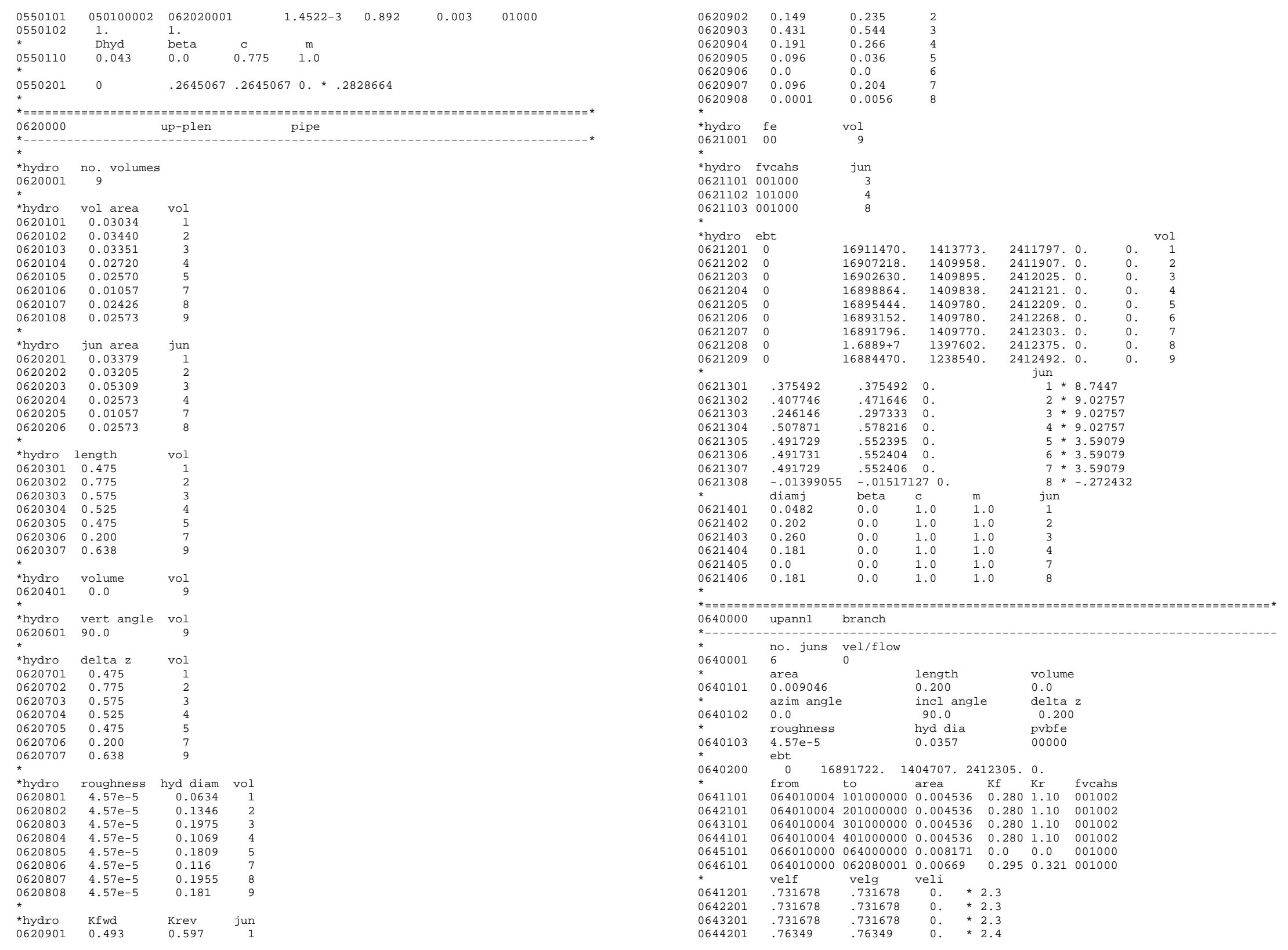




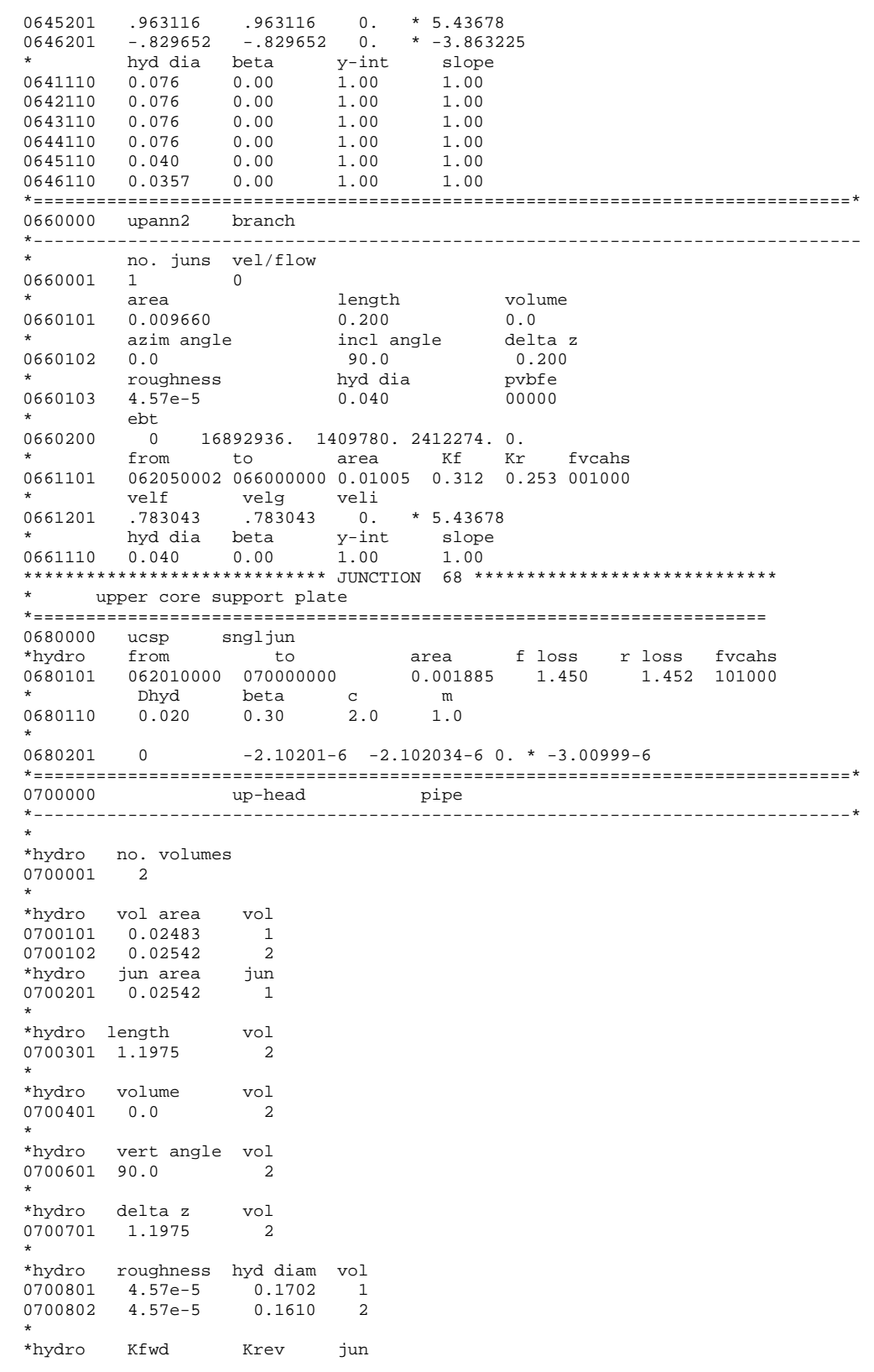

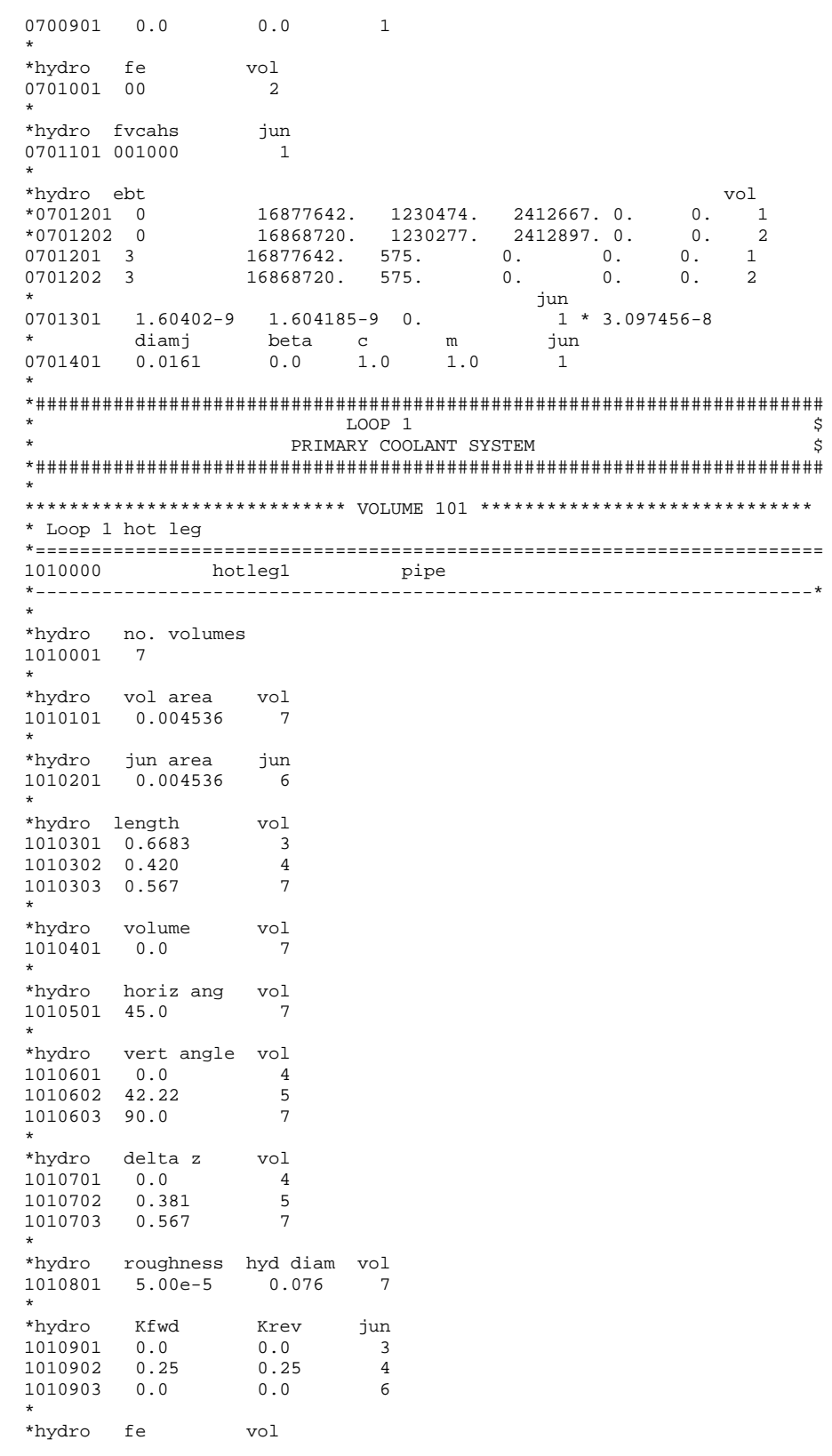




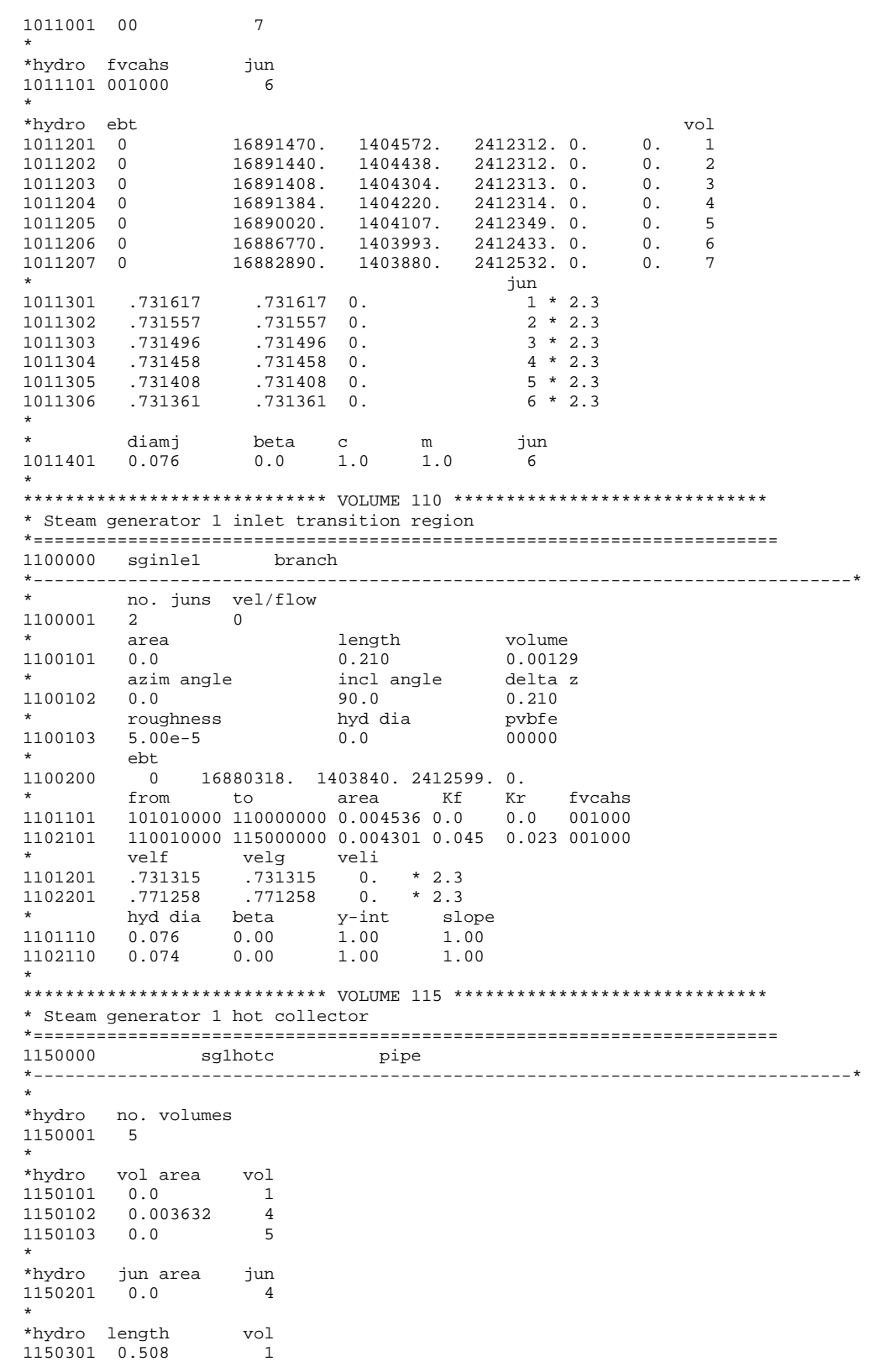




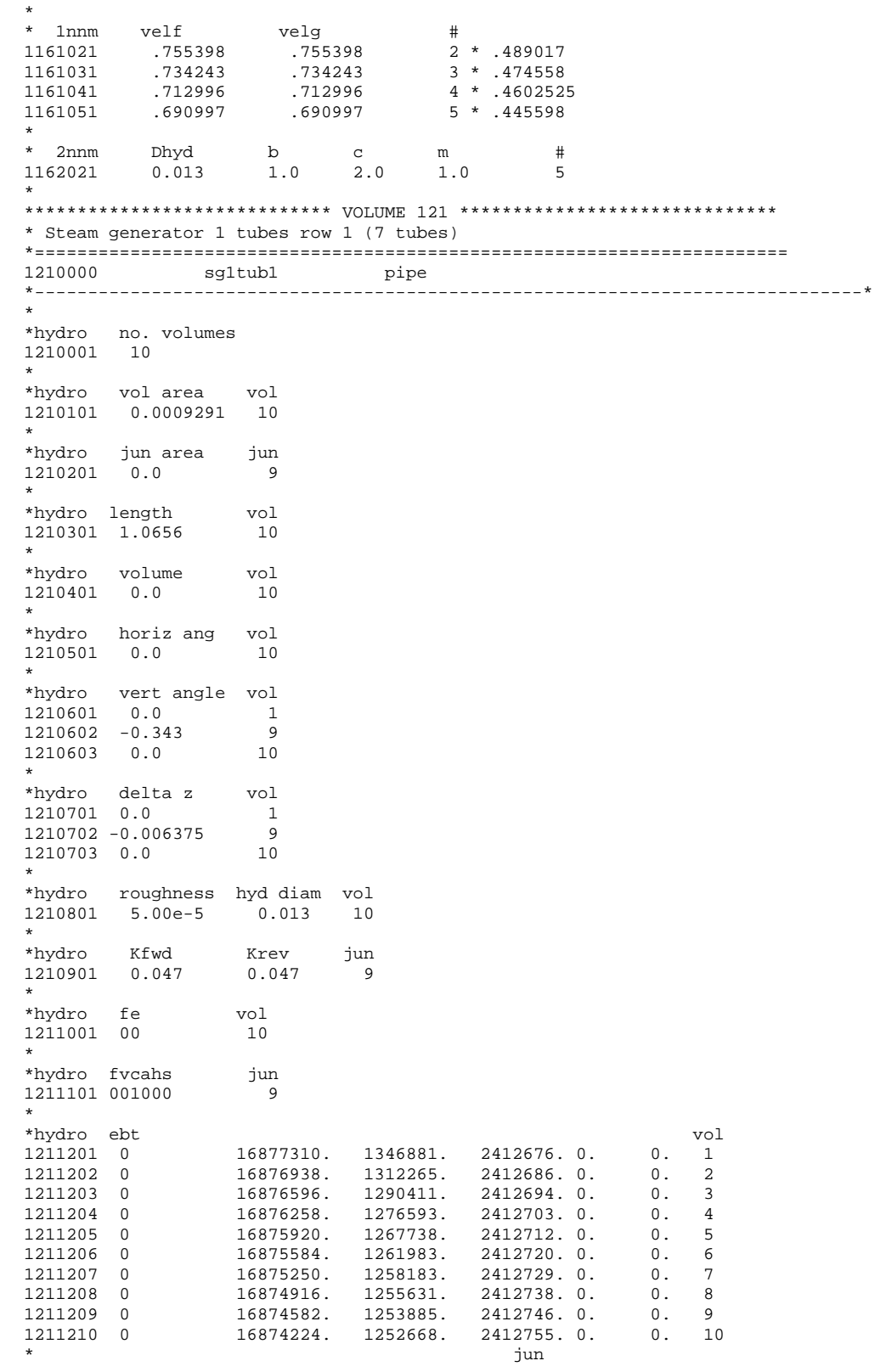

\begin{tabular}{|c|c|c|c|c|c|}
\hline 1211301 & .66942 & .66942 & 0. & & $1 * .445598$ \\
\hline 1211302 & .657102 & .657102 & 0. & & $2 * .445598$ \\
\hline 1211303 & .649846 & .649846 & 0. & & .445598 \\
\hline 1211304 & .645352 & .645352 & 0. & & .445598 \\
\hline 1211305 & .642559 & .642559 & 0. & & .445598 \\
\hline 1211306 & .640778 & .640778 & 0. & & .445598 \\
\hline 1211307 & .639617 & .639617 & 0. & & * . .445598 \\
\hline 1211308 & .638843 & .638843 & 0. & & *. .44559 \\
\hline 1211309 & .638317 & .638317 & 0. & & ^. .445598 \\
\hline * & diamj & beta & & $\mathrm{m}$ & jun \\
\hline 1211401 & 0.013 & 0.0 & 1.0 & 1.0 & \\
\hline
\end{tabular}

Steam generator 1 tubes row 2 ( 7 tubes)

\begin{tabular}{|c|c|}
\hline 1220000 & sg1tub2 \\
\hline
\end{tabular}

*hydro no. volumes

$1220001 \quad 10$

$\begin{array}{llr}* \text { hydro } & \text { vol area } & \text { vol } \\ 1220101 & 0.0009291 & 10\end{array}$

$1220201 \quad 0.0 \quad \begin{array}{lr}0 \\ 0.0\end{array}$

*hydro length vol

*

$\begin{array}{llr}* \text { hydro } & \text { volume } & \text { vol } \\ 1220401 & 0.0 & 10\end{array}$

*hydro horiz ang vol

$* 205010.0$ ang 10

*hydro vert angle vol

$\begin{array}{rcr}1220602 & -0.343 & 9 \\ 1220603 & 0.0 & 10\end{array}$

*hydro delta z vol

$\begin{array}{lll}1220702 & -0.006375 \\ 1220703 & 0.0 & \end{array}$

thydro roughness hyd diam vol

$220801 \quad 5.00 e-5 \quad 0.013-10$

$\begin{array}{lllr}\text { *hydro } & \text { Kfwd } & \text { Krev } & \text { jun } \\ 1220901 & 0.047 & 0.047 & 9\end{array}$

*hydro fe vol

* $122100100 \quad 10$

$\begin{array}{lrr}* \text { hydro fvcahs } & \text { jun } \\ 1221101001000 & 9\end{array}$

$\begin{array}{lllllllc}* & & & & & \\ * \text { hydro } & \text { ebt } & & & & & \\ 1221201 & 0 & 1.6874+7 & 1346356 . & 2412761 . & 0 . & 0 . & 1 \\ 1221202 & 0 & 16873610 . & 1312239 . & 2412771 . & 0 . & 0 . & 2 \\ 1221203 & 0 & 16873242 . & 1290567 . & 242781 . & 0 . & 0 . & 3 \\ 1221204 & 0 & 16872878 . & 1276781 . & 2412790 . & 0 . & 0 . & 4 \\ 1221205 & 0 & 16872516 . & 1267897 . & 2412799 . & 0 . & 0 . & 5 \\ 1221206 & 0 & 16872156 . & 1262091 . & 2412809 . & 0 . & 0 . & 6 \\ 1221207 & 0 & 16871796 . & 1258238 . & 2412818 . & 0 . & 0 . & 7 \\ 1221208 & 0 & 16871438 . & 1255639 . & 2412827.0 . & 0 . & 8\end{array}$




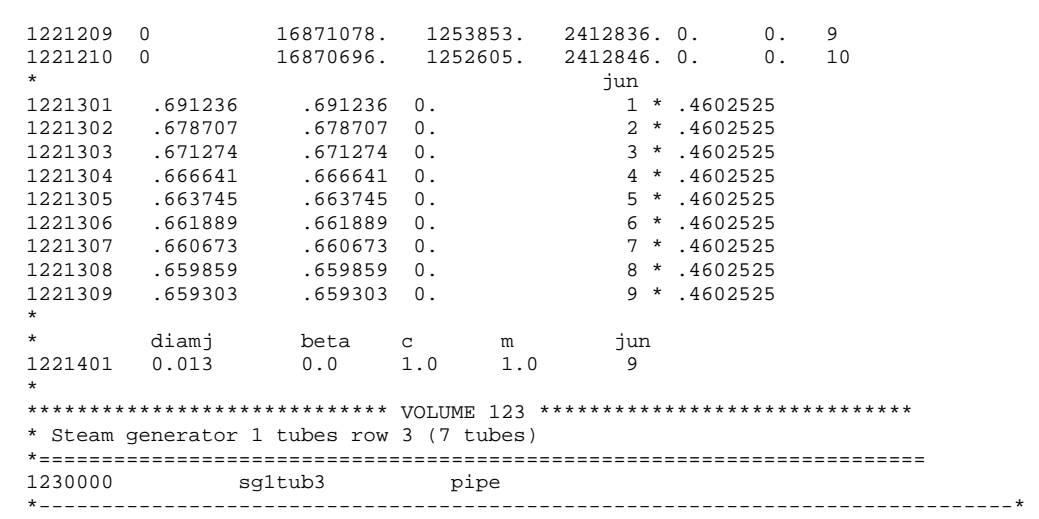

${ }^{\star}{ }^{\star}$ hydro no. volumes

$$
\text { * hydro vol area vol }
$$$$
\begin{array}{ccc} 
& & \\
1230101 & \text { vol area } & \text { vol } \\
0.0009291 & 10
\end{array}
$$$$
\text { *hydro jun area jun }
$$$$
\text { * } 1230201 \quad 0.0 \quad 9
$$$$
\begin{array}{lcr}
{ }^{*} \text { hydro } & \text { length } & \text { vol } \\
1230301 & 1.0656 & 10
\end{array}
$$

$\begin{array}{llr}\text { *hydro } & \text { volume } & \text { vol } \\ 1230401 & 0.0 & 10\end{array}$

$\begin{array}{lll}* \text { hydro } & \text { horiz ang vol } \\ 1230501 & 0.0 & 10\end{array}$

* *hydro vert angle vol

$\begin{array}{llr}* \text { hydro } & \text { vert angle } & \text { vol } \\ 1230601 & 0.0 & 1 \\ 1230602 & -0.343 & 9\end{array}$

$\begin{array}{llr}1230602 & -0.343 & 9 \\ 1230603 & 0.0 & 10\end{array}$

$\begin{array}{llr}\text { *hydro } & \text { delta z } & \text { vol } \\ 1230701 & 0.0 & 1\end{array}$

$\begin{array}{rrr}1230701 & 0.0 & 1 \\ 1230702 & -0.006375 & 9 \\ 1230703 & 0.0 & 10\end{array}$

$\begin{array}{cccc}\text { *hydro } & \text { roughness } & \text { hyd diam } & \text { vol } \\ 1230801 & 5.00 \mathrm{e}-5 & 0.013 & 10\end{array}$

*hydro Kfwd Krev jun

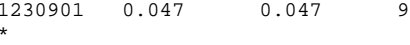

$\begin{array}{llr}* \text { hydro } & \text { fe } & \text { vol } \\ 1231001 & 00 & 10\end{array}$

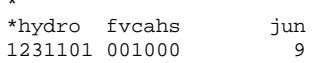

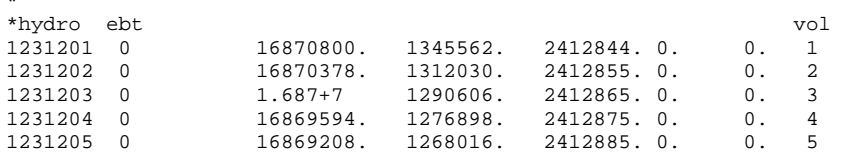

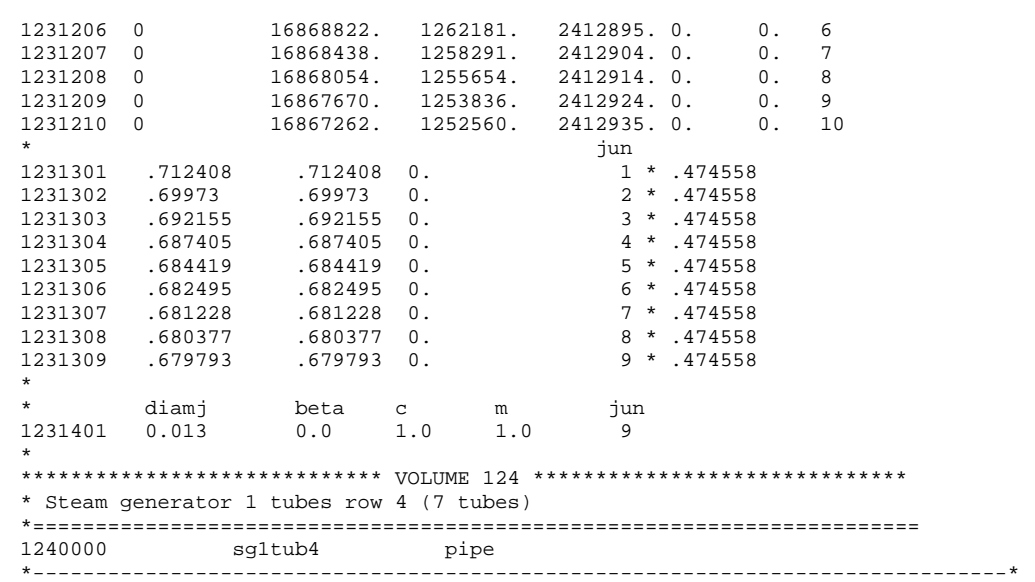

1240000

pip

*hydro no. volumes

*hydro vol area vol

*

$\begin{array}{llr}* \text { kydro } & \text { jun area } & \text { jun } \\ 1240201 & 0.0 & 9\end{array}$

* *hydro length vol

* $1240301 \quad 1.0656 \quad 10$

$\begin{array}{llr}* \text { hydro } & \text { volume } & \text { vol } \\ 1240401 & 0.0 & 10\end{array}$

*hydro horiz ang vol

$\begin{array}{lll}240501 & 0.0 & 10\end{array}$

*hydro vert angle vol

$\begin{array}{rcr}1240602 & -0.343 & 9 \\ 1240603 & 0.0 & 10\end{array}$

$\begin{array}{llr}* \text { hydro } & \text { delta z } & \text { vol } \\ 1240701 & 0.0 & 1 \\ 1240702 & -0.006375 & 9\end{array}$

$\begin{array}{lll}1240703 & 0.006375 & 10\end{array}$

*hydro roughness hyd diam vol

* $1240801 \quad 5.00 \mathrm{e}-5$ hyd 0.013 vol 10

$\begin{array}{lllr}* \text { *hydro } & \text { Kfwd } & \text { Krev } & \text { jun } \\ 1240901 & 0.047 & 0.047 & 9\end{array}$

*hydro fe vol

*

$\begin{array}{llr}* \text { kydro } & \text { fvcahs } & \text { jun } \\ 1241101 & 001000 & 9\end{array}$

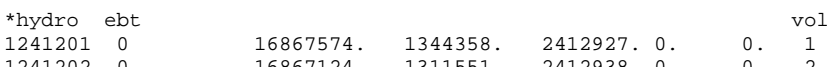




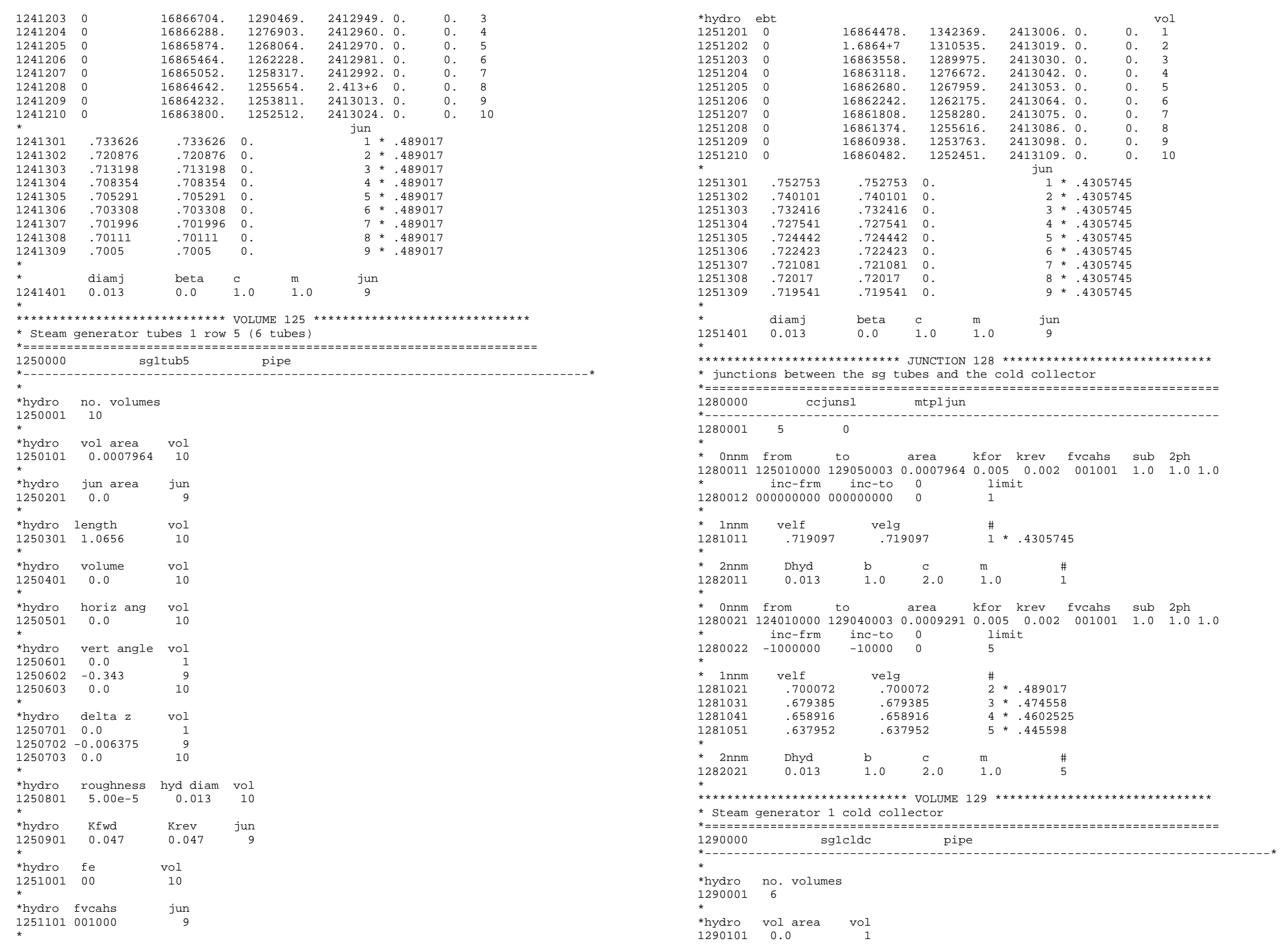




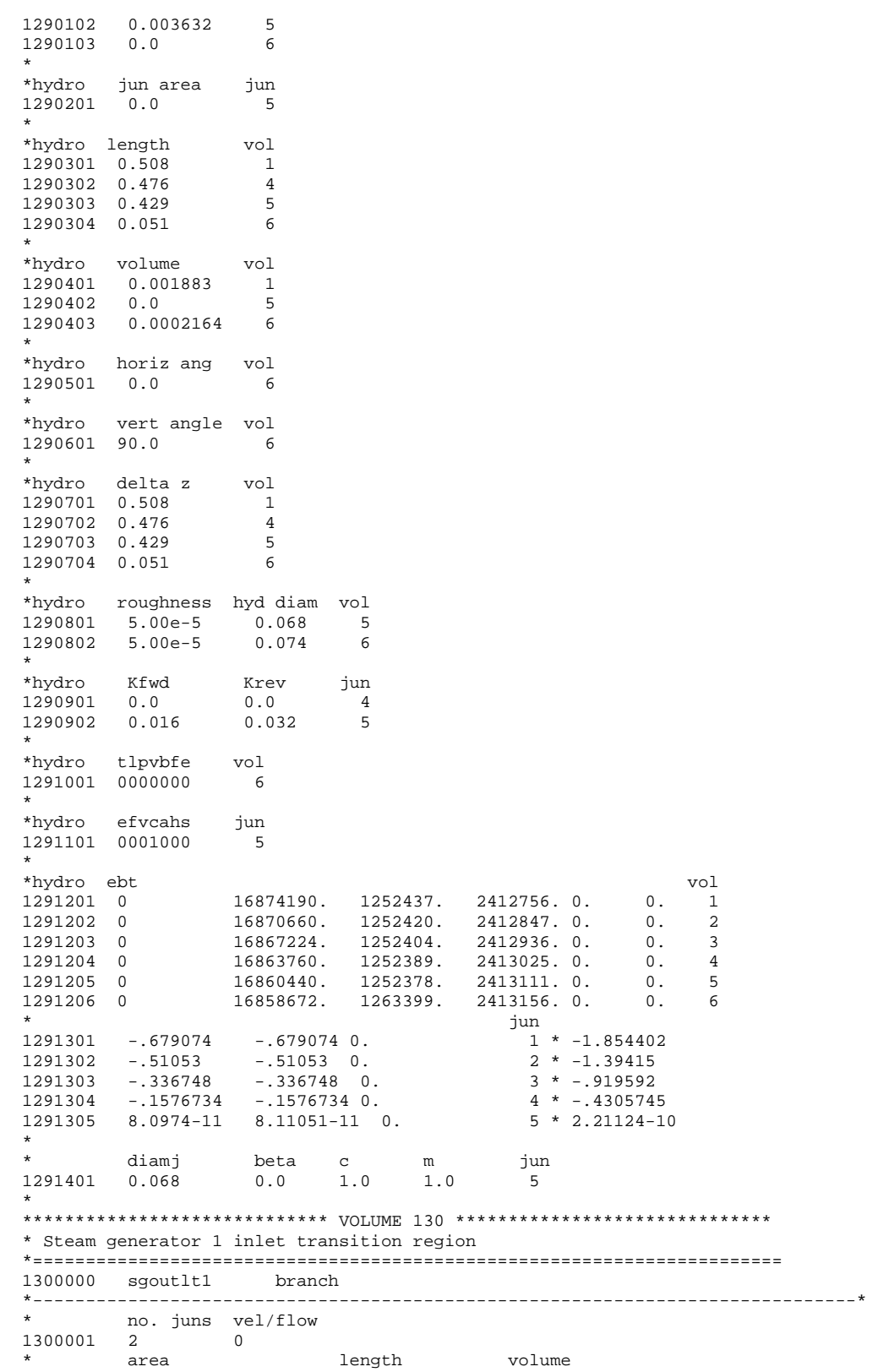

\begin{tabular}{|c|c|c|c|}
\hline 1300101 & \multirow{2}{*}{\multicolumn{2}{|c|}{$\begin{array}{l}0.0 \\
\text { azim angle }\end{array}$}} & \\
\hline & & & inc \\
\hline $\begin{array}{l}1300102 \\
\star\end{array}$ & \multicolumn{2}{|l|}{0.0} & $\begin{array}{l}-90.0 \\
\text { hyd }\end{array}$ \\
\hline 1300103 & \multicolumn{2}{|l|}{$\begin{array}{l}\text { roughness } \\
5.00 \mathrm{e}-5\end{array}$} & $\begin{array}{l}\text { hyd } \\
0.0\end{array}$ \\
\hline & \\
\hline $\begin{array}{l}1300200 \\
*\end{array}$ & \multicolumn{2}{|c|}{$\begin{array}{ccc}0 & 16876738 . & 12 \\
\text { from } & \text { to }\end{array}$} & $\begin{array}{r}125243 \\
\text { area }\end{array}$ \\
\hline 1301101 & \multirow{2}{*}{\multicolumn{3}{|c|}{ 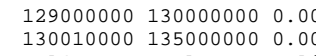 }} \\
\hline $\begin{array}{l}1302101 \\
\star\end{array}$ & & & \\
\hline 1301201 & $\begin{array}{l}\text { velf } \\
.711244\end{array}$ & $\begin{array}{l}.719 \\
.71244\end{array}$ & $4 \quad 0$ \\
\hline $\begin{array}{l}1302201 \\
*\end{array}$ & .674394 & .674394 & \\
\hline 1301110 & & $\begin{array}{l}\text { beta } \\
0.00\end{array}$ & \\
\hline $\begin{array}{l}1302110 \\
\star\end{array}$ & 0.076 & 0.00 & \\
\hline \multicolumn{4}{|c|}{ 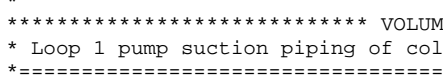 } \\
\hline 1350000 & \multicolumn{2}{|c|}{ 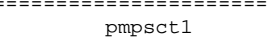 } & \\
\hline \\
\hline *hydro & \multirow{2}{*}{\multicolumn{3}{|c|}{14}} \\
\hline${ }_{\star}^{1350001}$ & & & \\
\hline *hydro & \multirow{4}{*}{$\begin{array}{l}\text { vol area } \\
0.004536 \\
0.0 \\
0.004536\end{array}$} & vol & \\
\hline & & & \\
\hline & & 11 & \\
\hline $\begin{array}{l}1350103 \\
*\end{array}$ & & 14 & \\
\hline *hydro & \multirow{2}{*}{$\begin{array}{l}\text { jun area } \\
0.004536\end{array}$} & jun & \\
\hline${ }_{\star}^{13502}$ & & 13 & \\
\hline thydr & \multirow{2}{*}{$\begin{array}{r}\text { length } \\
0.828\end{array}$} & vol & \\
\hline & & & \\
\hline 1350 & $\begin{array}{l}0.828 \\
1.042\end{array}$ & & \\
\hline 1350303 & $\begin{array}{l}1.042 \\
1.121\end{array}$ & 8 & \\
\hline 1350304 & \multirow{2}{*}{$\begin{array}{l}0.7495 \\
0.74525\end{array}$} & 10 & \\
\hline 1350305 & & 14 & \\
\hline *hydro & volume & vol & \\
\hline 1350401 & 0.0 & 10 & \\
\hline 13504 & 0.006897 & 11 & \\
\hline 1350403 & 0.0 & 14 & \\
\hline *hydro & horiz ang & vol & \\
\hline 1350501 & 95.0 & 14 & \\
\hline *hydro & vert angle & vol & \\
\hline 1350601 & -90.0 & 8 & \\
\hline 1350602 & 0.0 & 10 & \\
\hline 1350603 & 90.0 & 14 & \\
\hline *hydro & delta $z$ & vol & \\
\hline & -0.828 & 5 & \\
\hline & -0.7425 & 7 & \\
\hline 13507 & -0.935 & 8 & \\
\hline 13507 & 0.0 & 10 & \\
\hline 1350705 & 0.64925 & 11 & \\
\hline 1350706 & 0.74525 & 14 & \\
\hline${ }^{\star}$ *hydro & & hyd & m vol \\
\hline $\begin{array}{l}1350801 \\
\star\end{array}$ & $5.00 \mathrm{e}-5$ & & 14 \\
\hline & & & \\
\hline & 0.0 & 0.0 & \\
\hline 1350902 & 0.13 & 0.13 & \\
\hline
\end{tabular}




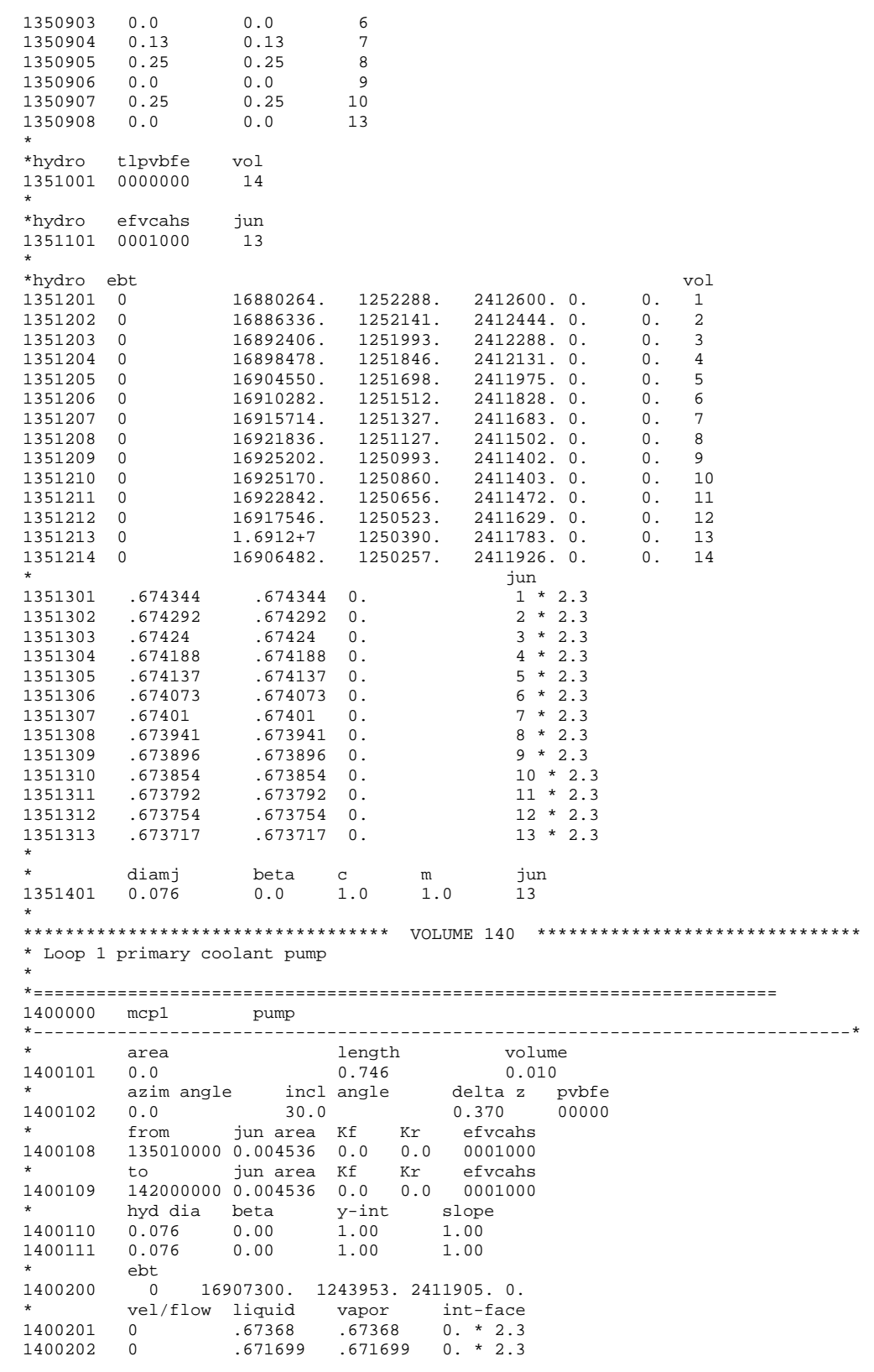

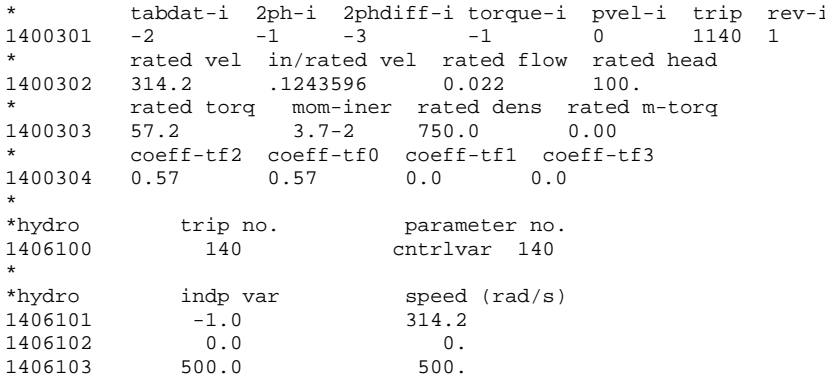

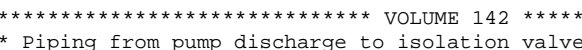

\begin{tabular}{|c|c|c|c|}
\hline $\begin{array}{l}\text { *hydro } \\
1420000\end{array}$ & $\begin{array}{l}\text { component name } \\
\text { pmplout }\end{array}$ & $\begin{array}{l}\text { component type } \\
\text { snglvol }\end{array}$ & \\
\hline $\begin{array}{l}\text { *hydro } \\
1420101 \\
\text { * }\end{array}$ & $\begin{array}{l}\text { area } \\
0.004536\end{array}$ & $\begin{array}{l}\text { length } \\
0.880\end{array}$ & $\begin{array}{l}\text { volume } \\
0.0\end{array}$ \\
\hline $\begin{array}{l}\text { *hydro } \\
1420102 \\
*\end{array}$ & $\begin{array}{l}\text { horz angle } \\
-100.0\end{array}$ & $\begin{array}{c}\text { vert angle } \\
0.0\end{array}$ & $\begin{array}{c}\text { delta } \mathrm{z} \\
0.0\end{array}$ \\
\hline $\begin{array}{l}\text { *hydro } \\
1420103 \\
\text { * }\end{array}$ & $\begin{array}{l}\text { roughness } \\
0.00005\end{array}$ & $\begin{array}{l}\text { hyd diam } \\
0.076\end{array}$ & $\begin{array}{l}\mathrm{fe} \\
00\end{array}$ \\
\hline
\end{tabular}

$\begin{array}{lrrl}* \text { hydro } & \text { ebt } & \text { pressure } & \text { tempe } \\ 1420200 & 0 & 16910562 . & 1243707.2411821 .0 .\end{array}$

法

* Cold leg isolation valve

\begin{tabular}{|c|c|}
\hline & cllvl \\
\hline
\end{tabular}

*hydro from to area kf $\mathrm{kr}$ vcahs

$\begin{array}{llllll}1430201 & 0 & .671617 .671617 & 0 . * 2.3\end{array}$

1430300 mtrvlv

$\begin{array}{lllll}* & \text { open } & \text { close } & \text { rate } & \text { ic } \\ 1430301 & 142 & 143 & 0.1 & 1 .\end{array}$

* Loop 1 reactor vessel inlet section of cold leg

$1450000 \quad$ cldleg1 $\quad$ pipe

*hydro no. volumes

$1450001 \quad 4$

thydro vol area vol

$\begin{array}{lll}450101 & 0.004536 \quad 4\end{array}$

$\begin{array}{lcr}\text { *hydro } & \text { jun area } & \text { jun } \\ 1450201 & 0.004536 & 3\end{array}$

*hydro length vol 


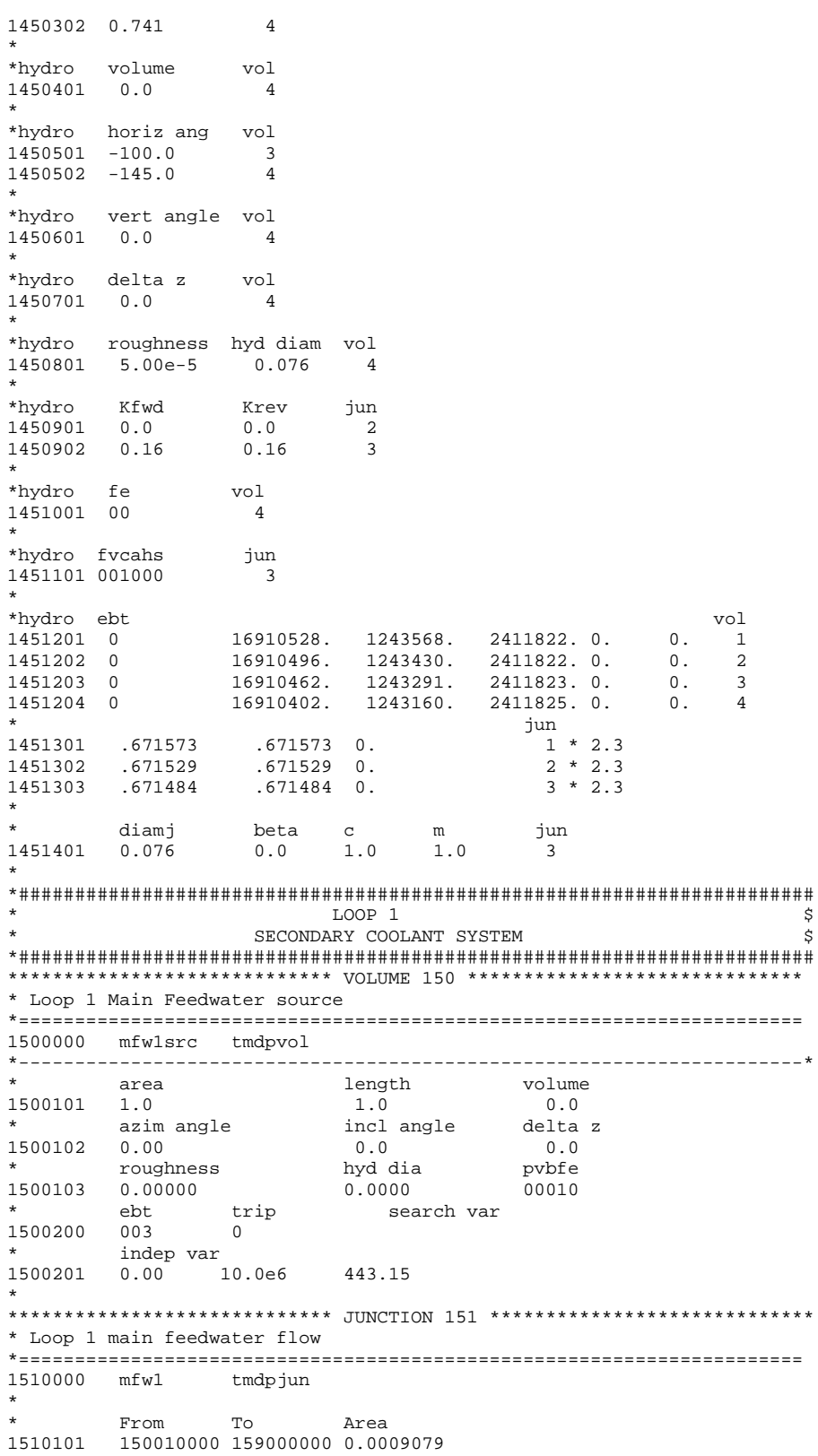

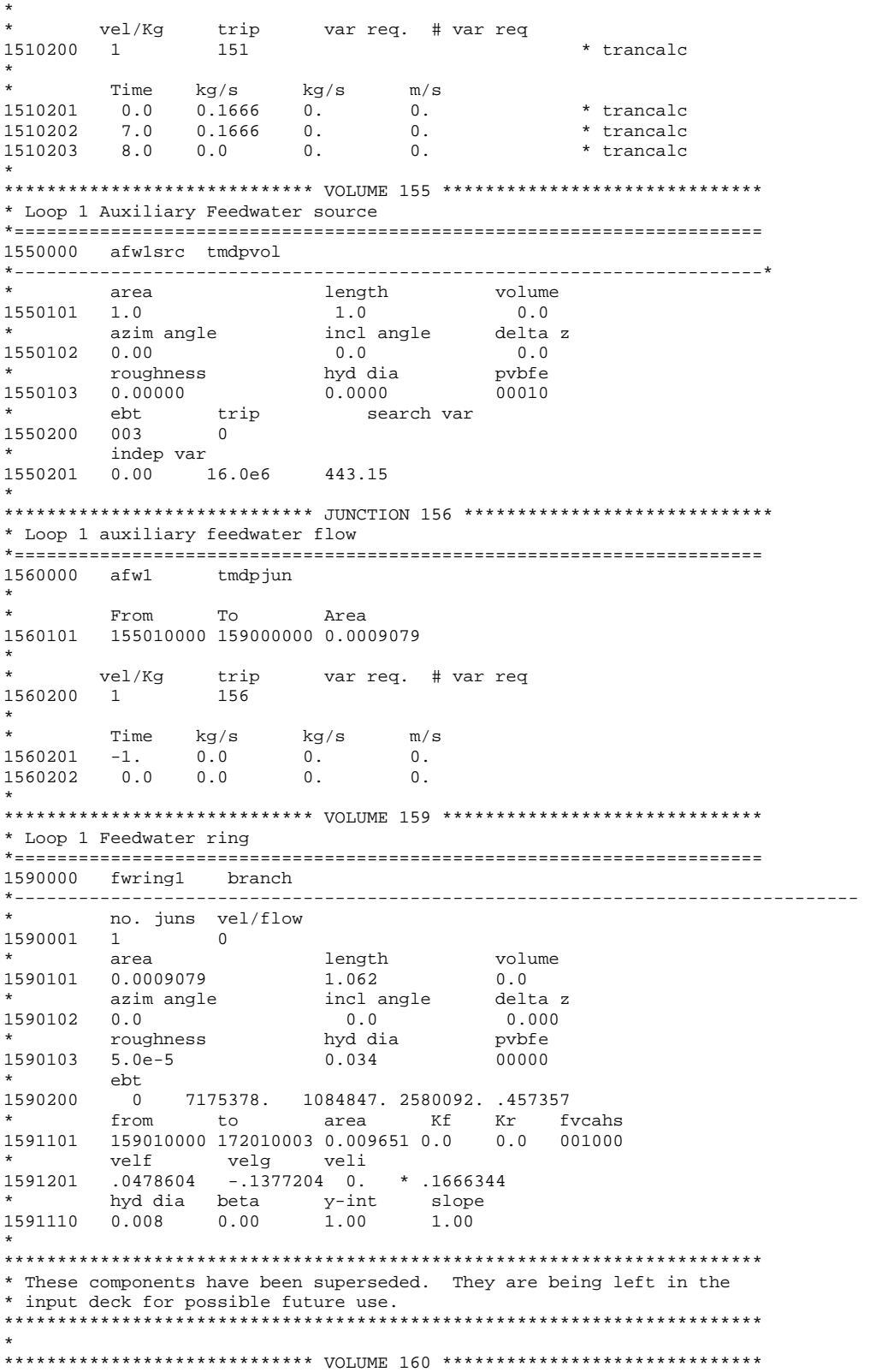




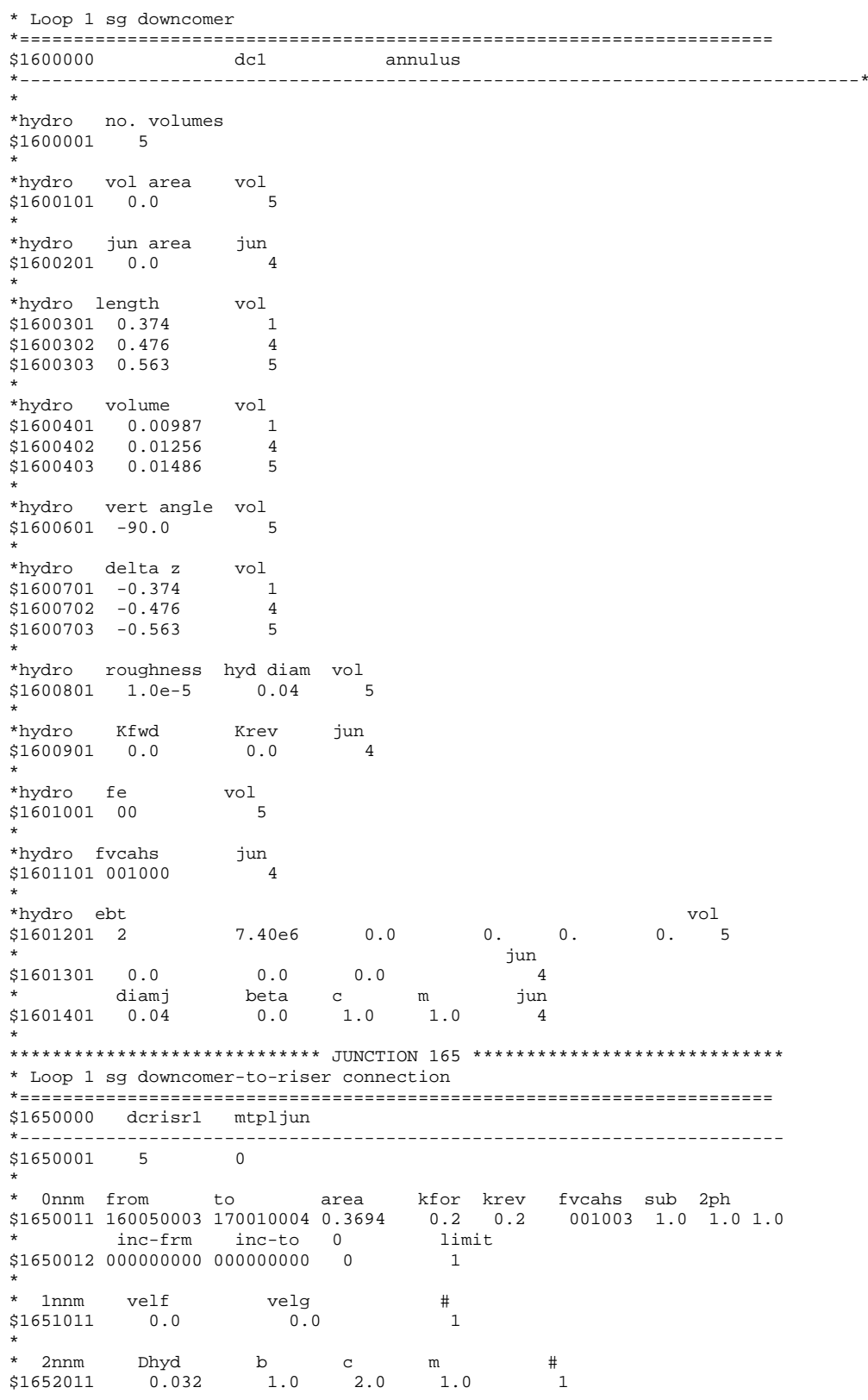

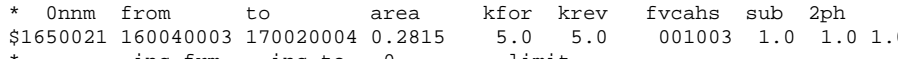
inc-frm inc-to 0 limit

* $1 \mathrm{nnm}$ velf velg \#

$\begin{array}{cccc}\text { Innm } & \text { velf } & \text { velg } & \# \\ \$ 1651021 & 0.0 & 0.0 & 2\end{array}$

$\begin{array}{cccccc}* 2 \mathrm{nnm} & \text { Dhyd } & \mathrm{b} & \mathrm{c} & \mathrm{m} & \# \\ \$ 1652021 & 0.032 & 1.0 & 2.0 & 1.0 & { }_{2}\end{array}$

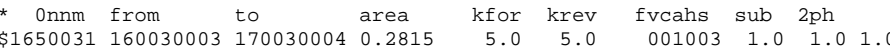

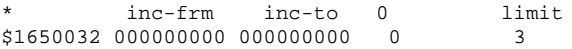

$\begin{array}{cccc}* \text { Innm } & \text { velf } & \text { velg } & \# \\ \$ 1651031 & 0.0 & 0.0 & 3\end{array}$

* 2 nnm Dhyd $\quad$ b $\quad c \quad c \quad m \quad$ m

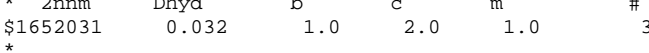
$\begin{array}{llllrrrrrr}* \quad \text { onnm from } & \text { to } & \text { area } & \text { kfor } & \text { krev } & \text { fvcahs } & \text { sub } & \text { 2ph } & \\ \$ 1650041 & 160020003 & 170040004 & 0.2815 & 5.0 & 5.0 & 001003 & 1.0 & 1.0 & 1.0\end{array}$

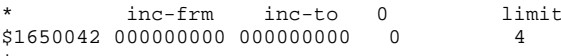

* $1 \mathrm{nnm}$ velf velg \#

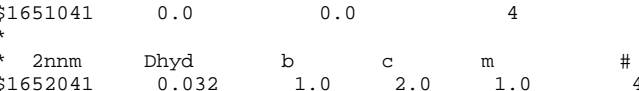

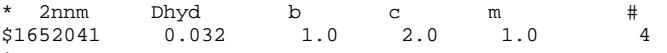

* Onnm from to area kfor krev fvcahs sub 2ph ing $\$ 1650052 \quad \begin{array}{llll}\text { inc-frm } & \text { inc-to } & 0 & \text { limit } \\ \$ & 00000000 & 000000000 & 0\end{array}$

$\begin{array}{cccc}* 1 \mathrm{nnm} & \text { velf } & \text { velg } & \# \\ \$ 1651051 & 0.0 & 0.0 & { }_{5}\end{array}$

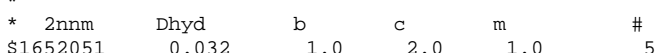

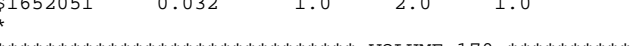

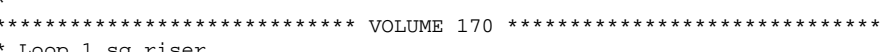

Loop 1 sg riser

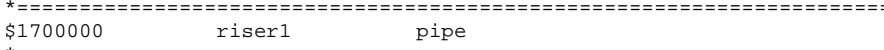

*hydro ${ }^{*}$ no. volumes

*hydro vol area vol

$\$ 1700101$ vol area vol 0.0

$\begin{array}{lll}* \text { hydro } & \text { jun area } \\ 01700201 & 0.0 & \text { jun }\end{array}$

*hydro length vol

$\begin{array}{lll}\$ 1700301 & 0.563 & 1 \\ \$ 100302 & 0.476 & 4 \\ \$ 1700303 & 0.374 & 5\end{array}$

*hydro volume

$\begin{array}{lll}\$ 1700401 & 0.04553 \quad \text { vol } \\ \$ 1700402 & 0.03701 & \end{array}$ 


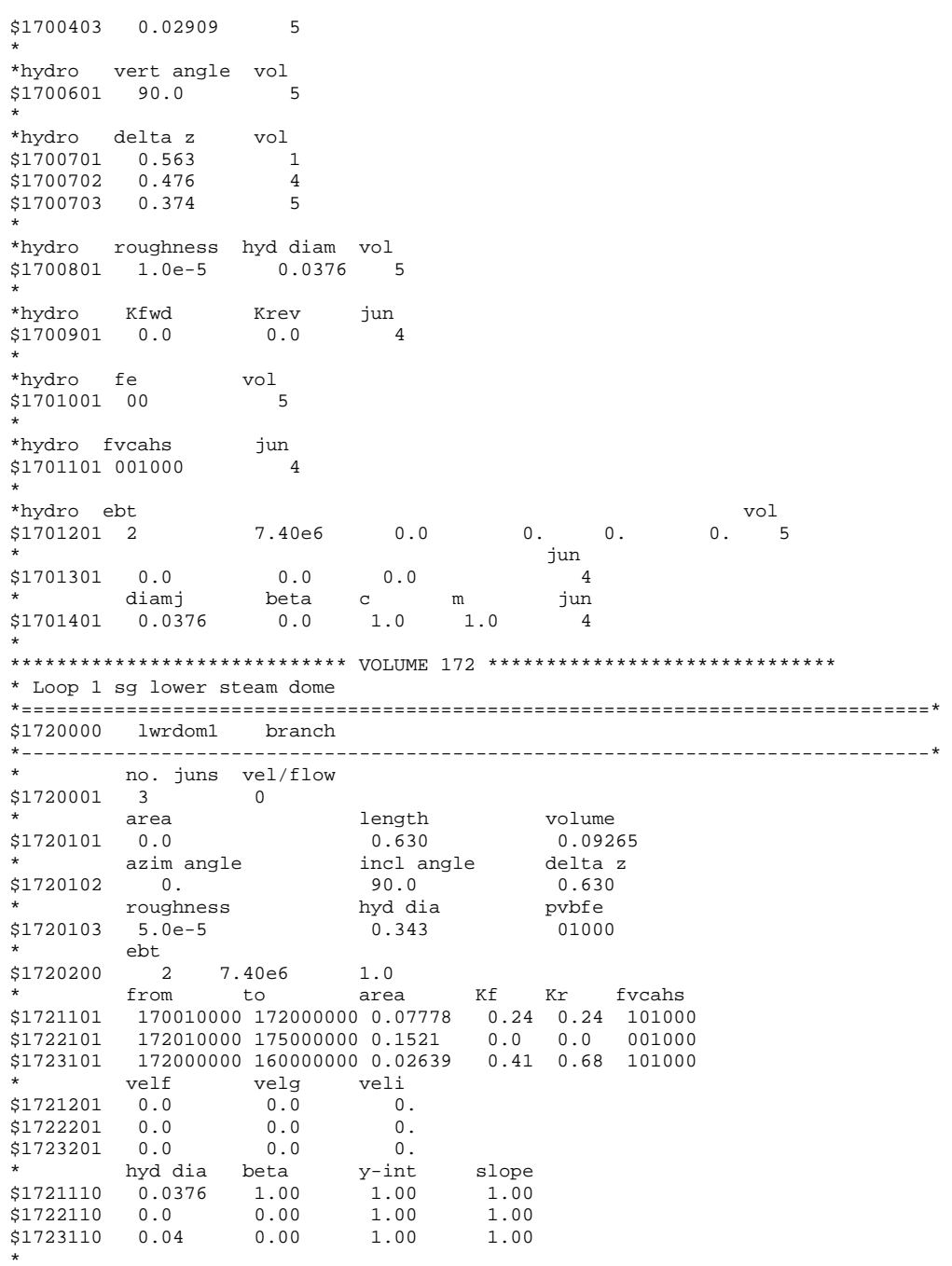

* End of superseded components

Wenchents

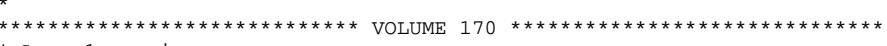

* Loop 1 sg riser

\begin{tabular}{|c|c|c|}
\hline & riser1 & pipe \\
\hline
\end{tabular}

*hydro no. volumes

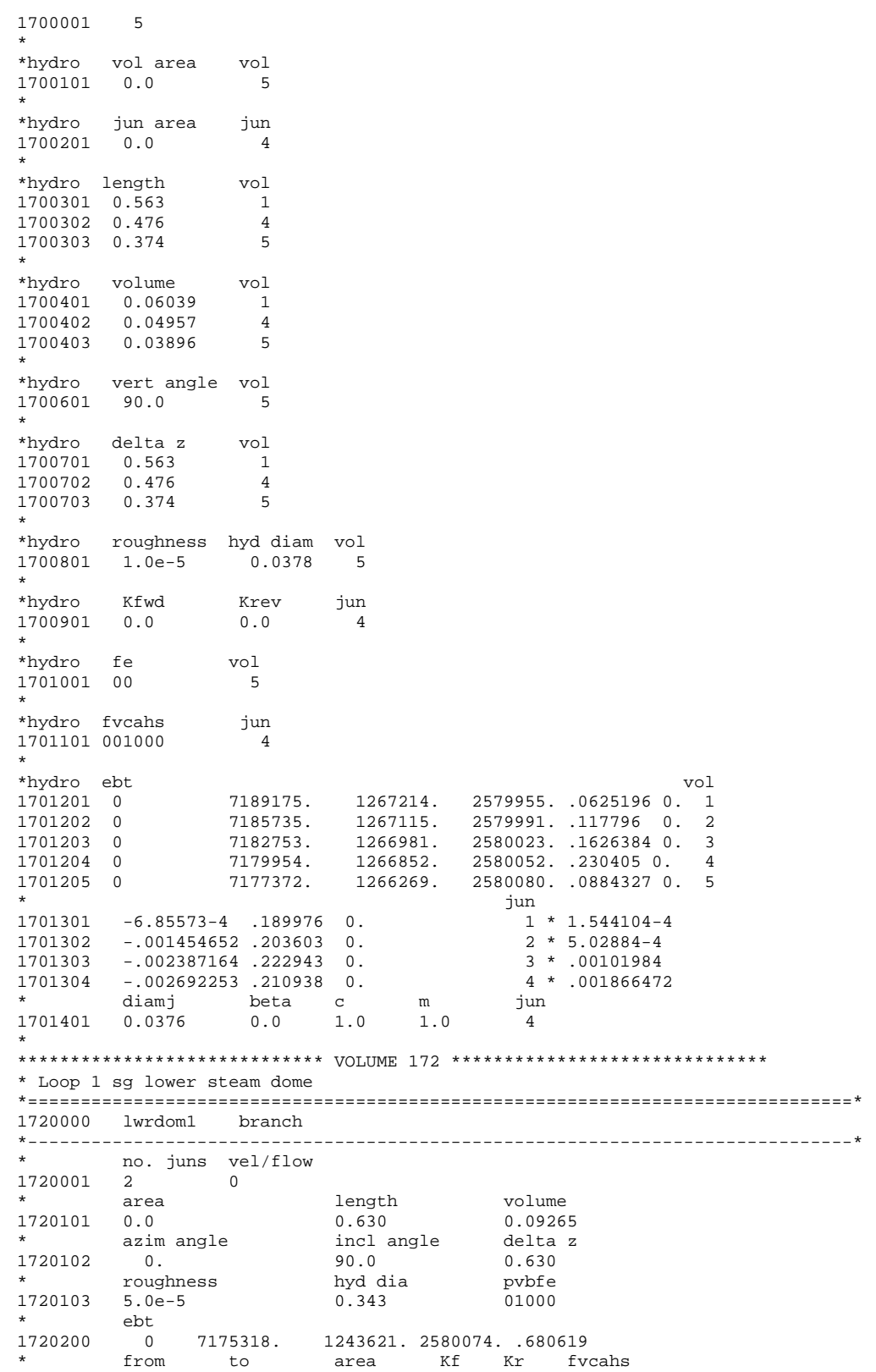




\begin{tabular}{|c|c|c|c|c|c|c|}
\hline 1721101 & 170010000 & $172000000 \quad 0$ & 0.10417 & 0.161 & 101000 & \\
\hline${ }_{*}^{1722101}$ & 172010000 & 1750000000 & 0.1521 & 0.0 & 001000 & \\
\hline * & velf & velg v & veli & & & \\
\hline $\begin{array}{l}1721201 \\
1722201\end{array}$ & $\begin{array}{l}-.00910946 \\
-.706497\end{array}$ & o. .658514 & $0 . * .00192$ & 22815 & & \\
\hline $\begin{array}{l}1722201 \\
*\end{array}$ & $\begin{array}{l}-.706497 \\
\text { hyd dia }\end{array}$ & $\begin{array}{l}.04342745 \\
\text { beta } y\end{array}$ & $\begin{array}{rl}0 . & * \\
y-i n t & .16712 \\
\text { slo }\end{array}$ & $\begin{array}{l}202 \\
\text { ope }\end{array}$ & & \\
\hline 1721110 & 0.0376 & 1.00 & $\begin{array}{ll}1.00 & 1.0\end{array}$ & & & \\
\hline${ }_{*}^{1722110}$ & 0.0 & 0.00 & 1.00 & & & \\
\hline 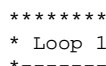 & $\begin{array}{l}\star \star \star \star \star \star \star \star \star \star \star \star \star \star \\
\text { sg upper por }\end{array}$ & $\begin{array}{l}* * * * * * * * \star * \\
\text { prtion of st }\end{array}$ & $\begin{array}{l}\text { VOLUME } 175 \text { ** } \\
\text { team dome }\end{array}$ & & & \\
\hline 1750000 & uprdon & & pipe & & & \\
\hline * & & & & & & \\
\hline $\begin{array}{l}\text { *hydro } \\
1750001\end{array}$ & no. volumes & & & & & \\
\hline $\begin{array}{l}1750001 \\
*\end{array}$ & 2 & & & & & \\
\hline *hydro & vol area & vol & & & & \\
\hline${ }_{*}^{1750101}$ & 0.1521 & 2 & & & & \\
\hline *hydro & jun area & jun & & & & \\
\hline $\begin{array}{l}1750201 \\
\star\end{array}$ & 0.0 & 1 & & & & \\
\hline *hydro & length & vol & & & & \\
\hline $\begin{array}{l}1750301 \\
*\end{array}$ & 0.470 & 2 & & & & \\
\hline *hydro & volume & vol & & & & \\
\hline $\begin{array}{l}1750401 \\
\star\end{array}$ & 0.0 & 2 & & & & \\
\hline *hydro & vert angle & vol & & & & \\
\hline${ }_{*}^{1750601}$ & 90.0 & 2 & & & & \\
\hline *hydro & delta $z$ & vol & & & & \\
\hline${ }_{*}^{1750701}$ & 0.470 & 2 & & & & \\
\hline *hydro & roughness & hyd diam & vol & & & \\
\hline${ }_{\star}^{1750801}$ & $1.0 e^{-5}$ & 0.440 & 2 & & & \\
\hline *hydro & Kfwd & Krev & jun & & & \\
\hline $\begin{array}{l}1750901 \\
\star\end{array}$ & 0.0 & 0.0 & 1 & & & \\
\hline *hydro & $\mathrm{fe}$ & vol & & & & \\
\hline${ }_{\star}^{1751001}$ & 00 & 2 & & & & \\
\hline *hydro & fvcahs & jun & & & & \\
\hline $\begin{array}{l}1751101 \\
*\end{array}$ & 001000 & 1 & & & & \\
\hline${ }^{*}$ *hydro & ebt & & & & vol & \\
\hline 1751201 & 0 & 7174418. & 1266640 . & 2580099. & .999978 0. 1 & 1 \\
\hline 1751202 & 0 & 7174244. & 1266631. & 2580109 & $.99994660 . \quad 2$ & 2 \\
\hline ״ & & & & jun & & \\
\hline${ }_{*}^{1751301}$ & $\begin{array}{l}-.1469628 \\
\text { diamj }\end{array}$ & $\begin{array}{l}.02947904 \\
\text { beta }\end{array}$ & $\begin{array}{ll}4 & 0 . \\
c & \end{array}$ & $\underset{\text { jun }}{1 *}$ & .1674956 & \\
\hline $\begin{array}{l}1751401 \\
*\end{array}$ & 0.440 & $0.0 \quad 1$ & $1.0 \quad 1.0$ & 1 & & \\
\hline $\begin{array}{l}\star \star \star \star \star \star \star \star \star \star \star ~ \\
* \text { Steam }\end{array}$ & $\begin{array}{l}\star \star \star \star \star \star \star \star \star \star \star \star \star \star \star ~ \\
\text { line } 1\end{array}$ & 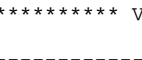 & VOLUME 180 ** & 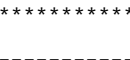 & & \\
\hline 1800000 & stmlin1 & branch & & & & \\
\hline * & no. juns & vel/flow & & & & \\
\hline 1800001 & 1 & 0 & & & & \\
\hline & area & & length & volume & & \\
\hline${ }_{\star}^{1800101}$ & 0.0003142 & & 4.74 & 0.0 & & \\
\hline * 1800102 & azim angle & & incl angle & $\begin{array}{l}\text { delta } \\
0.0\end{array}$ & & \\
\hline * & roughness & & hyd dia & pubfe & & \\
\hline
\end{tabular}

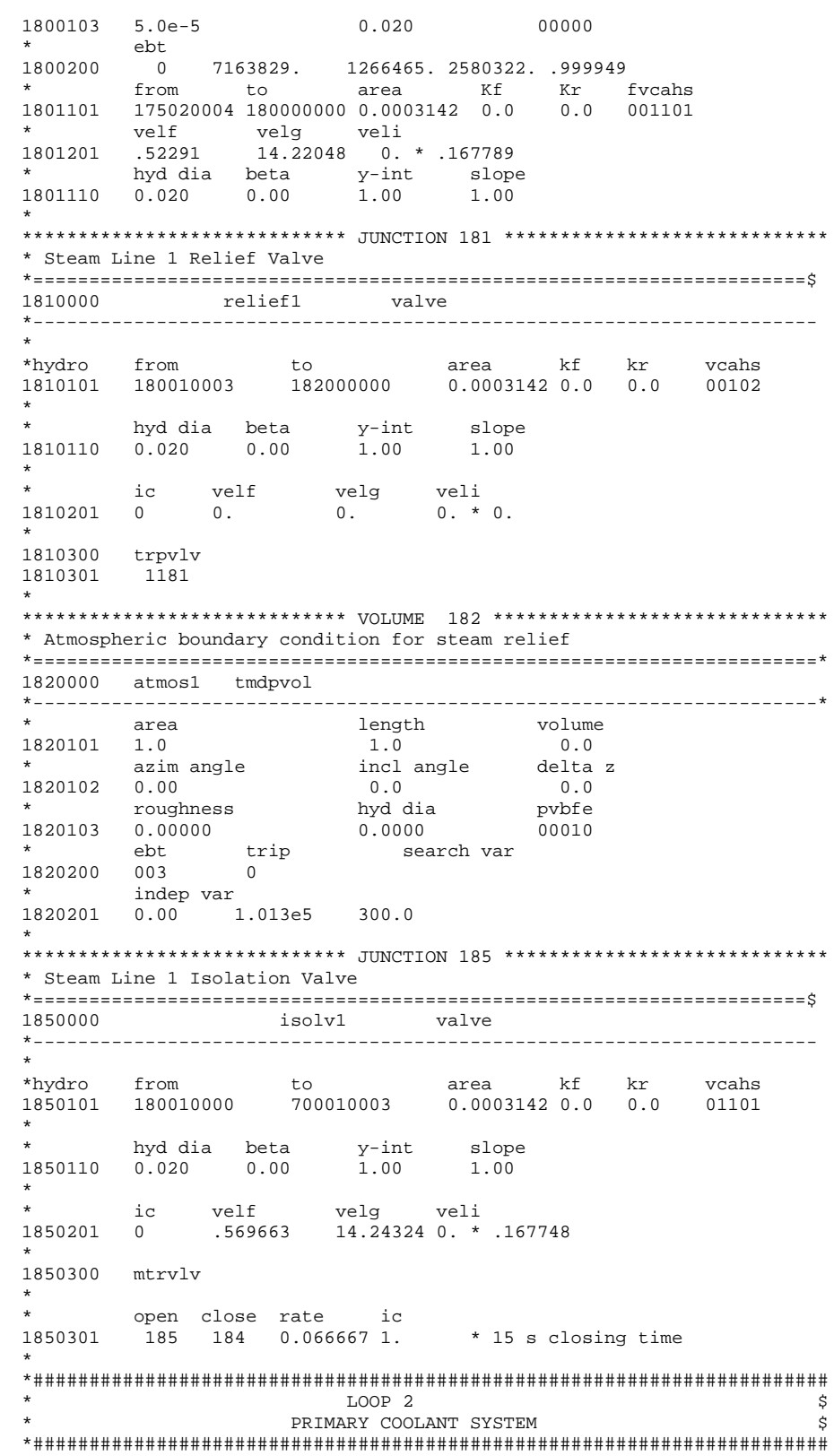




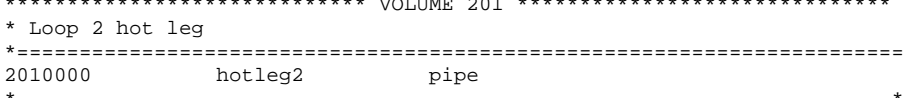

thydro no. volumes

2010001

*hydro vol area vol

20101010.004536

$\begin{array}{ccr}* \text { kydro } & \text { jun area } & \text { jun } \\ 2010201 & 0.004536 & 6\end{array}$

*hydro length

$2010301 \quad 0.6683$

$\begin{array}{ll}2010302 & 0.420 \\ 2010303 & 0.567\end{array}$

$\begin{array}{llr}* \text { hydro } & \text { volume } & \text { vol } \\ 2010401 & 0.0 & 7\end{array}$

$\begin{array}{lrr}* \text { *hydro } & \text { horiz ang vol } \\ 2010501 & -45.0 & 7\end{array}$

*hydro vert angle vol

$2010601 \quad 0.0$

$\begin{array}{ll}2010602 & 42.22 \\ 2010603 & 90.0\end{array}$

$\begin{array}{lll}* \text { hydro } & \text { delta } z \quad \text { vol } \\ 2010701 & 0.0 & \end{array}$
$2010702 \quad 0.381$

$\begin{array}{cccc}* \text { hydro } & \text { roughness } & \text { hyd diam } & \text { vol } \\ 2010801 & 5.00 e-5 & 0.076 & 7\end{array}$

*hydro Kfwd Krev jun

$\begin{array}{lllr}2010901 & 0.0 & 0.0 & 3 \\ 2010902 & 0.25 & 0.25 & 4 \\ 2010903 & 0.0 & 0.0 & 6\end{array}$

$\begin{array}{llr}\star \text { *hydro } & \text { fe } & \text { vol } \\ 2011001 & 00 & 7\end{array}$

*hydro fvcahs jun

*hydro ebt

2011201

2011202

2011204

2011205

2011206

*

$2011301 \quad .731617$

2011303.731496

2011305

2011306

.731457
.731408

.73136

diamj

\section{$\begin{array}{ll}16891470 . & 1404572 . \\ 16891440 . & 1404438 .\end{array}$}

16891408. 1404304.

6891384. 1404219.

6890020. 1404105.

16882870. 1403992.

2412312. 0.

2412313. 0 .

2412314 . 0.

2412433. 0 .

jun 0.

jun $1 * 2.3$

$\begin{array}{ll}.731617 & 0 . \\ .731557 & 0 . \\ .731496 & 0 .\end{array}$

.7314960.

$\begin{array}{ll}.731496 & 0 . \\ .731457 & 0 . \\ .731408 & 0 .\end{array}$

$\begin{array}{ll}.731408 & 0 . \\ .73136 & 0 .\end{array}$

beta c

$2 * 2.3$

$3 * 2.3$

$5 * 2.3$

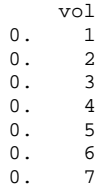

$\begin{array}{ll}0 . & 6 \\ 0 . & 7\end{array}$ 


\begin{tabular}{|c|c|c|c|c|c|c|c|}
\hline *hydro & Kfwd & Krev & jun & & & & \\
\hline 2150901 & 0.0 & 0.0 & 4 & & & & \\
\hline *hydro & $\mathrm{fe}$ & vol & & & & & \\
\hline 2151001 & 00 & 5 & & & & & \\
\hline *hydro & fvcahs & jun & & & & & \\
\hline 2151101 & 001000 & 4 & & & & & \\
\hline *hydro & ebt & & & & & & vol \\
\hline 2151201 & 0 & 16877684 & 14021 & & 2412666. 0 . & 0. & 1 \\
\hline 2151202 & 0 & 16874404 & 14005 & & 2412751.0 . & 0. & 2 \\
\hline 2151203 & 0 & 16871222 & 13984 & & 2412833. 0 . & 0. & 3 \\
\hline 2151204 & 0 & 16868020 & 13958 & & 2412915 . 0 . & 0. & 4 \\
\hline * 2151205 & 0 & 16864946 & 1.392 & & $\begin{array}{c}2412994.0 . \\
\text { jun }\end{array}$ & 0 & 5 \\
\hline 2151301 & .73562 & .73562 & 0. & & $1 * 1.8544$ & 402 & \\
\hline 2151302 & .55248 & .55248 & 0. & & $2 * 1.3941$ & & \\
\hline 2151303 & .363967 & .36396 & 670. & & $3 * .91959$ & & \\
\hline 2151304 & .170144 & .170144 & 440. & & $4 * .43057$ & & \\
\hline${ }_{\star \star}^{\star}$ & diami & beta & $c$ & $\mathrm{~m}$ & jun & & \\
\hline 2151401 & 0.068 & 0.0 & 1.0 & 1.0 & 4 & & \\
\hline $\begin{array}{l}\star \star \star \star \star \star \star \star \star \star ~ \\
\star * \text { junct }\end{array}$ & 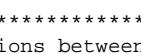 & 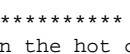 & $\begin{array}{l}\text { * JUNCTION } \\
\text { collector }\end{array}$ & $\begin{array}{l}216 \text { ** } \\
\text { and th }\end{array}$ & 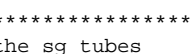 & & 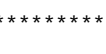 \\
\hline 2160000 & hoju & uns 2 & mtpl jus & & & & \\
\hline 2160001 & 5 & 0 & & & & & \\
\hline * onnm & from & to & area & kfor & krev efvcahs & sub & \\
\hline 2160011 & 2150500042 & 2250000000 & 0.0007964 & & 0.0020001002 & 1.0 & 1.01 .0 \\
\hline * 2160011 & inc-frm & inc-to & 0 & limi & & & \\
\hline 2160012 & 0000000000 & 000000000 & & 1 & & & \\
\hline * $1 \mathrm{nnm}$ & & & & $\#$ & & & \\
\hline 2161011 & .774177 & .77 & 74177 & $1 *$ & .4305744 & & \\
\hline * $2 \mathrm{nnm}$ & Dhyd & $\mathrm{b}$ & $c$ & $\mathrm{~m}$ & $\#$ & & \\
\hline 2162011 & 0.013 & 1.0 & 2.0 & 1.0 & 1 & & \\
\hline * Onnm & from & & area & $k f o r$ & krey efycahs & sub & \\
\hline $\begin{array}{l}\text { Onnm } \\
2160021\end{array}$ & $\begin{array}{l}\text { from } \\
2150400042\end{array}$ & $\begin{array}{l}\text { to } \\
224000000\end{array}$ & $\begin{array}{l}\text { area } \\
0.0009291\end{array}$ & $\begin{array}{l}\text { Kfor } \\
0.005\end{array}$ & $\begin{array}{l}\text { Krev efvcahs } \\
0.0020001002\end{array}$ & $\begin{array}{l}\text { sub } \\
1.0\end{array}$ & $\begin{array}{ll}2 \mathrm{ph} \\
1.0 & 1.0\end{array}$ \\
\hline & inc-frm & inc-to & 0 & limi & nit & & \\
\hline 2160022 & -10000 & -1000000 & 0 & & & & \\
\hline * $1 \mathrm{nnm}$ & velf & velg & & \# & & & \\
\hline 2161021 & .755397 & & 55397 & & .489017 & & \\
\hline 2161031 & .734242 & & 34242 & $3 *$ & .474558 & & \\
\hline 2161041 & .712996 & & 12996 & & .460253 & & \\
\hline 2161051 & .690996 & .690 & 90996 & $5 *$ & .445598 & & \\
\hline * $2 \mathrm{nnm}$ & Dhyd & $\mathrm{b}$ & $c$ & $\mathrm{~m}$ & \# & & \\
\hline 2162021 & 0.013 & 1.0 & 2.0 & 1.0 & 5 & & \\
\hline $\begin{array}{l}\star \star \star \star \star \star \star * * \\
* \text { Steam }\end{array}$ & $\begin{array}{l}\star \star \star \star \star \star \star \star \star \star \star \star \star \star \star \\
\text { generator }\end{array}$ & $\begin{array}{l}\star \star \star \star \star \star \star \star \star \star \star \star \star \\
2 \text { tubes ror }\end{array}$ & $\begin{array}{l}\text { * VOLUME } 2 \\
\text { pw } 1 \text { ( } 7 \text { tub }\end{array}$ & $\begin{array}{l}221 \text { k** } \\
\text { bes) }\end{array}$ & 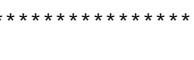 & & \\
\hline 2210000 & sg & g2tub1 & pipe & & & & \\
\hline * & & & & & & & \\
\hline $\begin{array}{l}\text { *hydro } \\
2210001 \\
\star\end{array}$ & $\begin{array}{l}\text { no. volume } \\
10\end{array}$ & & & & & & \\
\hline * ${ }^{*}$ hydro & vol area & vol & & & & & \\
\hline 2210101 & 0.0009291 & 10 & & & & & \\
\hline
\end{tabular}

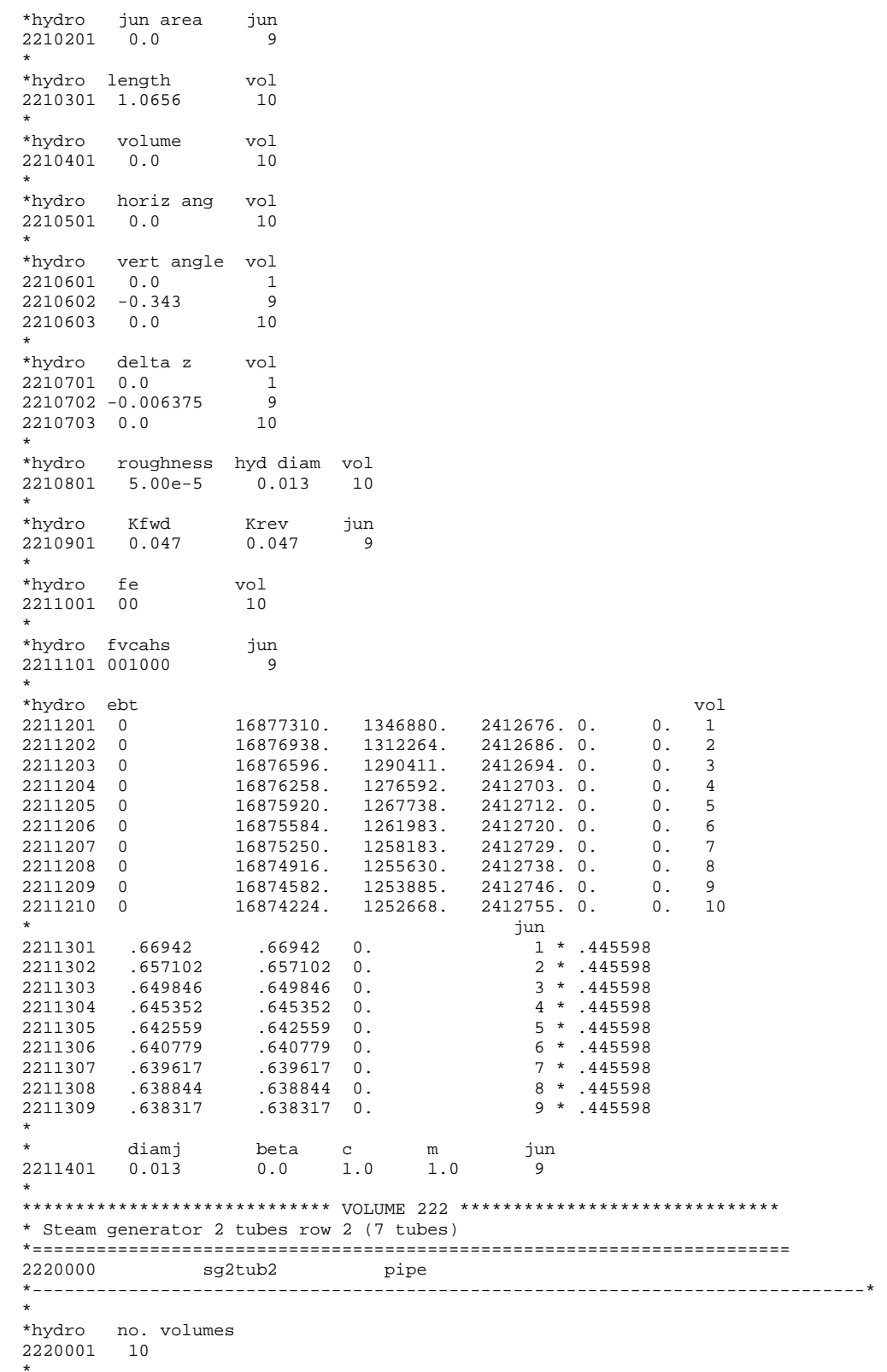




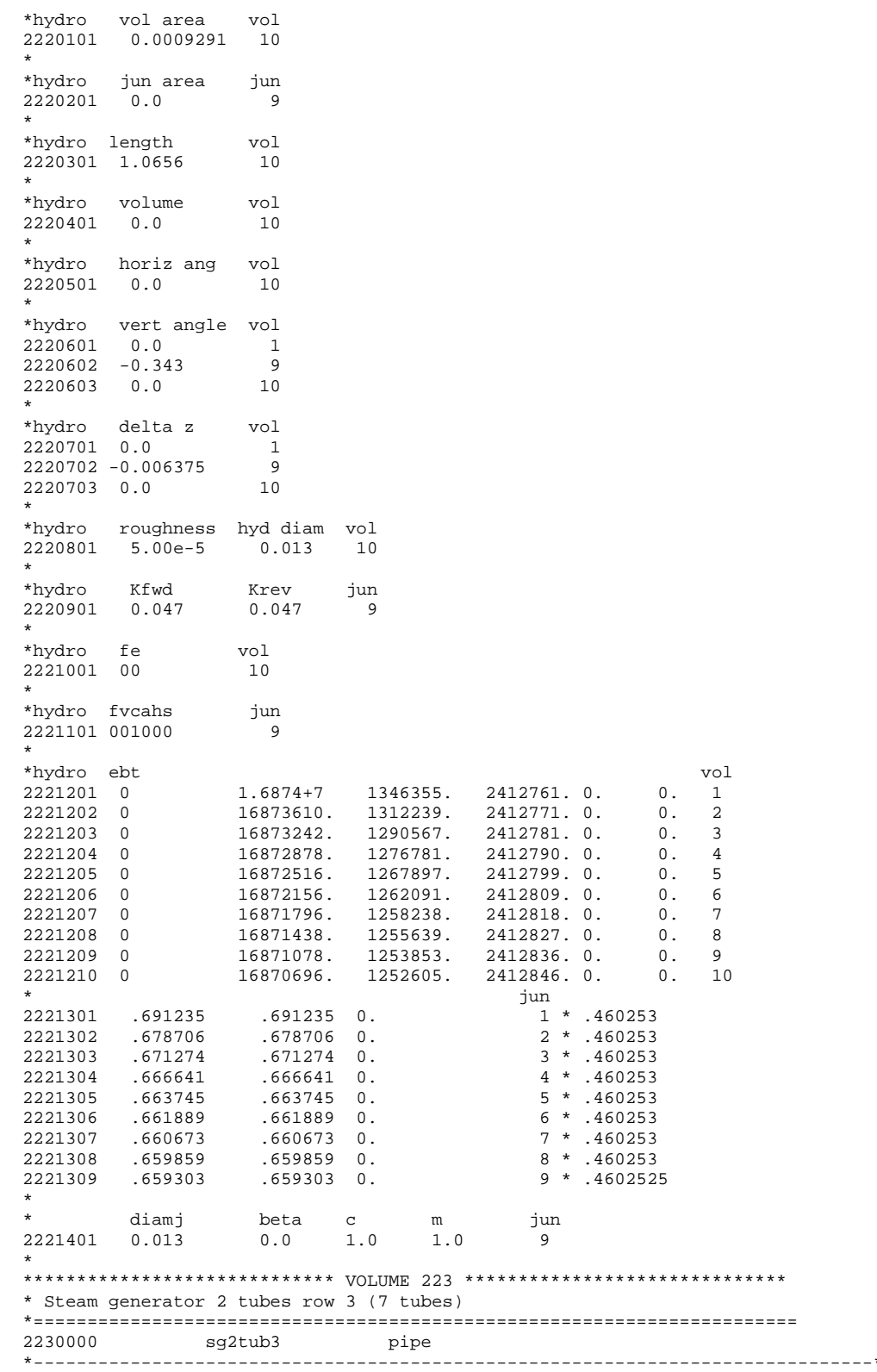

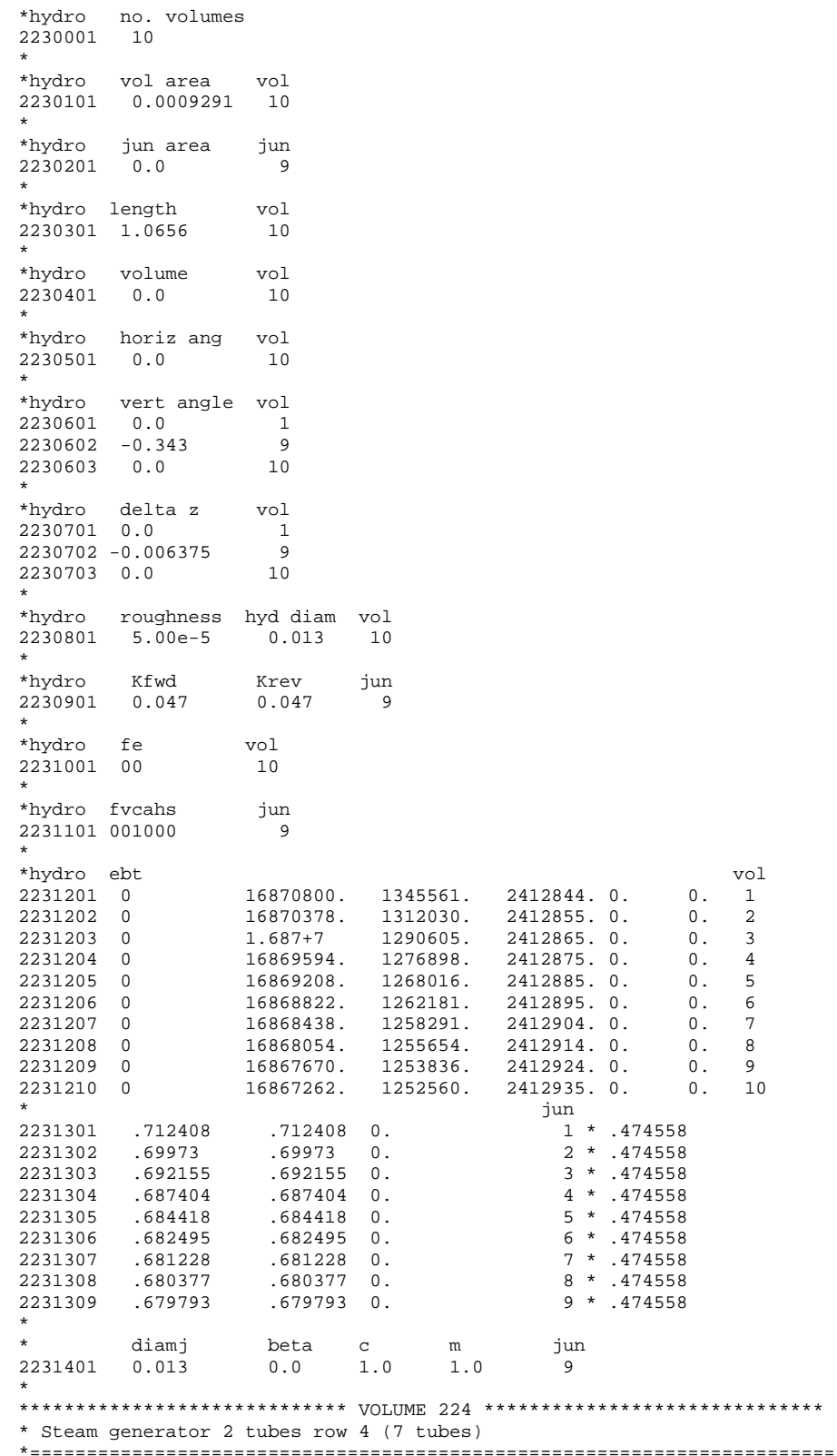




\begin{abstract}
2240000
\end{abstract}
sg2tub4

pipe

*hydro vol area vol

$\begin{array}{lll}2240101 & 0.0009291 & 10\end{array}$

*hydro jun area jun

$\begin{array}{llr}* \text { *hydro } & \text { length } & \text { vol } \\ 2240301 & 1.0656 & 10\end{array}$

*hydro volume vol

* 240401 v.0 10

$\begin{array}{ccc}* \text { khydro } & \text { horiz ang vol } \\ 2240501 & 0.0 & 10\end{array}$

*hydro vert angle vol

$\begin{array}{lcr}2240602 & -0.343 & 9 \\ 2240603 & 0.0 & 10\end{array}$

*hydro delta $z$ vol

$2240701 \quad 0.0$

$2240702-0.006375$

*

$\begin{array}{cccc} & & & \\ 2240801 & \text { roughness } & \text { hyd diam } & \text { vol } \\ 5.00 \mathrm{e}-5 & 0.013 & 10\end{array}$

$\begin{array}{lllr}\text { *hydro } & \text { Kfwd } & \text { Krev } & \text { jun } \\ 2240901 & 0.047 & 0.047 & 9\end{array}$ *hydro no. volumes

$\begin{array}{lll}2240601 & 0.0 & 1\end{array}$

*

$\begin{array}{llr}* \text { hydro } & \text { fe } & \text { vol } \\ 2241001 & 00 & 10\end{array}$

$\begin{array}{llr}* \text { hydro fvcahs } & \text { jun } \\ 2241101 & 001000 & 9\end{array}$

*hydro ebt

2241201

2241203

2241204
2241205
2241206

2241206

2241208

2241209

*

$\begin{array}{ll}2241301 & .733625 \\ 2241302 & .720875\end{array}$

$$
\begin{aligned}
& 16867574 . \\
& 16867124 . \\
& 16866704 .
\end{aligned}
$$

6866704. 1311550 .

$16866288 . \quad 1276903$.

$16865464 . \quad 1262227$.

$16865052 . \quad 1258316$.

16864642 . 1255654 .

$16864232 . \quad 1253810$.

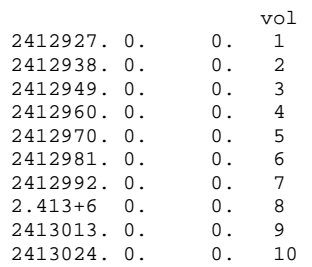

$\begin{array}{lll}.733625 & 0 . \\ 73625 & .720875 & 0 .\end{array}$

$\begin{array}{llll}2241303 & .713197 & .713197 & 0 . \\ 2241304 & .708353 & .708353 & 0 .\end{array}$

$\begin{array}{llll}2241305 & .705291 & .705291 & 0 .\end{array}$

$2241307-.701995 \quad .7033080$.

$\begin{array}{llll}2241308 & .70111 & .70111 & 0 .\end{array}$

$2241309 \quad .7005$

$\begin{array}{ll}* & \text { diamj } \\ 2241401 & 0.013\end{array}$ jun

$3 * .489017$

$4 * .489017$
$5 * .489017$

$5 * .489017$

$7 * .489017$

$8 * .489017$

jun
$1 * .489017$
$2 * .489017$
$3 * .489017$

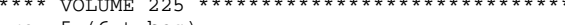

* Steam generator tubes 2 row 5 ( 6 tubes)

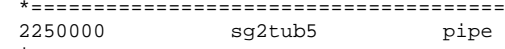

*hydro no. volumes

$2250001 \quad 10$

*hydro vol area vol

$\begin{array}{llr}\star \text { hydro jun area jun } \\ 2250201 & 0.0 & \end{array}$

*hydro length vol

*

$\begin{array}{lcr}\text { *hydro } & \text { volume } & \text { vol } \\ 2250401 & 0.0 & 10\end{array}$

*hydro horiz ang vol

$\begin{array}{lll}2250501 & 0.0 & 10\end{array}$

*hydro vert angle vol

$\begin{array}{rcr}2250601 & 0.0 & 1 \\ 2250602 & -0.343 & 9 \\ 250603 & 0.0 & 10\end{array}$

$\begin{array}{llr}\text { *hydro } & \text { delta } z & \text { vol } \\ 2250701 & 0.0 & 1\end{array}$

$\begin{array}{lll}2250702 & -0.006375 & 9 \\ 2250703 & 0.0 & 10\end{array}$

$\begin{array}{cccc}* \text { hydro } & \text { roughness } & \text { hyd diam } & \text { vol } \\ 2250801 & 5.00 \mathrm{e}-5 & 0.013 & 10\end{array}$

*

$\begin{array}{lllr}* \text { khydro } & \text { Kfwd } & \text { Krev } & \text { jun } \\ 2250901 & 0.047 & 0.047 & 9\end{array}$

*hydro fe vol

$225100100 \quad 10$

$\begin{array}{llr}* \text { *hydro } & \text { fvcahs } & \text { jun } \\ 2251101 & 001000 & 9\end{array}$

*hydro

2251201

2251202
2251203
2251204

2251204
2251205

2251206

$2251207 \quad 0$

$\begin{array}{ll}2251208 & 0 \\ 2251209 & 0 \\ 2251210 & 0\end{array}$

*

$2251301 \quad .752753$

$2251302 \quad .740101$

2251304
225132416

$2251305 \quad .724441$

$\begin{array}{ll}2251306 & .722423 \\ 2251307 & .72108 \\ 2251308 & .72017\end{array}$

$\begin{array}{ll}2251307 & .72108 \\ 2251308 & .72017\end{array}$

$\begin{array}{ll}2251308 & .72017 \\ 2251309 & .71954 \\ \times\end{array}$

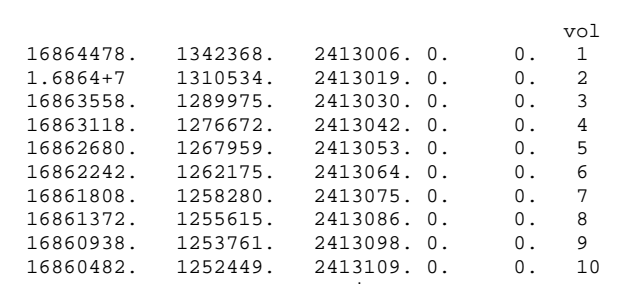

.7527530.

$\begin{array}{ll}.7740101 & 0 . \\ .732416 & 0 .\end{array}$

$\begin{array}{ll}.732416 & 0 . \\ .727541 & 0 .\end{array}$

.7244410.

$\begin{array}{ll}.72108 & 0 . \\ .72017 & 0 .\end{array}$

$\begin{array}{ll}.72017 & 0 . \\ .71954 & 0 .\end{array}$
Jun
$1 * .4305744$
$2 * .4305744$

$4 * .4305744$

$5 * .4305744$

$8 * .430574$ 
$\begin{array}{llllll}* & \text { diamj } & \text { beta } & c & m & \text { jun } \\ 2251401 & 0.013 & 0.0 & 1.0 & 1.0 & 9\end{array}$

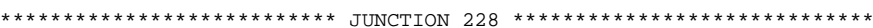

* junctions between the sg tubes and the cold collector

\begin{tabular}{|c|c|c|c|c|c|c|c|}
\hline 2280000 & & juns2 & mtpl jun & & & & \\
\hline $\begin{array}{l}2280001 \\
\star\end{array}$ & 5 & 0 & & & & & \\
\hline * Onnm & from & to & area & kfor krev & fvcahs & sub & $2 \mathrm{ph}$ \\
\hline 2280011 & 225010000 & 229050003 & 0.0007964 & $0.005 \quad 0.002$ & 001001 & 1.0 & 1.01. \\
\hline & inc-frm & inc-to & 0 & limit & & & \\
\hline 2280012 & 000000000 & 000000000 & 0 & & & & \\
\hline * $1 \mathrm{nnm}$ & velf & velo & & & & & \\
\hline 2281011 & .71909 & & 19096 & $1 * .43057$ & & & \\
\hline * $2 \mathrm{nnm}$ & Dhyd & $\mathrm{b}$ & c & $\mathrm{m}$ & \# & & \\
\hline 2282011 & 0.013 & 1.0 & 2.0 & 1.0 & 1 & & \\
\hline * $0 \mathrm{nnm}$ & from & to & area & kfor krev & fvcahs & sub & $2 \mathrm{ph}$ \\
\hline 2280021 & 224010000 & 229040003 & 0.0009291 & $0.005 \quad 0.002$ & 001001 & 1.0 & 1.01 .0 \\
\hline & inc-frm & inc-to & 0 & limit & & & \\
\hline 2280022 & -1000000 & -10000 & 0 & & & & \\
\hline * $1 \mathrm{nnm}$ & velf & velc & & \# & & & \\
\hline 2281021 & .70007 & & 00072 & $2 * .48901$ & & & \\
\hline 2281031 & .67938 & & 79385 & $3 * .474558$ & & & \\
\hline 2281041 & .65891 & & 58916 & $4 * .460252$ & & & \\
\hline 2281051 & .63795 & & 37952 & $5 * .445598$ & & & \\
\hline * $2 \mathrm{nnm}$ & Dhyd & $\mathrm{b}$ & c & $\mathrm{m}$ & \# & & \\
\hline 2282021 & 0.013 & 1.0 & 2.0 & 1.0 & 5 & & \\
\hline $\begin{array}{l}{ }^{*} \\
\star * \star \star \star \star \star * \\
{ }^{*} \text { Steam }\end{array}$ & $\begin{array}{l}\star \star \star \star \star \star \star \star \star \star \star \star \star \star ~ \\
\text { generator }\end{array}$ & $\begin{array}{l}\star \star \star \star \star \star \star \star \star \star \star \star \star ~ \\
2 \text { cold col }\end{array}$ & $\begin{array}{l}\text { * VOLUME } \\
\text { llector }\end{array}$ & 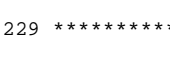 & & & \\
\hline 2290000 & & $\mathrm{sg} 2 \mathrm{cldc}$ & pipe & & & & \\
\hline
\end{tabular}

*hydro no. volumes

2290001

*hydro vol area vol

$2290101 \quad 0.0$

$2290102 \quad 0.003632$

* 22901030.0

*hydro jun area jun

$\begin{array}{lr}* \text { hydro } & \text { length } \\ 2290301 & 0.508\end{array}$

$2290302 \quad 0.476$

$\begin{array}{ll}2290302 & 0.476 \\ 2290303 & 0.429\end{array}$

$2290304 \quad 0.051$

*hydro volume

$2290401 \quad 0.001883 \quad$ vol

$2290403-0.0002164-5$

*

$\begin{array}{cc}* \text { hydro } & \text { horiz ang vol } \\ 2290501 & 0.0\end{array}$

*hydro vert angle vol

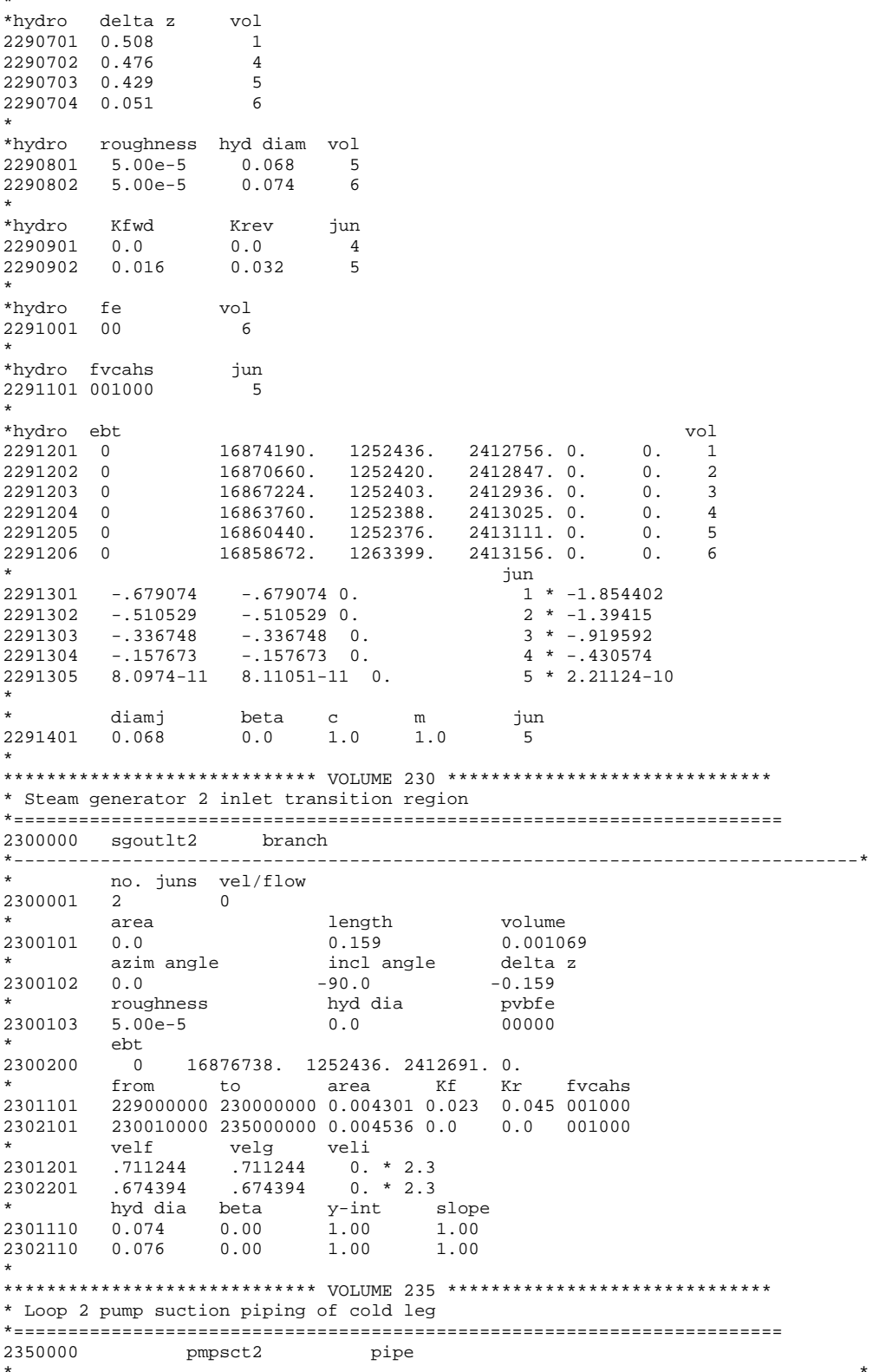




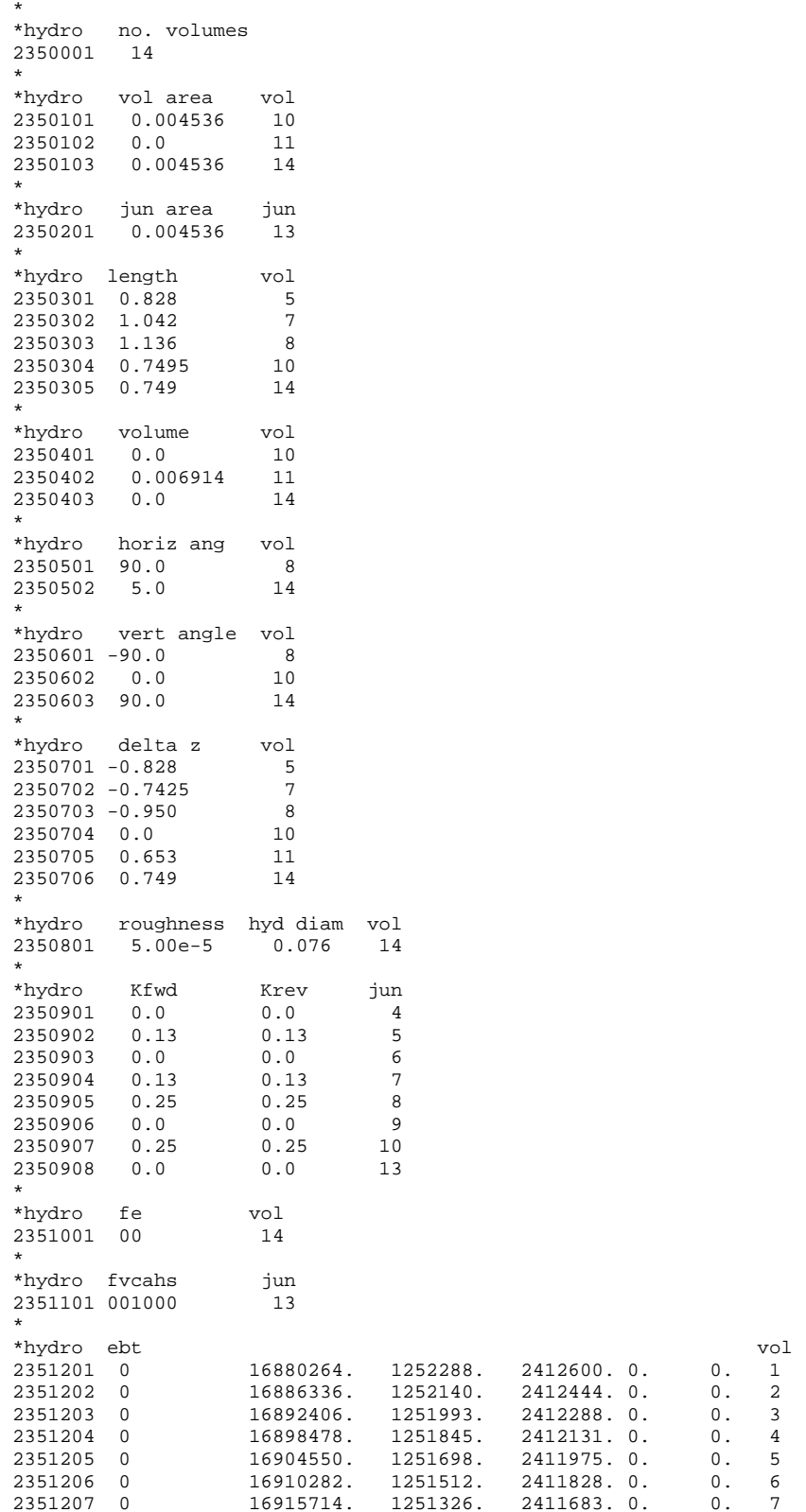

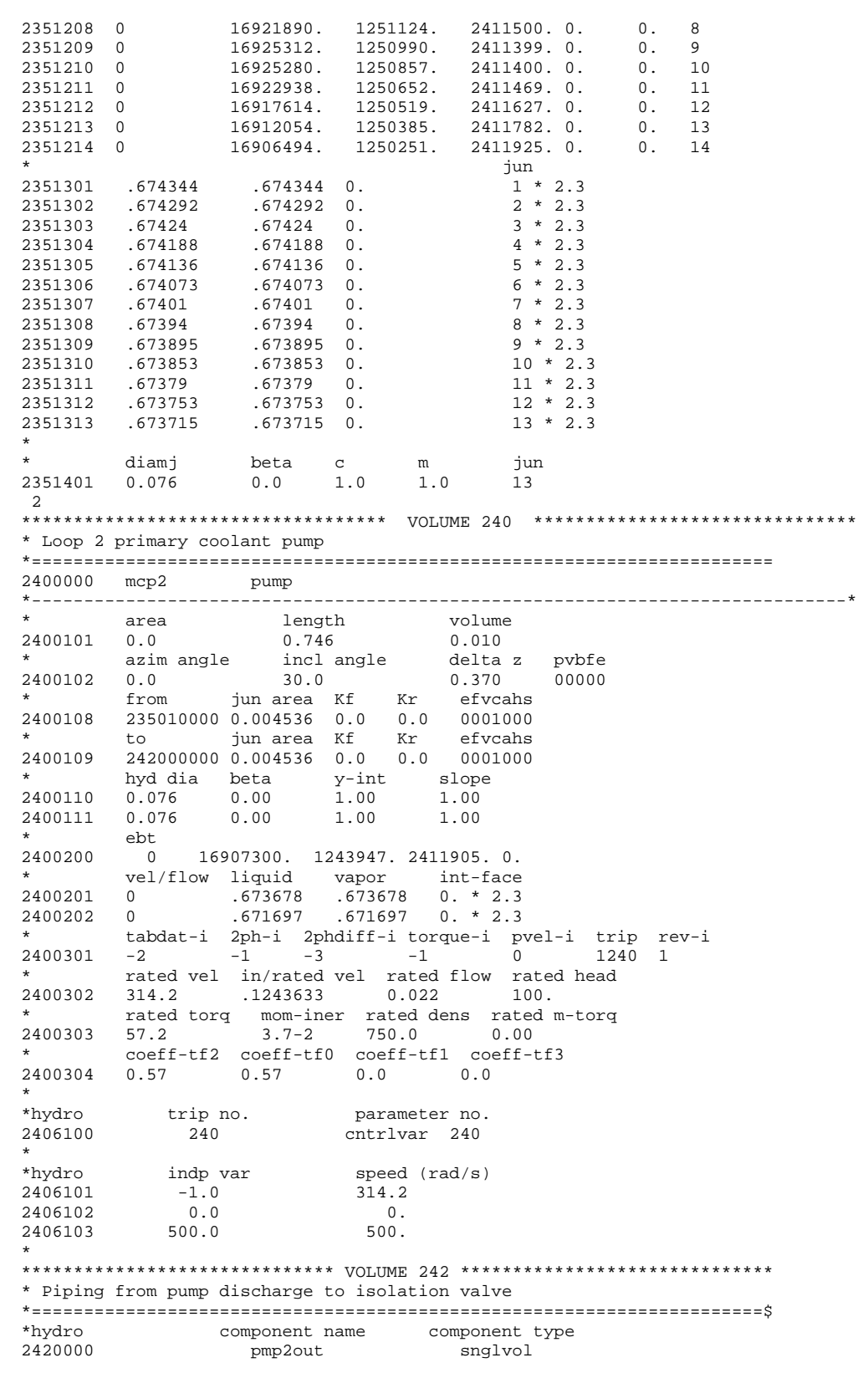




\begin{tabular}{|c|c|c|c|}
\hline $\begin{array}{l}\text { *hydro } \\
2420101\end{array}$ & $\begin{array}{l}\text { area } \\
0.004536\end{array}$ & $\begin{array}{l}\text { length } \\
0.880\end{array}$ & $\begin{array}{l}\text { volume } \\
0.0\end{array}$ \\
\hline $\begin{array}{l}{ }^{*} \text { *hydro } \\
2420102 \\
\\
*\end{array}$ & $\begin{array}{c}\text { horz angle } \\
170.0\end{array}$ & $\begin{array}{c}\text { vert angle } \\
0.0\end{array}$ & $\begin{array}{c}\text { delta } \\
0.0\end{array}$ \\
\hline $\begin{array}{l}\text { *hydro } \\
2420103 \\
\star\end{array}$ & $\begin{array}{c}\text { roughness } \\
0.00005\end{array}$ & $\begin{array}{l}\text { hyd diam } \\
0.076\end{array}$ & $\begin{array}{l}\mathrm{fe} \\
00\end{array}$ \\
\hline $\begin{array}{lr}* \text { hydro } & \text { ebt } \\
2420200 & 0 \\
\star\end{array}$ & $\begin{array}{l}\text { pressure } \\
\quad 16910562 .\end{array}$ & 2411821.0. & \\
\hline
\end{tabular}

*

* Cold leg isolation valve

\begin{tabular}{|c|c|c|c|c|c|}
\hline 2430000 & & $\mathrm{cl} 2 \mathrm{vlv}$ & valve & & \\
\hline * & & & & & \\
\hline *hydro & from & to & area $\mathrm{kf}$ & $\mathrm{kr}$ & vcahs \\
\hline $\begin{array}{l}2430101 \\
\star\end{array}$ & 242010000 & 245000000 & 0.0045360 .0 & 0.0 & 00100 \\
\hline ¿ 2430201 & .67 & 1615.671615 & $0 . * 2.3$ & & \\
\hline $\begin{array}{l}2430300 \\
\star\end{array}$ & mtrvlv & & & & \\
\hline & open close & rate ic & & & \\
\hline${ }_{\star}^{2430301}$ & $242 \quad 243$ & $0.1 \quad 1$. & & & \\
\hline
\end{tabular}

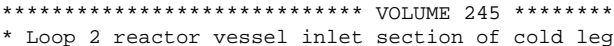

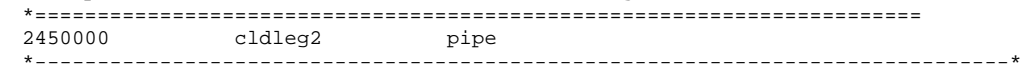

${ }^{*}$ hydro no, volumes

$\begin{array}{ll}* \text { hydro } & \text { no. volumes } \\ 2450001 & 4\end{array}$

*hydro vol area vol

$2450101 \quad 0.004536 \quad 4$

$\begin{array}{llr}* \text { hydro } & \text { jun area } & \text { jun } \\ 2450201 & 0.004536 & 3\end{array}$

${ }_{*} 402010.004536 \quad 3$

$\begin{array}{lrr}\text { *hydro } & \text { length } & \text { vol } \\ 2450301 & 0.782 & 3 \\ 2450302 & 0.741 & 4\end{array}$

*hydro volume vol

$\begin{array}{llr}* \text { kydro } & \text { volume } & \text { vol } \\ 2450401 & 0.0 & 4\end{array}$

$\begin{array}{llr}* \text { kydro } & \text { horiz ang vol } \\ 2450501 & 170.0 & 3\end{array}$

$\begin{array}{ll}2450501 & 170.0 \\ 2450502 & 125.0\end{array}$

$\begin{array}{lrr}* \text { hydro } & \text { vert angle vol } \\ 2450601 & 0.0 & 4\end{array}$

*hydro delta z vol

$2450701 \quad 0.0 \quad 4$

*hydro roughness hyd diam vol

$\begin{array}{lllr}* \text { *hydro } & \text { Kfwd } & \text { Krev } & \text { jun } \\ 2450901 & 0.0 & 0.0 & 2\end{array}$

$\begin{array}{llll}2450902 & 0.0 & 0.0 & 2 \\ 246 & 0.16 & 3\end{array}$

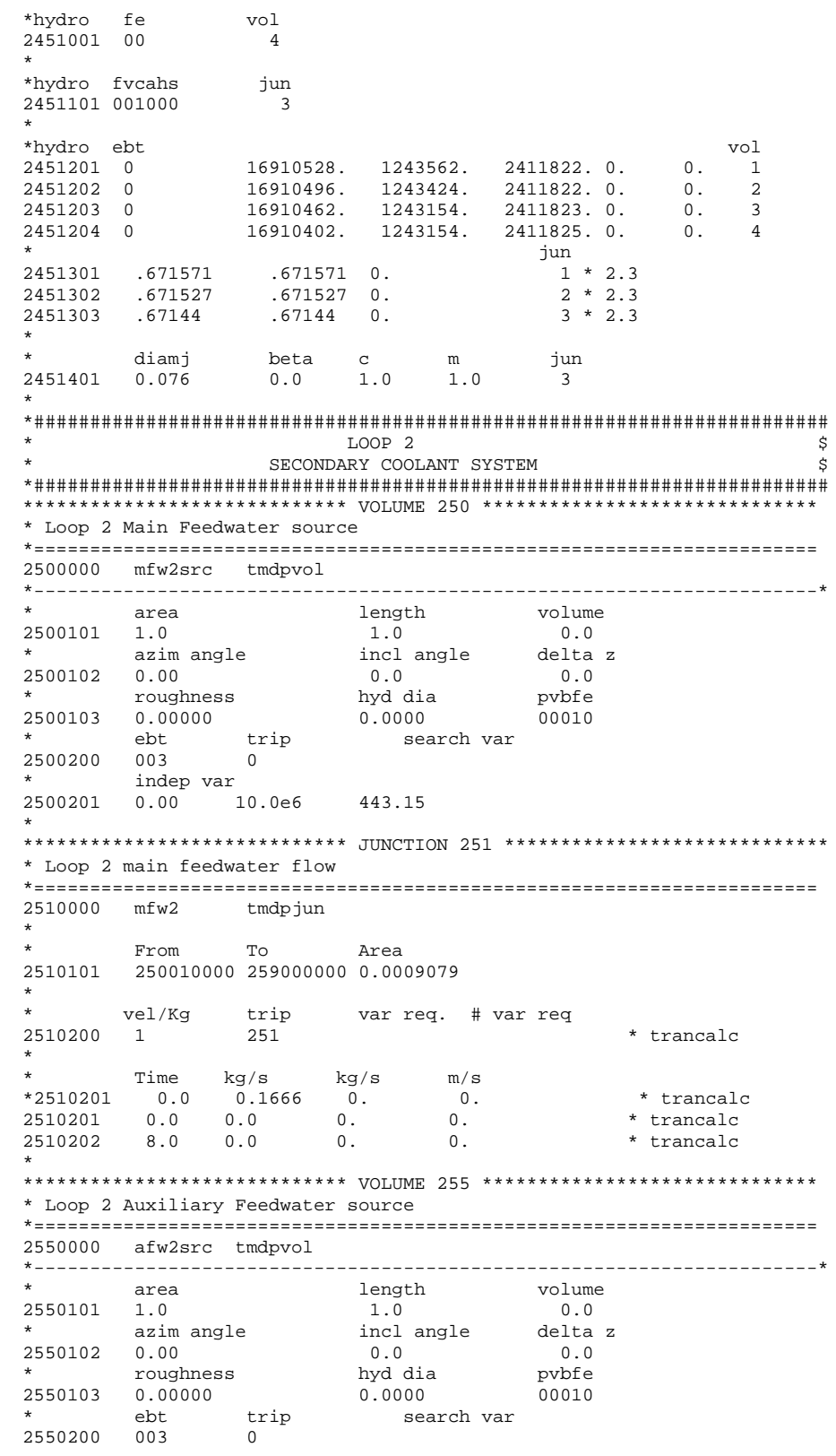


$\begin{array}{lll}\star & \text { indep var } \\ 2550201 & 0.00 \quad 16.0 e 6 \quad 443.15\end{array}$

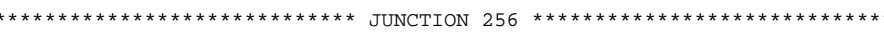
* Loop 2 auxiliary feedwater flow

2560000 afw2 tmdpjun

From To $\quad$ To Area

0.000907

* vel/Kg trip var req. \# var req

$\begin{array}{lllll}\star & \mathrm{Time} & \mathrm{kg} / \mathrm{s} & \mathrm{kg} / \mathrm{s} & \mathrm{m} / \mathrm{s} \\ 2560201 & -1 . & 0.0 & 0 . & 0 . \\ 2560202 & 0.0 & 0.0 & 0 . & 0 .\end{array}$

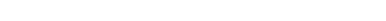

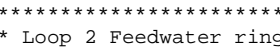

$*=========================$
2590000 fwring2 branch

$\begin{array}{lll}\star & \text { no. juns vel/flow } \\ 2590001 & 1 & 0\end{array}$

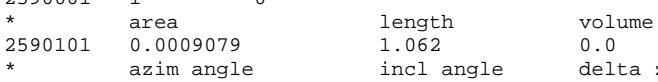

$\begin{array}{llll}* & \text { azim angle } & \text { incl angle delta } \\ 2590102 & 0.0 & 0.0 & 0.000\end{array}$

$\begin{array}{llll}* & \text { roughness } & \text { hyd dia } & \text { pvbfe } \\ 2590103 & 5.0 \mathrm{e}-5 & 0.034 & 00000\end{array}$

$\begin{array}{lrrrrr}* & 2590200 & \text { ebt } & & & \\ 0 & 7175361 . & 1084606.2580093 & .463851\end{array}$

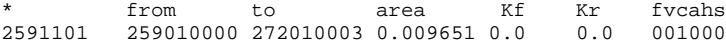

$\begin{array}{llll}2591201 & \text { velf } & \text { velg veli } & \text { veli } \\ 254272 & -.1360606 & 0 .\end{array} \quad * .166634$

$\begin{array}{lllll}* & \text { hyd dia } & \text { beta } & \text { y-int } & \text { slope } \\ 2591110 & 0.008 & 0.00 & 1.00 & 1.00\end{array}$

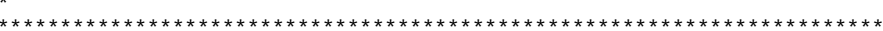

* These components have been superseded. They are being left in the

* input deck for possible future use.

$*$
$*$ Loop 2 sg downcomer

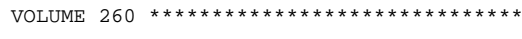

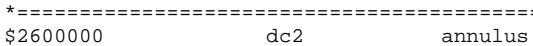

*hydro $\$ 2600001 \quad{ }_{5}^{*}$ volumes

$\begin{array}{lll}\text { *hydro } & \text { vol area } & \text { vol } \\ \$ 2600101 & 0.0 & 5\end{array}$

*

$\begin{array}{ll}{ }^{\star} \text { hydro } \\ \$ 2600201 & \text { jun area } \\ 0.0 & \text { jun }\end{array}$

*hydro length

$\begin{array}{ll}\$ 2600302 & 0.47 \\ \$ 2600303 & 0.563\end{array}$

*hydro volume

$\begin{array}{ll}\$ 2600401 & 0.00987 \\ \$ 2600402 & 0.01256\end{array}$

nnulus

vol 1

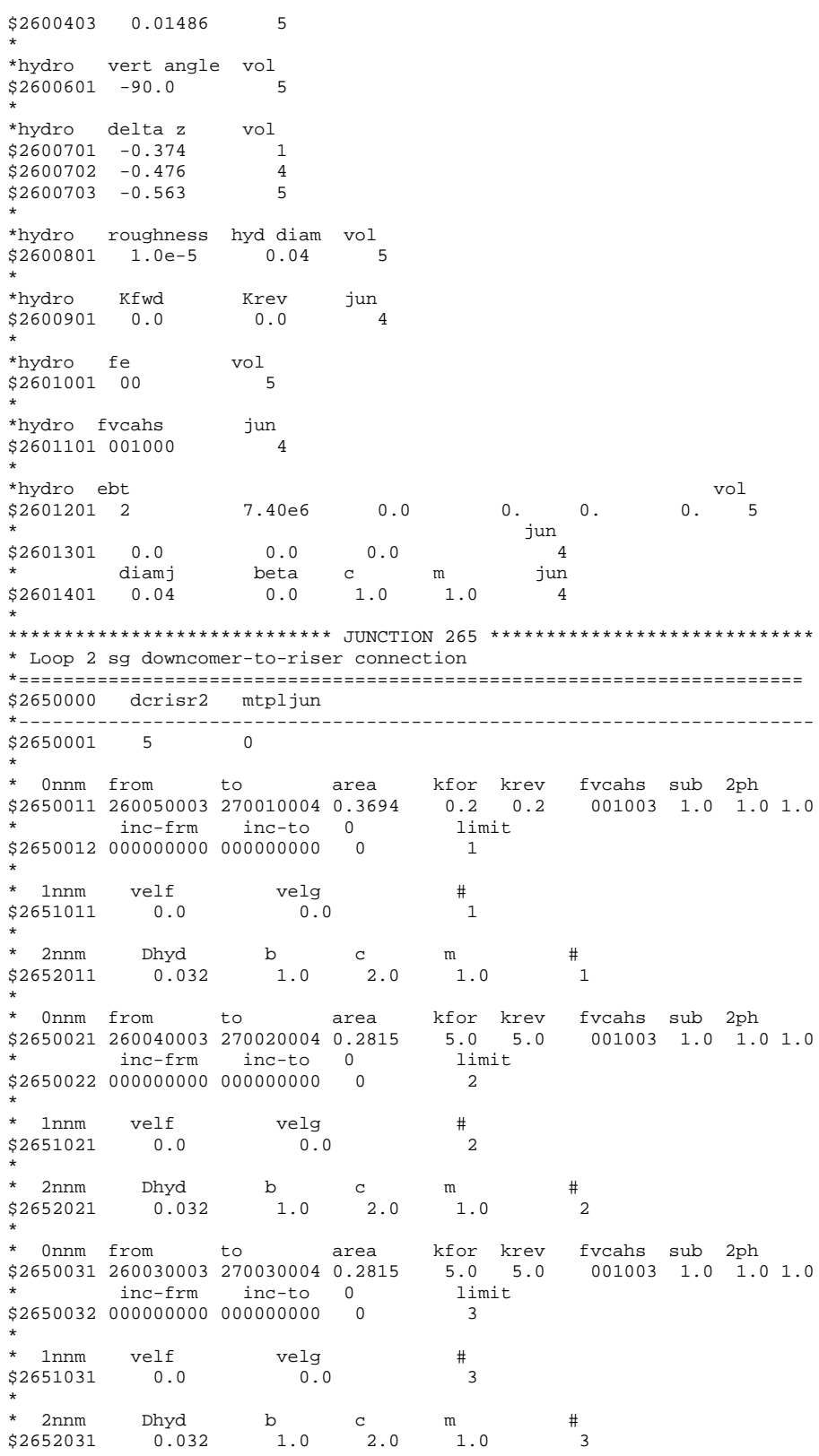




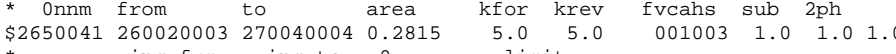
$\$ 2650042000000000 \quad 000000000 \quad 0$

$\begin{array}{cccc}* 1 \mathrm{nnm} & \text { velf } & \text { velg } & \# \\ \$ 2651041 & 0.0 & 0.0 & 4\end{array}$

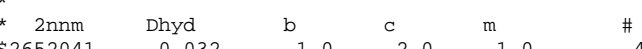

* Onnm from to area kfor krev fvcahs sub 2 ph

$\$ 2650051260010003270050004 \quad 0.2413 \quad 5.0$ inc 5.0

$\begin{array}{cccc}\text { * } \mathrm{nnm} & \text { velf } & \text { velg } & \# \\ \$ 2651051 & 0.0 & 0.0 & { }_{5}\end{array}$

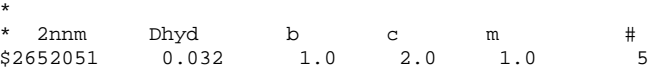

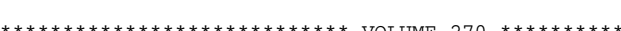

* Loop $2 \mathrm{sg}$ riser

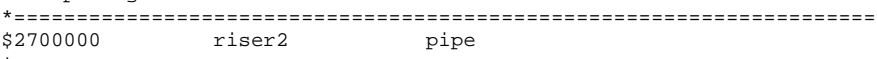

$\star$ hydro
$\$ 2700001$
$\$$

$\begin{array}{lll}* \text { hydro } & \text { vol area vol } \\ \$ 2700101 & 0.0 & \end{array}$

*hydro jun area jun

*hydro length vol

$\begin{array}{lrr}\$ 2700301 & 0.563 & 1 \\ \$ 2700302 & 0.476 & 4\end{array}$

$2700303 \quad 0.37$

$\begin{array}{lll}* \text { *hydro } & \text { volume } \\ \$ 2700401 & 0.04553\end{array}$

$\$ 2700402 \quad 0.03701$

$\$ 2700403 \quad 0.02909$

*hydro vert angle vol

* *hydro delta $z$ vol

$\begin{array}{lrr}\$ 2700701 & 0.563 & 1 \\ \$ 2700702 & 0.476 & 4\end{array}$

$\begin{array}{ll}\$ 2700702 & 0.476 \\ \$ 2700703 & 0.374\end{array}$

*hydro roughness hyd diam vol

$\$ 2700801 \quad 1.0 e^{-5} \quad 0.0376$

$\begin{array}{lrrr}* \text { Khydro } & \text { Kfwd } & \text { Krev } & \text { jun } \\ \$ 2700901 & 0.0 & 0.0 & 4\end{array}$

\$2.

$\begin{array}{lll}* \text { hydro } & \text { fe } & \text { vol } \\ \$ 2701001 & 00 & 5\end{array}$

*hydro fvcahs
$\$ 2701101001000$

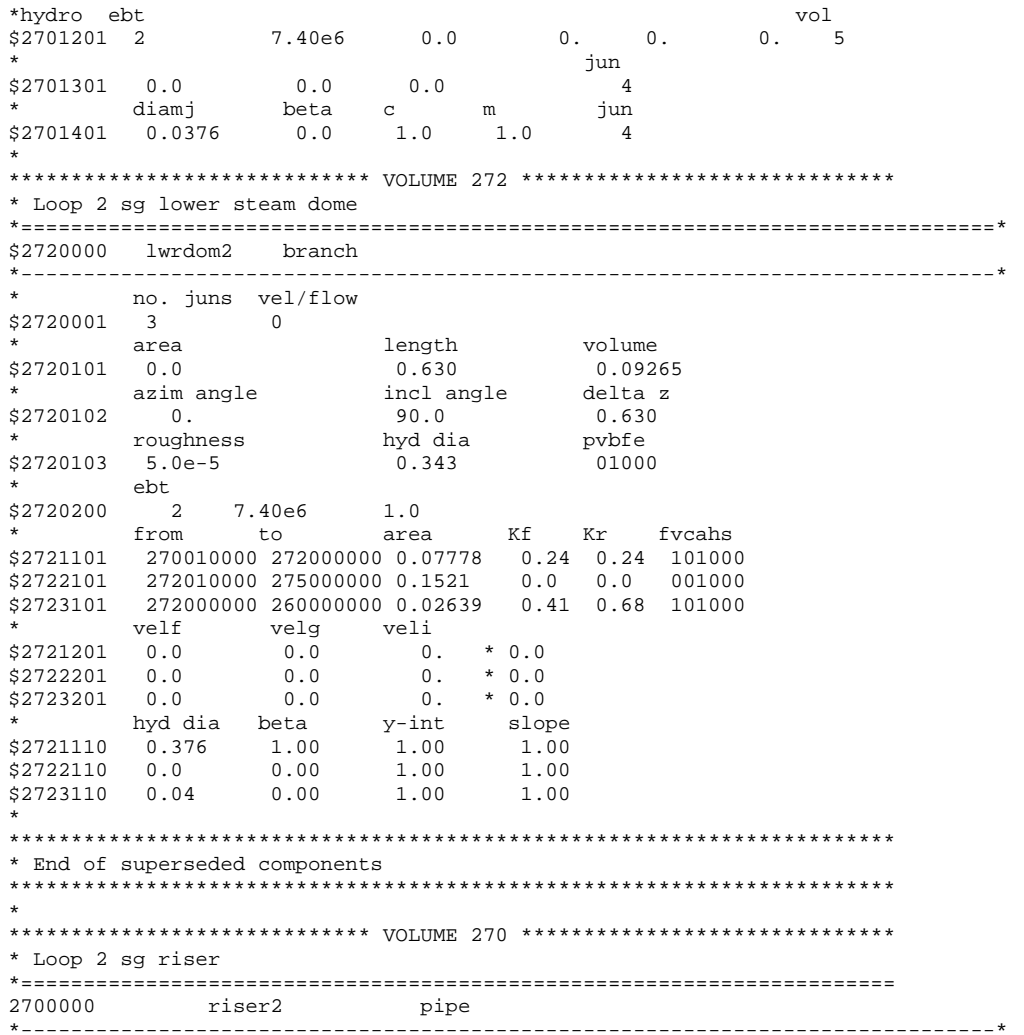

*hydro no. volumes

27000015

*hydro vol area vol

*

$\begin{array}{llr}* \text { kydro } & \text { jun area } & \text { jun } \\ 2700201 & 0.0 & 4\end{array}$

0.0

$\begin{array}{lr}* \text { hydro } & \text { length } \\ 2700301 & 0.563 \\ 2700302 & 0.476\end{array}$

$\begin{array}{ll}2700302 & 0.476 \\ 2700303 & 0.374\end{array}$

*hydro volume

$\begin{array}{lll} & & \\ 270040 & 0.06039 & 1\end{array}$

$2700403 \quad 0.03896$

thydro vert angle vol

$270060190.0 \quad 5$

*hydro delta $z$ vol 


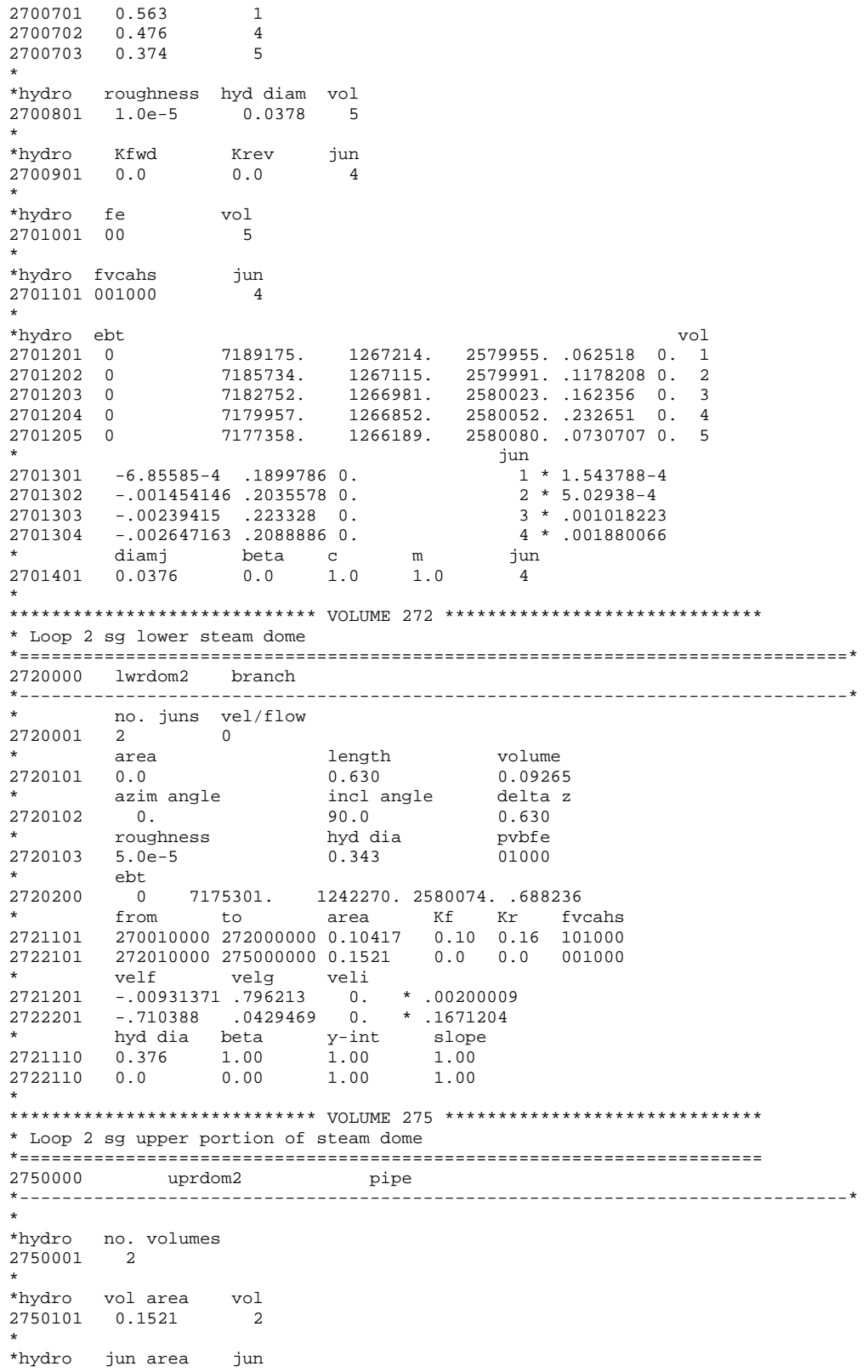

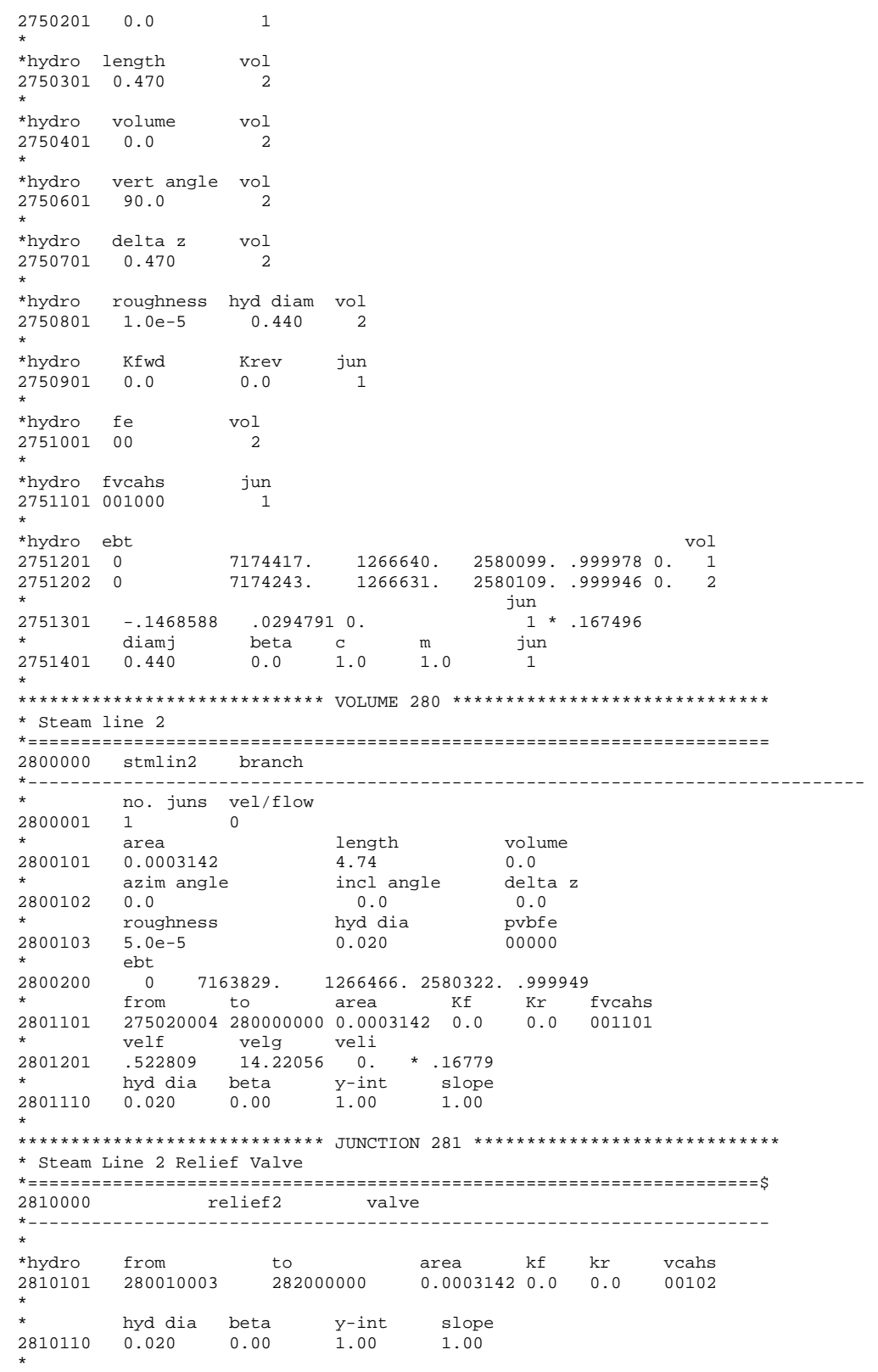




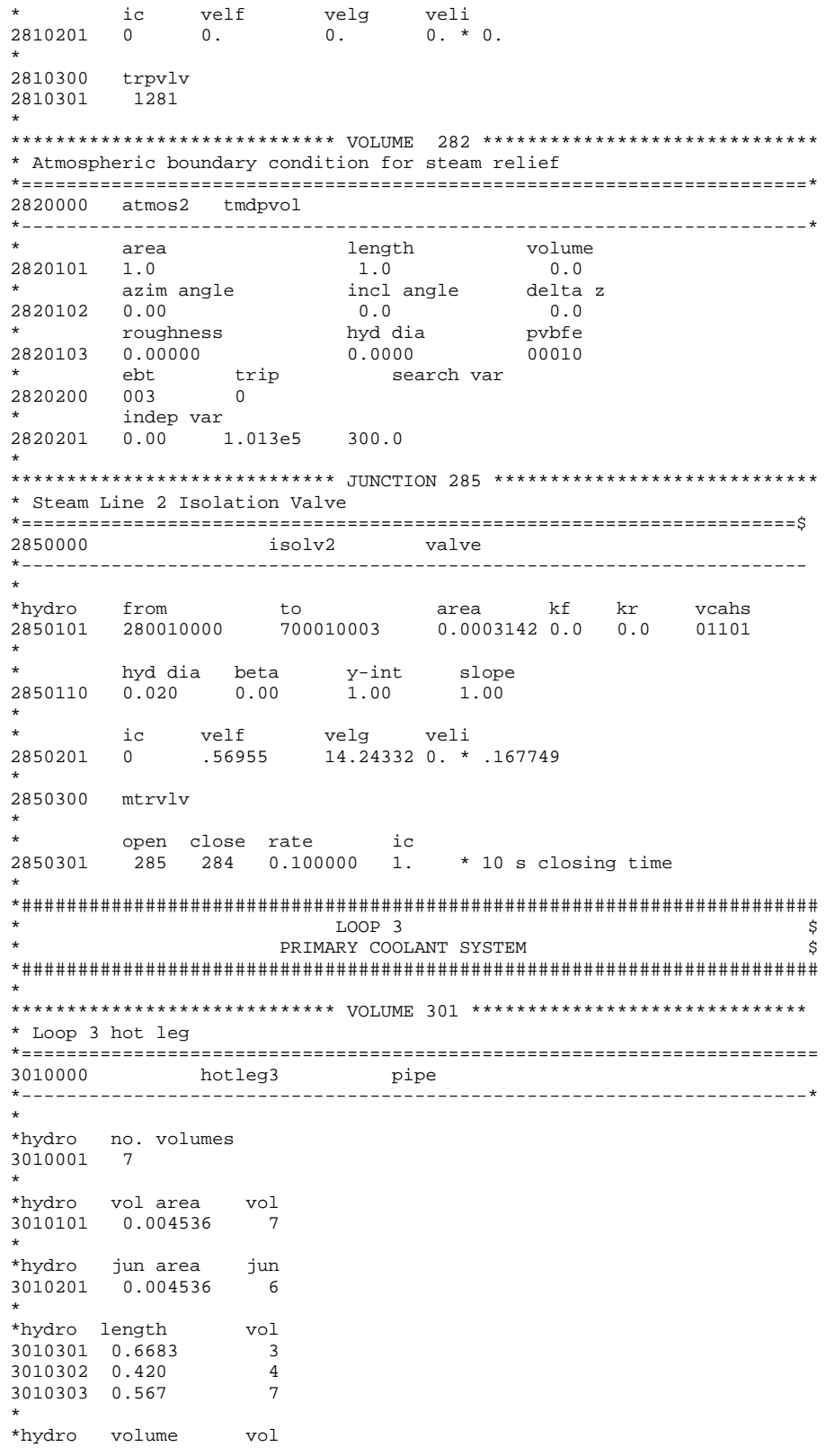

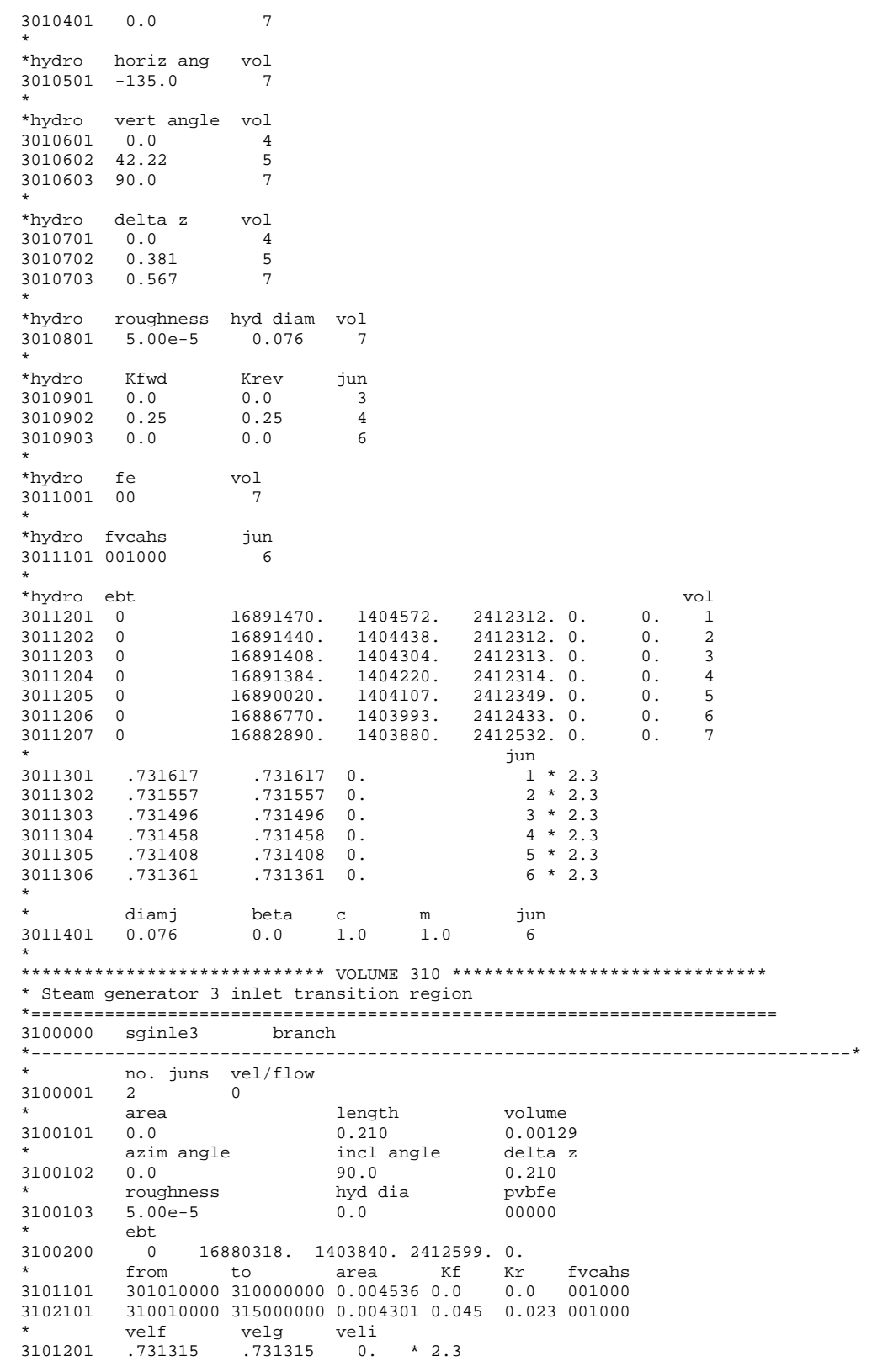




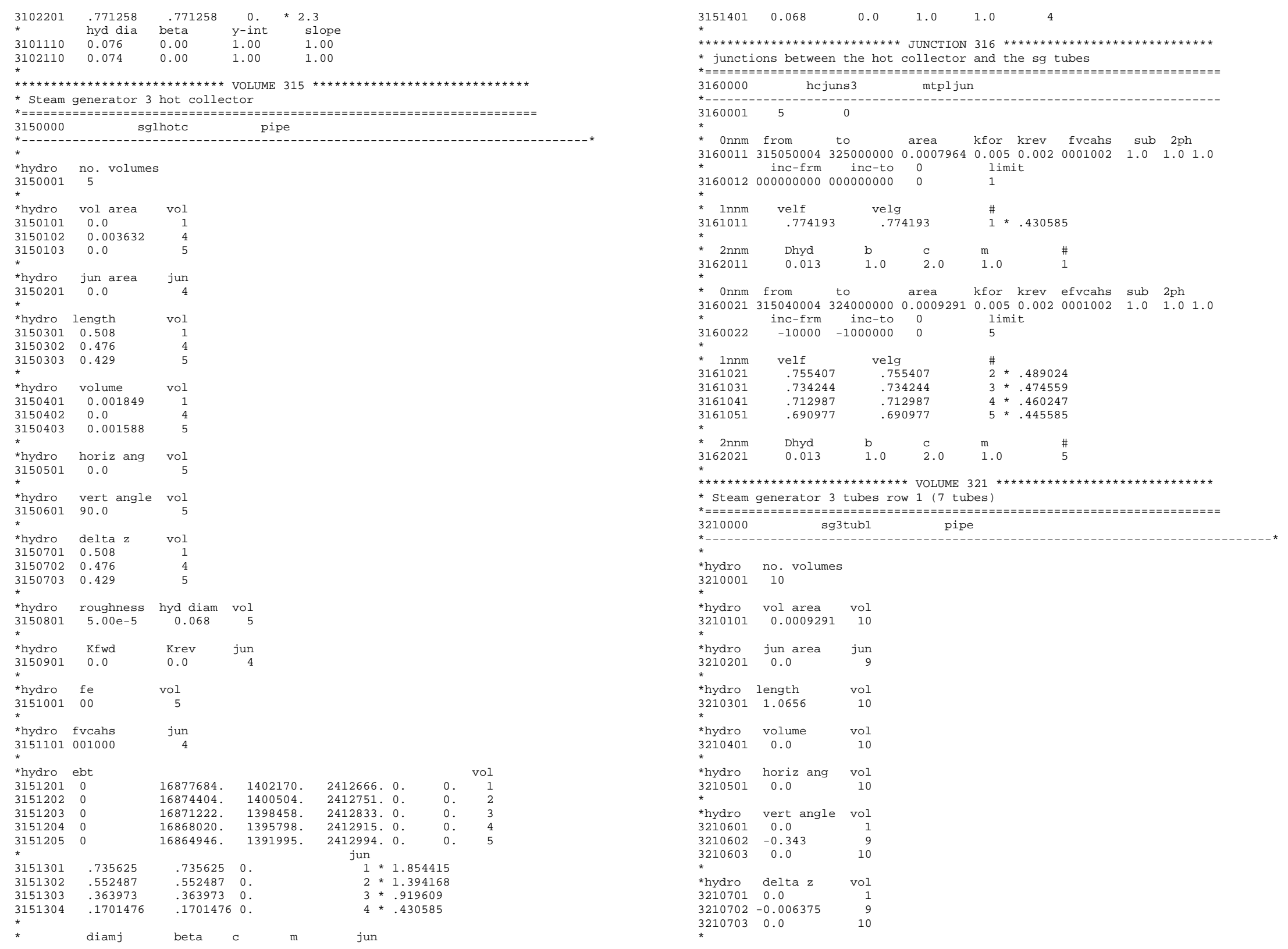




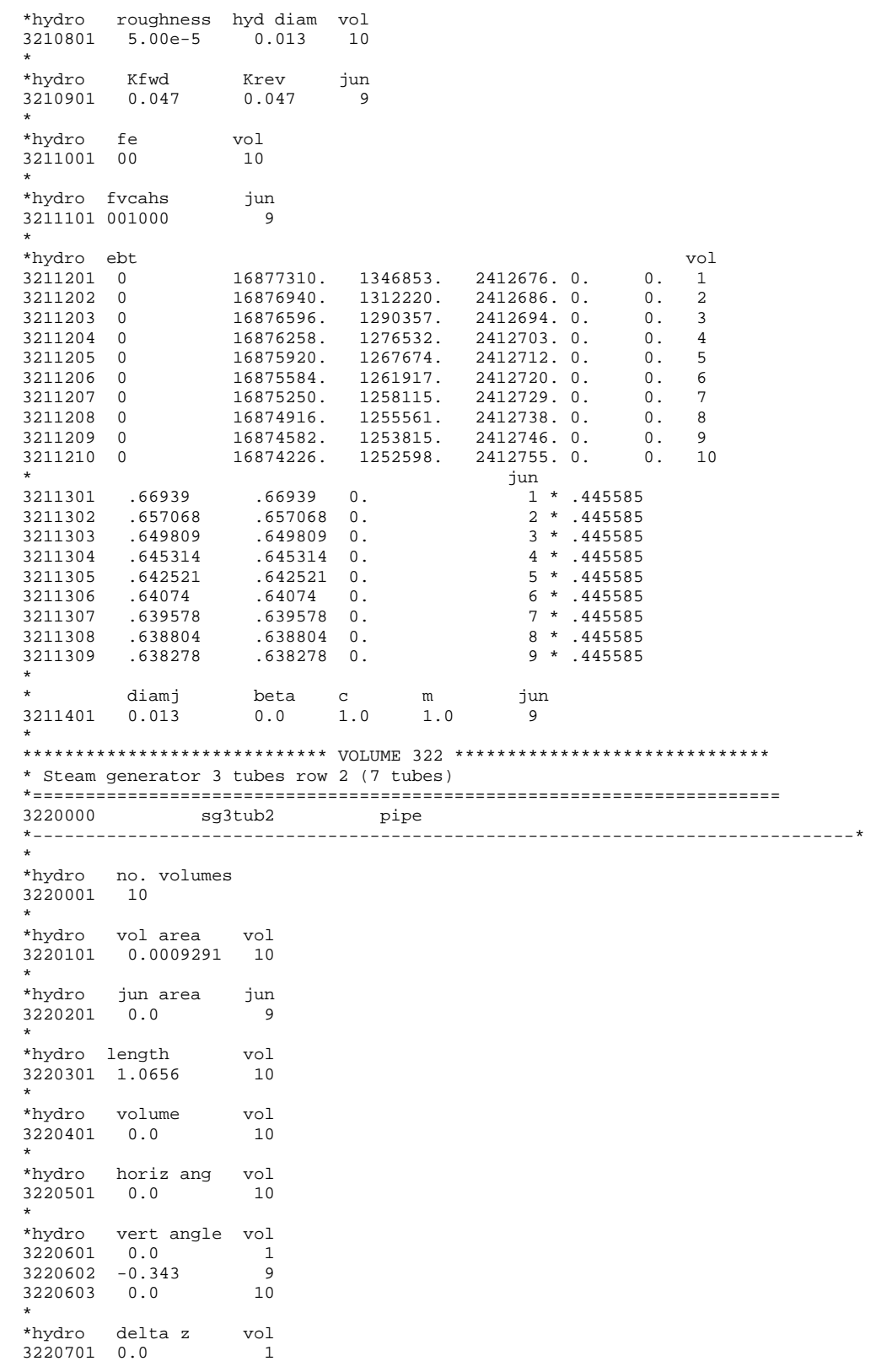




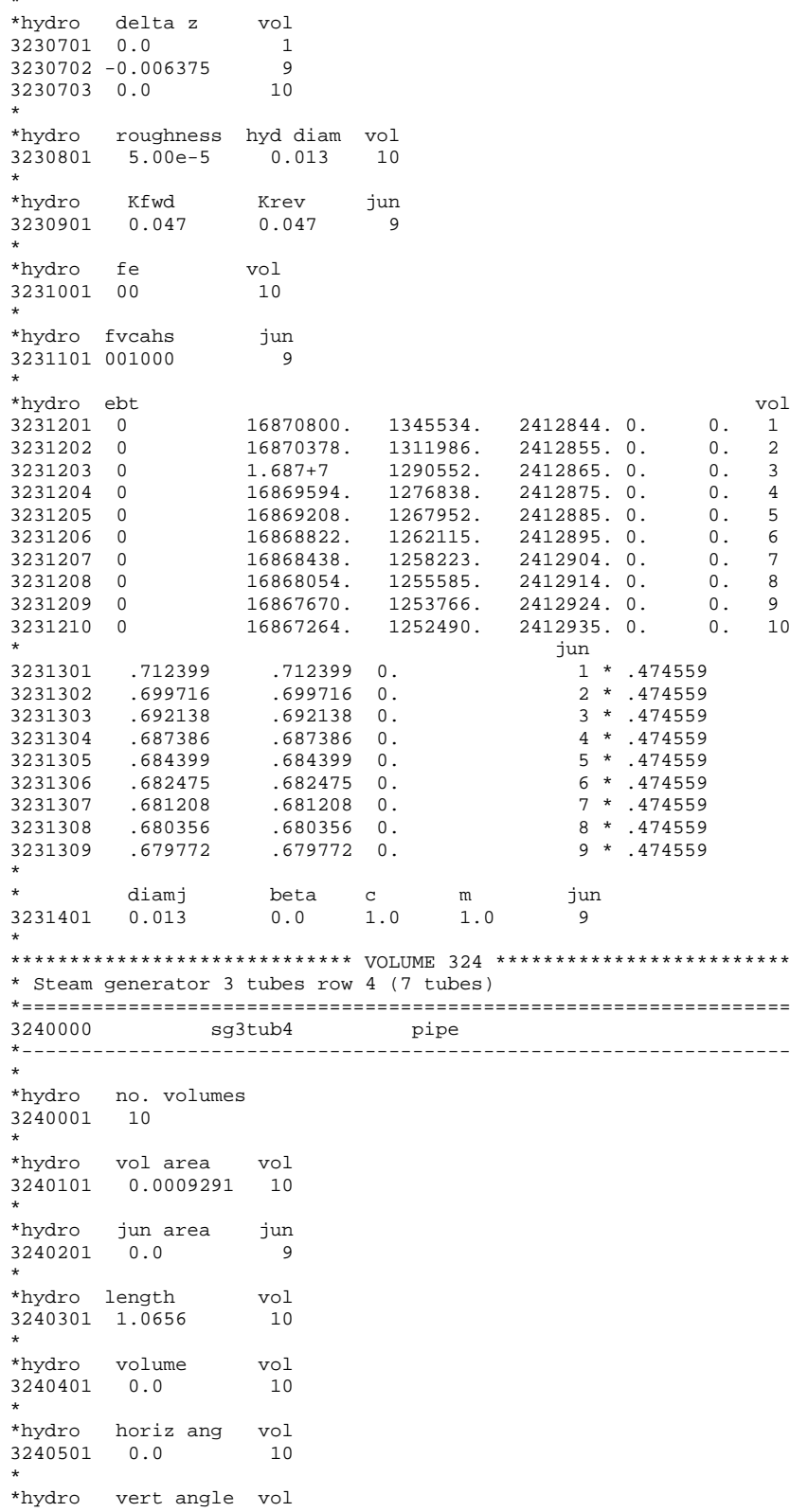

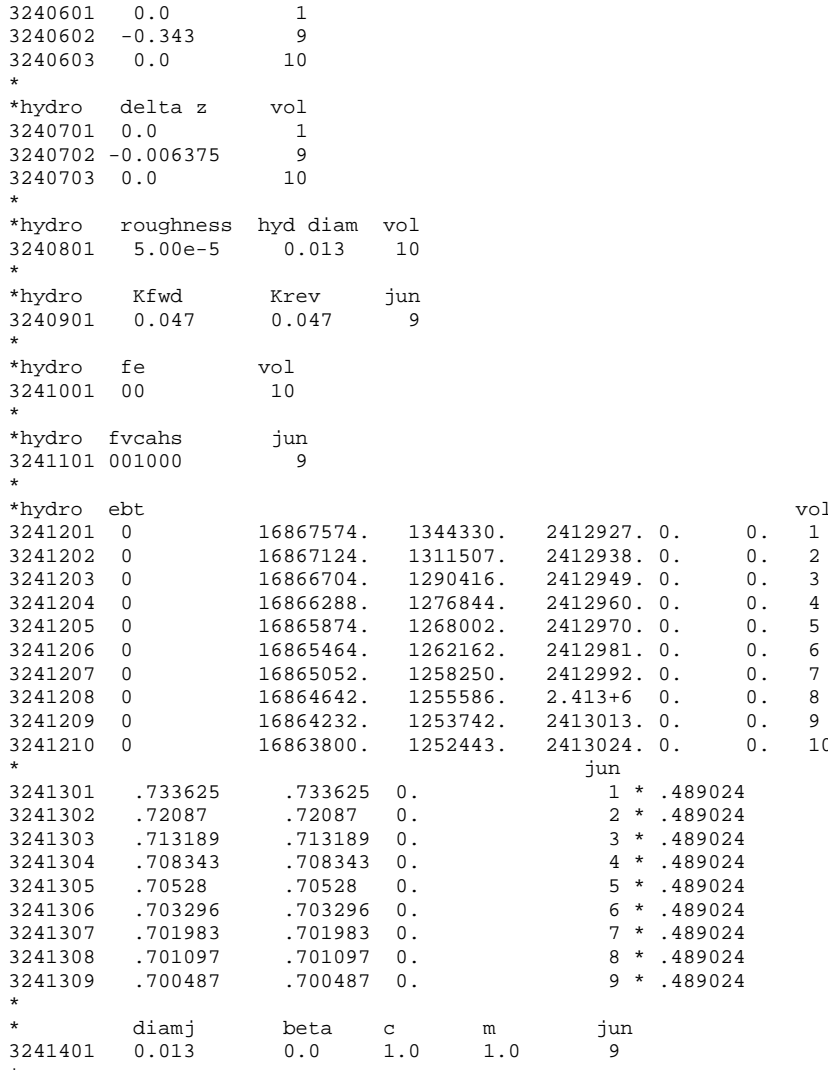




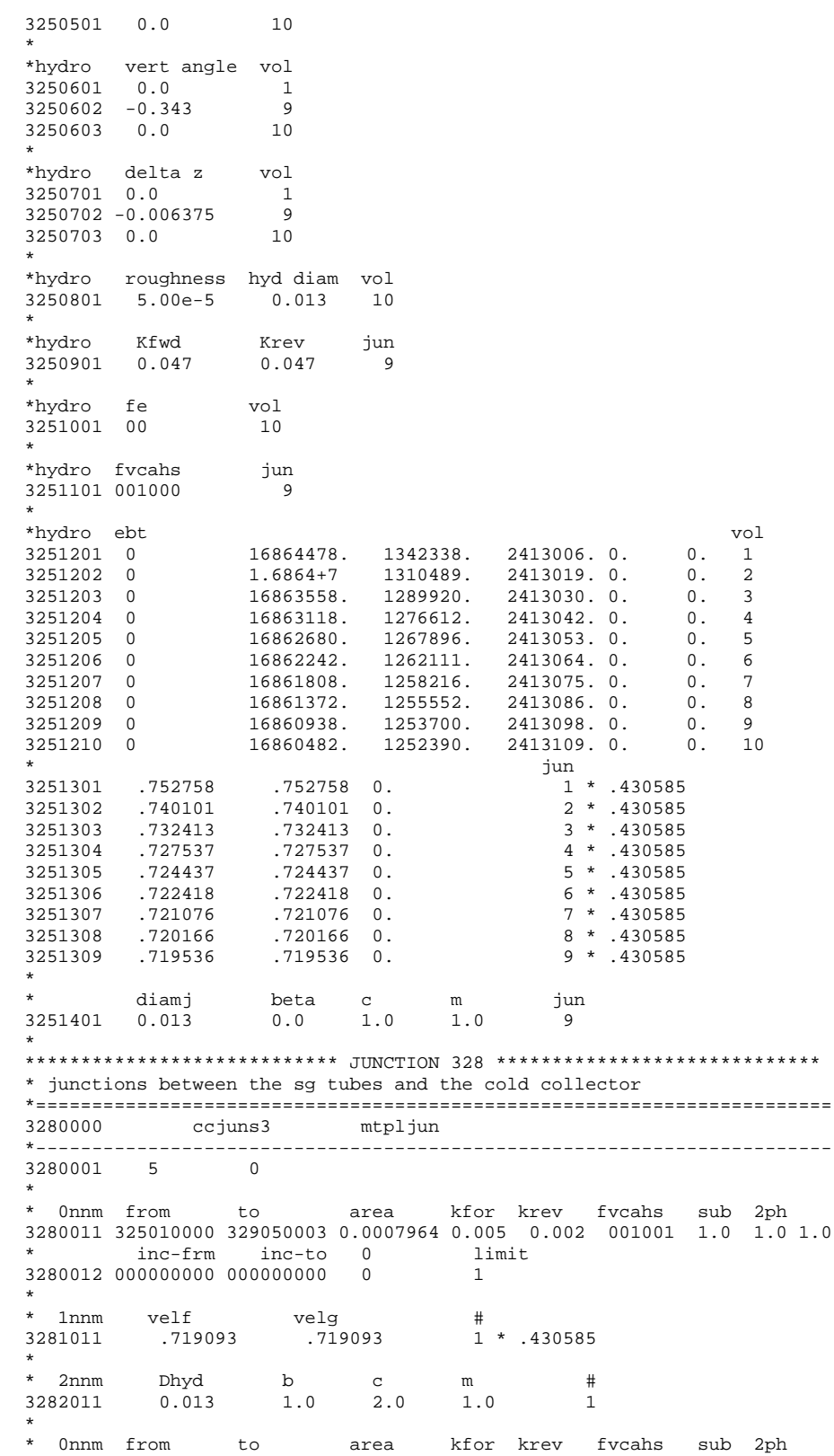

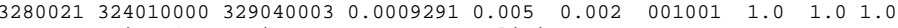

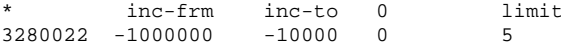

\begin{tabular}{|c|c|c|c|c|}
\hline * $1 \mathrm{nnn}$ & velf & velg & \# & \\
\hline 3281021 & .70006 & .70006 & & 489024 \\
\hline 3281031 & .679364 & .679364 & 3 * & 474559 \\
\hline 3281041 & .658887 & .658887 & $4 *$ & 460247 \\
\hline 3281051 & $\begin{array}{l}.6508013 \\
.637913\end{array}$ & .637913 & $\begin{array}{l}4 \\
5\end{array}$ & 445585 \\
\hline $2 \mathrm{nnm}$ & Dhyd & $c$ & $\mathrm{~m}$ & \\
\hline 282021 & 0.013 & 1.0 & 1.0 & $\begin{array}{l}\text { H } \\
5\end{array}$ \\
\hline
\end{tabular}

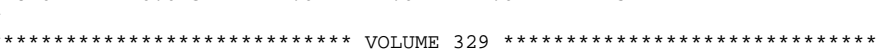
$*$
$\star$ Steam generator 3 cold collector

$\begin{array}{lll}* & *=============================== \\ 3290000 & \text { sg3cldc } & \text { pip }\end{array}$

*hydro no. volumes

32900016

*hydro vol area vol

$\begin{array}{lll}3290101 & 0.0 & 1 \\ 3290102 & 0.003632 & 5\end{array}$

$3290103 \quad 0.0$

*

$\begin{array}{llr}* \text { hydro } & \text { jun area } & \text { jun } \\ 3290201 & 0.0 & 5\end{array}$

*hydro length vol

$290302 \quad 0.476$

$3290303 \quad 0.429$

$3290304 \quad 0.051$

$\begin{array}{llr}3290401 & 0.001883 \quad \text { vol } & 1 \\ 3 & \end{array}$

$\begin{array}{lll}3290402 & 0.0 & 0 \\ 3290403 & 0.0002164 \quad 6\end{array}$

*hydro horiz ang vol

(290501

$\begin{array}{llr}* \text { kydro } & \text { vert angle } & \text { vol } \\ 3290601 & 90.0 & 6\end{array}$

$\begin{array}{lll}* & \\ 3290701 & \text { delta } z\end{array}$

$\begin{array}{ll}3290701 & 0.508 \\ 3290702 & 0.476\end{array}$

$\begin{array}{ll}3290703 & 0.429 \\ 3290704 & 0.051\end{array}$

$\begin{array}{lll}3290704 & 0.051 \quad 6\end{array}$

*hydro roughness hyd diam vol

$\begin{array}{llll}3290801 & 5.00 e-5 & 0.068 & 5 \\ 3290802 & 5.00 \mathrm{e}-5 & 0.074 & 6\end{array}$

$\begin{array}{lllr}* \text { *hydro } & \text { Kfwd } & \text { Krev } & \text { jun } \\ 3290901 & 0.0 & 0.0 & 4 \\ 3290902 & 0.016 & 0.032 & 5\end{array}$

$\begin{array}{llr}* \text { hydro } & \text { fe } & \text { vol } \\ 3291001 & 00 & 6\end{array}$

* jun

$3291101001000 \quad$ jun

*hydro ebt 


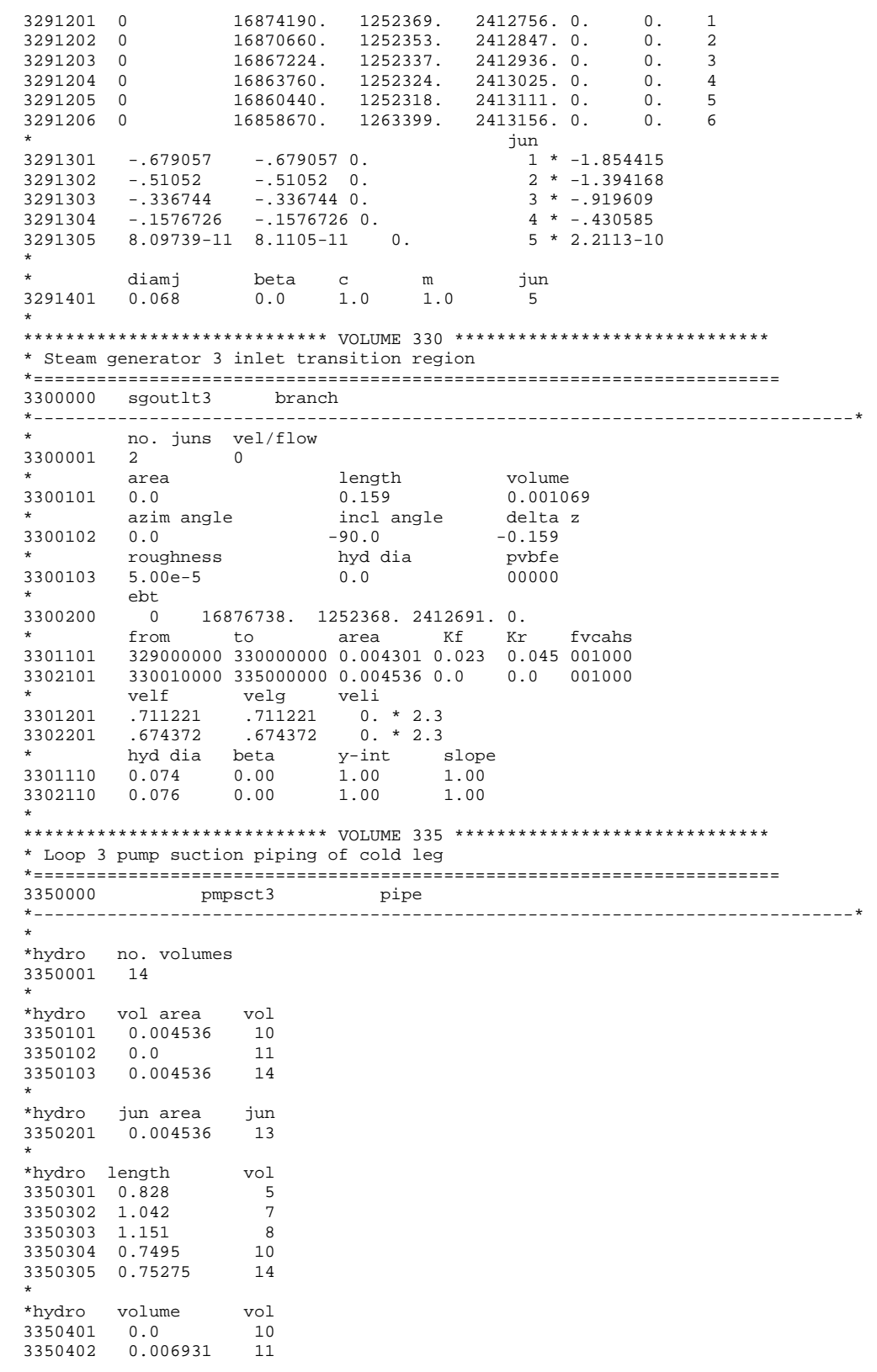

\begin{tabular}{|c|c|c|c|c|c|c|}
\hline $\begin{array}{l}3350403 \\
*\end{array}$ & 0.0 & 14 & & & & \\
\hline *hydro & horiz ang & vol & & & & \\
\hline 3350501 & 90.0 & 8 & & & & \\
\hline $\begin{array}{l}3350502 \\
*\end{array}$ & -85.0 & 14 & & & & \\
\hline *hydro & vert angle & vol & & & & \\
\hline 3350601 & -90.0 & 8 & & & & \\
\hline 3350602 & 0.0 & 10 & & & & \\
\hline $\begin{array}{l}3350603 \\
*\end{array}$ & 90.0 & 14 & & & & \\
\hline *hydro & delta $z$ & vol & & & & \\
\hline 3350701 & -0.828 & 5 & & & & \\
\hline 3350702 & -0.7425 & 7 & & & & \\
\hline 3350703 & -0.965 & 8 & & & & \\
\hline 3350704 & 0.0 & 10 & & & & \\
\hline 3350705 & 0.65675 & 11 & & & & \\
\hline $\begin{array}{l}3350706 \\
*\end{array}$ & 0.75275 & 14 & & & & \\
\hline *hydro & roughness & hyd diam & vol & & & \\
\hline $\begin{array}{l}3350801 \\
*\end{array}$ & $5.00 e-5$ & 0.076 & 14 & & & \\
\hline *hydro & Kfwd & Krev & jun & & & \\
\hline 3350901 & 0.0 & 0.0 & 4 & & & \\
\hline 3350902 & 0.13 & 0.13 & 5 & & & \\
\hline 3350903 & 0.0 & 0.0 & 6 & & & \\
\hline 3350904 & 0.13 & 0.13 & 7 & & & \\
\hline 3350905 & 0.25 & 0.25 & 8 & & & \\
\hline 3350906 & 0.0 & 0.0 & 9 & & & \\
\hline 3350907 & 0.25 & 0.25 & 10 & & & \\
\hline 3350908 & 0.0 & 0.0 & 13 & & & \\
\hline * *hydro & $\mathrm{fe}$ & vol & & & & \\
\hline 3351001 & 00 & 14 & & & & \\
\hline *hydro & fvcahs & jun & & & & \\
\hline $\begin{array}{l}3351101 \\
*\end{array}$ & 001000 & 13 & & & & \\
\hline *hydro & ebt & & & & & \\
\hline 3351201 & & 16880266 & & 2412600.0 & & \\
\hline 3351202 & 0 & 16886336 . & 1252073 . & 2412444.0 . & 0. & \\
\hline 3351203 & 0 & 16892408 . & 1251925 & 2412287.0 . & 0 . & \\
\hline 3351204 & 0 & 16898480. & 1251777 . & 2412131.0 . & & \\
\hline 3351205 & 0 & 16904552 . & 1251630 . & 2411975.0 & 0. & 5 \\
\hline 3351206 & 0 & 16910282 . & 1251444 . & 2411828. 0 & 0. & 6 \\
\hline 3351207 & 0 & 16915716 . & 1251259 . & 2411683. 0 . & 0. & \\
\hline 3351208 & 0 & 16921946. & 1251053 . & 2411498.0. & 0. & 8 \\
\hline 3351209 & 0 & 16925424 . & 1250920 . & 2411395. 0 . & & \\
\hline 3351210 & 0 & 16925392. & 1250786 . & 2411396. 0. & 0. & 10 \\
\hline 3351211 & 0 & 16923034 . & 1250581 . & 2411466. 0 . & 0. & 11 \\
\hline 3351212 & 0 & 16917684 . & 1250447 . & 2411625.0 . & 0 . & 12 \\
\hline 3351213 & 0 & 16912096. & 1250312 & 2411781. 0 . & 0. & 13 \\
\hline $\begin{array}{l}3351214 \\
\star\end{array}$ & 0 & 16906508. & 1250178 & 2411925.0 . & 0 . & \\
\hline 3351301 & .674322 & .674322 & 0. & $\underset{1}{\operatorname{Jun}} * 2.3$ & & \\
\hline 3351302 & .67427 & .67427 & 0. & $2 * 2.3$ & & \\
\hline 3351303 & .674219 & .674219 & 0. & $3 * 2.3$ & & \\
\hline 335130 & .6741 & .674167 & 0. & $4 * 2.3$ & & \\
\hline 335130 & .6741 & .674115 & 0. & $5 * 2.3$ & & \\
\hline 335130 & .6740 & .674051 & 0. & $6 * 2.3$ & & \\
\hline 3351307 & .673988 & .673988 & 0. & $7 * 2.3$ & & \\
\hline 3351308 & .673918 & .673918 & 0. & $8 * 2.3$ & & \\
\hline 3351309 & .673873 & .673873 & 0. & $9 * 2.3$ & & \\
\hline 3351310 & .673831 & .673831 & 0. & $10 * 2.3$ & & \\
\hline 3351311 & .673768 & .673768 & 0. & $11 * 2.3$ & & \\
\hline 3351312 & .67373 & .67373 & 0. & $12 * 2.3$ & & \\
\hline 3351313 & .673693 & .673693 & 0. & $13 * 2.3$ & & \\
\hline
\end{tabular}


$\begin{array}{llllll}* & \text { diamj } & \text { beta } & \text { c } & m & \text { jun } \\ 3351401 & 0.076 & 0.0 & 1.0 & 1.0 & 13\end{array}$

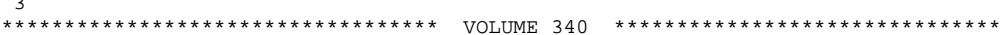

* Loop 3 primary coolant pump

\begin{tabular}{|c|c|c|c|}
\hline 3400000 & mср3 & pump & \\
\hline $\begin{array}{l}* \\
3400101\end{array}$ & $\begin{array}{l}\text { area } \\
0.0\end{array}$ & $\begin{array}{l}\text { length } \\
0.746\end{array}$ & $\begin{array}{l}\text { volume } \\
0.010\end{array}$ \\
\hline
\end{tabular}

$\begin{array}{llll}3400101 & 0.0 & 0.746 & 0.010\end{array}$

$\begin{array}{lllll}* & & & \\ 3400102 & \text { azim angle incl angle delta } z & \text { pvbfe } \\ 0.0 & 30.0 & 0.370 & 00000\end{array}$

$\begin{array}{llllll}* & \text { from } & \text { jun area } & \mathrm{Kf} & \mathrm{Kr} & \text { efvcahs } \\ 3400108 & 335010000 & 0.004536 & 0.0 & 0.0 & 0001000\end{array}$

to jun area $\mathrm{Kf} \mathrm{Kr}$ efvcahs

$\begin{array}{lllll}* & \text { hyd dia } & \text { beta } & \text { y-int } & \text { slope } \\ 3400110 & 0.076 & 0.00 & 1.00 & 1.00\end{array}$

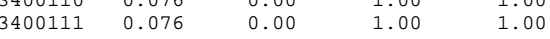

$\begin{array}{lrrrrr}* & \text { ebt } & & & & \\ 3400200 & 0 & 16907300 . & 1243874.2411905 . & 0 .\end{array}$

$\begin{array}{lllll}* & \text { vel/flow liquid } & \text { vapor } & \text { int-face } \\ 3400201 & 0 & .673655 & .673655 & 0 . * 2.3 \\ 340202 & 0 & .671674 & .671674 & 0 . * 2.3\end{array}$

$3400202 \quad 0 \quad 671674 \quad 671674 \quad 0 * 2.3$

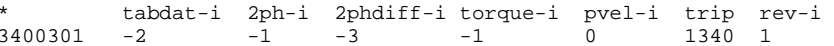

* rated vel in/rated vel rated flow rated head

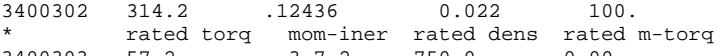

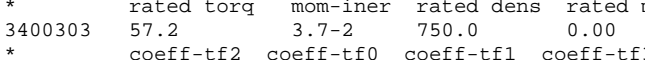

$\begin{array}{lllll}3400304 & \text { coeff-tf2 } & \text { coeff-tf0 } & \text { coeff-tf1 } & \text { coeff-tf3 } \\ 0.57 & 0.57 & 0.0 & 0.0\end{array}$

$\begin{array}{ccc}* \text { khydro } & \text { trip no. } & \text { parameter no. } \\ 3406100 & 340 & \text { cntrlvar } 340\end{array}$

$*$ hydro
340610

indp var
-1.0

speed
314.2

3406102

0 .

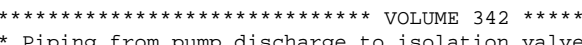

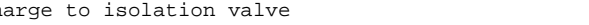

$\begin{array}{lll}* & \text { component name } & \text { component type } \\ \text { *hydro } & \text { pmp3out } & \text { snglvol }\end{array}$

\begin{tabular}{|c|c|c|c|}
\hline 000 & pmp3out & & \\
\hline $\begin{array}{l}\text { *hydro } \\
3420101\end{array}$ & $\begin{array}{l}\text { area } \\
0.004536\end{array}$ & $\begin{array}{l}\text { length } \\
0.880\end{array}$ & $\begin{array}{l}\text { volume } \\
0.0\end{array}$ \\
\hline
\end{tabular}

0.004536

vert angle
0.0

delta
0.0

$*$ hydro
3420102

horz angle
80.0

hyd diam
0.076

$\mathrm{fe}$
00

${ }^{*}$ hydro
3420103

roughness
0.00005

$\begin{array}{lccc}* \text { thydro } & \text { ebt pressure } & \text { tempe } \\ 3420200 & 0 & 16910562 . & 1243628.2411821 .\end{array}$

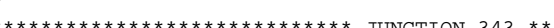

* Cold leg isolation valve

\begin{tabular}{|c|c|c|}
\hline 3430000 & $\mathrm{cl} 3 \mathrm{vlv}$ & valve \\
\hline
\end{tabular}

$\begin{array}{lllcccc}* \text { *hydro } & \text { from } & \text { to } & \text { area } & \text { kf } & \text { kr } & \text { vcahs } \\ 3430101 & 342010000 & 345000000 & 0.004536 & 0.0 & 0.0 & 00100\end{array}$

3430201

$.671592 .6715920 . * 2.3$

3430300 mtrvlv

* $3430301 \quad 342$ close rate ic

Loop 3 reactor vessel inlet section of cold leg

$3450000 \quad$ cldleg 3 pipe

* *hydro no. volumes

$3450001 \quad 4$

$\begin{array}{ccc}* \text { hydro } & \text { vol area } & \text { vol } \\ 3450101 & 0.004536 & 4\end{array}$

*hydro jun area jun

$\begin{array}{lll}3450201 & 0.004536 \quad 3\end{array}$

*hydro length

$\begin{array}{ll}3450302 & 0.741\end{array}$

$\begin{array}{ccr} & & \\ 3450401 & \text { volume } & \text { vol } \\ 0.0 & 4\end{array}$

*hydro horiz ang vol

$\begin{array}{lll}3450501 & 80.0 & 3 \\ 3450502 & 35.0 & 4\end{array}$

*hydro vert angle vol

*

$\begin{array}{lcr}* \text { *hydro } & \text { delta } z & \text { vol } \\ 3450701 & 0.0 & 4\end{array}$

*hydro roughness hyd diam vol

$\begin{array}{llll}3450801 & 5.00 \mathrm{e}-5 & 0.076 \quad 4\end{array}$

$\begin{array}{lllr}* \text { hydro } & \text { Kfwd } & \text { Krev } & \text { jun } \\ 3450901 & 0.0 & 0.0 & 2\end{array}$

$\begin{array}{llll}3450902 & 0.16 & 0.0 & 2 \\ & 0.16 & 3\end{array}$

$\begin{array}{llr}* \text { thydro } & \text { fe } & \text { vol } \\ 3451001 & 00 & 4\end{array}$

$\begin{array}{llr}* \text { hydro } & \text { fvcahs } & \text { jun } \\ 3451101 & 001000 & 3\end{array}$

*

*hydro ebt

$\begin{array}{ll}3451201 & 0 \\ 3451202 & 0 \\ 3451203 & 0\end{array}$

34512030

3451204

16910528.

2411822. 0. $0 . \quad 1$

16910402 .

$\begin{array}{llll}3451302 & .671548 & .671548 & 0 .\end{array}$

\begin{tabular}{llll}
3451303 & .671548 & .671548 & 0.671504 \\
\hline & .671459 & .671459 & 0.
\end{tabular}

$\begin{array}{llllll}* & \text { diamj } & \text { beta } & c & \mathrm{~m} & \text { jun } \\ 3451401 & 0.076 & 0.0 & 1.0 & 1.0 & 3\end{array}$

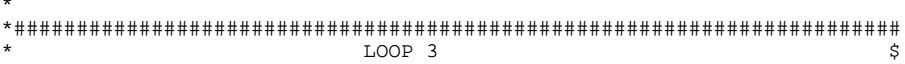


SECONDARY COOLANT SYSTEM

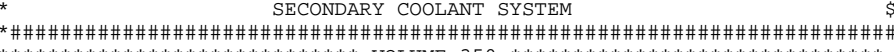
* Loop 3 Main Feedwater source

\begin{tabular}{|c|c|c|c|c|}
\hline 3500000 & $\mathrm{mfw} 3 \mathrm{src}$ & tmdpvol & & \\
\hline & area & & length & volume \\
\hline 3500101 & & & 1.0 & 0.0 \\
\hline & azim angle & & incl angle & $\operatorname{delta} z$ \\
\hline 3500102 & 0.00 & & 0.0 & 0.0 \\
\hline & roughness & & hyd dia & pvbfe \\
\hline 3500103 & 0.00000 & & 0.0000 & 00010 \\
\hline & ebt & trip & search var & \\
\hline 3500200 & 003 & 0 & & \\
\hline 3500201 & $\begin{array}{l}\text { indep } \text { var } \\
0.00\end{array}$ & $10.0 \mathrm{e} 6$ & 443.15 & \\
\hline
\end{tabular}

$3500201 \quad 0.00 \quad 10.0 e 6$

* JUNCTION 351

* Loop 3 main feedwater flow

$*========================= \pm$
3510000 mfw3 tmdpjun

$\begin{array}{llll}* & \text { From } & \text { To } & \text { Area } \\ 3510101 & 350010000 & 359000000 & 0.0009079\end{array}$

* $\begin{array}{llll} & \text { vel/Kg } & \text { trip } \\ 3510200 & 1 & 351\end{array} \quad$ var req. \# var req $\quad$ * trancalc

$\begin{array}{lrllll}* & \text { Time } & \mathrm{kg} / \mathrm{s} & \mathrm{kg} / \mathrm{s} & \mathrm{m} / \mathrm{s} & \\ 3510201 & 0.0 & 0.1667 & 0 . & 0 . & * \text { trancalc }\end{array}$

$\begin{array}{rrllll}3510202 & 9.0 & 0.1667 & 0 . & 0 . & \text { * } \\ 3510203 & 10.0 & 0.0 & 0 . & 0 . & \text { * trancalc } \\ & & 0.0 & \text { * } & 0 . & \text { * trancalc }\end{array}$

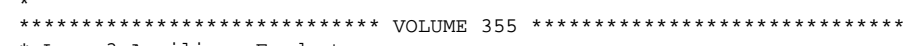

Loop 3 Auxiliary Feedwater source

\begin{tabular}{|c|c|c|c|}
\hline & area & length & volume \\
\hline 3550101 & $\begin{array}{l}\text { l.ea } \\
1.0\end{array}$ & $\begin{array}{l}1.0 \\
1.0\end{array}$ & 0.0 \\
\hline & azim angle & incl angle & delta $z$ \\
\hline 3550102 & 0.00 & & 0.0 \\
\hline & roughness & hyd dia & pubfe \\
\hline 3550103 & 0.00000 & 0.0000 & 00010 \\
\hline & trip & search var & \\
\hline 3550200 & $003 \quad 0$ & & \\
\hline 3550201 & $\begin{array}{l}\text { 1ndep } \operatorname{var} \\
0.00 \\
16.0 \mathrm{e} 6\end{array}$ & 443.15 & \\
\hline
\end{tabular}

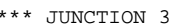

* Loop 3 auxiliary feedwater flow

3560000 afw3 tmdpjun

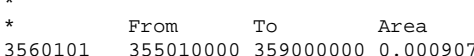

$\begin{array}{llll}* & \text { vel/Kg } & \text { trip } & \text { var req. \# var req } \\ 3560200 & 1 & 356\end{array} \quad$.

$\begin{array}{lllll}* & \text { Time } & \mathrm{kg} / \mathrm{s} & \mathrm{kg} / \mathrm{s} & \mathrm{m} / \mathrm{s} \\ 3560201 & -1 . & 0.0 & 0 . & 0 .\end{array}$

$\begin{array}{ccccc}3560201 & -1 . & 0.0 & 0 . & 0 . \\ 3560202 & 0.0 & 0.0 & 0 . & 0 .\end{array}$

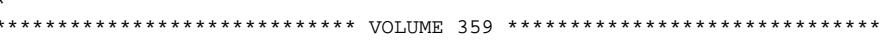

Loop 3 Feedwater rin

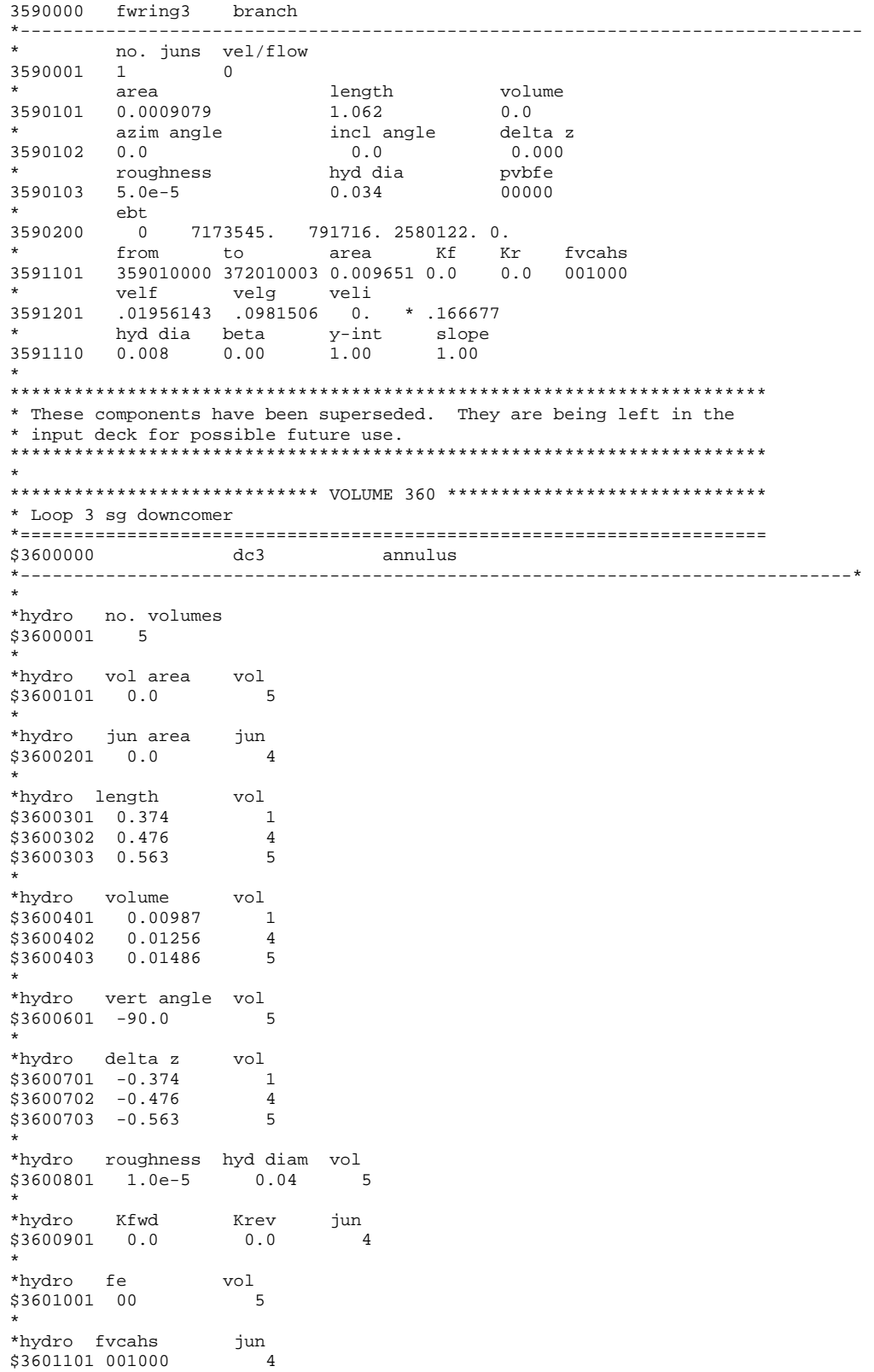




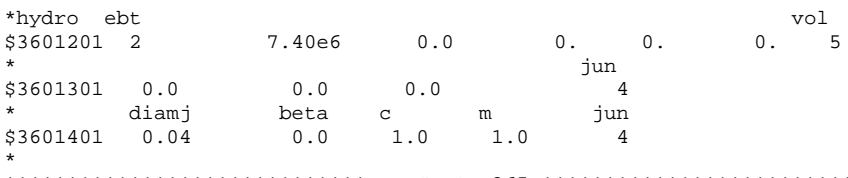

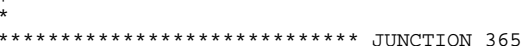

* Loop $3 \mathrm{sg}$ downcomer-to-riser connection

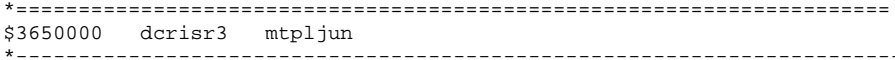

$\$ 3650001-05-10$

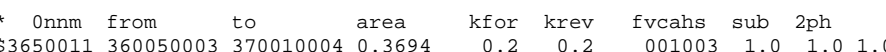

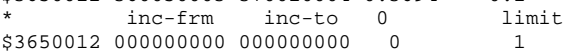

$\begin{array}{cccc}* 1 \mathrm{nnm} & \text { velf } & \text { velg } & \# \\ \$ 3651011 & 0.0 & 0.0 & { }_{1}\end{array}$

$\begin{array}{cccccc}* 2 \mathrm{nnm} & \text { Dhyd } & \mathrm{b} & \mathrm{c} & \mathrm{m} & \# \\ \$ 3652011 & 0.032 & 1.0 & 2.0 & 1.0 & { }_{1}\end{array}$

Onnm from to area kfor krev fvcahs sub $2 \mathrm{ph}$

$\begin{array}{llllllllll}\$ 3650021 & 360040003 & 370020004 & 0.2815 & 5.0 & 5.0 & 001003 & 1.0 & 1.0 & 1.0\end{array}$

$\$ 3650022000000000 \quad 000000000 \quad 0 \quad 2$

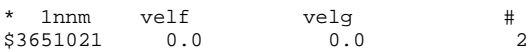

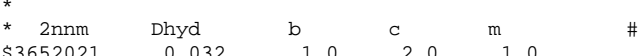

$\$ 3652021 \quad 0.032 \quad 1.0 \quad 2.0 \quad 1.0 \quad 0$

$\begin{array}{llllllllll}* & \text { Onnm from } & \text { to } & \text { area } & \text { kfor } & \text { krev } & \text { fvcahs } & \text { sub } & \text { 2ph } & \\ \$ 3650031 & 360030003 & 370030004 & 0.2815 & 5.0 & 5.0 & 001003 & 1.0 & 1.0 & 1.0\end{array}$ * $\$ 3650032000000000 \quad 0000000000003$

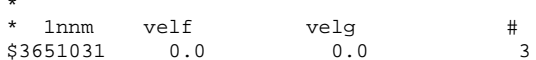

$\begin{array}{llllll}* & & & & & \\ * 2 \mathrm{nnm} & \text { Dhyd } & \mathrm{b} & \mathrm{c} & \mathrm{m} & \# \\ \$ 3652031 & 0.032 & 1.0 & 2.0 & 1.0 & { }_{3}\end{array}$

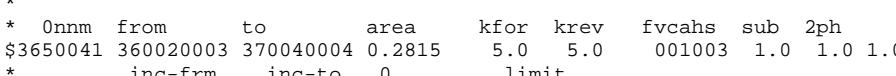
$\$ 36500420000000000000000000 \quad$ ind

$\begin{array}{cccc}* \text { Innm } & \text { velf } & \text { velg } & \# \\ \$ 3651041 & 0.0 & 0.0 & 4\end{array}$

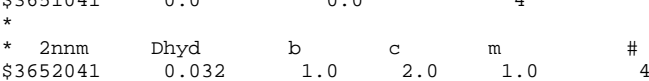

$\begin{array}{lllllll}\$ 3652041 & 0.032 & 1.0 & 2.0 & 1.0 & 4\end{array}$

$\begin{array}{llllrrrrrr}* \quad \text { Onnm from } & \text { to } & \text { area } & \text { kfor } & \text { krev } & \text { fvcahs } & \text { sub } & \text { 2ph } & \\ \$ 3650051 & 360010003 & 370050004 & 0.2413 & 5.0 & 5.0 & 001003 & 1.0 & 1.0 & 1.0\end{array}$ $\begin{array}{ccccc}\$ 3650051 & 360010003 & 370050004 & 0.2413 & 5.0 \\ * & \text { inc-frm } & \text { incto } & 0 & \text { limit }\end{array}$

* 1 nnm velf velg \#

$\begin{array}{ccc}* \text { nnm } & \text { velf } & \text { velg } \\ \$ 3651051 & 0.0 & 0.0\end{array}$

* 2 nnm Dhyd

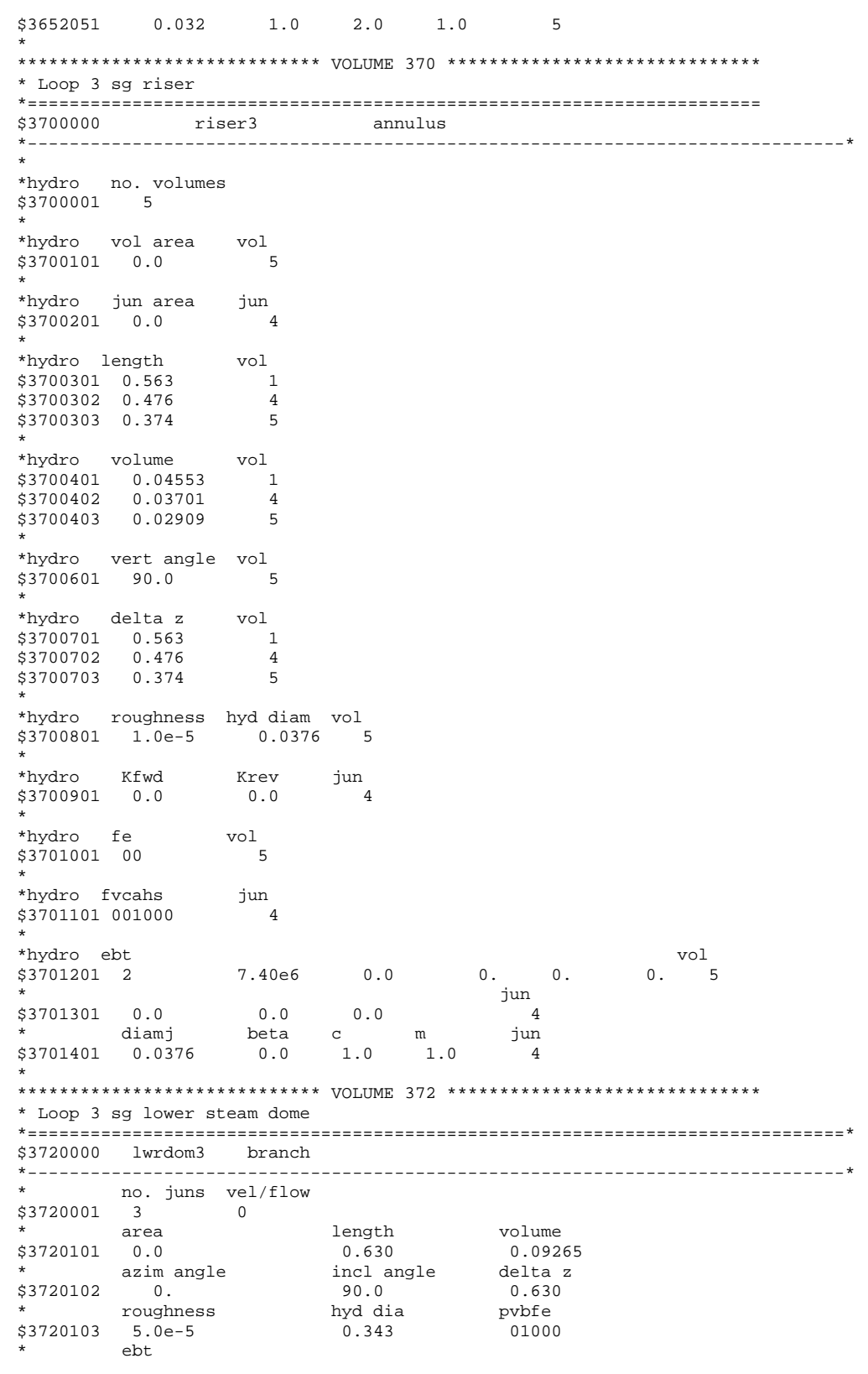




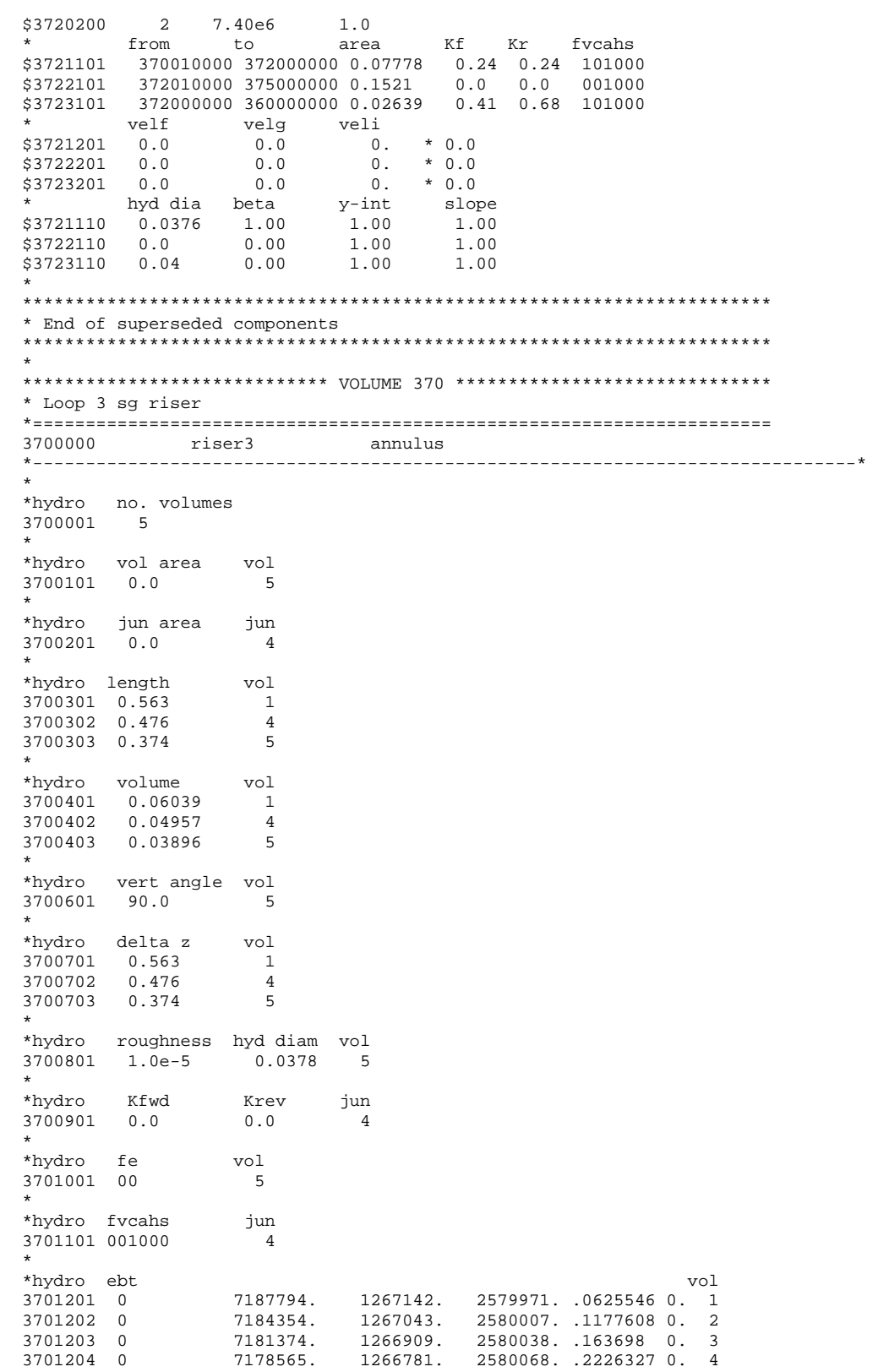

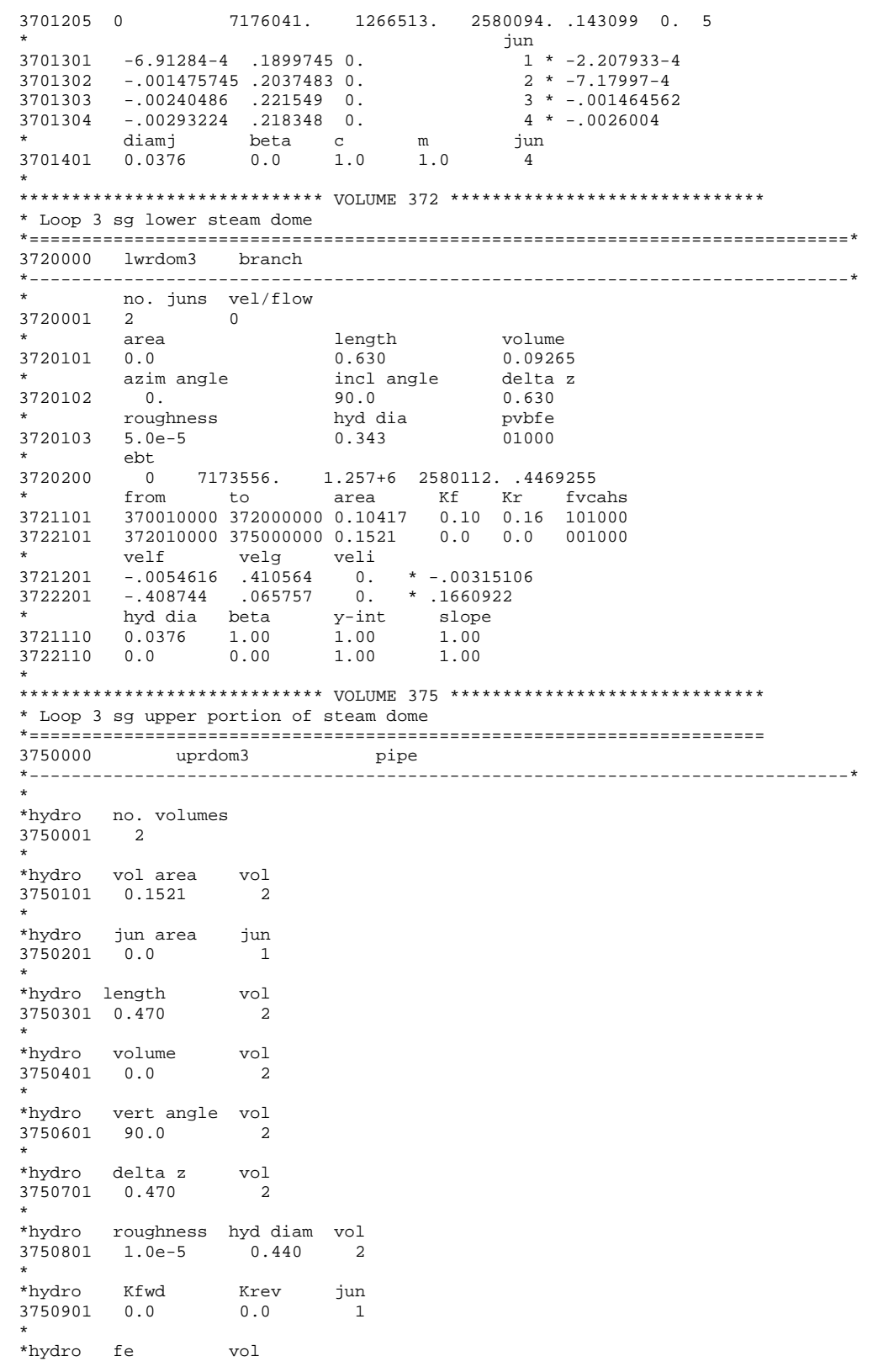




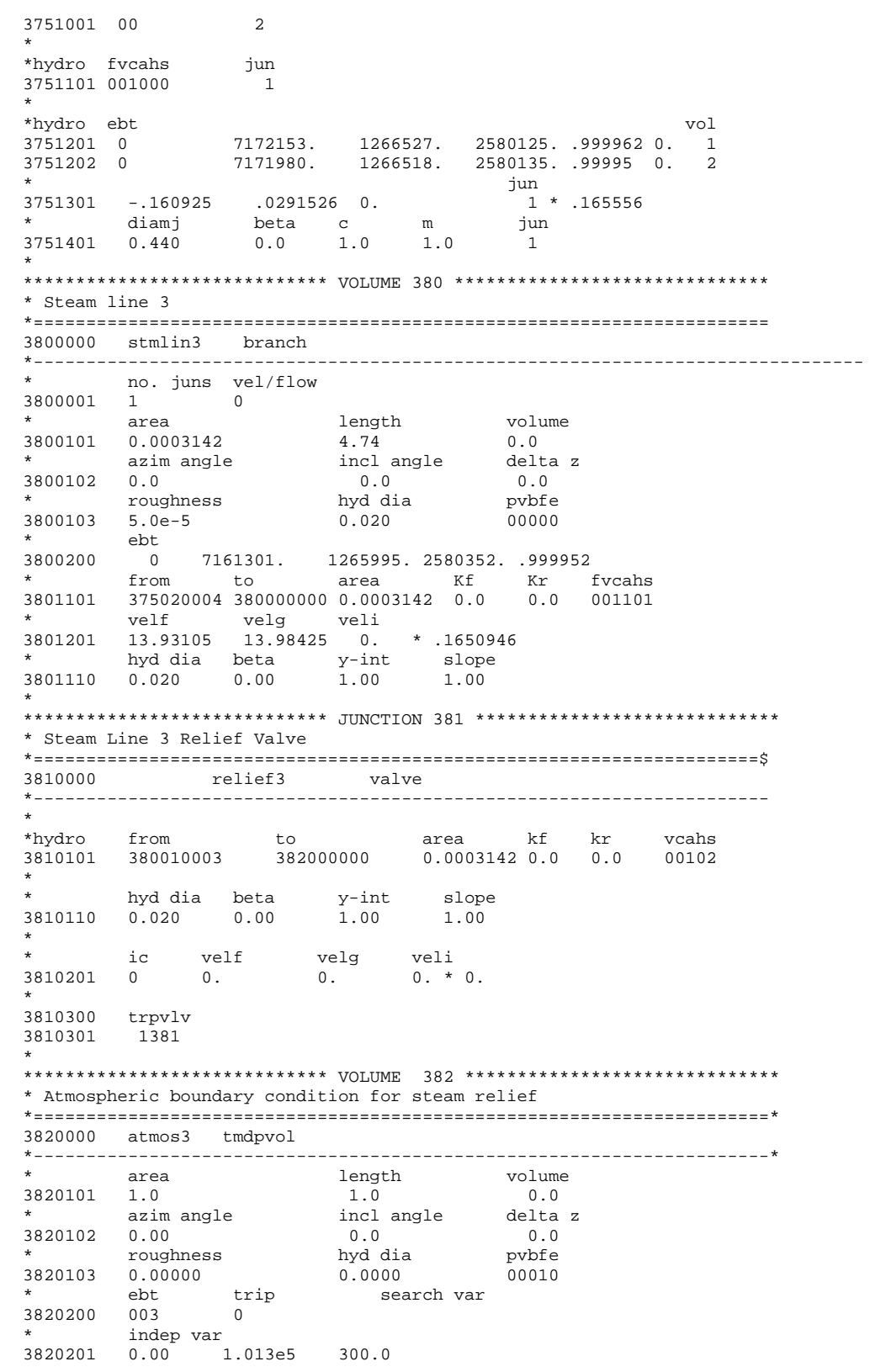

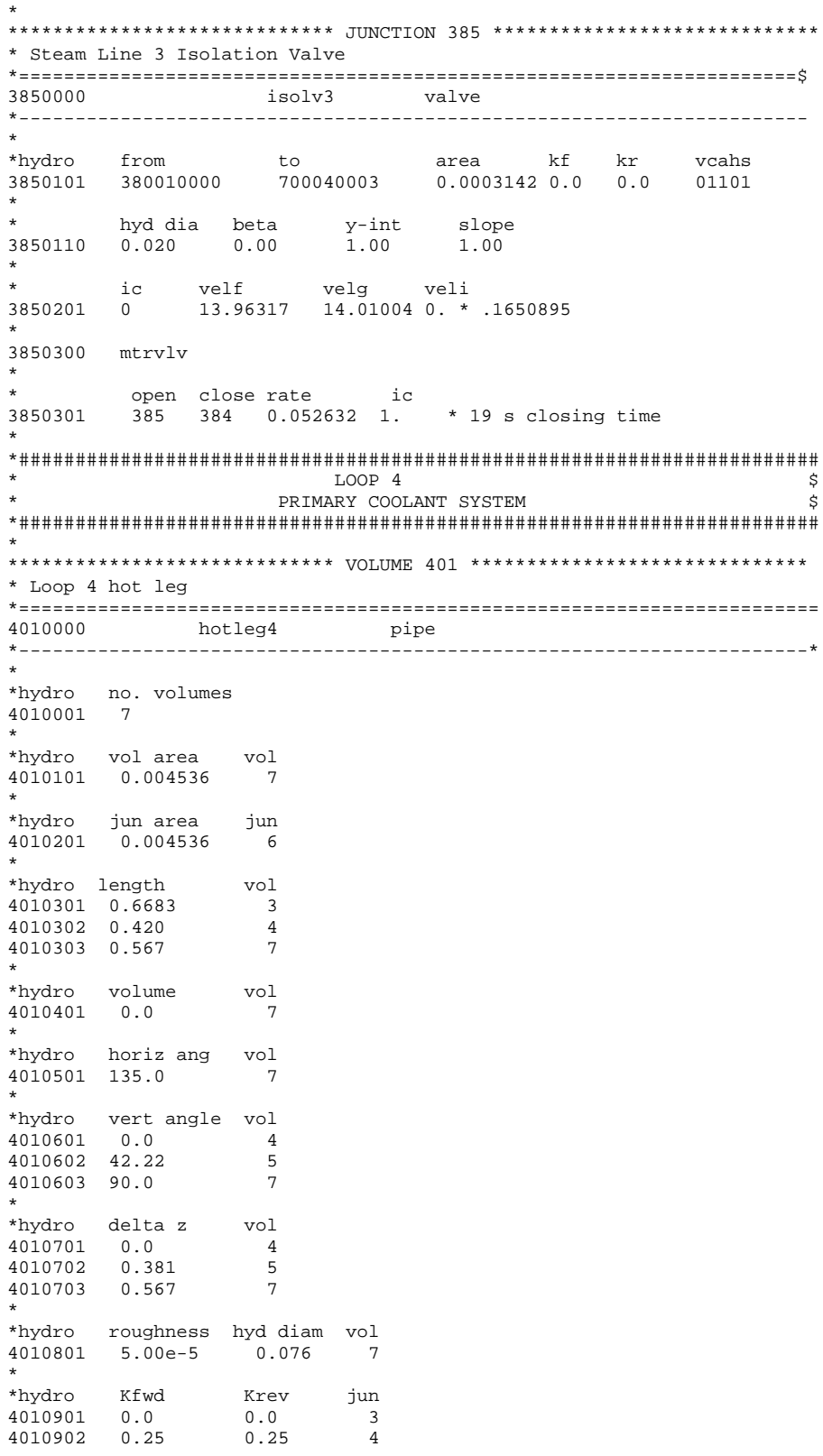




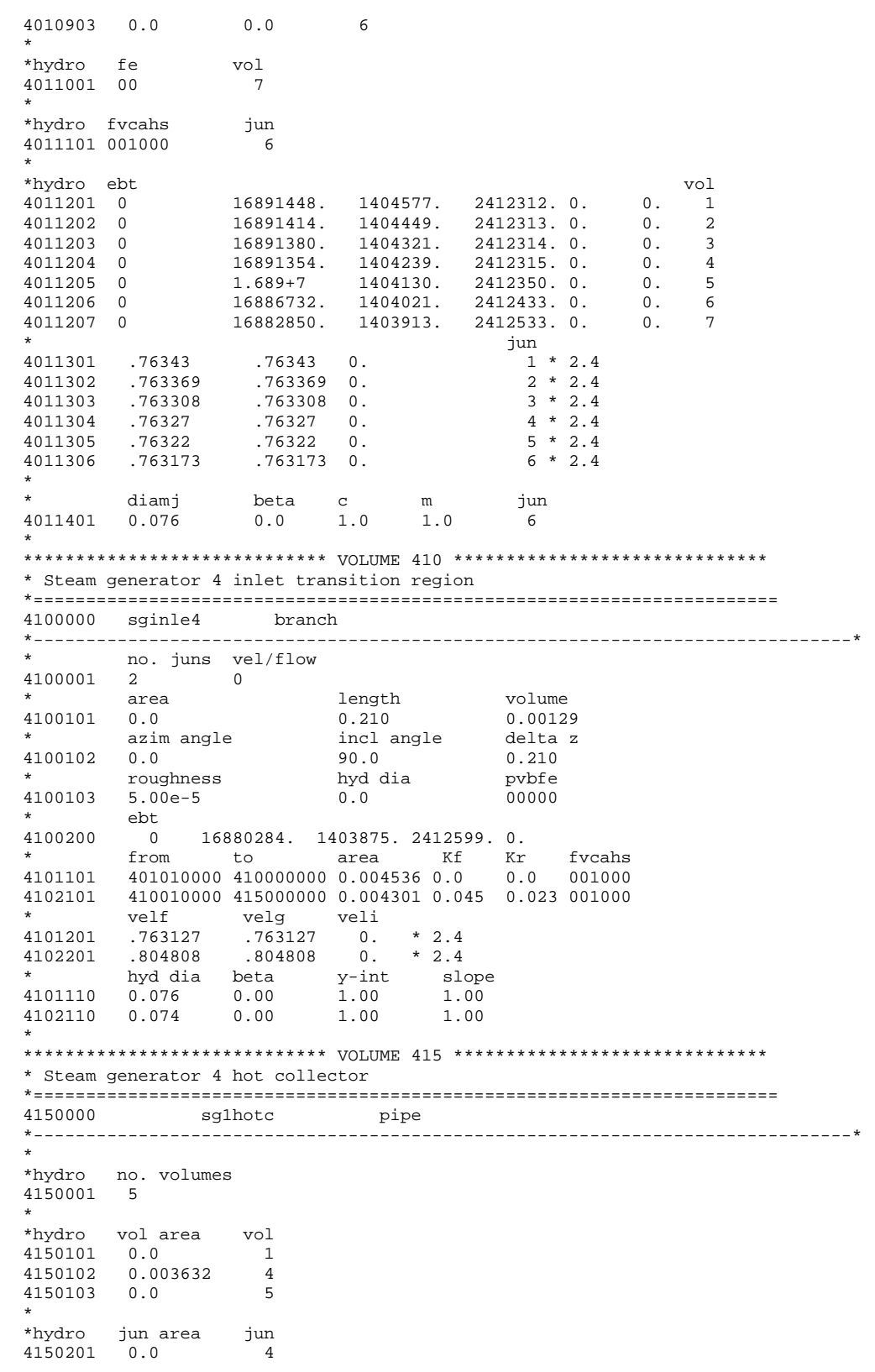

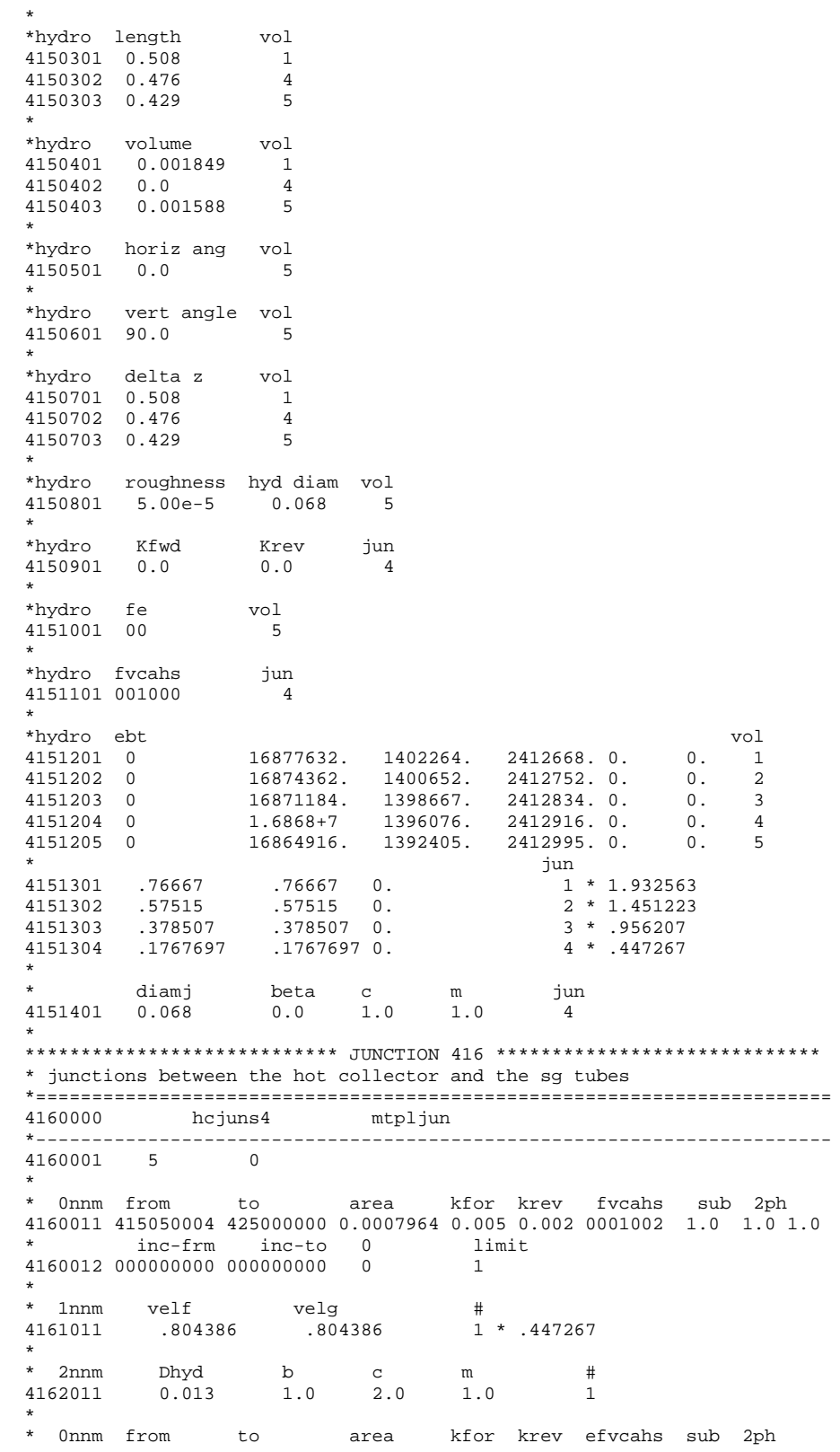




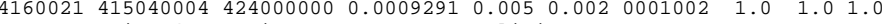

$\begin{array}{lrrrr}* & \text { inc-frm } & \text { inc-to } & 0 & \text { limit } \\ 4160022 & -10000 & -1000000 & 0 & 5\end{array}$

\begin{tabular}{|c|c|c|c|}
\hline * $1 \mathrm{nnm}$ & velf & velg & $\#$ \\
\hline 416102 & .786303 & .786303 & $2 * .508939$ \\
\hline 610 & .765993 & .765993 & $3 * .495016$ \\
\hline 10 & .74573 & .74573 & .48134 \\
\hline 1051 & .724905 & .724905 & .467437 \\
\hline & & c & $\mathrm{m}$ \\
\hline 021 & 0.013 & 2.0 & 1.0 \\
\hline
\end{tabular}

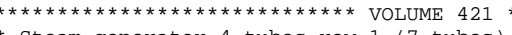

* Steam generator 4 tubes row 1 (7 tubes)

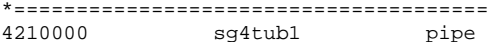

*hydro no. volumes

$4210001 \quad 10$

*hydro vol area vol

$\begin{array}{llr}* \text { hydro } & \text { jun area } & \text { jun } \\ 4210201 & 0.0 & 9\end{array}$

*hydro length vol

*

$\begin{array}{llr}* \text { hydro } & \text { volume } & \text { vol } \\ 4210401 & 0.0 & 10\end{array}$

$\begin{array}{llr}4210501 & \text { horiz } \\ 0.0 & \text { ang } & \text { vol } \\ * & & \end{array}$

*hydro vert angle vol

$\begin{array}{lll}4210601 & 0.0 & 1\end{array}$

$\begin{array}{llr}4210602 & -0.343 & 9 \\ 4210603 & 0.0 & 10\end{array}$

$\begin{array}{llr}* \text { hydro } & \text { delta } & \text { vol } \\ 4210701 & 0.0 & 1 \\ 4210702 & -0.006375 & 9\end{array}$

$\begin{array}{rrr}4210702 & -0.006375 & 9 \\ 4210703 & 0.0 & 10\end{array}$

$\begin{array}{lccc}\text { * } & & & \\ \text { *hydro } & \text { roughness } & \text { hyd diam } & \text { vol } \\ 4210801 & 5.000-5 & 0.013 & 10\end{array}$

$\begin{array}{llll}4210801 & 5.00 e^{-5} & 0.013 & 10\end{array}$

$\begin{array}{lllr}\text { *hydro } & \text { Kfwd } & \text { Krev } & \text { jun } \\ 4210901 & 0.047 & 0.047 & 9\end{array}$

*hydro fe vol

*

$\begin{array}{llr}* \text { hydro } & \text { fvcahs } & \text { jun } \\ 4211101 & 001000 & 9\end{array}$

$\begin{array}{llllllll}* & & & & & \\ \text { *hydro } & \text { ebt } & & & & & \\ 421201 & 0 & 16877222 . & 1347809 . & 2412678 . & 0 . & 0 . & 1 \\ 4211202 & 0 & 16876812 . & 1313410 . & 2412689 . & 0 . & 0 . & 2 \\ 4211203 & 0 & 16876432 . & 1291490 . & 2412699 . & 0 . & 0 . & 3 \\ 421204 & 0 & 16876054 . & 1277512 . & 2412708 . & 0 . & 0 . & 4 \\ 4211205 & 0 & 16875680 . & 1268484 . & 2412718 . & 0 . & 0 . & 5 \\ 4211206 & 0 & 16875306 . & 1262573 . & 2412728 . & 0 . & 0 . & 6 \\ 421207 & 0 & 16874934 . & 125862 . & 2412737 . & 0 . & 0 . & 7 \\ 4211208 & 0 & 16874562 . & 1255986 . & 2412747 . & 0 . & 0 . & 8\end{array}$

\begin{tabular}{|c|c|c|c|c|c|c|c|}
\hline \multirow{2}{*}{$\begin{array}{l}4211209 \\
4211210 \\
\star\end{array}$} & \multirow{2}{*}{$\begin{array}{l}0 \\
0 \\
0\end{array}$} & 16874192 . & \multicolumn{2}{|c|}{1254159 . } & \multicolumn{2}{|c|}{$2412756 \cdot 0$} & \\
\hline & & 16873798. & & & $\begin{array}{c}2412766 . \\
\text { jun }\end{array}$ & 0 & 0. \\
\hline 4211301 & .702594 & .702594 & 0. & & $1 *$ & .467437 & \\
\hline 4211302 & .689715 & .689715 & 0. & & & .467437 & \\
\hline 4211303 & .682072 & .682072 & 0. & & $3 *$ & .467437 & \\
\hline 4211304 & .67729 & .67729 & 0. & & $4 *$ & .467437 & \\
\hline 4211305 & .674297 & .674297 & 0. & & $5 *$ & .467437 & \\
\hline 4211306 & .672374 & .672374 & 0. & & & .467437 & \\
\hline 4211307 & .671113 & .671113 & 0. & & & .467437 & \\
\hline 4211308 & .670267 & .670267 & 0. & & & .467437 & \\
\hline 4211309 & .66969 & .66969 & 0. & & 9 * & .467437 & \\
\hline${ }^{*}$ & & beta & & & & & \\
\hline 4211401 & 0.013 & 0.0 & 1.0 & 1.0 & 9 & & \\
\hline
\end{tabular}

* Steam generator 4 tubes row 2 (7 tubes) 422

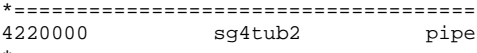

$\begin{array}{lll}* \text { hydro } & \text { no. volumes } \\ 4220001 & 10\end{array}$

4.

$\begin{array}{llr}* \text { hydro } & \text { vol area } & \text { vol } \\ 4220101 & 0.0009291 & 10\end{array}$

$\begin{array}{llr}* \text { hydro } & \text { jun area } & \text { jun } \\ 4220201 & 0.0 & 9\end{array}$

*

$\begin{array}{lcr}* \text { *hydro } & \text { length } & \text { vol } \\ 4220301 & 1.0656 & 10\end{array}$

* ${ }^{*}$ hydro volume vol

$*$ *

$\begin{array}{lcr}* \text { hydro } & \text { horiz ang } & \text { vol } \\ 4220501 & 0.0 & 10\end{array}$

* *hydro vert angle vol

$\begin{array}{ccc}4220601 & 0.0 & 1 \\ 4220602 & -0.343 & 9\end{array}$

$\begin{array}{lll}4220602 & -0.343 & 10 \\ 4220603 & 0.0 & 10\end{array}$

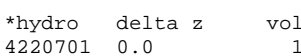

$\begin{array}{rrr}4220701 & 0.0 & 1 \\ 4220702 & -0.006375 & 9 \\ 4220703 & 0.0 & 10\end{array}$

$\begin{array}{lccc}* \text { thydro } & \text { roughness } & \text { hyd diam } & \text { vol } \\ 4220801 & 5.00 \mathrm{e}-5 & 0.013 & 10\end{array}$

*hydro Kfwd Krev jun

$\begin{array}{llll}* & 220901 & 0.047 & 0.047\end{array}$

$\begin{array}{llr}* \text { *hydro } & \text { fe } & \text { vol } \\ 4221001 & 00 & 10\end{array}$

$\begin{array}{llr}* \text { kydro } & \text { fvcahs } & \text { jun } \\ 4221101 & 001000 & 9\end{array}$

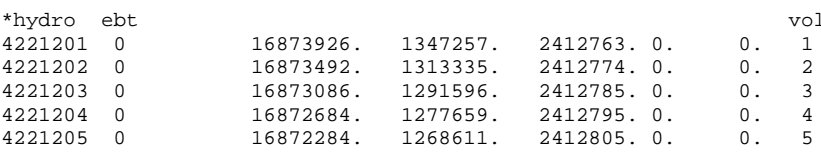




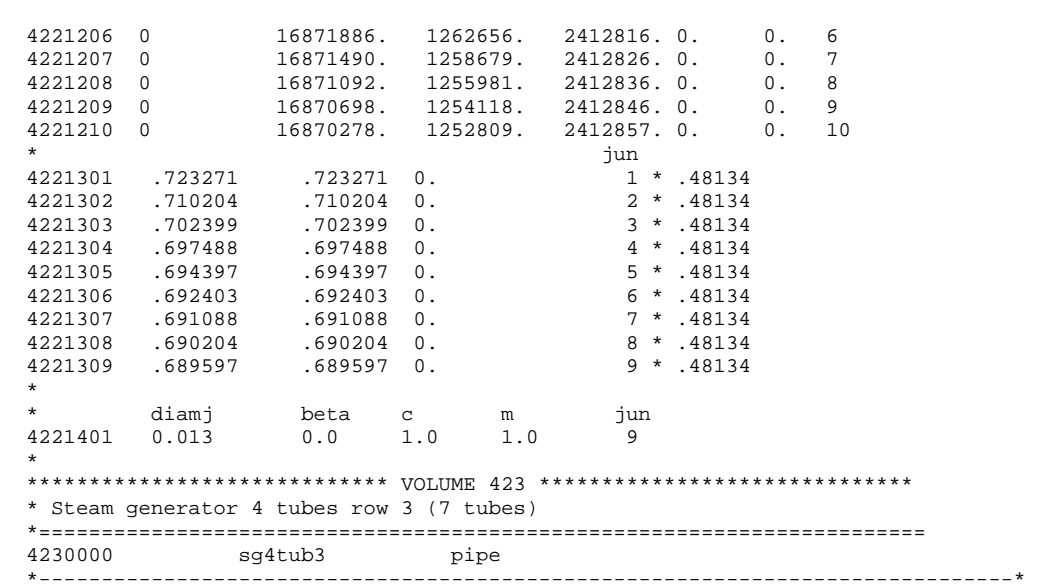

*hydro no. volumes

$4230001 \quad 10$

*hydro vol area vol$$
\begin{array}{llr}
* \text { hydro } & \text { jun area } & \text { jun } \\
4230201 & 0.0 & 9
\end{array}
$$

$\begin{array}{lcr}* \text { hydro } & \text { length } & \text { vol } \\ 4230301 & 1.0656 & 10\end{array}$

*

$\begin{array}{llr}* \text { hydro } & \text { volume } & \text { vol } \\ 4230401 & 0.0 & 10\end{array}$

$\begin{array}{lcr}* \text { hydro } & \text { horiz ang vol } \\ 4230501 & 0.0 & 10\end{array}$

*hydro vert angle vol

$\begin{array}{lll}4230601 & 0.0 & 1 \\ 430602 & -0.343 & 9\end{array}$

$\begin{array}{rrr}4230602 & -0.343 & 9 \\ 4230603 & 0.0 & 10\end{array}$

*hydro delta z vol

$\begin{array}{rrr}4230701 & 0.0 & 1 \\ 4230702 & -0.006375 & 9 \\ 4230703 & 0.0 & 10\end{array}$

* hydro roughness hyd diam vol

$\begin{array}{llll}4230801 & 5.00 \mathrm{e}-5 & 0.013 & 10\end{array}$

$\begin{array}{lllr}* \text { hydro } & \text { Kfwd } & \text { Krev } & \text { jun } \\ 4230901 & 0.047 & 0.047 & 9\end{array}$

$\begin{array}{llr}* \text { hydro } & \text { fe } & \text { vol } \\ 4231001 & 00 & 10\end{array}$

$\begin{array}{llr}* & & \\ * \text { hydro } & \text { fvcahs } & \text { jun } \\ 4231101 & 001000 & 9\end{array}$

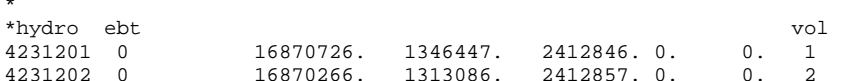

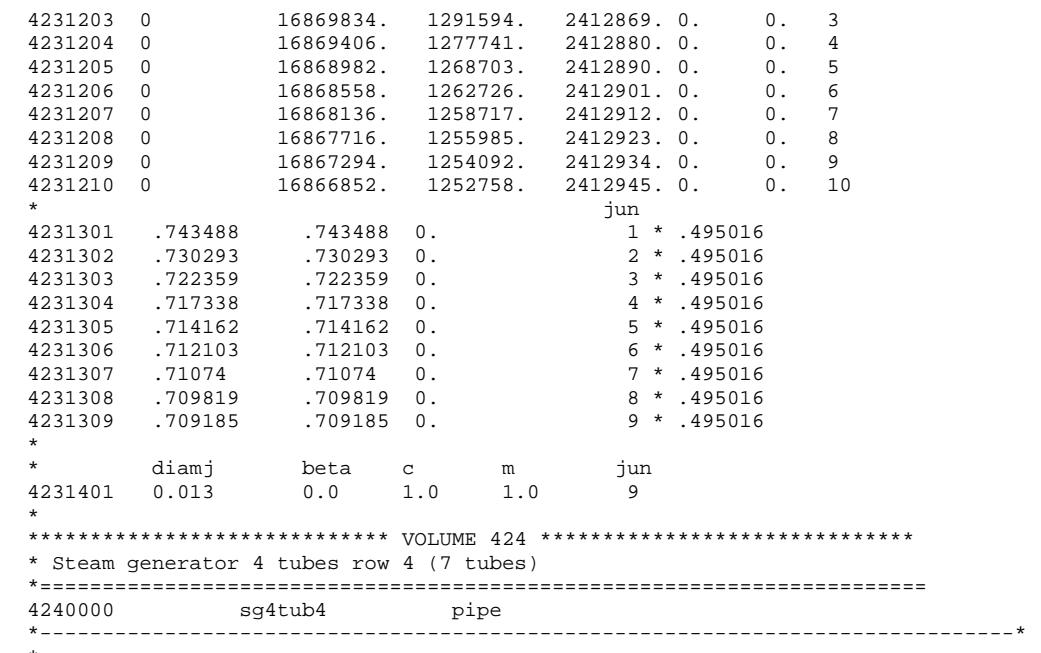

*hydro no. volumes

4240001

thydro vol area vol

$\begin{array}{lll}4240101 & 0.0009291 & 10\end{array}$

$\begin{array}{llr}* \text { hydro } & \text { jun area } & \text { jun } \\ 4240201 & 0.0 & 9\end{array}$

$*$

$\begin{array}{llr}* \text { *hydro } & \text { length } & \text { vol } \\ 4240301 & 1.0656 & 10\end{array}$

$\begin{array}{llr}* \text { hydro } & \text { volume } & \text { vol } \\ 4240401 & 0.0 & 10\end{array}$

$\begin{array}{llr}* & \\ * \text { hydro } & \text { horiz ang } & \text { vol } \\ 4240501 & 0.0 & 10\end{array}$

*hydro vert angle vol

$\begin{array}{ccc}4240601 & 0.0 & 1 \\ 4240602 & -0.343 & 9 \\ & 0.030603 & 0.0\end{array}$

$\begin{array}{llr}4240603 & 0.0 & 10\end{array}$

$\begin{array}{llr}* \text { hydro } & \text { delta z } & \text { vo } \\ 4240701 & 0.0 & \\ 4240702 & -0.006375\end{array}$

$\begin{array}{llr}4240702 & -0.006375 & 9 \\ 4240703 & 0.0 & 10\end{array}$

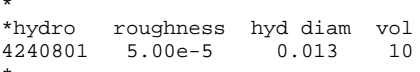

$\begin{array}{lllr}\text { *hydro } & \text { Kfwd } & \text { Krev } & \text { jun } \\ 4240901 & 0.047 & 0.047 & 9\end{array}$

$\begin{array}{llr}* \text { hydro } & \text { fe } & \text { vol } \\ 4241001 & 00 & 10\end{array}$

*hydro fvcahs jun

$4241101001000 \quad 9$ 


\begin{tabular}{|c|c|c|c|c|c|c|}
\hline *hydro & ebt & & & & vo & ol \\
\hline 4241201 & 0 & 16867504 & 1345236 & 2412929. 0 . & 0 . & 1 \\
\hline 4241202 & 0 & $1.6867+7$ & 1312574 . & 2412941. 0 . & & \\
\hline 4241203 & 0 & 16866558 . & 1291422 . & 2412953. 0. & & \\
\hline 4241204 & 0 & 16866104 . & 1277716 . & 2412965. 0. & & \\
\hline 4241205 & 0 & 16865654 . & 1268726 . & 2412976.0. & & \\
\hline 4241206 & 0 & 16865204 . & 1262754 . & 2412988. 0. & & \\
\hline 4241207 & 0 & 16864756 . & 1258729 . & $2.413+6 \quad 0$. & 0. & \\
\hline 4241208 & 0 & 16864308 & 1255975 . & 2413011.0. & 0. & \\
\hline 4241209 & 0 & 16863862 . & 1254059 . & 2413022.0. & 0 . & \\
\hline $\begin{array}{l}4241210 \\
\star\end{array}$ & 0 & 16863392. & 1252705 . & $\begin{array}{c}2413034.0 . \\
\text { jun }\end{array}$ & 0 . & 10 \\
\hline 4241301 & .763887 & .763887 & 0. & $1 * .508939$ & & \\
\hline 4241302 & .750639 & .750639 & 0. & $2 * .508939$ & & \\
\hline 4241303 & .742614 & .742614 & 0. & $3 * .508939$ & & \\
\hline 4241304 & .737508 & .737508 & 0. & $4 * .508939$ & & \\
\hline 4241305 & .73426 & .73426 & 0. & $5 * .508939$ & & \\
\hline 4241306 & .732145 & .732145 & 0. & $6 * .508939$ & & \\
\hline 4241307 & $\begin{array}{l}.730738 \\
.730738\end{array}$ & .730738 & 0. & $7 * .508939$ & & \\
\hline 4241308 & $\begin{array}{l}.750783 \\
.729783\end{array}$ & $\begin{array}{l}.729783 \\
.72978\end{array}$ & 0. & $8 * .508939$ & & \\
\hline 4241309 & .729123 & .729123 & 0 . & $9 * .508939$ & & \\
\hline & & & & jun & & \\
\hline 4241401 & 0.013 & 0.0 & 1.0 & 9 & & \\
\hline \multicolumn{7}{|c|}{ 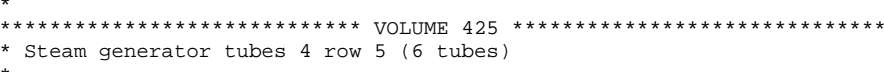 } \\
\hline $\begin{array}{l}*====== \\
4250000\end{array}$ & & $\begin{array}{l}==========- \\
y 4 \text { tub5 }\end{array}$ & $\begin{array}{c}========== \\
\text { pipe }\end{array}$ & & & \\
\hline
\end{tabular}

*hydro no. volumes

$$
4250001 \quad 10
$$

*hydro vol area vol

$\begin{array}{ccc}* \text { hydro } & \text { jun area } & \text { jun } \\ 4250201 & 0.0 & 9\end{array}$

$\begin{array}{lcr}* & & \\ * \text { hydro } & \text { length } & \text { vol } \\ 4250301 & 1.0656 & 10\end{array}$

* $2503011.0656 \quad 10$

$\begin{array}{lcr}* \text { hydro } & \text { volume } & \text { vol } \\ 4250401 & 0.0 & 10\end{array}$

*hydro horiz ang vol

$\begin{array}{lll}4250501 & 0.0 & 10\end{array}$

*hydro vert angle vol

$\begin{array}{ccr}4250601 & 0.0 & 1 \\ 4250602 & -0.343 & 9 \\ 4250603 & 0.0 & 10\end{array}$

*hydro delta z vol

$\begin{array}{ll}4250702 & -0.006375 \\ 4250703 & 0.0\end{array}$

$\begin{array}{cccc}\text { *hydro } & \text { roughness } & \text { hyd diam } & \text { vol } \\ 4250801 & 5.00 \mathrm{e}-5 & 0.013 & 10\end{array}$

$*$

$\begin{array}{lllr}\text { *hydro } & \text { Kfwd } & \text { Krev } & \text { jun } \\ 4250901 & 0.047 & 0.047 & 9\end{array}$

$\begin{array}{llr}* \text { hydro } & \text { fe } & \text { vol } \\ 4251001 & 00 & 10\end{array}$

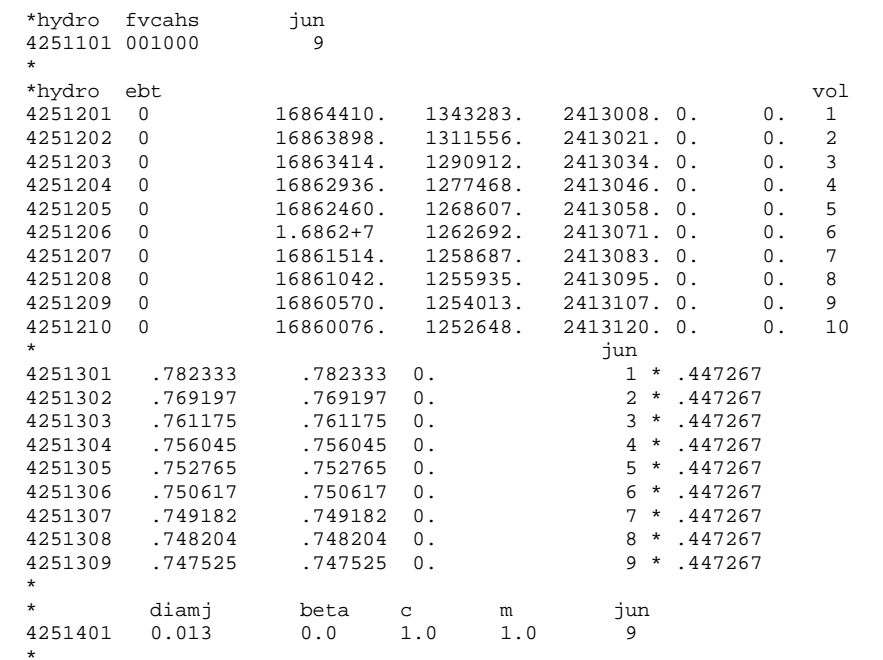

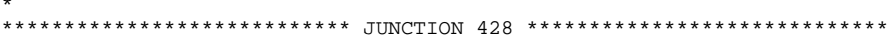

* junctions between the sg tubes and the cold collector

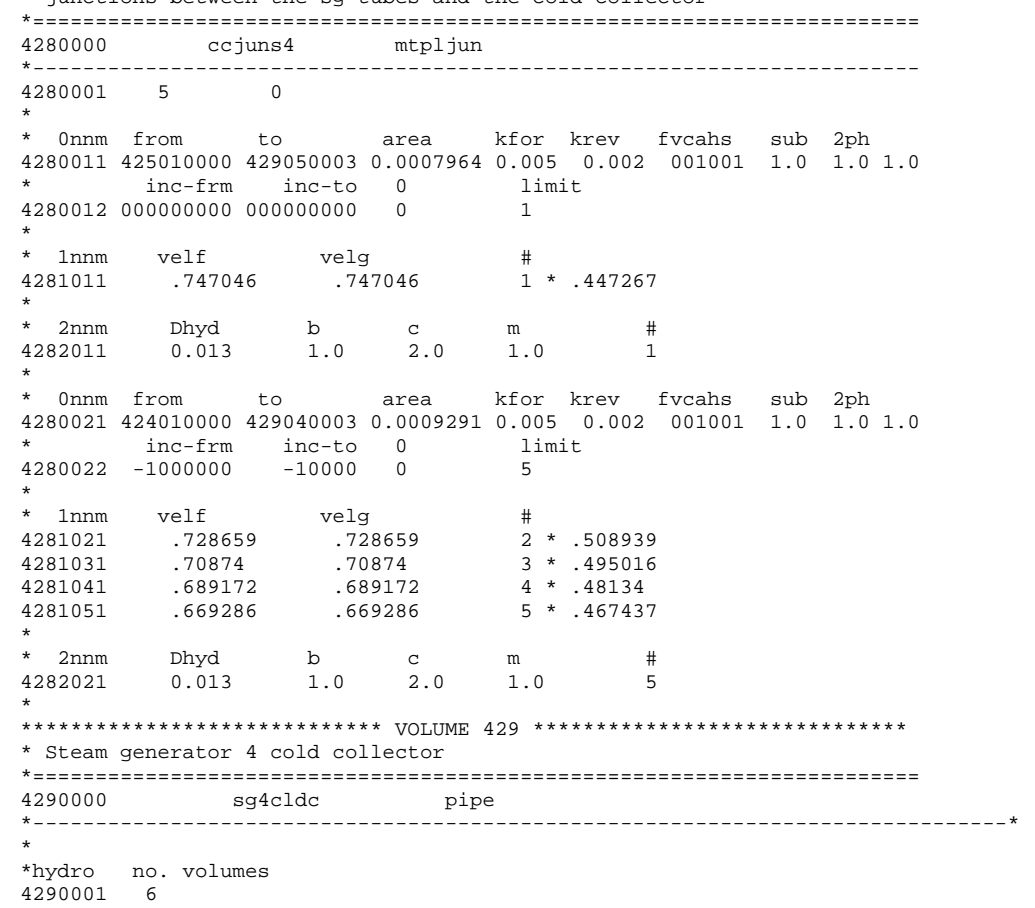




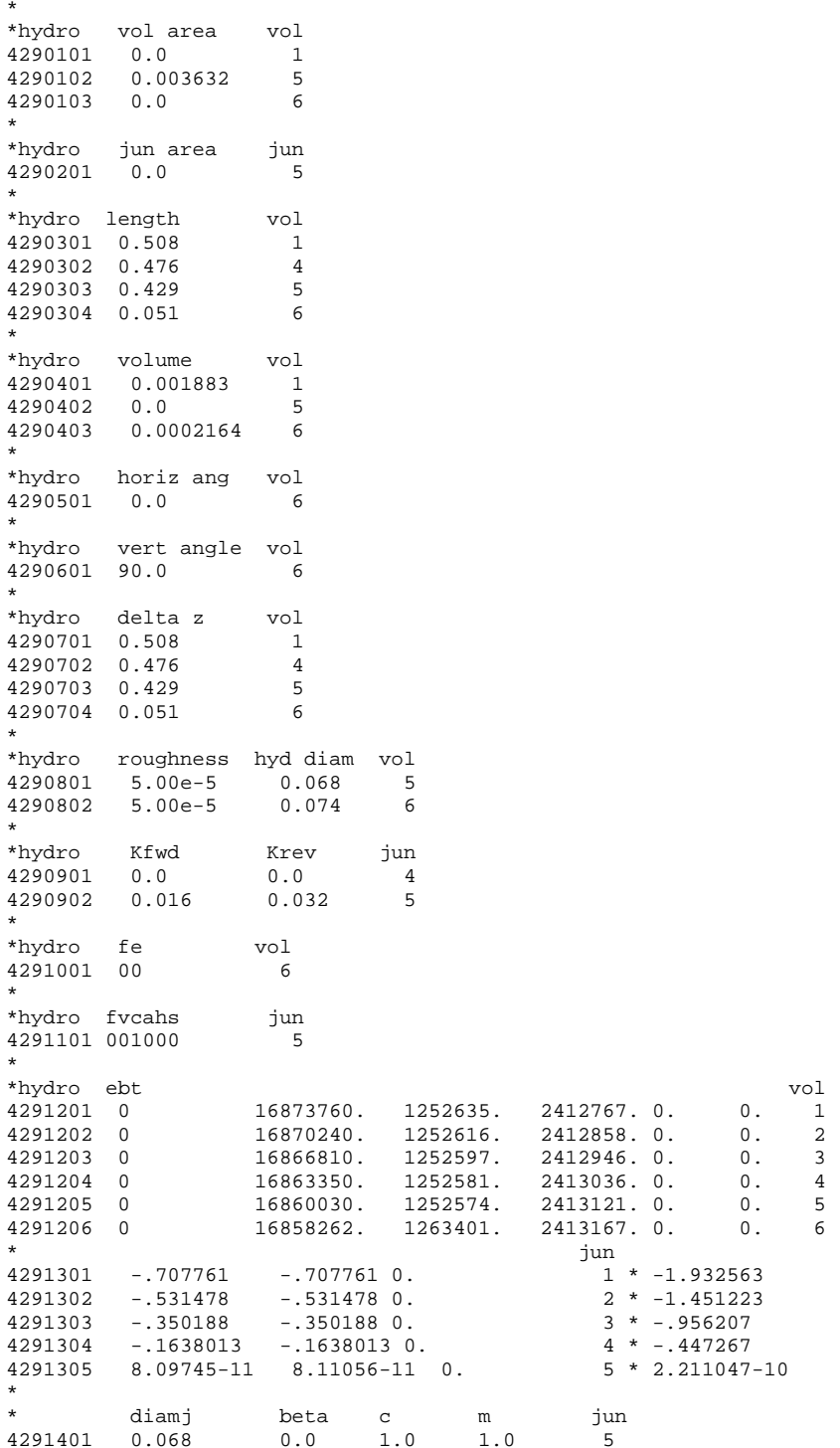

$\begin{array}{lllllc}* & \text { diamj } & \text { beta } & c & m & \text { jun } \\ * 291401 & 0.068 & 0.0 & 1.0 & 1.0 & 5\end{array}$

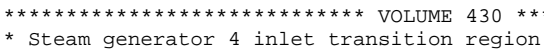

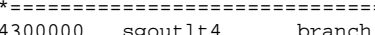

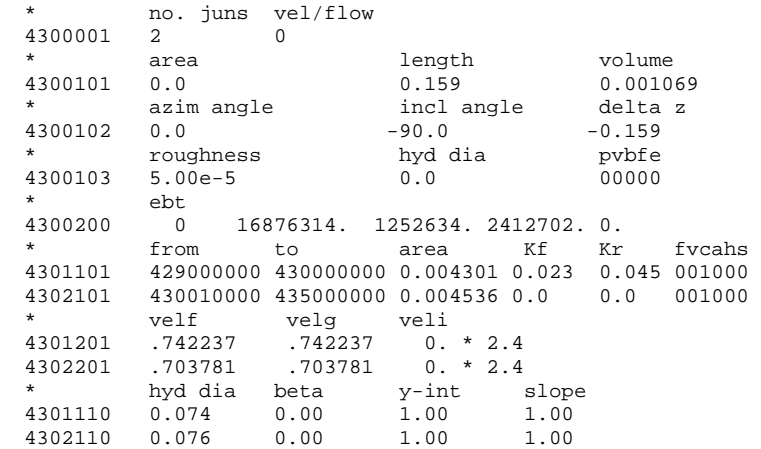

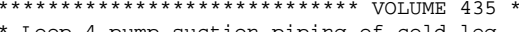

$=================================0$

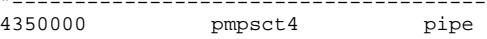

hydro no. volumes

$4350001 \quad 14$

$\begin{array}{ccc}\text { *hydro } & \text { vol area } & \text { vol } \\ 4350101 & 0.004536 & 10\end{array}$

$\begin{array}{lll}4350102 & 0.0 & 11 \\ 4350103 & 0.004536 & 14\end{array}$

*hydro jun area jun

*hydro length

$4350302 \quad 1.042$

$4350303 \quad 1.131$

$\begin{array}{ll}4350304 & 0.7495 \\ 4350305 & 0.74775\end{array}$

thydro volume vol

$\begin{array}{lll}4350401 & 0.0 & 10 \\ 4350402 & 0.006908 & 11\end{array}$

$\begin{array}{lll}350403 & 0.0 & 14\end{array}$

*hydro horiz ang vol

$\begin{array}{rrr}4350501 & 90.0 & 8 \\ 4350502 & 185.0 & 14\end{array}$

*hydro vert angle vol

$\begin{array}{rrr}4350601 & -90.0 & 8 \\ 4350602 & 0.0 & 10 \\ 4350603 & 90.0 & 14\end{array}$

*hydro delta z

$4350701-0.828$

$4350703-0.945$

$4350704 \quad 0.0$

$\begin{array}{ll}350705 & 0.65175\end{array}$

$\begin{array}{lll}4350706 & 0.74775\end{array}$

thydro roughness hyd diam vol 


\begin{tabular}{|c|c|c|c|c|c|c|}
\hline *hydro & Kfwd & Krev & jun & & & \\
\hline 4350901 & 0.0 & 0.0 & 4 & & & \\
\hline 4350902 & 0.13 & 0.13 & 5 & & & \\
\hline 4350903 & 0.0 & 0.0 & 6 & & & \\
\hline 4350904 & 0.13 & 0.13 & 7 & & & \\
\hline 4350905 & 0.25 & 0.25 & 8 & & & \\
\hline 4350906 & 0.0 & 0.0 & 9 & & & \\
\hline 4350907 & 0.25 & 0.25 & 10 & & & \\
\hline 4350908 & 0.0 & 0.0 & 13 & & & \\
\hline ^hydro & $\mathrm{fe}$ & vol & & & & \\
\hline 4351001 & 00 & 14 & & & & \\
\hline *hydro & fvcahs & jun & & & & \\
\hline $\begin{array}{l}4351101 \\
*\end{array}$ & 001000 & 13 & & & & \\
\hline *hydro & ebt & & & & vol & \\
\hline 4351201 & 0 & 16879832 & 1252492 . & 2412611. 0 . & & \\
\hline 4351202 & 0 & 16885898 . & 1252351. & 2412455.0 . & 0 . & 2 \\
\hline 4351203 & 0 & 16891966 . & 1252209. & 2412299.0. & 0. & 3 \\
\hline 4351204 & 0 & 16898034 . & 1252068 . & 2412143.0. & 0. & 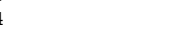 \\
\hline 4351205 & 0 & 16904102 . & 1251926. & 2411987. 0. & 0 . & \\
\hline 4351206 & 0 & 16909828 . & 1251748 . & 2411840.0. & 0. & 5 \\
\hline 4351207 & 0 & 16915256 . & 1251570 . & 2411697. 0. & 0. & \\
\hline 4351208 & 0 & 16921406 . & 1251377. & 2411514.0. & 0. & B \\
\hline 4351209 & 0 & 16924802 . & 1251249 . & 2411414.0. & 0. & 9 \\
\hline 4351210 & 0 & 16924768 . & 1251121. & 2411415.0. & 0. & 10 \\
\hline 4351211 & 0 & 16922436 . & 1250925 . & 2411484.0. & 0. & 1 \\
\hline 4351212 & 0 & 16917110. & 1250797. & 2411642.0. & 0. & 2 \\
\hline 4351213 & 0 & 16911558. & 1250670 . & 2411795.0. & 0. & 3 \\
\hline 4351214 & 0 & $1.6906+7$ & 1250542 . & 2411938.0. & 0. & 4 \\
\hline 4351301 & .703731 & .703731 & 0. & $1 * 2.4$ & & \\
\hline 4351302 & .703679 & .703679 & 0. & $2 * 2.4$ & & \\
\hline 4351303 & .703627 & .703627 & 0. & $3 * 2.4$ & & \\
\hline 4351304 & .703575 & .703575 & 0. & $4 * 2.4$ & & \\
\hline 4351305 & .703523 & .703523 & 0. & & & \\
\hline 4351306 & .703459 & .703459 & 0. & $6 * 2.4$ & & \\
\hline 4351307 & .703395 & .703395 & 0. & $7 * 2.4$ & & \\
\hline 4351308 & .703326 & .703326 & 0. & $8 * 2.4$ & & \\
\hline 4351309 & .703281 & .703281 & 0. & $9 * 2.4$ & & \\
\hline 4351310 & $\begin{array}{l}.703239 \\
.703239\end{array}$ & .703239 & 0. & $10 * 2.4$ & & \\
\hline $\begin{array}{l}4351311 \\
4351310\end{array}$ & .703176 & .703176 & 0. & $11 * 2.4$ & & \\
\hline 4351312 & $\begin{array}{r}.703139 \\
.703139\end{array}$ & .703139 & 0. & $12 * 2.4$ & & \\
\hline 4351313 & .703102 & .703102 & 0. & $13 * 2.4$ & & \\
\hline * & & & & & & \\
\hline 4351401 & $\begin{array}{l}\text { diamj } \\
0.076\end{array}$ & $\begin{array}{l}\text { beta } \\
0.0\end{array}$ & $\begin{array}{l}c \\
1.0\end{array}$ & $\begin{array}{l}\text { Jun } \\
13\end{array}$ & & \\
\hline \multicolumn{7}{|c|}{ 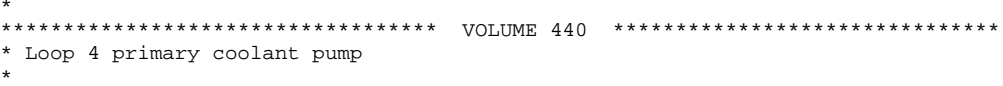 } \\
\hline 4400000 & mсp4 & pump & & & & \\
\hline * & area & & lenath & volume & & \\
\hline 4400101 & 0.0 & & 0.746 & 0.010 & & \\
\hline & azim angle & incl & angle & delta $z$ pvbfe & & \\
\hline 4400102 & 0.0 & 30.0 & & $0.370 \quad 00000$ & & \\
\hline & from $\quad j$ & jun area & $\mathrm{Kf}$ & efvcahs & & \\
\hline 4400108 & 4350100000 & 0.004536 & 0.0 & 0001000 & & \\
\hline & & jun area & $\mathrm{Kf}$ & efvcahs & & \\
\hline 4400109 & 4420000000 & 0.004536 & $0.0 \quad 0.0$ & 0001000 & & \\
\hline & hyd dia b & beta & $y$-int & slope & & \\
\hline 4400110 & 0.076 & 0.00 & 1.00 & 1.00 & & \\
\hline 4400111 & 0.076 & 0.00 & 1.00 & 1.00 & & \\
\hline
\end{tabular}

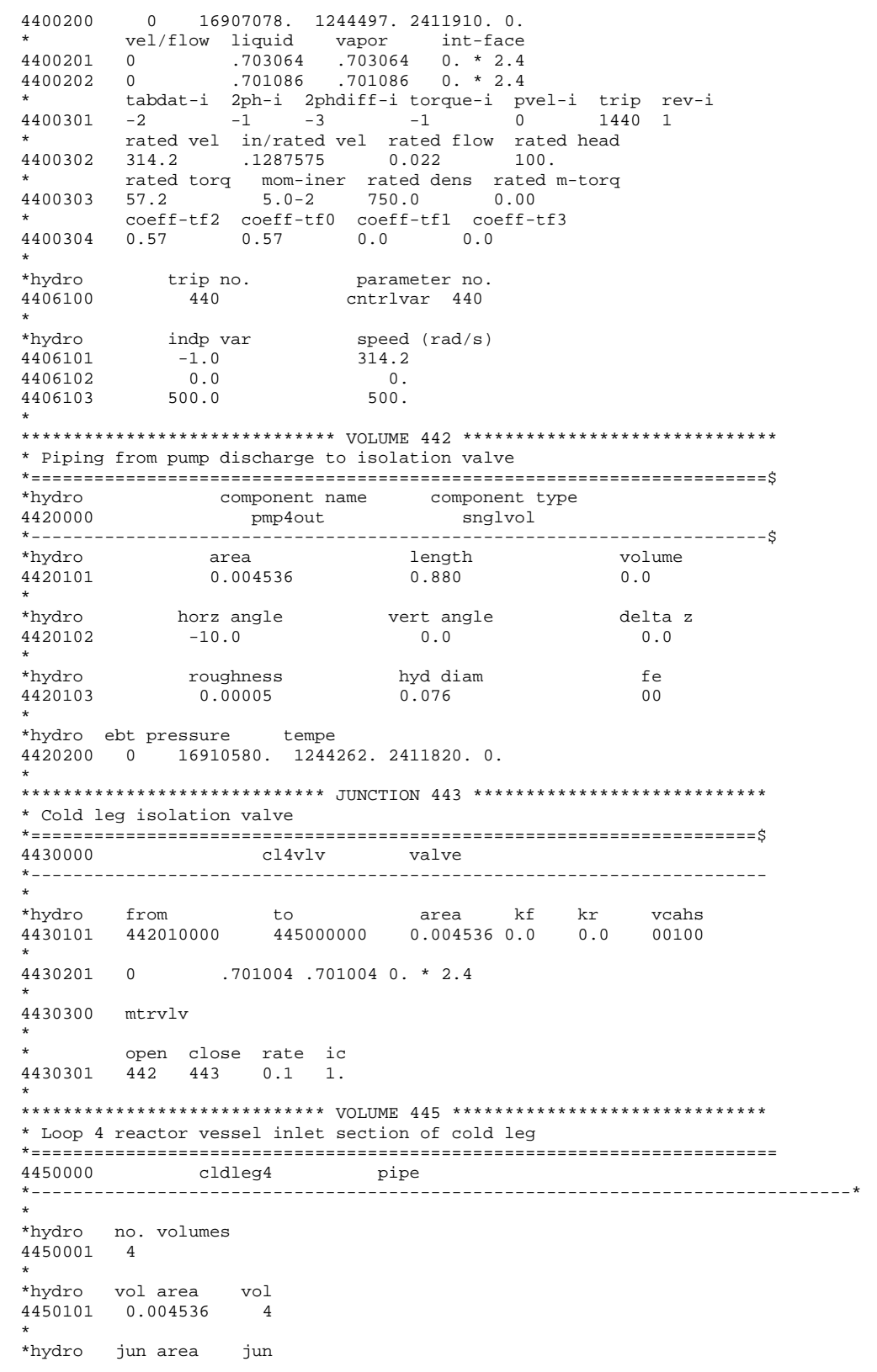




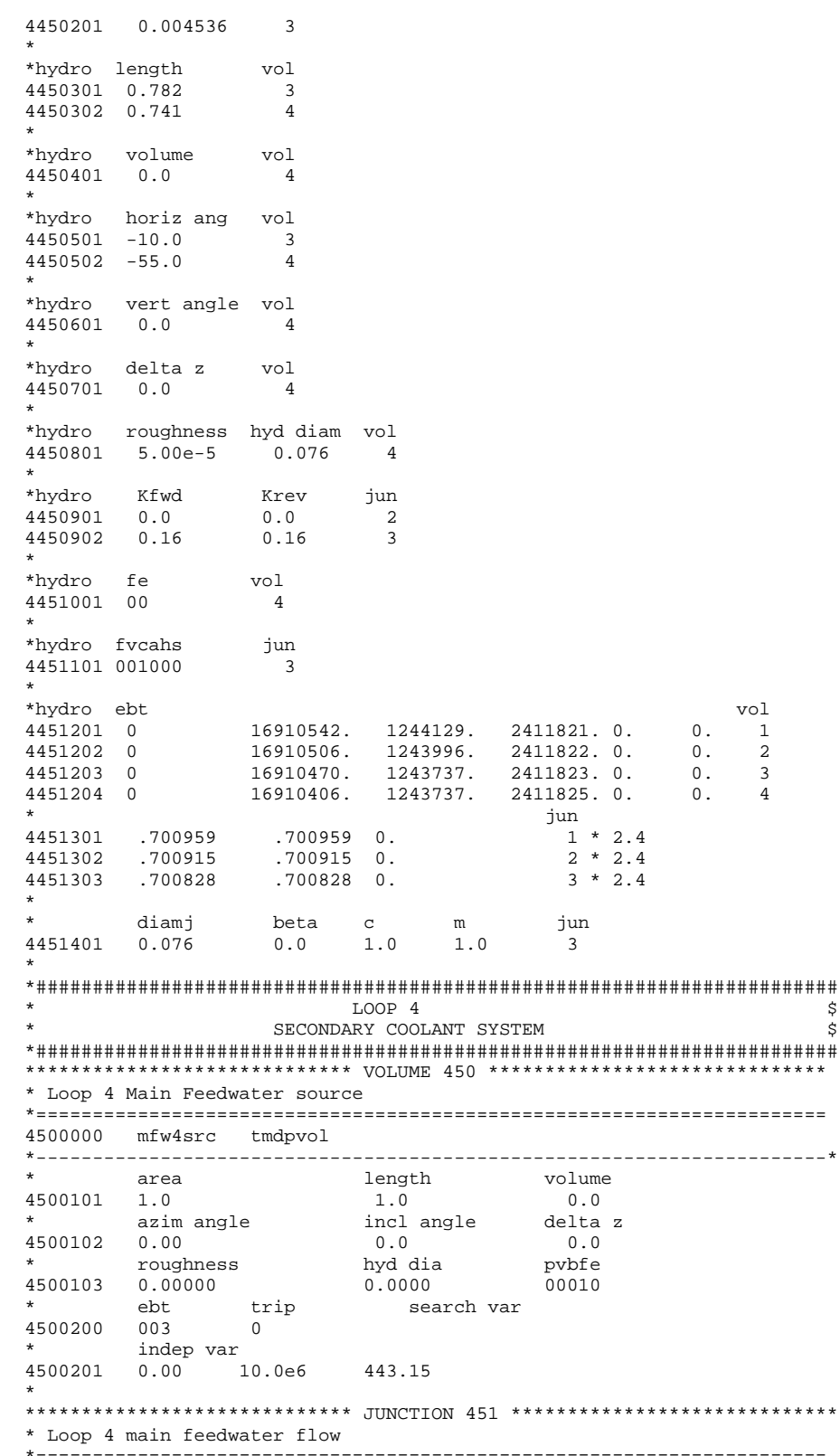

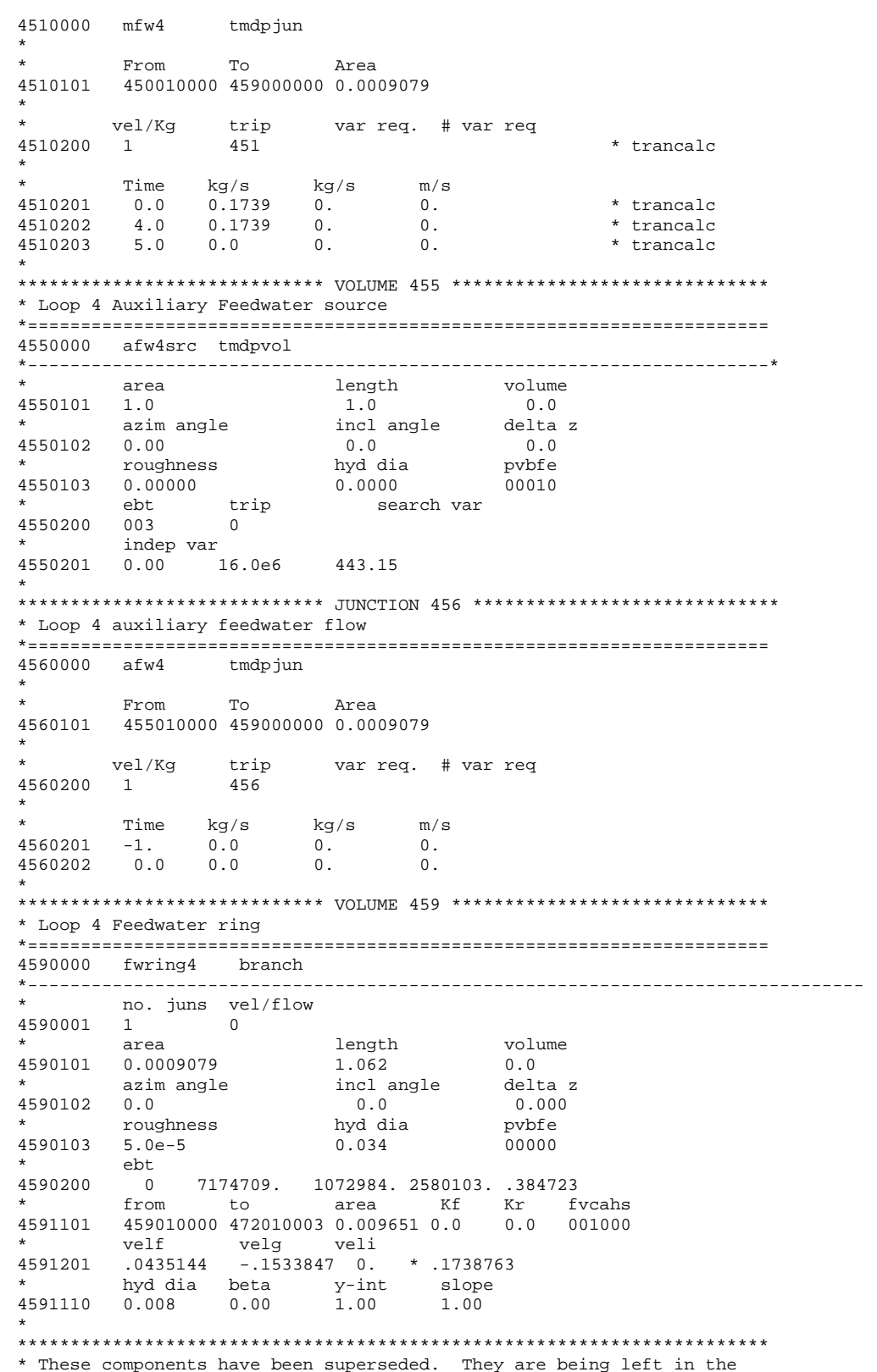


* input deck for possible future use.

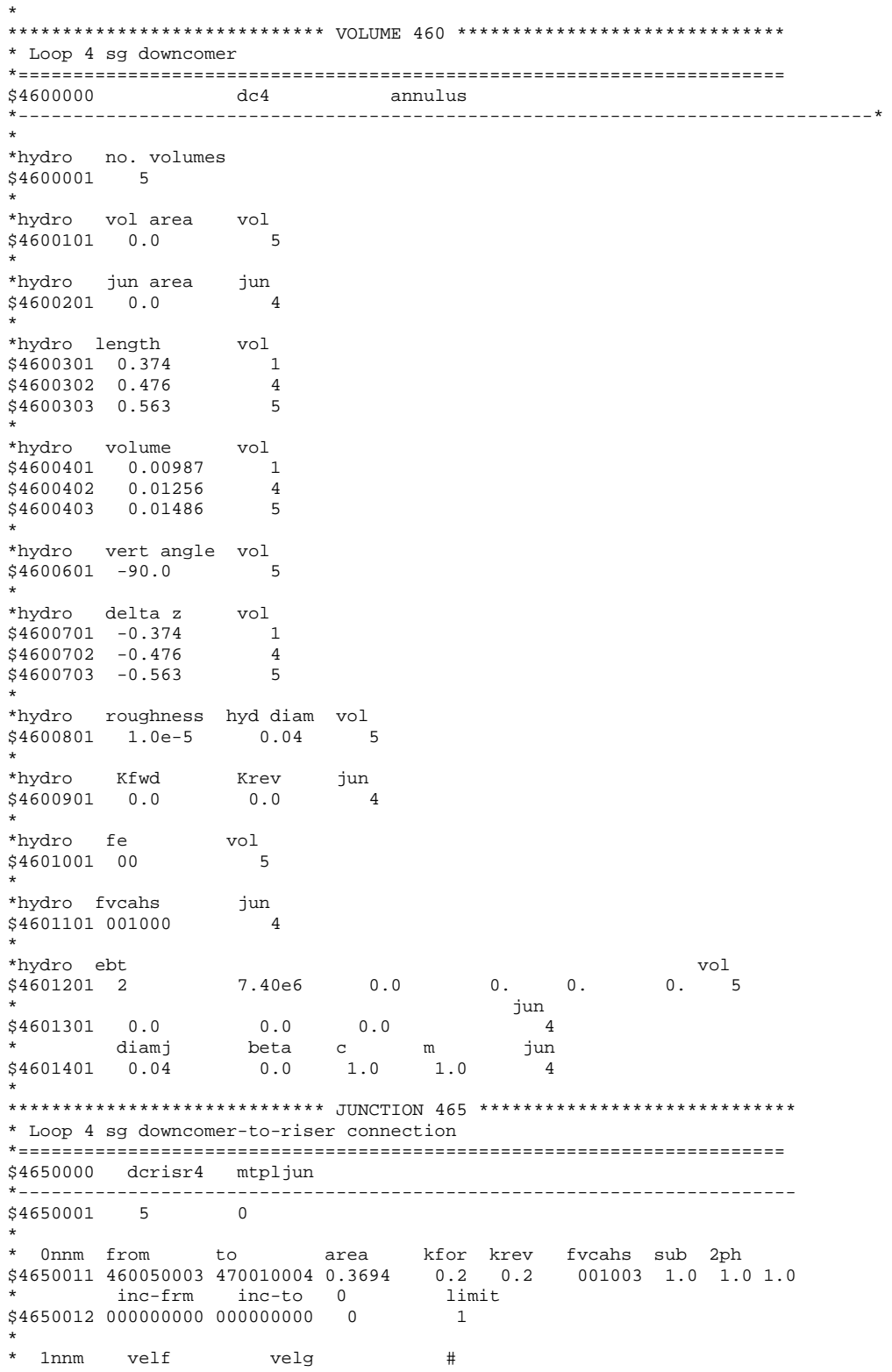

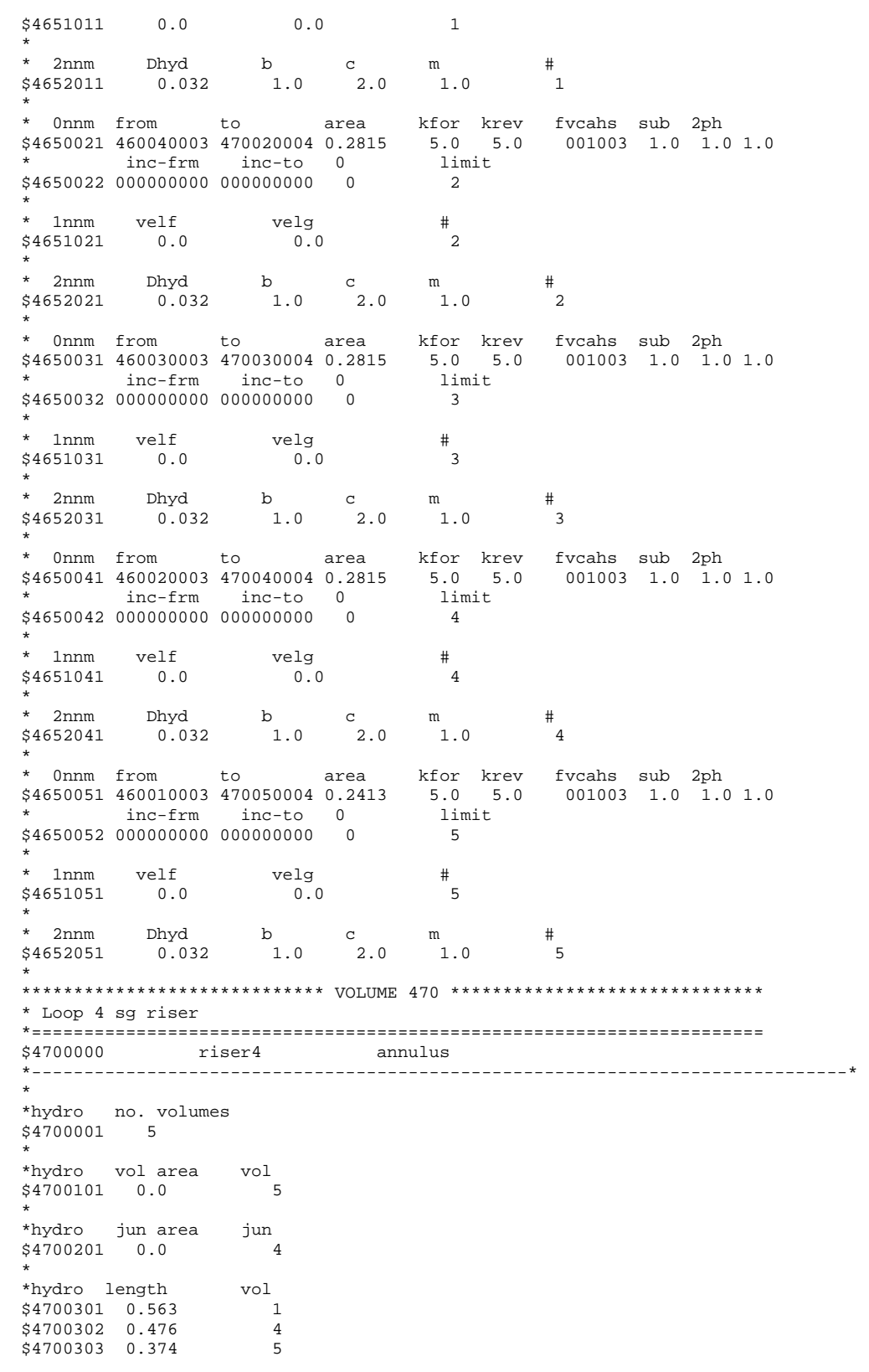


*hydro volume

$\begin{array}{lll}\$ 4700401 & 0.04553 \quad \text { vol } \\ \$ 4700402 & 0.03701\end{array}$

$\$ 4700402 \quad 0.0370$

$\begin{array}{lcr}* \text { kydro vert angle vol } \\ \$ 4700601 & 90.0 & 5\end{array}$

$\$ 4700601-90.0$

*hydro delta $z$ vol

$\begin{array}{lll}\$ 4700702 & 0.563 & 0.476\end{array}$

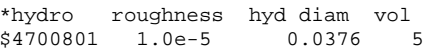

*hydro Kfwd Krev jun

*hydro fe vol

$\$ 470100100 \quad 5$

*hydro fvcahs jun

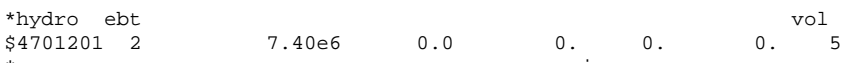

\begin{tabular}{llrcrrr}
$\star$ & & & & \multicolumn{3}{c}{ jun } \\
$\$ 4701301$ & 0.0 & 0.0 & 0.0 & & 4 \\
$\star$ & diamj & beta & $c$ & m & jun \\
$\$ 4701401$ & 0.0376 & 0.0 & 1.0 & 1.0 & 4
\end{tabular}

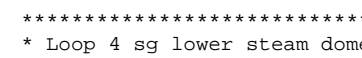

4 sg lower steam dome

$\$======================$

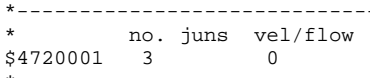

$\begin{array}{cccc}\$ 4720101 & \text { length } & \text { volume } \\ 0.0 & 0.630 & 0.09265\end{array}$

$\begin{array}{ccc}* & \text { azim angle } & \text { incl angle } \\ \$ 4720102 \quad 0.01 t a z & 0.630\end{array}$

$\begin{array}{lccc} & \text { roughness } & \text { hyd dia } & \text { pvbfe } \\ \$ 4720103 & 5.0 \mathrm{e}-5 & 0.343 & 01000\end{array}$

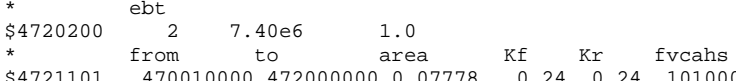

$\begin{array}{llllllll}* & \text { from } & \text { to } & \text { area } & & & & \\ \$ 4721101 & 470010000 & 472000000 & 0.07778 & 0.24 & 0.24 & 101000\end{array}$

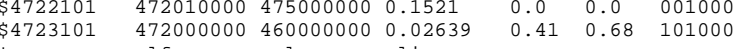

$\begin{array}{ccccc}\star & \text { velf } & \text { velg } & \text { veli } & \\ \$ 4721201 & 0.0 & 0.0 & 0 . & * 0.0\end{array}$

$\begin{array}{lllll}\$ 4722201 & 0.0 & 0.0 & 0 . & * 0.0 \\ \$ 4723201 & 0.0 & 0.0 & 0 . & * 0.0\end{array}$

$\begin{array}{rrrrr}* & \text { hyd dia } & \text { beta } & \text { y-int } & \text { slope } \\ \$ 4721110 & 0.0376 & 1.00 & 1.00 & 1.00\end{array}$

$\begin{array}{lllll}\$ 4721110 & 0.0376 & 1.00 & 1.00 & 1.00 \\ \$ 4722110 & 0.0 & 0.00 & 1.00 & 1.00 \\ \$ 4723110 & 0.04 & 0.00 & 1.00 & 1.00\end{array}$

$*$ End of superseded components

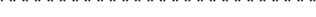

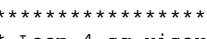

* Loop 4 sg riser

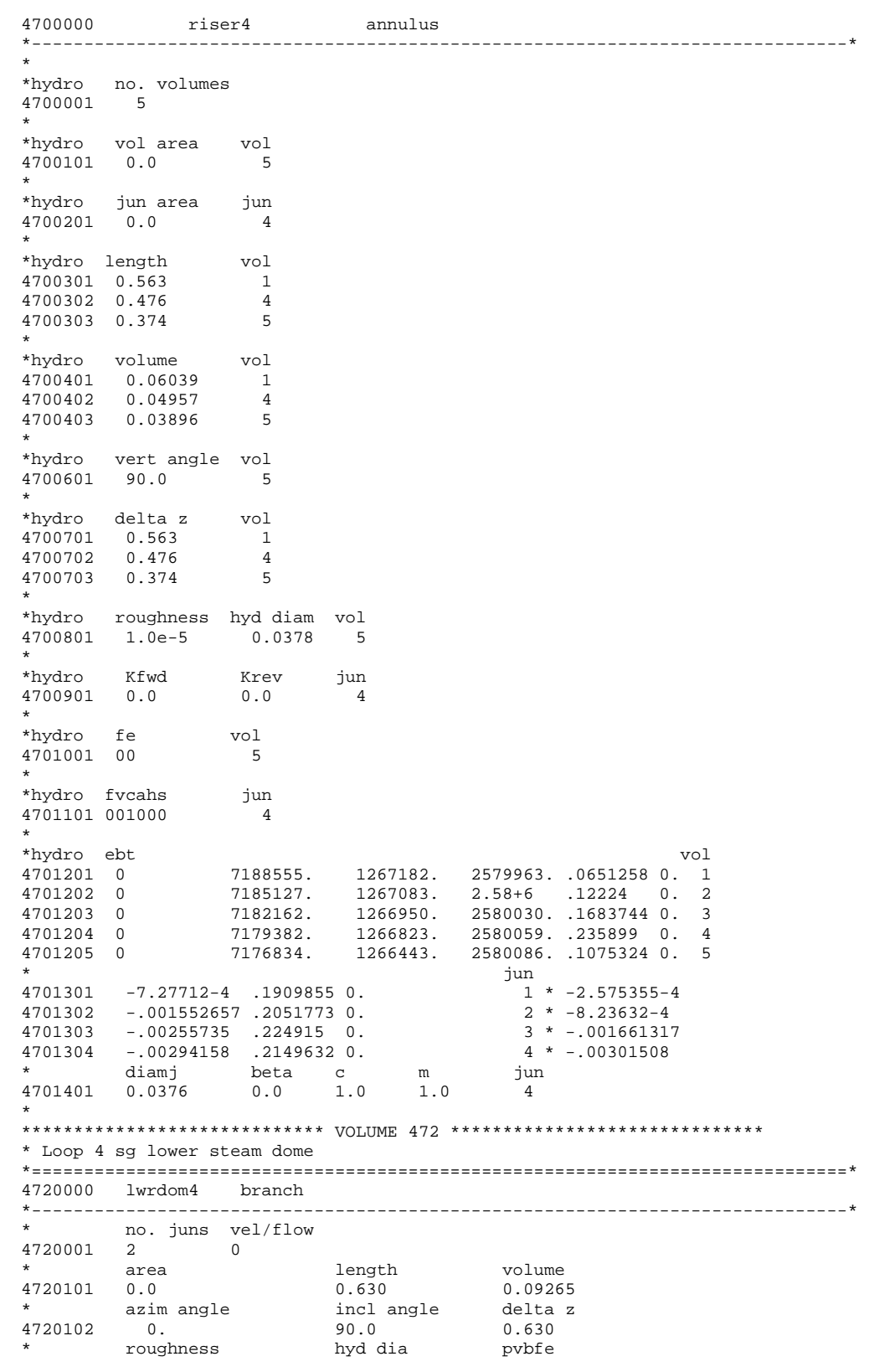




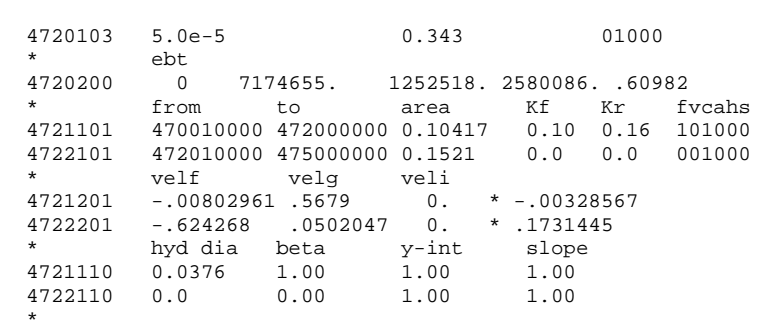

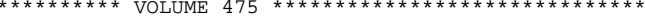
* Loop $4 \mathrm{sg}$ upper portion of steam dome

\begin{tabular}{|c|c|c|}
\hline 4750000 & uprdom 4 & pipe \\
\hline
\end{tabular}

$\begin{array}{lll}* \text { hydro } & \text { no. volumes } \\ 4750001 & 2\end{array}$

$\begin{array}{ccr}* \text { hydro } & \text { vol area } & \text { vol } \\ 4750101 & 0.1521 & 2\end{array}$

$\begin{array}{llr}* \text { thydro } & \text { jun area } & \text { jun } \\ 4750201 & 0.0 & 1\end{array}$

*hydro length vol

$\begin{array}{llr}* \text { hydro } & \text { volume } & \text { vol } \\ 4750401 & 0.0 & 2\end{array}$

$\begin{array}{llr}* & \\ * \text { hydro } & \text { vert angle } & \text { vol } \\ 4750601 & 90.0 & 2\end{array}$$$
\begin{array}{llr}
* \text { *hydro } & \text { delta } & \text { vol } \\
4750701 & 0.470 & 2
\end{array}
$$

*hydro roughness hyd diam vol

$\begin{array}{llll}4750801 & 1.0 \mathrm{e}-5 & 0.440 & 2\end{array}$

$\begin{array}{lllr}\text { *hydro } & \text { Kfwd } & \text { Krev } & \text { jun } \\ 4750901 & 0.0 & 0.0 & 1\end{array}$

* hydro fe vol

$4751001 \quad 00 \quad 2$

$\begin{array}{llr}* \text { hydro } & \text { fvcahs } & \text { jun } \\ 4751101 & 001000 & 1\end{array}$

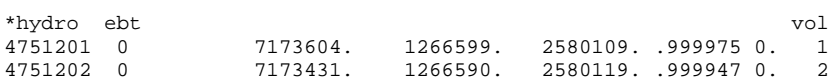

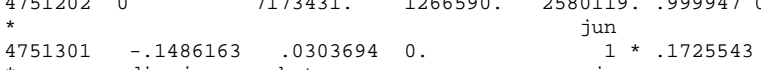

$\begin{array}{llllll}* & \text { diamj } & \text { beta } & c & \text { m } & \text { jun } \\ 4751401 & 0.0161 & 0.0 & 1.0 & 1.0 & 1\end{array}$

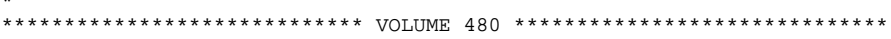

* Steam line 4

$\begin{array}{lll}*======================== & \\ 4800000 & \text { stmlin4 } & \text { branch }\end{array}$

$\begin{array}{lll}\star & \star \\ 4800001 & \text { no. juns } & \text { vel/flow } \\ \star & & 0\end{array}$

rea 0 math

volume

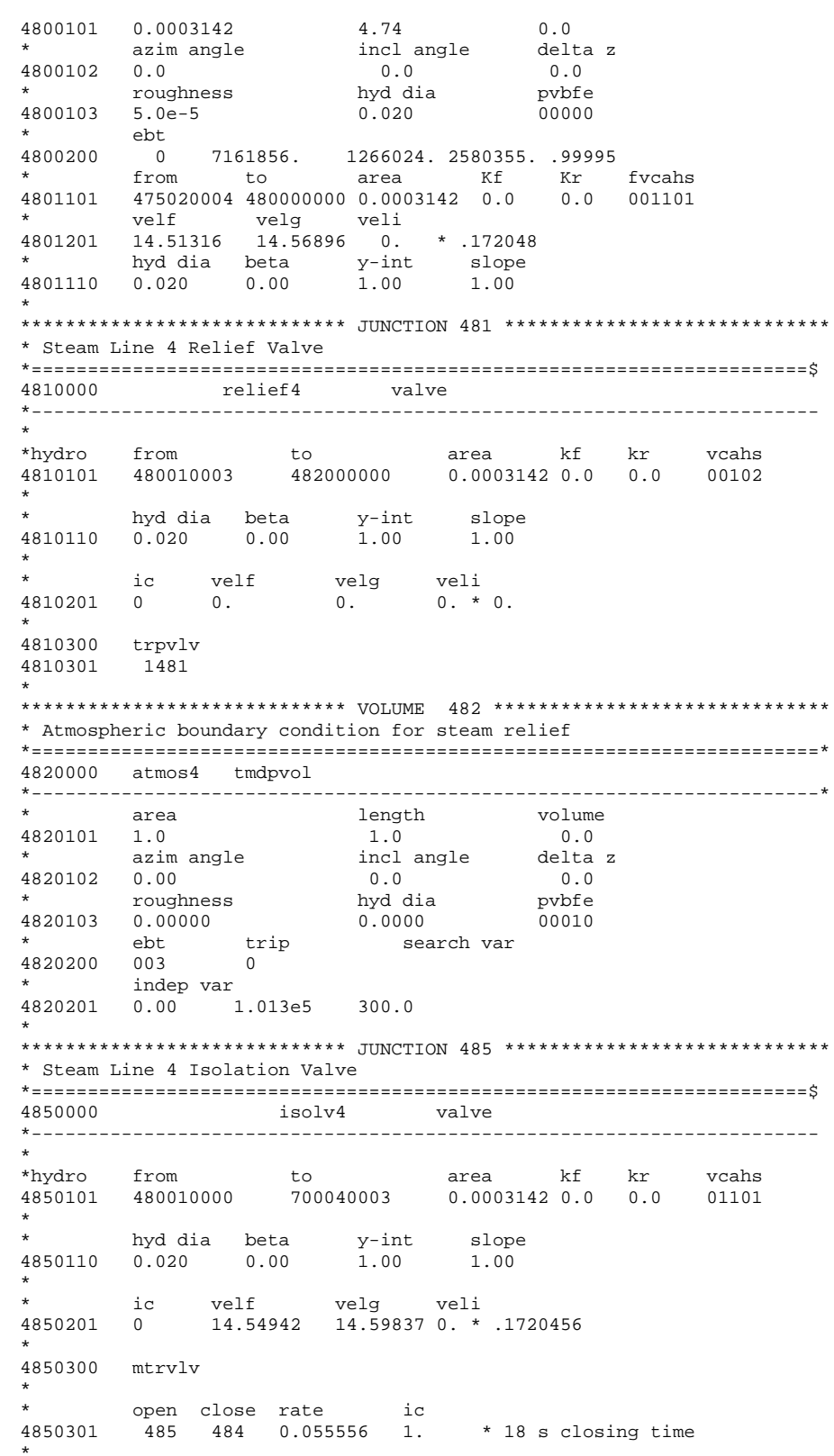




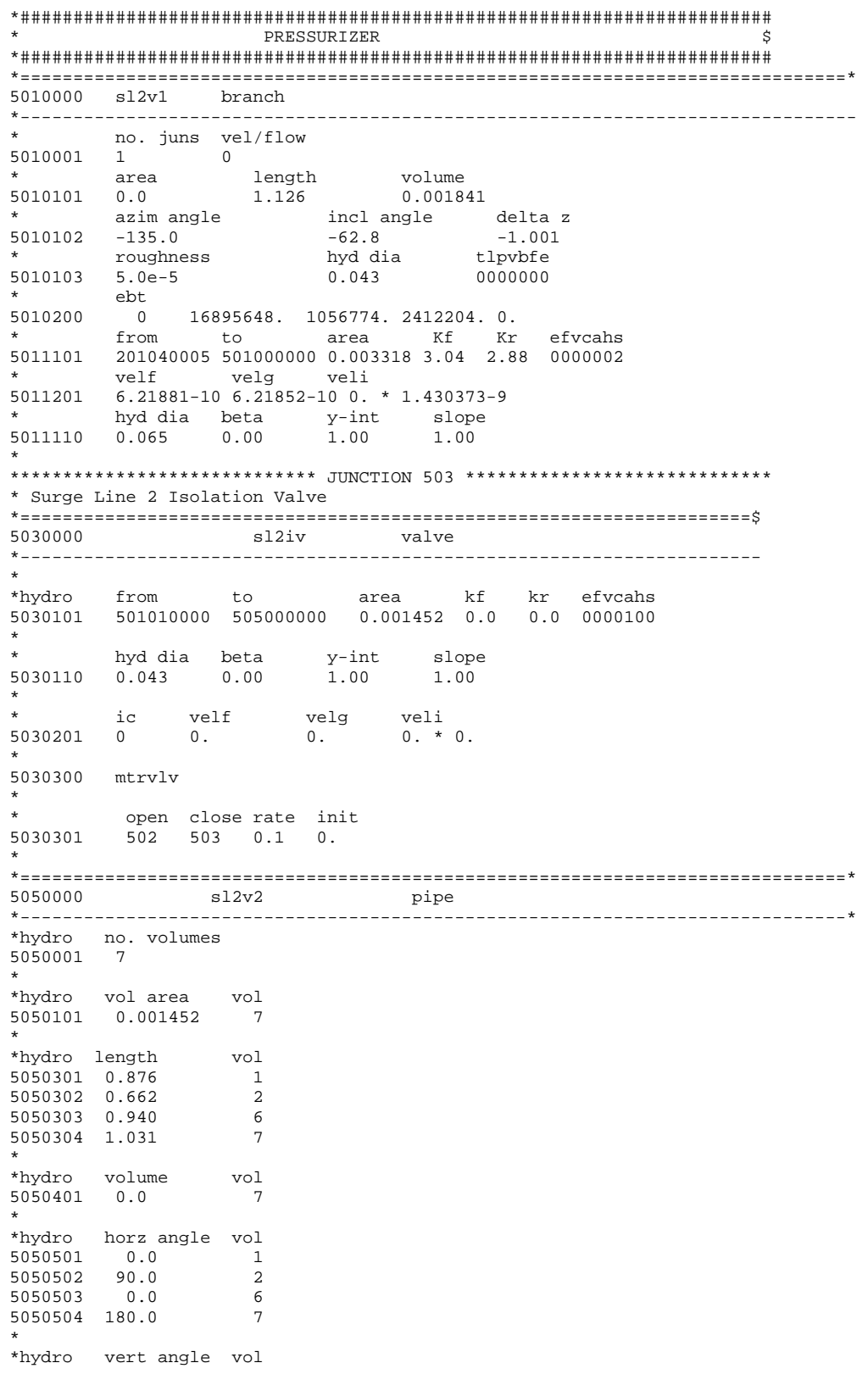

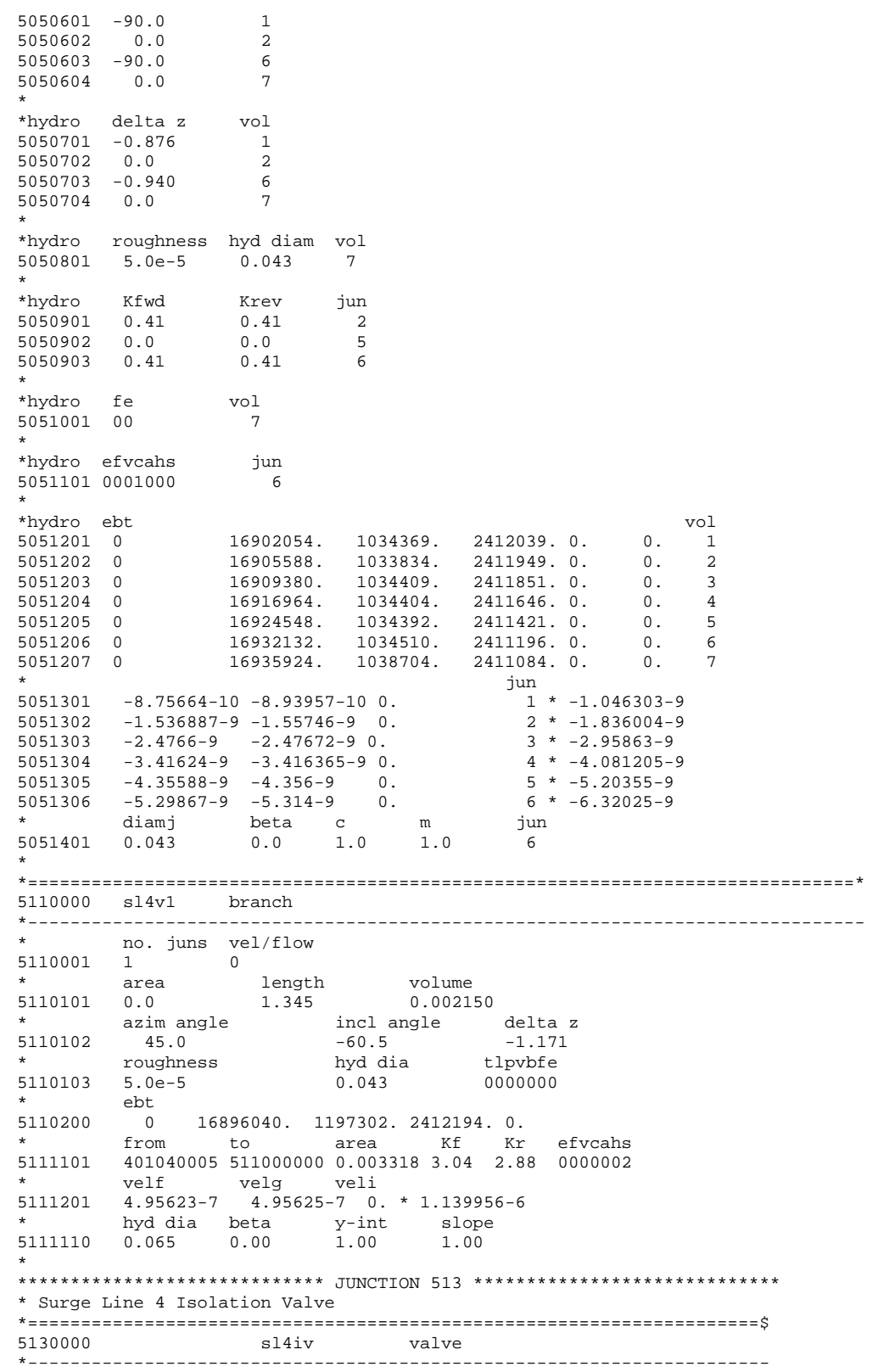


$\begin{array}{lllllll}* \text { *hydro } & \text { from } & \text { to } & \text { area } & \mathrm{kf} & \mathrm{kr} & \text { efvcahs } \\ 5130101 & 511010000 & 515000000 & 0.001452 & 0.0 & 0.0 & 0000100\end{array}$

$\begin{array}{lllll}* & \text { hyd dia } & \text { beta } & \text { y-int } & \text { slope } \\ 5130110 & 0.043 & 0.00 & 1.00 & 1.00\end{array}$

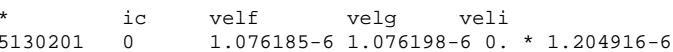

5130300 mtrvlv

$\begin{array}{lllll}* & \text { open } & \text { close rate } & \text { init } \\ 5130301 & 512 & 513 & 0.1 & 1 .\end{array}$

\begin{tabular}{|c|c|}
\hline 5150000 & $\mathrm{~s} 14 \mathrm{v} 2$ \\
\hline
\end{tabular}

*hydro no. volumes

$5150001 \quad 6$

thydro vol area vol

$5150101-0.001452$ vol

$\begin{array}{rr}* \text { *hydro length } \\ 5150301 & 1.338\end{array}$

$150302 \quad 1.32$

$\begin{array}{ll}5150303 & 1.790 \\ 5150304 & 1.091\end{array}$

*hydro

$\begin{array}{ll}5150401 & 0.0\end{array}$

*hydro horz angle vol

$\begin{array}{rrr}5150501 & 0.0 \\ 5150502 & -90.0\end{array}$

$\begin{array}{rr}5150502 & -90.0 \\ 5150503 & 0.0\end{array}$

$50501-0.0$
$503-0.0$

*hydro vert angle vol

$\begin{array}{ll}5150601 & -90.0 \\ 5150602 & 0.0\end{array}$

$5150602-0.0$

$\begin{array}{rr}5150604 & 0.0\end{array}$

*hydro delta $z$

$5150701-1.338$

$\begin{array}{ll}5150702 & 0.0 \\ 5150703 & -1.790\end{array}$

$\begin{array}{cc}5150703 & -1.790 \\ 5150704 & 0.0\end{array}$

thydro roughness hyd diam vol

$\begin{array}{llll}5150801 & 5.0 \mathrm{e}-5 & 0.043 & 6\end{array}$

*hydro Kfwd

Krev jun

$5150901 \quad 0.0$

$\begin{array}{ll}5150903 & 0.0\end{array}$

$\begin{array}{lll}5150904 & 0.41\end{array}$

$\begin{array}{ll}\text { *hydro } & \text { fe } \\ 5151001 & 00\end{array}$

$\begin{array}{ll}0.41 & 2 \\ 0.0 & 3 \\ 0.41 & 5\end{array}$

vol 6

$\begin{array}{ll}* \text { hydro efvcah } \\ 5151101 & 000100\end{array}$

jun
5

*hydro ebt

5151201

$\begin{array}{lllll}16905716 . & 1108657 . & 2411945.0 . & 0 . & \text { vol } \\ 16916284 & 1074555 & 2411666.0 & 0 . & 2\end{array}$

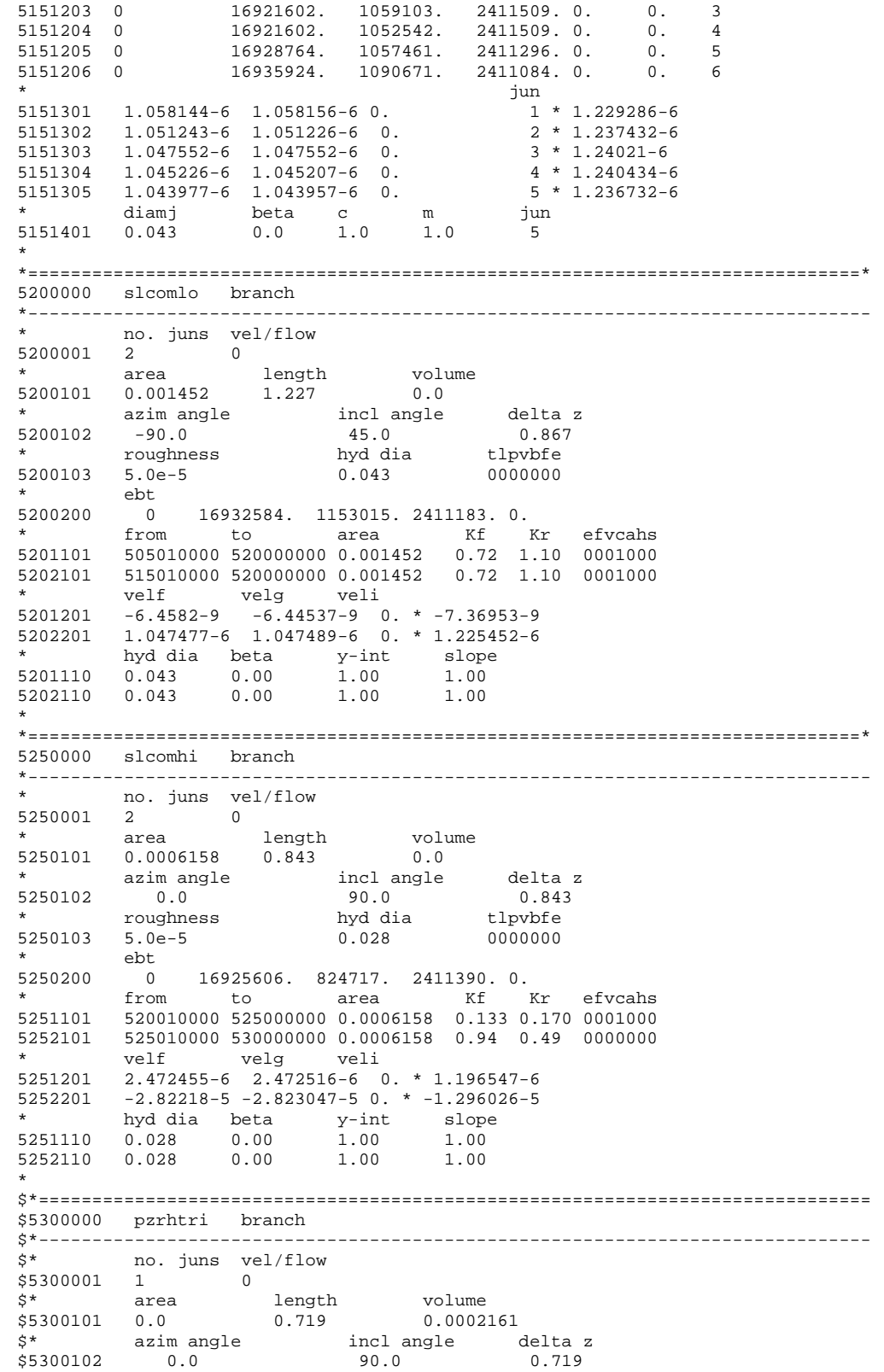




\begin{tabular}{|c|c|c|c|c|c|c|}
\hline \$* & roughness & & hyd dia & & lpvbfe & \\
\hline$\$ 5300103$ & $5.0 e-5$ & & 0.020 & & 000000 & \\
\hline $\begin{array}{l}\text { \$* } \\
\$ 5300200\end{array}$ & $\begin{array}{rl}\text { ebt } & \\
3 & 15.7\end{array}$ & & 563.15 & & & \\
\hline & from $\quad t$ & to & $\begin{array}{l}\text { area } \\
\text { are }\end{array}$ & $\mathrm{Kf}$ & $\mathrm{Kr}$ & efvcahs \\
\hline$\$ 5301101$ & 5300100005 & 535000000 & $0 \quad 0.00001257$ & 71.71 & 1.65 & 0000000 \\
\hline & velf & velg & & & & \\
\hline$\$ 5301201$ & $\begin{array}{l}0.0 \\
\text { hyd dia b }\end{array}$ & $\begin{array}{c}0.0 \\
\text { beta }\end{array}$ & $\begin{array}{c}0 . \\
y-i n t\end{array}$ & slope & & \\
\hline $\begin{array}{l}\$ 5301110 \\
\$ \star\end{array}$ & 0.004 & 0.00 & 1.00 & 1.00 & & \\
\hline $\begin{array}{l}\$ *===== \\
\$ 5320000\end{array}$ & $\begin{array}{l}======= \\
\text { pzrhtra }\end{array}$ & $\begin{array}{l}====== \\
\text { branch }\end{array}$ & & & & \\
\hline & & & & & & \\
\hline$\$$ & $\begin{array}{l}\text { no. juns } \\
2\end{array}$ & $\begin{array}{l}\text { vel/flow } \\
0\end{array}$ & & & & \\
\hline$\$ *$ & area & length & vol & lume & & \\
\hline $\begin{array}{l}\$ 5320101 \\
\$ *\end{array}$ & 0.0 & 0.719 & 0.0 & 0009219 & & \\
\hline & azim angle & & incl angle & & delta $z$ & \\
\hline$\$ 5320102$ & 0.0 & & 90.0 & & 0.719 & \\
\hline & roughness & & hyd dia & & lpvbfe & \\
\hline $\begin{array}{l}\$ 5320103 \\
\$ *\end{array}$ & $5.0 e-5$ & & 0.044 & & 000000 & \\
\hline$\$$ \$5 $\$ 520200$ & $\begin{array}{ll}\text { ebt } \\
3\end{array}$ & $.7 \mathrm{e} 6$ & 563.15 & & & \\
\hline$\$ *$ & from & to & area & $\mathrm{Kf}$ & & efvcahs \\
\hline$\$ 5321101$ & 530010004 & 532010003 & $\begin{array}{ll}30 & 0.001608\end{array}$ & 1.5 & 1.5 & 0001000 \\
\hline$\$ 5322101$ & 532010000 & 535000000 & $\begin{array}{ll}0 & 0.00005027\end{array}$ & 71.71 & 1.65 & 0000000 \\
\hline$\$ \star$ & velf & velg & & & & \\
\hline$\$ 5321201$ & 0.0 & 0.0 & 0. & & & \\
\hline$\$ 5322201$ & & 0.0 & 0 & & & \\
\hline$\$ \star ~ \$$ & hyd dia & beta & $y$-int & slope & & \\
\hline$\$ 5321110$ & 0.008 & 0.00 & 1.00 & 1.00 & & \\
\hline $\begin{array}{l}\$ 5322110 \\
\$\end{array}$ & 0.004 & 0.00 & 1.00 & 1.00 & & \\
\hline$\$ 5340000$ & pzrlowa & branch & & & & \\
\hline \$* & no. juns & vel/flow & & & & \\
\hline$\$ 5340001$ & 2 & 0 & & & & \\
\hline & area & length & volu & lume & & \\
\hline$\$ 5340101$ & 0.0 & 0.719 & & 013233 & & \\
\hline & azim angle & & incl angle & & delta $z$ & \\
\hline$\$ 5340102$ & 0.0 & & 90.0 & & 0.719 & \\
\hline$\$ *$ & roughness & & hyd dia & & lpvbfe & \\
\hline$\$ 5340103$ & $5.0 e-5$ & & 0.107 & & 000000 & \\
\hline & ebt & & & & & \\
\hline$\$ 5340200$ & 3 & & 563.15 & & & \\
\hline & from & & area & $\mathrm{Kf}$ & $\mathrm{Kr}$ & efvcahs \\
\hline$\$ 5341101$ & 532010004 & 534010003 & 30.032464 & 1.0 & 0.5 & 0001000 \\
\hline$\$ 5342101$ & 534010000 & 535000000 & $0 \quad 0.01840$ & 0.014 & 40.059 & 0001000 \\
\hline & velf & velg & veli & & & \\
\hline$\$ 5341201$ & 0.0 & 0.0 & 0. & & & \\
\hline$\$ 5342201$ & & 0.0 & 0. & & & \\
\hline & hyd dia & beta & $y$-int & slope & & \\
\hline$\$ 5341110$ & 0.0278 & 0.00 & 1.00 & 1.00 & & \\
\hline $\begin{array}{l}\$ 5342110 \\
\$ *\end{array}$ & 0.107 & 0.00 & 1.00 & 1.00 & & \\
\hline 5300000 & & zrbody & pip & & & \\
\hline $\begin{array}{l}\text { *hydro } \\
5300001 \\
{ }^{2}\end{array}$ & $\begin{array}{l}\text { no. volumes } \\
8\end{array}$ & & & & & \\
\hline *hydro & vol area & vol & & & & \\
\hline 5300101 & 0.0 & 1 & & & & \\
\hline 5300102 & 0.02087 & 8 & & & & \\
\hline *hydro & ength & vol & & & & \\
\hline
\end{tabular}

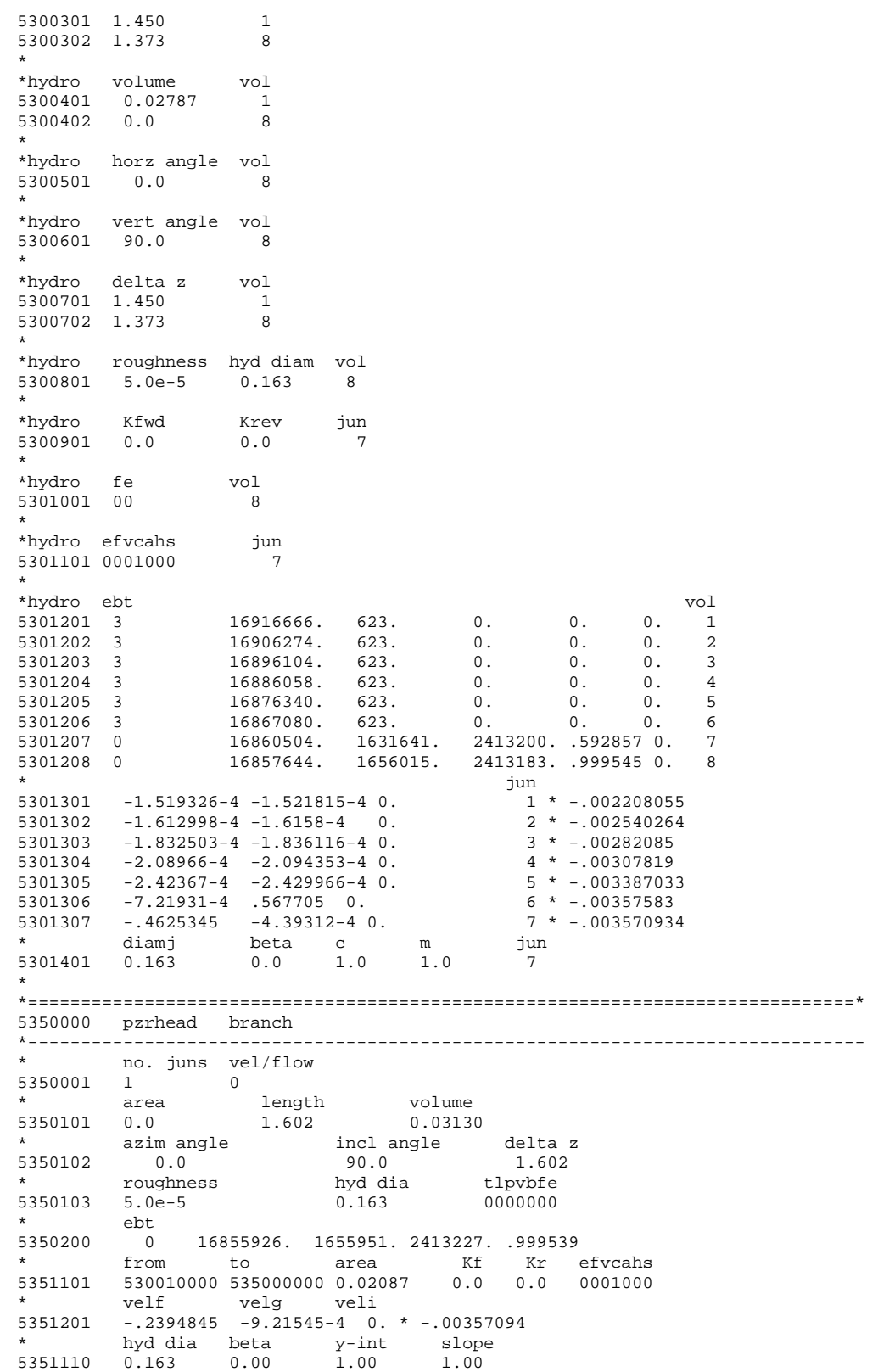




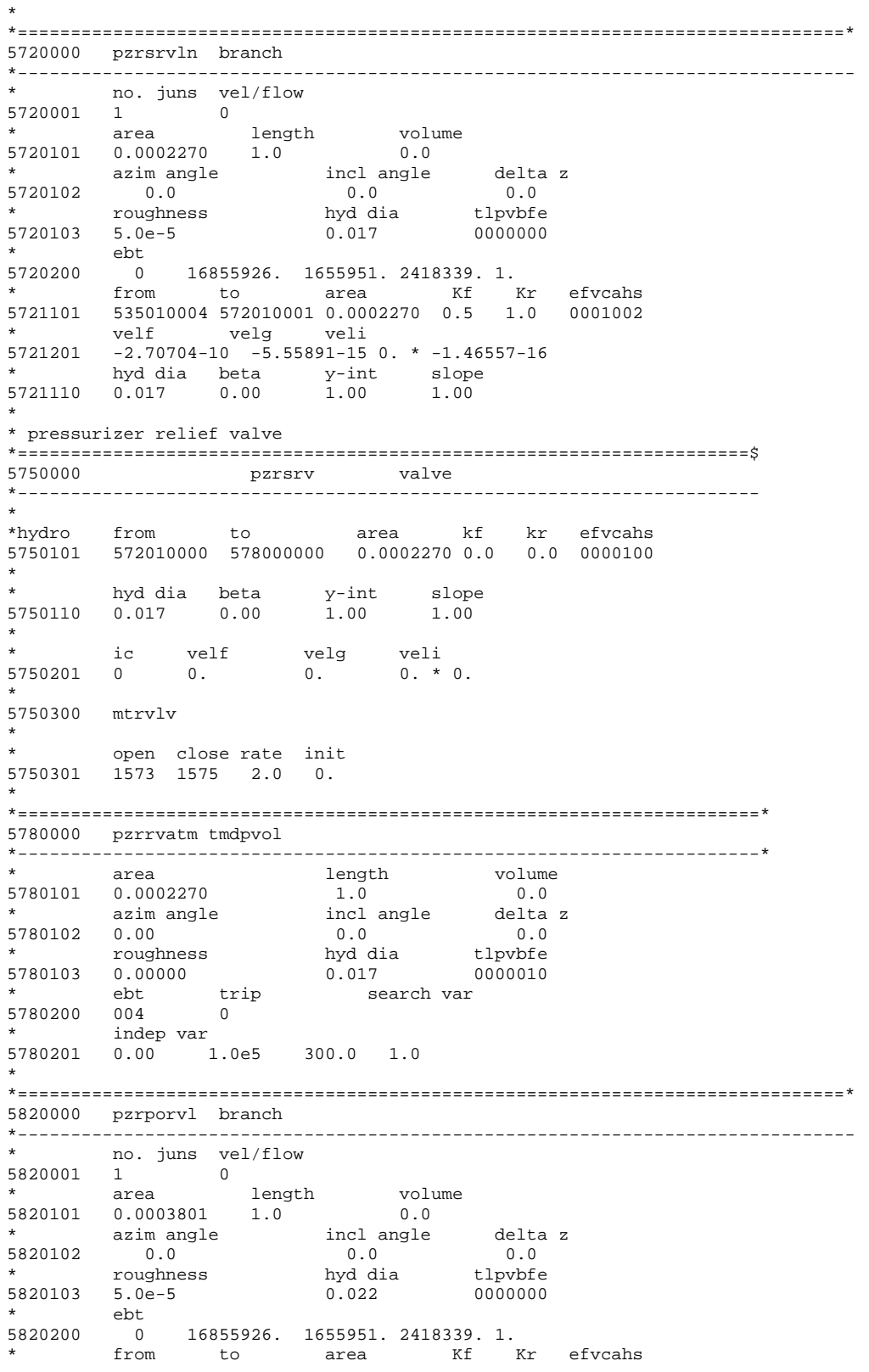

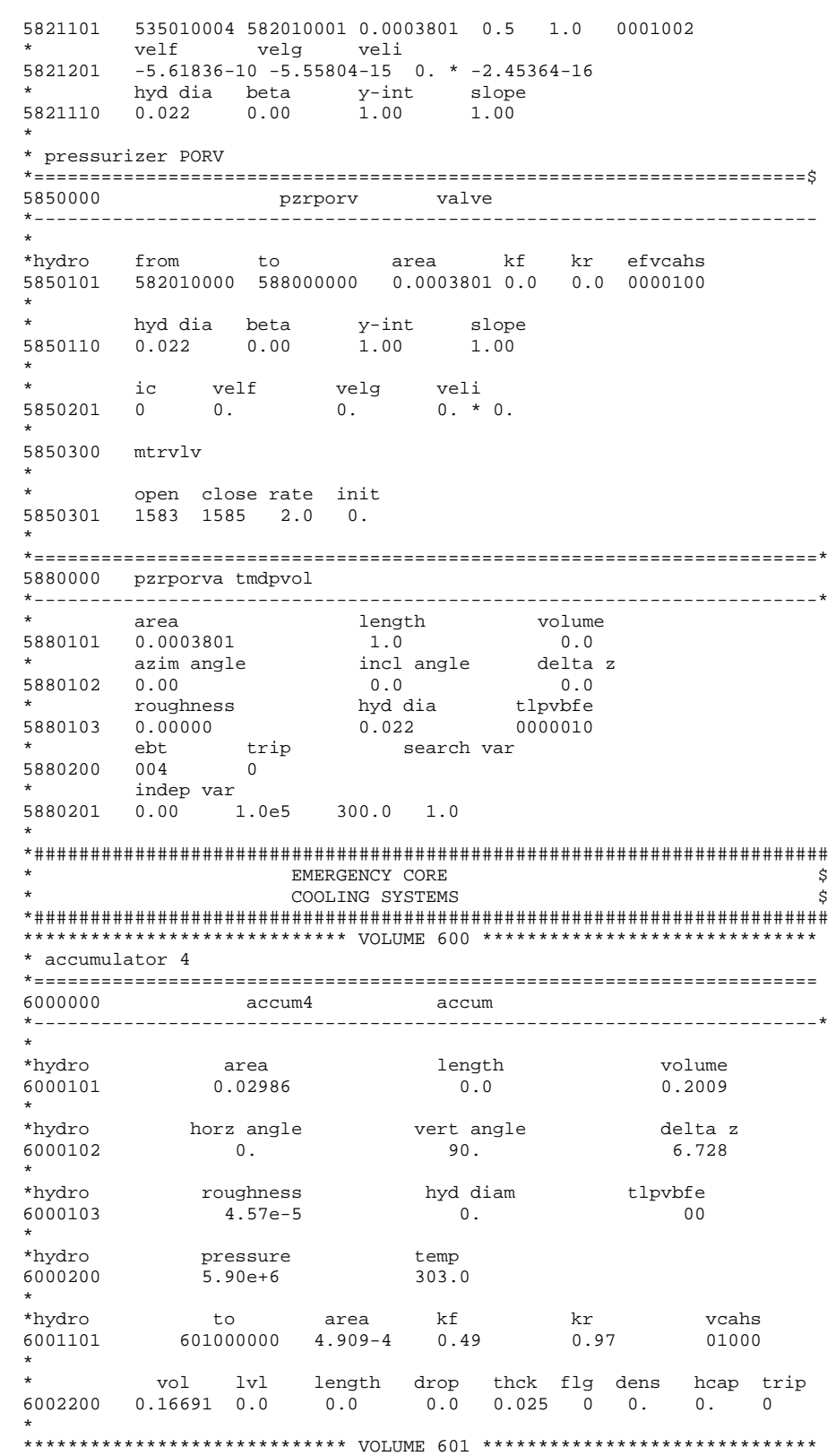




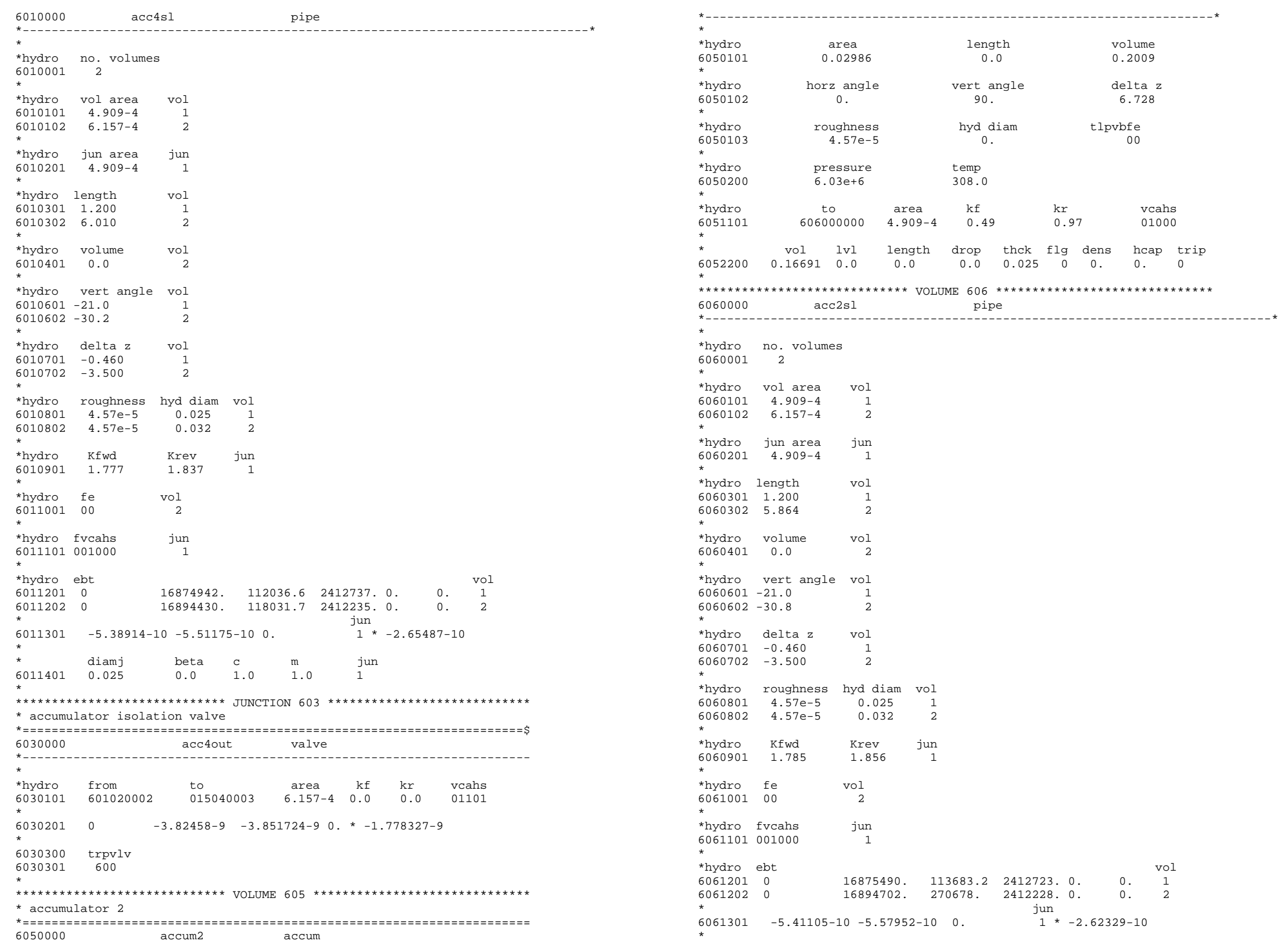




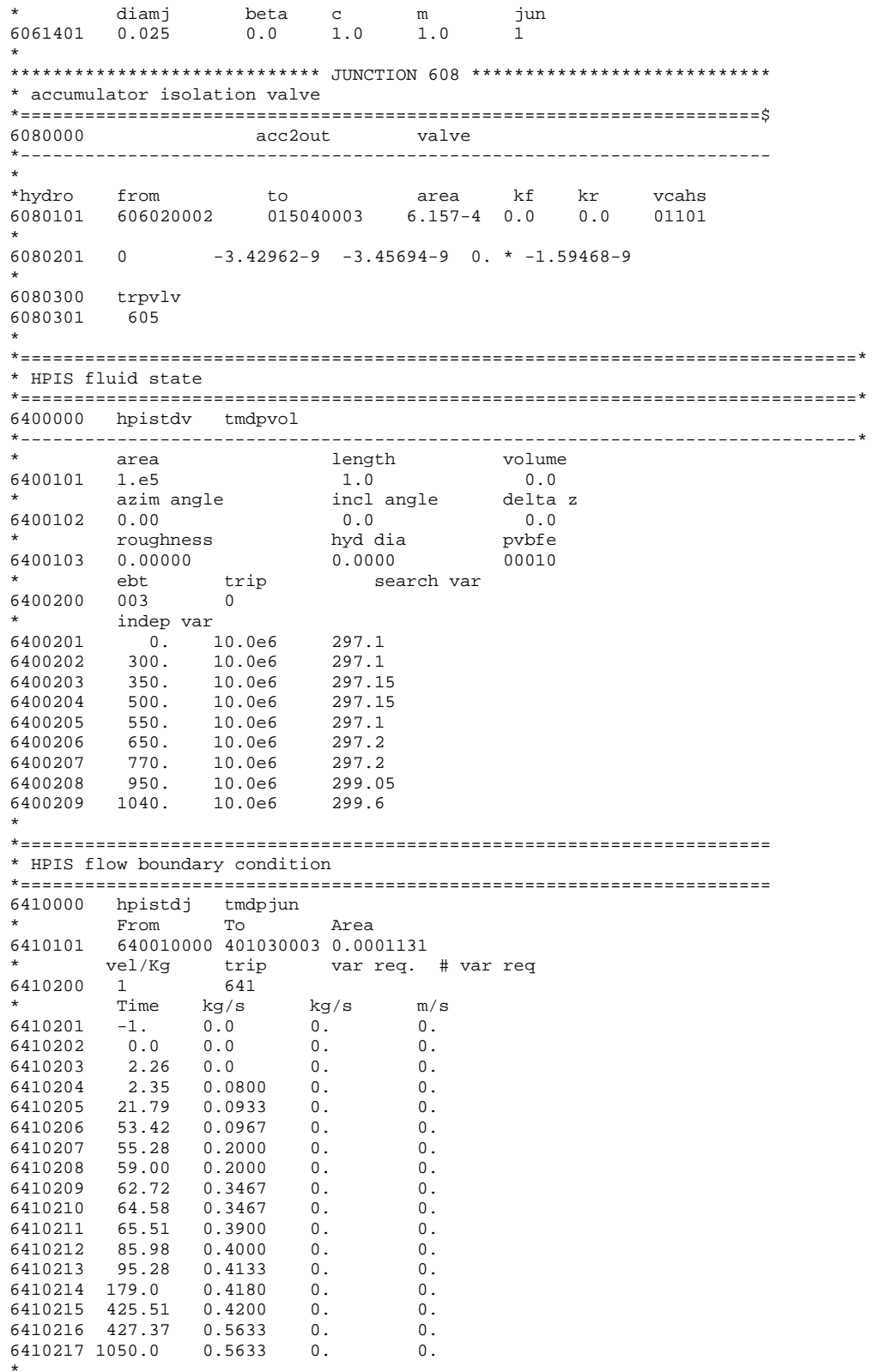

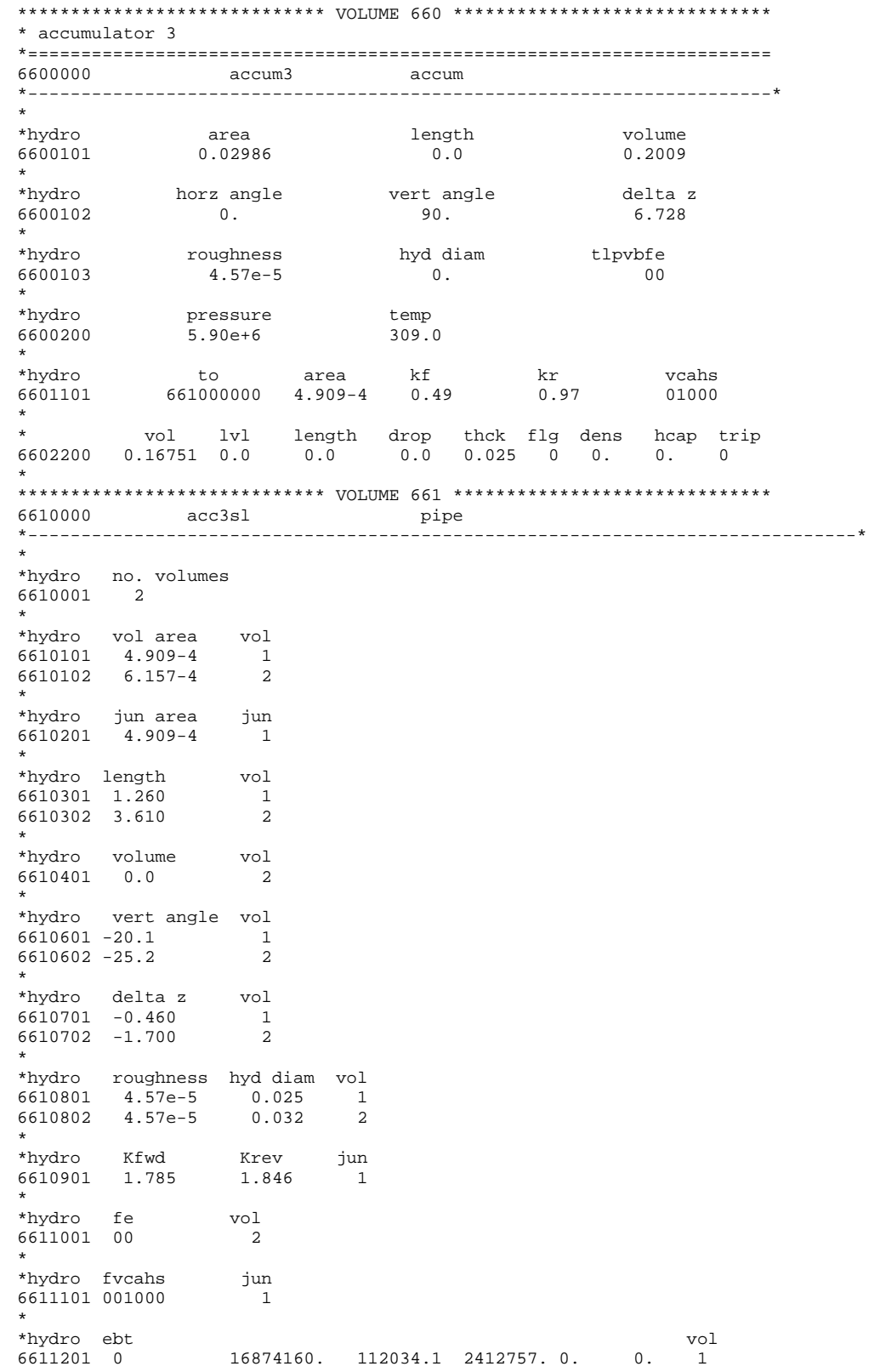




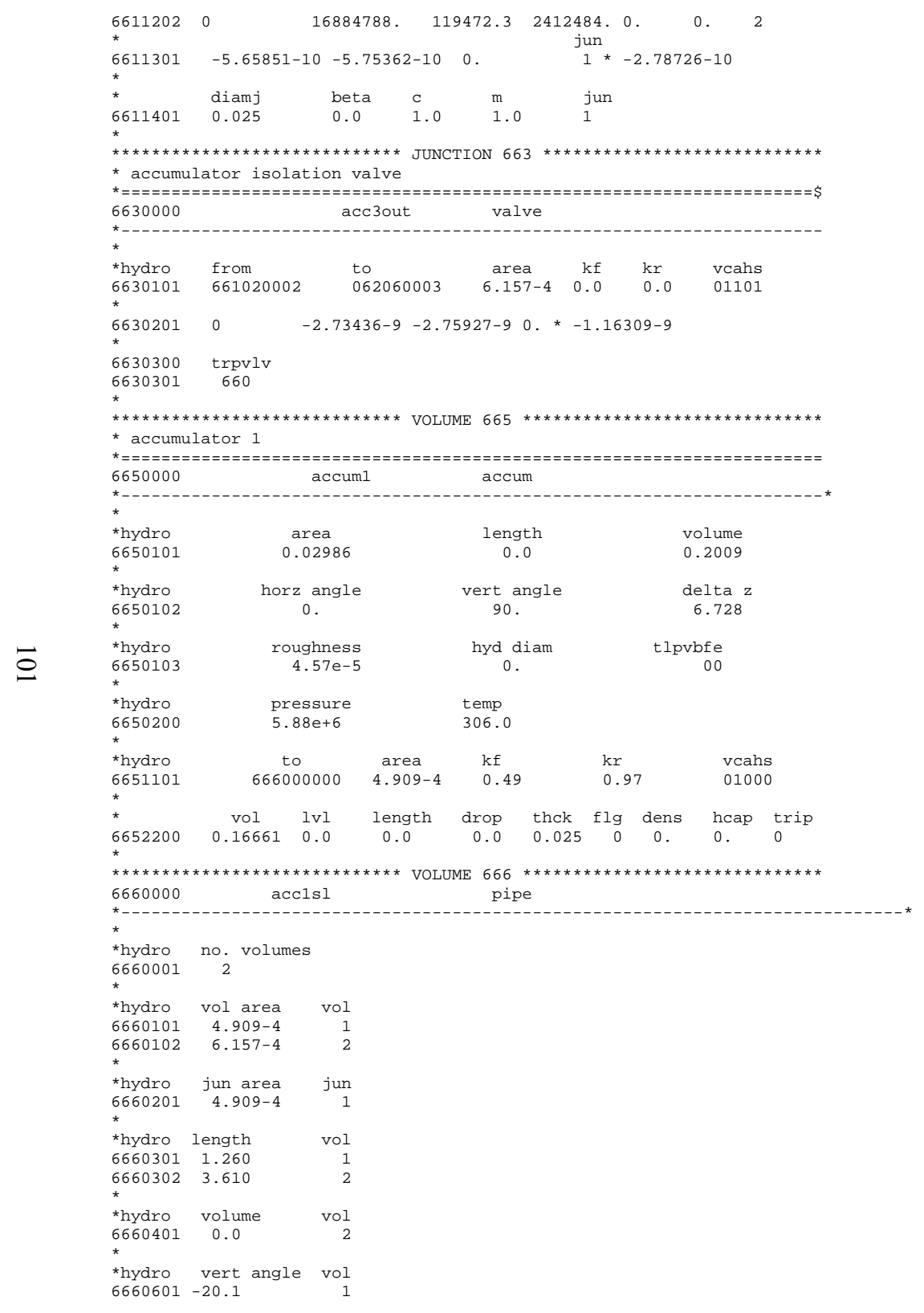

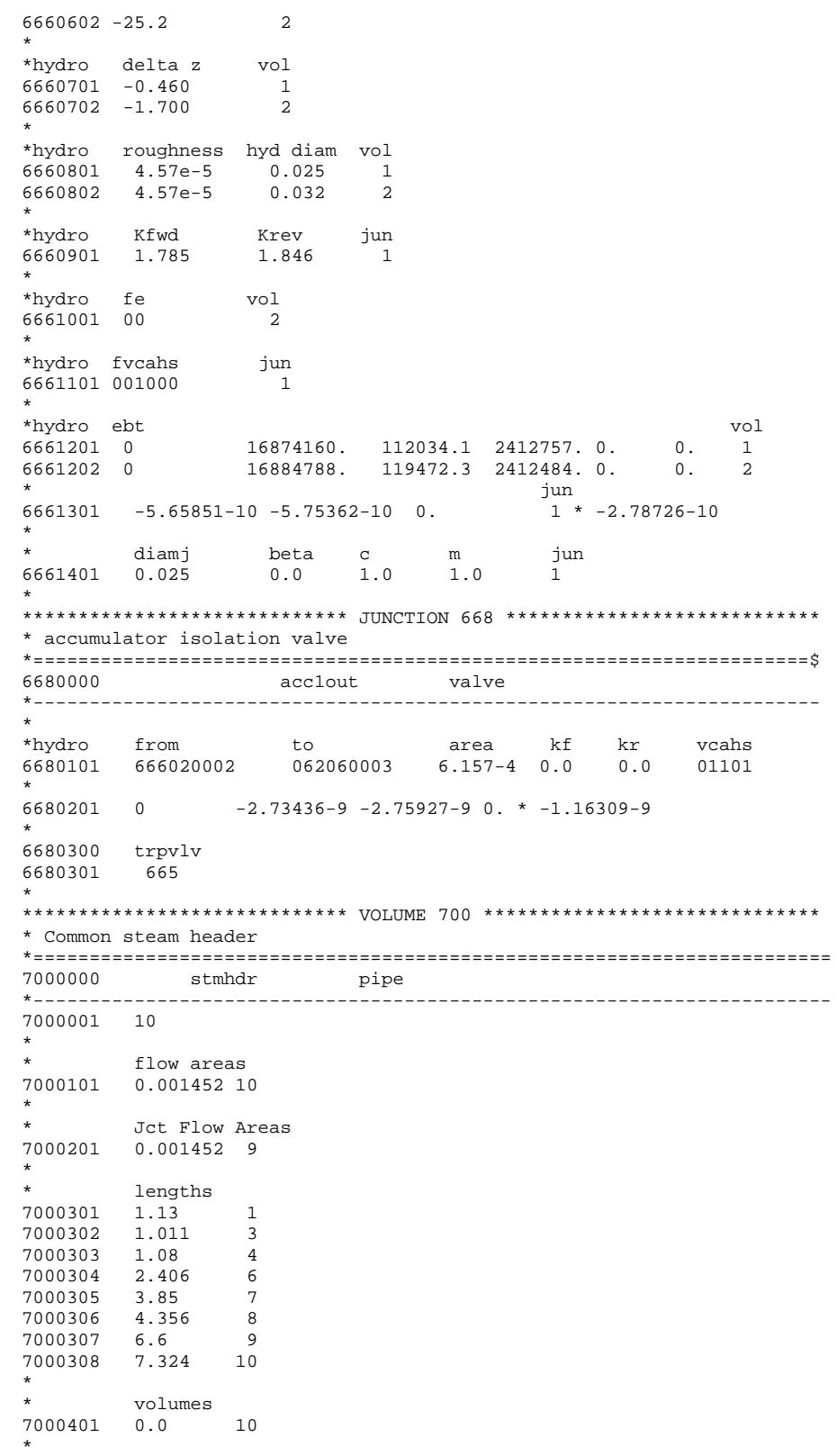




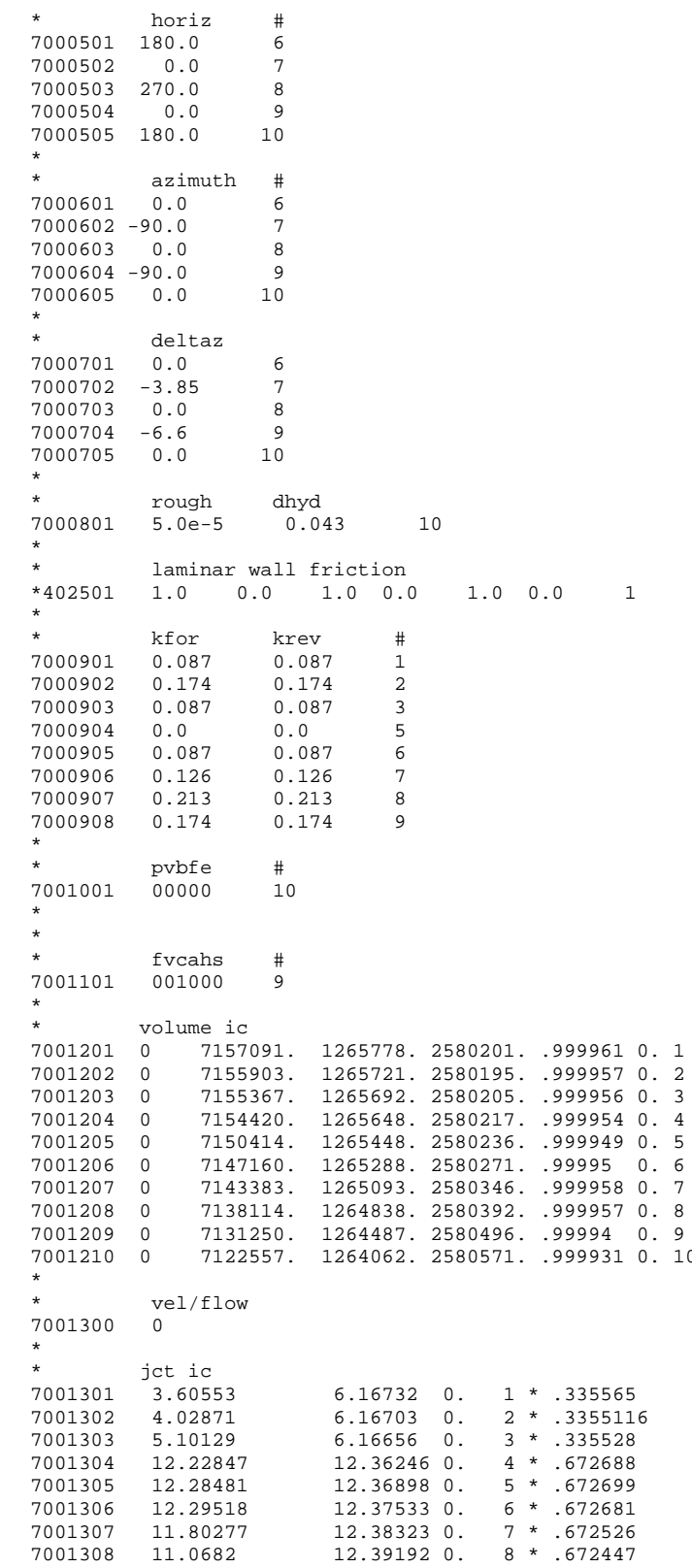

$7001309 \quad 12.33807 \quad 12.399360 . \quad 9 * .672361$

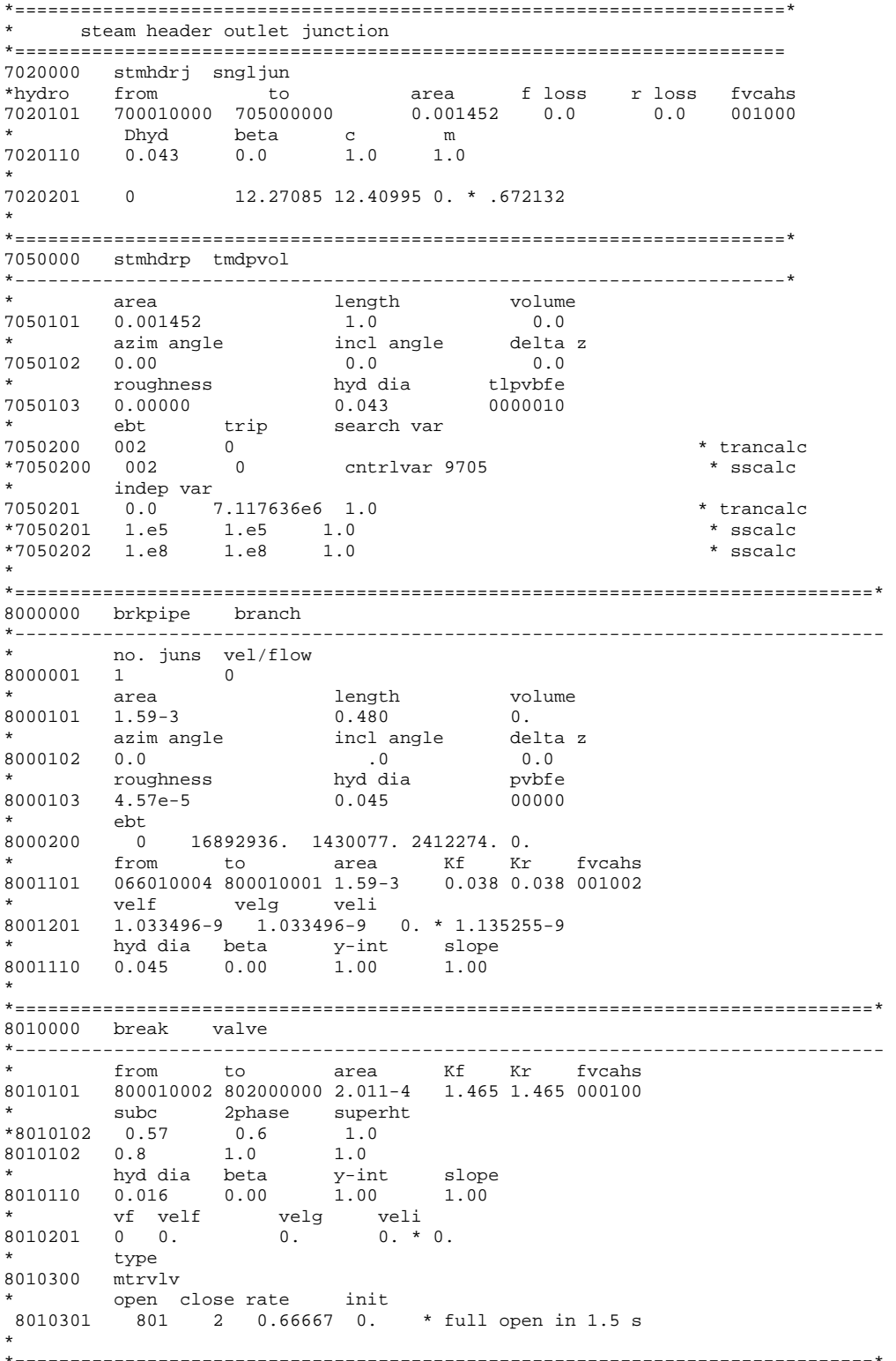




\begin{tabular}{|c|c|c|c|c|}
\hline 8020000 & atmosph & tmdpvol & & \\
\hline * & area & & length & volume \\
\hline 8020101 & $1 . e 5$ & & 1.0 & \\
\hline & azim angle & & incl angle & delta $z$ \\
\hline 8020102 & 0.00 & & 0.0 & 0.0 \\
\hline & roughness & & hyd dia & pvbfe \\
\hline 8020103 & 0.00000 & & 0.0000 & 00010 \\
\hline & & trip & search var & \\
\hline 8020200 & & 0 & & \\
\hline${ }^{\star} 8020201$ & $\begin{array}{l}\text { indep var } \\
0.00\end{array}$ & $c_{1.013+5}$ & 375.0 & \\
\hline
\end{tabular}

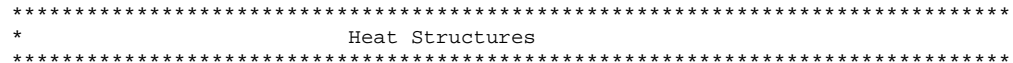

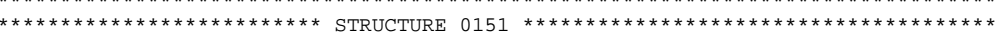

* downcomer external wall

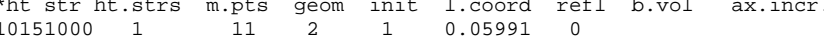

* 10151100 loc flag

* $\mathrm{dx}$ int

$10151101 \quad 0.00139 \quad 2$

$\begin{array}{lll}10151102 & 0.00278 \\ 10151103 & 0.00417 & 6\end{array}$

$\begin{array}{lll}10151103 & 0.00417 & 6 \\ 10151104 & 0.00555 & 8 \\ 10151105 & 0.04116 & 10\end{array}$

10151201 compos. $\quad$ int

$\begin{array}{lll}* & \text { source } & \text { int } \\ 10151301 & 0.0 & 10\end{array}$

* $10151400 \stackrel{\text { temperature } \mathrm{flag}}{0}$

* temperature pt

$\begin{array}{lllllll}* & \text { vol } & \text { inc } & \text { type } & \text { code } & \text { factor } & \text { hs } \\ 10151501 & 015010000 & 0 & 1 & 1 & 0.525 & 1\end{array}$

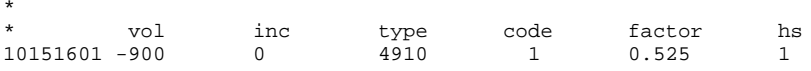

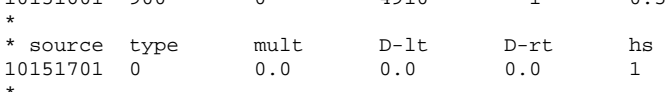

$10151800{ }^{*}{ }^{1}$ Dhe LHEf LHEr LGSf LGSr Kfwd Krev Fboil nclf povd ff hs

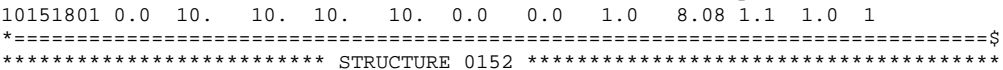

* downcomer external wall

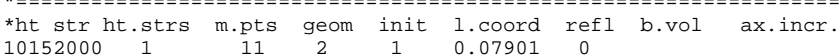

$\begin{array}{lll}* & \text { loc } & \text { flag } \\ 10152100 & 0 & 2\end{array}$

* $\mathrm{dx}$ int

$10152101 \quad 0.00197 \quad 2$

$10152102 \quad 0.00394$

$\begin{array}{ll}10152103 & 0.00591 \\ 10152104 & 0.00788\end{array}$

$\begin{array}{lll}10152104 & 0.00788 & 8 \\ 10152105 & 0.02580 & 10\end{array}$

compos. int

$\begin{array}{lll}10152202 & 3 & 8 \\ 10 & 10\end{array}$

* $\quad$ source int

* $\quad$ temperature flag

* temperature pt

$\begin{array}{lllllll}* & \text { vol } & \text { inc } & \text { type } & \text { code } & \text { factor } & \text { hs } \\ 10152501 & 015020000 & 0 & 1 & 1 & 0.390 & 1\end{array}$

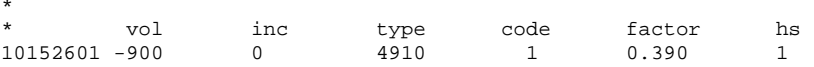

$\begin{array}{llllll}* & \text { mult } & \text { D-1t } & \text { D-rt } & \text { hs } \\ \text { * source } & \text { type } & \text { mult } & 0.0 & 0.0 & 1\end{array}$

101528001

${ }^{\star} 0152800$ Dhe LHEf LHEr LGSf LGSr Kfwd Krev Fboil nclf povd ${ }^{1}$ h

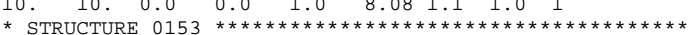

* downcomer external wall

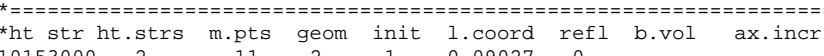

$\begin{array}{lll}* & \text { loc } & \text { flag } \\ 10153100 & 0 & 2\end{array}$

* $\mathrm{dx}$ int

$\begin{array}{lll}10153101 & 0.00251 & 2 \\ 10153102 & 0.00501 & 4\end{array}$

$\begin{array}{ll}10153103 & 0.00752\end{array}$

$\begin{array}{lll}10153104 & 0.01003 & 8 \\ 10153105 & 0.01480 & 10\end{array}$

$\begin{array}{lll}* & \text { compos. } & \text { int } \\ 10153201 & 1 & 8 \\ 10153202 & 3 & 10\end{array}$

10

$\begin{array}{lll}* & \text { source } & \text { int } \\ 10153301 & 0.0 & 10\end{array}$

* temperature flag

0153400

$\begin{array}{lll}* & \text { temperature pt } \\ 10153401 & 563.15 & 11\end{array}$

* vol inc

$\begin{array}{lll}* & \text { vol } & \text { inc } \\ 10153501 & 015030000 & 10000\end{array}$

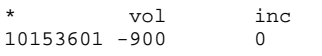

* source type mult

$\begin{array}{ll}\text { mult } & \mathrm{D}-1 \mathrm{t} \\ 0.0 & 0.0\end{array}$

$\begin{array}{llll}\text { type } & \text { code } & \text { factor } & \text { hs } \\ 1 & 1 & 0.200 & 2 \\ \text { type } & \text { code } & \text { factor } & \text { hs } \\ 4910 & 1 & 0.200 & 2 \\ \text { D-lt } & \text { D-rt } & \text { hs } & \\ 0.0 & 0.0 & 2 & \end{array}$


10153800 Dhe LHEf LHEr LGSf LGSr Kfwd Krev Fboil nclf povd $f f$ hs

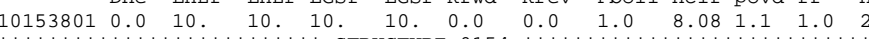
* downcomer external wal

$\begin{array}{llccccccc}* \text { ht str ht.strs } & \text { m.pts } & \text { geom } & \text { init } & 1 . \text { coord } & \text { refl b.vol ax.incr. } \\ 10154000 & 1 & 11 & 2 & 1 & 0.06938 & 0 & & \end{array}$

* 10154100 loc flag

* $\mathrm{dx}$ int

$\begin{array}{lll}10154101 & 0.00152 & 2\end{array}$

$101541020.00304 \quad 4$

101541040.00457 r

$\begin{array}{lll}10154105 & 0.03509 & 10\end{array}$

0154201 compos. int

$10154202 \quad 3 \quad 10$

* $\quad$ source int

temperature fla

* $10154400 \stackrel{\text { tenpe }}{0}$

* temperature pt

\begin{tabular}{|c|c|c|c|c|c|c|c|}
\hline * & $\begin{array}{l}\text { vol } \\
015050000\end{array}$ & $\begin{array}{l}\text { inc } \\
0\end{array}$ & $\begin{array}{l}\text { type } \\
1\end{array}$ & $\begin{array}{l}\text { cod } \\
1\end{array}$ & de & $\begin{array}{l}\text { factor } \\
0.560\end{array}$ & $\begin{array}{l}\text { hs } \\
1\end{array}$ \\
\hline * & vol & inc & type & & de & factor & hs \\
\hline $\begin{array}{l}10154601 \\
*\end{array}$ & -900 & 0 & 4910 & & 1 & 0.560 & 1 \\
\hline $\begin{array}{l}\text { * source } \\
10154701\end{array}$ & type & mult & D-1t & D-r & $-\mathrm{rt}$ & hs & \\
\hline $\begin{array}{l}\text { 10154701 } \\
\text { * }\end{array}$ & 0 & 0.0 & 0.0 & 0.0 & & & \\
\hline 54800 & 1 & & & & & & \\
\hline 154801 & $\begin{array}{ll}\text { Dhe } & \text { LHEf } \\
0.0 & 10 .\end{array}$ & $\begin{array}{l}\text { LHEr LGSf } \\
10 . \quad 10 .\end{array}$ & $\begin{array}{l}\text { LGSY } \\
10 .\end{array}$ & $\begin{array}{ll}\text { Kfwd } & \text { K } \\
0.0 & 0\end{array}$ & $\begin{array}{ll}\text { Krev } & F \\
0.0 & 1\end{array}$ & $\begin{array}{ll}\text { Fboil } & \text { nclf } \\
1.0 & 8.08\end{array}$ & $\begin{array}{lll}\text { povd } \mathrm{ff} & \mathrm{hs} \\
1.1 & 1.0 & 1\end{array}$ \\
\hline 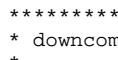 & 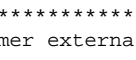 & $\begin{array}{l}* \star \star \star * \star \star * \text { STR } \\
\text { al wall }\end{array}$ & RUCTURE & E 0155 * & & & \\
\hline *ht str $\mathrm{h}$ & ht.strs & pts geom & init & 1. coord & refl & b.vol & ax.incr. \\
\hline $\begin{array}{l}10155000 \\
{ }_{*}\end{array}$ & 9 & 112 & 1 & 0.05950 & 0 & & \\
\hline & $10 \mathrm{c}$ & flag & & & & & \\
\hline${ }_{*}^{10155100}$ & 0 & 2 & & & & & \\
\hline & $d x$ & int & & & & & \\
\hline $\begin{array}{l}10155101 \\
1015102\end{array}$ & 0.00100 & 2 & & & & & \\
\hline 10155102 & 0.00200 & 4 & & & & & \\
\hline $\begin{array}{l}10155103 \\
10155104\end{array}$ & $\begin{array}{l}0.00300 \\
0.00400\end{array}$ & $\begin{array}{l}6 \\
8\end{array}$ & & & & & \\
\hline $\begin{array}{l}10155104 \\
10155105\end{array}$ & 0.04525 & 10 & & & & & \\
\hline & compos. & int & & & & & \\
\hline 10155201 & & 8 & & & & & \\
\hline 10155202 & 3 & 10 & & & & & \\
\hline & source & int & & & & & \\
\hline 10155301 & 0.0 & 10 & & & & & \\
\hline
\end{tabular}

temperature flag

* $\quad$ temperature pt

vol inc

101555010150600000

10155502015070000

1015550301508000000000

$10155601-900 \quad$ inc

$10155602-900$

$10155603-900$

0

* source type mult

$\begin{array}{llll}\text { type } & \text { code } & \text { factor } & \text { hs } \\ 1 & 1 & 0.475 & 1 \\ 1 & 1 & 0.275 & 2 \\ 1 & 1 & 0.470 & 3 \\ 1 & 1 & 0.510 & 9\end{array}$

101557010

type code factor

* 10155800

10155800 Dhe LHEf LHEr LGSf LGSr Kfwd Krev Fboil nclf povd $f f$ hs

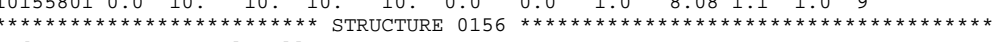
downcomer external wall

*ht str ht.strs m.pts geom init l.coord refl b.vol ax.incr.

$10156100 \quad \begin{array}{lll}\text { loc } & \text { flag }\end{array}$

* $\mathrm{dx}$ in

$\begin{array}{lll}0156101 & 0.00132 & 2\end{array}$

$\begin{array}{lll}10156103 & 0.00396\end{array}$

$\begin{array}{lll}10156104 & 0.00527 & 8 \\ 10156105 & 0.04080 & 10\end{array}$

10156201 compos. $\quad 8$

(1)

$\begin{array}{lll}* & \text { source } & \text { int } \\ 10156301 & 0.0 & 10\end{array}$

* temperature flag

$\begin{array}{lll}* & \text { temperature } & \mathrm{pt} \\ 10156401 & 563.15 & 11\end{array}$

*

$\begin{array}{lllllll}* & \text { vol } & \text { inc } & \text { type } & \text { code } & \text { factor } & \text { hs } \\ 10156501 & 015050000 & 0 & 1 & 1 & 0.345 & 1\end{array}$

$\begin{array}{lllccll}* & \text { vol } & \text { inc } & \text { type } & \text { code } & \text { factor } & \text { hs } \\ 10156601-900 & 0 & 4910 & 1 & 0.345 & 1\end{array}$

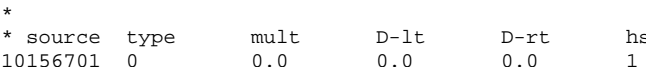

$10156800{ }^{1}$ LHEf LHEr LGSf LGSr Kfwd Krev Fboil nclf povd ff hs

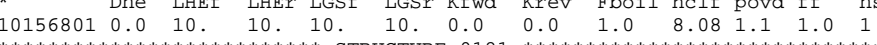

downcomer external wal 
$\begin{array}{ccccccccc}* \text { ht str ht.strs } & \text { m.pts } & \text { geom } & \text { init } & 1 . \text { coord } & \text { refl b.vol ax.incr. } \\ 10181000 & 1 & 11 & 2 & 1 & 0.08650 & 0 & & \end{array}$

* 10181100 0 0

$\begin{array}{lll}* & \text { floc } & \text { fla } \\ 10181100 & 0 & 2\end{array}$

* dx int

$\begin{array}{lll}10181101 & 0.00107 & 2 \\ 10181102 & 0.00214 & 0\end{array}$

$\begin{array}{lll}10181103 & 0.00321 & 6\end{array}$

$10181104 \quad 0.00428$

*

10181201 compos. $\quad$ in

$10181202 \quad 3 \quad 10$

$\begin{array}{lll}* & \text { source } & \text { int } \\ 10181301 & 0.0 & 10\end{array}$

temperature fla

* $10181400 \stackrel{\text { tem }}{0}$

* temperature pt

+

$\begin{array}{lllllll}* & \text { vol } & \text { inc } & \text { type } & \text { code } & \text { factor } & \text { hs } \\ 10181501 & 018010000 & 0 & 1 & 1 & 0.826 & 1\end{array}$

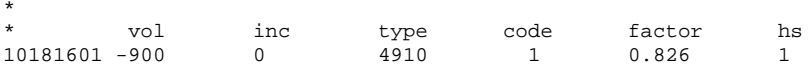

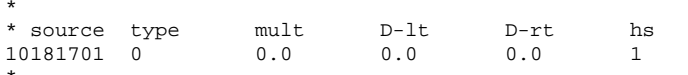

$10181800{ }^{1}$ LHEf LHEr LGSf LGSr Kfwd Krev Fboil nclf povd $f f$

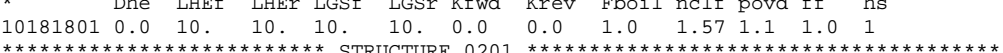

* downcomer external wall

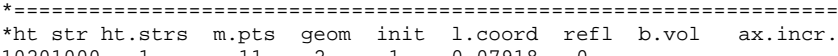

$\begin{array}{lll}* & \text { loc } & \text { flag } \\ 10201100 & 0 & 2\end{array}$

* $\quad \mathrm{dx}$ int

$\begin{array}{lll}10201101 & 0.00189 \\ 10201102 & 0.00379 & 2\end{array}$

$10201103 \quad 0.00568$

$\begin{array}{lll}10201104 & 0.00758 & 8 \\ 10201105 & 0.02648 & 10\end{array}$

$\begin{array}{lll}* & \text { compos. } & \text { int } \\ 10201201 & 1 & 8 \\ 10201202 & 3 & 10\end{array}$

$\begin{array}{lll}* & \text { source } & \text { int } \\ 10201301 & 0.0 & 10\end{array}$

* $\quad$ temperature flag

* temperature pt

10201401 temperature pt

vol inc type code factor hs

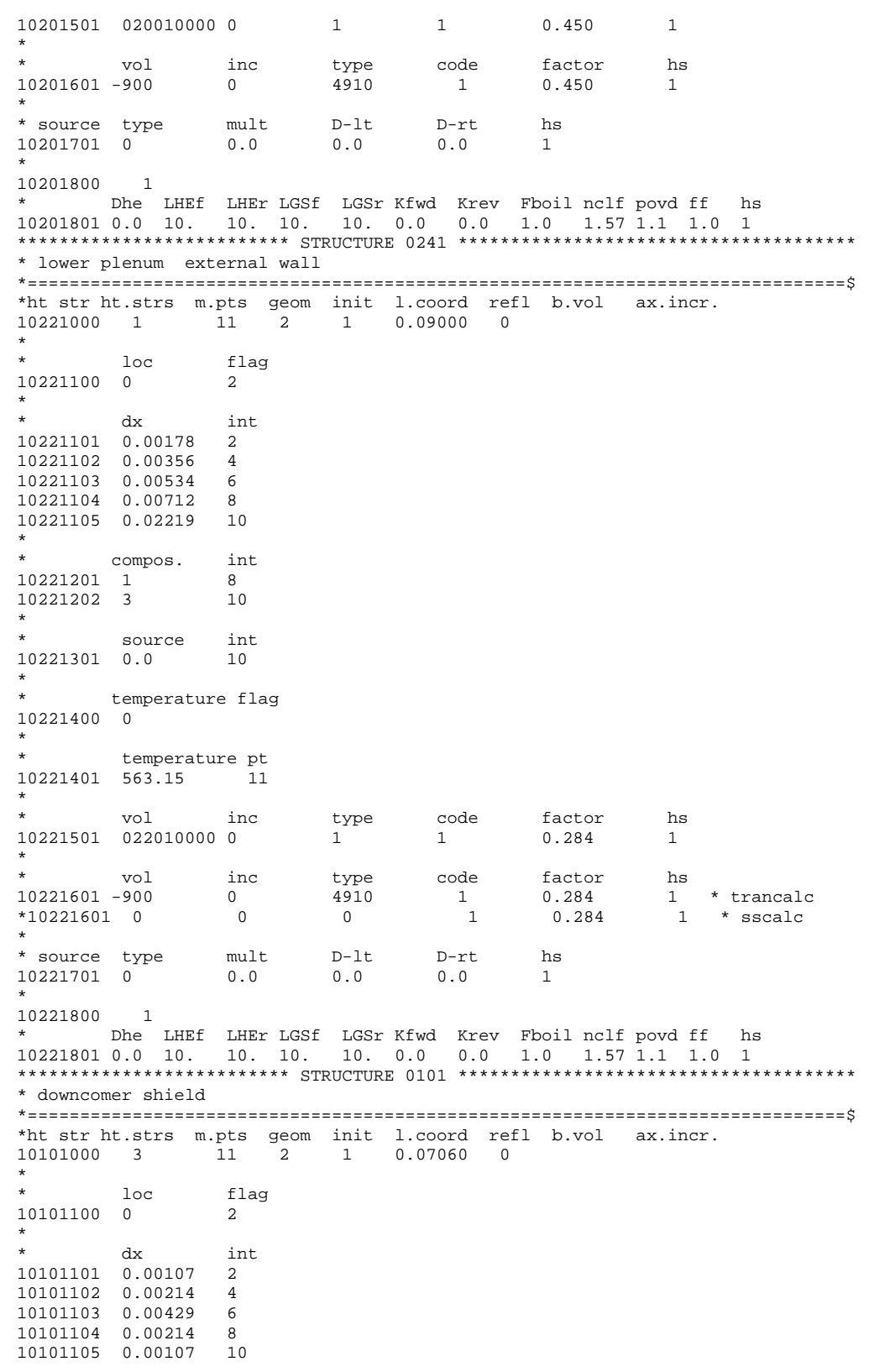


$\begin{array}{lll}* & \text { compos. } & \text { int } \\ 1^{*} & 101201 & 1\end{array}$

$\begin{array}{lll}* & \text { source } & \text { int } \\ 10101301 & 0.0 & 10\end{array}$

* temperature flag

$10101400 \quad 0$

* temperature pt

* vol inc

$\begin{array}{lll}* & \text { vol } & \text { inc } \\ 10101501 & 015020000 & 0\end{array}$

0101502015030000

10101601015020000 inc

10101602010010000

01016030120100000

$\begin{array}{llllll}\text { * source } & \text { type } & \text { mult } & \text { D-lt } & \text { D-rt } & \text { hs } \\ 10101701 & 0 & 0.0 & 0.0 & 0.0 & 3\end{array}$

1010180011

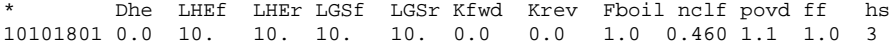
$10101900 \quad 1$

01019010.0 LHef LHEr LGSf LGSr Kfwd Krev Fboil nclf povd ff hs

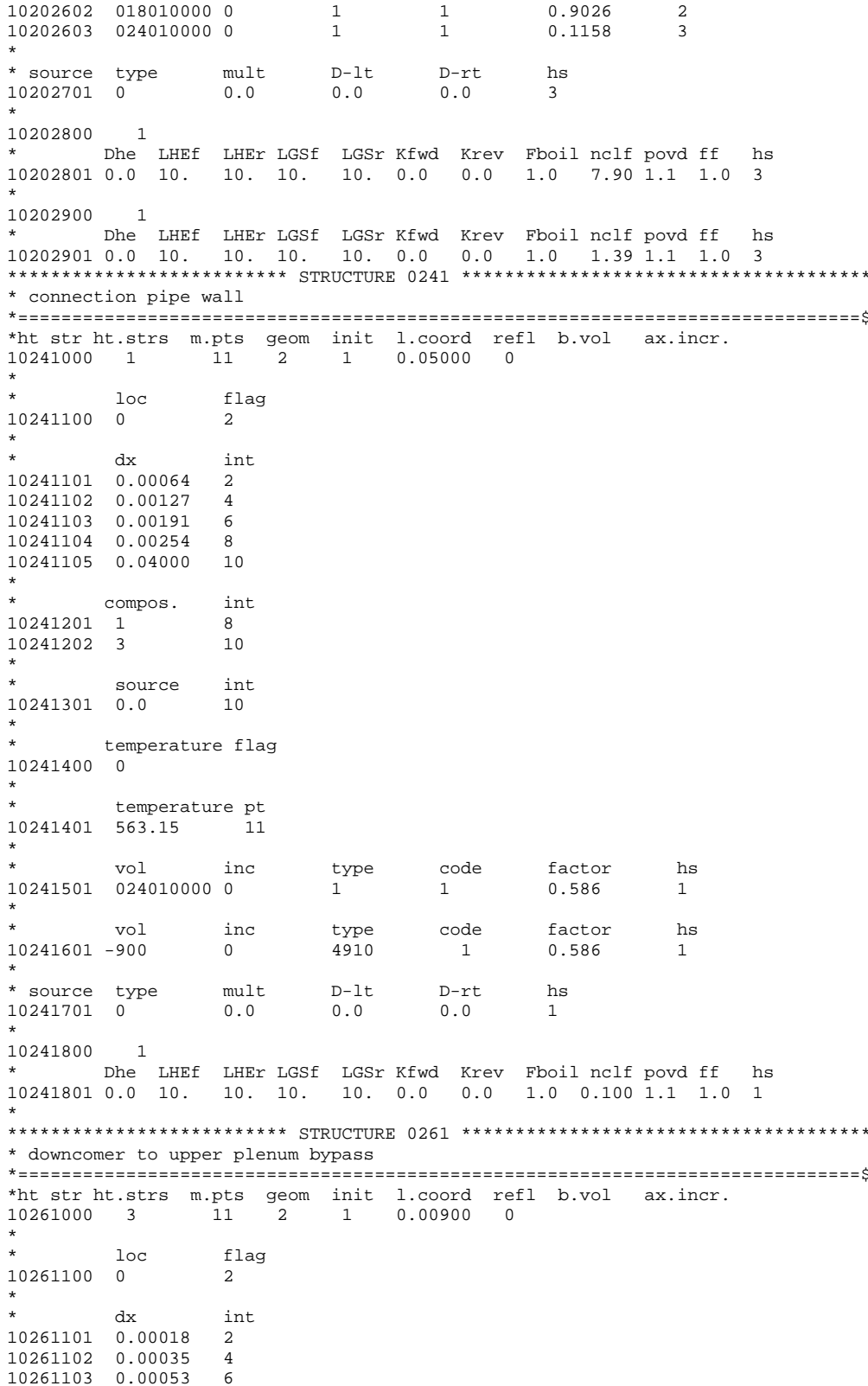




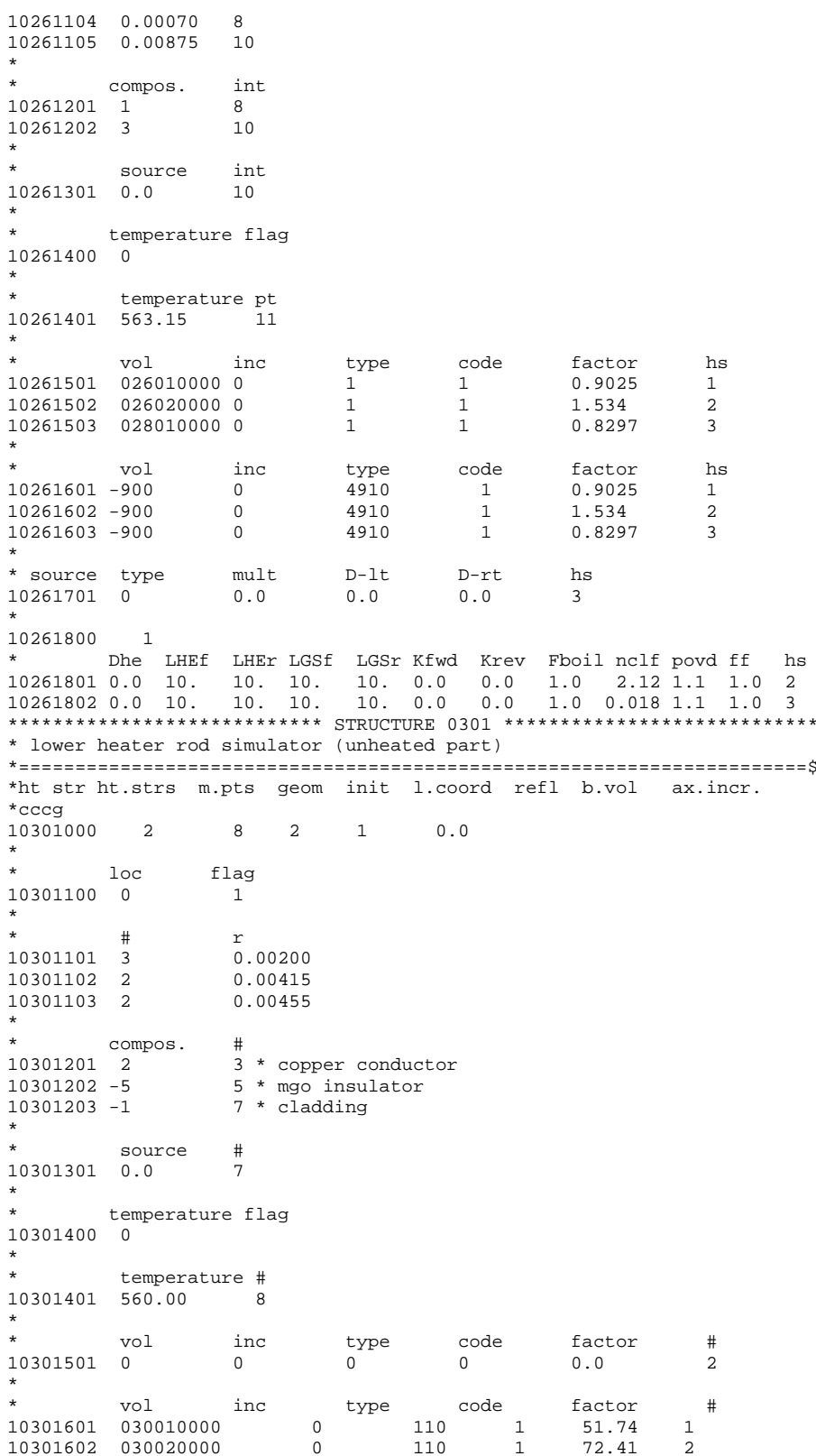

* lower heater rod simulator (unheated part)

*ht str ht.strs m.pts geom init 1.coord refl b.vol ax.incr.

$\begin{array}{llllll}10301000 & 2 & 8 & 2 & 1 & 0.0\end{array}$

$\begin{array}{ccc}* & \text { loc } & \text { flag } \\ 10301100 & 0 & 1\end{array}$

$\begin{array}{lll}* & \# & r \\ 10301101 & 3 & 0.00200\end{array}$

$\begin{array}{lll}10301102 & 2 & 0.00200 \\ 10301103 & 2 & 0.00415 \\ + & 0.00455\end{array}$

$\begin{array}{lll}10301103 & 2 \\ * & \text { compos. \# }\end{array}$

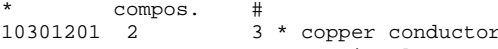
$\begin{array}{ll}10301202-5 & 5 * \text { mgo insulator } \\ 10301203-1 & 7 * \text { cladding }\end{array}$

$10301203-1$

$\begin{array}{lll}* & \text { source \# } \\ 10301301 & 0.0 & \#\end{array}$

* temperature flag

$10301400 \quad 0$

* temperature \#

$\begin{array}{lllllll}* & \text { vol } & \text { inc } & \text { type } & \text { code } & \text { factor } & \# \\ 10301501 & 0 & 0 & 0 & 0 & 0.0 & 2\end{array}$

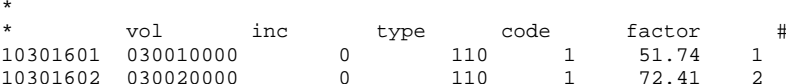

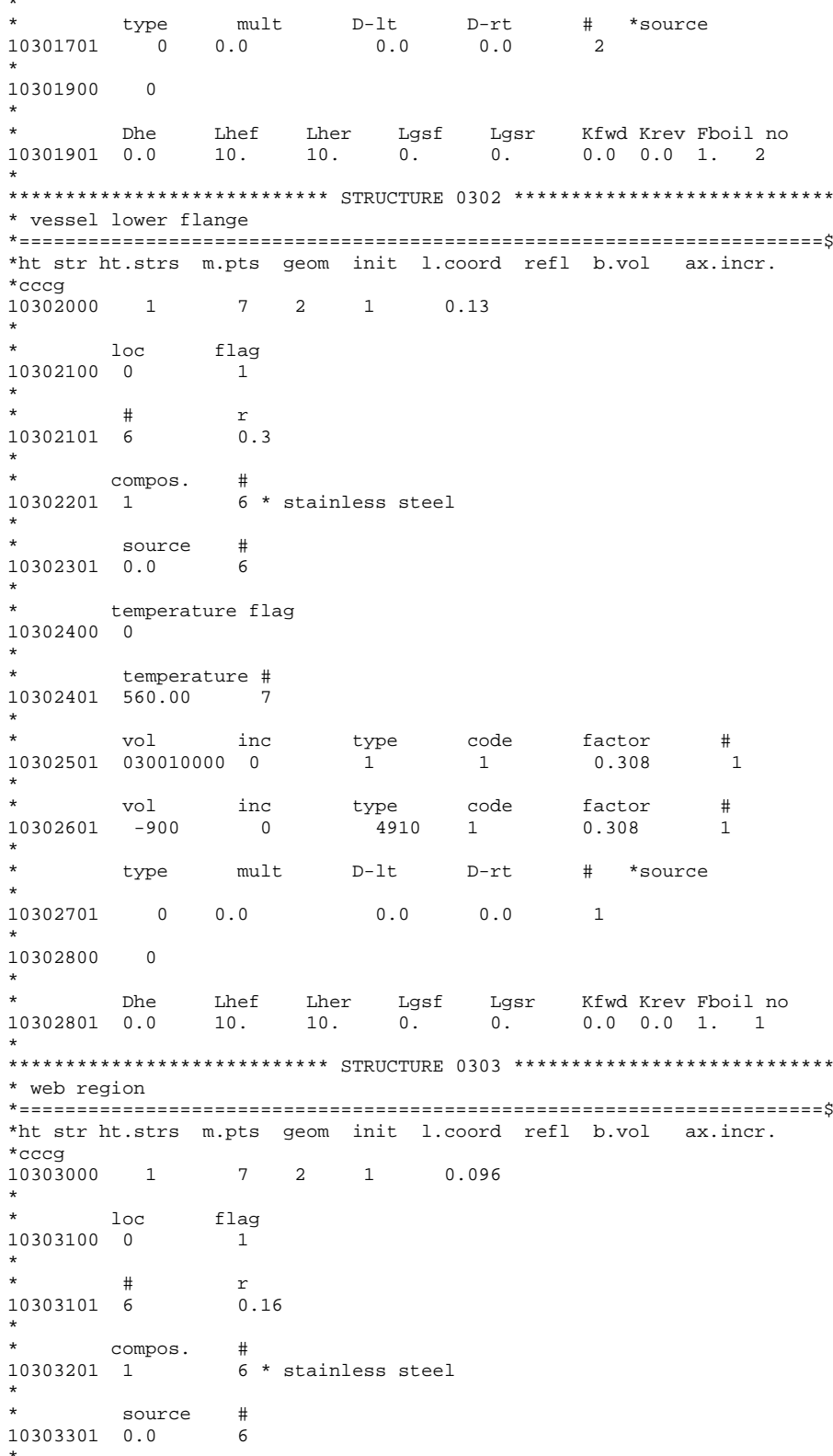




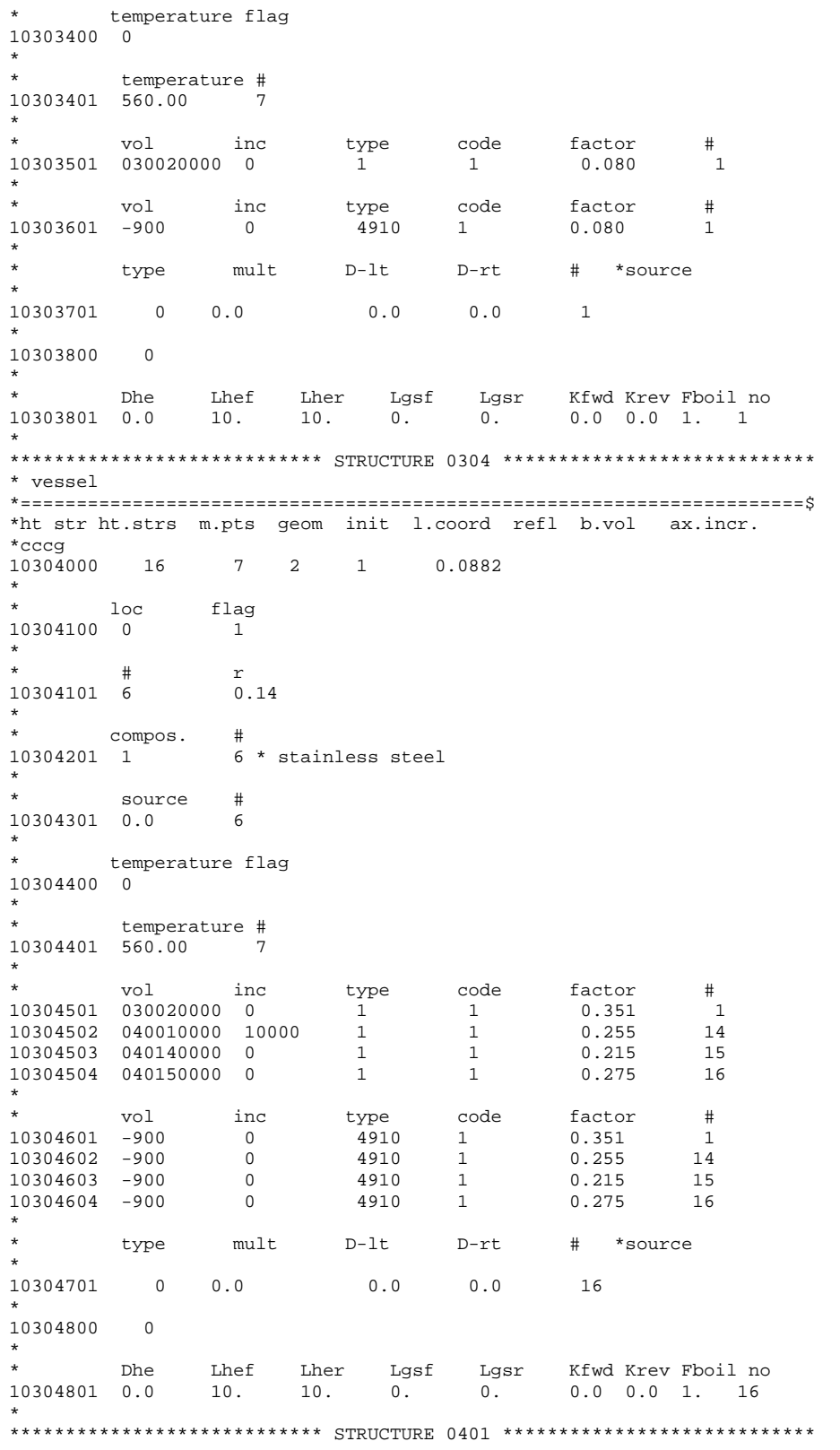

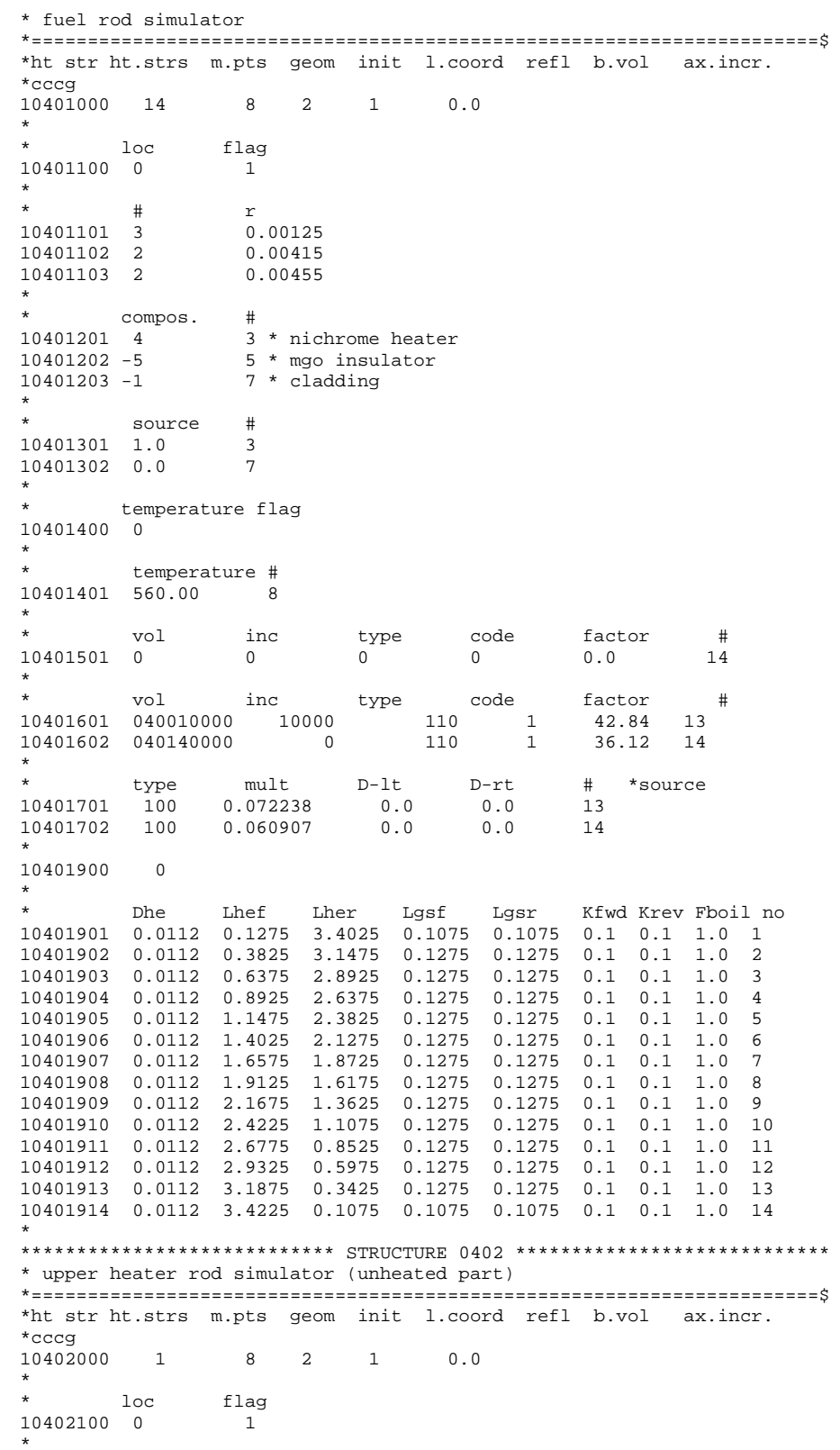




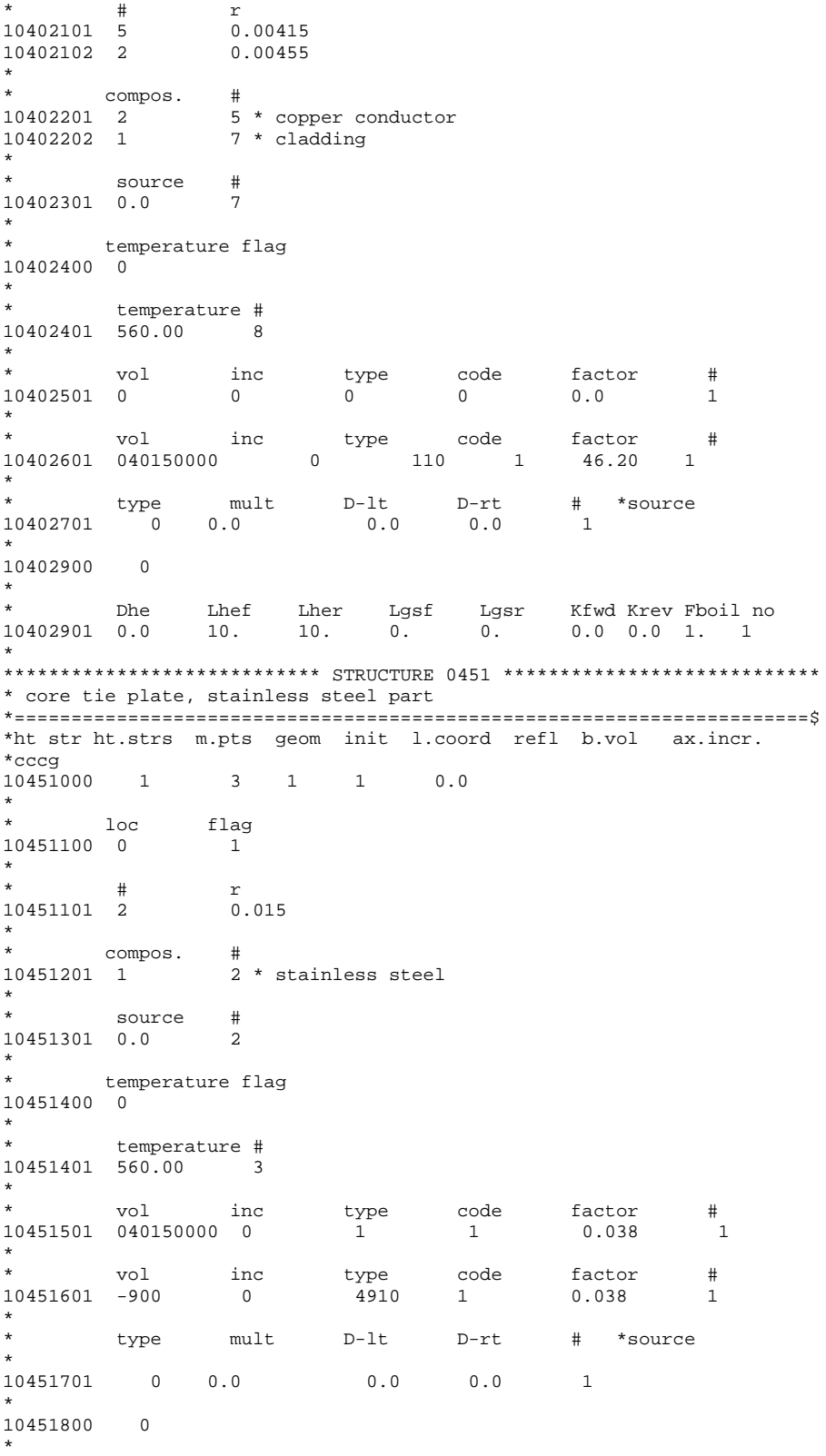

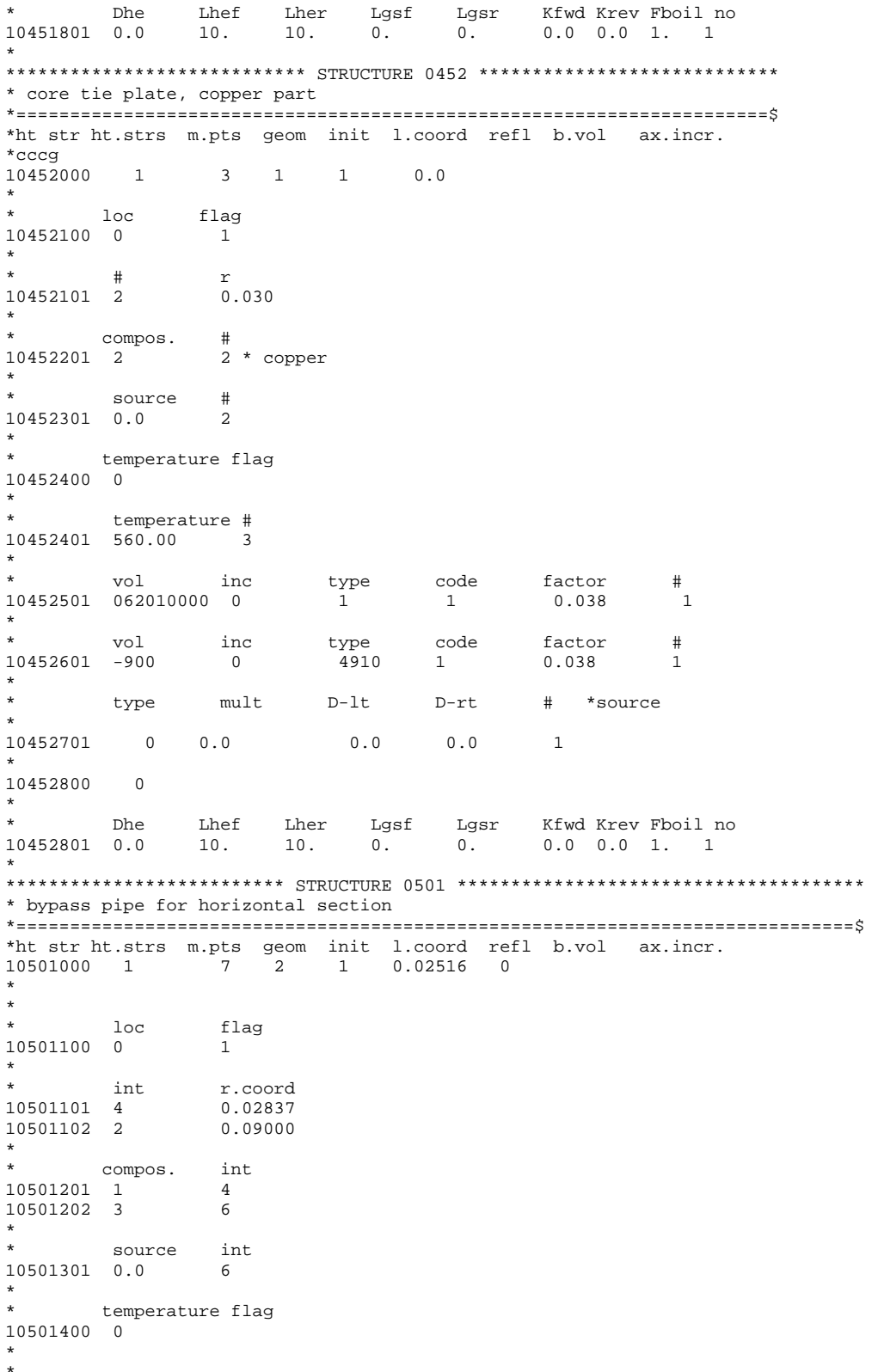




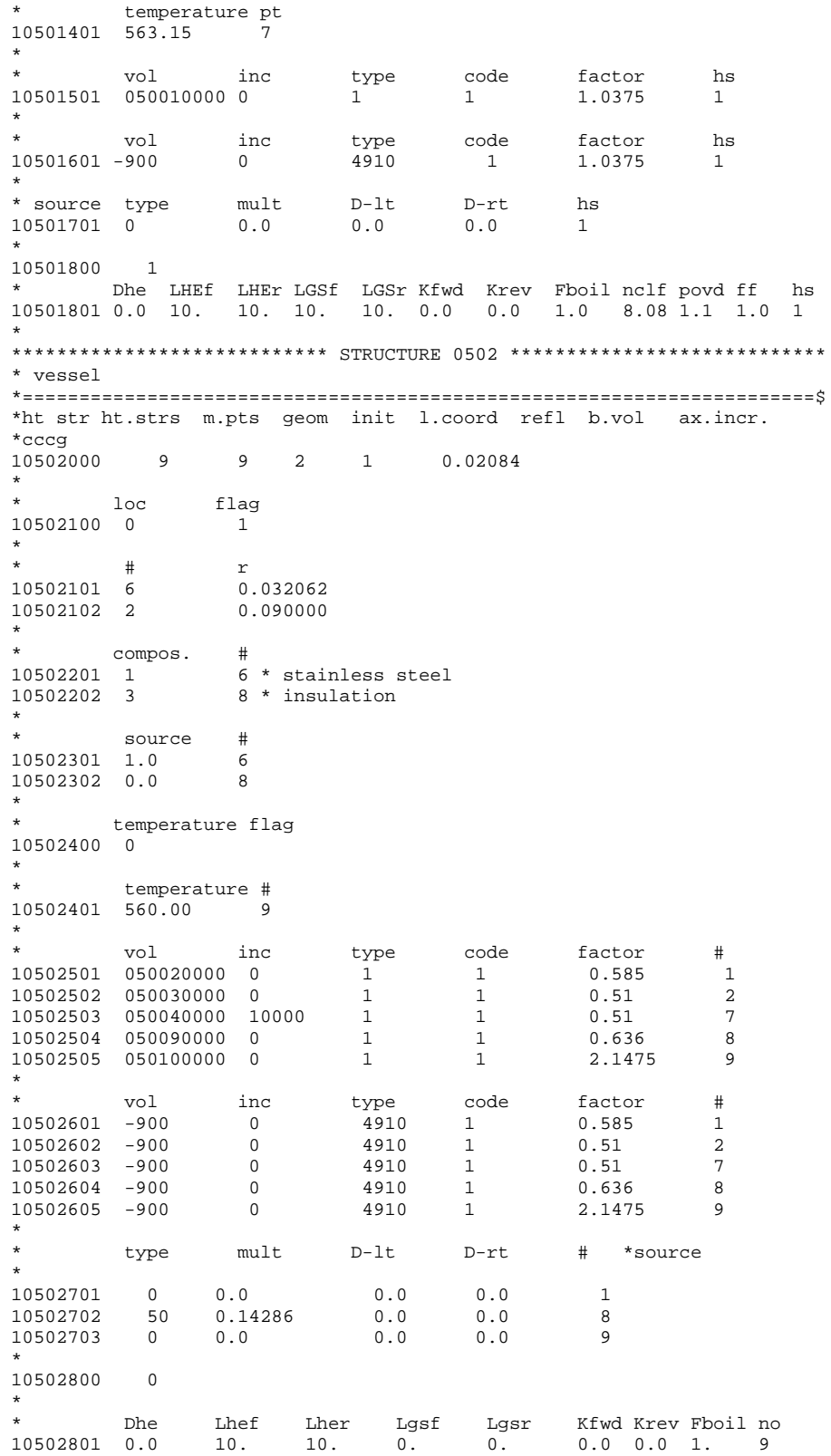

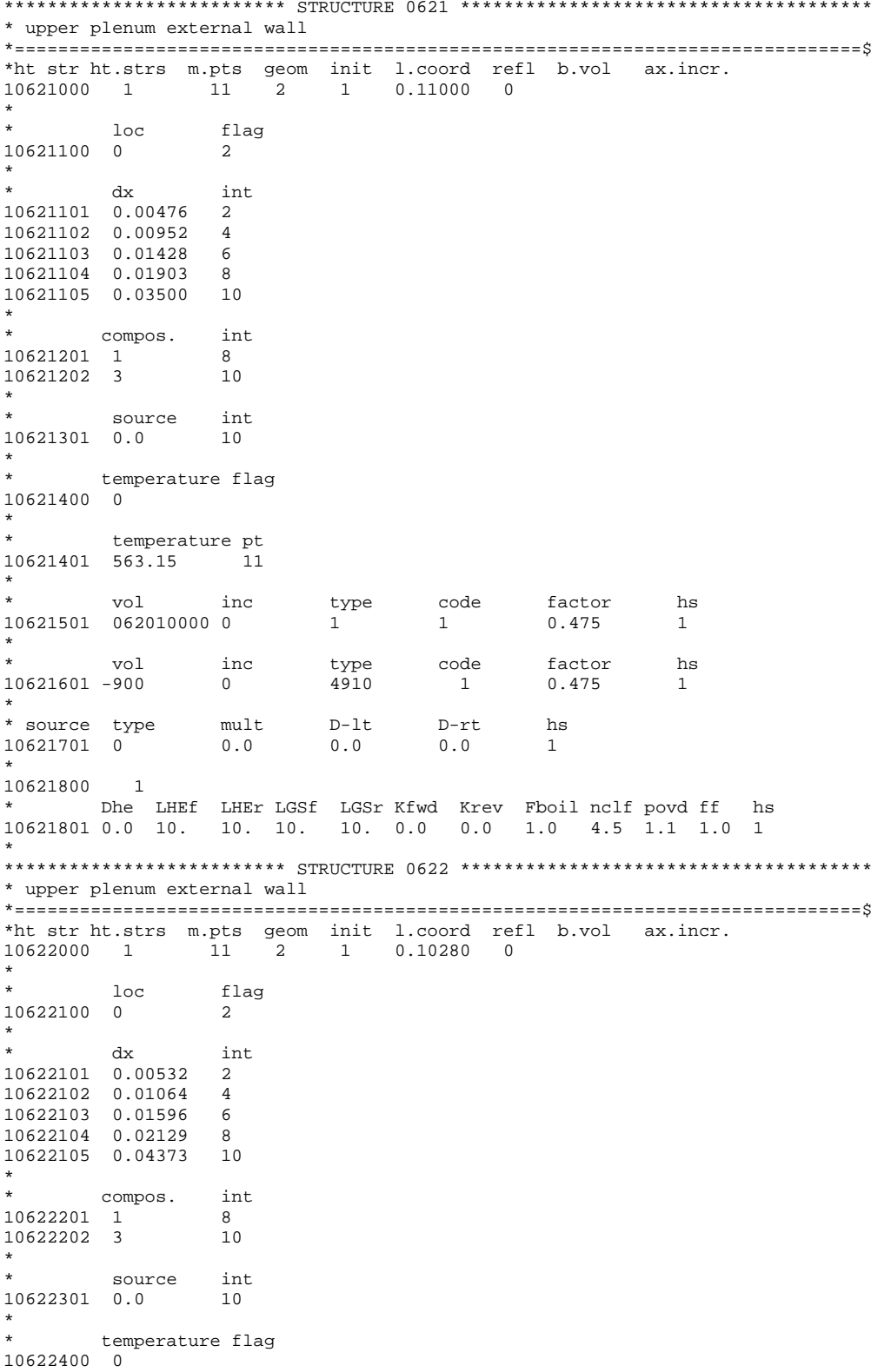




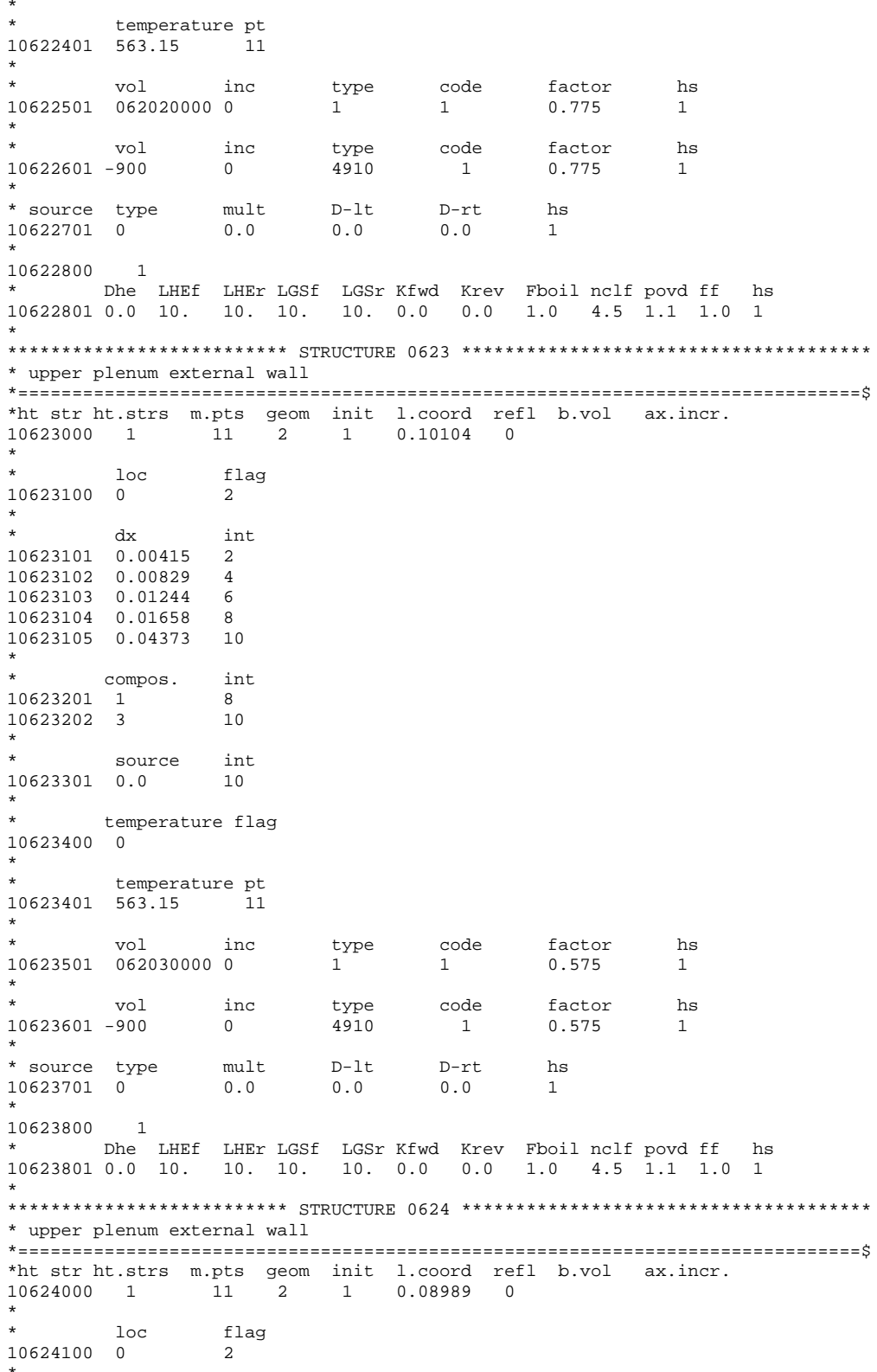




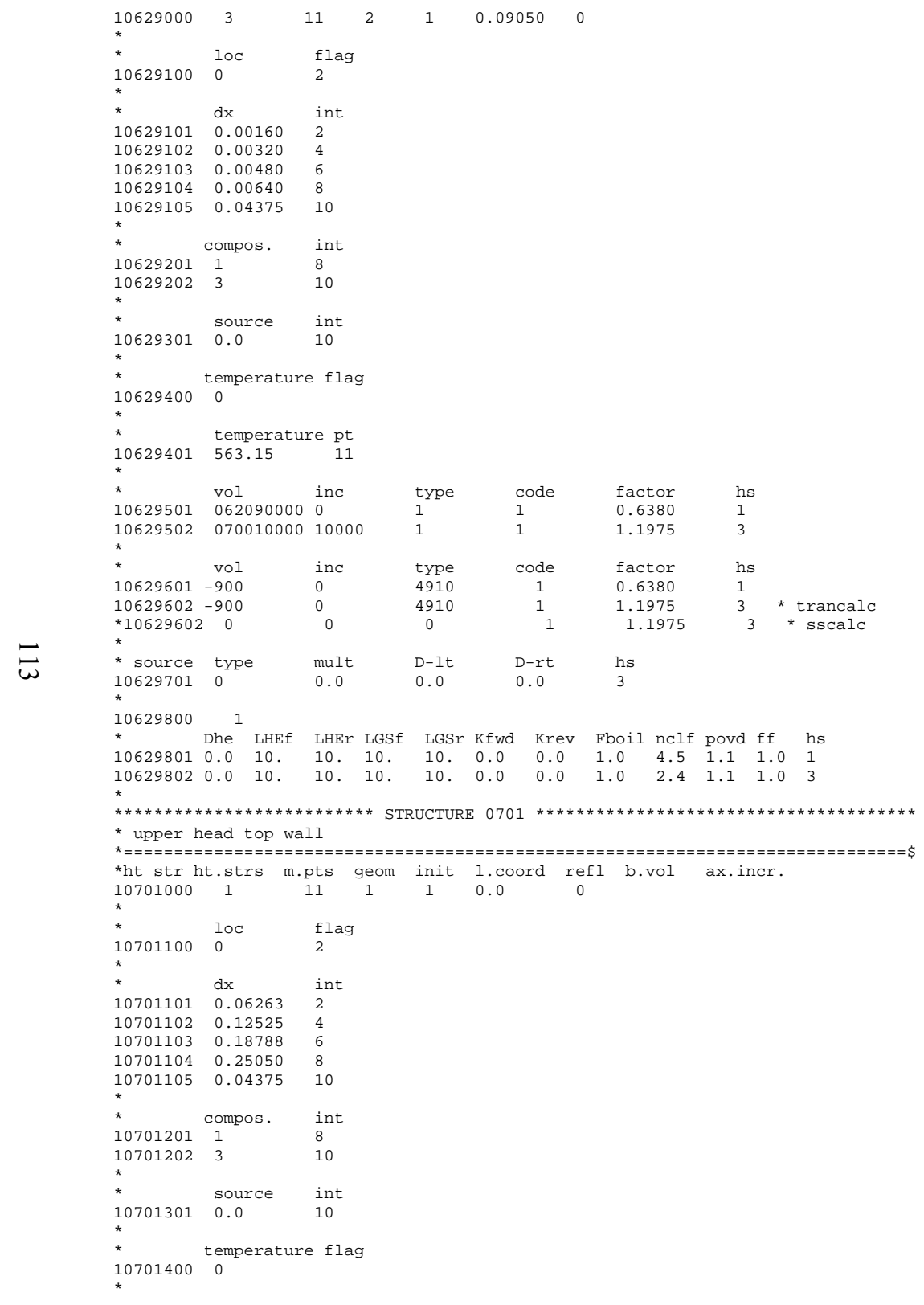



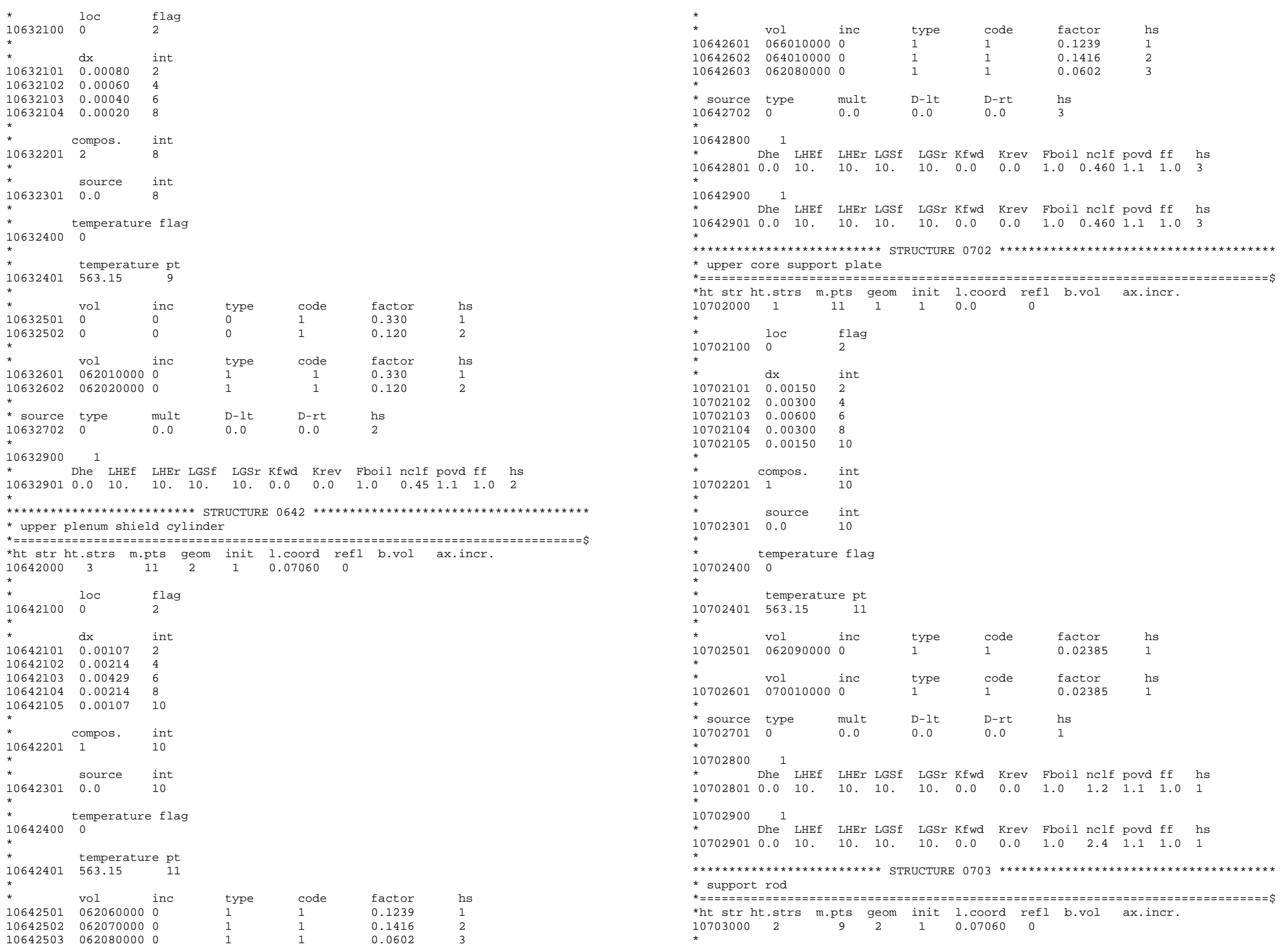

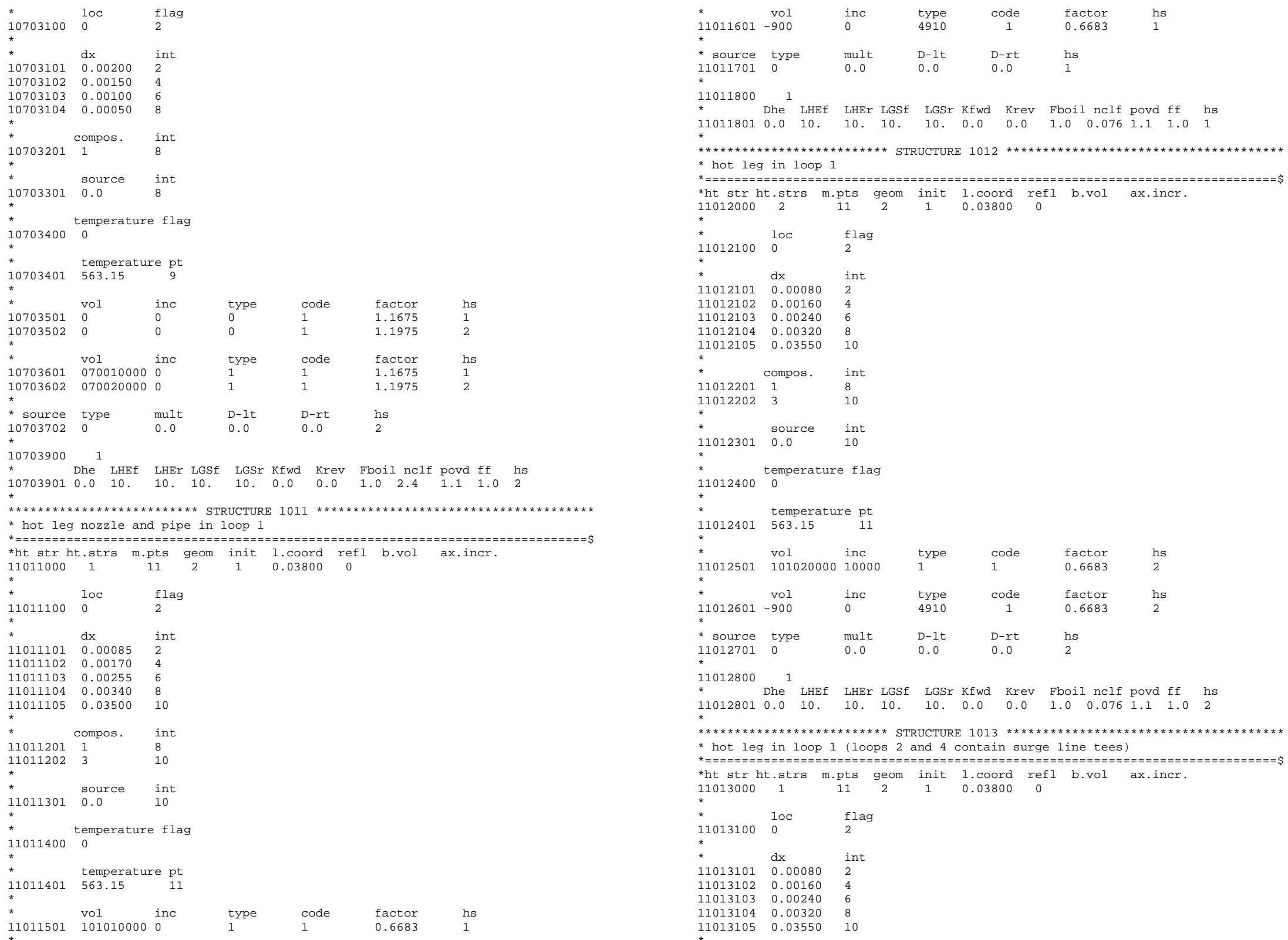


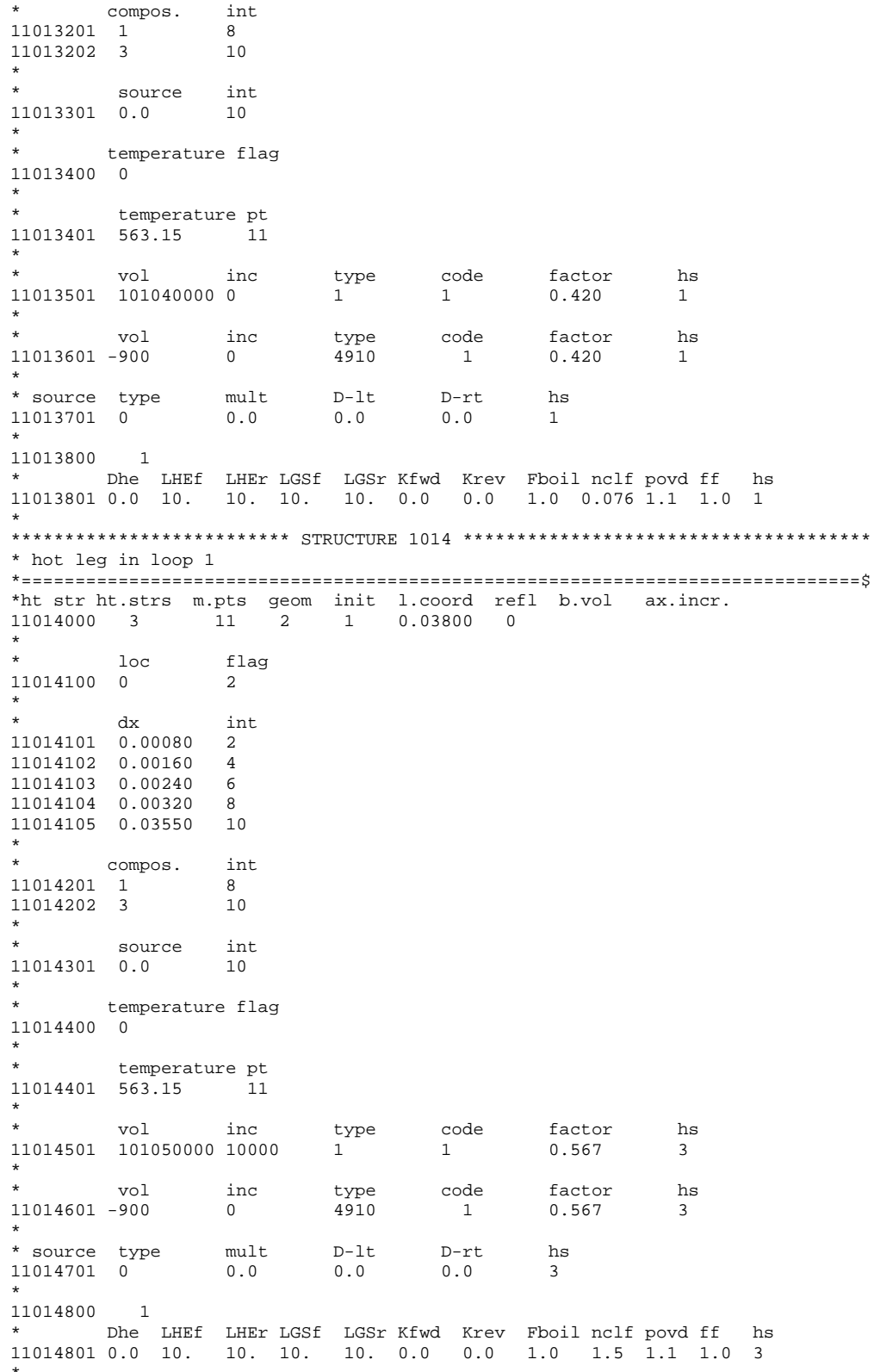

* compos. int

$\begin{array}{lll}11013201 & 1 & 8 \\ 11013202 & 3 & 10\end{array}$

* Source int

* temperature flag

$11013400 \quad 0$

* temperature pt

*

¿ 11013501 vol $1010400000^{\text {inc }}$

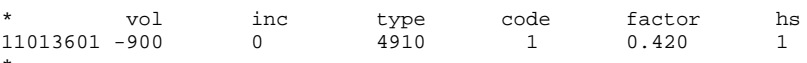

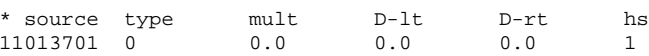

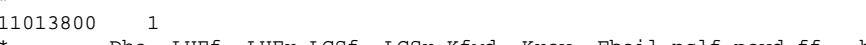

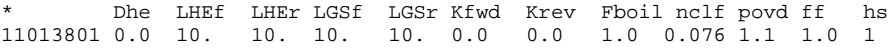

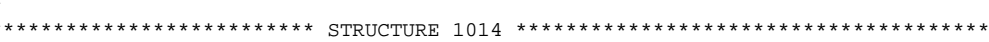

* hot leg in loop 1

*ht str ht. strs m.pts geom init 1. coord refl b.vol ax.incr.

$\begin{array}{lll}* & \text { floc } & \text { flag } \\ 11014100 & 0 & 2\end{array}$

* $\quad \mathrm{dx}$ int

$\begin{array}{ll}11014101 & 0.00080 \\ 11014102 & 0.00160\end{array}$

$\begin{array}{ll}1014103 & 0.00240\end{array}$

$\begin{array}{lll}11014104 & 0.00320 & 8 \\ 11014105 & 0.03550 & 10\end{array}$

$\begin{array}{lll}* & \text { compos. } & \text { int } \\ 11014201 & 1 & 8 \\ 11014202 & 3 & 10\end{array}$

$\begin{array}{lll}* & \text { source } & \text { int } \\ 11014301 & 0.0 & 10\end{array}$

* temperature flag

* temperature pt

$\begin{array}{lll}11014401 & 563.15 \quad 11\end{array}$

$\begin{array}{lllllll}* & \text { vol } & \text { inc } & \text { type } & \text { code } & \text { factor } & \text { hs } \\ 11014501 & 101050000 & 10000 & 1 & 1 & 0.567 & 3\end{array}$

$\begin{array}{lllccll}* & \text { vol } & \text { inc } & \text { type } & \text { code } & \text { factor } & \text { hs } \\ & * & 4910 & 1 & 0.567 & 3\end{array}$

$\begin{array}{llllll}* & \text { mult } & \text { D-1t } & \text { D-rt } & \text { hs } \\ \text { * source } & \text { type } & \text { mult } & \text { D } & \text { D } & \text {. } \\ 11014701 & 0 & 0.0 & 0.0 & 0.0 & 3\end{array}$

*

$11014800{ }^{1}{ }^{1}$ LHEf LHEr LGS LGSr KfWd Krev Fboil nclf povd ff hs

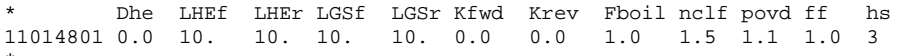

* hot collector in loop 1

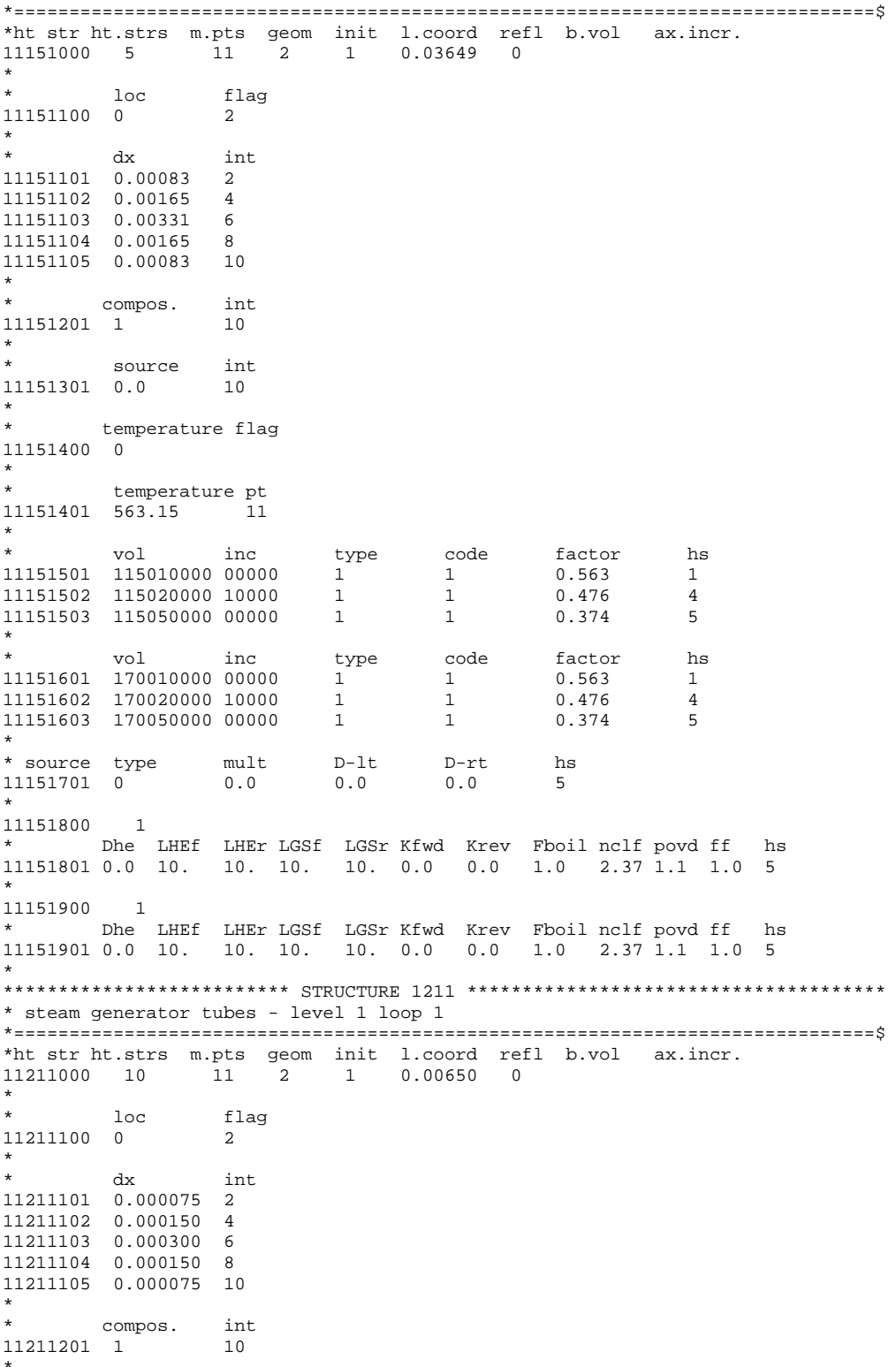


$\begin{array}{lll}* & \text { source } & \text { int } \\ 11211301 & 0.0 & 10\end{array}$

* temperature flag

11211400

$\begin{array}{lll}* & \text { temperature } \mathrm{pt} \\ 11211401 & 563.15 & 11\end{array}$

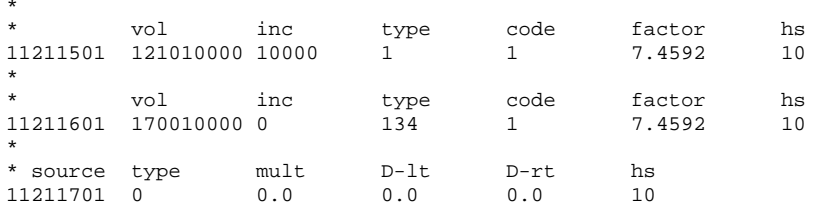

* 1211701 type mult D-1t D-rt hs

$\begin{array}{lll}11211800 \quad 1 & 1 & 0.0\end{array}$

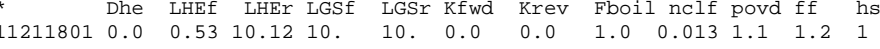
$\begin{array}{lllllllllllll}11211802 & 0.0 & 1.60 & 9.06 & 10 . & 10 . & 0.0 & 0.0 & 1.0 & 0.013 & 1.1 & 1.2 & 2\end{array}$

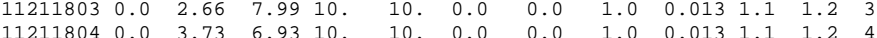

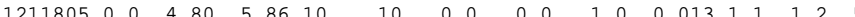
$\begin{array}{llllllllllllll}11211806 & 0.0 & 5.86 & 4.80 & 10 . & 10 . & 0.0 & 0.0 & 1.0 & 0.013 & 1.1 & 1.2 & 6\end{array}$ $\begin{array}{lllllllllllll}11211807 & 0.0 & 6.93 & 3.73 & 10 . & 10 . & 0.0 & 0.0 & 1.0 & 0.013 & 1.1 & 1.2 & 7\end{array}$ $\begin{array}{lllllllllllll}11211808 & 0.0 & 7.99 & 2.66 & 10 . & 10 . & 0.0 & 0.0 & 1.0 & 0.013 & 1.1 & 1.2 & 8 \\ 11211809 & 0.0 & 9.06 & 1.60 & 10 . & 10 . & 0.0 & 0.0 & 1.0 & 0.013 & 1.1 & 1.2 & 9\end{array}$ $\begin{array}{lllllllllllll}11211809 & 0.0 & 9.06 & 1.60 & 10 . & 10 . & 0.0 & 0.0 & 1.0 & 0.013 & 1.1 & 1.2 & 9 \\ 11211810 & 0.0 & 10.12 & 0.53 & 10 . & 10 . & 0.0 & 0.0 & 1.0 & 0.013 & 1.1 & 1.2 & 10\end{array}$ $11211900 \quad 1$

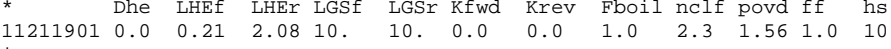

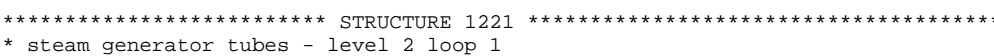

*ht str ht.strs m.pts geom init l.coord refl b.vol ax.incr.

$\begin{array}{llllllll}11221000 & 10 & 11 & 2 & 1 & 0.00650 & 0\end{array}$

* $\quad$ loc flag

* $\quad$ temperature flag

$\begin{array}{lll}* & \text { temperature pt } \\ 11221401 & 563.15 & 11\end{array}$

$\begin{array}{lllllll}\star & \text { vol } & \text { inc } & \text { type } & \text { code } & \text { factor } & \text { hs } \\ 11221501 & 122010000 & 10000 & 1 & 1 & 7.4592 & 10\end{array}$

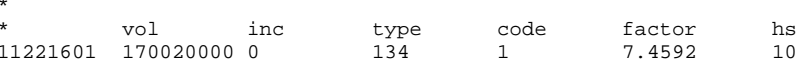

$\begin{array}{llllll}11221601 & 170020000 & 0 & 134 & 1 & 7.45 \\ * & & & & \\ * & \text { source } & \text { type } & \text { mult } & \text { D-lt } & \text { D-rt }\end{array}$

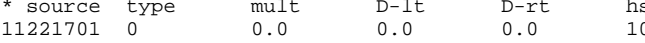

$11221800{ }^{1}$ LHEf LHEr LGSf LGSr KfWd Krev Fboil nclf povd ff hs

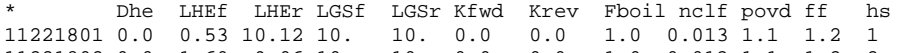
$\begin{array}{lllllllllllll}11221802 & 0.0 & 1.60 & 9.06 & 10 . & 10 . & 0.0 & 0.0 & 1.0 & 0.013 & 1.1 & 1.2 & 2\end{array}$ $\begin{array}{lllllllllllll}11221803 & 0.0 & 2.66 & 7.99 & 10 . & 10 . & 0.0 & 0.0 & 1.0 & 0.013 & 1.1 & 1.2 & 3 \\ 11221804 & 0.0 & 3.73 & 6.93 & 10 . & 10 . & 0.0 & 0.0 & 1.0 & 0.013 & 1.1 & 1.2 & 4\end{array}$ $\begin{array}{llllllllllllll}11221805 & 0.0 & 4.80 & 5.86 & 10 . & 10 . & 0.0 & 0.0 & 1.0 & 0.013 & 1.1 & 1.2 & 5\end{array}$ $\begin{array}{lllllllllllll}11221806 & 0.0 & 5.86 & 4.80 & 10 . & 10 . & 0.0 & 0.0 & 1.0 & 0.013 & 1.1 & 1.2 & 6\end{array}$ $\begin{array}{lllllllllllll}11221808 & 0.0 & 7.99 & 2.66 & 10 . & 10 . & 0.0 & 0.0 & 1.0 & 0.013 & 1.1 & 1.2 & 8\end{array}$

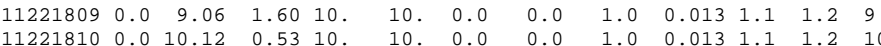
* 1221900 Dhe LHEf LHEr LGSf LGSr Kfwd Krev Fboil nclf povd ff hs

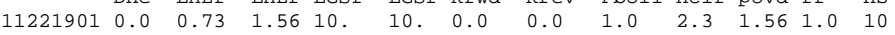
* * *ht str ht. strs m.pts geom init 1. coord refl b.vol ax.incr.

$\begin{array}{ll}\star & \text { loc } \\ 11231100 & 1211\end{array}$

* temperature flag

$\begin{array}{lll}* & \text { temperature } & \mathrm{pt} \\ 11231401 & 563.15 & 11\end{array}$

* 11231501 vol 123010000 inc 10000

$\begin{array}{lllllll}* & \text { vol } & \text { inc } & \text { type } & \text { code } & \text { factor } & \text { hs } \\ 11231601 & 170030000 & 0 & 134 & 1 & 7.4592 & 10\end{array}$

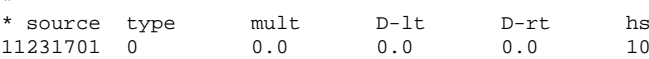

11231800 Dhe LHEf LHEr LGSf LGSr Kfwd Krev Fboil nclf povd ff hs

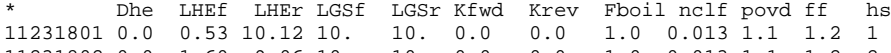
$\begin{array}{lllllllllllll}11231802 & 0.0 & 1.60 & 9.06 & 10 . & 10 . & 0.0 & 0.0 & 1.0 & 0.013 & 1.1 & 1.2 & 2\end{array}$ $\begin{array}{lllllllllllll}11231805 & 0.0 & 4.80 & 5.86 & 10 . & 10 . & 0.0 & 0.0 & 1.0 & 0.013 & 1.1 & 1.2 & 5\end{array}$ $\begin{array}{lllllllllllll}11231806 & 0.0 & 5.86 & 4.80 & 10 . & 10 . & 0.0 & 0.0 & 1.0 & 0.013 & 1.1 & 1.2 & 6 \\ 11231807 & 0.0 & 6.93 & 3.73 & 10 . & 10 . & 0.0 & 0.0 & 1.0 & 0.013 & 1.1 & 1.2 & 7\end{array}$ $\begin{array}{llllllllllllll}11231808 & 0.0 & 7.99 & 2.66 & 10 . & 10 . & 0.0 & 0.0 & 1.0 & 0.013 & 1.1 & 1.2 & 8\end{array}$

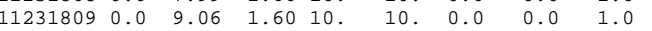

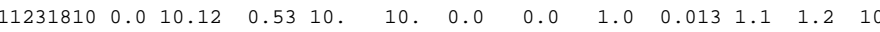
11231900

Dhe LHEf LHEr LGSf LGSr Kfwd Krev Fboil nclf povd ff hs $\begin{array}{lllllllllllll}11231901 & 0.0 & 1.21 & 1.09 & 10 . & 10 . & 0.0 & 0.0 & 1.0 & 2.3 & 1.56 & 1.0 & 10\end{array}$ $\star$
$\star$
$*$ steam generator tubes - level 4 loop 1

*ht str ht.strs m.pts geom init 1. coord refl b.vol ax.incr.

* $11241100 \quad$ loc $1211 \quad$ flag

$*$
$11241400 \quad 0$
$*$

* temperature pt

$\begin{array}{lllllll}* & \text { vol } & \text { inc } & \text { type } & \text { code } & \text { factor } & \text { hs } \\ 11241501 & 124010000 & 10000 & 1 & 1 & 7.4592 & 10\end{array}$

* vol inc type code factor hs 


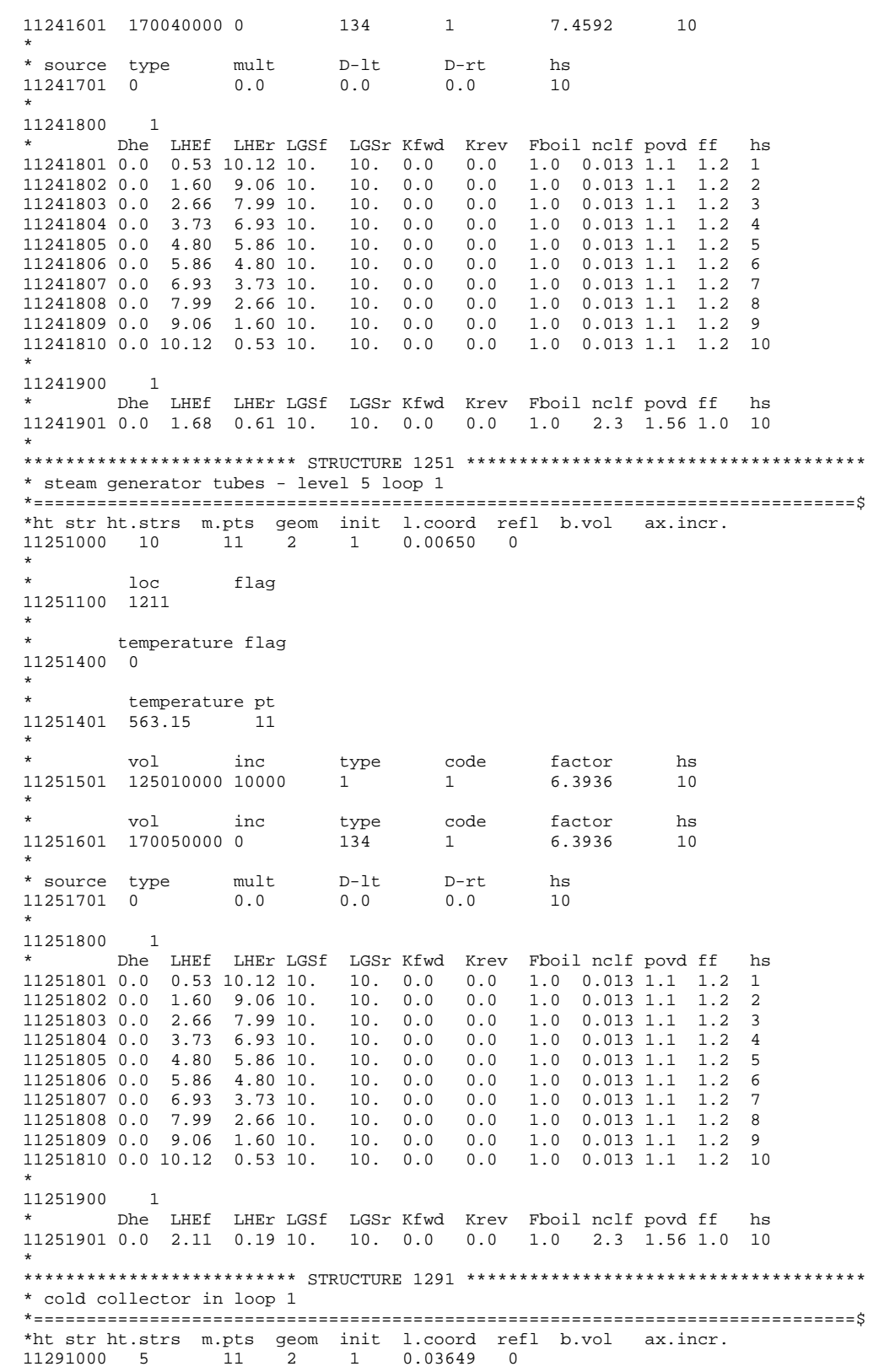

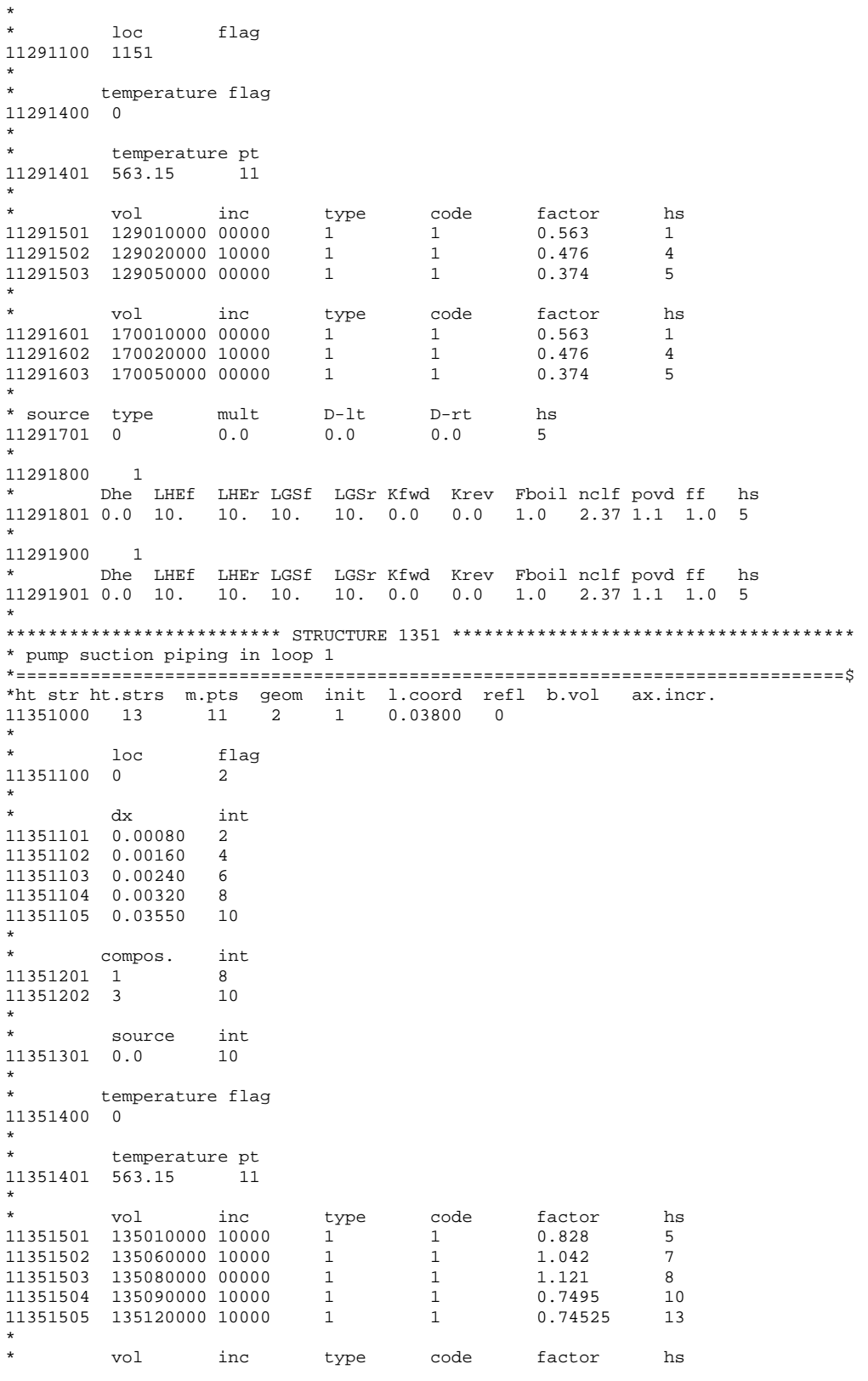




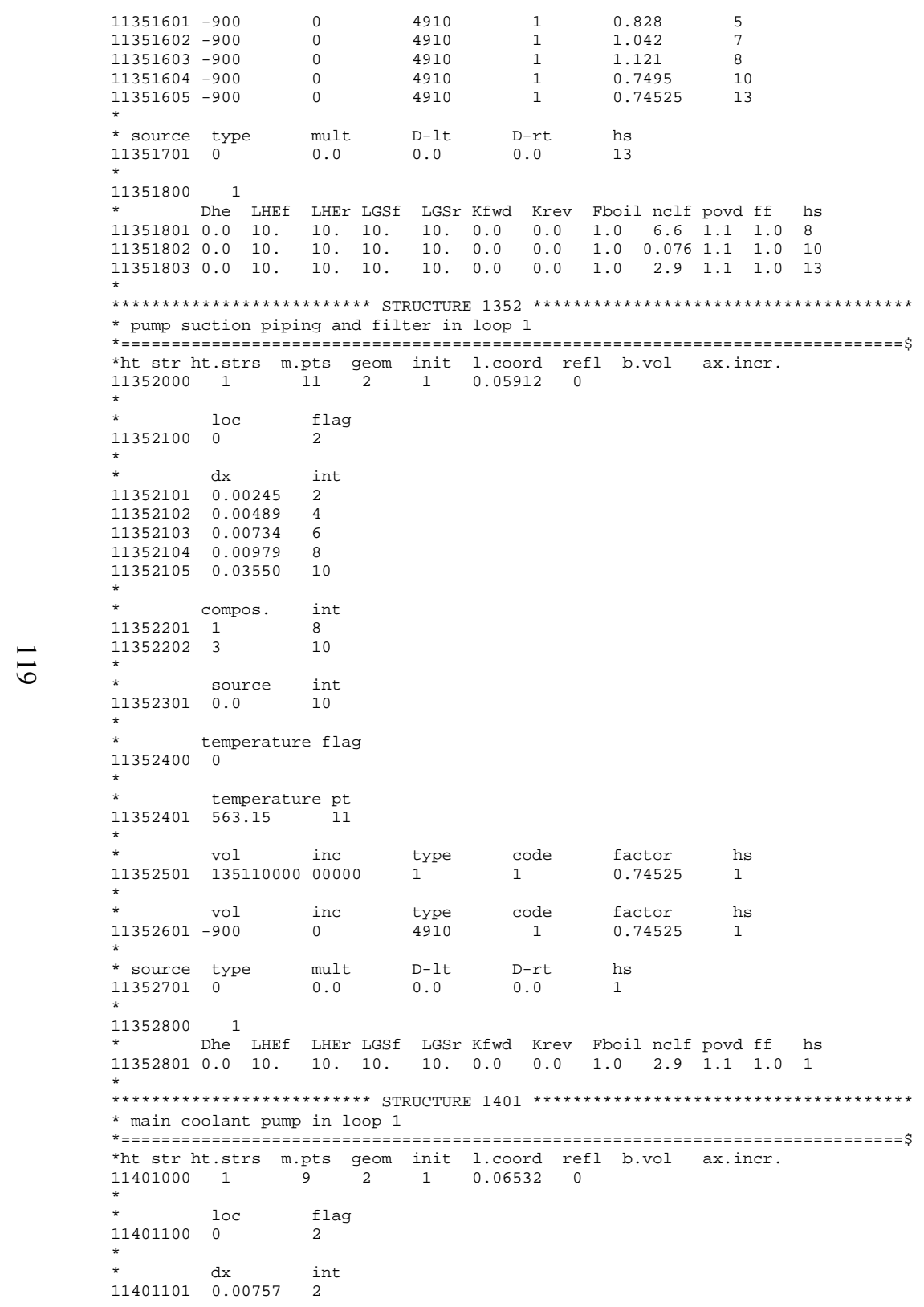




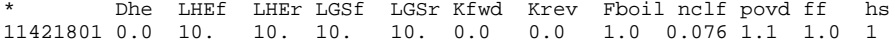

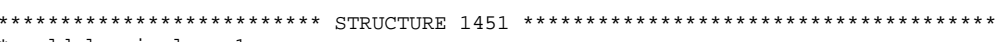

* cold leg in loop 1

*ht str ht.strs m.pts geom init $\begin{aligned} & 1 . \text { coord } \\ & 11451000 \\ & 4\end{aligned}$

flag

* $\mathrm{dx}$ int

$\begin{array}{lll}11451101 & 0.00080 \\ 11451102 & 0.00160 & 2\end{array}$

$\begin{array}{ll}11451102 & 0.00160 \\ 11451103 & 0.00240\end{array}$

$\begin{array}{ll}11451104 & 0.00320\end{array}$

$\begin{array}{lll}1451105 & 0.03550 \quad 10\end{array}$

compos. in

$\begin{array}{lll}11451201 & 1 & 8 \\ 11451202 & 3 & 10\end{array}$

* source int

* $\quad$ temperature flag

$\begin{array}{ll}* & \text { temperature pt } \\ 11451401 & 563.15\end{array}$

$\begin{array}{lllllll}* & \text { vol } & \text { inc } & \text { type } & \text { code } & \text { factor } & \text { hs } \\ 11451501 & 145010000 & 10000 & 1 & 1 & 0.782 & 3\end{array}$

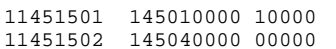$$
\begin{array}{lll}
114516 \\
114516
\end{array}
$$$$
11451602-900
$$

ton -900

$\begin{array}{rl}\text { source } & \text { type } \\ 11451701 & 0\end{array}$

* $11451800 \quad 1$

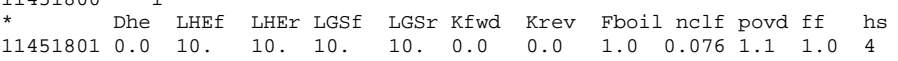

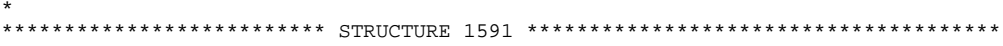

* feedwater header for loop 1

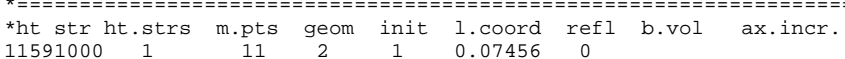

$\begin{array}{lll}* & \text { loc } & \text { flag } \\ 11591100 & 0 & 2\end{array}$

* ${ }^{*} \quad \mathrm{dx}$ int

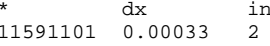

$\begin{array}{lll}11591102 & 0.00066 \\ 11591103 & 0.00133 & \end{array}$

$\begin{array}{lll}11591103 & 0.00133 \\ 11591104 & 0.00066\end{array}$

$\begin{array}{lll}11591104 & 0.00066 & 8 \\ 11591105 & 0.00033 & 10\end{array}$

$\begin{array}{lll}* & \text { compos. } & \text { int } \\ 11591201 & 1 & 10\end{array}$

source int

$\begin{array}{lll}11591301 & \text { source } & \text { int } \\ 0.0 & 10\end{array}$

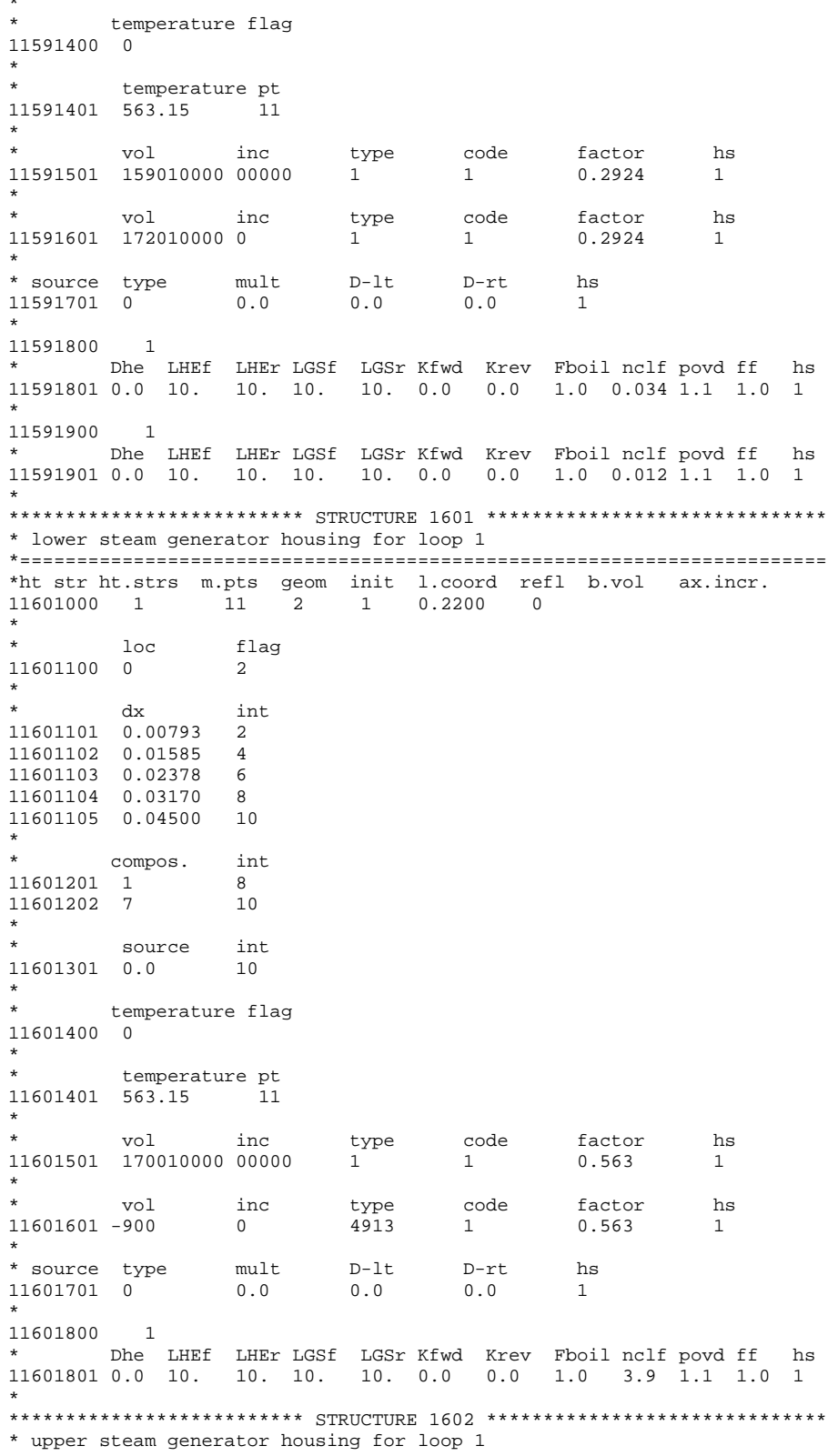




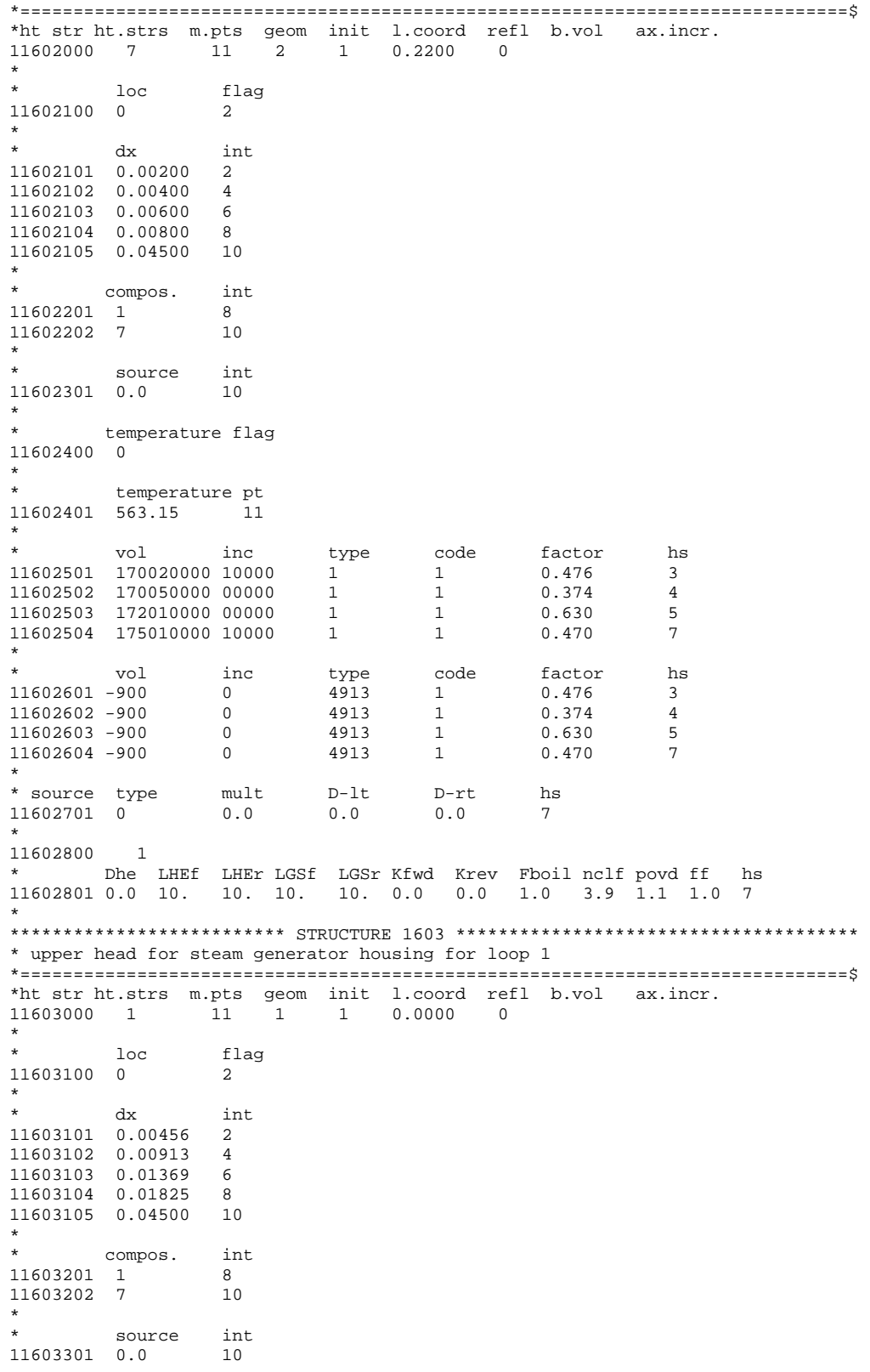


$\begin{array}{llllclccc}* \text { tht str ht.strs } & \text { m.pts } & \text { geom } & \text { init } & 1 . \text { coord } & \text { refl b.vol ax.incr. } \\ 12011000 & 1 & 11 & 2 & 1 & 0.03800 & 0 & & \end{array}$ 100

$\begin{array}{lll}* & 2 \\ * & \mathrm{dx} & 2 \\ * & & \end{array}$

$\begin{array}{lll}12011101 & 0.00085 \quad 2\end{array}$

$12011102 \quad 0.00170$

$\begin{array}{ll}12011103 & 0.00255 \\ 12011104 & 0.00340\end{array}$

$12011105 \quad 0.00340$

compos. in

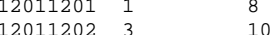

$\begin{array}{lll}* & \text { source } & \text { int } \\ 12011301 & 0.0 & 10\end{array}$

*

* $12011400 \stackrel{\text { tem }}{0}$

* temperature pt

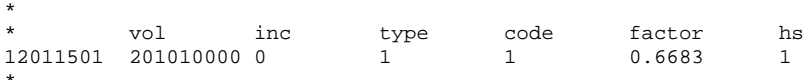

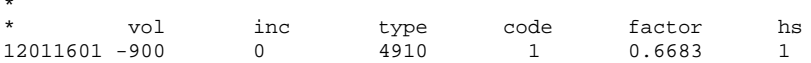

$\begin{array}{llllll}* \text { source } & \text { type } & \text { mult } & \text { D-1t } & \text { D-rt } & \text { hs } \\ 12011701 & 0 & 0.0 & 0.0 & 0.0 & 1\end{array}$

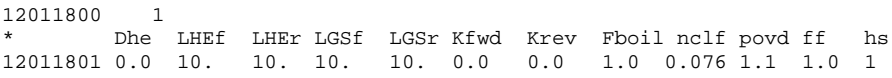

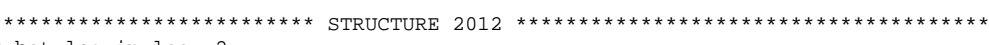

* hot leg in loop 2

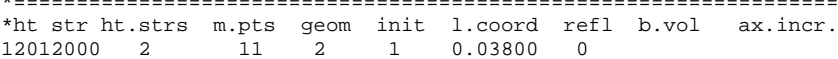

*

$\begin{array}{lll}* & \text { loc } & \text { flag } \\ 12012100 & 0 & 2\end{array}$

* $\mathrm{dx}$ int

$\begin{array}{ll}12012101 & 0.00080 \\ 12012102 & 0.00160\end{array}$

$12012103 \quad 0.00240$

$\begin{array}{lll}12012104 & 0.00320 & 8 \\ 12012105 & 0.03550 & 10\end{array}$

* 12012201 compos. $\quad$ int

$12012202 \quad 3 \quad 10$

$\begin{array}{lll}* & \text { source } & \text { int } \\ 12012301 & 0.0 & 10\end{array}$

* temperature flag

$\begin{array}{lll}* & \text { temperature pt } \\ 12012401 & 563.15 & 11\end{array}$

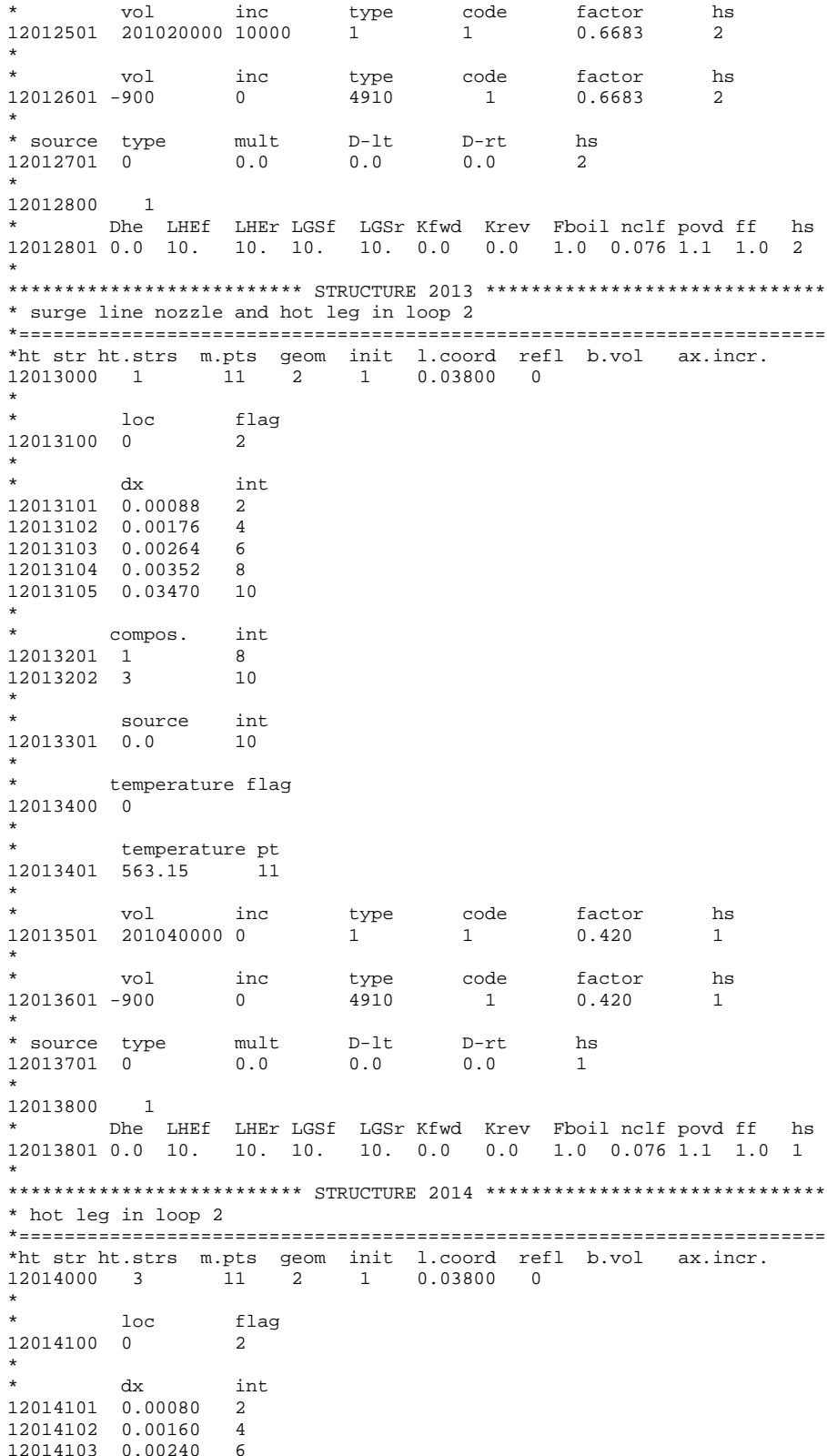




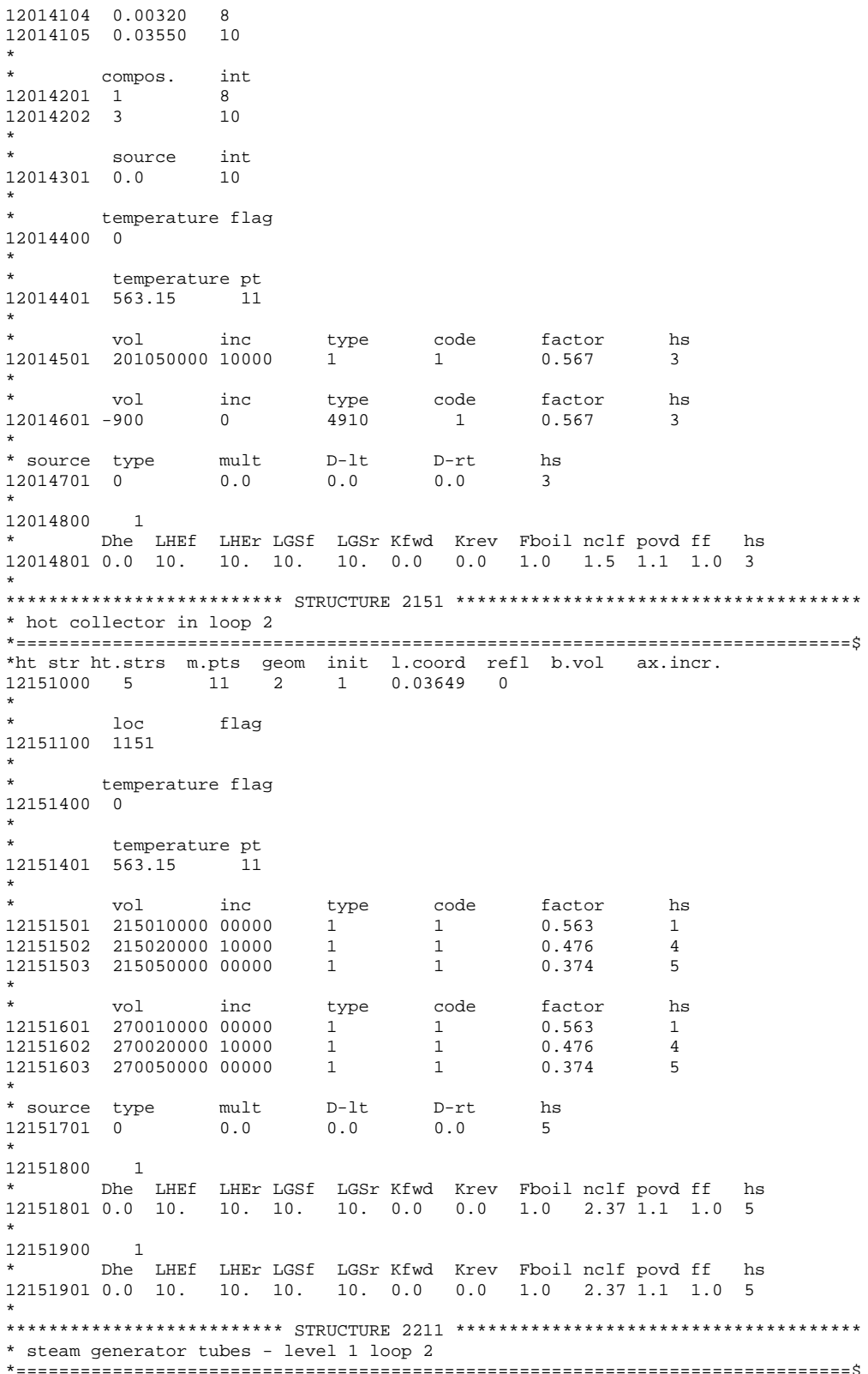

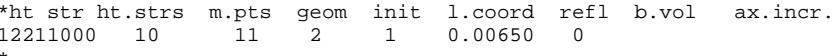

* $\mathrm{dx}$ int

$\begin{array}{lll}12211101 & 0.000075 & 2 \\ 12211102 & 0.000150 & 4\end{array}$

$\begin{array}{lll}12211102 & 0.000150 & 4 \\ 12211103 & 0.000300 & 6\end{array}$

$\begin{array}{lll}12211103 & 0.000300 & 6 \\ 12211104 & 0.000150 & 8 \\ .2211105 & 0.000075 & 10\end{array}$

$\begin{array}{lll}* & \text { compos. } & \text { int } \\ 12211201 & 1 & 10\end{array}$

* 12211301 source int

*

$12211400 \stackrel{\text { te }}{0}$

$\begin{array}{ll}* & \text { temperature pt } \\ 12211401 \quad 563.15 & 11\end{array}$

$\begin{array}{lllllll}* & \text { vol } & \text { inc } & \text { type } & \text { code } & \text { factor } & \text { hs } \\ 12211501 & 221010000 & 10000 & 1 & 1 & 7.4592 & 10\end{array}$

$\begin{array}{lllllll}* & \text { vol } & \text { inc } & \text { type } & \text { code } & \text { factor } & \text { hs } \\ 12211601 & 270010000 & 0 & 134 & 1 & 7.4592 & 10\end{array}$

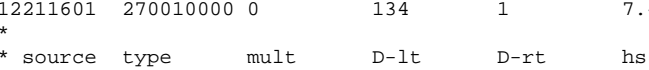

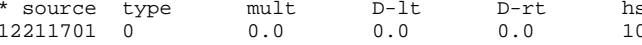

$12211800{ }^{1}$ LhEf LHEr LGSf LGSr Kfwd Krev Fboil nclf povd ff hs

Dhe LHEf LHEr LGSf LGSr Kfwd Krev Fboil nclf povd ff hs $\begin{array}{rrrrrrrrrrrrr}12211801 & 0.0 & 0.53 & 10.12 & 10 . & 10 . & 0.0 & 0.0 & 1.0 & 0.013 & 1.1 & 1.2 & 1 \\ 12211802 & 0.0 & 1.60 & 9.06 & 10 . & 10 . & 0.0 & 0.0 & 1.0 & 0.013 & 1.1 & 1.2 & 2\end{array}$ $\begin{array}{llllllllllllll}12211803 & 0.0 & 2.66 & 7.99 & 10 . & 10 . & 0.0 & 0.0 & 1.0 & 0.013 & 1.1 & 1.2 & 3\end{array}$

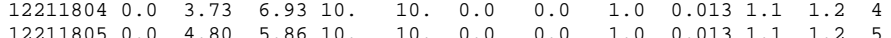
$\begin{array}{lllllllllllll}12211805 & 0.0 & 4.80 & 5.86 & 10 . & 10 . & 0.0 & 0.0 & 1.0 & 0.013 & 1.1 & 1.2 & 5 \\ 12211806 & 0.0 & 5.86 & 4.80 & 10 . & 10 . & 0.0 & 0.0 & 1.0 & 0.013 & 1.1 & 1.2 & 6\end{array}$ $\begin{array}{lllllllllllll}12211806 & 0.0 & 5.86 & 4.80 & 10 . & 10 . & 0.0 & 0.0 & 1.0 & 0.013 & 1.1 & 1.2 & 6 \\ 12211807 & 0.0 & 6.93 & 3.73 & 10 . & 10 . & 0.0 & 0.0 & 1.0 & 0.013 & 1.1 & 1.2 & 7\end{array}$ $\begin{array}{llllllllllllll}12211808 & 0.0 & 7.99 & 2.66 & 10 . & 10 . & 0.0 & 0.0 & 1.0 & 0.013 & 1.1 & 1.2 & 8\end{array}$

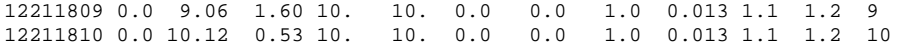
$12211900 \quad 1$

* Dhe LHEf LHEr LGSf LGSr Kfwd Krev Fboil nclf povd ff hs $\begin{array}{lllllllllllll}90 & 0.0 & 0.21 & 2.08 & 10 & 10 . & 0.0 & 0.0 & 1.0 & 2.3 & 1.56 & 1.0 & 10\end{array}$

* steam generator tubes - level 2 loop 2

*ht str ht.strs m.pts geom init 1.coord refl b.vol ax.incr.
*he

$12221100 \quad 121$

* temperature flag

$12221400 \quad 0$

$\begin{array}{lll}* & \text { temperature pt } \\ 12221401 & 563.15 & 11\end{array}$

$\begin{array}{lllllll}* & \text { vol } & \text { inc } & \text { type } & \text { code } & \text { factor } & \text { hs } \\ 12221501 & 222010000 & 10000 & 1 & 1 & 7.4592 & 10\end{array}$ 


\begin{tabular}{|c|c|c|c|c|c|c|c|c|c|c|c|}
\hline * & vol & & inc & type & & code & fact & tor & & hs & \\
\hline 221601 & 270 & 020000 & 0 & 134 & & 1 & & 592 & & 10 & \\
\hline * source & typ & & mult & $\mathrm{D}-1 \mathrm{t}$ & & D-rt & hs & & & & \\
\hline 12221701 & 0 & & 0.0 & 0.0 & & 0.0 & 10 & & & & \\
\hline * & 1 & & & & & & & & & & \\
\hline & Dhe & LHEf & LHEr LGSf & & Kfwd & Krev & Fboil & nclf & povd & & hs \\
\hline 12221801 & 0.0 & 0.53 & 10.1210 & 10. & 0.0 & 0.0 & 1.00 & 0.013 & 1.1 & 1.2 & 1 \\
\hline 12221802 & 0.0 & 1.60 & 9.0610 & 10. & 0.0 & 0.0 & 1.0 & 0.013 & 1.1 & 1.2 & 2 \\
\hline 12221803 & 0.0 & 2.66 & 7.9910. & 10. & 0.0 & 0.0 & 1.0 & 0.013 & 1.1 & 1.2 & 3 \\
\hline 12221804 & 0.0 & 3.73 & 6.9310. & 10. & 0.0 & 0.0 & 1.0 & 0.013 & 1.1 & 1.2 & 4 \\
\hline 12221805 & 0.0 & 4.80 & 5.8610 & 10. & 0.0 & 0.0 & 1.0 & 0.013 & 1.1 & 1.2 & 5 \\
\hline 12221806 & 0.0 & 5.86 & 4.8010 & 10. & 0.0 & 0.0 & 1.0 & 0.013 & 1.1 & 1.2 & 6 \\
\hline 12221807 & 0.0 & 6.93 & 3.7310 & 10. & 0.0 & 0.0 & 1.0 & 0.013 & 1.1 & 1.2 & 7 \\
\hline 12221808 & 0.0 & 7.99 & 2.6610 & 10. & 0.0 & 0.0 & 1.0 & 0.013 & 1.1 & 1.2 & 8 \\
\hline 12221809 & 0.0 & 9.06 & 1.6010 . & 10. & 0.0 & 0.0 & 1.0 & 0.013 & 1.1 & 1.2 & 9 \\
\hline 12221810 & 0.0 & 10.12 & 0.5310. & 10. & 0.0 & 0.0 & 1.0 & 0.013 & 1.1 & 1.2 & 10 \\
\hline * & & & & & & & & & & & \\
\hline 12221900 & & & & & & & & & & & \\
\hline & & LHEf & LHEr LGSf & LGSr & Kfwd & Krev & Fboil & nclf & povd & $d$ ff & hs \\
\hline 12221901 & & 0.73 & 1.5610. & 10. & 0.0 & 0.0 & 1.0 & 2.3 & 1.56 & 61.0 & 10 \\
\hline 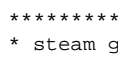 & $\begin{array}{l}\star \star \star \star \star \star \\
\text { gener }\end{array}$ & $\begin{array}{l}\star \star \star \star \star \star \star \star ~ \\
\text { ator }\end{array}$ & $\begin{array}{l}* \star \star \star \star \star \star \star \star \text { STH } \\
=\text { ubes }- \text { leve }\end{array}$ & $\begin{array}{l}\text { RUCTURE } \\
\text { el } 3 \text { la }\end{array}$ & $\begin{array}{l}\text { E } 2231 \\
\text { oop } 2\end{array}$ & & $\star \star \star \star \star$ & & & & \\
\hline *ht $\operatorname{str} \mathrm{h}$ & ht.st & rs m. & pts geom & init & $1 . \operatorname{coc}$ & oord & efl b.v & vol & $a x . i$ & incr. & \\
\hline 12231000 & 10 & & 112 & 1 & 0.006 & 650 & & & & & \\
\hline * & $10 \mathrm{c}$ & & flag & & & & & & & & \\
\hline 12231100 & $\begin{array}{l}10 \mathrm{c} \\
121\end{array}$ & & & & & & & & & & \\
\hline & & & & & & & & & & & \\
\hline * & $\begin{array}{c}\text { temp } \\
0\end{array}$ & eratur & fe flag & & & & & & & & \\
\hline * & & & & & & & & & & & \\
\hline * & tem & nperatu & ure pt & & & & & & & & \\
\hline 12231401 & 563 & .15 & 11 & & & & & & & & \\
\hline * & vol & & inc & type & & code & fact & tor & & & \\
\hline 12231501 & 223 & 3010000 & 10000 & 1 & & 1 & 7.45 & 5592 & & 10 & \\
\hline * & & & & & & 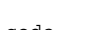 & f & & & & \\
\hline & vol & & inc & & & code & fact & & & hs & \\
\hline $\begin{array}{l}12231601 \\
\text { * }\end{array}$ & 270 & 030000 & 0 & 134 & & 1 & & 1592 & & 10 & \\
\hline * source & typ & & mult & D-1t & & D-rt & hs & & & & \\
\hline 12231701 & 0 & & 0.0 & 0.0 & & 0.0 & 10 & & & & \\
\hline $\begin{array}{l}* 2231800 \\
1\end{array}$ & 1 & & & & & & & & & & \\
\hline & Dhe & LHEf & LHEr LGSf & LGSr & Kfwd & Krev & Fboil & & povd & $d \mathrm{ff}$ & hs \\
\hline 12231801 & & 0.53 & 10.1210 . & 10. & 0.0 & 0.0 & 1.00 & 0.013 & 1.1 & 1.2 & 1 \\
\hline 12231802 & 0.0 & 1.60 & 9.0610 & 10. & 0.0 & 0.0 & 1.0 & 0.013 & 1.1 & 1.2 & 2 \\
\hline 12231803 & 0.0 & 2.66 & 7.9910. & 10. & 0.0 & 0.0 & 1.0 & 0.013 & 1.1 & 1.2 & 3 \\
\hline 12231804 & 0.0 & 3.73 & 6.9310. & 10. & 0.0 & 0.0 & 1.0 & 0.013 & 1.1 & 1.2 & 4 \\
\hline 12231805 & 0.0 & 4.80 & 5.8610. & 10. & 0.0 & 0.0 & 1.0 & 0.013 & 1.1 & 1.2 & 5 \\
\hline 12231806 & 0.0 & 5.86 & 4.8010 & 10. & 0.0 & 0.0 & 1.0 & 0.013 & 1.1 & 1.2 & 6 \\
\hline 12231807 & 0.0 & 6.93 & 3.7310 & 10. & 0.0 & 0.0 & 1.0 & 0.013 & 1.1 & 1.2 & 7 \\
\hline 12231808 & 0.0 & 7.99 & 2.6610. & 10. & 0.0 & 0.0 & 1.0 & 0.013 & 1.1 & 1.2 & 8 \\
\hline 12231809 & 0.0 & 9.06 & 1.6010 & 10. & 0.0 & 0.0 & 1.0 & 0.013 & 1.1 & 1.2 & 9 \\
\hline 12231810 & 0.0 & 10.12 & 0.5310 . & 10. & 0.0 & 0.0 & 1.0 & 0.013 & 1.1 & 1.2 & 10 \\
\hline & & & & & & & & & & & \\
\hline $\begin{array}{l}12231900 \\
*\end{array}$ & Dhe ${ }^{1}$ & LHEf & LHEr LGSf & LGSr & Kfwd & Krev & Fboil & & povd & $d \mathrm{ff}$ & hs \\
\hline 12231901 & 0.0 & 1.21 & 1.0910 . & 10. & 0.0 & 0.0 & 1.0 & 2.3 & 1.56 & 6 & 10 \\
\hline
\end{tabular}

*ht str ht.strs m.pts geom init 1.coord refl b.vol ax.incr. $\begin{array}{llllllll}12241000 & 10 & 11 & 2 & 1 & 0.00650 & 0\end{array}$

* $\quad$ loc flag

temperature flag

$\begin{array}{lll}* & \text { temperature pt } \\ 12241401 & 563.15 & 11\end{array}$

$\begin{array}{lllllll}* & \text { vol } & \text { inc } & \text { type } & \text { code } & \text { factor } & \text { hs } \\ 12241501 & 224010000 & 10000 & 1 & 1 & 7.4592 & 10\end{array}$

$\begin{array}{lllllll}* & & & & & & \\ * & \text { vol } & \text { inc } & \text { type } & \text { code } & \text { factor } & \text { hs } \\ 12241601 & 270040000 & 0 & 134 & 1 & 7.4592 & 10\end{array}$

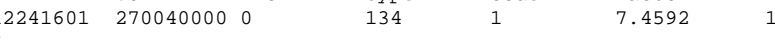

$\begin{array}{llllll}\text { * source } & \text { type } & \text { mult } & \text { D-1t } & \text { D-rt } & \text { hs } \\ 12241701 & 0 & 0.0 & 0.0 & 0.0 & 10\end{array}$

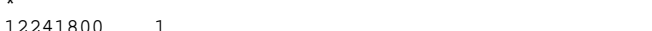

* Dhe LHEf LHEr LGSf LGSr Kfwd Krev Fboil nclf povd ff hs $\begin{array}{lllllllllllll}12241801 & 0.0 & 0.53 & 10.12 & 10 . & 10 . & 0.0 & 0.0 & 1.0 & 0.013 & 1.1 & 1.2 & 1 \\ 12241802 & 0.0 & 1.60 & 9.06 & 10 . & 10 . & 0.0 & 0.0 & 1.0 & 0.013 & 1.1 & 1.2 & 2\end{array}$ $\begin{array}{lllllllllllll}12241803 & 0.0 & 2.66 & 7.99 & 10 . & 10 . & 0.0 & 0.0 & 1.0 & 0.013 & 1.1 & 1.2 & 3\end{array}$ $\begin{array}{lllllllllllll}12241804 & 0.0 & 3.73 & 6.93 & 10 . & 10 . & 0.0 & 0.0 & 1.0 & 0.013 & 1.1 & 1.2 & 4\end{array}$ $\begin{array}{lllllllllllll}12241805 & 0.0 & 4.80 & 5.86 & 10 . & 10 . & 0.0 & 0.0 & 1.0 & 0.013 & 1.1 & 1.2 & 5 \\ 12241806 & 0.0 & 5.86 & 4.80 & 10 . & 10 . & 0.0 & 0.0 & 1.0 & 0.013 & 1.1 & 1.2 & 6\end{array}$ $\begin{array}{lllllllllllll}12241806 & 0.0 & 5.86 & 4.80 & 10 . & 10 . & 0.0 & 0.0 & 1.0 & 0.013 & 1.1 & 1.2 & 6 \\ 12241807 & 0.0 & 6.93 & 3.73 & 10 . & 10 & 0.0 & 0.0 & 1.0 & 0.013 & 1.1 & 1.2 & 7\end{array}$ $\begin{array}{lllllllllllll}12241807 & 0.0 & 6.93 & 3.73 & 10 . & 10 . & 0.0 & 0.0 & 1.0 & 0.013 & 1.1 & 1.2 & 7 \\ 12241808 & 0.0 & 7.99 & 2.66 & 10 . & 10 . & 0.0 & 0.0 & 1.0 & 0.013 & 1.1 & 1.2 & 8\end{array}$ $\begin{array}{rrrrrrrrrrrrr}12241809 & 0.0 & 9.06 & 1.60 & 10 . & 10 . & 0.0 & 0.0 & 1.0 & 0.013 & 1.1 & 1.2 & 9 \\ 12241810 & 0.0 & 10.12 & 0.53 & 10 . & 10 . & 0.0 & 0.0 & 1.0 & 0.013 & 1.1 & 1.2 & 10\end{array}$ $12241900 \quad 1$

Dhe LHEf LHEr LGSf LGSr Kfwd Krev Fboil nclf povd ff hs

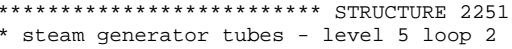

\begin{tabular}{|c|c|c|c|c|c|c|c|c|c|c|c|}
\hline $\begin{array}{l}\text { *ht str } \\
12251000\end{array}$ & $\begin{array}{r}\text { ht. st } \\
10\end{array}$ & $\mathrm{~m} \cdot \mathrm{F}$ & $\begin{array}{l}\text {.pts } \\
11\end{array}$ & $\begin{array}{l}\text { geom } \\
2\end{array}$ & $\begin{array}{c}\text { init } \\
1\end{array}$ & $\begin{array}{l}1 . c 001 \\
0.0065\end{array}$ & $\begin{array}{ll}\text { rod } \\
550\end{array}$ & $\begin{array}{c}\text { refl } \\
0\end{array}$ & b.vol & ax.incr. & \\
\hline * & $\begin{array}{l}\text { loc } \\
121\end{array}$ & & flag & & & & & & & & \\
\hline * 12251400 & $\begin{array}{l}\text { tempe } \\
0\end{array}$ & erature & re fla & & & & & & & & \\
\hline * 12251401 & $\begin{array}{l}\text { tem } \\
563\end{array}$ & $\begin{array}{l}\text { oeratur } \\
.15\end{array}$ & $\begin{aligned} & \text { ure } p t \\
& 11\end{aligned}$ & & & & & & & & \\
\hline * & $\begin{array}{l}\text { vol } \\
225\end{array}$ & 010000 & $\begin{array}{l}\text { inc } \\
01000\end{array}$ & & $\begin{array}{l}\text { type } \\
1\end{array}$ & $\begin{array}{l}\text { cc } \\
1\end{array}$ & code & & $\begin{array}{l}\text { factor } \\
6.3936\end{array}$ & $\begin{array}{l}\text { hs } \\
10\end{array}$ & \\
\hline ‘ 12251601 & $\begin{array}{l}\text { vol } \\
2700\end{array}$ & 050000 & $\begin{array}{l}\text { inc } \\
0\end{array}$ & & $\begin{array}{l}\text { type } \\
134\end{array}$ & & code & & $\begin{array}{l}\text { factor } \\
6.3936\end{array}$ & $\begin{array}{l}\text { hs } \\
10\end{array}$ & \\
\hline $\begin{array}{l}\text { * source } \\
12251701 \\
{ }^{*}\end{array}$ & $\begin{array}{l}\text { type } \\
0\end{array}$ & & $\begin{array}{l}\text { mult } \\
0.0\end{array}$ & & $\begin{array}{l}\text { D-1t } \\
0.0\end{array}$ & & $\begin{array}{l}-r-r t \\
.0\end{array}$ & & $\begin{array}{l}\text { hs } \\
10\end{array}$ & & \\
\hline 12251800 & 1 & & & & & & & & & & \\
\hline & Dhe & LHEf & LHEr & I LGS & LGSr & Kfwd & Krev & & boil nclf & povd ff & hs \\
\hline 12251801 & 0.0 & 0.531 & 10.12 & 210. & 10. & 0.0 & 0.0 & 1. & $\begin{array}{ll}.0 & 0.013\end{array}$ & $1.1 \quad 1.2$ & 1 \\
\hline $\begin{array}{l}12251802 \\
12251803\end{array}$ & $\begin{array}{l}0.0 \\
0.0\end{array}$ & $\begin{array}{l}1.60 \\
2.66\end{array}$ & $\begin{array}{l}9.06 \\
7.99\end{array}$ & $\begin{array}{ll}6 & 10 . \\
9 & 10 .\end{array}$ & $\begin{array}{l}10 . \\
10 .\end{array}$ & $\begin{array}{l}0.0 \\
0.0\end{array}$ & $\begin{array}{l}0.0 \\
0.0\end{array}$ & $\begin{array}{l}1 . \\
1 .\end{array}$ & $\begin{array}{ll}.0 & 0.013 \\
.0 & 0.013\end{array}$ & $\begin{array}{ll}1.1 & 1.2 \\
1.1 & 1.2\end{array}$ & $\begin{array}{l}2 \\
3\end{array}$ \\
\hline 12251804 & 0.0 & 3.73 & 6.93 & 310. & 10. & 0.0 & 0.0 & 1. & $.0 \quad 0.013$ & 1.11 .2 & 4 \\
\hline
\end{tabular}


$\begin{array}{lllllllllllll}12251805 & 0.0 & 4.80 & 5.86 & 10 . & 10 . & 0.0 & 0.0 & 1.0 & 0.013 & 1.1 & 1.2 & 5\end{array}$ $\begin{array}{lllllllllllll}12251806 & 0.0 & 5.86 & 4.80 & 10 . & 10 . & 0.0 & 0.0 & 1.0 & 0.013 & 1.1 & 1.2 & 5 \\ 12251.1 & 0.0 & 1.2 & 6\end{array}$ $\begin{array}{lllllllllllll}12251807 & 0.0 & 6.93 & 3.73 & 10 . & 10 . & 0.0 & 0.0 & 1.0 & 0.013 & 1.1 & 1.2 & 6\end{array}$ $\begin{array}{llllllllllllll}12251809 & 0.0 & 9.06 & 1.60 & 10 . & 10 . & 0.0 & 0.0 & 1.0 & 0.013 & 1.1 & 1.2 & 9\end{array}$

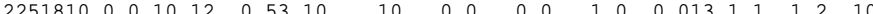
Dhe LHEf LHEr LGSf LGSr Kfwd Krev Fboil nclf povd ff hs $\begin{array}{lllllllllllll}12251901 & 0.0 & 2.11 & 0.19 & 10 . & 10 . & 0.0 & 0.0 & 1.0 & 2.3 & 1.56 & 1.0 & 10\end{array}$ * cold collector in loop

*ht strht.strs m.pts geom init 1.coord refl b.vol ax.incr.

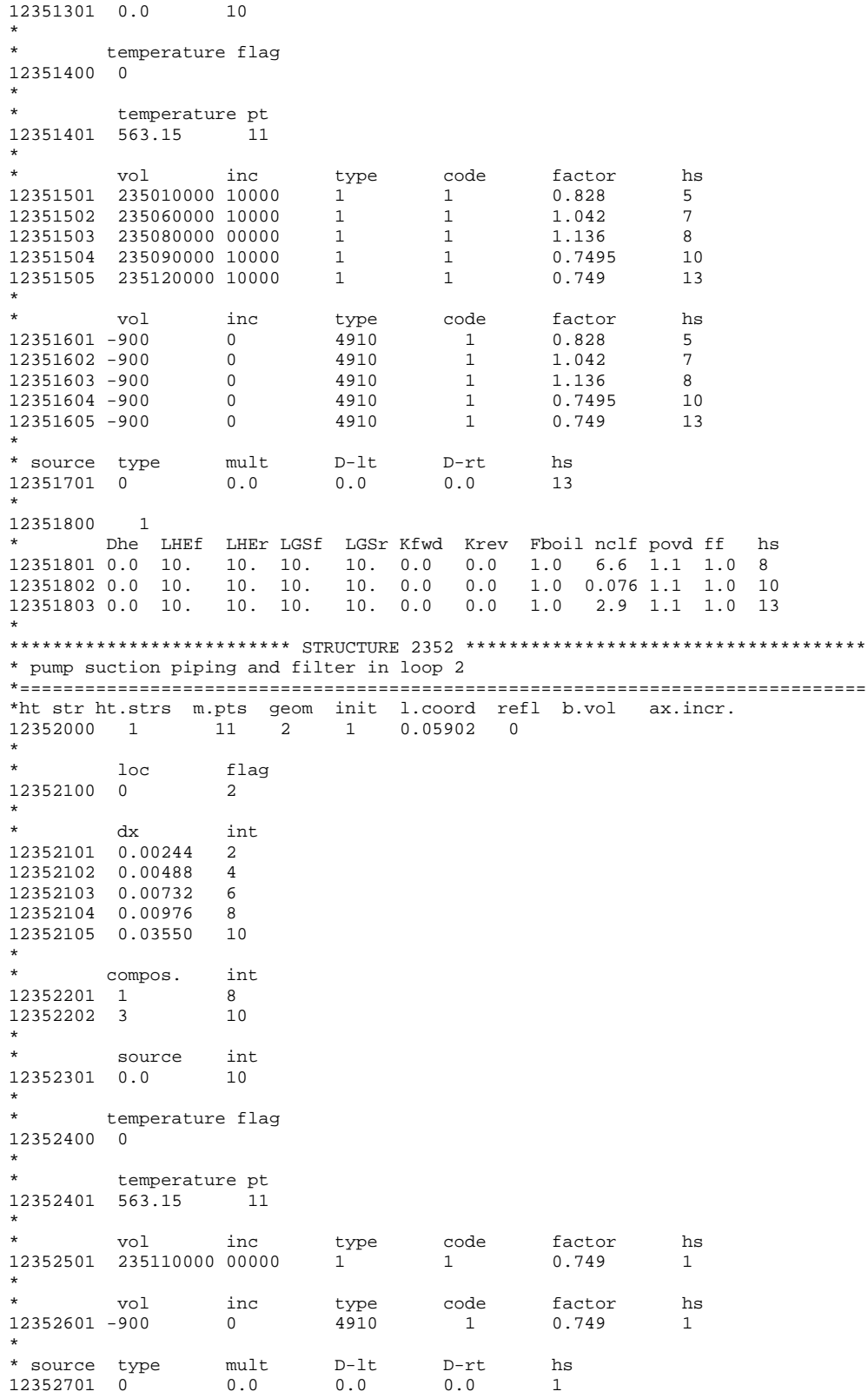


$12352800{ }^{1}$ Dhe LHEf LHEr LGSf LGSr Kfwd Krev Fboil nclf povd ff hs

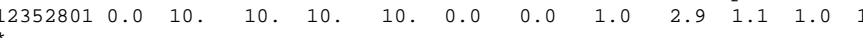
* main coolant pump in loop 2

*ht str ht.strs m.pts geom init 1.coord refl b.vol ax.incr.

1oc

flag

temperature flag

* temperature pt

$401401 \quad 563.15$

$\begin{array}{lllllll}* & \text { vol } & \text { inc } & \text { type } & \text { code } & \text { factor } & \text { hs } \\ 12401501 & 240010000 & 00000 & 1 & 1 & 0.746 & 1\end{array}$

$\begin{array}{lllllll}* & \text { vol } & \text { inc } & \text { type } & \text { code } & \text { factor } & \text { hs } \\ 12401601 & -900 & 0 & 4911 & 1 & 0.746 & 1\end{array}$

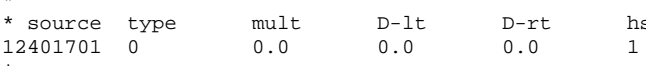

$12401800{ }^{1}$ Dhe LHEf LHEr LGSf LGSr Kfwd Krev Fboil nclf povd ff hs $\begin{array}{llllllllllll}12401801 & 0.0 & 10 . & 10 . & 10 . & 10 . & 0.0 & 0.0 & 1.0 & 2.9 & 1.1 & 1.0\end{array}$

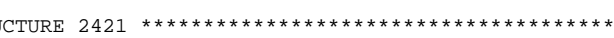

* cold leg isolation valve in loop 2

*ht str ht.strs m.pts geom init 1.coord refl b.vol ax.incr.

$\begin{array}{lll}* & \text { loc } & \text { flag } \\ 12421100 & 0 & 2\end{array}$

$\begin{array}{lll}* & \mathrm{dx} & \text { int } \\ 12421101 & 0.00352 & 2\end{array}$

$12421102 \quad 0.00704$

$\begin{array}{lll}12421103 & 0.01056 & 6 \\ 12421104 & 0.01407 & 8\end{array}$

$\begin{array}{lll}12421104 & 0.01407 & 8 \\ 12421105 & 0.03550 & 10\end{array}$

compos. int

$\begin{array}{lll}* & * \\ 12421201202 & 3 & 8 \\ * & 10\end{array}$

source int

*

* $12421400 \quad 0$ temperature flag

$\begin{array}{lll}* & \text { temperature pt } \\ 12421401 & 563.15 & 11\end{array}$

$\begin{array}{lllllll}* & \text { vol } & \text { inc } & \text { type } & \text { code } & \text { factor } & \text { hs } \\ 12421501 & 242010000 & 00000 & 1 & 1 & 0.880 & 1\end{array}$

$\begin{array}{lrlccll}* & \text { vol } & \text { inc } & \text { type } & \text { code } & \text { factor } & \text { hs } \\ 12421601 & -900 & 0 & 4910 & 1 & 0.880 & 1\end{array}$

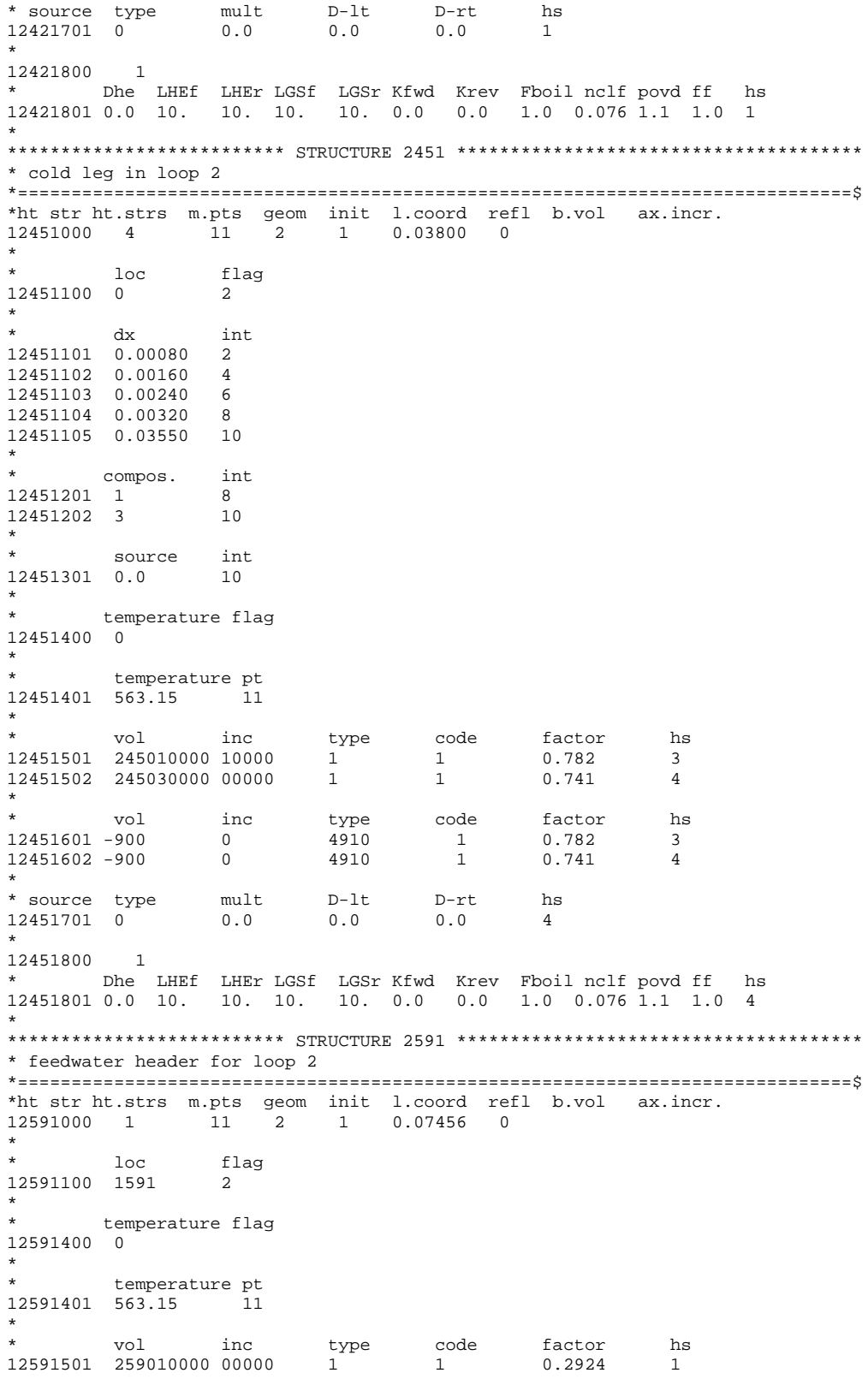




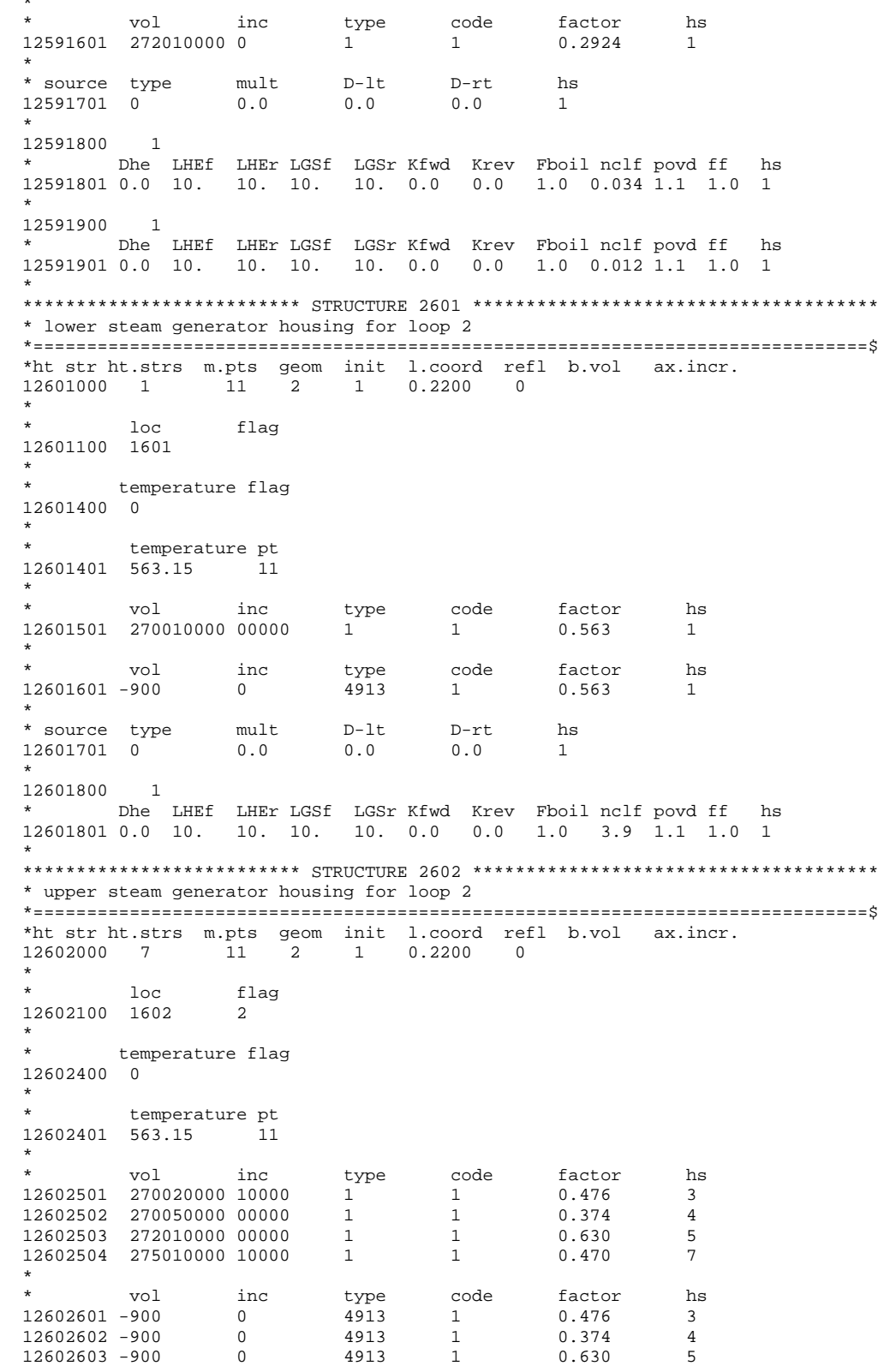

$\begin{array}{llll}\text { type } & \text { code } & \text { factor } & \text { hs } \\ 1 & 1 & 0.476 & 3 \\ 1 & 1 & 0.374 & 4 \\ 1 & 1 & 0.630 & 5 \\ 1 & 1 & 0.470 & 7 \\ & & & \\ \text { type } & \text { code } & \text { factor } & \text { hs } \\ 4913 & 1 & 0.476 & 3 \\ 4913 & 1 & 0.374 & 4 \\ 4913 & 1 & 0.630 & 5\end{array}$



* hot leg nozzle and pipe in loop 3

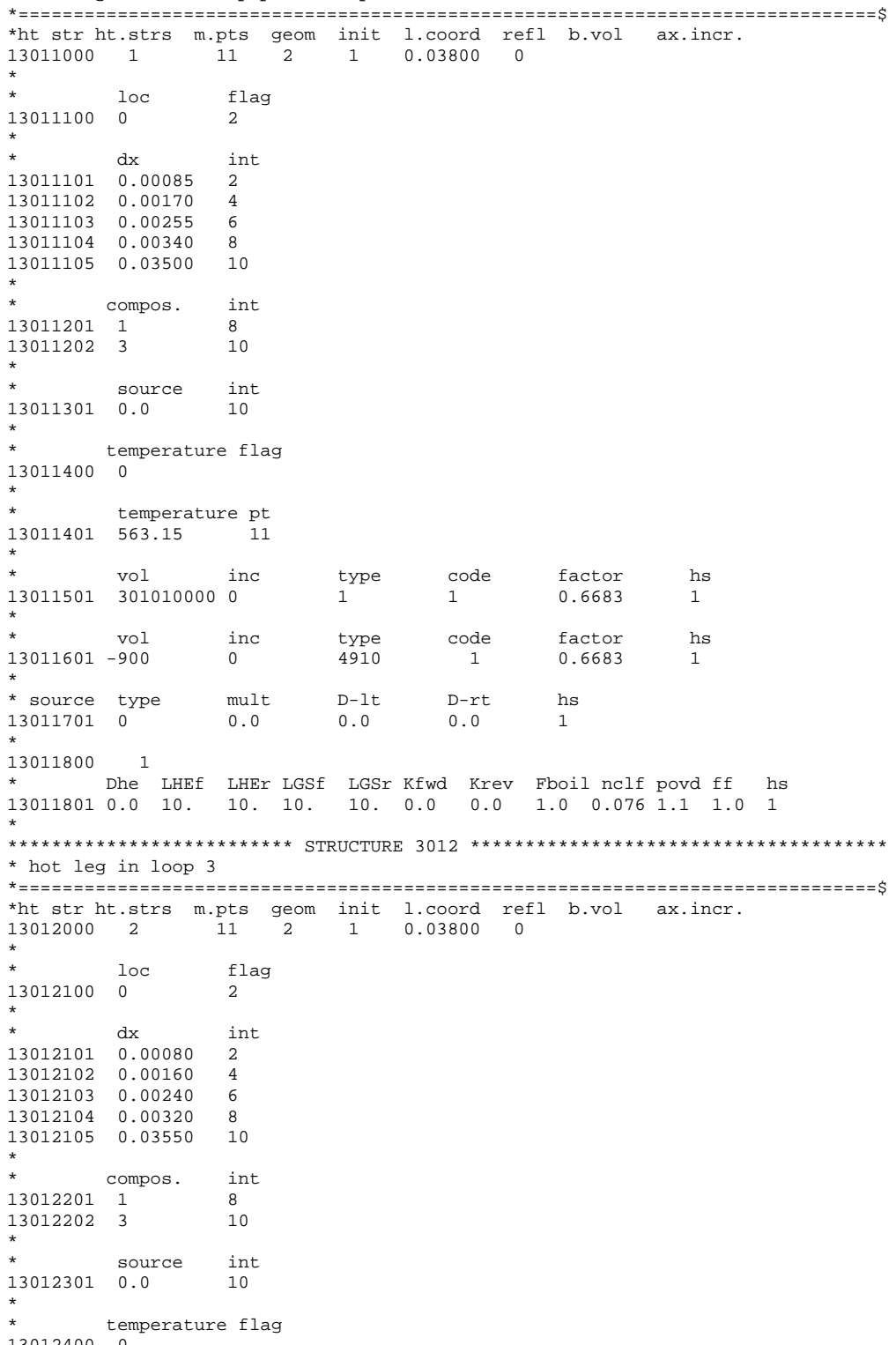

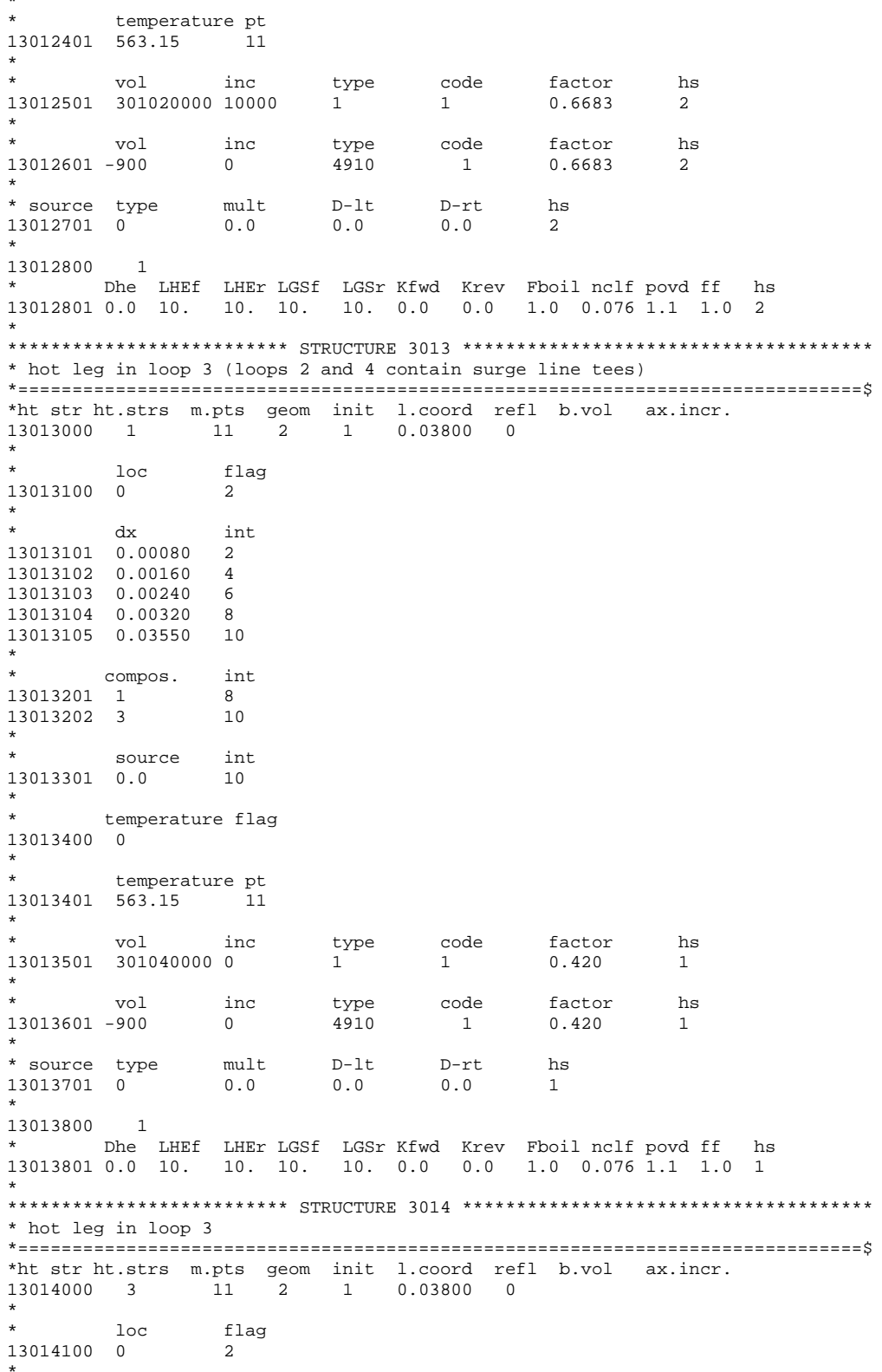




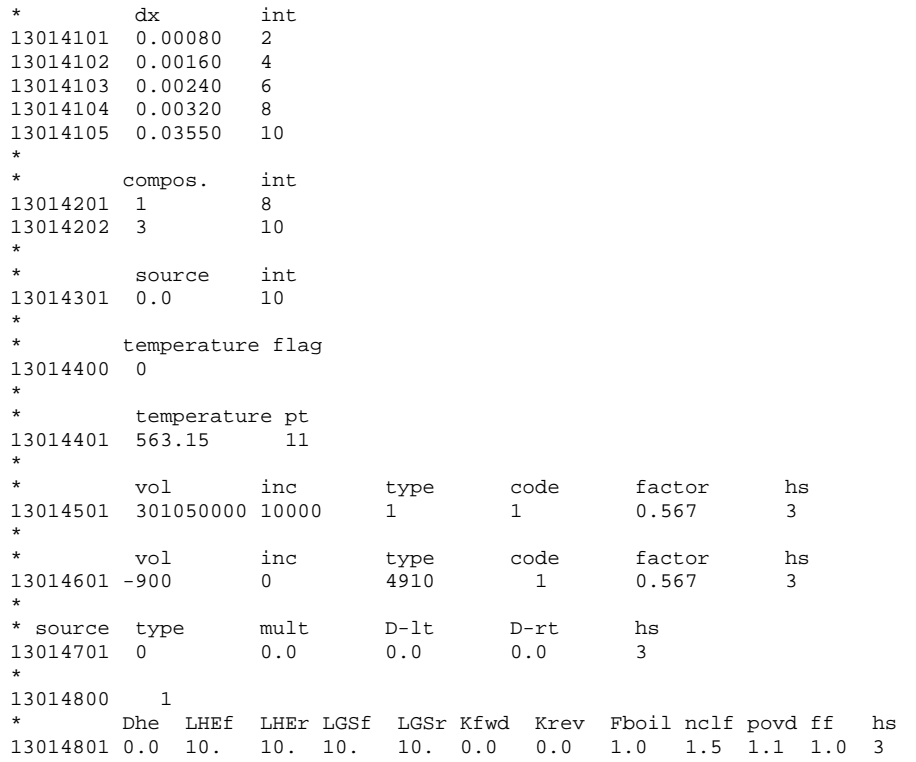

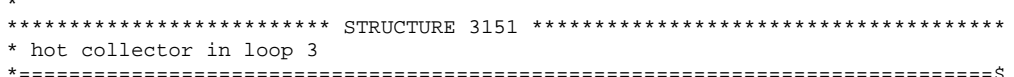

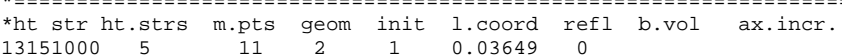

$\begin{array}{ll}* & 10 c \\ 13151100 & 115\end{array}$

* temperature flag

$\begin{array}{lll}* & \text { temperature pt } \\ 13151401 & 563.15 & 11\end{array}$

$\begin{array}{lll}* & \text { vol } & \text { inc } \\ \text { * } & \text { in } \\ 13151501 & 315010000 & 00000\end{array}$ $\begin{array}{lll}13151502 & 315020000 & 10000 \\ 13151503 & 315050000 & 00000\end{array}$

$\begin{array}{lll}* & \text { vol } & \text { inc } \\ 13151601 & 370010000 & 00000\end{array}$

1315160237002000010000

315160337005000000000

$\begin{array}{lll}* \text { source } & \text { type } & \text { mu.t } \\ 13151701 & 0 & 0.0\end{array}$

* 13151800

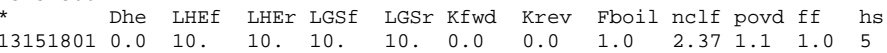

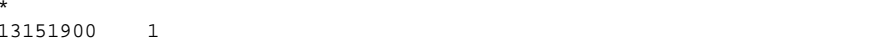

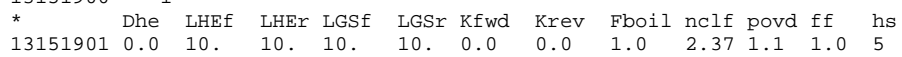

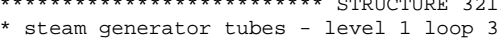

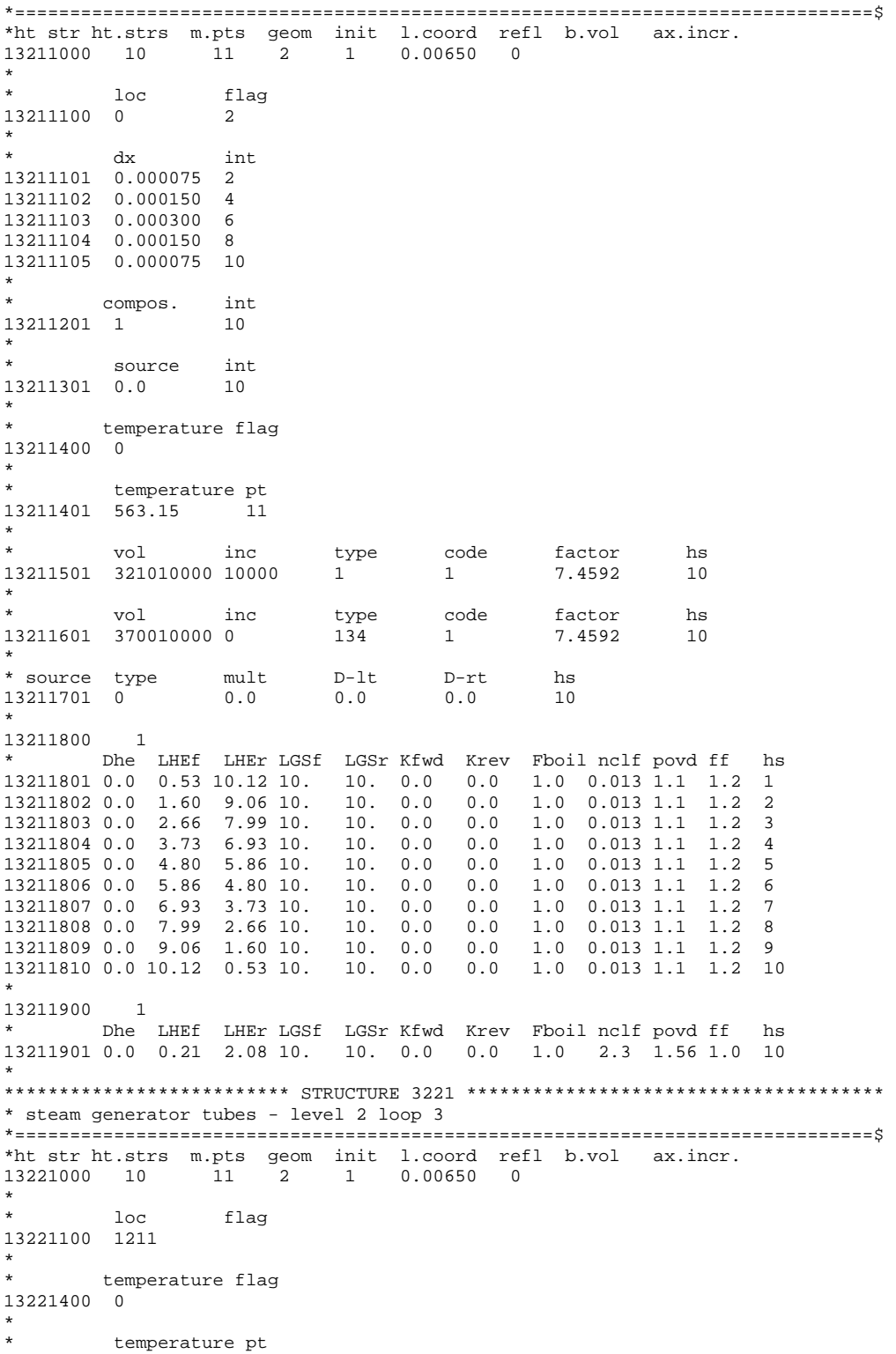


$13221401 \quad 563.15 \quad 11$

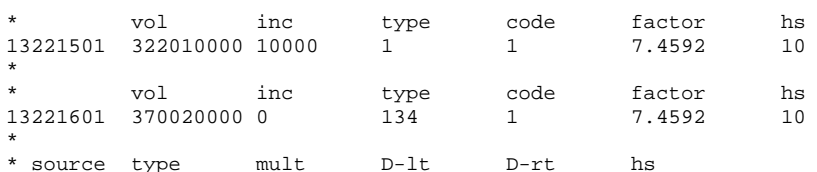

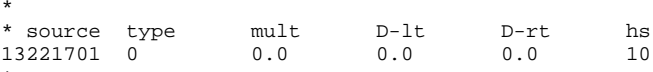

13221800

Dhe LHEf LHEr LGSf LGSr Kfwd Krev Fboil nclf povd ff hs $\begin{array}{lllllllllllll}13221801 & 0.0 & 0.53 & 10.12 & 10 . & 10 & 0.0 & 0.0 & 1.0 & 0.013 & 1.1 & 1.2 & 1\end{array}$ $\begin{array}{llllllllllllll}13221802 & 0.0 & 1.60 & 9.06 & 10 . & 10 . & 0.0 & 0.0 & 1.0 & 0.013 & 1.1 & 1.2 & 2 \\ 13221803 & 0.0 & 2.66 & 7.99 & 10 . & 10 . & 0.0 & 0.0 & 1.0 & 0.013 & 1.1 & 1.2 & 3\end{array}$ $\begin{array}{lllllllllllll}13221803 & 0.0 & 2.66 & 7.99 & 10 . & 10 . & 0.0 & 0.0 & 1.0 & 0.013 & 1.1 & 1.2 & 2 \\ 13221804 & 0.0 & 3.73 & 6.93 & 10 . & 10 . & 0.0 & 0.0 & 1.0 & 0.013 & 1.1 & 1.2 & 4\end{array}$ $\begin{array}{lllllllllllll}13221804 & 0.0 & 3.73 & 6.93 & 10 . & 10 . & 0.0 & 0.0 & 1.0 & 0.013 & 1.1 & 1.2 & 4 \\ 13221805 & 0.0 & 4.80 & 5.86 & 10 . & 10 . & 0.0 & 0.0 & 1.0 & 0.013 & 1.1 & 1.2 & 5\end{array}$ $\begin{array}{lllllllllllll}13221806 & 0.0 & 5.86 & 4.80 & 10 . & 10 . & 0.0 & 0.0 & 1.0 & 0.013 & 1.1 & 1.2 & 6\end{array}$

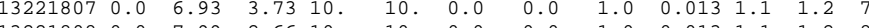
$\begin{array}{lllllllllllll}13221808 & 0.0 & 7.99 & 2.66 & 10 . & 10 . & 0.0 & 0.0 & 1.0 & 0.013 & 1.1 & 1.2 & 8 \\ 13221809 & 0.0 & 9.06 & 1.60 & 10 . & 10 . & 0.0 & 0.0 & 1.0 & 0.013 & 1.1 & 1.2 & 9\end{array}$

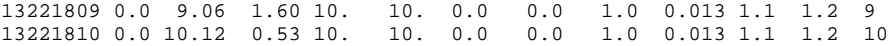
13221900

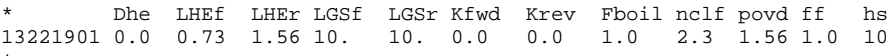

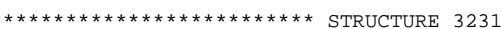

* steam generator tubes - level 3 loop 3

*ht str ht.strs m.pts geom init l.coord refl b.vol ax.incr.

* $\begin{array}{lll}13231100 & \text { loc } & 1211\end{array}$

* temperature flag

$13231400 \quad 0$

* temperature pt

$\begin{array}{lll}13231401 & 563.15 \quad 11\end{array}$

$\begin{array}{lllllll}* & \text { vol } & \text { inc } & \text { type } & \text { code } & \text { factor } & \text { hs } \\ 13231501 & 323010000 & 10000 & 1 & 1 & 7.4592 & 10\end{array}$

$\begin{array}{lllllll}* & \text { vol } & \text { inc } & \text { type } & \text { code } & \text { factor } & \text { hs } \\ 13231601 & 370030000 & 0 & 134 & 1 & 7.4592 & 10\end{array}$

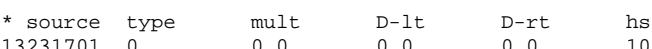

*

${ }_{\star} 13231800$ Dhe ${ }^{1}$ LHEf LHEr LGSf LGSr Kfwd Krev Fboil nclf povd ff hs

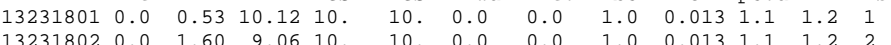
$\begin{array}{lllllllllllll}13231803 & 0.0 & 2.66 & 7.99 & 10 . & 10 . & 0.0 & 0.0 & 1.0 & 0.013 & 1.1 & 1.2 & 3\end{array}$

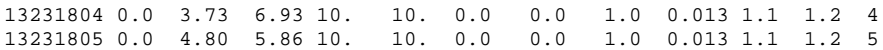
$\begin{array}{lllllllllllll}13231805 & 0.0 & 4.80 & 5.86 & 10 . & 10 . & 0.0 & 0.0 & 1.0 & 0.013 & 1.1 & 1.2 & 5 \\ 13231806 & 0.0 & 5.86 & 4.80 & 10 . & 10 . & 0.0 & 0.0 & 1.0 & 0.013 & 1.1 & 1.2 & 6\end{array}$ $\begin{array}{lllllllllllll}13231807 & 0.0 & 6.93 & 3.73 & 10 . & 10 . & 0.0 & 0.0 & 1.0 & 0.013 & 1.1 & 1.2 & 7\end{array}$

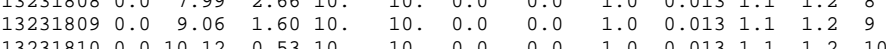
$\begin{array}{lllllllllllll}13231810 & 0.0 & 10.12 & 0.53 & 10 . & 10 . & 0.0 & 0.0 & 1.0 & 0.013 & 1.1 & 1.2 & 10\end{array}$ 13231900

$\begin{array}{lllllllllllll}* & \text { Dhe } & \text { LHEf } & \text { LHEr LGSf } & \text { LGSr } & \text { Kfwd } & \text { Krev } & \text { Fboil nclf povd ff } & \text { hs } \\ 13231901 & 0.0 & 1.21 & 1.09 & 10 . & 10 . & 0.0 & 0.0 & 1.0 & 2.3 & 1.56 & 1.0 & 10\end{array}$ * steam generator tubes - level 4 loop 3

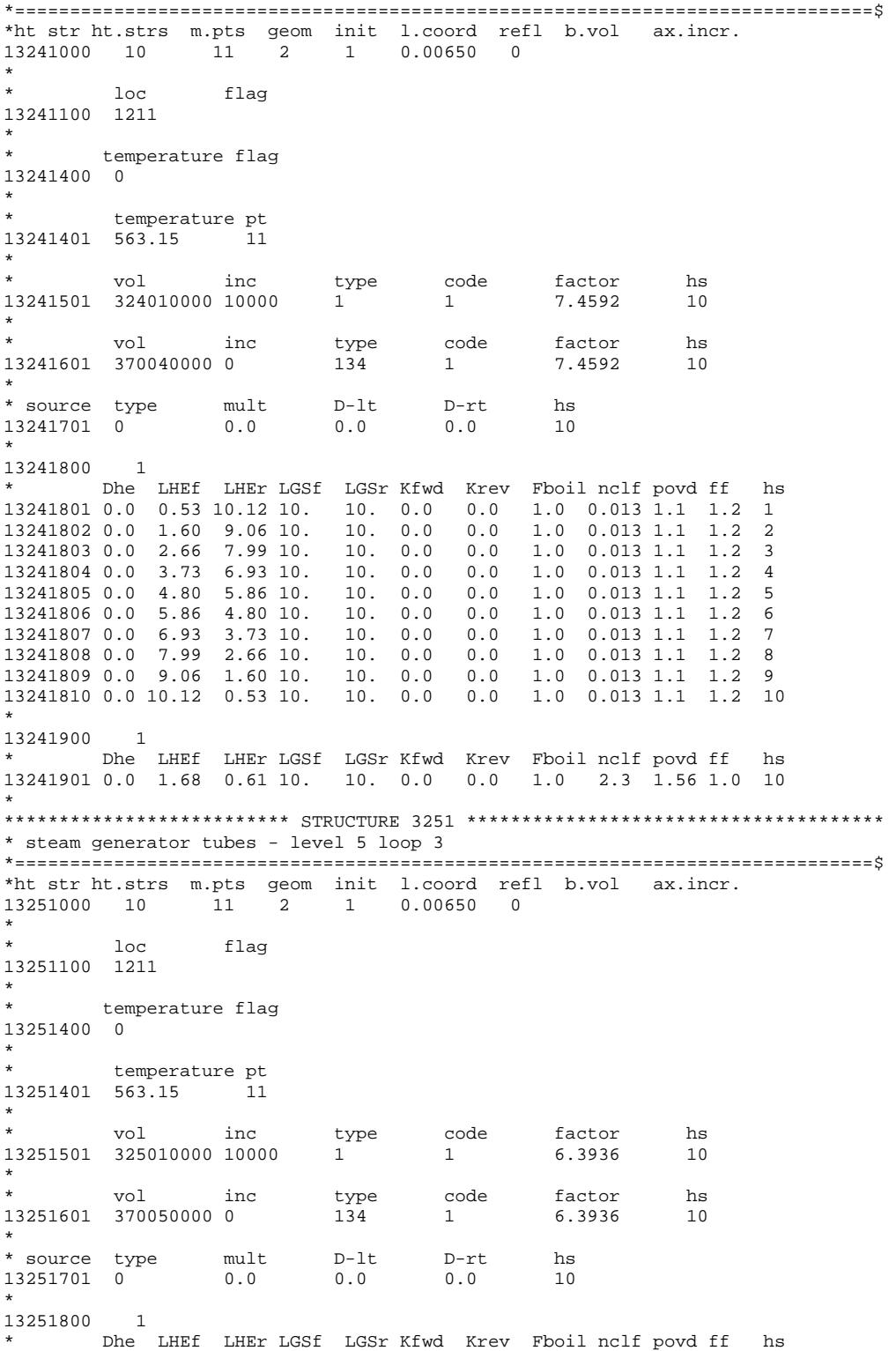




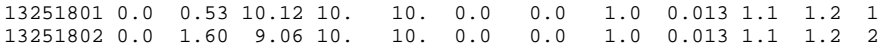
$\begin{array}{lllllllllllll}13251802 & 0.0 & 1.60 & 9.06 & 10 . & 10 . & 0.0 & 0.0 & 1.0 & 0.013 & 1.1 & 1.2 & 2 \\ 13251803 & 0.0 & 2.66 & 7.99 & 10 . & 10 . & 0.0 & 0.0 & 1.0 & 0.013 & 1.1 & 1.2 & 3\end{array}$ $\begin{array}{lllllllllllllll}13251804 & 0.0 & 3.73 & 6.93 & 10 . & 10 . & 0.0 & 0.0 & 1.0 & 0.013 & 1.1 & 1.2 & 4\end{array}$ $\begin{array}{lllllllllllllll}13251806 & 0.0 & 5.86 & 4.80 & 10 . & 10 . & 0.0 & 0.0 & 1.0 & 0.013 & 1.1 & 1.2 & 5\end{array}$ $\begin{array}{lllllllllllllll}13251807 & 0.0 & 6.93 & 3.73 & 10 . & 10 . & 0.0 & 0.0 & 1.0 & 0.013 & 1.1 & 1.2 & 7\end{array}$

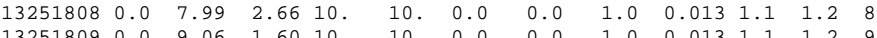

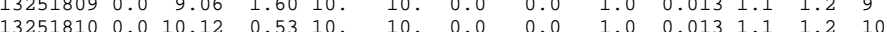
13251900

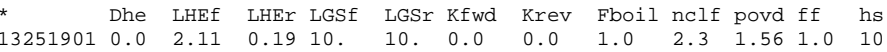

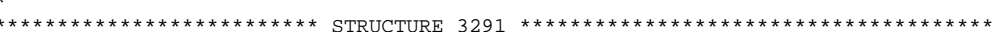
* cold collector in loop 3 $\begin{array}{lcccccccc}* \text { kt str ht.strs } & \text { m.pts } & \text { geom } & \text { init } & 1 . \text { coord } & \text { refl b.vol ax.incr. } \\ 13291000 & 5 & 11 & 2 & 1 & 0.03649 & 0 & & \end{array}$

* $\quad$ loc flag

* temperature flag

$\begin{array}{lll}* & \text { temperature pt } \\ 13291401 & 563.15 & 11\end{array}$

$\begin{array}{lllllll}* & \text { vol } & \text { inc } & \text { type } & \text { code } & \text { factor } & \text { hs } \\ 13291501 & 329010000 & 00000 & 1 & 1 & 0.563 & 1\end{array}$

$\begin{array}{lllllll}13291502 & 329020000 & 10000 & 1 & 1 & 0.563 & 1 \\ 13291503 & 329050000 & 00000 & 1 & 1 & 0.476 & 4 \\ *\end{array}$ $\begin{array}{lll}* & \text { vol } & \text { inc } \\ 13291601 & 370010000 & 00000\end{array}$

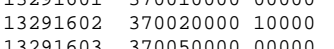

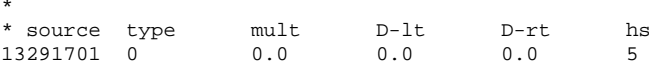

* 13291800

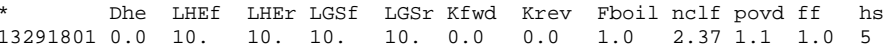

$13291900{ }^{1}$ LHef LHEr LGSf LGSr Kfwd Krev Fboil nclf povd ff hs

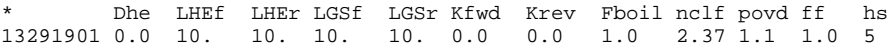

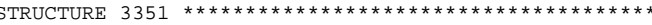

* pump suction piping in loop 3

*ht str ht.strs m.pts geom init 1.coord refl b.vol ax.incr.
13351000

$\begin{array}{lll}* & \text { loc } & \text { flag } \\ 13351100 & 0 & 2\end{array}$

* $\mathrm{dx} \quad$ int

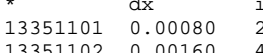

$13351103 \quad 0.00240$

$\begin{array}{lll}13351104 & 0.00320 & 8 \\ 13351105 & 0.03550 & 10\end{array}$

compos. int

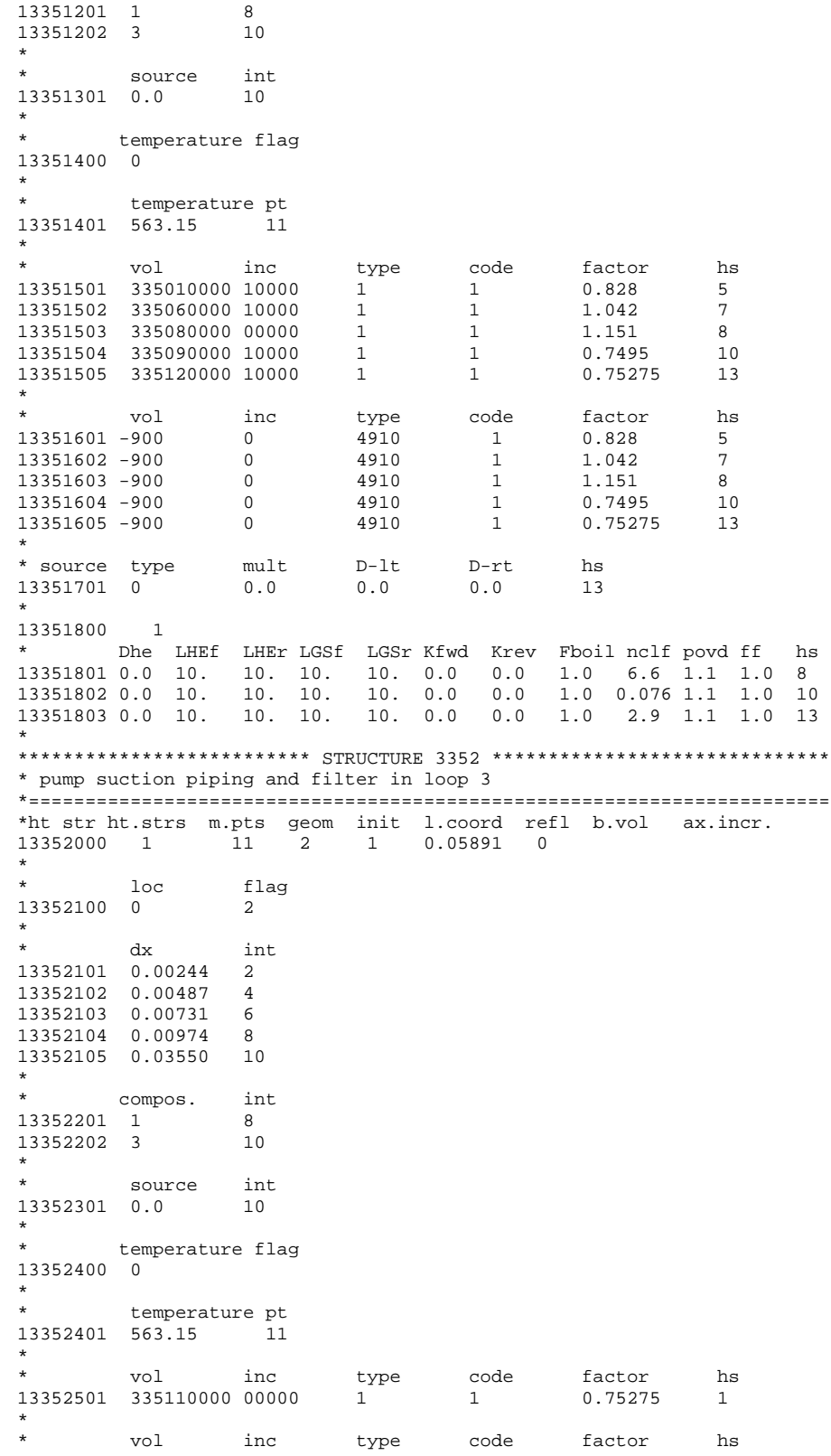




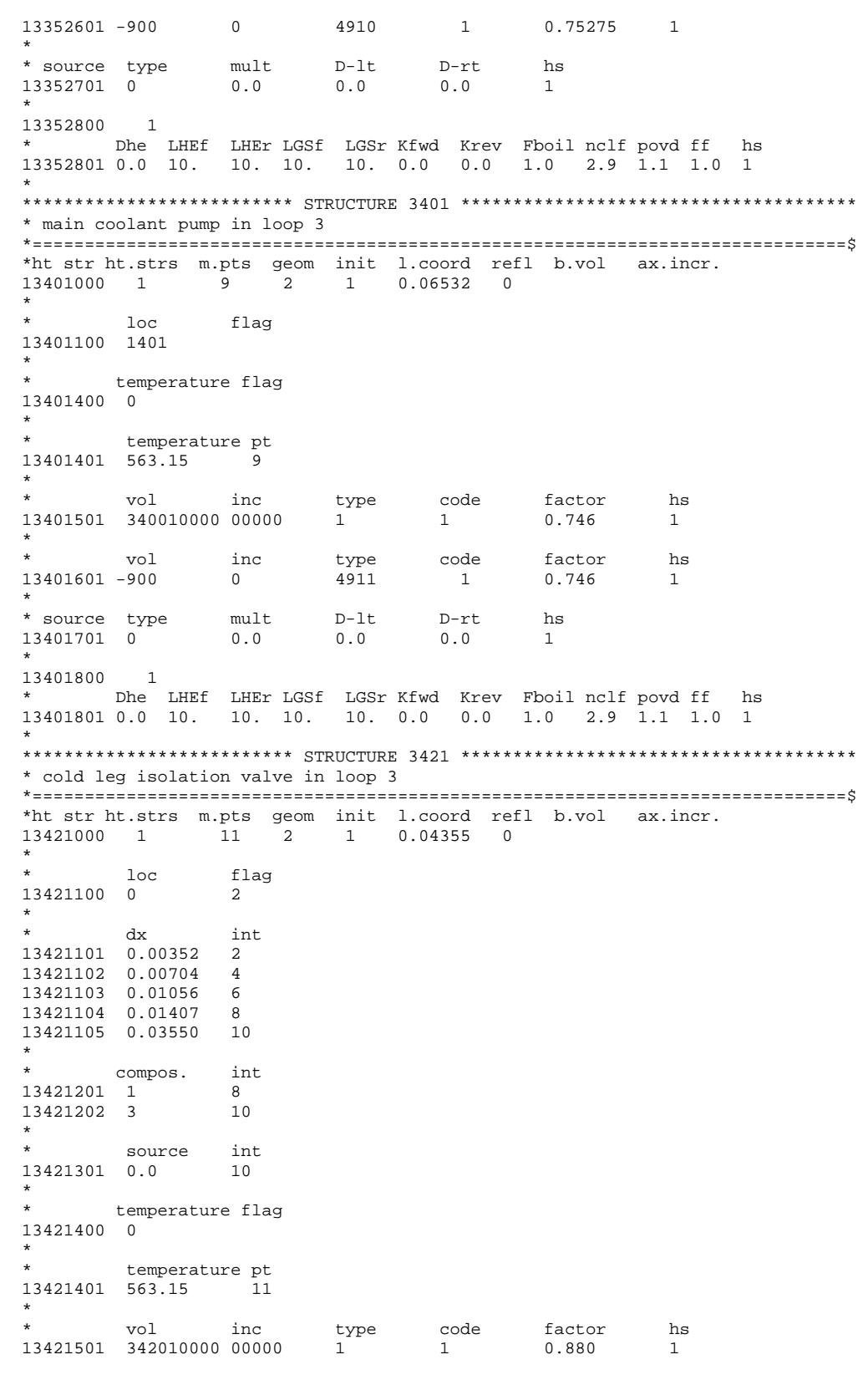

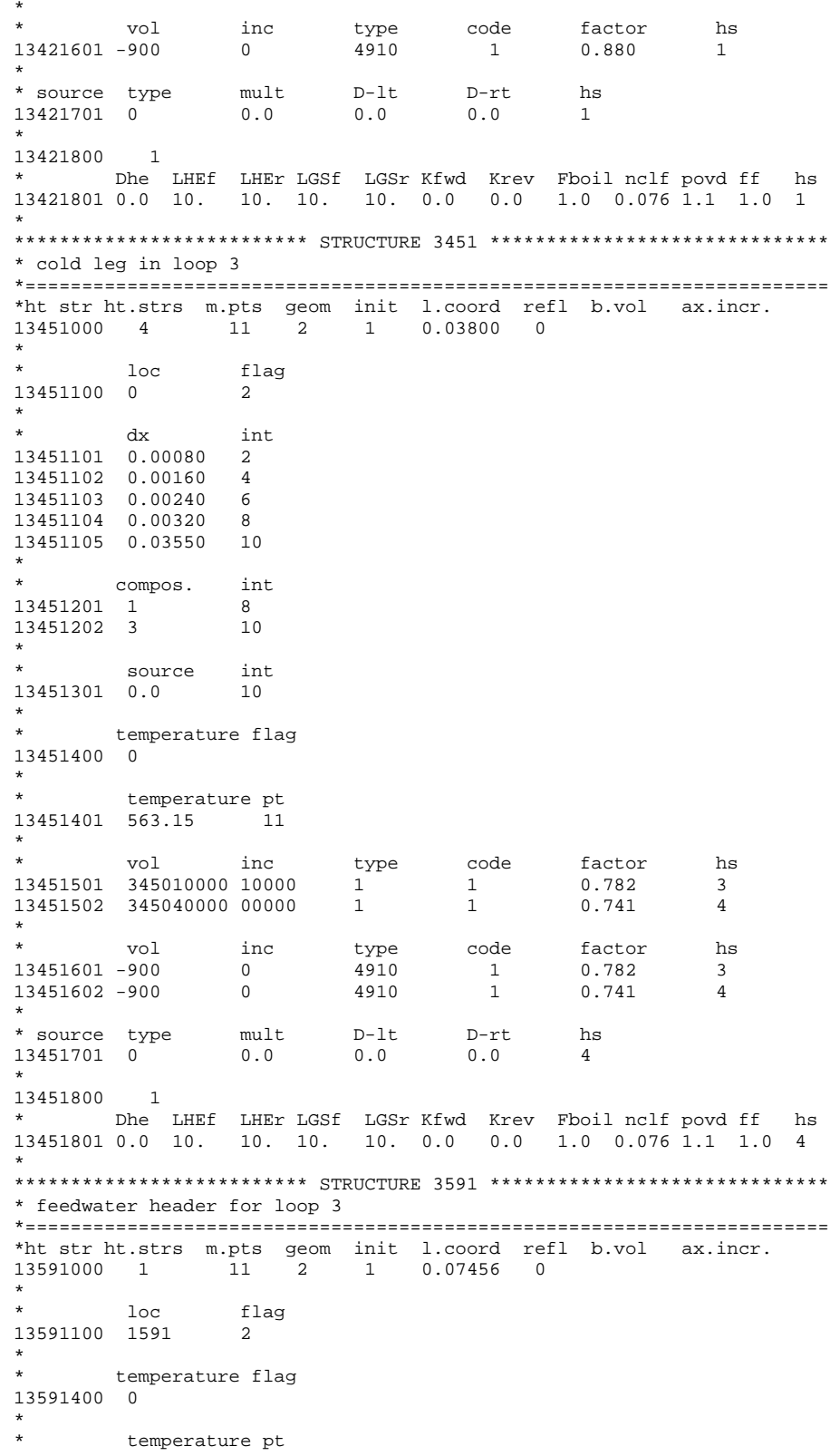

* temperature pt 


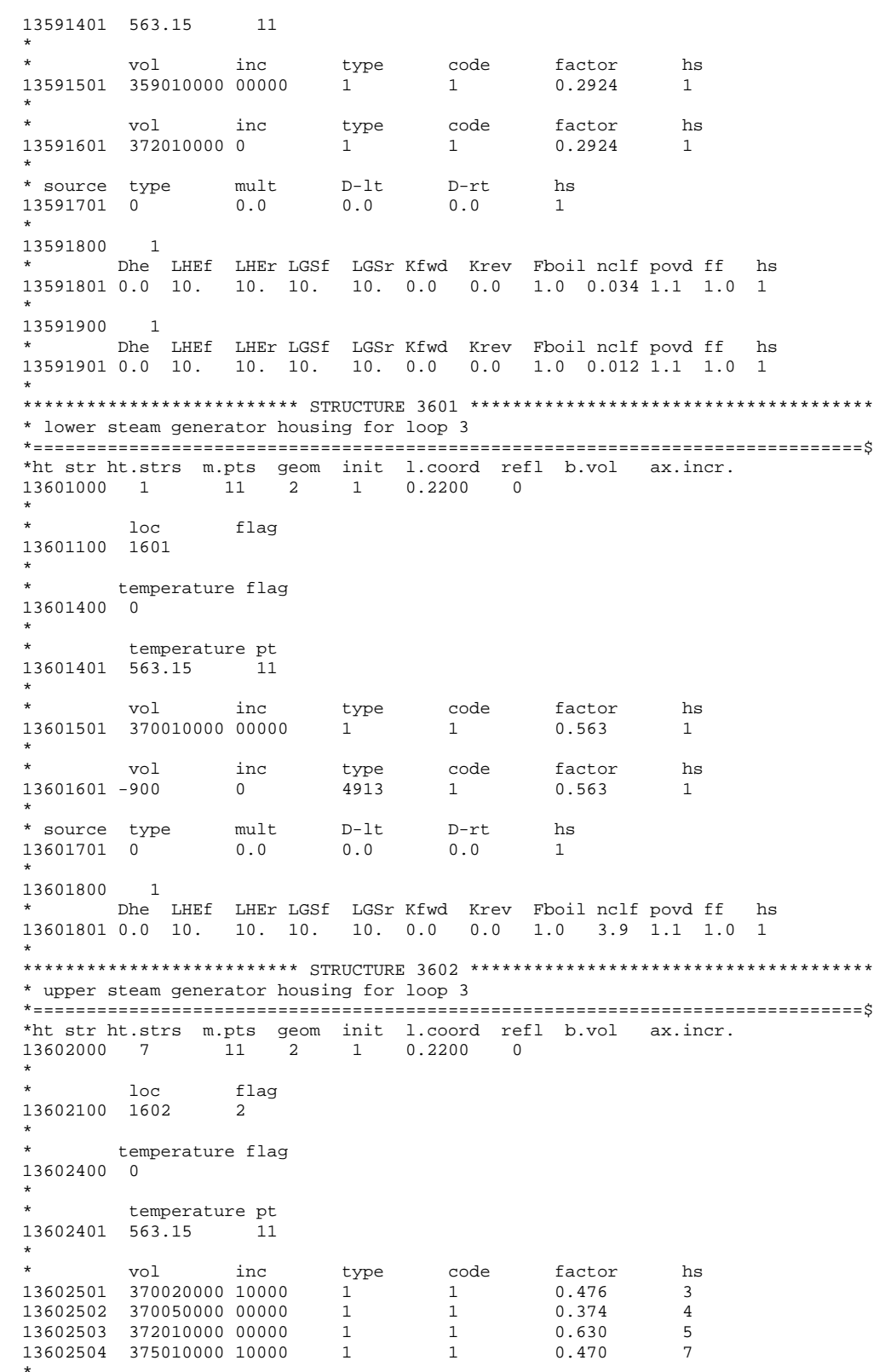

\begin{tabular}{|c|c|c|c|c|c|c|c|c|}
\hline * & vol & inc & type & & code & factor & $h s$ & \\
\hline 13602601 & $\begin{array}{l}\text { - } \\
-900\end{array}$ & ${ }_{0}^{\text {nn }}$ & $\begin{array}{l}\text { type } \\
4913\end{array}$ & & & 0.476 & 3 & \\
\hline 13602602 & -900 & 0 & 4913 & 1 & & 0.374 & 4 & \\
\hline 13602603 & -900 & 0 & 4913 & 1 & & 0.630 & 5 & \\
\hline 13602604 & -900 & 0 & 4913 & 1 & & 0.470 & 7 & \\
\hline * source & type & mult & $D-1 t$ & & D-rt & hs & & \\
\hline 13602701 & 0 & 0.0 & 0.0 & & 0.0 & $\begin{array}{l}\text { ns } \\
7\end{array}$ & & \\
\hline 13602800 & & & & & & & & \\
\hline * & Dhe ${ }^{1}$ LHEf & LHEr LGSf & LGSr & $\mathrm{Kfwd}$ & & Fboil nclf & povd fff & hs \\
\hline 13602801 & 0.010 & $10 . \quad 10$. & 10. & 0.0 & 0.0 & $\begin{array}{ll}1.0 & 3.9\end{array}$ & $\begin{array}{ll}1.1 & 1.0\end{array}$ & 7 \\
\hline 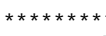 & 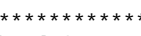 & 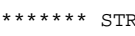 & RUCTURE & 3603 & 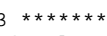 & 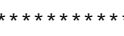 & 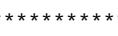 & \\
\hline upper & head for ste & eam generat & tor hor & ousing & for loop & & & \\
\hline *ht str & ht.strs m.p & pts geom & init & 1.0001 & refl & l b.vol & ax.incr. & \\
\hline 13603000 & 1 & $11 \quad 1$ & 1 & 0.0000 & & & & \\
\hline * & loc & flag & & & & & & \\
\hline 13603100 & 1603 & 2 & & & & & & \\
\hline & temperature & e flag & & & & & & \\
\hline${ }_{*}^{13603400}$ & 0 & & & & & & & \\
\hline * & temperatu & re $p t$ & & & & & & \\
\hline 13603401 & 563.15 & 11 & & & & & & \\
\hline * & vol & inc & type & & code & factor & hs & \\
\hline 13603501 & 375020000 & 00000 & 1 & & & 0.14941 & 1 & \\
\hline * & vol & inc & type & & code & factor & hs & \\
\hline 13603601 & -900 & 0 & 4913 & 1 & & 0.14941 & 1 & \\
\hline * source & type & mult & $D-1 t$ & & D-rt & hs & & \\
\hline 13603701 & 0 & 0.0 & 0.0 & & 0.0 & 1 & & \\
\hline 13603800 & 1 & & & & & & & \\
\hline & Dhe LHEf & LHEr LGSf & LGSr & Kfwd & Krev & Fboil nclf & povd ff & hs \\
\hline 13603801 & $0.0 \quad 10$ & 10. 10 & 10. & 0.0 & 0.0 & $\begin{array}{ll}1.0 & 0.11\end{array}$ & $\begin{array}{lll}1.1 & 1.0\end{array}$ & 1 \\
\hline 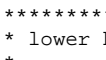 & $\begin{array}{l}* \star \star \star \star \star \star \star \star \star \star * \\
\text { head of the }\end{array}$ & $\begin{array}{l}\star \star \star \star \star \star \star \star \text { STR } \\
\text { steam gene }\end{array}$ & $\begin{array}{l}\text { RUCTURE } \\
\text { erator }\end{array}$ & $\begin{array}{l}E \text { E } 3701 \\
=\text { housir }\end{array}$ & $\begin{array}{l}1 * \star \star \star \star \star \star \star ~ \\
\text { ing for } 1\end{array}$ & 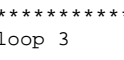 & & \\
\hline $\begin{array}{l}\star_{h t} \text { str } \\
13701000\end{array}$ & $\begin{array}{ll}\text { ht.strs } \\
2\end{array}$ & $\begin{array}{lc}\text { pts } & \text { geom } \\
11 & 2\end{array}$ & $\underset{1}{\text { init }}$ & $\begin{array}{l}1 . c 001 \\
0.669]\end{array}$ & $\begin{array}{ll}\text { ord } & \text { ref } 1 \\
91 & 0\end{array}$ & l b.vol & ax.incr. & \\
\hline & & & & & & & & \\
\hline${ }^{*} 13701100$ & $\begin{array}{l}10 \mathrm{c} \\
1701\end{array}$ & flag & & & & & & \\
\hline & & & & & & & & \\
\hline${ }^{*} 13701400$ & $\begin{array}{c}\text { temperature } \\
0\end{array}$ & e flag & & & & & & \\
\hline & & & & & & & & \\
\hline $\begin{array}{l}* \\
13701401\end{array}$ & temperatur & re pt & & & & & & \\
\hline * & 563.15 & 11 & & & & & & \\
\hline * & vol & & type & & code & factor & hs & \\
\hline${ }_{*}^{13701501}$ & 3100100000 & 20000000 & 1 & 1 & & 0.01701 & 2 & \\
\hline * & vol & inc & type & & code & factor & hs & \\
\hline 13701601 & 370010000 & 0 & 1 & & & 0.01701 & 2 & \\
\hline * source & type & mult & $D-1 t$ & & D-rt & hs & & \\
\hline 13701701 & 0 & 0.0 & 0.0 & & 0.0 & 2 & & \\
\hline 13701800 & & & & & & & & \\
\hline & Dhe LHEf & LHEr LGSf & LGSr & Kfwd & Krev & Fboil nclf & povd ff & hs \\
\hline 13701801 & $0.0 \quad 10$. & 10. 10 & 10. & 0.0 & 0.0 & $\begin{array}{ll}1.0 & 0.200\end{array}$ & $\begin{array}{ll}1.1 & 1.0\end{array}$ & 2 \\
\hline
\end{tabular}


13701900 Dhe LHEf LHEr LGSf LGSr Kfwd Krev Fboil nclf povd ff hs 137019010.0 10. 10. 10. 10. 0.0 0.0 $1.0 \quad 0.11 \quad 1.1 \quad 1.0$ $\star$ hot leg nozzle and pipe in loop 4 kht str ht.strs m.pts geom init 1.coord refl b.vol ax.incr. $\begin{array}{lll}* & \text { loc } & \text { flag } \\ 14011100 & 0 & 2\end{array}$

* $\mathrm{dx} \quad$ in

$\begin{array}{lll}14011101 & 0.00085 & 2 \\ 14011102 & 0.00170 & 0\end{array}$

$\begin{array}{lll}14011102 & 0.00170 & 4 \\ 14011103 & 0.00255 & 6\end{array}$

$\begin{array}{lll}14011104 & 0.00340 \quad 8\end{array}$

$14011105 \quad 0.03500 \quad 10$

14011201 compos. $\quad 8$

*

$\begin{array}{lll}* & \text { source } & \text { int } \\ 14011301 & 0.0 & 10\end{array}$

* temperature flag

4011400

$\begin{array}{lll} & \text { temperature pt } \\ 14011401 & 563.15 & 11\end{array}$

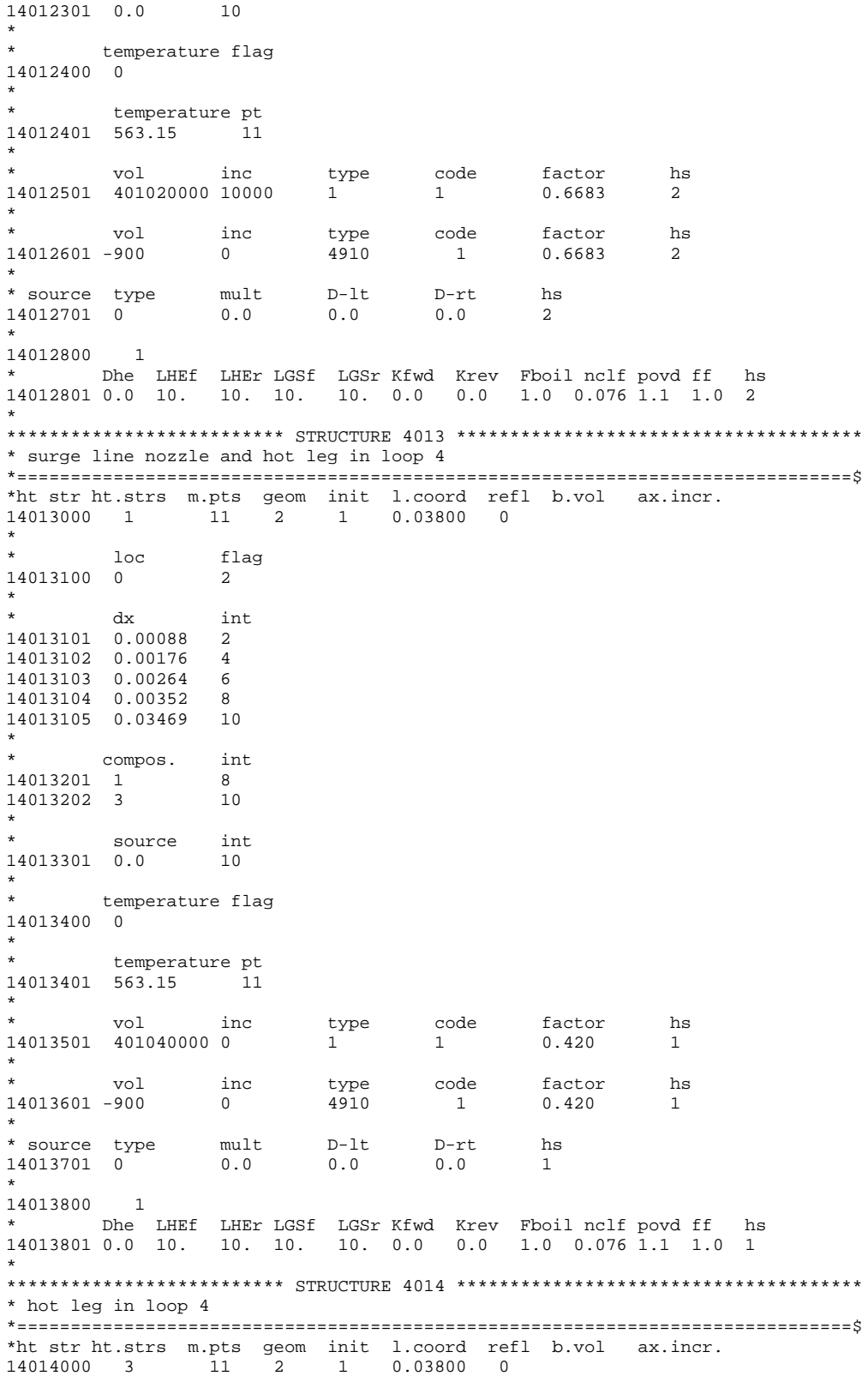




\begin{tabular}{|c|c|c|c|c|c|c|}
\hline * 14014100 & $\begin{array}{l}\text { loc } \\
0\end{array}$ & $\frac{\text { flag }}{2}$ & & & & \\
\hline * & $d x$ & int & & & & \\
\hline 14014101 & 0.00080 & & & & & \\
\hline 14014102 & 0.00160 & 4 & & & & \\
\hline 14014103 & 0.00240 & 6 & & & & \\
\hline 14014104 & 0.00320 & 8 & & & & \\
\hline 14014105 & 0.03550 & 10 & & & & \\
\hline * & compos. & int & & & & \\
\hline $\begin{array}{l}14014201 \\
14014202\end{array}$ & & $\begin{array}{l}8 \\
10\end{array}$ & & & & \\
\hline * & source & int & & & & \\
\hline 14014301 & 0.0 & 10 & & & & \\
\hline 14014400 & $\begin{array}{l}\text { temperature } \\
0\end{array}$ & e flag & & & & \\
\hline * & temperatur & re pt & & & & \\
\hline 14014401 & 563.15 & 11 & & & & \\
\hline 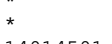 & & & & code & & hs \\
\hline $\begin{array}{l}14014501 \\
*\end{array}$ & 401050000 & 10000 & 1 & 1 & 0.567 & 3 \\
\hline 14601 & vol & inc & type & code & factor & hs \\
\hline 14601 & -900 & 0 & 4910 & 1 & 0.567 & 3 \\
\hline & type & mult & $D-1 t$ & D-rt & hs & \\
\hline 14701 & 0 & 0.0 & 0.0 & 0.0 & 3 & \\
\hline
\end{tabular}

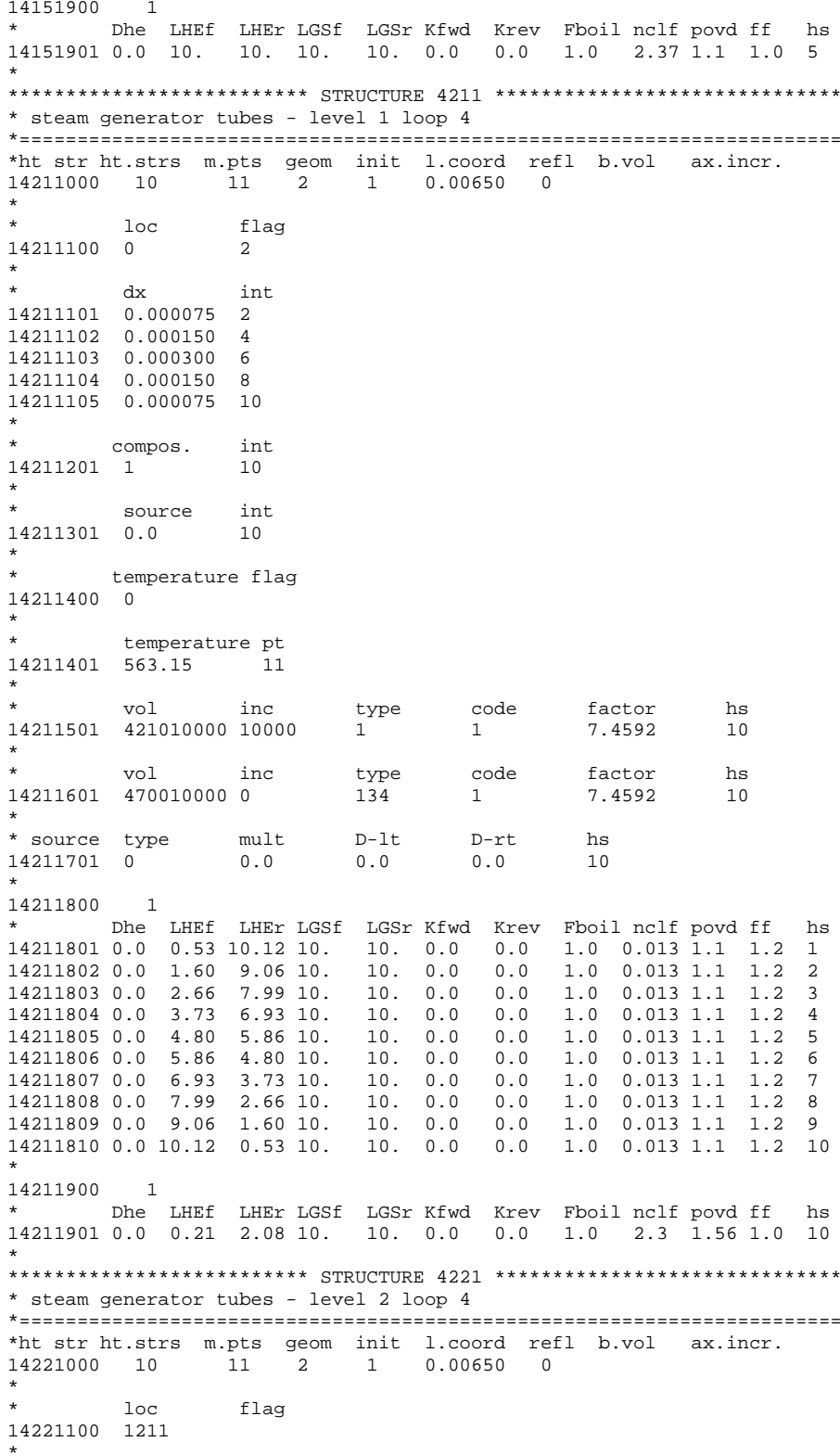


* $14221400 \quad$ temperature flag

$\begin{array}{lll}* & \text { temperature pt } \\ 14221401 & 563.15 & 11\end{array}$

$\begin{array}{lllllll}* & \text { vol } & \text { inc } & \text { type } & \text { code } & \text { factor } & \text { hs } \\ 14221501 & 422010000 & 10000 & 1 & 1 & 7.4592 & 10\end{array}$

$\begin{array}{lllllll}* & \text { vol } & \text { inc } & \text { type } & \text { code } & \text { factor } & \text { hs } \\ 14221601 & 470020000 & 0 & 134 & 1 & 7.4592 & 10\end{array}$

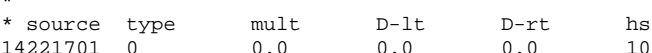

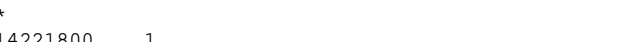

$14221800{ }^{1}$ Dhe LHEf LHEr LGSf LGSr Kfwd Krev Fboil nclf povd ff hs

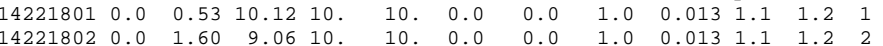
$\begin{array}{lllllllllllll}14221803 & 0.0 & 2.66 & 7.99 & 10 . & 10 . & 0.0 & 0.0 & 1.0 & 0.013 & 1.1 & 1.2 & 3\end{array}$ $\begin{array}{lllllllllllll}14221804 & 0.0 & 3.73 & 6.93 & 10 . & 10 . & 0.0 & 0.0 & 1.0 & 0.013 & 1.1 & 1.2 & 4 \\ 14221805 & 0.0 & 4.80 & 5.86 & 10 . & 10 . & 0.0 & 0.0 & 1.0 & 0.013 & 1.1 & 1.2 & 5\end{array}$ $\begin{array}{lllllllllllll}14221805 & 0.0 & 4.80 & 5.86 & 10 . & 10 . & 0.0 & 0.0 & 1.0 & 0.013 & 1.1 & 1.2 & 5 \\ 14221806 & 0.0 & 5.86 & 4.80 & 10 . & 10 . & 0.0 & 0.0 & 1.0 & 0.013 & 1.1 & 1.2 & 6\end{array}$ $\begin{array}{lllllllllllll}14221806 & 0.0 & 5.86 & 4.80 & 10 . & 10 . & 0.0 & 0.0 & 1.0 & 0.013 & 1.1 & 1.2 & \\ 14221807 & 0.0 & 6.93 & 3.73 & 10 . & 10 . & 0.0 & 0.0 & 1.0 & 0.013 & 1.1 & 1.2 & 7\end{array}$ $\begin{array}{llllllllllll}14221808 & 0.0 & 7.99 & 2.66 & 10 . & 10 . & 0.0 & 0.0 & 1.0 & 0.013 & 1.1 & 1.2\end{array}$ $\begin{array}{rrrrrrrrrrrrr}14221809 & 0.0 & 9.06 & 1.60 & 10 . & 10 . & 0.0 & 0.0 & 1.0 & 0.013 & 1.1 & 1.2 & 9 \\ 14221810 & 0.0 & 10.12 & 0.53 & 10 . & 10 . & 0.0 & 0.0 & 1.0 & 0.013 & 1.1 & 1.2 & 10\end{array}$ * 14221900

* Dhe LHEf LHEr LGSf LGSr Kfwd Krev Fboil nclf povd ff hs

* steam generator tubs - levUCTURE 423

*ht str ht.strs m.pts geom init 1.coord refl b.vol ax.incr.

$\begin{array}{ll}* & 100 \\ 14231100 & 1211\end{array}$

* temperature flag

$14231400 \quad 0$

$\begin{array}{lll}* & \text { temperature } & \text { pt } \\ 14231401 & 563.15 & 11\end{array}$

$\begin{array}{lllllll}* & \text { vol } & \text { inc } & \text { type } & \text { code } & \text { factor } & \text { hs } \\ 14231501 & 423010000 & 10000 & 1 & 1 & 7.4592 & 10\end{array}$

$\begin{array}{lllllll}* & \text { vol } & \text { inc } & \text { type } & \text { code } & \text { factor } & \text { hs } \\ 14231601 & 470030000 & 0 & 134 & 1 & 7.4592 & 10\end{array}$

* source type mult D-1t D-rt hs

$14231800 \quad 1$

4231801 Dhe LHEf LHEr LGSf LGSr Kfwd Krev Fboil nclf povd ff hs $\begin{array}{lllllllllllll}14231801 & 0.0 & 0.53 & 10.12 & 10 . & 10 . & 0.0 & 0.0 & 1.0 & 0.013 & 1.1 & 1.2 & 1\end{array}$

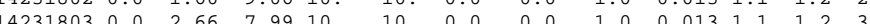
$\begin{array}{llllllllllllll}4231804 & 0.0 & 3.73 & 6.93 & 10 . & 10 . & 0.0 & 0.0 & 1.0 & 0.013 & 1.1 & 1.2 & 4\end{array}$ $\begin{array}{lllllllllllll}14231805 & 0.0 & 4.80 & 5.86 & 10 . & 10 . & 0.0 & 0.0 & 1.0 & 0.013 & 1.1 & 1.2 & 5\end{array}$ $\begin{array}{llllllllllllll}14231807 & 0.0 & 6.93 & 3.73 & 10 . & 10 . & 0.0 & 0.0 & 1.0 & 0.013 & 1.1 & 1.2 & 7\end{array}$ $\begin{array}{lllllllllllll}14231808 & 0.0 & 7.99 & 2.66 & 10 . & 10 . & 0.0 & 0.0 & 1.0 & 0.013 & 1.1 & 1.2 & 8 \\ 14231809 & 0.0 & 9.06 & 1.60 & 10 . & 10 . & 0.0 & 0.0 & 1.0 & 0.013 & 1.1 & 1.2 & 9\end{array}$

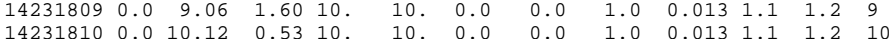

14231900

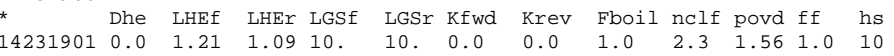

$* \star \star \star \star \star \star \star \star \star \star \star \star \star \star \star \star \star ~$
steam generator tubes - level 4 loop 4

*ht str ht.strs m.pts geom init l.coord refl b.vol ax.incr.

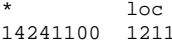

flag

temperature flag

* $\quad$ temperature pt

$\begin{array}{lllllll}* & \text { vol } & \text { inc } & \text { type } & \text { code } & \text { factor } & \text { hs } \\ 14241501 & 424010000 & 10000 & 1 & 1 & 7.4592 & 10\end{array}$

$\begin{array}{lllllll}* & \text { vol } & \text { inc } & \text { type } & \text { code } & \text { factor } & \text { hs } \\ 14241601 & 470040000 & 0 & 134 & 1 & 7.4592 & 10\end{array}$

$\begin{array}{llllll}* \text { source } & \text { type } & \text { mult } & \text { D-lt } & \text { D-rt } & \text { hs } \\ 14241701 & 0 & 0.0 & 0.0 & 0.0 & 10\end{array}$

$14241800 \quad 1$

* $4241800{ }^{1}$ Dhe LHEf LHEr LGSf LGSr Kfwd Krev Fboil nclf povd ff hs

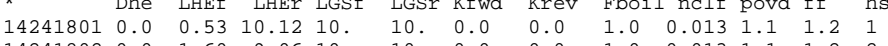
$\begin{array}{lllllllllllll}14241802 & 0.0 & 1.60 & 9.06 & 10 . & 10 . & 0.0 & 0.0 & 1.0 & 0.013 & 1.1 & 1.2 & 2 \\ 14241803 & 0.0 & 2.66 & 7.99 & 10 . & 10 . & 0.0 & 0.0 & 1.0 & 0.013 & 1.1 & 1.2 & 3\end{array}$ $\begin{array}{lllllllllllll}14241803 & 0.0 & 2.66 & 7.99 & 10 . & 10 . & 0.0 & 0.0 & 1.0 & 0.013 & 1.1 & 1.2 & 3 \\ 14241804 & 0.0 & 3.73 & 6.93 & 10 . & 10 . & 0.0 & 0.0 & 1.0 & 0.013 & 1.1 & 1.2 & 4\end{array}$

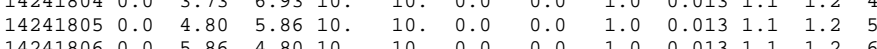
$\begin{array}{llllllllllllll}14241806 & 0.0 & 5.86 & 4.86 & 10 & 10 . & 0.0 & 0.0 & 1.0 & 0.013 & 1.1 & 1.2 & 4 \\ 14.0 .0 & 0.013 & 1.1 & 1.2 & 5\end{array}$ $\begin{array}{lllllllllllll}14241807 & 0.0 & 6.93 & 3.73 & 10 . & 10 . & 0.0 & 0.0 & 1.0 & 0.013 & 1.1 & 1.2 & 6 \\ 14241808 & 0.0 & 7.99 & 2.66 & 10 . & 10 . & 0.0 & 0.0 & 1.0 & 0.013 & 1.1 & 1.2 & 8\end{array}$

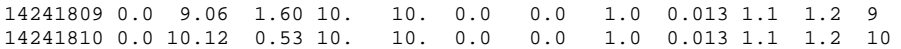

* Dhe LHEf LHEr LGSf LGSr Kfwd Krev Fboil nclf povd ff hs

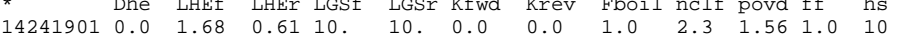

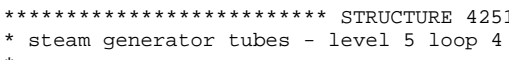

*ht str ht. strs m.pts geom init 1. coord refl b.vol ax.incr.

$*$

$\begin{array}{ll}* & 100 \\ 14251100 & 1211\end{array}$

* temperature flag

$\begin{array}{lll}* & \text { temperature } & \text { pt } \\ 14251401 & 563.15 & 11\end{array}$

$\begin{array}{lll}* & \text { vol } & \text { inc } \\ 14251501 & 425010000 & 10000\end{array}$

$\begin{array}{lll}* & \text { vol } & \text { inc } \\ 14251601 & 470050000 & 0\end{array}$

* source type mult

typ
1

typ
1
typ
134

1

factor
6.3936

hs
10

$\begin{array}{llll} & \text { code } & \text { factor } & \text { hs } \\ 134 & 1 & 6.3936 & 10\end{array}$

D-lt $\quad$ D-rt $h s$ 


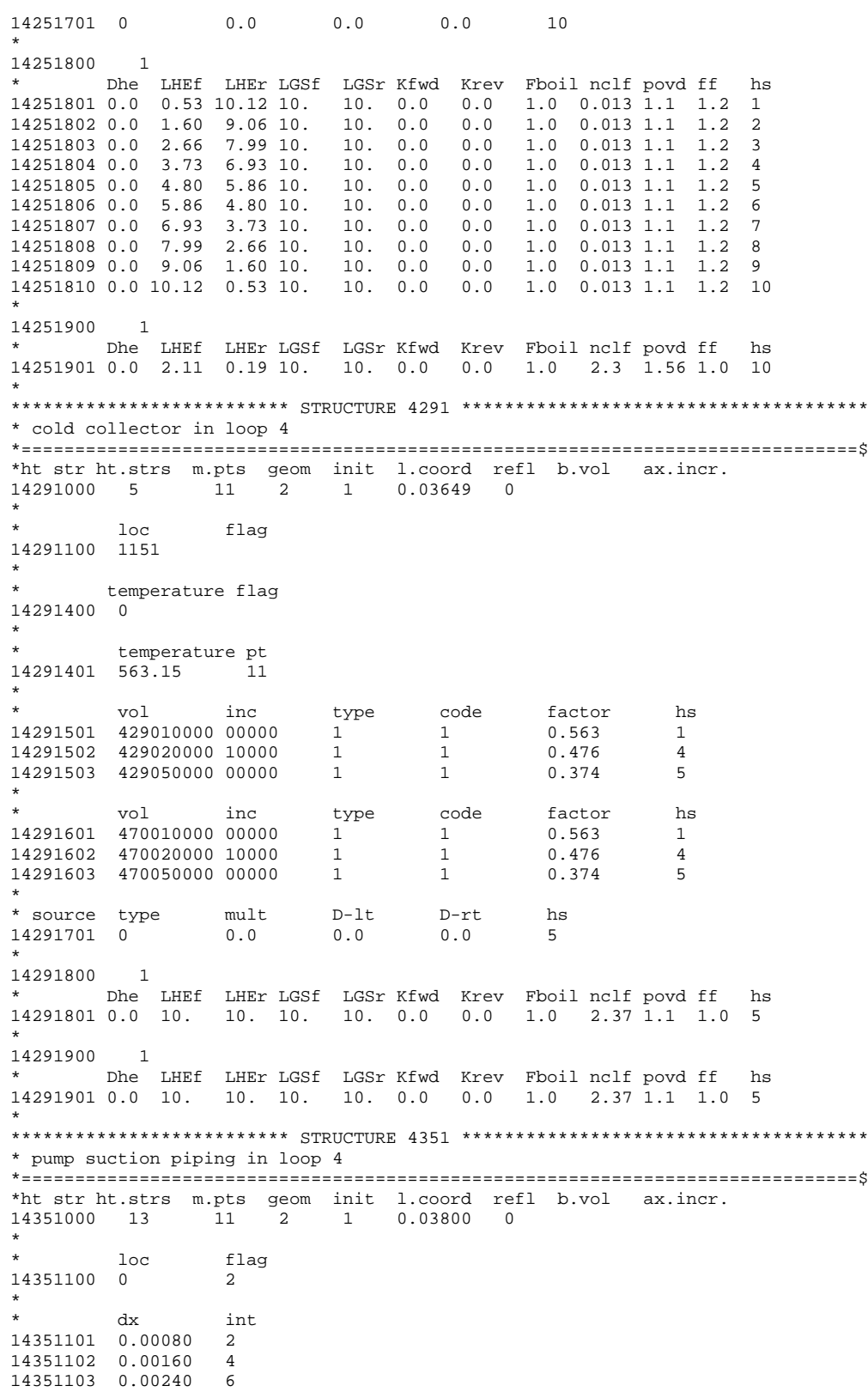

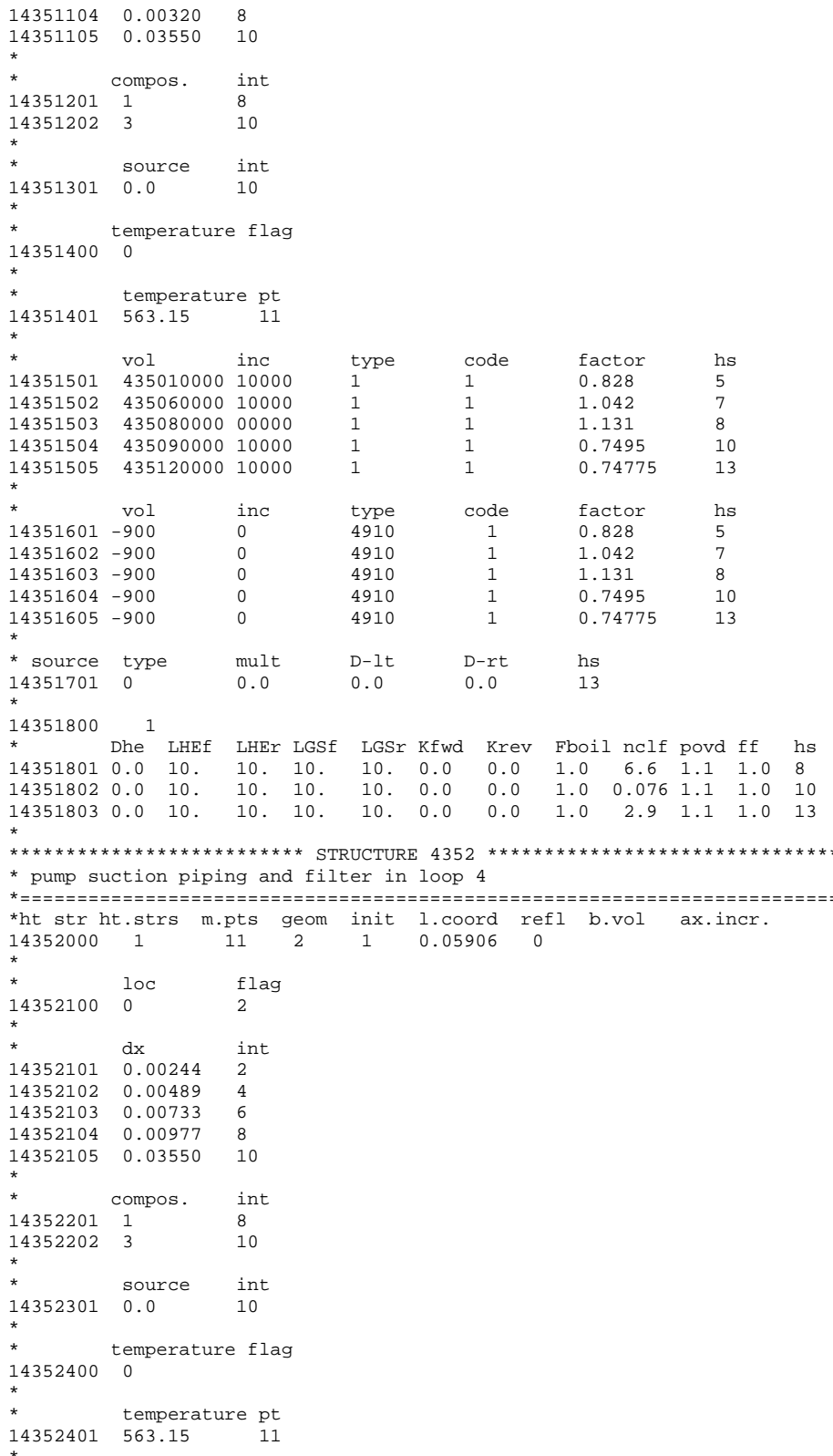




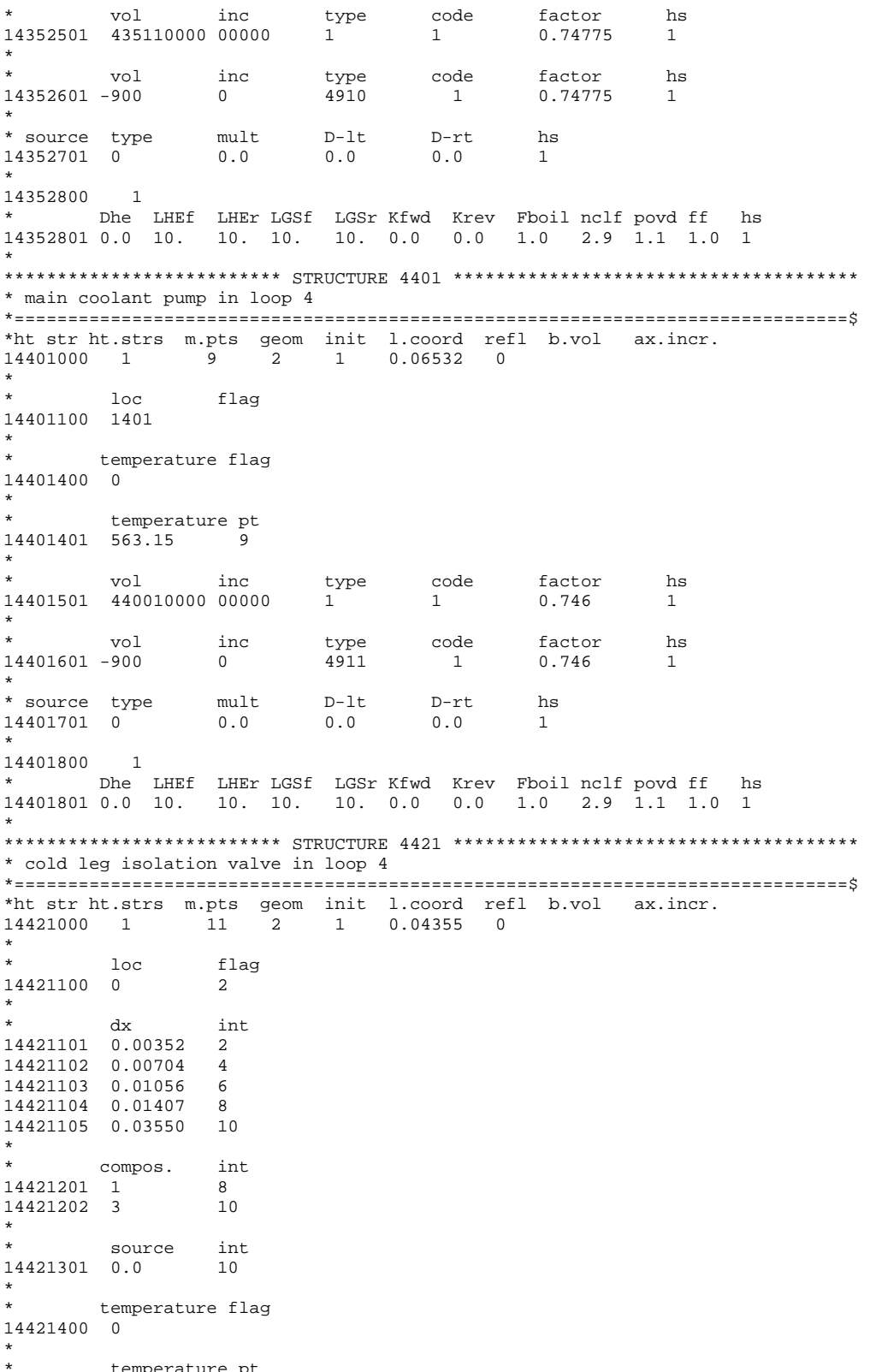

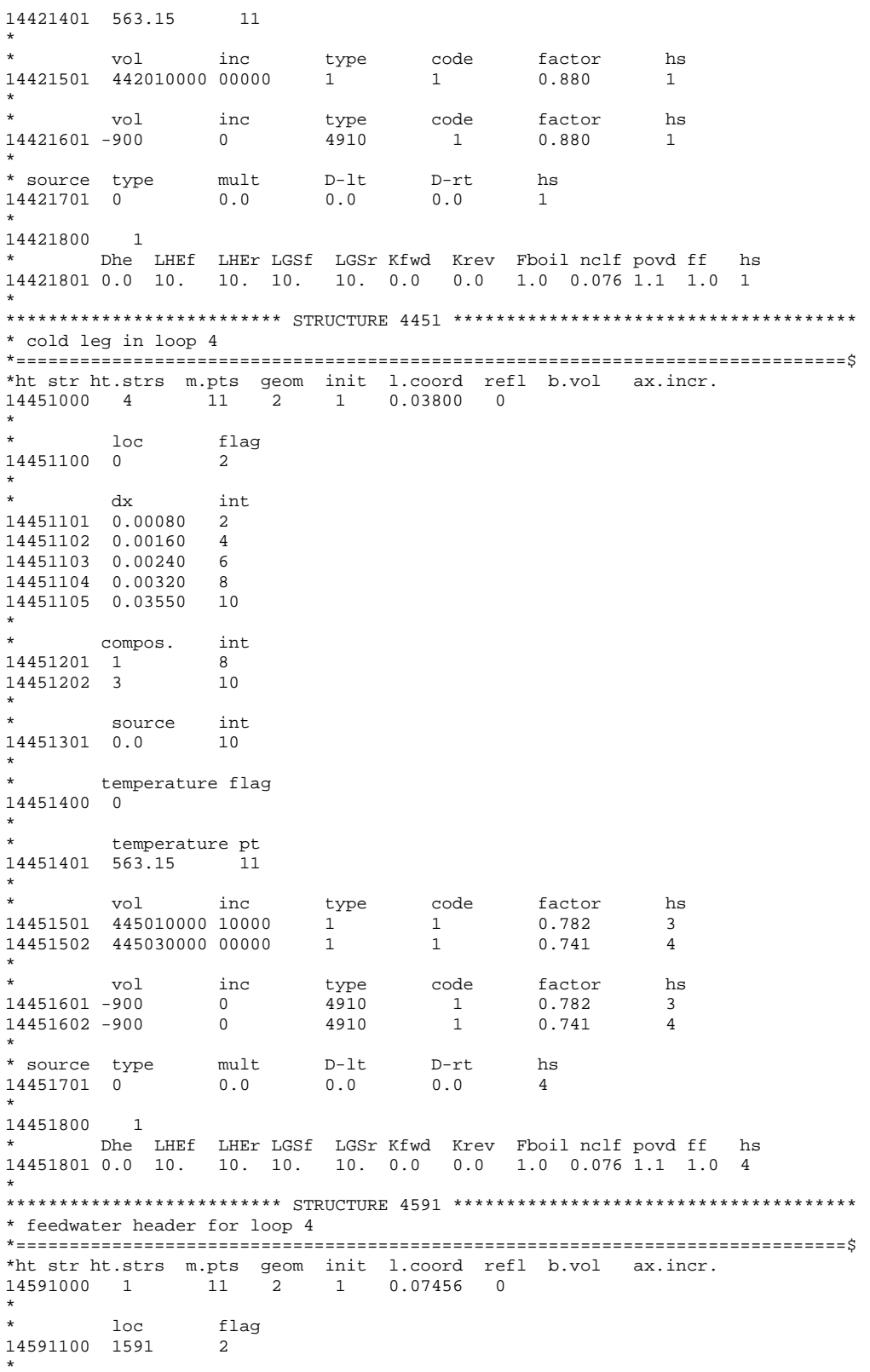




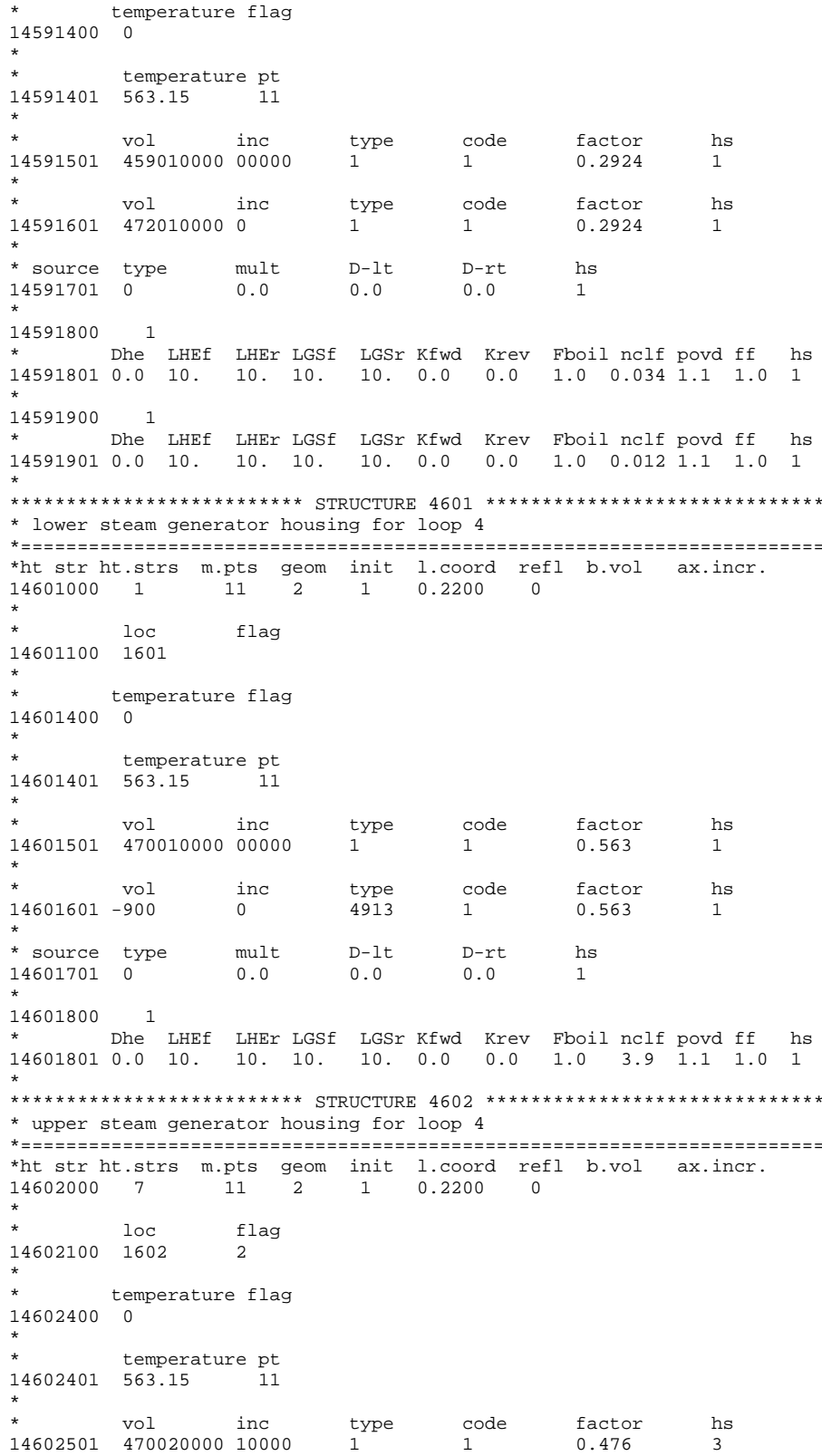


* $4701800{ }^{1}$ Dhe LHEf LHEr LGSf LGSr Kfwd Krev Fboil nclf povd ff hs $\begin{array}{llllllllllllllll}14701801 & 0.0 & 10 & 10 . & 10 & 10, & 0.0 & 0.0 & 1.0 & 0.200 & 1.1 & 1.0 & \end{array}$ $14701900 \quad 1$

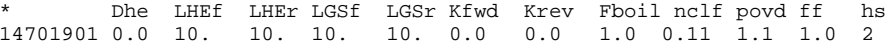

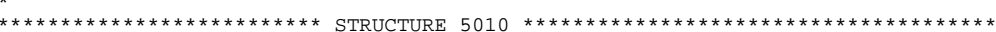
* pressurizer surge line in loop 2

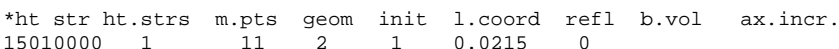

* loc flag

* intervals radius

$\begin{array}{lll}15010101 & 2 & 0.0222\end{array}$

$\begin{array}{lll}15010102 & 2 & 0.0236 \\ 15010103 & 2 & 0.0257 \\ 15010105 & 2 & 0.0285\end{array}$

$\begin{array}{lll}15010104 & 2 & 0.0285 \\ 15010105 & 2 & 0.090\end{array}$

compos. in

150102011 . 8

$150102023 \quad 10$

$\begin{array}{lll}* & \text { source } & \text { int } \\ 15010301 & 0.0 & 10\end{array}$

* $15010400 \quad$ temperature flag

* $\quad$ temperature pt

$\begin{array}{lllllll}\star & \text { vol } & \text { inc } & \text { type } & \text { code } & \text { factor } & \text { hs } \\ 15010501 & 501010000 & 00000 & 1 & 1 & 1.126 & 1\end{array}$

$\begin{array}{lllccll}* & \text { vol } & \text { inc } & \text { type } & \text { code } & \text { factor } & \text { hs } \\ 15010601 & -900 & 0 & 4912 & 1 & 1.126 & 1\end{array}$

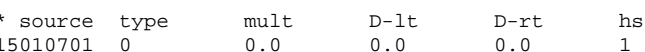

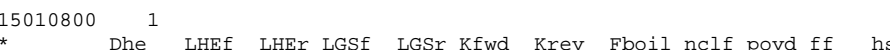

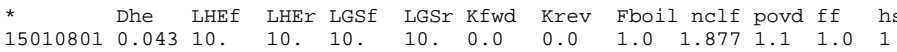

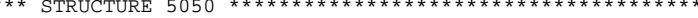

$*$ pressurizer surge line in loop 2

*ht str ht. Strs m.pts geom init l.coord refl b.vol ax.incr.
15050000
7

$15050100 \quad \begin{array}{ll}100 \\ 5010\end{array}$

* temperature flag

$15050400 \quad 0$

$\begin{array}{lll}* & \text { temperature } \mathrm{pt} \\ 15050401 & 550.0 & 11\end{array}$

$\begin{array}{lllllll}* & \text { vol } & \text { inc } & \text { type } & \text { code } & \text { factor } & \text { hs } \\ 15050501 & 505010000 & 00000 & 1 & 1 & 0.876 & 1\end{array}$ $\begin{array}{lllllll}15050502 & 505020000 & 00000 & 1 & 1 & 0.662 & 2 \\ 15050503 & 505030000 & 10000 & 1 & 1 & 0.940 & 6 \\ 15050504 & 505070000 & 00000 & 1 & 1 & 1.031 & 7 \\ \star & & & & & & \\ * & \text { vol } & \text { inc } & \text { type } & \text { code } & \text { factor } & \text { hs } \\ 15050601 & -900 & 0 & 4912 & 1 & 0.876 & 1 \\ 15050602 & -900 & 0 & 4912 & 1 & 0.662 & 2 \\ 15050603-900 & 0 & 4912 & 1 & 0.940 & 6 \\ 15050604 & -900 & 0 & 4912 & 1 & 1.031 & 7 \\ \text { * } & & & & & \\ \text { * source } & \text { type } & \text { mult } & \text { D-1t } & \text { D-rt } & \text { hs } & \\ 15050701 & 0 & 0.0 & 0.0 & 0.0 & 7 & \end{array}$

$15050800{ }^{1}$ LHE

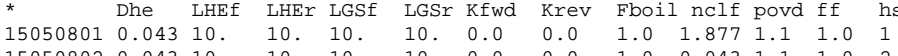

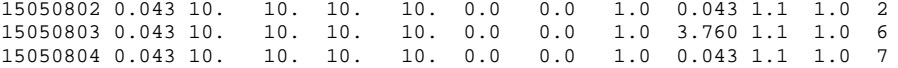

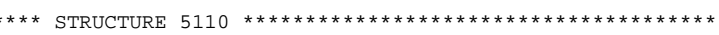

* pressurizer surge line in loop 4

*ht str ht.strs m.pts geom init l.coord refl b.vol ax.incr.

$\begin{array}{ll}* & 10 \mathrm{C} \\ 15110100 & 5010\end{array}$

* temperature flag

$\begin{array}{lll} & \text { temperature } \mathrm{pt} \\ 15110401 & 550.0 & 11\end{array}$

$\begin{array}{lllllll}* & \text { vol } & \text { inc } & \text { type } & \text { code } & \text { factor } & \text { hs } \\ 15110501 & 511010000 & 00000 & 1 & 1 & 1.345 & 1\end{array}$

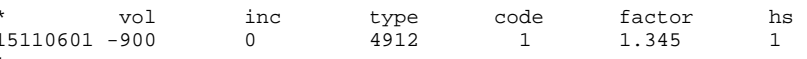

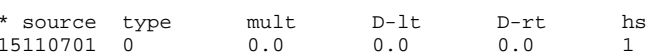

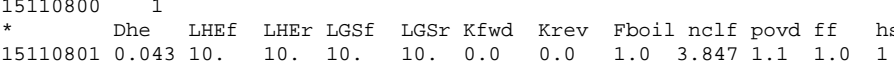

年

* pressurizer surge line in loop 4

*ht str ht.strs m.pts geom init $\begin{aligned} & 1 . \text { coord } \\ & 15150000 \\ & 6\end{aligned}$

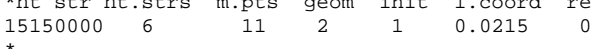

* $15150100 \quad$ loc

* $15150400 \stackrel{\text { temperature flag }}{0}$

* temperature pt

vol inc

1515050151501000010000

151505025150300001000

151505045150600000000

$\begin{array}{llll}\text { type } & \text { code } & \text { factor } & \text { hs } \\ 1 & 1 & 1.338 & 2 \\ 1 & 1 & 1.321 & 4 \\ 1 & 1 & 1.790 & 5 \\ 1 & 1 & 1.091 & 6\end{array}$




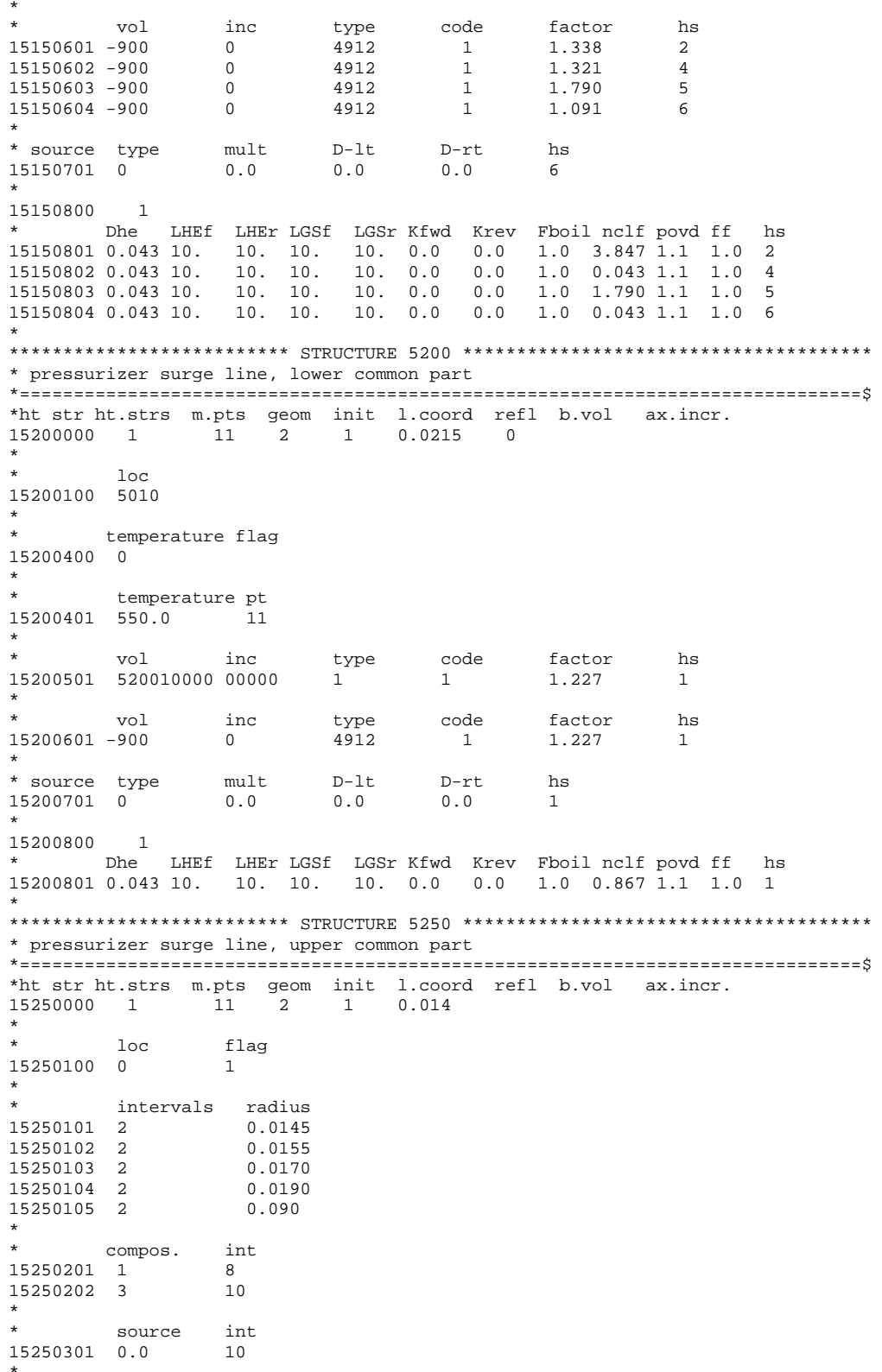

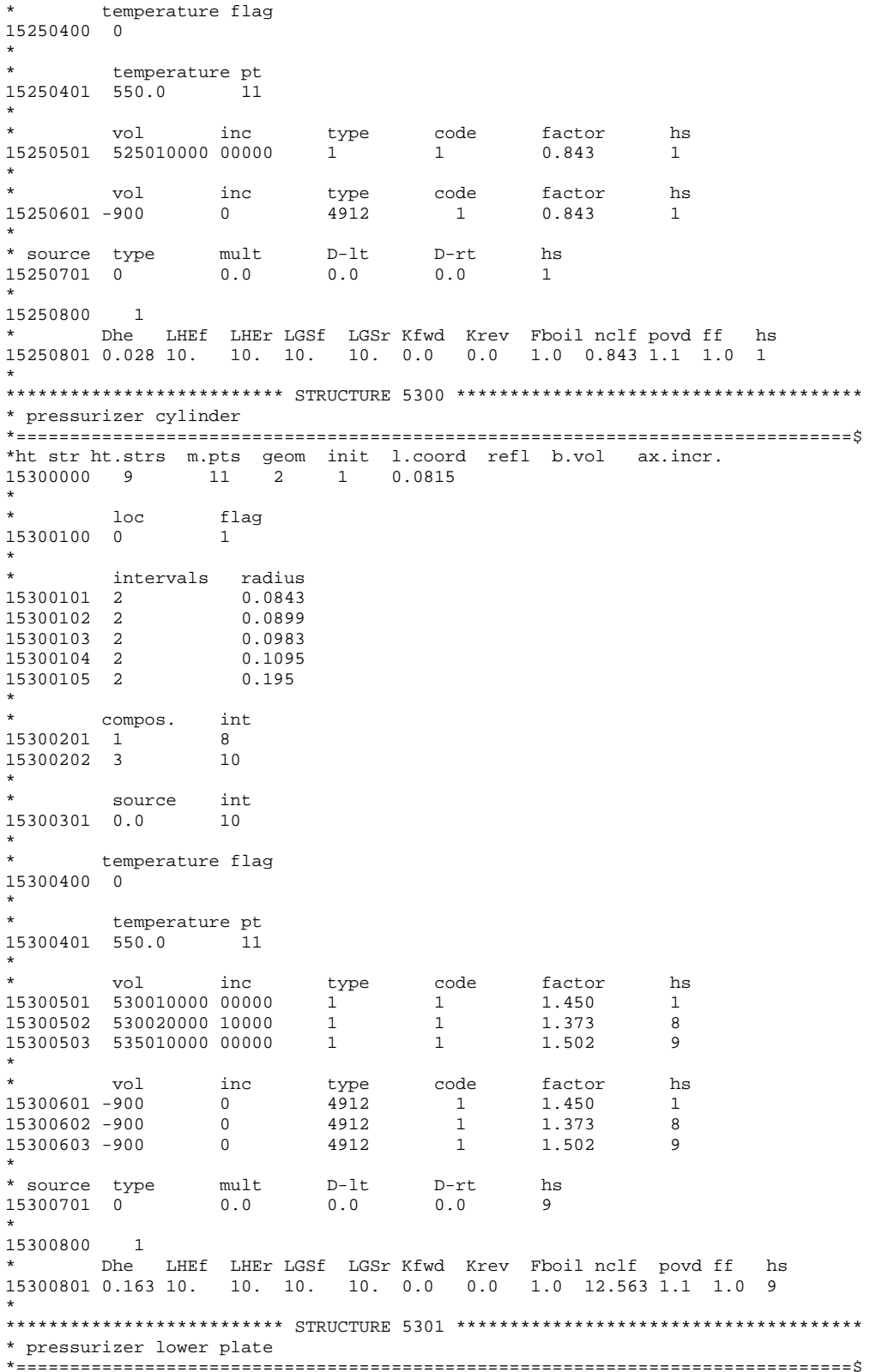




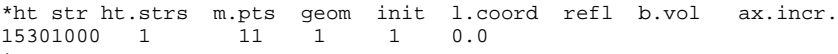

* $15301100 \quad$ loc fla

* intervals radius

$\begin{array}{lll}15301101 & 2 & 0.0111 \\ 15301102 & 2 & 0.0333\end{array}$

$\begin{array}{lll}15301103 & 2 & 0.0666\end{array}$

$\begin{array}{lll}15301104 & 2 & 0.1110 \\ 15301105 & 2 & 0.1965\end{array}$

compos. int

$\begin{array}{lll}15301201 & 1 & 8 \\ 15301202 & 3 & 10\end{array}$

*

$\begin{array}{lll}* & \text { source } & \text { int } \\ 15301301 & 0.0 & 10\end{array}$

* $\quad$ temperature flag

* temperature pt

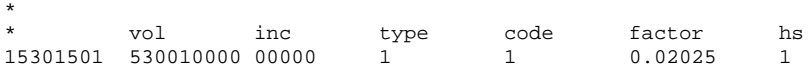

$\begin{array}{lllccll}* & \text { vol } & \text { inc } & \text { type } & \text { code } & \text { factor } & \text { hs } \\ 15301601 & -900 & 0 & 4912 & 1 & 0.02025 & 1\end{array}$

$\begin{array}{llllll}* \text { source } & \text { type } & \text { mult } & \text { D-1t } & \text { D-rt } & \text { hs } \\ 15301701 & 0 & 0.0 & 0.0 & 0.0 & 1\end{array}$

* $15301800{ }^{1}$ Dhe LHEf LHEr LGSf LGSr Kfwd Krev Fboil nclf povd ff hs

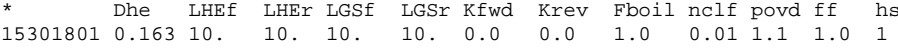

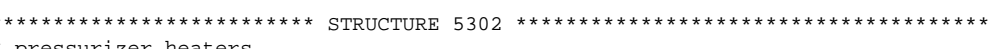
* pressurizer heaters

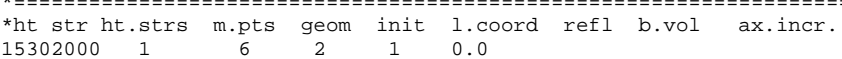

$\begin{array}{lll}* & \text { loc } & \text { flag } \\ 15302100 & 0 & 1\end{array}$

* intervals radius

$\begin{array}{lll}15302101 & 1 & 0.005 \\ 15302102 & 4 & 0.0065\end{array}$

* compos. int

1530220160.1

*

$\begin{array}{lll}15302301 & 1.0 & 1 \\ 15302302 & 0.0 & 5\end{array}$

* temperature fla

$15302400 \stackrel{\text { ten }}{0}$

$\begin{array}{lll}* & \text { temperature } \\ 15302401 & 550.0 & 6\end{array}$

$+$

$\begin{array}{lllllll}* & \text { vol } & \text { inc } & \text { type } & \text { code } & \text { factor } & \text { hs } \\ 15302501 & 0 & 0 & 0 & 1 & 18.0\end{array}$

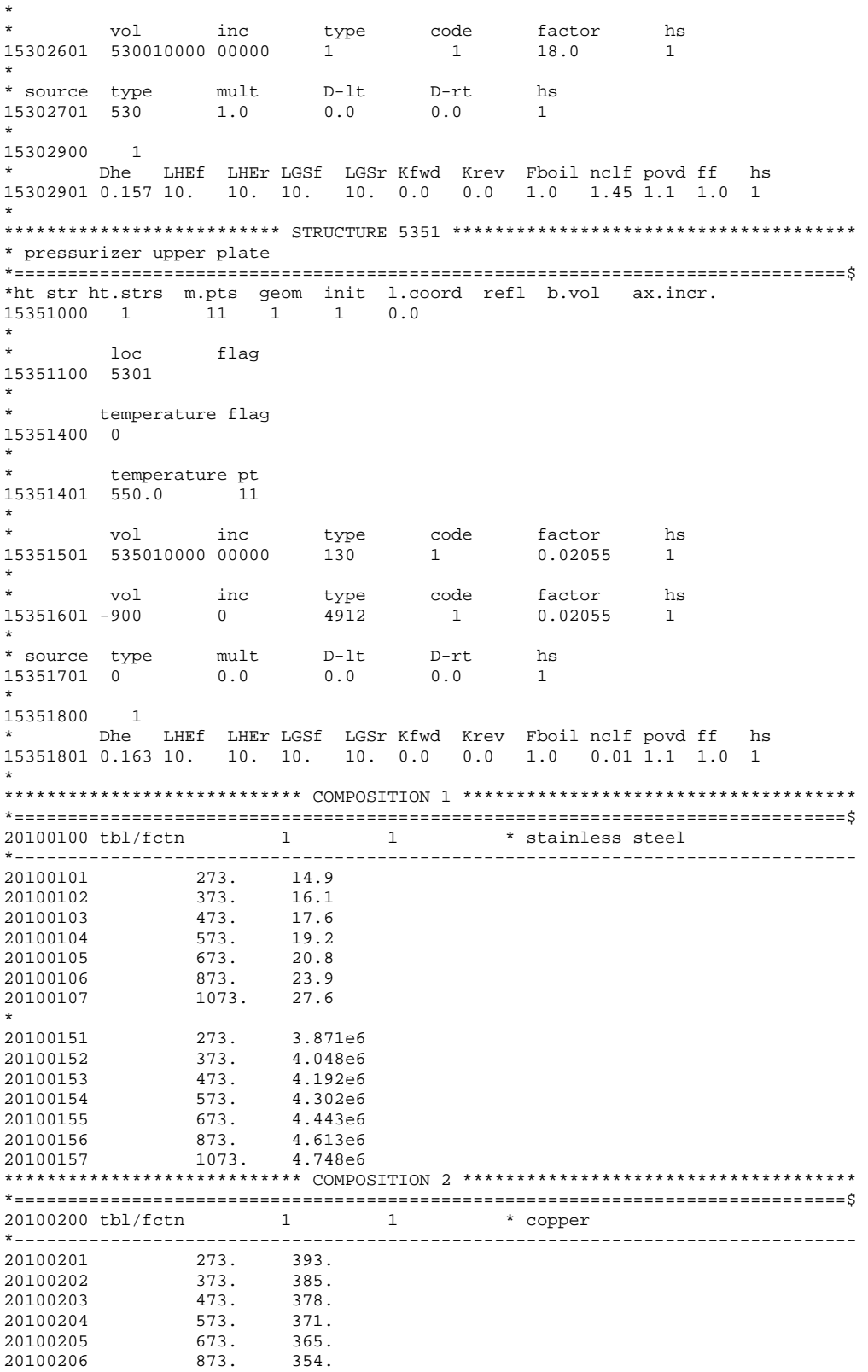




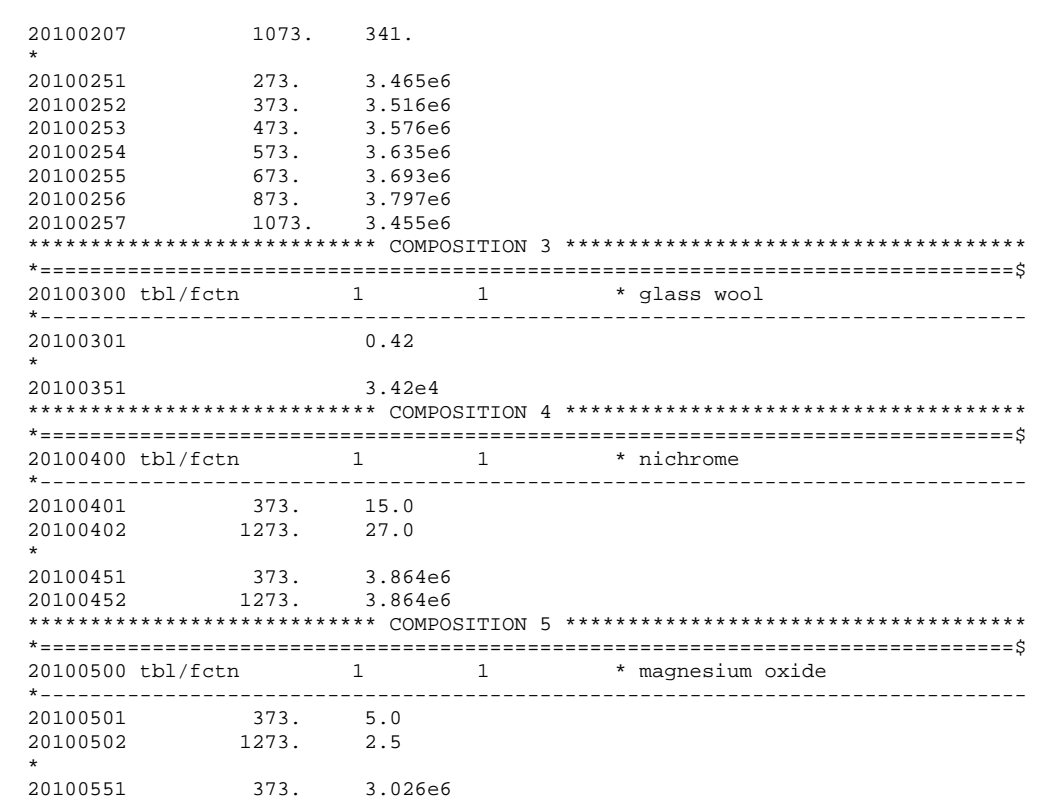

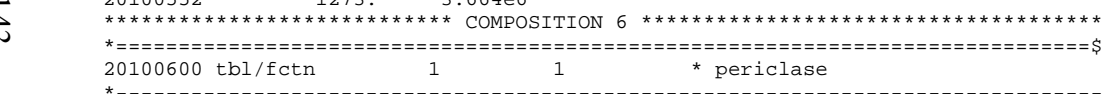

$\begin{array}{llll}20100600 \mathrm{tbl} / \mathrm{fctn} & 1 & 1 & \text { * } \\ \star & \text { periclase } \\ 20100601 & 373 . & 3.73 & \\ 20100602 & 473 . & 3.35 & \end{array}$

$\begin{array}{lll}3700601 & 3.73 \\ 20100602 & 473 . & 3.35\end{array}$

$\begin{array}{lll}20100603 & 673 . & 2.60 \\ 20100604 & 773 . & 2.33\end{array}$

$\begin{array}{lll}20100604 & 773 . & 2.33 \\ 20100605 & 873 . & 2.15 \\ 20100606 & 823 & 2.12\end{array}$

$\begin{array}{ll}923 . & 2.12 \\ 0 & 1073.306\end{array}$

$\begin{array}{lll} & 1073 . & 2.30 \\ 20100608 & 1173 . & 2.50\end{array}$

$20100609 \quad 1273 . \quad 2.80$

$20100651 \quad 373 . \quad 3.026 e 6$

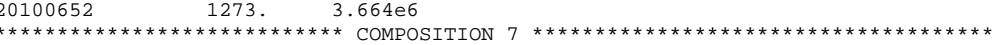

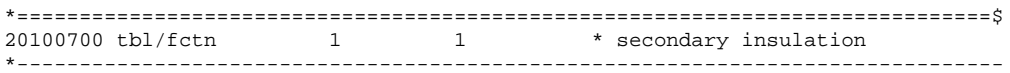

$20100701 \quad 1.0$

20100751

$3.42 \mathrm{e} 4$

\begin{tabular}{|c|c|c|c|}
\hline 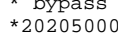 & $\begin{array}{l}\text { er tabe } \\
\text { powe }\end{array}$ & 0 & * sscalc \\
\hline$\star 20205001$ & 0.0 & $17.4 \mathrm{e} 3$ & $\begin{array}{l}\text { Ascalc } \\
\text { * sscalc }\end{array}$ \\
\hline 20205000 & power & & * trancalc \\
\hline 20205001 & -1.0 & 0.0 & * trancalc \\
\hline 20205002 & 0.0 & $17.4 \mathrm{e} 3$ & * trancalc \\
\hline 20205003 & 5.0 & $17.4 \mathrm{e} 3$ & * trancalc \\
\hline 20205004 & 6.0 & $16.86 \mathrm{e} 3$ & * trancalc \\
\hline 20205005 & 24.0 & $16.86 \mathrm{e} 3$ & * trancalc \\
\hline 20205006 & 30.0 & $14.0 \mathrm{e} 3$ & * trancalc \\
\hline
\end{tabular}

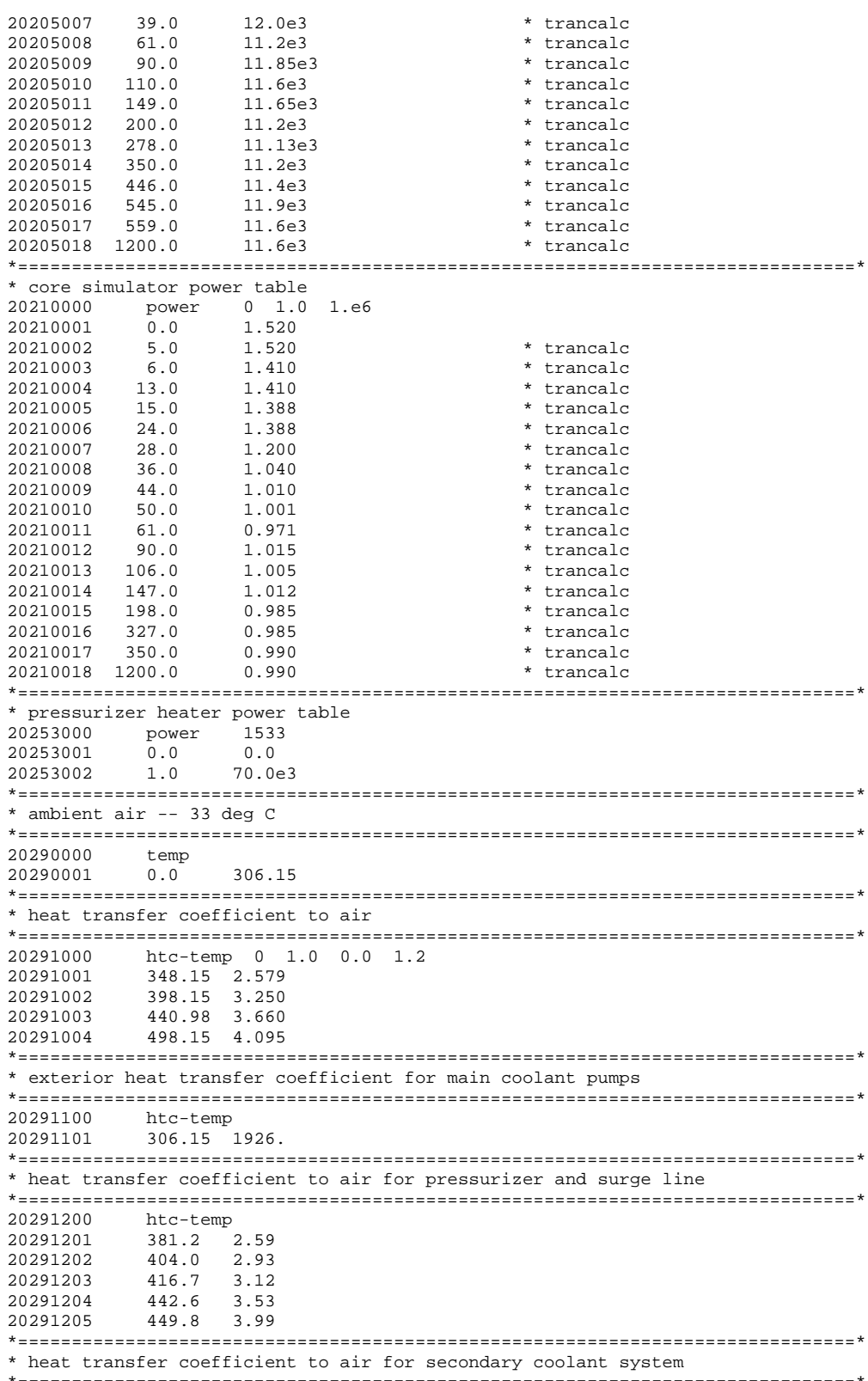

* heat transfer coefficient to air for secondary coolant system 


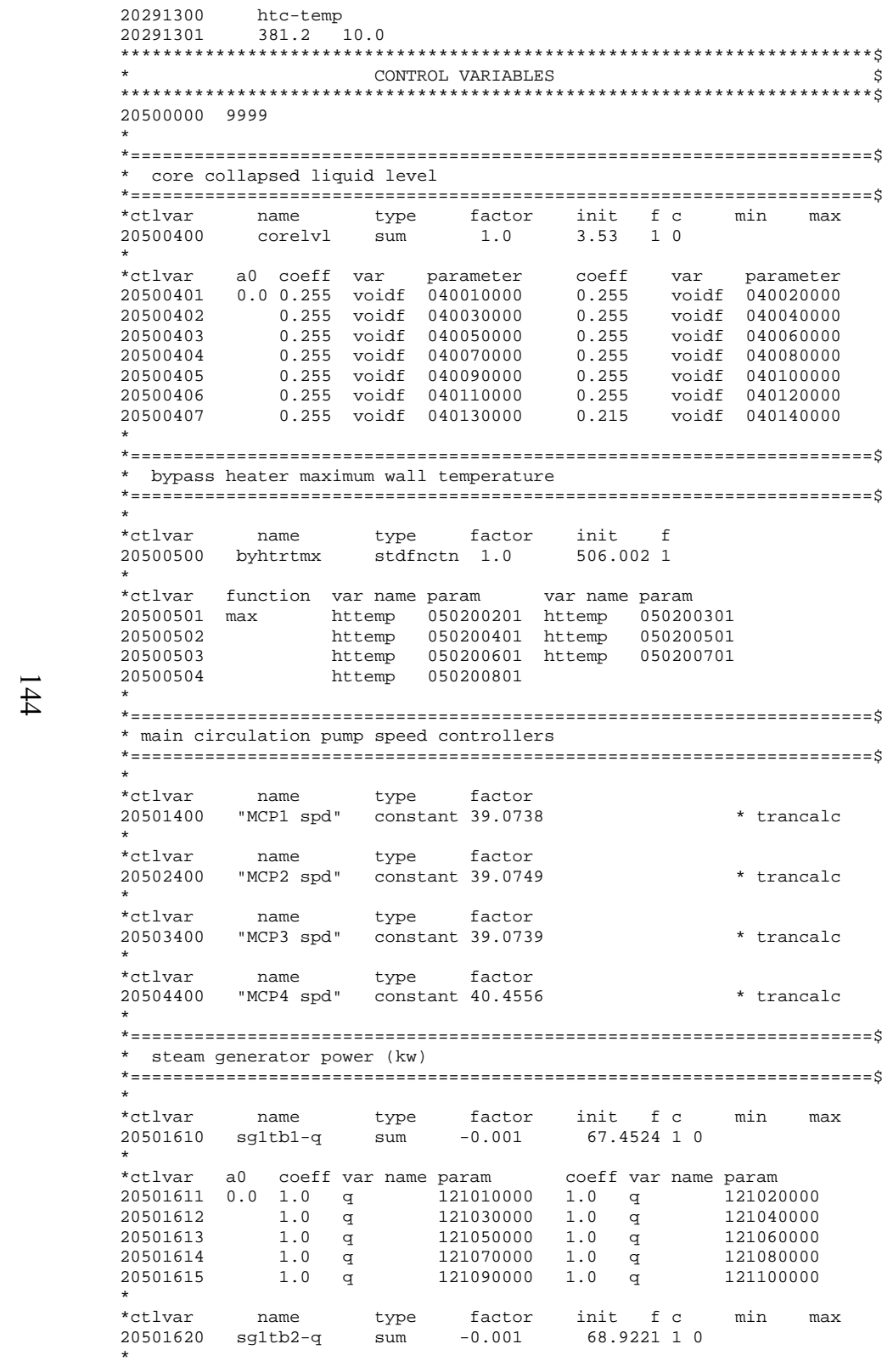




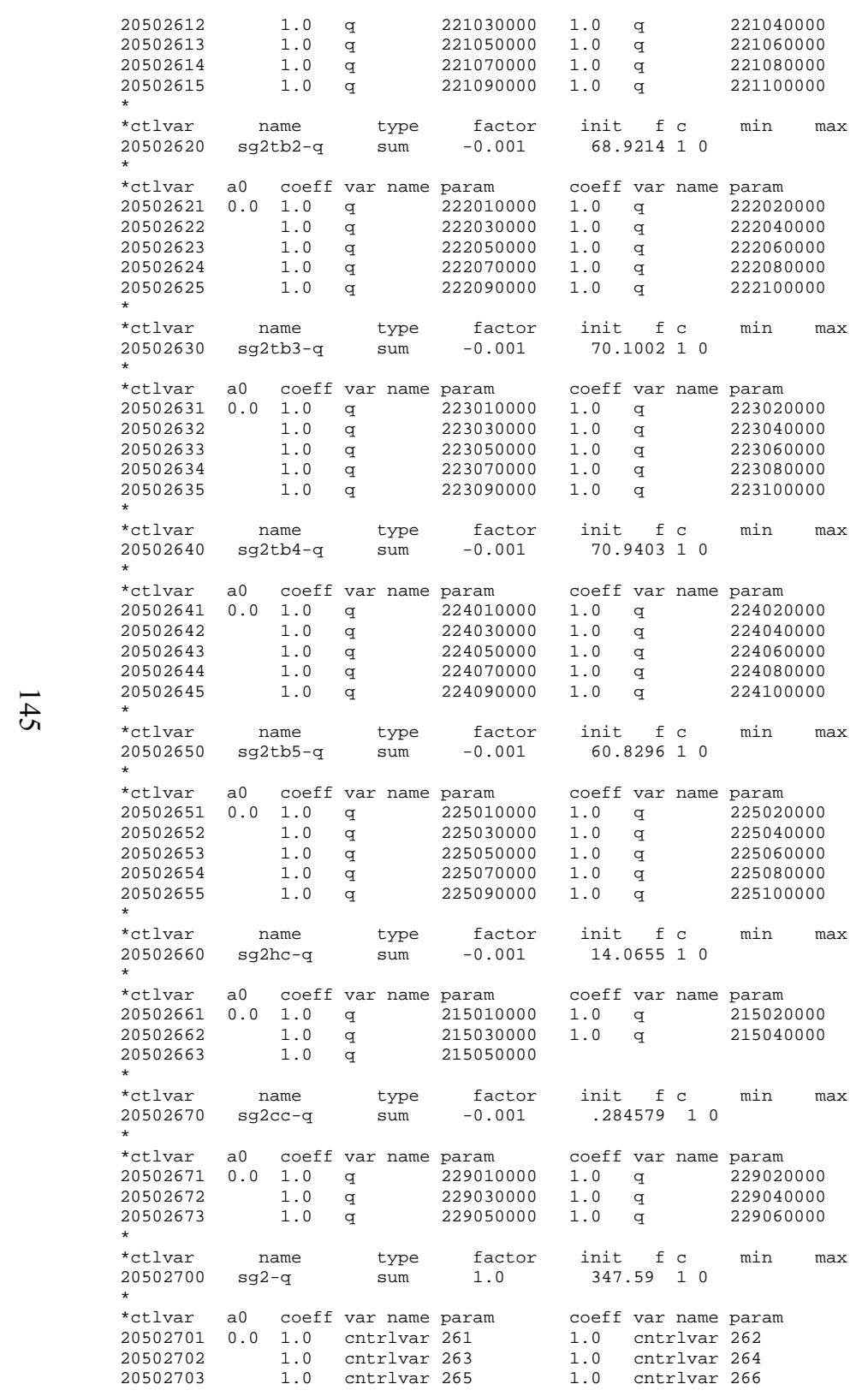

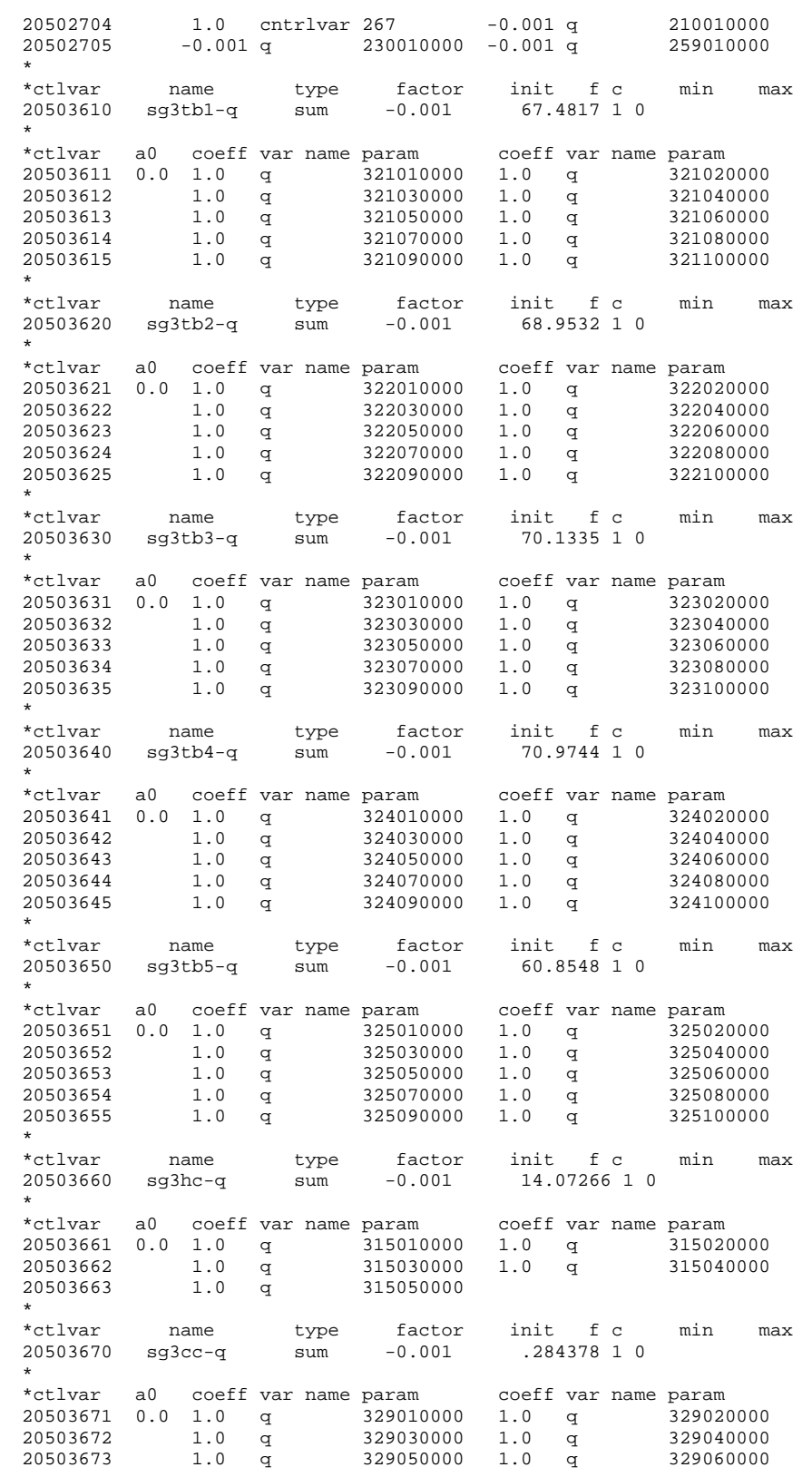




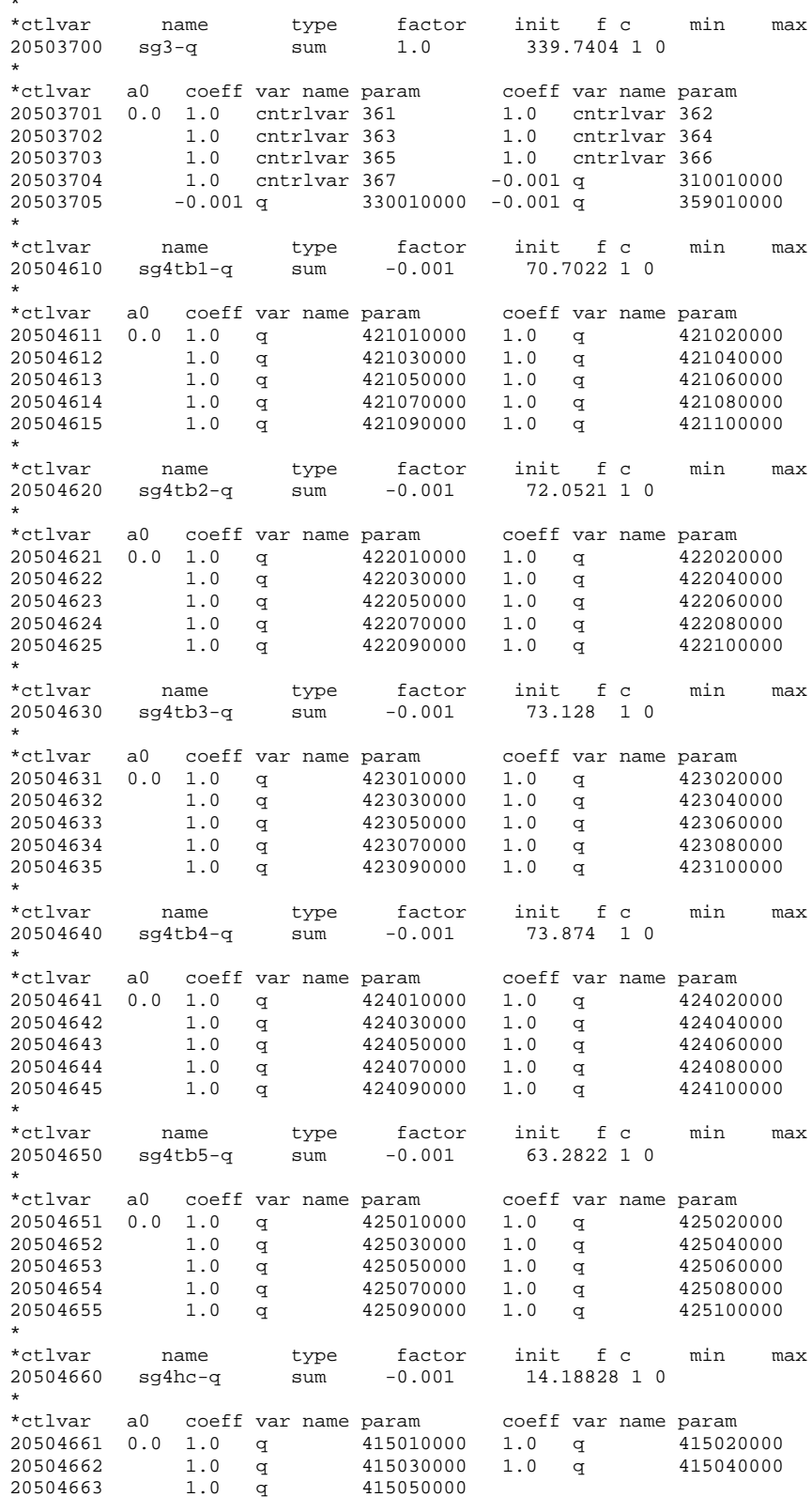

$\operatorname{ax}$

$\times$




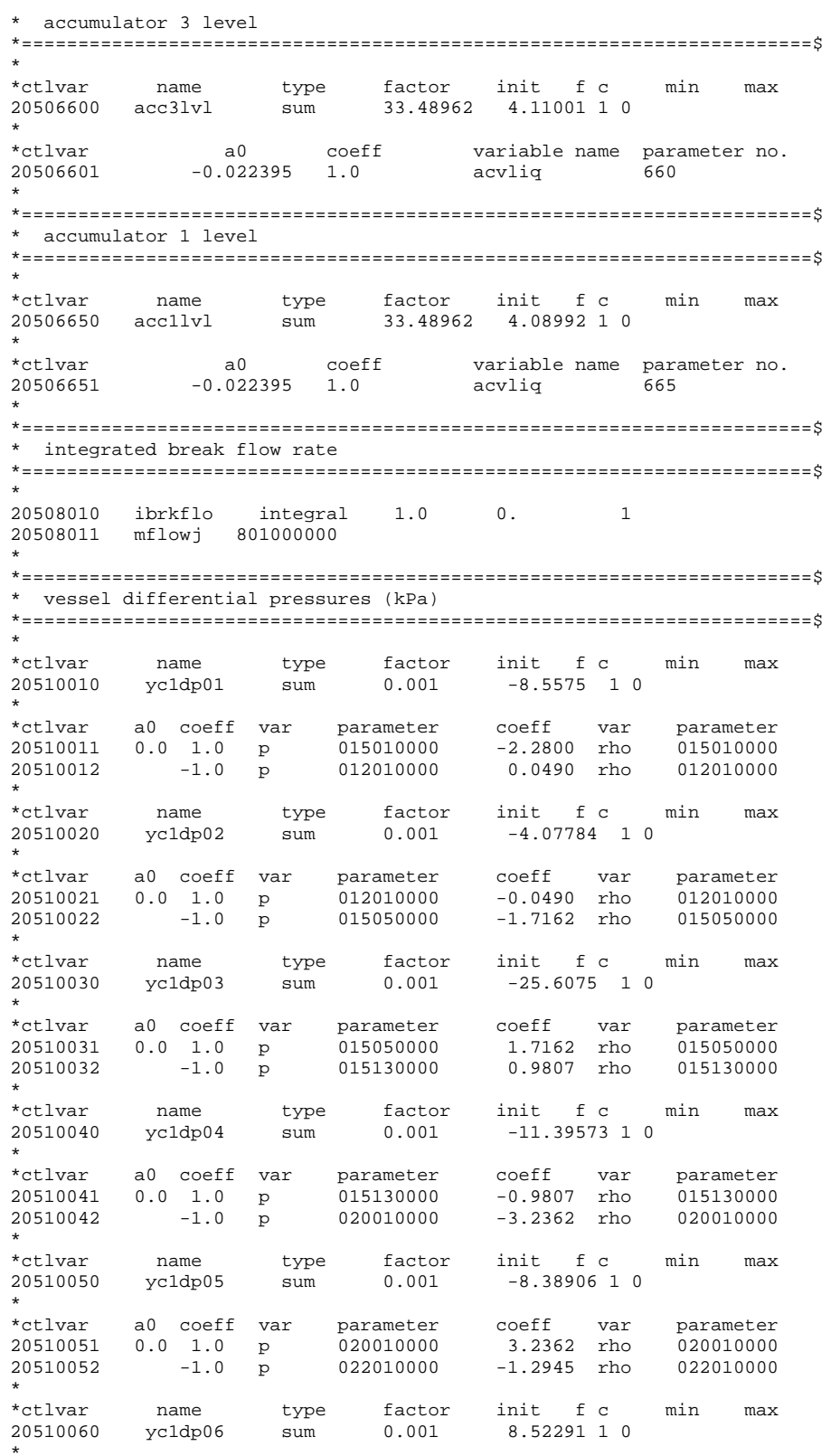

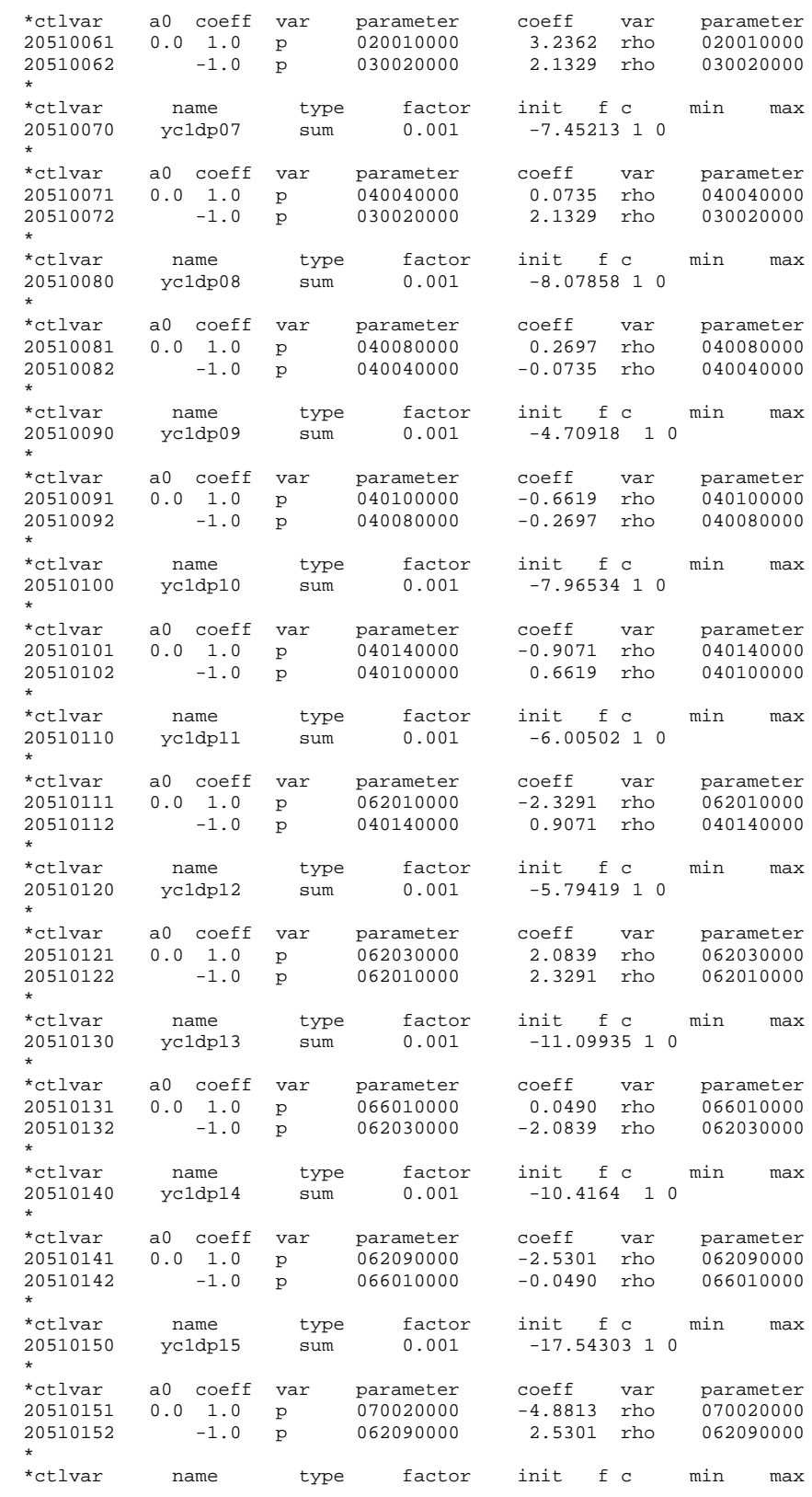




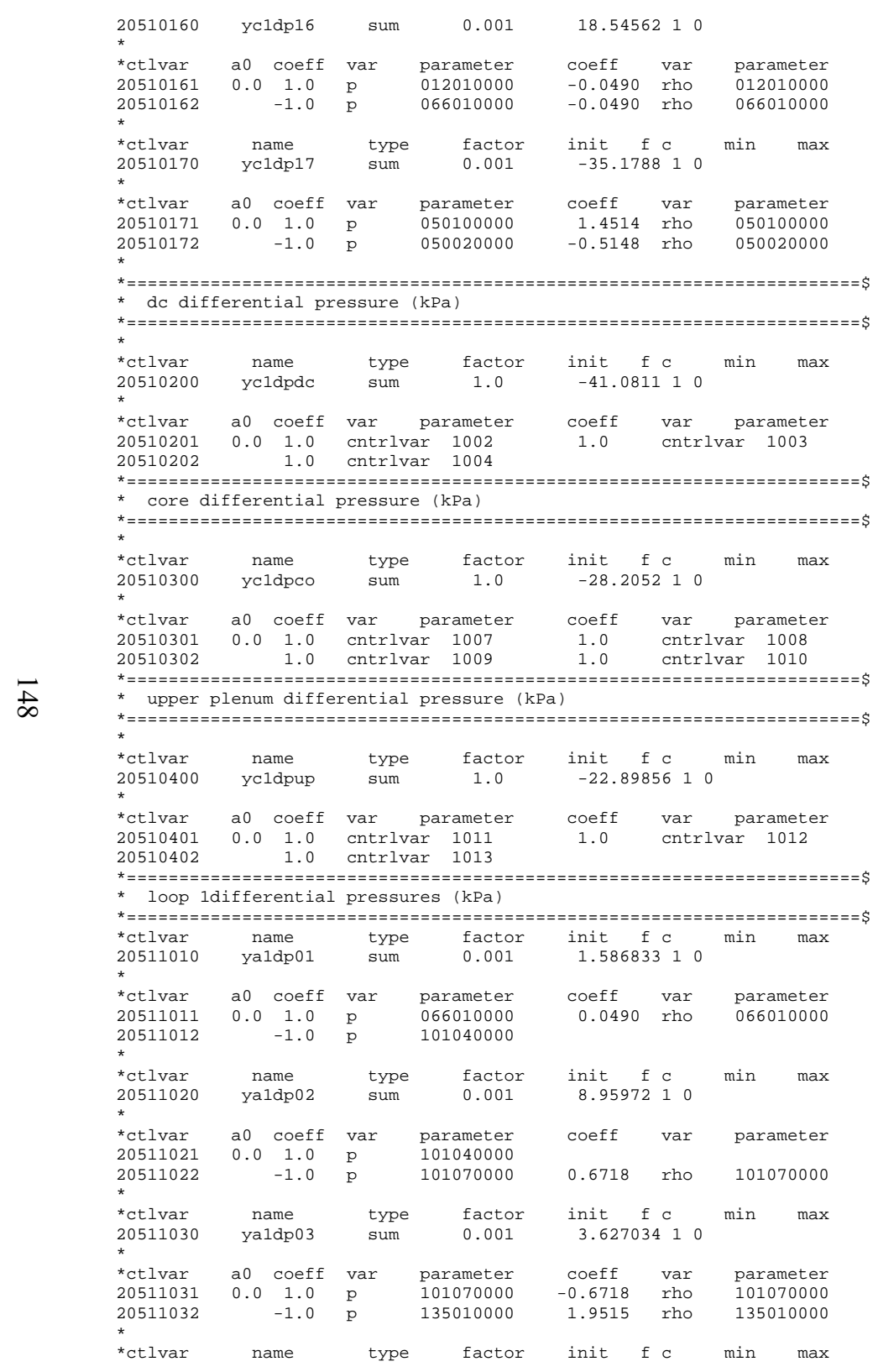

\begin{tabular}{|c|c|c|c|c|c|}
\hline $\begin{array}{l}20511040 \\
*\end{array}$ & ya1dp 04 & sum & 0.001 & -22.0563 & \\
\hline tlvar & a0 coeff & var & parameter & $\operatorname{coeff}$ & parameter \\
\hline 20511041 & $0.0 \quad 1.0$ & $\mathrm{p}$ & 135010000 & -1.9515 & 135010000 \\
\hline 20511042 & -1.0 & $\mathrm{p}$ & 135040000 & -3.1577 & 135040000 \\
\hline $\begin{array}{l}\text { *ctlvar } \\
20511050\end{array}$ & $\begin{array}{l}\text { name } \\
\text { ya1dp05 }\end{array}$ & $\begin{array}{l}\text { type } \\
\text { sum }\end{array}$ & $\begin{array}{l}\text { factor } \\
0.001\end{array}$ & $\begin{array}{l}\text { init } f c c \\
-24.3481 \quad 10\end{array}$ & $\min$ \\
\hline ctlvar & a 0 coeff & var & parameter & coeff & parameter \\
\hline 20511051 & $0.0 \quad 1.0$ & $\mathrm{p}$ & 135040000 & 3.1577 & 135040000 \\
\hline 20511052 & -1.0 & $\mathrm{p}$ & 135090000 & & \\
\hline $\begin{array}{l}\text { *ctlvar } \\
20511060\end{array}$ & $\begin{array}{l}\text { name } \\
\text { ya1dp06 }\end{array}$ & type & factor & init $f \mathrm{C}$ & $\min$ \\
\hline & & sum & 0.001 & & \\
\hline tlvar & a0 coeff & var & parameter & coeff & parameter \\
\hline 511061 & $0.0 \quad 1.0$ & p & 145030000 & & \\
\hline 20511062 & -1.0 & $\mathrm{p}$ & 135090000 & & \\
\hline $\begin{array}{l}\text { *ctlvar } \\
20511080\end{array}$ & $\begin{array}{c}\text { name } \\
\text { ya1dp08 }\end{array}$ & $\begin{array}{l}\text { type } \\
\text { sum }\end{array}$ & $\begin{array}{l}\text { factor } \\
0.001\end{array}$ & 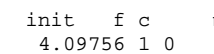 & $\min$ \\
\hline & & & & & \\
\hline 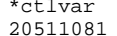 & $\begin{array}{l}\text { a0 } \\
0.0 \quad 1.0\end{array}$ & var & $\begin{array}{l}\text { parameter } \\
135090000\end{array}$ & coeff & parameter \\
\hline 20511082 & -1.0 & $\mathrm{p}$ & 135110000 & 2.3082 rho & 135110000 \\
\hline $\begin{array}{l}{ }^{*} \operatorname{ctl} 1 \text { var } \\
20511090\end{array}$ & $\begin{array}{c}\text { name } \\
\text { ya1dp09 }\end{array}$ & $\begin{array}{l}\text { type } \\
\text { sum }\end{array}$ & $\begin{array}{l}\text { factor } \\
0.001\end{array}$ & 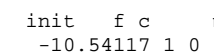 & $\min$ \\
\hline & & & & & \\
\hline *ctlvar & a0 coeff & var & parameter & coeff & parameter \\
\hline 20511091 & $0.0 \quad 1.0$ & $\mathrm{p}$ & 142010000 & & \\
\hline 20511092 & -1.0 & $\mathrm{p}$ & 135110000 & 2.3082 & 135110000 \\
\hline $\begin{array}{l}\text { *ctlvar } \\
20511100\end{array}$ & $\begin{array}{l}\text { name } \\
\text { ya1dp10 }\end{array}$ & $\begin{array}{l}\text { type } \\
\text { sum }\end{array}$ & $\begin{array}{l}\text { factor } \\
0.001\end{array}$ & 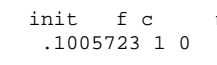 & $\min$ \\
\hline $\begin{array}{l}{ }^{*} \operatorname{ctl} l v a r \\
20511101\end{array}$ & a0 coeff & $\begin{array}{l}\text { var } \\
\text { var }\end{array}$ & parameter & coeff & parameter \\
\hline 20511102 & $\begin{array}{ll}1.0 \\
-1.0\end{array}$ & $\mathrm{p}$ & 145030000 & & \\
\hline *ctlvar & & type & & & $\min$ \\
\hline 20511110 & ya1dp11 & sum & 0.001 & $-1.054094 \quad 10$ & \\
\hline${ }^{*} \operatorname{ctl}$ var & a0 coeff & var & parameter & coeff & parameter \\
\hline 20511111 & $0.0 \quad 1.0$ & $\mathrm{p}$ & 145030000 & & \\
\hline 20511112 & -1.0 & $\mathrm{p}$ & 012010000 & 0.0490 & 012010000 \\
\hline $\begin{array}{l}{ }^{*} \operatorname{ctl} l v a r \\
20511130\end{array}$ & $\begin{array}{l}\text { name } \\
\text { ya1dp13 }\end{array}$ & $\begin{array}{l}\text { type } \\
\text { sum }\end{array}$ & $\begin{array}{l}\text { factor } \\
0.001\end{array}$ & 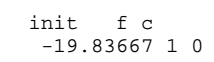 & $\min$ \\
\hline *ctlvar & a0 coeff & var & iramet & coef & parameter \\
\hline 20511131 & $0.0 \quad 1.0$ & p & 1150500 & -3.3784 & 115050000 \\
\hline 20511132 & -1.0 & $\mathrm{p}$ & 101070000 & 0.6718 & 101070000 \\
\hline $\begin{array}{l}{ }^{*} \operatorname{ctl} 1 \mathrm{var} \\
20511140\end{array}$ & $\begin{array}{l}\text { name } \\
\text { ya1dp14 }\end{array}$ & $\begin{array}{l}\text { type } \\
\text { sum }\end{array}$ & $\begin{array}{l}\text { factor } \\
0.001\end{array}$ & 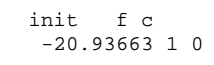 & $\min$ \\
\hline${ }^{\star}{ }^{\star} \operatorname{ctl} l \mathrm{var}$ & & var & & & parameter \\
\hline 20511141 & $0.0 \quad 1.0$ & par & 1290600 & $\begin{aligned} c o e \\
-1.0\end{aligned}$ & 129060000 \\
\hline 20511142 & -1.0 & $\mathrm{p}$ & 135010000 & 1.9515 & 135010000 \\
\hline \\
\hline & & & & & \\
\hline $\begin{array}{l}{ }^{*} \operatorname{ctl} 1 \mathrm{var} \\
20511200 \\
{ }_{*}\end{array}$ & $\begin{array}{l}\text { name } \\
\text { yalhleg }\end{array}$ & $\begin{array}{l}\text { type } \\
\text { sum }\end{array}$ & $\begin{array}{c}\text { factor } \\
1.0\end{array}$ & $\begin{array}{l}\text { init } f c \\
10.5465510\end{array}$ & $\min$ \\
\hline
\end{tabular}




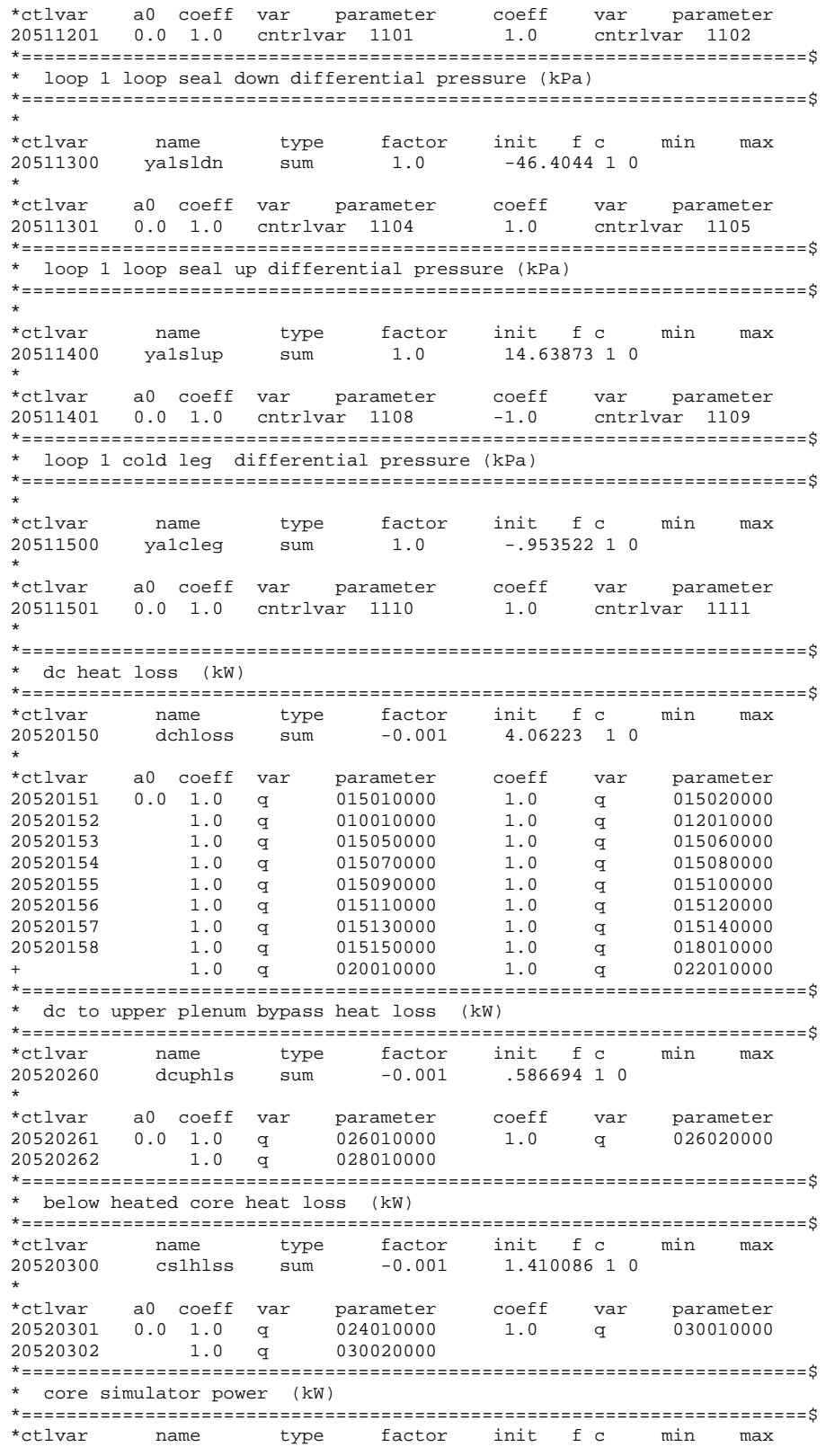

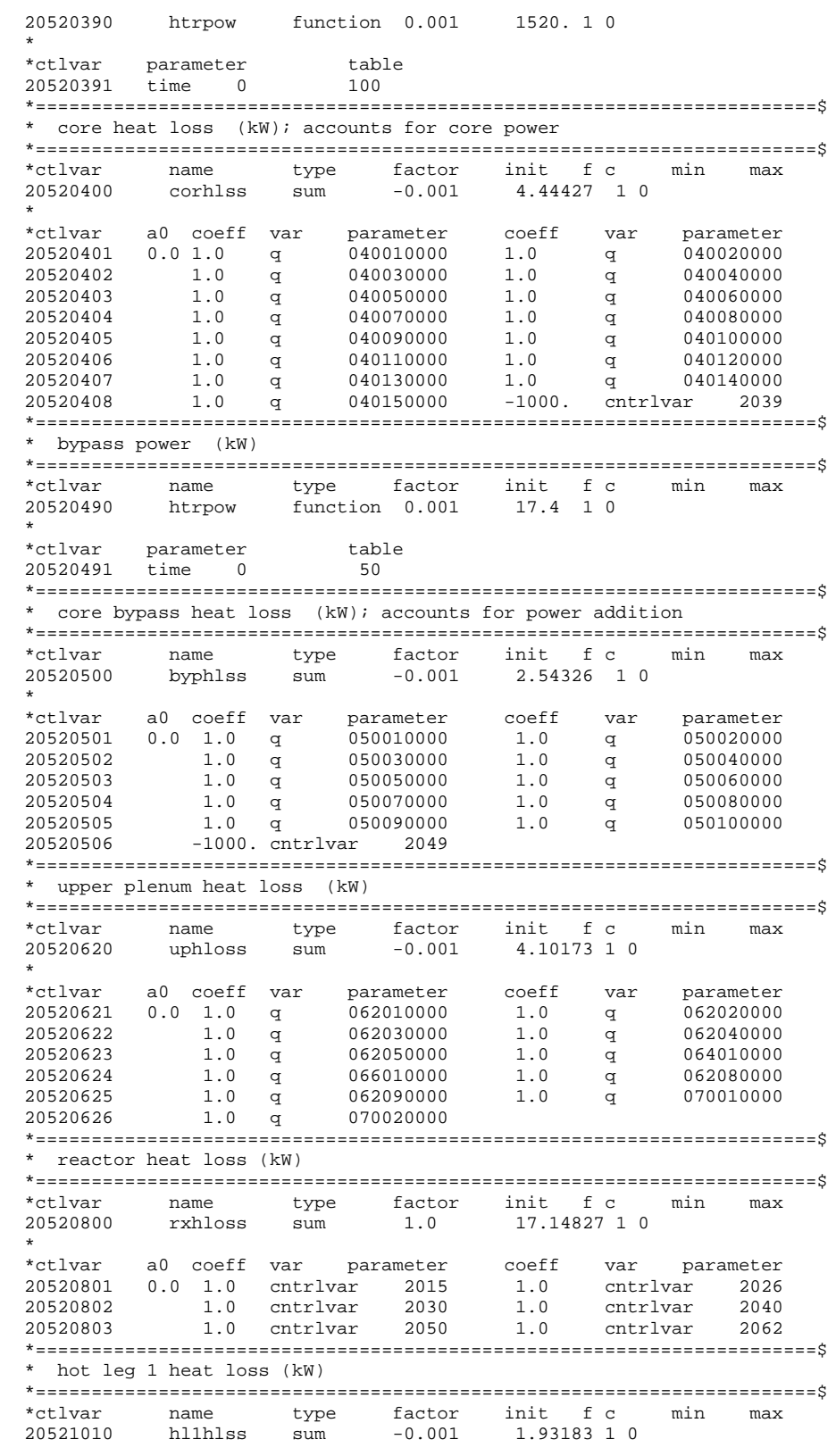




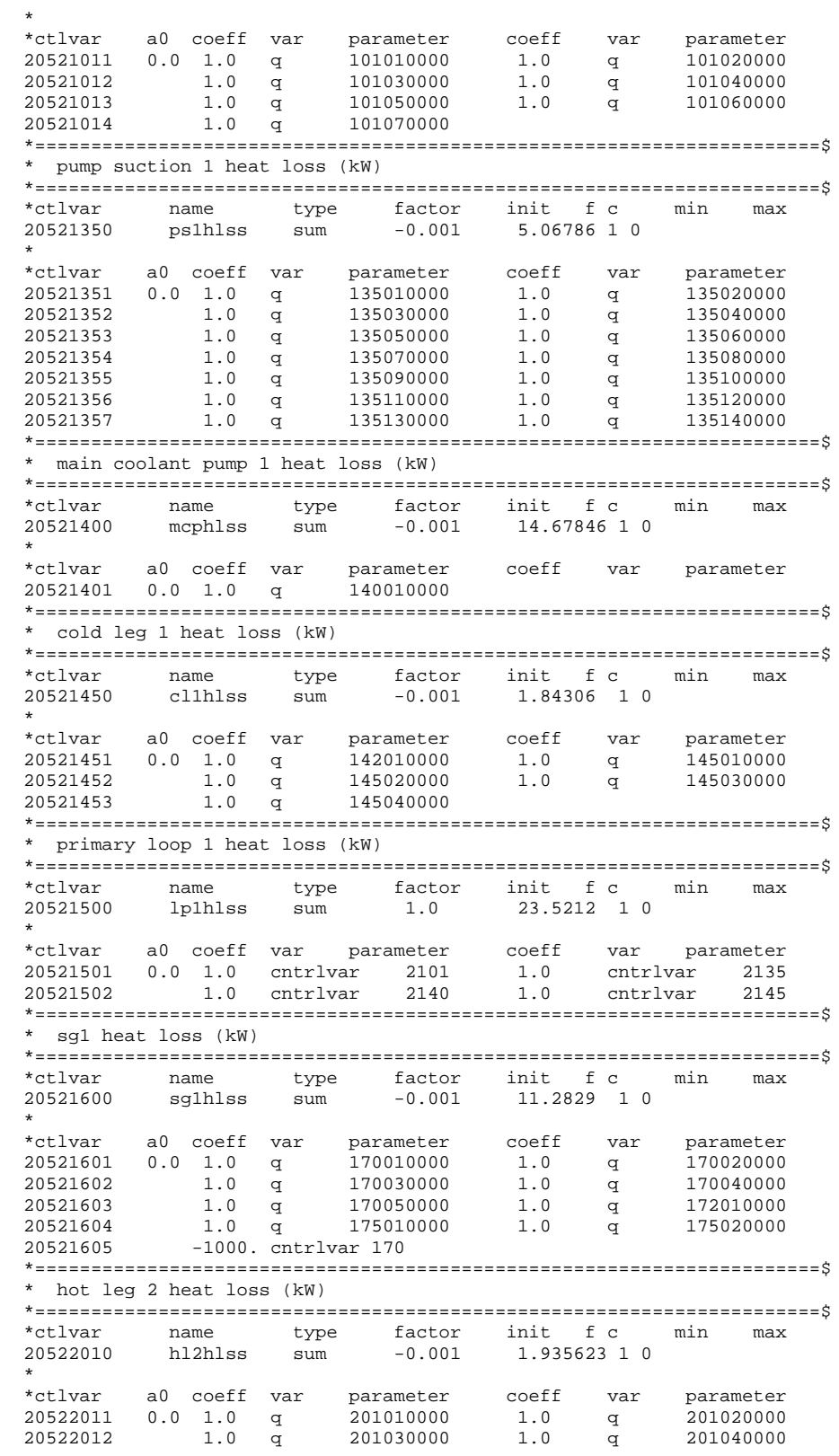

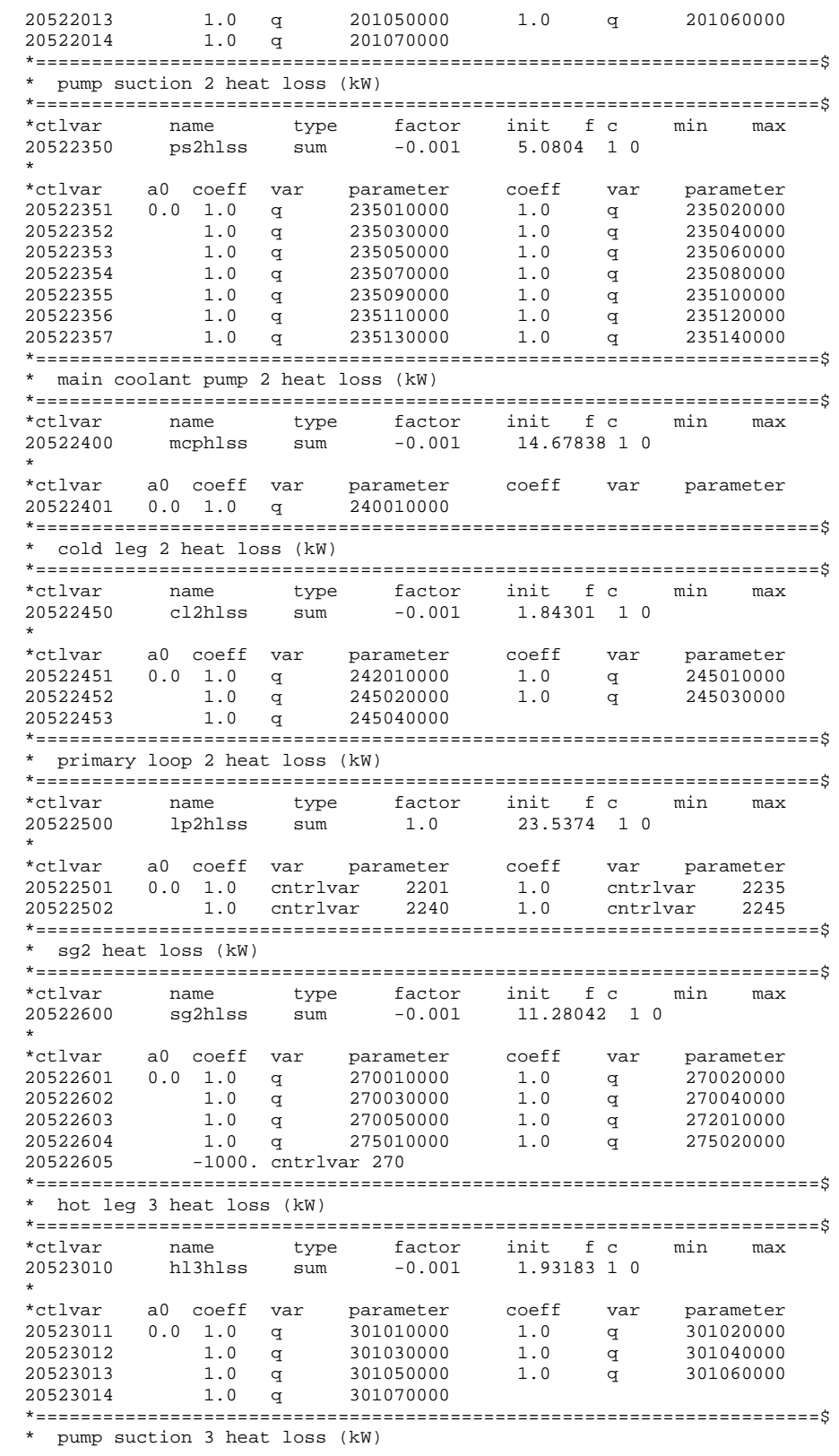




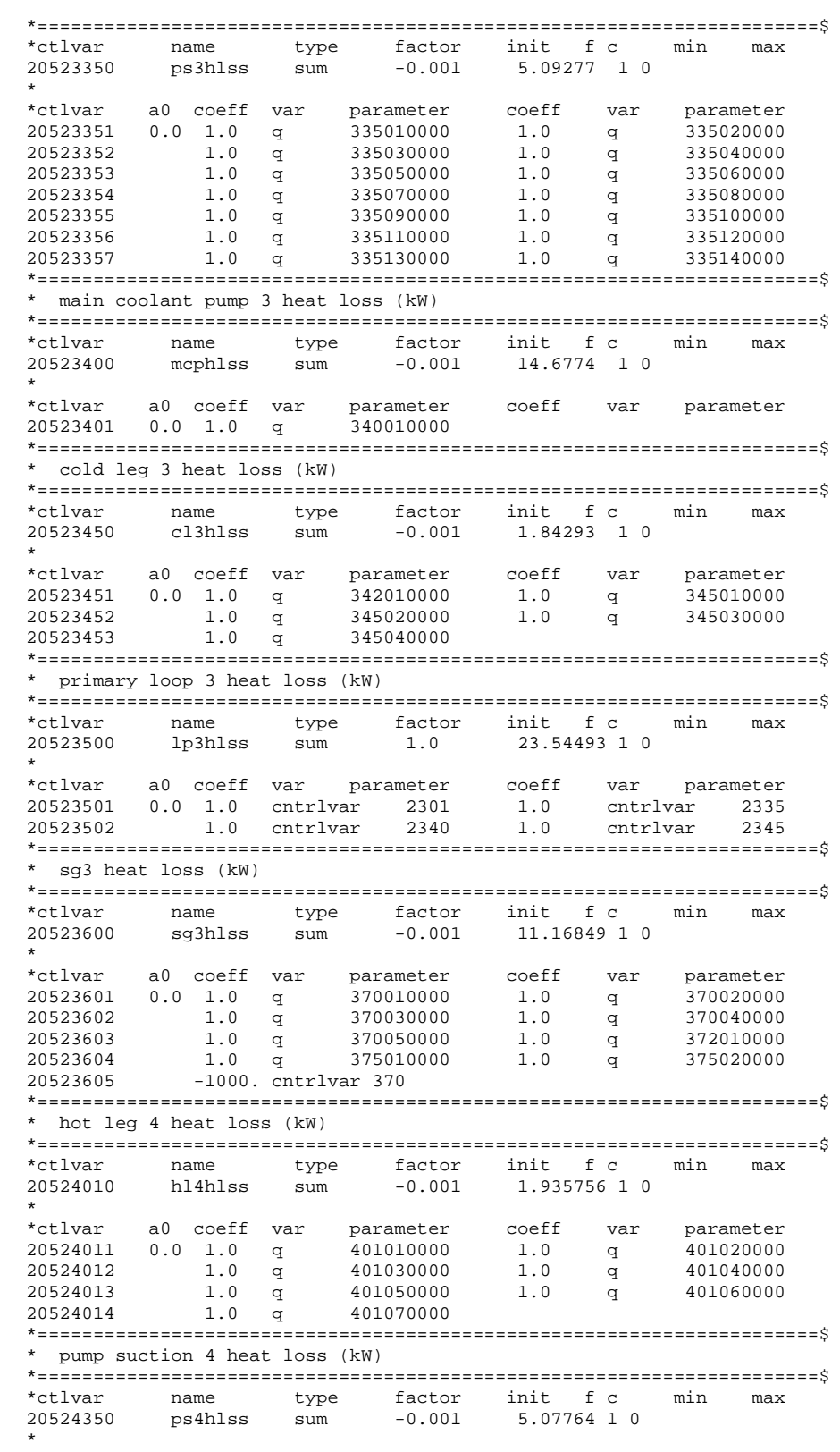

\begin{tabular}{|c|c|c|c|c|c|c|c|}
\hline *ctlvar & a0 coeff & var & parameter & coeff & var & parameter & \\
\hline 20524351 & 0.01 .0 & q & 435010000 & 1.0 & q & 435020000 & \\
\hline 20524352 & 1.0 & $q$ & 435030000 & 1.0 & q & 435040000 & \\
\hline 20524353 & 1.0 & q & 435050000 & 1.0 & q & 435060000 & \\
\hline 20524354 & $\begin{array}{l}1.0 \\
1.0\end{array}$ & q & 435070000 & $\begin{array}{l}1.0 \\
1.0\end{array}$ & q & 435080000 & \\
\hline 20524355 & $\begin{array}{l}1.0 \\
1.0\end{array}$ & q & 435090000 & $\begin{array}{l}1.0 \\
1.0\end{array}$ & g & 435100000 & \\
\hline 20524356 & $\begin{array}{l}1.0 \\
1.0\end{array}$ & g & 435110000 & $\begin{array}{l}1.0 \\
1.0\end{array}$ & q & 435120000 & \\
\hline 20524357 & 1.0 & $q$ & 435130000 & 1.0 & q & 435140000 & \\
\hline main $c$ & olant pump 4 & 4 heat 10 & loss (kW) & & & & \\
\hline $\begin{array}{l}\text { *ctivar } \\
20524400\end{array}$ & $\begin{array}{l}\text { name } \\
\text { mophlss }\end{array}$ & type & $\begin{array}{l}\text { factor } \\
-0.001\end{array}$ & init $f$ & $c_{10}$ & $\min$ & $a x$ \\
\hline $\begin{array}{l}\text { * } 20524400 \\
{ }_{*}\end{array}$ & mcph1ss & & & & & & \\
\hline $\begin{array}{l}\text { *ctlvar } \\
20524401\end{array}$ & a0 coeff & var & $\begin{array}{l}\text { parameter } \\
440010000\end{array}$ & coeff & var & parameter & \\
\hline * cold 1 & g 4 heat los & ss (kW) & & & & & \\
\hline & & & & & & & \\
\hline *ctlvar & name & type & factor & init $f$ & & $\min$ & $a x$ \\
\hline $\begin{array}{l}20524450 \\
\star\end{array}$ & cl3hlss & sum & -0.001 & 1.844066 & 610 & & \\
\hline *ctlvar & a0 coeff & var & parameter & coeff & var & parameter & \\
\hline 20524451 & $0.0 \quad 1.0$ & q & 442010000 & 1.0 & q & 445010000 & \\
\hline 20524452 & $\begin{array}{ll}1.0 \\
1.0\end{array}$ & $q$ & 445020000 & 1.0 & $q$ & 445030000 & \\
\hline 20524453 & 1.0 & $q$ & 445040000 & & & & \\
\hline * primar & loop 4 heat & t loss & (kW) & & & & \\
\hline *ctlvar & name & type & factor & init $f$ & & $\min$ & $a x$ \\
\hline 20524500 & lp4h1ss & sum & 1.0 & 23.54327 & $\begin{array}{lll}7 & 10\end{array}$ & & \\
\hline *ctlvar & a0 coeff & var & parameter & coeff & var & parameter & \\
\hline 20524501 & 0.01 .0 & cntrlvas & ar 2401 & 1.0 & cntrlva & ar 2435 & \\
\hline 20524502 & 1.0 & cntrlvar & 2440 & 1.0 & cntrlva & 2445 & \\
\hline * $\mathrm{sg} 4 \mathrm{he}$ & $t$ loss (kW) & & & & & & \\
\hline $\begin{array}{l}\text { *ctlvar } \\
20524600\end{array}$ & $\begin{array}{l}\text { name } \\
\text { sg4hlss }\end{array}$ & $\begin{array}{l}\text { type } \\
\text { sum }\end{array}$ & $\begin{array}{l}\text { factor } \\
-0.001\end{array}$ & $\begin{array}{c}\text { init } \mathrm{f} \\
11.11618\end{array}$ & $\begin{array}{lll}c & \\
8 & 1 & 0\end{array}$ & $\min$ & $a x$ \\
\hline & a soeff & rar & parameter & Ceff & yar & narameter & \\
\hline $\begin{array}{l}\text { Cetervar } \\
20524601\end{array}$ & $\begin{array}{lc}\text { au } \\
0.0 & 1.0\end{array}$ & var & $\begin{array}{l}\text { parameter } \\
470010000\end{array}$ & $\begin{array}{l}\text { Coett } \\
1.0\end{array}$ & $\begin{array}{l}\text { var } \\
\text { q }\end{array}$ & $\begin{array}{l}\text { parameter } \\
470020000\end{array}$ & \\
\hline 20524602 & 1.0 & $q$ & 470030000 & 1.0 & $q$ & 470040000 & \\
\hline 20524603 & 1.0 & $q$ & 470050000 & 1.0 & $q$ & 472010000 & \\
\hline 20524604 & 1.0 & $q$ & 475010000 & 1.0 & $\mathrm{q}$ & 475020000 & \\
\hline 20524605 & -1000. & cntrlvar & $\operatorname{ar} 470$ & & & & \\
\hline * pzr su & ge line heat & t loss & (kW) & & & & \\
\hline *ctlvar & name & type & factor & init $\mathrm{f}$ & c & $\min$ & \\
\hline 20525050 & $\begin{array}{l}\text { psihlss } \\
\text { plat }\end{array}$ & sum & -0.001 & .056419 & 10 & & \\
\hline *ctlvar & a0 coeff & var & parameter & coeff & var & parameter & \\
\hline 20525051 & 0.01 .0 & q & 501010000 & 1.0 & q & 505010000 & \\
\hline 20525052 & $\begin{array}{ll}1.0 \\
1.0\end{array}$ & q & 505020000 & $\begin{array}{l}1.0 \\
1.0\end{array}$ & q & 505030000 & \\
\hline 20525053 & 1.0 & q & 505040000 & 1.0 & q & 505050000 & \\
\hline 20525054 & 1.0 & q & 505060000 & 1.0 & $q$ & 505070000 & \\
\hline 20525055 & 1.0 & $q$ & 511010000 & 1.0 & q & 515010000 & \\
\hline 20525056 & 1.0 & q & 515020000 & 1.0 & q & 515030000 & \\
\hline 20525057 & $\begin{array}{l}1.0 \\
1.0\end{array}$ & q & 515040000 & 1.0 & q & 515050000 & \\
\hline 20525058 & $\begin{array}{l}1.0 \\
1.0\end{array}$ & q & 515060000 & 1.0 & q & 520010000 & \\
\hline $\begin{array}{l}20000 \\
+\end{array}$ & $\begin{array}{l}1.0 \\
1.0\end{array}$ & $q$ & 525010000 & & & & \\
\hline * pzr he & ter power & (kW) & & & & & \\
\hline $\begin{array}{l}\text { *ctlvar } \\
20525300\end{array}$ & $\begin{array}{l}\text { name } \\
\text { htrpow }\end{array}$ & $\begin{array}{l}\text { type } \\
\text { funct: }\end{array}$ & $\begin{array}{rr}\text { factor } \\
\text { tion } & 0.001\end{array}$ & $\begin{array}{l}\text { init } \\
0 .\end{array}$ & $\begin{array}{l}c \\
0\end{array}$ & $\min$ & \\
\hline
\end{tabular}




\begin{tabular}{|c|c|c|c|c|c|c|c|}
\hline $\begin{array}{l}\text { *ctlvar } \\
20525301\end{array}$ & $\begin{array}{l}\text { parameter } \\
\text { time } 0\end{array}$ & & $\begin{array}{l}\text { table } \\
530\end{array}$ & & & & \\
\hline \multicolumn{8}{|c|}{ 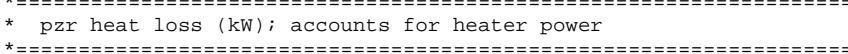 } \\
\hline \multirow{2}{*}{$\begin{array}{l}* \text { ctlvar } \\
20525350 \\
\star \\
* \operatorname{ctl} 1 \mathrm{var} \\
20525351 \\
20525352 \\
20525353 \\
20525354 \\
20525355\end{array}$} & $\begin{array}{l}\text { name } \\
\text { pzrhlss }\end{array}$ & $\begin{array}{l}\text { type } \\
\text { sum }\end{array}$ & $\begin{array}{l}\text { factor } \\
-0.001\end{array}$ & $\begin{aligned} \text { init } \\
7.89802\end{aligned}$ & \multicolumn{2}{|c|}{$\min$} & $\max$ \\
\hline & $\begin{array}{lc}\text { a0 } & \text { coeff } \\
0.0 & 1.0 \\
1.0 \\
1.0 \\
1.0 \\
1.0 \\
\end{array}$ & $\begin{array}{ll}\text { var } & p \\
q & 5 \\
q & 5 \\
q & 5 \\
q & 5 \\
q & 5 \\
q & \end{array}$ & $\begin{array}{l}\text { parameter } \\
530010000 \\
530030000 \\
530050000 \\
53007000 \\
535010000\end{array}$ & $\begin{array}{c}\text { coeff } \\
1.0 \\
1.0 \\
1.0 \\
1.0 \\
-1000 .\end{array}$ & $\begin{array}{ll}\text { var } & \mathrm{p} \\
\mathrm{q} & 5 \\
\mathrm{q} & 5 \\
\mathrm{q} & 5 \\
\mathrm{q} & 5 \\
\text { cntrlvar }\end{array}$ & \multicolumn{2}{|c|}{$\begin{array}{l}\text { parameter } \\
530020000 \\
530040000 \\
530060000 \\
530080000 \\
\text { var } \quad 2530\end{array}$} \\
\hline \multirow{2}{*}{\multicolumn{8}{|c|}{ pzr and surge line heat loss (kW) }} \\
\hline & & & & & & & \\
\hline \multirow{2}{*}{$\begin{array}{l}{ }^{*} \text { ctlvar } \\
20525400 \\
{ }^{*} \\
{ }^{*} \text { ctl } 1 \mathrm{var} \\
20525401 \\
{ }^{2}==========\end{array}$} & $\begin{array}{l}\text { name } \\
\text { tpzrlss }\end{array}$ & $\begin{array}{l}== \pm= \pm== \pm \\
\text { type } \\
\text { sum }\end{array}$ & $\begin{array}{c}\text { factor } \\
1.0\end{array}$ & \multicolumn{2}{|c|}{$\begin{array}{ccc}\text { init f } & c \\
7.95444 & 1 & 0\end{array}$} & $\min$ & $\max$ \\
\hline & $\begin{array}{l}\text { a0 } \\
0.0 \quad 1.0\end{array}$ & \multicolumn{2}{|c|}{$\begin{array}{l}\text { var parameter } \\
\text { cntrlvar } \quad 2505\end{array}$} & $\begin{array}{l}\text { coeff } \\
1.0 \\
\end{array}$ & \multicolumn{3}{|c|}{$\begin{array}{l}\text { var paramete } \\
\text { cntrlvar } 2535\end{array}$} \\
\hline \multicolumn{8}{|c|}{ 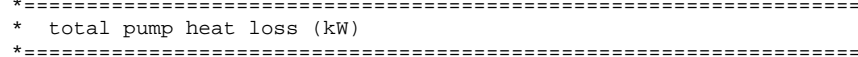 } \\
\hline \multicolumn{2}{|c|}{ 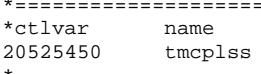 } & $\begin{aligned}======= & = \\
& \text { type } \\
& \text { sum }\end{aligned}$ & $\begin{array}{l}\text { factor } \\
1.0\end{array}$ & $\begin{array}{l}\text { init } f \\
58.7201\end{array}$ & & nin & $\max$ \\
\hline $\begin{array}{l}{ }^{*} \operatorname{ctl} 1 \mathrm{var} \\
20525451 \\
20525452\end{array}$ & $\begin{array}{l}\text { a0 coeff } \\
0.0 \quad 1.0\end{array}$ & $\begin{array}{l}\text { var por } \\
\text { cntrlvar } \\
\text { cntrlvar }\end{array}$ & $\begin{array}{r}\text { parameter } \\
r r \\
2140 \\
r \quad 2340\end{array}$ & $\begin{array}{l}\text { coeff } \\
1.0 \\
1.0\end{array}$ & $\begin{array}{l}\text { var } p \\
\text { cntrlvar } \\
\text { cntrlvar }\end{array}$ & $\begin{array}{l}\text { param } \\
\text { ar } \\
\text { ar }\end{array}$ & $\begin{array}{r}\text { meter } \\
2240 \\
2440\end{array}$ \\
\hline total & rimary heat & loss & & & & & \\
\hline $\begin{array}{l}\text { ctlvar } \\
0525500\end{array}$ & $\begin{array}{l}\text { name } \\
\text { pcstot }\end{array}$ & $\begin{array}{l}\text { type } \\
\text { sum }\end{array}$ & $\begin{array}{l}\text { factor } \\
1.0\end{array}$ & $\begin{array}{l}\text { init f } \\
119.2495\end{array}$ & $\begin{array}{llll}c & \\
5 & 1 & 0\end{array}$ & nin & $\max$ \\
\hline $\begin{array}{l}\text { *ctlvar } \\
20525501 \\
20525502 \\
2055503 \\
20525504 \\
*\end{array}$ & $\begin{array}{lc}\text { a0 } & \text { coeff } \\
0.0 & 1.0 \\
& 1.0 \\
& 1.0 \\
1.0 & \end{array}$ & $\begin{array}{l}\text { var pa } \\
\text { cntrlvar } \\
\text { cntrlvar } \\
\text { cntrlvar } \\
\text { cntrlvar }\end{array}$ & $\begin{array}{lr}\text { parameter } \\
\text { r } & 2080 \\
\mathrm{ar} & 2250 \\
\mathrm{ar} & 2450 \\
\mathrm{r} & 2535 \\
\end{array}$ & $\begin{array}{l}\text { coeff } \\
1.0 \\
1.0 \\
1.0\end{array}$ & $\begin{array}{l}\text { var p p } \\
\text { cntrlvar } \\
\text { cntrlvar } \\
\text { cntrlvar }\end{array}$ & $\begin{array}{l}\text { paran } \\
\text { ar } \\
\text { ar } \\
\text { ar }\end{array}$ & $\begin{array}{r}\text { meter } \\
2150 \\
2350 \\
2505\end{array}$ \\
\hline total & rimary heat & loss with & thout mcp a & $\operatorname{pzr}(\mathrm{kW})$ & & & \\
\hline $\begin{array}{l}\text { ctctlvar } \\
20525550\end{array}$ & $\begin{array}{l}\text { name } \\
\text { tpcswo }\end{array}$ & $\begin{array}{l}\text { type } \\
\text { sum }\end{array}$ & $\begin{array}{c}\text { factor } \\
1.0\end{array}$ & $\begin{array}{l}\text { init f } \\
52.575\end{array}$ & $\begin{array}{ll}c & \\
1 & 0\end{array}$ & nin & $\max$ \\
\hline $\begin{array}{l}{ }^{*} \text { ctlvar } \\
20525551 \\
20525552\end{array}$ & $\begin{array}{lc}\text { a0 } & \text { coeff } \\
0.0 & 1.0 \\
& -1.0\end{array}$ & $\begin{array}{l}\text { var po } \\
\text { cntrlvar } \\
\text { cntrlvar }\end{array}$ & $\begin{array}{lr}\text { parameter } \\
2 r & 2550 \\
2 & 2545\end{array}$ & $\begin{array}{l}\text { coeff } \\
-1.0\end{array}$ & $\begin{array}{ll}\text { var } & p \\
\text { cntrlvar }\end{array}$ & $\begin{array}{l}\text { paran } \\
\text { ar }\end{array}$ & $\begin{array}{r}\text { meter } \\
2540\end{array}$ \\
\hline $\begin{array}{l}t======= \\
\text { total }\end{array}$ & secondary he & at loss & & & & & \\
\hline $\begin{array}{l}\text { *ctlvar } \\
20525600\end{array}$ & $\begin{array}{l}\text { name } \\
\text { scstot }\end{array}$ & $\begin{array}{l}\text { type } \\
\text { sum }\end{array}$ & $\begin{array}{c}\text { factor } \\
1.0\end{array}$ & $\operatorname{init}_{44.848} \mathrm{f}$ & $\begin{array}{ll}c \\
1 & 0\end{array}$ & $\min$ & $\max$ \\
\hline $\begin{array}{l}\text { *ctlvar } \\
20525601 \\
20525602\end{array}$ & $\begin{array}{lc}\text { a0 } & \text { coeff } \\
0.0 & 1.0 \\
& 1.0\end{array}$ & $\begin{array}{l}\text { var pa } \\
\text { cntrlvar } \\
\text { cntrlvar }\end{array}$ & $\begin{array}{lr}\text { parameter } \\
\text { ir } \\
\text { r } & 2160 \\
2360\end{array}$ & $\begin{array}{l}\text { coeff } \\
1.0 \\
1.0\end{array}$ & $\begin{array}{l}\text { var } p \\
\text { cntrlvar } \\
\text { cntrlvar }\end{array}$ & $\begin{array}{l}\text { paran } \\
\text { ar } \\
\text { ar }\end{array}$ & $\begin{array}{r}\text { meter } \\
2260 \\
2460\end{array}$ \\
\hline total & imary and & secondary & $y$ heat loss & (kw) & & & \\
\hline $\begin{array}{l}\text { ctlvar } \\
0525650\end{array}$ & $\begin{array}{l}\text { name } \\
\text { prisec }\end{array}$ & $\begin{array}{l}\text { type } \\
\text { sum }\end{array}$ & $\begin{array}{l}\text { factor } \\
1.0\end{array}$ & $\begin{array}{l}\text { init } \\
164.0975\end{array}$ & $\begin{array}{ll}c \\
5\end{array}$ & $\operatorname{nin}$ & $\max$ \\
\hline
\end{tabular}

$20525651 \quad 0.0 \quad 1.0 \quad$ cntrlvar $2550 \quad 1.0 \quad$ cntrlvar 2560

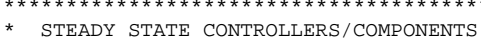

* MCP controllers for loop flow rate

$\begin{array}{lll}\star 20501390 & \text { lplflerr sum } 1.0 & -5.91028-9 \\ \star 20501391 & 2.3 \quad-1.0 \text { mflowj } 143000000\end{array}$

* sscalc

*20501400 mcp1spd integral $10.039 .07380030 .400 . \quad$ * sscalc

*20501401 cntrlvar 139

*20502390 lp2flerr sum $1.0 \quad-5.91648-9 \quad 0 \quad$ * sscalc

*20502391 2.3 $\quad-1.0$ mflowj 243000000 * sscalc

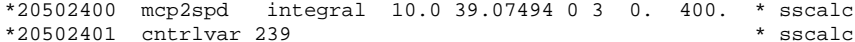

*20503390 lp3flert sum $1.0-5.79646-9$ - 0 -

$\begin{array}{llllll}20503390 & \text { lp3flerr sum } 1.0 & -5.79646-9 & 0 & * \\ * 20503391 & 2.3 & -1.0 \text { mflowj } 343000000 & *\end{array}$

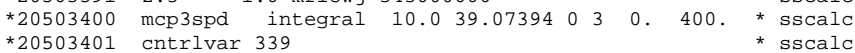

*20504390 lp4flerr sum $1.0 \quad-6.28985-9 \quad 0 \quad$ * sscalc

* 20504400 mep4spd integral 10.0 .40 .45560030 .400 * 3 scalc

*20504401 cntrlvar 439 * sscalc

* Primary coolant system pressure control

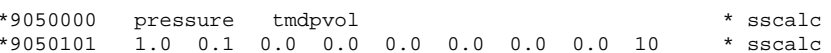

* sscalc

$\begin{array}{llllll}* 9050201 & 0.0 & 16.855 e 6 & 1.0 & *\end{array}$

*9060000 prescon sngljun * sscalc

*9060201 5350101.12652 -3.03643-4 0. 0. 0.0000000 * sscalc

* Pressurizer level control

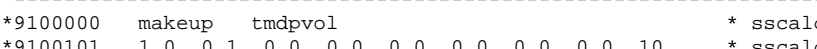

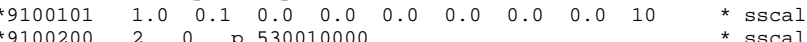

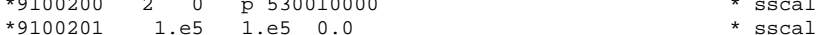

*9100202 17.e6 $17 . e 6 \quad 0.0$ * sscalc

*9110000 pzlvlct l tmdpjun * sscalc

* $91101019100100005300000000.05 \quad$ * sscalc

* $9110201-10.0-10.0 \quad 0.0 \quad 0.0$ *

$\begin{array}{llllll}* 9110202 & 0.0 & 0.0 & 0.0 & 0.0\end{array}$

$\begin{array}{lllllll}* 9110203 & 10.0 & 10.0 & 0.0 & 0.0 & \end{array}$

*20595000 pzrlvler sum $1.0-2.17335-70 \quad 0 \quad$ * sscalc

$\begin{array}{lllllllll}20595001 & 6.99 & -1.0 & \text { cntrlvar } 532 & * & \text { * sscalc }\end{array}$

*20595011 $1.0 \quad 1.0$ cntrlvar 9500 (200

* Steam generator pressure controller

20500450 tcoldave sum $0.25 \quad 559.71$

$205004510.0 \quad 1.0$ tempf $145040000 \quad 1.0$ tempf 245040000

$20500452 \quad 1.0$ tempf $345040000 \quad 1.0$ tempf 445040000

*20597040 cltmperr sum 1.0e5.1903553 0

*20597041 $559.7-1.0$ cntrlvar $45 \quad 3117636.0 \quad$ * sscalc

*20597050 stmvlv1p prop-int 1.0 7117636.0 * sscalc 


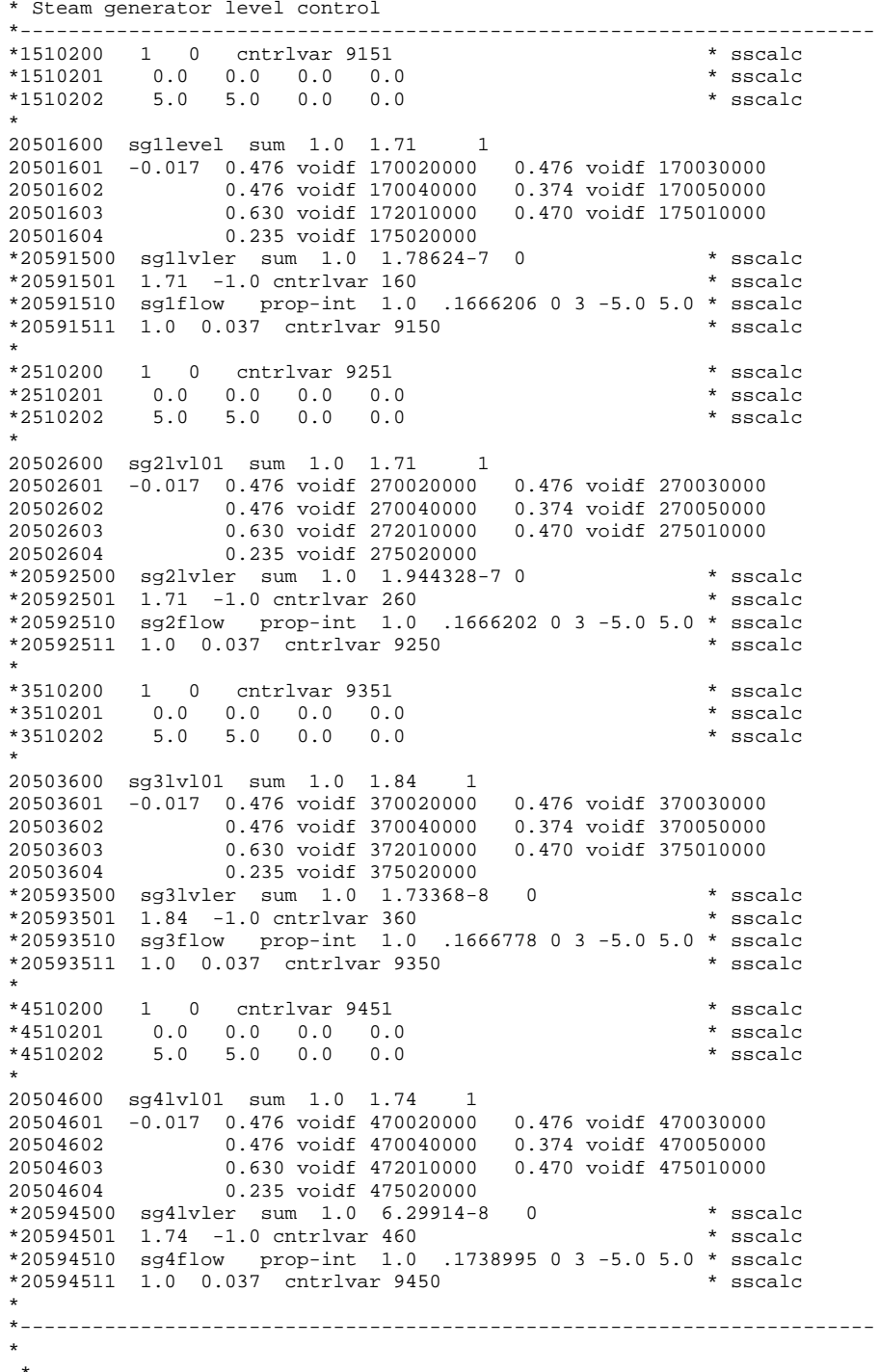

